
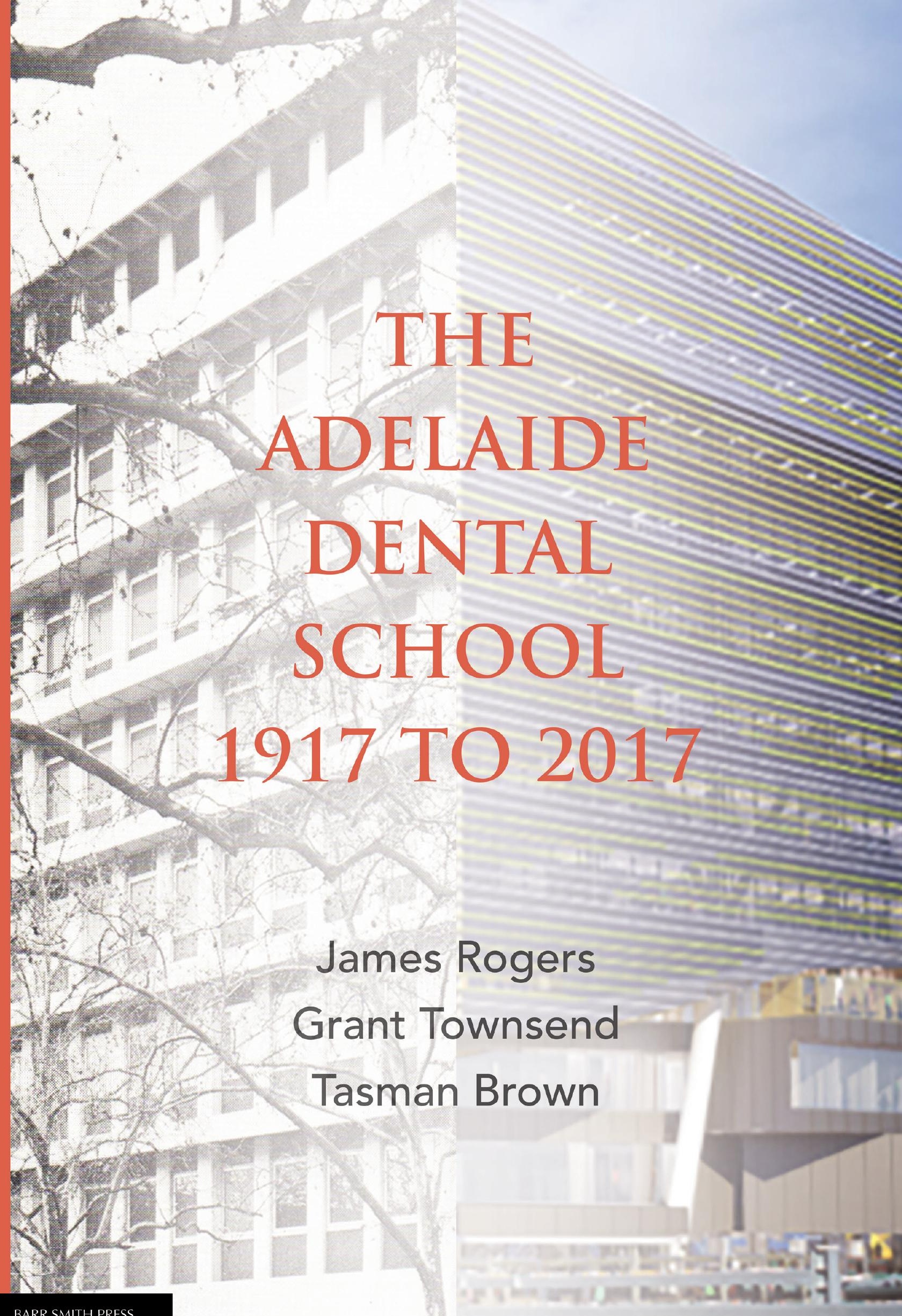


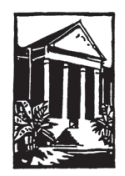

BARR SMITH PRESS

An imprint of

The University of Adelaide Press

\section{THE ADELAIDE DENTAL SCHOOL 1917 TO 2017}

\section{James Rogers • Grant Townsend • Tasman Brown}

The Adelaide Dental School has built a proud history over a period of 100 years, gaining a reputation as one of the world's top dental schools. This book records some of the key events that have shaped the School's excellence in teaching and research, whilst also exploring the lives of some of the personalities who have driven change within the School. In addition, the book considers both the future of dental education as well as likely developments in dental research and practice, and the way these two things are linked. The book also contains three chapters in which former students of the Dental School provide personal viewpoints of their education at the Adelaide Dental School. The final appendices contain a potpourri of archival material, including copies of documents and examples of lecture notes and examination papers. As a whole, this book provides both a record of the key achievements that have made the School what it is today and an insight into what the next 100 years may hold for the School. adelaide.edu.au/press 


$$
\begin{gathered}
\text { THE } \\
\text { ADELAIDE } \\
\text { DENTAL } \\
\text { SCHOOL } \\
1917 \text { TO } 2017
\end{gathered}
$$



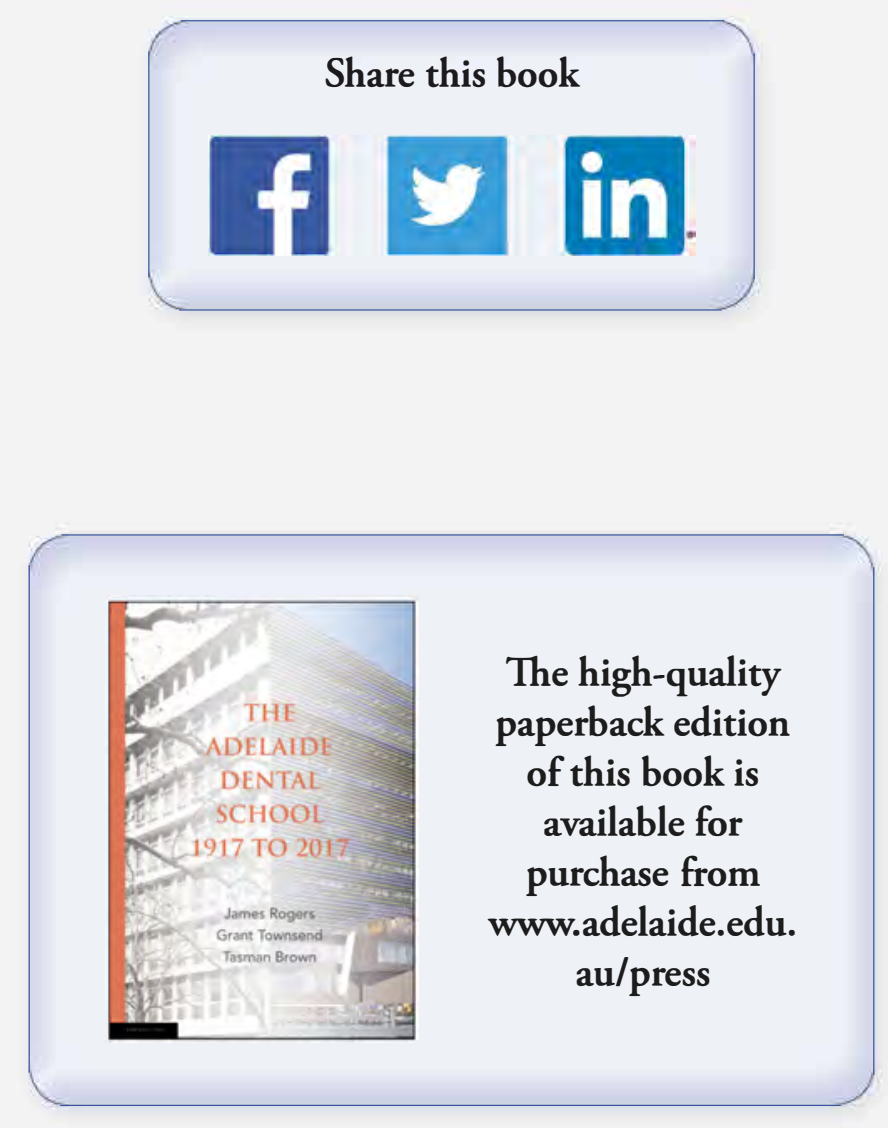

Suggested citation:

Rogers, J, Townsend, G and Brown, T (2018).

The Adelaide Dental School 1917 to 2017. Adelaide: Barr Smith Press.

DOI: http://dx.doi.org/10.20851/dental-history License: CC-BY-NC-ND 4.0 


\section{THE \\ ADELAIDE \\ DENTAL \\ SCHOOL \\ 1917 TO 2017 \\ by}

James Rogers

Grant Townsend

Tasman Brown

BARR SMITH PRESS

An imprint of

The University of Adelaide Press 
Published in Adelaide by

University of Adelaide Press

Barr Smith Library

The University of Adelaide

South Australia 5005

press@adelaide.edu.au

www.adelaide.edu.au/press

The Barr Smith Press is an imprint of the University of Adelaide Press, under which titles about the history of the University are published. The University of Adelaide Press publishes peer-reviewed scholarly books. It aims to maximise access to the best research by publishing works through the internet as free downloads and for sale as high-quality printed volumes. This book is typeset in Helvetica Neue and Adobe Garamond Pro and uses minimal capitalisation, reflecting the preferred style of the University of Adelaide Press and its imprint, the Barr Smith Press.

(C) 2018 James Rogers, Grant Townsend and Tasman Brown

This work is licenced under the Creative Commons Attribution-NonCommercialNoDerivatives 4.0 International (CC BY-NC-ND 4.0) License. To view a copy of this licence, visit http://creativecommons.org/licenses/by-nc-nd/4.0 or send a letter to Creative Commons, 444 Castro Street, Suite 900, Mountain View, California, 94041, USA. This licence allows for the copying, distribution, display and performance of this work for non-commercial purposes providing the work is clearly attributed to the copyright holders. Address all inquiries to the Director at the above address.

\section{(๑) $\Theta \Theta$}

For the full Cataloguing-in-Publication data please contact the National Library of Australia: cip@nla.gov.au

ISBN (paperback) 978-1-925261-73-8

ISBN (ebook: pdf) 978-1-925261-74-5

Editors: Rebecca Burton and Julia Keller

Cover and book design: Zoë Stokes

Cover images: The photographs on the front cover, courtesy of ADASA Archives and the University of Adelaide, show the former School of Dental Science on Frome Road (left), and the University of Adelaide's new Adelaide Health and Medical Sciences Building on North Terrace, incorporating the Adelaide Dental Hospital, opened in 2017 (right). 


\section{Dedication}

This book is dedicated to the staff and students of the Adelaide Dental School, past and present. 



\section{Contents}

Foreword $\quad x v$

Preface 1

Section I: The past, present and future 7

1 Foundations from dental apprentice to dental undergraduate 9

Apprenticeship

The introduction of a Dentists' Act and a Dental Board

Dental education begins at the University of Adelaide

The Odontological Society of South Australia

The Dental Graduates' Society

The need for a new dental school and degree course

The Dental Students' Society of the University of Adelaide

Sir Joseph Verco - first dean of Dentistry

The first meeting of the Faculty of Dentistry

The first women graduates

APR Moore

TD Campbell

Early faculty issues

Early staff appointments

The appointment of PR Begg

A new dental hospital 
Superintendent of the Dental Hospital

Articles of Apprenticeship

A higher degree course and research

The Dental Committee and the BDS course in the 1920s

Early staff and student photographs

References

2 Development of the School and the evolving curriculum -

1930s and 1940s

Setting educational standards

GO Lawrence

The colour of the academic hood

On the faculty's agenda

The importance of the Eighth Australian Dental Congress

Wartime

Student numbers

The evolving BDS curriculum

The Commonwealth Reconstruction and Training Programme

Fiftieth anniversary of graduates

References

3 A period of expansion and curriculum development - 1950s and 1960s

New blood - AM Horsnell and JC Thonard

A chair in restorative dentistry

Staff appointments and building research

A preventive approach

Postgraduate and honours programmes

Adelaide graduates' overseas study

The new Dental Hospital

Dental technology 
Consideration of using the courtesy title 'Doctor'

BDS curriculum development

Objectives of the Adelaide Dental School

Key staffing and curriculum issues

Recommendations on the BDS curriculum

Reflections on the BDS recommendations of the 1960s

References

4 The Raywood workshops and BDS curriculum reform - 1970s and 1980s

Restructuring the School — one department becomes four

Staffing during increasingly difficult financial times

A 'dental manpower crisis'

Back to a single department

Establishment of the South Australian Dental Service (SADS)

Amalgamation of medicine and dentistry

The Dawkins reforms

Integration of dental education

The new BDS curriculum - 1970s version

Graduate and postgraduate education

Recommendations in the Dental Curriculum 1/74 Report

Reports from the Advisory Centre for University Education

The BDS course in the 1980 s

References

5 A new Problem-Based Learning (PBL) BDS curriculum 1990 s to 2000

The context

Staffing matters

Upgrading of facilities

Establishment of SAFDER 
Australian Centre for Oral Health

Restructuring in the university

Accreditation

A new Problem-Based Learning BDS curriculum

Some reasons for change

Broad goals of the new BDS curriculum

The process of curriculum review in the $1990 \mathrm{~s}$

The model for the new BDS curriculum - 1993

Features of the PBL BDS curriculum

Dental Learning Packages

Evaluation of the BDS curriculum

Admission to the BDS course

References

6 A revised integrated $\mathrm{BDS}$ curriculum and a $\mathrm{BOH}$ programme -

2000s to the present

Quo vadis dentistry? (Where are you going, dentistry?)

The context of the School

Joint ventures

Staffing matters

Loss of professorial positions

Accommodation issues

A new simulation clinic

The tender

A review of the Faculty of Health Sciences and a Professional

Services Review (PSR)

Other factors impacting the School

The Australian Dental Council (ADC) and the Dental Board of Australia (DBA)

$\mathrm{ADC}$ reports

ADC recommendations 
Revised BDS curriculum (2010 version)

The Australian Universities Quality Agency (AUQA)

commendation

Proposed changes to the BDS programme

Appointment of an educational consultant

Vision statements

Ngutto: A web-enabled core curriculum database

A School Assessment Strategy

Key aspects of the revised BDS curriculum - 2010 version

Management of the revised BDS curriculum

Integrated Learning Activities in the revised BDS curriculum

The stages of implementation of the revised BDS curriculum

Reflecting on the revised BDS curriculum

The Bachelor of Oral Health $(\mathrm{BOH})$ programme

Dental therapy

Dental hygiene

Bachelor of Oral Health

ADC accreditation of the $\mathrm{BOH}$ programme

Graduate Certificate in Oral Health Science

References

7 Postgraduate education and research

The beginning

BDS honours degree

PhD degree

MDS and DClinDent degrees

Postgraduate Committee in Dentistry

GJ Mount

A tradition of research in the School

Excellence in Research for Australia (ERA) 
QS worldwide ranking

The research-teaching nexus

Australian Research Centre for Population Oral Health (ARCPOH)

Establishment of the Colgate Australian Clinical Dental Research Centre (CACDRC)

Centre for Oro-facial Research and Learning (CORAL)

Research groups within the School

References

8 Where to now and in the future - dental education and practice?

Leadership, governance and management in dental education new societal challenges

Strategic management and organisational behaviour in dental education

Comments from previous deans and leaders of the Adelaide Dental School

Adjunct Professor Kaye Roberts-Thomson

Emeritus Professor John Spencer

Professor Wyatt (Rory) Hume, professor and dean,

University of Utah School of Dentistry, USA

Emeritus Professor Alastair Goss

Emeritus Professor Wayne Sampson

Clinical Professor Geoffrey Heithersay

Published comments by Dr John McIntyre

Comments by other dental academics

The growth of new dental schools in Australia

Concluding comments by the authors

References

Section II: Personal reflections 
10 Learning to be a dentist (1946-50) — Tasman Brown 263

11 Learning to be a dentist (1968-72) — Grant Townsend 291

Section III: Appendices 305

Appendix 1: Adelaide Dental School staff 307

Deans of dentistry

List of staff 1921-2016

Appendix 2: BDS and $\mathrm{BOH}$ graduates 339

Bachelor of Dental Surgery (BDS) graduates (1921-2016)

Bachelor of Oral Health (BOH) graduates (2004-16)

Appendix 3: Selected documents

The opening of the new Royal Adelaide Hospital Dental

Department and the University of Adelaide School of Dental

Science (1969)

Appointment of a professor of restorative dentistry -

correspondence from the registrar to the dean, 16 March 1965

Grant Townsend's notes from one of the lectures in biochemistry in 1969

Programme and written examination in biochemistry in 1969

Glossary

$\begin{array}{ll}\text { About the authors } & 411\end{array}$

$\begin{array}{ll}\text { Acknowledgements } & 413\end{array}$ 



\section{Foreword}

To convey an understanding of how, over a century, an organisation as complex as a dental school was conceived, became established and subsequently evolved to become a world-ranked institution is a significant challenge. As students and staff in the School, with a total of more than 160 years of combined experience spanning almost three-quarters of that century, James Rogers, Grant Townsend and Tasman Brown have taken up that challenge.

The result of their work is much more than a chronology of 100 years of activity. The first section outlines and interprets the way in which the dental profession and the university have worked together to establish and maintain a dental school with an outstanding international reputation for high-impact research and quality education. It follows the 'pendulum' as it has swung from integration with medicine, to independence as a faculty and back to operation as a school within a broader health science framework while, at the same time, educational philosophies and paradigms have continually changed and clinical practice has evolved from its surgical beginnings to the present time, with the focus moving to an anticipated future involving community-based, integrated healthcare. The characters and the events as they are revealed will bring back all sorts of memories for everyone with a connection to the School.

The second section adds a very valuable personal dimension to the story, with the late John Lavis, Tasman Brown and Grant Townsend reflecting on their diverse experiences as students spanning wartime, the post-War period with the associated boom in student numbers, and more recent times. The common themes and contrasting challenges add a sense of 'having been there' to the earlier descriptions of events, places and people. It is fascinating reading.

The appendices provide important and equally fascinating primary resource material. This is another very valuable dimension to the story. The diverse contents will refresh memories and be available for future generations when they in turn come to reflect on the School's continual evolution. The opportunity to revisit a biochemistry examination from the 1960s will be an interesting experience for many, as will be 
the opportunity to browse through the complete list of BDS graduates to remember friends past and present, or read the 1969 story of the new School of Dental Science at a time when the School has recently moved from its traditional Frome Road 'home' to a new location and an exciting future.

The breadth and depth of information that the authors have brought together in this book make it valuable not only as a story well worth telling, but also as a stimulus for reflection, and as a context within which we can contemplate our future as we continually evolve and strive to maintain a reputation established by 100 years of excellence in education and quality research.

Professor Lindsay Richards

Former dean and head of School

Adelaide Dental School 


\section{Preface}

This history considers 100 years of education at the Adelaide Dental School. Although some compulsory training for dental students was introduced in 1906 at the University of Adelaide, the date of 4 October 1917 has been chosen as the beginning of these 100 years because it was then that three critical recommendations arose from a special meeting of representatives of the Odontological Society of South Australia, the Dental Graduates' Society of South Australia, the University of Adelaide and the Royal Adelaide Hospital. These recommendations, taken together, proposed the establishment of a dental school that would be affiliated with the university and the hospital for the education of dental students.

The recommendations were

- that the University of Adelaide and the Adelaide Hospital agree to assist the dental profession to secure a diploma in dental science

- that the members of the Odontological Society of SA are prepared to give gratuitous clinical service at the proposed Dental School

- that the proposed Dental School shall be under the control and direction of the University of Adelaide, and that a degree in dental science be granted.

From this meeting, it is possible to trace the events leading to the foundation and operation of the Adelaide Dental School, as well as the people involved in its development. One can also appreciate the influence that the establishment of a school had on both the dental apprenticeship system that had operated up until that time and the dental profession.

1917 is an important date, not only because of the meeting mentioned above but because, as historian Arthur Chapman noted (1937, p. 32), a Bill for The Dentists' Further Amendment Act 1917 (SA) was assented to on 15 November 1917. With reference to this Bill, Chapman stated that ' $[t]$ he Minister indicated that a movement was on foot to establish dental clinics in the State, and that the University of Adelaide and the Adelaide Hospital would be able to provide facilities for men to qualify' (p. 33). This Bill underpinned the formation of the School and the Faculty of Dentistry. Therefore, 
the year 1917 is considered to be an appropriate date to celebrate the beginning of the Adelaide Dental School.

It should be noted that several other important events occurred between 1917 and 1921, including the formation of the Adelaide Dental Students' Society (1919); the first intake of dental students into the degree of Bachelor of Dental Surgery (1919); the passing of regulations by the Council of the University of Adelaide that formalised the Faculty of Dentistry (1920); and the first meeting of the Faculty of Dentistry (1920). All are important events worthy of celebration when their respective centenaries occur.

Much of the information used in this work has been compiled from archived Minutes, held in the Barr Smith Library, of meetings of the Faculty of Dentistry and the Faculty's Curriculum Committee. The works of Arthur Chapman (History of Dentistry 1836-1936) and Mervyn Wyke Evans (The History of the Dental Students' Society of the University of Adelaide) have also provided much valuable information in relation to the formative years of the School. The Short History of the Faculty of Dentistry produced by Tasman Brown in 1971 has also been an important reference, as have the annual issues of the Adelaide Dental Students' Society magazine, Probe, particularly the deans' reports in these issues.

In Section I, we have focused on six periods of dental education at the Adelaide Dental School: the foundation years from a system of apprenticeship to the late 1920s; the development of the School and the evolving BDS curriculum from the 1930s and 1940s; the period of expansion and curriculum development during the 1950s and 1960s; the Raywood workshops and subsequent curriculum reform during the 1970 s and 1980s; the introduction of a new Problem-Based Learning (PBL) curriculum in the 1990s; and the introduction of a revised Bachelor of Dental Surgery (BDS) programme and a new Bachelor of Oral Health (BOH) programme in the 2000s.

We thought it would be valuable to ask some graduates to relate their personal memories about how well their education equipped them for their future professional careers. These personal reminiscences begin in the late 1940s and extend up to recent years. It could be argued that, as we chose the graduates, their feedback represents a biased sample. However, our aim was to choose graduates of the past seventy years or so who were 'good students' and then to ask them to reflect on their education. Obviously, there would be some graduates who did not enjoy their experience in the School, but our aim in marking 100 years of dental education at the Adelaide Dental School has been to provide an aspirational perspective. Most of the students' comments are very positive, suggesting that the BDS programme and, more recently, the $\mathrm{BOH}$ programme at any given point of time have provided a good educational basis for students committed to learning.

We hope that the reader will form an overall impression of how the dental curriculum at the Adelaide Dental School has evolved over 100 years and gain some 
understanding of the context in which changes have occurred. Our focus has been on the undergraduate curricula, especially the BDS programme, but we do mention aspects of postgraduate and continuing education. The importance of research in informing curriculum development and content is also noted.

Views of what constitutes a 'curriculum' vary considerably from the narrow view of a curriculum being only what is taught to the much broader view that a curriculum is all-encompassing and includes all of the dimensions of a complex system that aims to provide an effective learning environment. These dimensions include not only what is taught and how it is organised, but also, just as importantly, the facilities, resources (both physical and human), procedures, culture and outcomes. While there is a 'written' curriculum that can be thought of as the 'intended' curriculum, there is also the 'implemented' curriculum and the 'achieved' curriculum (Toombs \& Tierney 1993). Then there is the 'hidden' curriculum that includes all of the contexts that influence how and what students learn outside the formal and intended curriculum (Hafferty \& O'Donnell 2015). The hidden curriculum is particularly important in health professional education, especially dentistry, where there is close interaction between students and staff, often in a stressful clinical environment.

From the initial apprenticeship form of training, dental students were then accepted to complete certain subjects at the university to provide some academic rigour to their education. As the curriculum evolved, it included various subjects in the basic sciences presented by staff from non-dental departments as well as more clinically related subjects taught by dental staff.

A major review of the BDS curriculum occurred in the 1970 s, which led to the introduction of dental subjects earlier in the course, as well as the introduction of topic courses that covered areas, such as dental occlusion and pain control, in an interdisciplinary manner. However, it was not until 1980 that some aspects of this curriculum were implemented, highlighting that curriculum review and eventual implementation tend to be very lengthy processes.

In the 1990s, when a new Problem-Based Learning BDS curriculum was introduced, a small number of streams replaced the previous large number of separate subjects. The School assumed control of the whole curriculum, including assessment, although staff from non-dental departments continued to contribute to teaching. Students spent time in the dental clinics from the commencement of their course and an emphasis was placed on application of knowledge in clinical contexts. The implementation of this new curriculum was facilitated by the move from four departments to a single Department of Dentistry in 1984.

In 2002, a new Bachelor of Oral Health curriculum was introduced to educate dental therapists and hygienists. In 2010, another major revision of the BDS curriculum occurred, with each year consisting of only a single stream, referred to as 
Dental Science and Practice. A more co-ordinated and integrated form of assessment was also introduced according to an approved School Assessment Strategy.

In each of the chapters describing the $\mathrm{BDS}$ and $\mathrm{BOH}$ curricula, we have attempted to provide the context for change, including both internal and external drivers. Some of the key players are also mentioned. We have not attempted to produce a comprehensive history of the School over 100 years, but have rather focused on summarising the main changes that have occurred in dental education and the key events that have provided an environment for change.

Curriculum change at the Adelaide Dental School seems to have followed a process of punctuated evolution, with periods of relative stasis interspersed by bursts of activity linked to internal and/or external pressures. We have identified three major periods of curriculum change — the 1970s leading into the 1980s; the 1990s; and the 2000s.

Section II contains three chapters in which two of the authors, Tasman Brown and Grant Townsend, provide personal viewpoints of their education at the Adelaide Dental School. Brown's undergraduate career spanned the years from 1946 to 1950 , and Townsend's undergraduate years spanned the period from 1968 to 1972 . With the permission of his family, we have also included a description by Dr John Lavis of his experiences as a dental student at the Adelaide Dental School during the period 1941 to 1945 . These stories tend to emphasise a very 'male, white' perspective but this reflects the composition of the dental student body in those times. More recently there has been a strong shift for more women and also students with non-European heritage to study dentistry, as evidenced by the student lists in Appendix 2, and we have included contributions from some of these students in the short reflective pieces at the end of Chapters 3 to 6 .

Lists of the names of deans and staff of the Adelaide Dental School are provided in Section III (Appendix 1), while lists of graduates of the BDS and BOH programmes are provided in Appendix 2. This section also contains a potpourri of material, including copies of documents and examples of lecture notes and examination papers. The booklet that was produced for the official opening of the Royal Adelaide Hospital Dental Department and The University of Adelaide School on Frome Road in 1969 is provided in full in Appendix 3 as a nostalgic reminder of the past, made even more nostalgic by the imminent decommissioning of the building. Thus, this book can be used as both an historical document and a reference. We believe that it will be important for future staff and students to be able to source the beginnings and development of their Dental School - to see, in fact, where the School has come from and how its curricula have evolved.

A recurring theme that emerges throughout the book is that there has been a continual tension between, on the one hand, the School's plans to be a highly innovative world leader in terms of its teaching and research and, on the other hand, its ability to 
gain the funding needed to secure appropriate resources to support excellence. This has meant that educational arguments for curriculum change have needed to be considered within the existing political and financial environment of the university.

Although there has always been this tension since the formation of the School, the loss of faculty status in 1999 resulted in diminished control over our own destiny. The School now often relies on others to advocate on its behalf within the university and with stakeholders outside the university.

One thing that we can be sure of is that there will be more changes ahead. The School has adapted to many changes over the years and the pace of change seems to be quickening. As former vice-chancellor Professor Warren Bebbington (2017) has noted:

Of my 40 years in universities, I cannot think of a moment that ever presented as many challenges and opportunities as the present one. The next few years will sorely test the resilience of the University's mission and values as it faces new circumstances on every front.

What may happen to dentistry in the future remains to be seen, but several opinions are presented in Chapter 8 of Section I about the future of dental education and the practice of dentistry, with contributions from former deans, including John Spencer and Kaye Roberts-Thomson, as well as the long-serving members of the School, Geoffrey Heithersay, Alastair Goss and Wayne Sampson. Adelaide graduate and former head of the Department of Dentistry in Adelaide Professor Rory Hume, who has had extensive experience nationally and internationally as a dental dean and senior university manager, also provides some comments. Thoughts provided in published articles by John McIntyre and other dental academics, including Professors Bartold, Schwarz and Freer, are also included. We feel it is important to consider both the future of dental education as well as likely developments in dental research and the practice of dentistry, as these are intimately linked — or should be. The material in this volume encompasses all of these considerations.

Our hope is that the high quality of dental education and research that has led to the Adelaide Dental School's strong international reputation can be maintained in the future despite the pressures that it will undoubtedly continue to face.

\section{References}

Bebbington W (2017) Facing the winds of change. Lumen (Alumni Magazine, The University of Adelaide), Autumn Issue: 1.

Brown T (1971) The University of Adelaide, Faculty of Dentistry, a short history. The University of Adelaide.

Chapman A (1937) History of dentistry in South Australia 1836-1936. Australian Dental Association, South Australian Branch Incorporated, Adelaide. 
Evans MW (1988) The history of the Adelaide University Dental Students' Society. Published by the author, Adelaide.

Hafferty FW, O’Donnell JF (2015) The hidden curriculum in health professional education. Dartmouth College Press, Lebanon.

The Dentists' Further Amendment Act 1917 (SA).

Toombs WE, Tierney WG (1993) Curriculum definitions and reference points. Journal of Curriculum and Supervision 8: 175-195. 
Section I:

The past, present and future 



\section{1}

\section{Foundations from dental apprentice to dental undergraduate}

\section{Apprenticeship}

Any attempt to trace the origin of dental education at the Adelaide Dental School needs to consider what was happening in the nineteenth century. This was a time when prospective students of dentistry sought a registered dental practitioner in the hope that they would be articled as an apprentice. Mr Robert Norman, South Australia's first dental surgeon, advertised for a 'gentlemanly youth who would be taken as a pupil for a period of 3 to 5 years' in the $S A$ Register in 1846. It is not known whether any pupil was appointed but, if so, he would probably have been the first dental student in South Australia (Chapman 1937, p. 47).

Articles of Apprenticeship ranged from three to six years, and pupils were expected to pay premiums related to the depth of their studies. A full course, including instruction in the clinical and mechanical aspects of dentistry, was the most expensive. If a pupil chose only the mechanical aspects of dentistry, the costs were much less.

In his book The History of Dentistry in South Australia, Arthur Chapman (1937) noted that the quality of the practical work in those days was usually of a high standard. However, a serious weakness in training was a lack of supporting knowledge. Being articled to one person meant that the educational experience was limited by the knowledge of the trainer. So the educational experience of apprentices varied considerably.

As Chapman (1937, p. 46) noted,

[t] he experience of the pupil naturally varied with the temperament, learning, social status and technical ability of his preceptor, and there is perhaps more 


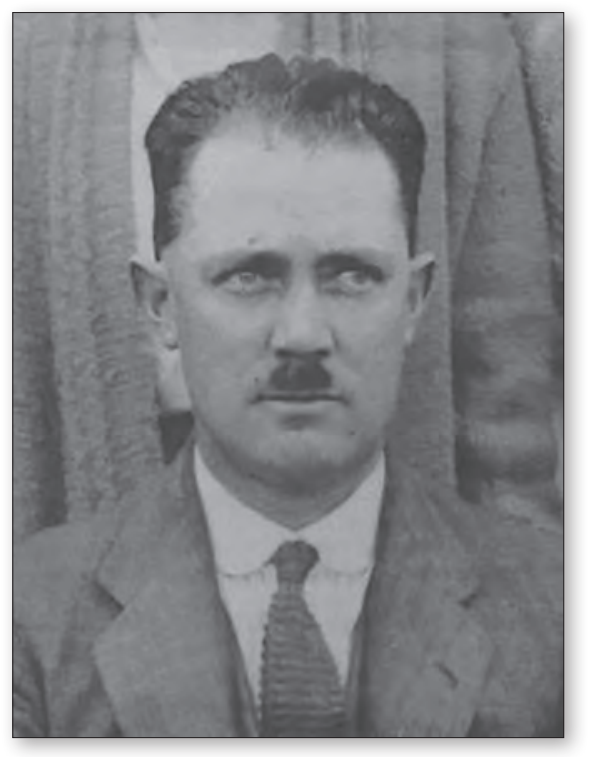

Figure 1.1 Arthur Chapman (ADASA Archives, courtesy of A Lake). than a modicum of truth in the oftheard statement that the quality of his education varied according to the amount of premium, and the social standing of the pupil's family. That many of these early pupils suffered a condition of service little short of a mild form of slavery is undoubtedly true - hours were long and remuneration, if any, small, while duties often included the executing of the most menial of household chores.

It was often remarked by those who had trained under this system and could appreciate the benefits of a university-based comprehensive dental education that to be able to access knowledge and experience from the best teachers and practitioners represented the greatest advance in dental education.

Not everyone who was indentured became a dentist. Some elected to become dental mechanics, while others could become operative dental assistants. Much of their training took place in 'workshops' attached to the practices.

Perhaps one saving grace, mentioned by Chapman, for those who had to suffer the many difficulties of being a dental apprentice, was that they were spared the 'apotheosis of academicity', a term coined by Chapman (p. 45) to denote time spent on studying theory. There was neither the availability of literature nor the equipment to aid in diagnosis that was limited to visible signs and symptoms. However, in general, the dentists of this era were considered to be competent operators.

\section{The introduction of a Dentists' Act and a Dental Board}

At the turn of the century, there were two outstanding problems confronting the dental profession. One was the absence of a legal structure that could apply rules and regulations to the profession. The other was the development of a structure to promote the acquisition of knowledge so necessary for the future of the profession. Another relevant concern in the 1880s was the influx of many 'dentists' from Victoria who flooded into South Australia, no doubt as a result of the restrictions imposed by the new Dentists' Act in Victoria. Apart from this influx of doubtful and often downright charlatan visitor practitioners, there also emerged the establishment of dental 
companies, dental parlours, competitive advertising and the inevitable price-cutting for services.

These issues provided a stimulus for the dental profession to lobby parliamentarians to introduce legislation establishing rules and standards for registration. By 1898, the South Australian government was asked to introduce the necessary legislation and this resulted in a Bill of 1901. The Dentists' Act was assented to on 13 November 1902. As noted by Chapman (1937, p. 30):

By this Act, the practice of dentistry in South Australia was made subject to Statute

Law. A dentist was defined as 'a person entitled to be registered under the Act.'

This Act vested the administration of the Act in a Dental Board, and empowered the Board to make regulations and to conduct examinations. It also prescribed the keeping of a Dentists' Register and the appointment of a Registrar.

The members of that first Board were Dr EA Wigg, Dr B Smeaton, Dr P Crank, Dr EJ Counter, JT Hardy Esq and B Thomson Esq.

The functions of the South Australian Dental Board included:

1. registration

2. education of dental students

3. examination of applicants for registration

4. education of the public in dental health matters

5. suppression of unregistered practice

6. suppression of unprofessional conduct

7. initiation of dental legislation

8. the statutory power of summary jurisdiction.

From 1903, these men were instrumental in setting out regulations to clarify the conditions under which students could study dentistry. The old apprenticeship system was legalised. All students were classified as having registered Articles of Apprenticeship. It was also decided that apprenticeships should last for four years and, importantly, that all students should pass an examination before they could be registered as dentists. It is not at all clear who set these examinations; whether it was, for example, those who taught the students or the members of the Dental Board, or whether suitable candidates were found through contacts with dental institutions interstate. Victoria was ahead of South Australia in that their Odontological Society was founded in 1884 and their Dental Board in 1888. The Dental Hospital in Melbourne was opened in 1890 . 


\section{Dental education begins at the University of Adelaide}

The question of compulsory university education was not addressed until 1906. There was a need to formalise dental education and move away from the existing arbitrary examination system. The University of Adelaide became the vehicle necessary to accomplish these educational requirements. The first lecturer in the Dental Board/University of Adelaide dental course was Herbert Gill Williams, who gave lectures in dental surgery and pathology. Courses were arranged to cover subjects such as inorganic chemistry (thought to be part of the Bachelor of Science (BSc) curriculum in the Faculty of Science), organic chemistry, anatomy, surgery, pathology, material medica, therapeutics, metallurgy and dental surgery. It is assumed that many, if not all, of these subjects were under the direction of academics who were managing the medical programme.

Allied to these academic changes, there were also changes to entry requirements for students wishing to study dentistry. Before this time, success in the Junior Public Examination was considered to be sufficient for entry but, with an awareness of the higher academic entry standards elsewhere, particularly in England, the standard was raised to the Senior Public Examination in 1908. The Senior Public Examination was the 'matriculation' requirement for entry into university. All of these changes were brought about by the South Australian Dental Board, under the regulations of the existing Dentists' Act.

By 1908, dental students in Adelaide followed a course of study that was equivalent to the diploma course presented in other states of Australia. As Brown (1971) notes, these requirements remained much the same until the Faculty of Dentistry was established in 1920.

\section{The Odontological Society of South Australia}

From 1908 to 1920, several important events occurred that culminated in the formation of the Adelaide Dental School. The first of these events was the formation of the Odontological Society of South Australia. Inaugurated in 1907, this society became the main means of promoting dentistry in the state.

The society was formed at the York Hotel on Rundle Street on 8 November 1907. Beginning as a dinner given for two dentists from interstate, this gathering ended up resolving to form the Odontological Society of South Australia. Drs Crank, Counter, JT Hardy and B Thompson, all members of the Dental Board, were at the meeting in the York Hotel. Their willingness to devote their time to the promotion and advancement of those practising dentistry makes them the true pioneers in establishing the dental profession in South Australia. 

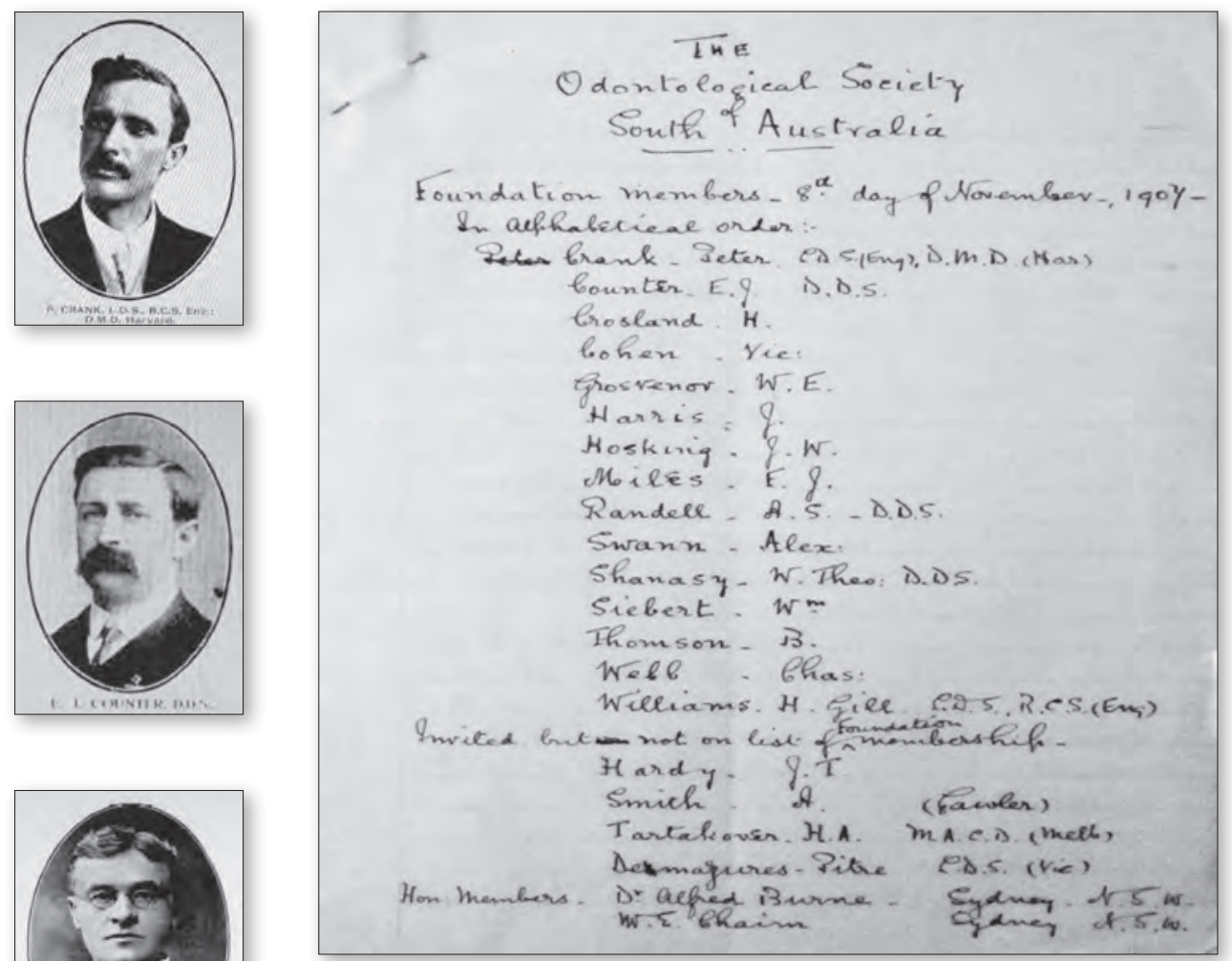

Figure 1.2 (above) The inaugural meeting of the Odontological Society of South Australia was held at the York Hotel, 8 November 1907 (ADASA Archives, courtesy of A Lake).

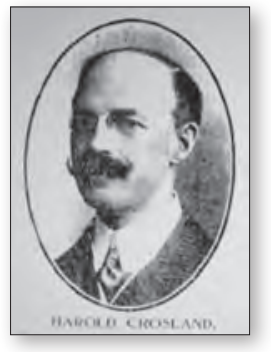

Figure 1.3 (left) Some of the foundation members of the Odontological Society of South Australia, (from top to bottom), P Crank, EJ Counter, WT Shanasy, H Crosland and A Swann. (ADASA Archives, courtesy of A Lake).

\section{The Dental Graduates' Society}

It appears that the Odontological Society was not the only society organised and run by dentists. The Dental Graduates' Society

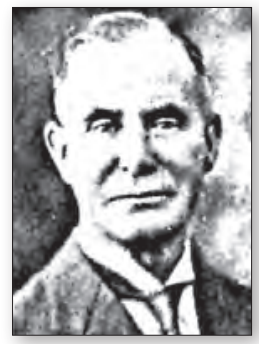
was formed in 1912 with H Gill Williams as its first president. The Registered Dentists' Association was also formed from those registered and unregistered practitioners in 1916. In 1923, the Odontological Society and the Dental Graduates' Society combined to form a new society named the State Dental Society of South Australia. In 1927, this society became the Australian Dental Association, South Australian Branch (ADASA). 


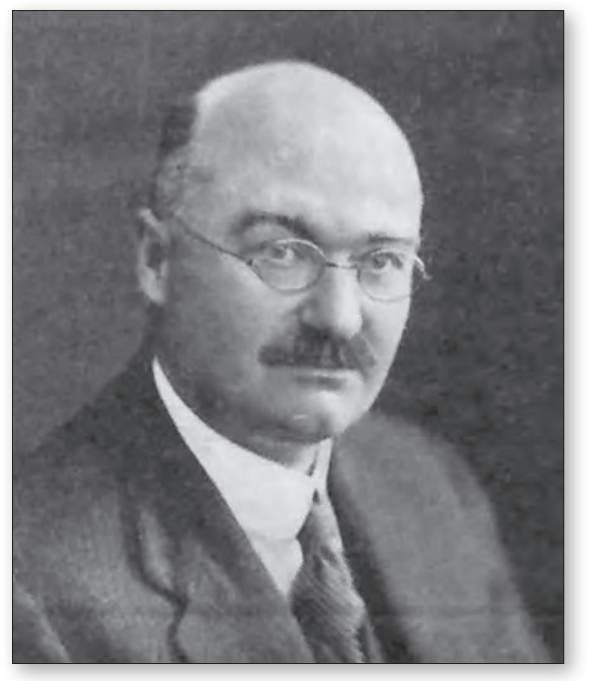

Figure 1.4 Herbert Gill Williams (ADASA Archives, courtesy of A Lake).
From this time, the ADASA Branch has represented dental practitioners working in various areas, including private practice, universities, armed services, government service, the school dental service and public hospitals.

A second issue to emerge was concern over the poor condition of children's teeth. The State Children's Department had approached the Odontological Society asking what could be done to remedy this problem. At the annual meeting of the Odontological Society in November 1908, children's dental health became the main topic for discussion. After much debate, it was decided that the best remedy for this serious state of affairs was the establishment

of a dental hospital and a training school. One year later, Mr RL Sims was appointed to the State Children's Department to provide dental care for children in need.

\section{The need for a new dental school and degree course}

The issue of a hospital and a school became an agenda item in 1911 and remained on the agenda until 1917 when a revision of the Dental Board/University dental curriculum became the main topic under debate. The need for a dental hospital and school, as well as the need to modify and improve the dental curriculum, caused the society to bring together interested parties to debate these issues. Members of the Odontological Society, the Dental Graduates' Society and the University of Adelaide met, and plans were set in motion to establish a degree course in dental surgery.

The following is a copy of the transactions of the first meeting of the conjoint committee that provided the foundation for one of the most important educational changes in dental education in South Australia (Chapman 1937, pp. 50-53).

Minutes of the first meeting held at the Council Rooms, Adelaide University, North Terrace, Adelaide, Thursday, October 4, 1917, at 8 p.m.

Present: Professor Rennie occupied the Chair, and with Dr. A. M. Cudmore represented the University. Mr. W. G. Coombs (Chairman of the Adelaide Hospital Board) and Dr. R. S. Rogers (Deputy Chairman) represented the Adelaide Hospital. Dr. E. J. Counter, Messrs. H. Gill Williams L.D.S., R.C.S. (Eng.), W.A. Harrop, L.D.S., R.C.S. (Glas.), and Alex Swann represented the dental profession. 
Professor Rennie, in declaring the meeting open, reviewed the circumstances under consideration, and suggested, as it necessarily was a request from the dental profession, it might be as well to consider the recommendations advanced by that body. In doing so the Chairman reminded members that progress with the University along the lines of securing a degree course had been made some years ago.

Dr. A.M. Cudmore submitted a progress report of the occasion of the first attempt to secure a degree at the University, but as dental members had already perused the same it was not brought forward for consideration.

The Chairman then requested that the dental recommendations be taken seriatim:Recommendations:

(a) The Adelaide University and the Adelaide Hospital agree to assist the Dental Profession to secure a Diploma in Dental Science. (Carried unanimously.)

(b) That the members of the Odontological Society of S.A. are prepared to give gratuitous clinical service at the proposed Dental School. H. Gill Williams explained that the demonstrators would be honorary officers. (Carried unanimously.)

(c) That the proposed Dental School shall be under the control and direction of the Adelaide University, and that a degree in dental science be granted. (Carried unanimously.)

Sub-section (1) of Recommendation (c): That provision shall be made for students who are registering under present conditions to complete the curriculum for the said degree.

Professor Rennie desired to define the difference between 'diploma' and 'degree'. It was a degree in dental science that was requested. These students had matriculated, and it was a matter of permitting them facilities to secure the said degree by extending to them the opportunity for contesting the increased subject matter for such a degree. (Agreed.)

Sub-section (2) of Recommendation (c): That past students who have completed and registered under Section (e) of the Dental Board Regulations shall have provision made so as to enable them to complete the curriculum of the said diploma.

Considerable discussion took place upon this matter, and it was agreed that a diploma be granted to such dental pupils and apprentices so favoured under the Sub-section (e), Section 19, and credit be given for the subject already secured with the privilege of sitting for the increased subject matter to entitle him to such diploma. These pupils or apprentices under Sub-section (e) had not matriculated and consequently could not enter for that degree in dental science. (Carried.)

It would appear that the main topic of debate at this important meeting was the creation of a structured degree course managed by the University of Adelaide, which was to be operational as soon as was practically possible. It also appears that there was some confusion at this meeting about the difference between a diploma and a degree. 
Students who graduated after these recommendations were put into effect would obtain a degree in dental science.

After this meeting in 1917, and at the time when the Faculty of Medicine began to administer the dental course (1919), there appears to have been a name change to the degree, so that the qualification became a Bachelor of Dental Surgery degree. Given that many of the changes during this time concerned clinical aspects of the course, it is not surprising that the emphasis changed from science to surgery.

\section{The Dental Students' Society of the University of Adelaide}

It was also in 1919 that ten students met at the Theatre Royal Café on Hindley Street to discuss the possibility of forming the Dental Students' Society. The students were APR Moore, R Smith, JO Donnell, OL Ziegler, M Schafer, J Clark, C Rankin, W Marshman, with Herron and Roennfeldt (their first names were not listed) making up a group who later became known as the foundation members of the Dental Students' Society of the University of Adelaide.

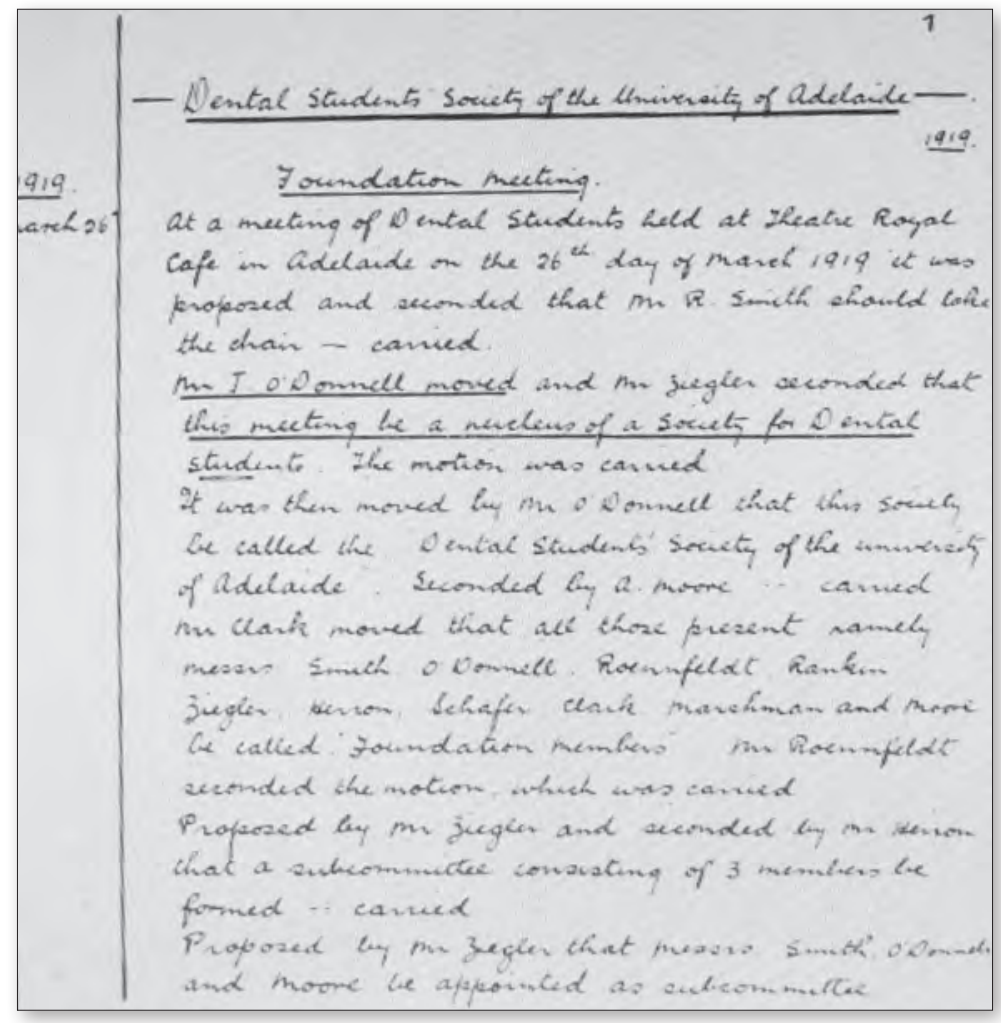

Figure 1.5 Minutes of the first meeting of the Dental Students' Society of the University of Adelaide. Minutes recorded by Arthur PR Moore on 26 March 1919 (Evans 1988). 
One of the prime reasons for the formation of this society was the need for the students of dentistry to communicate with each other. With so many students scattered in the city, the suburbs and the country, geographical separation meant that there was no common meeting ground. There was no provision for them to discuss issues affecting either their education or their personal interests, nor to foster friendships. It should be noted that the limitations imposed by the apprenticeship system and their university education, divided between the Faculties of Medicine and Science, made it important for students to have an organisation that could represent them at all levels of their education.

The objectives of the society were

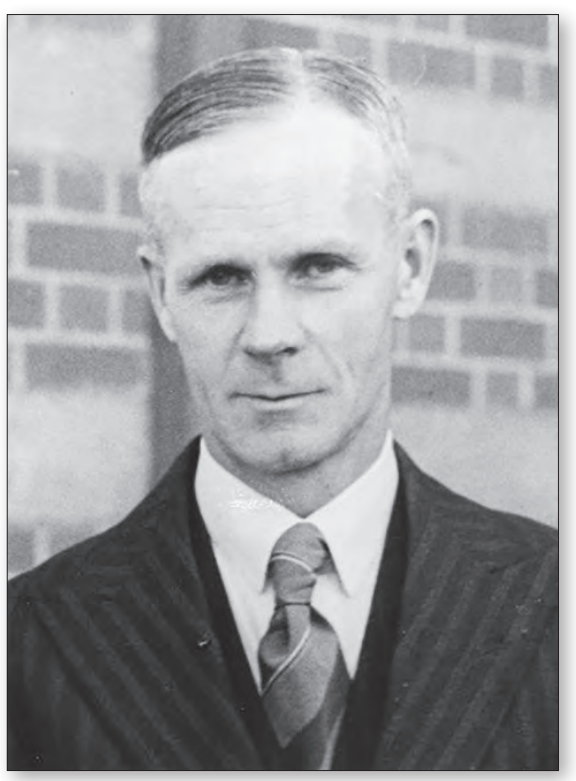

Figure 1.6 Arthur Pariss Reading Moore (courtesy of Kevin Moore). incorporated in their original constitution and they aimed

a. to establish and maintain student interest in their own profession with a view to securing their future success as practitioners

b. to promote and conserve the rights of bone fide dental students

c. to encourage the principles of dental ethics

d. to require each student to contribute from their own personal knowledge for the benefit of others, and also, by interchange of ideas, to encourage the habit of close observation and investigation

e. to cultivate the pleasure and stimulation derived from personal contact with fellow students. (Evans 1988, p. 166)

One important feature of the Dental Students' Society was the presentation of dentally relevant papers for discussion. In an age where debating societies were in vogue and public speaking universally endorsed, the society managed to enhance its standing through these presentations. Amongst those who approved the initiatives of the Students' Society was Sir Joseph Verco, the dean of Medicine.

\section{Sir Joseph Verco - first dean of Dentistry}

Sir Joseph Verco's input into the formation of the Faculty of Dentistry was critically important. He strongly believed that the practice of dentistry should be seen as a separate 
discipline from medicine and should have its own academic foundation. One of the important promotional measures that he supported was the generation of sufficient funds to enable the Faculty of Dentistry to cover its operating costs. All this had to be done within the existing financial framework of the university. Also, it was necessary to encourage suitable staff to offer their services (including offering himself as the first dean of Dentistry). Sir Joseph was able to tap into Red Cross funds left over from World War I and convince the Red Cross Finance Committee to donate $£ 15000$ toward a dental school as well as securing another $£ 10000$ from the South Australian government. The money was eventually used to build a new dental hospital on Frome Road, Adelaide, which

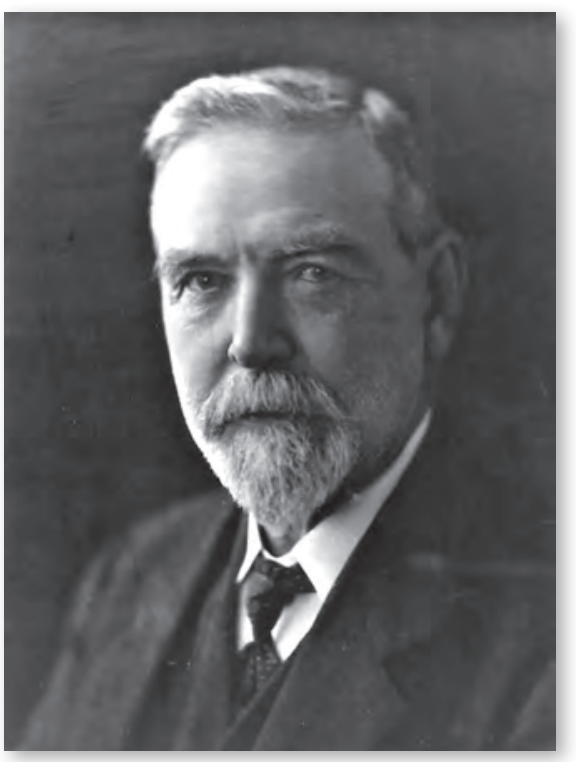

Figure 1.7 Sir Joseph Verco Kt, MD, FRCS (ADASA Archives, courtesy of A Lake). was opened on 10 July 1923.

The establishment and the success of the Dental Students' Society, coupled with earlier amendments to the Dentists' Act in 1917, further reinforced the case for a faculty of dentistry to be established at the University of Adelaide. The important amendments to the Dentists' Act that affected the education of dental students at the university included a definition of the practice of dentistry; prohibiting the practice of unqualified persons; and a restriction on certain types of advertising.

By 1919, the first intake of students to study dentistry was officially admitted to the Bachelor of Dental Surgery degree course under the direction of the Faculty of Medicine. Students who enrolled in the dental course had previously registered as students under the provisions of sub-section (e) of the Dental Board Regulations. In April 1920, regulations were finally passed by the University of Adelaide Council to formalise the Faculty of Dentistry.

\section{The first meeting of the Faculty of Dentistry}

In the university's Archives and Record Keeping Section of the Barr Smith Library, there is a document that records a Faculty of Dentistry meeting held on Tuesday 15 June 1920. It is not known whether there were other meetings of the faculty before this date. No earlier references appear in the bound Minute volumes of 1920-81. Therefore, it can be reasonably assumed that this was the first meeting of the Faculty of Dentistry. In 
noting the people present and the matters under discussion, much can be understood about the faculty and the complex issues it faced. Those present at this meeting were: Sir Joseph Verco, dean of Medicine; Mr WG Coombs; Drs WT Shanasy, AI Chapman, WT Hayward, EJ Counter and TH Smeaton; Messrs H Gill Williams, FM Swann, A Swann and W Fuller; Professors TB Robertson, JB Cleland and F Wood-Jones. Those members who agreed to serve in the faculty for one year were: WG Coombs (chairman of the Hospital Board), Mr F Johnson (chairman of the Dental Board), Dr EJ Counter and Messrs A Swann, H Gill Williams and FM Swann.

The agenda for this meeting was as follows:

1. to appoint a dean

2. to fix a day and hour for the meeting of the faculty

3. to consider application for admission with status for the BDS course

4. to consider articles for apprenticeship submitted by students

5. to consider the question of amending regulation IV of the BDS degree

6. to discuss the question of a fee for a special examination in anatomy.

Under 'Any Other Business', letters were received from Professor Cleland and an unnamed lecturer in metallurgy, presumably seeking information regarding teaching fee structures.

This meeting formalised the structure that the Faculty of Dentistry would take into the future. Sir Joseph Verco was elected as dean for 1920 and the third Tuesday of the month was chosen for meetings of the faculty.

With regard to the apprenticeship system and how it was to be assimilated into the BDS course, agenda items 2, 3 and 4 clarified many of the issues facing the new faculty. For example, Faculty now had the power to approve Articles of Apprenticeship and, at this first meeting, the following students were approved as apprentices: Emmeline Cobbin, Leslie C Maiden, Harold R Coombe, James Mallon, Enid Kinmont and Wesley M Marshman.

The amended Regulation IV now stated:

Before admission to the degree candidates must have served under Articles of Apprenticeship for a period of three years to a dentist registered in any part of the British Empire or at a recognised Dental Hospital. Such apprenticeship shall not be recognised if a number of students apprenticed to any one dentist in his private practice is thereby increased to three or more at one and the same time. A copy of the Articles of Apprenticeship shall in every case be filed with the Registrar within three months from the date of their execution or within such further time as the Faculty of Dentistry may in any special case determine. (Faculty of Dentistry 1920)

Although academic instruction was conducted at the University of Adelaide by 1920 , the practical side of the profession was still to a large degree managed under the old 
apprenticeship system by registered practitioners. This included students who did not wish to attend university courses, but preferred to receive instruction as a dental assistant or a dental mechanic. After the establishment of the Faculty of Dentistry, those who had been practising clinical dentistry and who were not registered, but who did not wish to enter the new BDS course, for whatever reason, were allowed to continue practising under a 'grandfather clause'.

The names of those students who were listed in the first Minutes of the Faculty of Dentistry were as follows:

\begin{tabular}{|l|l|l|l|}
\hline Name of student & To whom articled & Date of articles & Year of study \\
\hline Clark JF & ER Brown & 5.3 .18 & Second \\
\hline Cobbin Emmaline & EP Rowley & 20.2 .20 & First \\
\hline Coombe HR & GA Miller-Randle & 5.12 .19 & ditto \\
\hline Fischer FHG & RG Gibson & 16.1 .20 & ditto \\
\hline Kinmont Enid & AF Randle & 29.3 .20 & ditto \\
\hline Maiden LC & H Gill-Williams & 16.3 .20 & ditto \\
\hline Mallan Jas & HD Mallan & 2.2 .20 & ditto \\
\hline Marshman WMT & FM Swann & 3.2 .20 & ditto \\
\hline Moore APR & PR Newling & & Third \\
\hline O’Donnell JA & PR Newling & & Third \\
\hline Rankine CR & PR Newling & 8.3 .20 & \\
\hline Roenfeldt CO & WC Todd & 9.12 .19 & Non-graduating \\
\cline { 2 - 4 } & RJB Smith & 8.6 .20 & Second \\
\hline Schafer MEH & AL White & 5.4 .19 & Non-graduating \\
\hline Ziegler CL & & & \\
\hline
\end{tabular}

Figure 1.8 Student names listed in the first Minutes of the Faculty of Dentistry.

\section{The first women graduates}

The list shown above must be one of the very early student lists of the Faculty of Dentistry. It is interesting to note that the female members are listed with their given or first names, but not the males. Although the names of Ms Cobbin and Kinmont are recorded, they were not the first women to receive a BDS degree. The first woman 


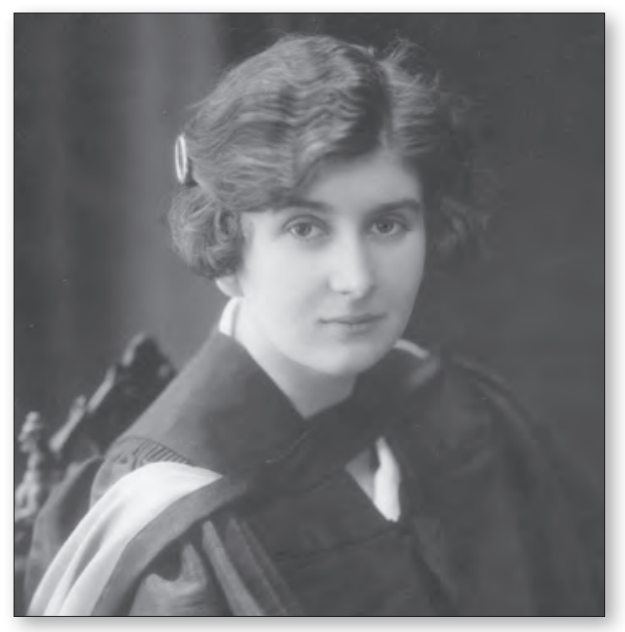

Figure 1.9 Linda Thompson, graduated 1926 (ADASA Archives, courtesy of A Lake).

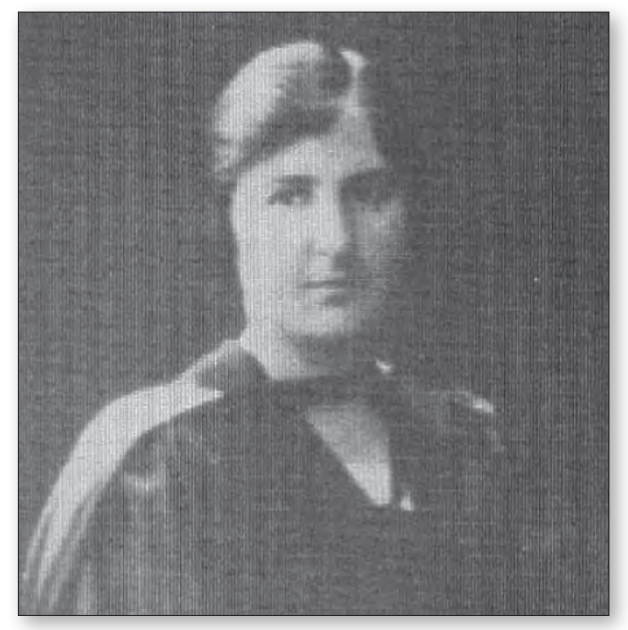

Figure 1.10 Winifred Preedy, graduated 1927 (ADASA Archives, courtesy of A Lake).

to receive the BDS degree from the University of Adelaide was Linda Thompson, who received her degree in 1926. The second female graduate was Winifred Preedy, who graduated in 1927.

According to Evans (1988), many young women were attracted to the profession through the success of Beatrix Bennet, a registered dentist who had made a name for herself treating children. Many parents began to see that dentistry might well be a suitable occupation for their daughters - so much so that, according to the student enrolments listed by the Dental Students' Society, females often made up a quarter of those wishing to join the society. Today, dental student records show that females comprise about $55 \%$ of the total number of enrolled students in the BDS degree course and make up most of the students enrolled in the $\mathrm{BOH}$ programme.

\section{APR Moore}

Of the fourteen names of students listed in the Faculty Minutes in 1920, two were in their third year. They were APR Moore and JA O'Donnell. It is known that Arthur Moore was apprenticed to PR Newling; he must have been in his third year in the profession at the time of the formation of the faculty. As he graduated with a BDS degree in the first graduate list (1921), he must have spent a year establishing his credentials with those in authority to be awarded the degree. A similar arrangement must have applied to his fellow students who graduated at the same time.

Much has been written about Arthur Moore's involvement in the Dental Students' Society and his passion for overcoming problems and getting things done. 


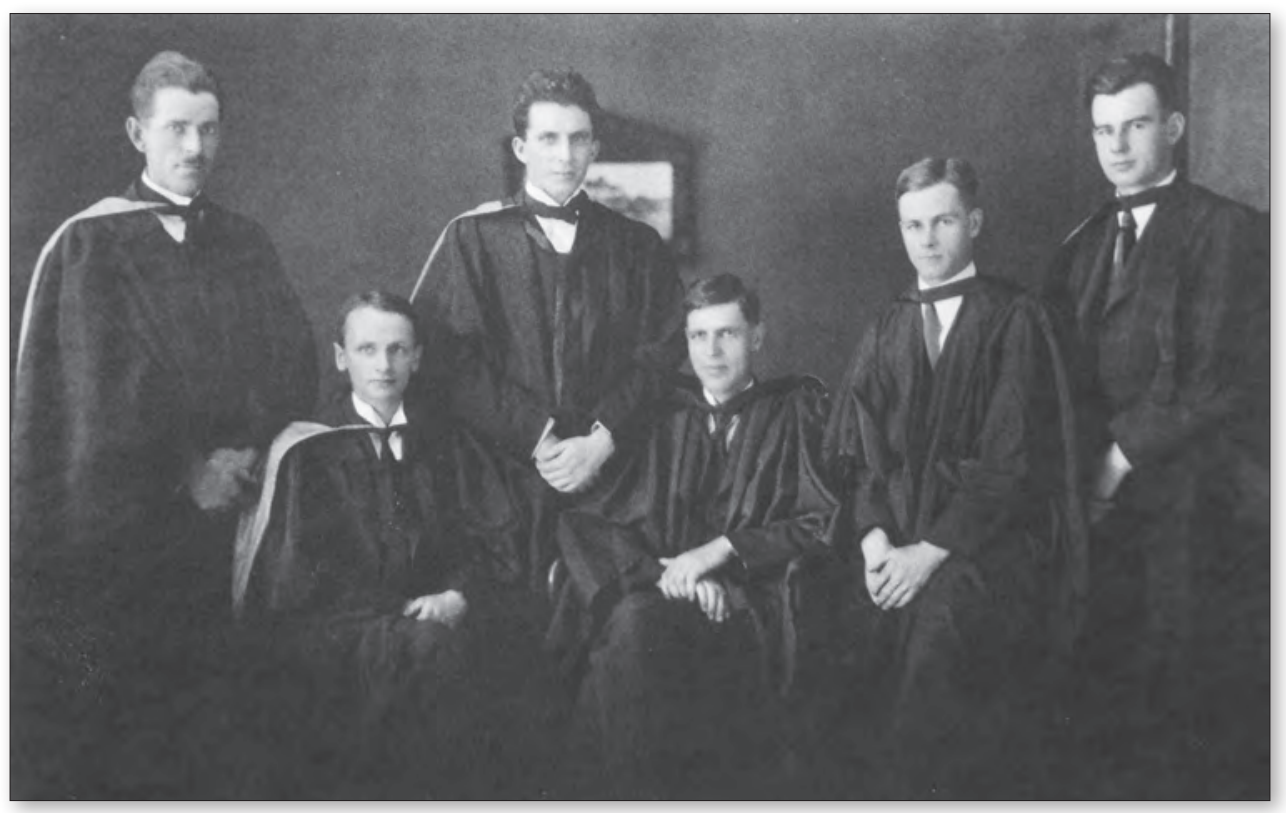

Figure 1.11 The first dental graduates of the University of Adelaide, 1921. (From left to right) HTJ Edwards, TD Campbell, RJ Brazil Smith, JL Eustace, APR Moore, JA O'Donnell (ADASA Archives, courtesy of A Lake).

His long-term interest in the society and his advice to those who followed him in the management of the society shows him to be a person who had the future of the profession uppermost in his mind. It is not surprising, therefore, that he has been regarded as the founding father of the organisation. In fact, the Moore name has become a byword in the profession, with three generations of the Moore family practising dentistry Arthur, Kevin, Grahame, Jon, Simon and David. Arthur spent most of his working life in private practice in Goldsborough House, North Terrace.

\section{TD Campbell}

Thomas Draper Campbell had commenced his training, presumably under the apprenticeship scheme in 1913, aged twenty years. It is not known who apprenticed him but, after he became a registered dentist in 1917, he joined the Royal Australian Army Medical Corps Reserve and served as an honorary lieutenant. In his late twenties, he must have seen the value of a university degree and, like Arthur Moore, had to prove himself worthy of being awarded a BDS degree.

Thomas Draper Campbell chose a career in academia rather than in private practice. His contributions set the high standards for excellence in both research and teaching for 
which the Dental School at the University of Adelaide has become renowned. His academic ability was such that he graduated with a BDS degree in 1921, a DDSc in 1923 and a DSc in 1939. His interest in anthropology led him to become a pioneer physical and dental anthropologist, and a scientist of international repute. His work with Indigenous populations in Central Australia was so detailed and extensive that it has remained a source of inspiration for his successors to this day. Although his reputation internationally was in research, he certainly neglected neither his duties relating to the University of Adelaide nor those to the Adelaide Dental Hospital. He became dean of the Faculty of Dentistry in 1939, a position he held until his retirement in 1958 . He became a house surgeon in the Dental Department at the Royal Adelaide Hospital immediately after graduation in 1921 and, following the retirement of Arthur Chapman, was appointed superintendent in 1926. With a keen interest in oral surgery, he kept up his clinical skills throughout his career. In 1954, he was offered the first chair in dental science and held this position until

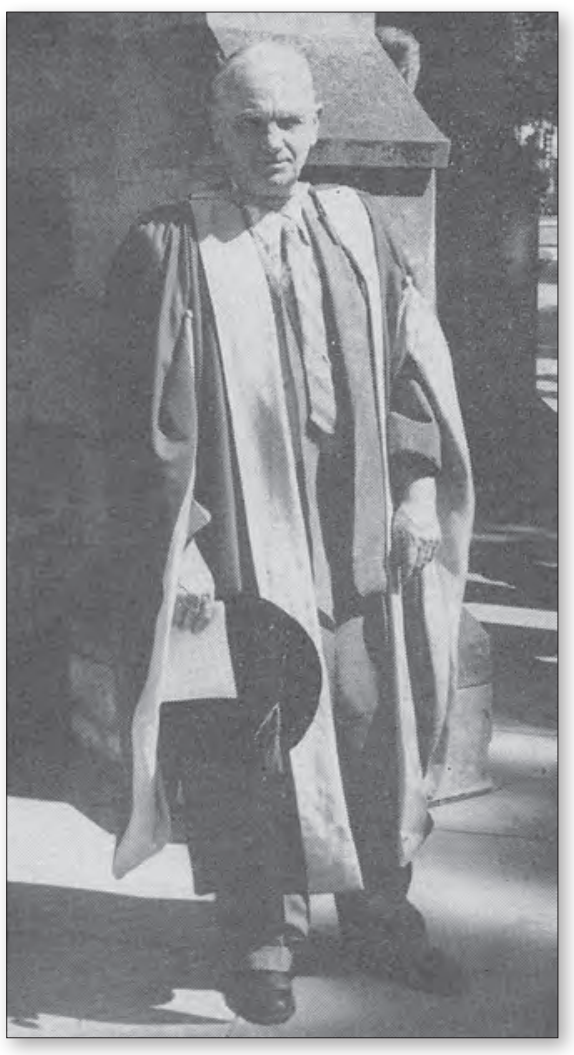

Figure 1.12 Professor Thomas Draper Campbell, Dean of the Faculty, 19381958 (Probe, 1958-59, courtesy of AUDSS and ADASA Archives, courtesy of A Lake). his retirement.

Arthur Moore and Thomas Draper Campbell both had a profound effect on the early years of the new era of dentistry and dental education in South Australia. They both balanced their careers by focusing more on what they could do to promote the dental profession and less upon the need to establish lucrative dental practices. Without doubt, Moore and Campbell laid the educational foundations upon which future dental academics at the Adelaide Dental School have built.

\section{Early faculty issues}

Once the Faculty of Dentistry was established within the university structure, it had to devote its efforts to managing a dental school. Some of the problems that the faculty 
had to solve can be seen from the Minutes of the Faculty for 1921. There were seven issues which, over the following years, were central to the debates at faculty meetings:

1. appointment and remuneration of staff

2. the opening of the Dental Hospital at the Royal Adelaide Hospital

3. defining the rules and regulations governing students using the Dental Hospital to determine student fees and staff remuneration using the Dental Hospital facilities

4. Articles of Apprenticeship

5. a higher degree course in dentistry

6. yearly election of a dean

7. the establishment of a Dental Committee.

\section{Early staff appointments}

Influential early graduates included John Leonard 'Bob' Eustace and Hurtle Thomas Jack Edwards. Eustace (well-remembered as the kindly 'Uncle Bob' by a generation of dental students) lectured in materia medica and therapeutics from 1929 and also became a senior tutor in restorative dentistry until his retirement in 1960. Hurtle Thomas Jack Edwards was appointed a lecturer in orthodontics and was also appointed

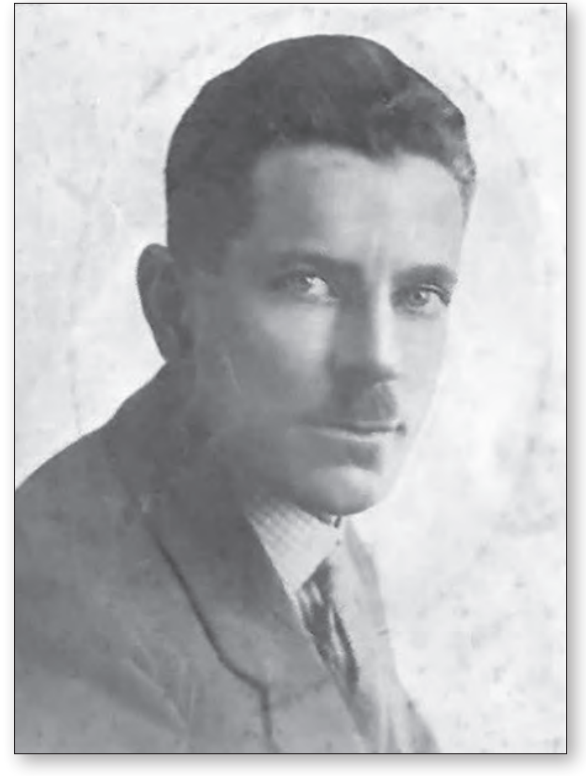

Figure 1.13 HTJ 'Jack' Edwards (ADASA Archives, courtesy of A Lake). a demonstrator in crown and bridgework, both appointments occurring in 1923. He was the first member of the Dental School teaching staff to hold two separate teaching commitments concurrently. Because of the number of years they held their respective appointments, one must assume that they, too, shared a passion to give back to the system they had enjoyed as students. Another early appointee was Robert L Brazil Smith, who is listed in the Adelaide University Calendar (1928) as an instructor in prosthetic dentistry.

\section{The appointment of PR Begg}

Another important appointment to the teaching staff occurred when a graduate from the University of Melbourne sought a position as a lecturer. The name of this 


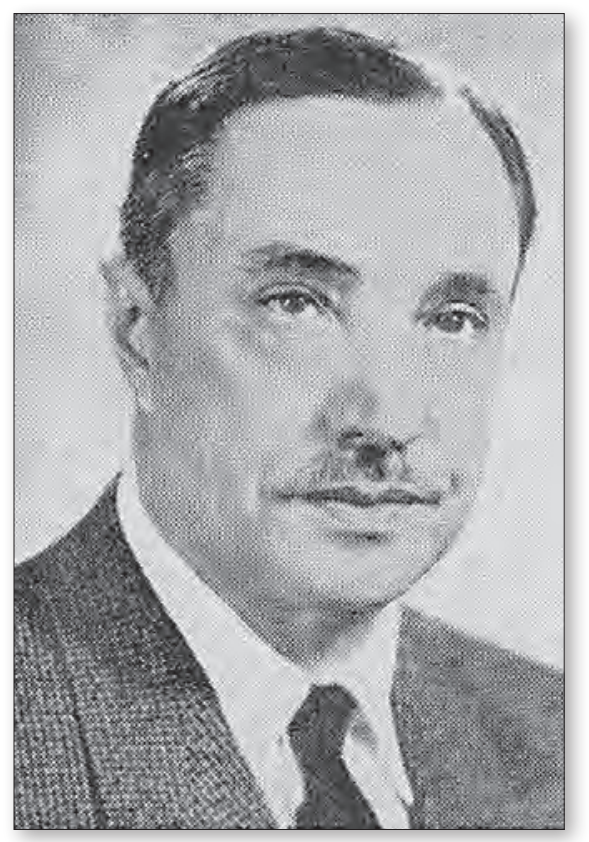

Figure 1.14 Percy Raymond Begg (Probe 1964, courtesy of AUDSS).

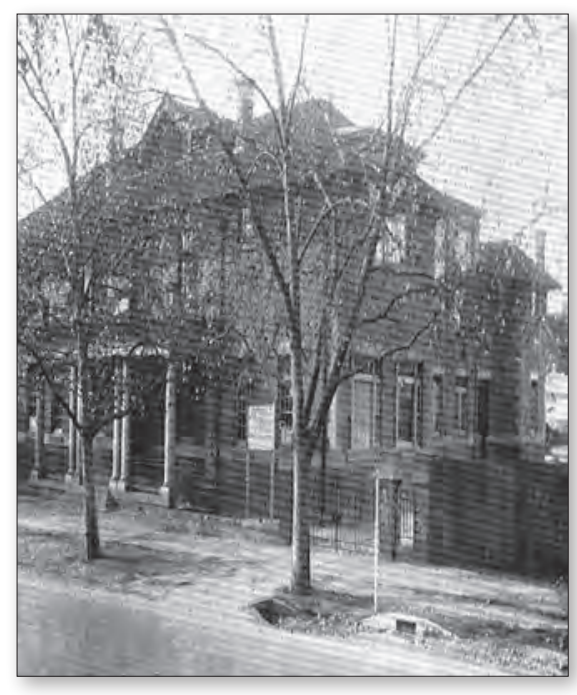

Figure 1.15 The Adelaide Dental Hospital and the University of Adelaide Dental School, opened in July 1923 (ADASA Archives, courtesy of A Lake). candidate was Percy Raymond Begg. His appointment was ratified on 17 November 1925 and his lectureship made a considerable difference to the teaching of orthodontics.

\section{A new dental hospital}

The building of the Dental Hospital or, to be more precise, the Dental Hospital/ Department at the Royal Adelaide Hospital, was a major step forward in the clinical training of dental students. Built on Frome Road in July 1923 with funds obtained from the British Red Cross (£15 000) and from the South Australian government ( $£ 10$ 000), it was the first permanent structure involved in the clinical training of dental students. Prior to its construction, limited clinical instruction had been managed in a small area of the Old Exhibition Building on the eastern side of Frome Road. This was a location previously used for many years by the military as both a storage facility for military ordinance and a dental treatment centre.

\section{Superintendent of the Dental Hospital}

The first university-appointed superintendent of the new Dental Hospital was Dr Arthur I Chapman. The importance of the role of the superintendent becomes clear when reading the Faculty Minutes. He had not only to manage all the educational needs of the dental students, as well as staff requirements and curriculum development, but also to represent the Dental Hospital at faculty meetings and argue issues relating to student complaints and student attendances, and to discuss matters 
concerning the student fee structure. At this early stage of the Faculty of Dentistry, the role of superintendent was crucial in establishing good working relations between the University of Adelaide and the South Australian Government Hospital Service.

The importance of these relations between the state-government-run dental facilities and the University of Adelaide's Dental School has continued to the present day. In an address given to the Sixth Foundation Day Ceremony at the Royal Adelaide Hospital on 11 July 1984, Dr James (Bill) Scollin, a 1932 Adelaide

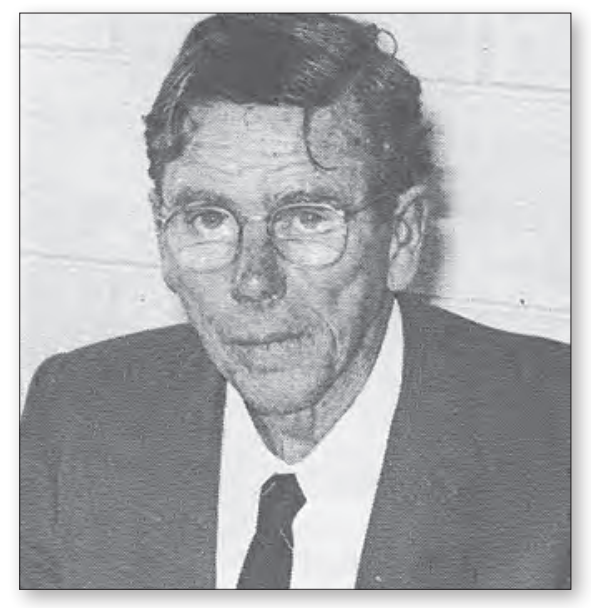

Figure 1.16 James (Bill) Scollin (Probe 1973, courtesy of AUDSS). graduate who was superintendent of the Dental Department of the Royal Adelaide Hospital from 1949 to 1975, stated: 'The origins of the dental school and the dental hospital are so closely intertwined that they can be likened to a set of Siamese twins — born together and never capable of separation' (Scollin 1984).

\section{Articles of Apprenticeship}

Of all the issues that confronted the new faculty, the problem of the Articles of Apprenticeship was the most difficult to solve. With the establishment of the Dental Hospital, students were expected to attend the hospital for their clinical training. This meant that for those students who were still under their Articles of Apprenticeship, their time was divided between their employers and the university. Soon after the clinical courses had started, the registered dentists complained that their apprentices were not spending enough time in their practices. It was an issue that was to continue beyond 1922 when a compromise was reached and the registered dentists allowed more time for their apprentices to attend the Dental Hospital. Outcomes of this debate with the registered dentists may be seen in the University Student Schedules for 1921 (p. 187).

During the first academic year every student should attend the practical demonstrations in Dental Prosthesis at the Department of Dentistry of the Adelaide Hospital. Students articled to a private practitioner, and receiving from him private instruction in dental prosthesis, may be exempted from attendance at the Department of Dentistry of the Adelaide Hospital in the second year's requirements in Dental Prosthesis. 
In the same context it was noted that students in the fourth year should '[a]ttend diligently the dental practice of the Department of Dentistry and the Adelaide Hospital during the whole of the clinical year' (p. 189).

On 18 May 1926, the case of Mr Mathieson came before the faculty. This case highlighted two issues. The first was that Mr Mathieson was a dental mechanic who had received his training under the articled system but presumably had not completed any clinical instruction. He approached the faculty with a request to receive instruction in operative dentistry. At the faculty meeting on 18 May, his request was denied. There was no reason given. It is assumed that a 'line in the sand' must have been drawn by the faculty to emphasise the point that articled apprentices who had not been involved in the clinical component of training could not be admitted, either as a dental student or as a member of the profession. Obviously, the concept of further dental education for members other than those with clinical experience had not been considered at this time.

The second issue was that the dental profession as a whole seems to have been unwilling or unable to effect any significant changes on decisions made by the faculty. There is no evidence that the decision relating to Mr Mathieson's case caused any disturbance outside of the Faculty of Dentistry.

It is not known exactly when the apprenticeship system finally ended. It is recorded in the Faculty Minutes that on 19 April 1921 some students who were not articled were admitted to the university dental degree course. It is assumed that allowing for the four-year dental course, student repeat years, course withdrawals or other genuine reasons for breaks in the dental degree course, by the mid- to late 1920 s all students studying dentistry were unarticled university undergraduates.

\section{A higher degree course and research}

Almost from the moment the Faculty of Dentistry was formed it began to consider the possibility of a higher degree for dental graduates. Some considered that it should be a Doctor of Dental Surgery, others a Doctor of Dental Science. This topic was listed on many faculty agendas until 1922, when the Doctor of Dental Science (DDSc) degree was adopted, with Thomas Draper Campbell being the first person to be awarded the degree in 1923. More details of postgraduate programmes in dentistry are provided in Chapter 7.

In the Faculty Minutes for the years 1922-26, there were several items on the agendas relating to the educational needs of both staff and students. On 19 September 1922, reference was made to the creation of a memorandum relating to the publication of research work by staff and students of the Faculty of Dentistry. This was the first indication by the newly established faculty of formal recognition of dental research. It can be assumed that it was an avenue that was developed and enhanced by the 


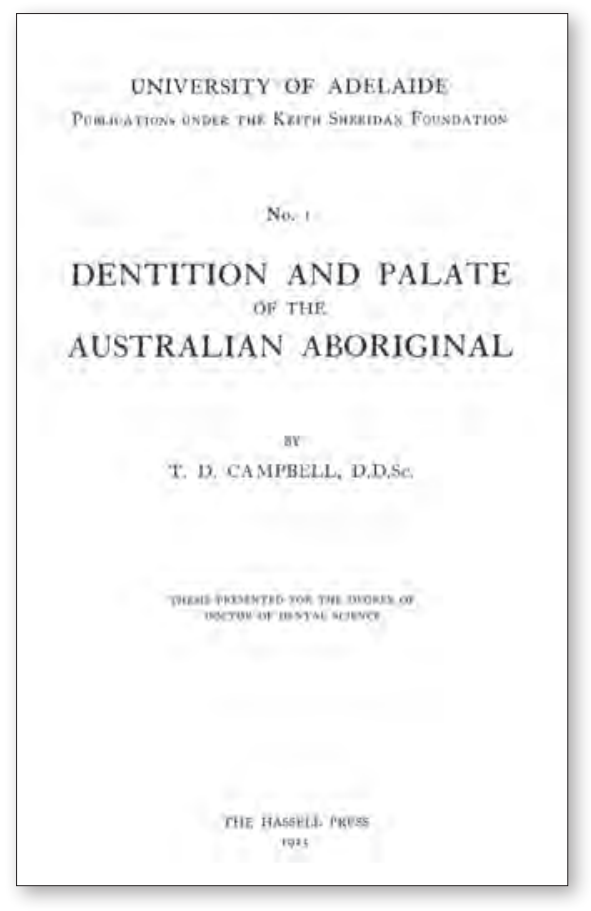

Figure 1.17 The cover page of Campbell's DDSc thesis (courtesy of Adelaide Dental School). inclusion of Thomas Draper Campbell on the teaching staff. Also on this date it was noted that all lectureship re-appointments were to be for a fixed three-year term. This was the first recorded commitment by the University of Adelaide to a system of tenure for dental teaching staff.

In the following year, on 5 March 1923, reference was made to the restructuring of the Library Committee. This committee was required to report to the faculty on all matters concerning literature for staff and students. Notably, any member of Faculty who wished to purchase books on their own, or for their teaching needs, had to consult and receive approval from the convenor of the committee (which was another hat worn by the dean).

Later in that year, on 17 July 1923, it was proposed that two external examiners and one internal examiner be appointed to examine every thesis submitted for the DDSc degree. The first thesis to be subjected to this examination body was TD Campbell's thesis, Dentition and Palate of the Australian Aboriginal. Having satisfied his examiners, Campbell's thesis was approved for both the award of the degree and publication.

\section{The Dental Committee and the BDS course in the 1920s}

The Dental Committee of the Faculty of Dentistry determined the rules and regulations that governed both the activities of staff and students. This committee, formed in January 1921, was staffed by the dentally qualified members of the Faculty of Dentistry. The committee also decided the subjects for each year of the course.

For 1921, the course schedules were as follows: 


\begin{tabular}{|c|c|}
\hline $\begin{array}{l}\text { First Year } \\
\text { Anatomy } \\
\text { Chemistry } \\
\text { Physics } \\
\text { Dental Metallurgy } \\
\text { Dental Prosthesis }\end{array}$ & $\begin{array}{l}\text { Second Year } \\
\text { Anatomy } \\
\text { Dental Anatomy, human and comparative } \\
\text { Physiology } \\
\text { Dental Histology }\end{array}$ \\
\hline $\begin{array}{l}\text { Third Year } \\
\text { General Surgery } \\
\text { General Pathology and Bacteriology } \\
\text { Dental Patho-histology } \\
\text { Dental Materia Medica and Therapeutics } \\
\text { Dental Prosthesis } \\
\text { Operative Dentistry }\end{array}$ & $\begin{array}{l}\text { Fourth Year } \\
\text { General Medicine } \\
\text { Dental Surgery and Dental Pathology } \\
\text { Dental Prosthesis } \\
\text { Orthodontics }\end{array}$ \\
\hline
\end{tabular}

Marks were awarded for each subject in each year. For example:

\begin{tabular}{|l|l|l|l|}
\hline First Year & & Second Year & \\
Anatomy & 200 & Anatomy & 200 \\
Inorganic Chemistry & 150 & Dental Anatomy & 100 \\
Organic Chemistry & 50 & Physiology etc. & 300 \\
Physics & 200 & Prosthesis paper and practical & 300 \\
Metallurgy & 150 & Total marks for Second Year & 900 \\
Total marks for First Year & 750 & & \\
\hline Third Year & & Fourth Year & \\
Surgery & 100 & Medicine & 100 \\
Pathology, Bacteriology and & 250 & Dental Surgery and Pathology paper & 100 \\
Patho-histology & 100 & Practical & 200 \\
Materia Medica and Therapeutics & 250 & Prosthesis paper & 100 \\
Prosthesis & 300 & Practical & 200 \\
Operative Dentistry & & Orthodontics paper & 100 \\
Total marks for Third Year & 1000 & Practical & 50 \\
& & Anaesthetics & 100 \\
& & Total marks for Fourth Year & 950 \\
\hline
\end{tabular}

From this information it is possible to see the scope of the 1921 university dental degree course, as well as which subjects were thought to be important. It is also noticeable that Third Year subjects rated the highest number of marks and First Year subjects the lowest. The total number of marks for the degree was 3600. The total cost of a four- 
year course of study for the BDS degree in 1921 was $£ 226.80$, which included the cost of all examinations (Brown 1971). In 2017, the fees are AU\$10 600/year for domestic students enrolled in the BDS programme and AU\$76 500/year for international students.

In 1924, consideration was given to student assessments, with examination order of merit grades created. It was decided by the Dental Committee that the pass mark should be $50 \%$ for all examination papers and that any result of $70 \%$ or above should be awarded a credit rating. This committee also made decisions on matters concerning awarding of degrees ad eundem gradum; that is, to decide whether an honorary degree should be awarded to acknowledge that a qualification of an individual from another institution is considered to be of the same rank or standing as the qualification at the University of Adelaide (for example, BDS or DDSc).

On 16 November 1926, the Faculty of Dentistry discussed extending the dental course from four years to five years to conform with the requirements of the General Medical Council of Great Britain. From 1928, the Adelaide BDS course was extended to a five-year programme with advice provided from those involved in the existing five-year dental course at the University of Melbourne; therefore, there were no graduates in 1931 .

\section{Early staff and student photographs}

The photographs of early staff and students of the Adelaide Dental School on the following pages are provided courtesy of the ADASA archivist, Dr A Lake.

\section{References}

Brown T (1971) The University of Adelaide, Faculty of Dentistry, a short history. University of Adelaide, Adelaide.

Chapman A (1937) History of dentistry in South Australia 1836-1936. Australian Dental Association, South Australian Branch Incorporated, Adelaide.

Evans MW (1988) The history of the Adelaide University Dental Students' Society, 1919-1979. Published by the author, Adelaide.

Faculty of Dentistry (1920) Faculty Minutes. University of Adelaide, Adelaide. 15 June.

Faculty of Dentistry (1921) Faculty Minutes. University of Adelaide, Adelaide. 19 April.

Scollin J (1984) 1984 - A history of dentistry in South Australia. An address delivered at the Sixth Foundation Day Ceremony held at the Royal Adelaide Hospital on 11 July 1984. www.healthmuseum.org.au (accessed on 4 April 2017).

University Student Schedules for the Degree of Bachelor of Dental Surgery (1921) University of Adelaide, Adelaide. 


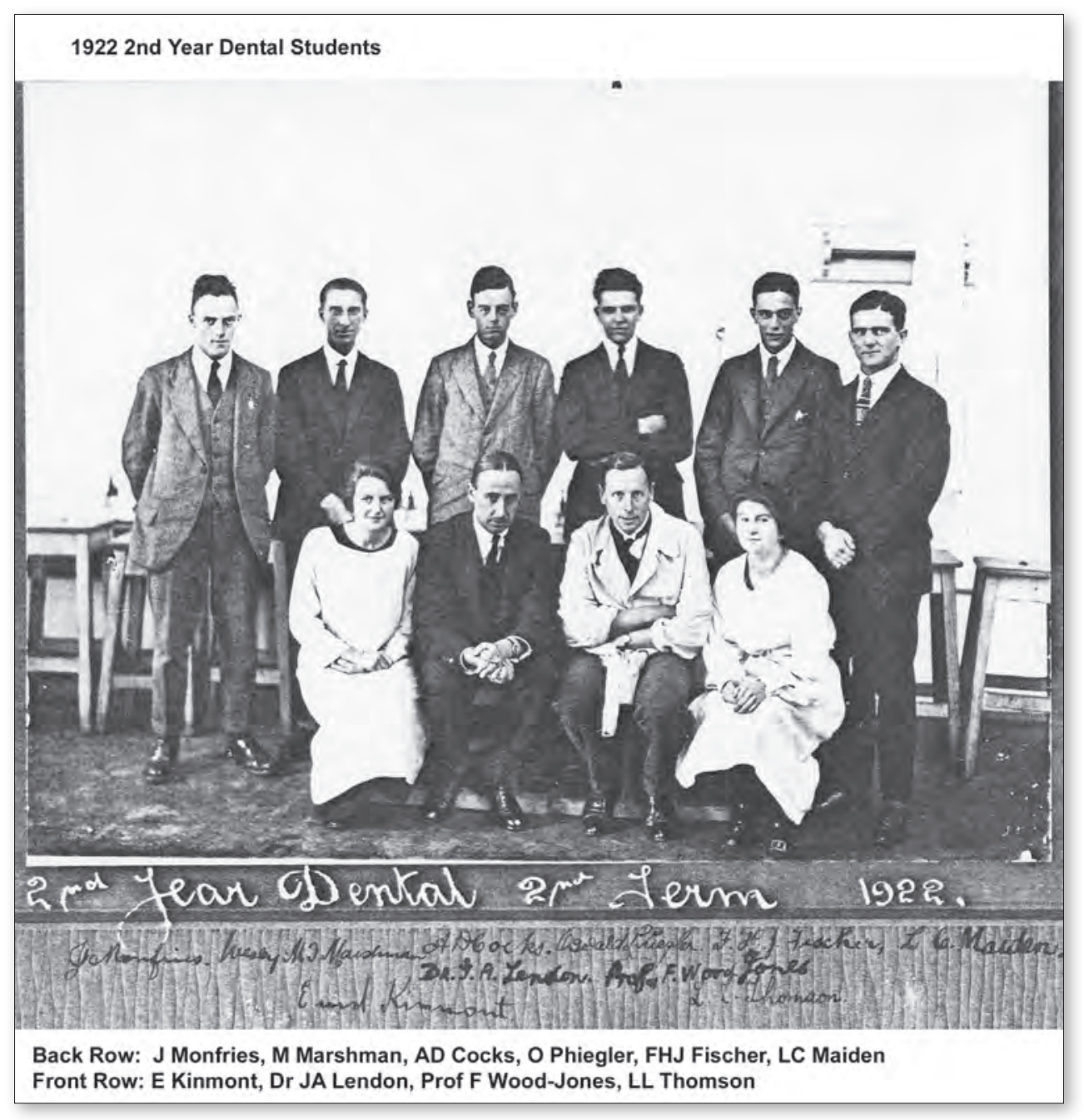

Figure 1.18 Dental students in the second year of their BDS course (1922) with Professor Wood-Jones, Professor of Anatomy in the Medical School. 


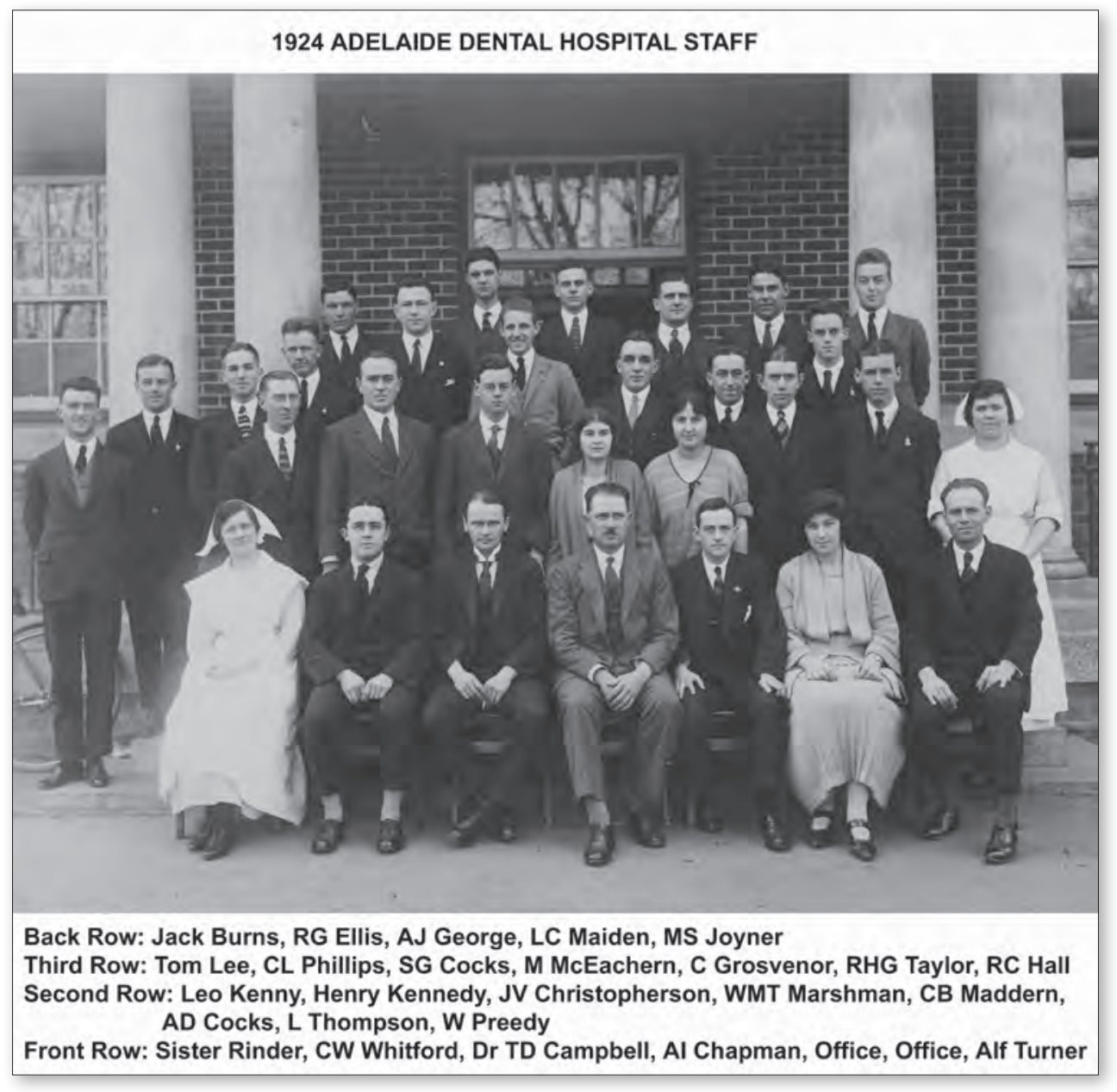

Figure 1.19 Although labelled as Adelaide Dental Hospital Staff, this 1924 photograph includes University of Adelaide Dental School staff and students. 


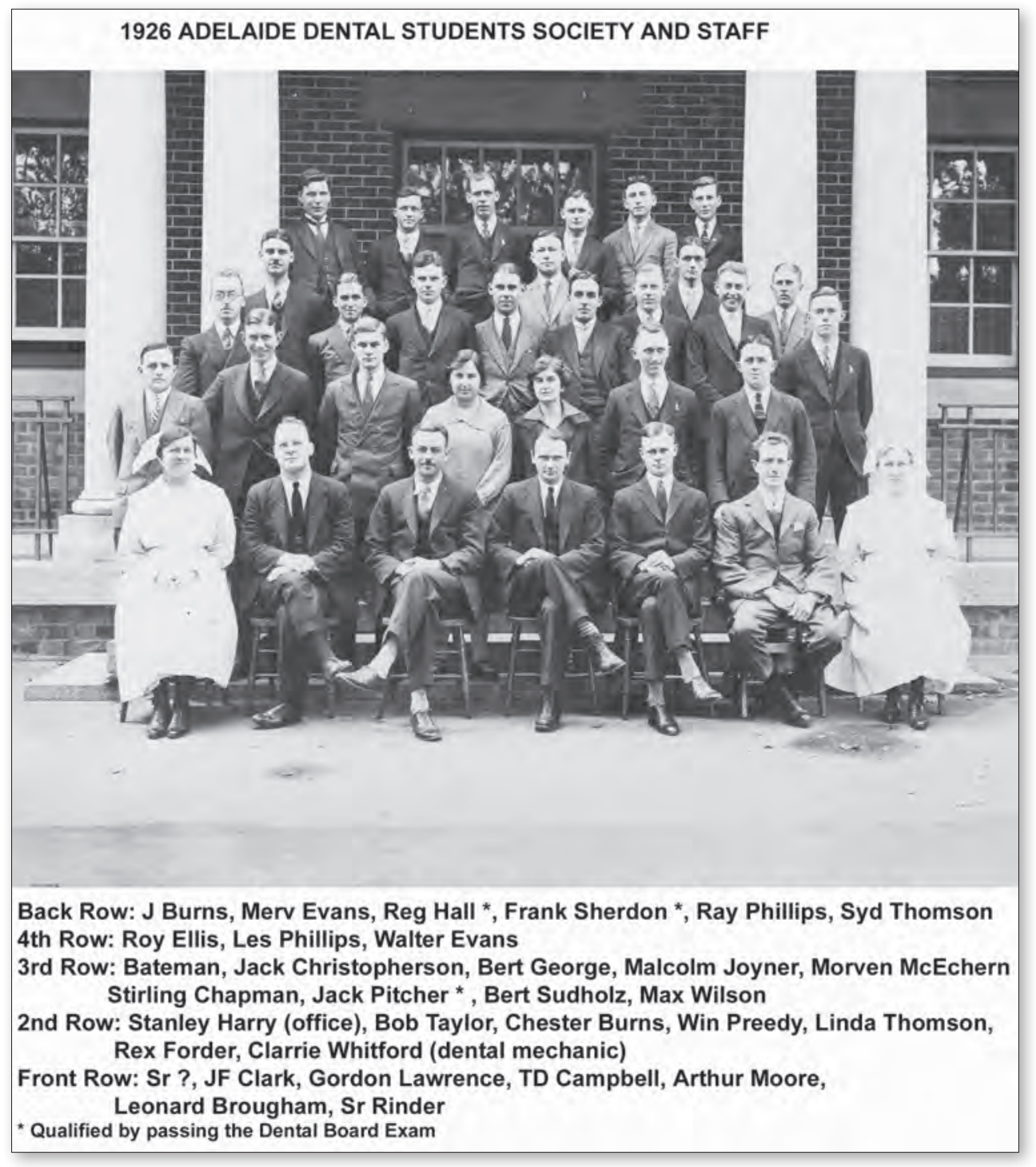

Figure 1.20 Adelaide Dental School staff and students in 1926, with many well-known names. 



\section{2}

\section{Development of the School and the evolving curriculum - 1930s and 1940s}

\section{Setting educational standards}

In the years following its establishment, it became necessary for the Faculty of Dentistry to consolidate and develop its standing with both the university and the profession. Problems had to be addressed that had not surfaced in 1921. Politicians had generally been very favourable to the formation of the Dental School but, on 16 July 1929, a matter appeared before Faculty from the Dental Students' Society. This submission stated that the students had received notification of a proposed bill to be submitted before Parliament that would enable untrained dental assistants to become registered dentists without fulfilling the prescribed educational requirements. All that is recorded in the Faculty Minutes regarding this issue is that a sub-committee was formed to investigate the matter that would challenge the School's educational standing in the community and then to report back to the faculty with their findings. No record in the Minutes has been found referring to the outcome of the sub-committee's deliberations. What did emerge, however, was recognition that the problem of unqualified people practising dentistry needed to be addressed beyond the confines of the University of Adelaide's Dental School or the South Australian government. This was a problem that had widespread implications for Australian dental education as a whole. Other states shared similar problems and, over a period of time (1924-33), meetings of all Australian dental faculties were convened to deal with common issues relating to dental education. These meetings have continued over the years and the group is now referred to as the Australian Council of Dental Schools (ACODS). 
By August 1933, agreement had been reached about the educational standards required to be able to practise dentistry. The Eighth Australian Dental Congress was held in Adelaide in 1933 (Chapman 1933), as well as a meeting that included representatives of the Australian dental faculties for the prime purpose of reaching an agreement on matters of the education and training of dentists. In Sections 3 (Training for Dentists) and 4 (Conference on Teaching of Dentistry) of the Minutes of this meeting the following is noted:

3. After full discussion the following resolution was adopted unanimously:

In the opinion of this conference the following minimum basis of training for the profession of dentistry should be adopted throughout all the States of Australia:

A common standard of entry consisting of either at least four subjects at the Senior Public or School Leaving Examination, or the requirements for matriculation in an Australian University.

A minimum of four calendar years spent wholly in an approved dental college, the curriculum of which shall conform to the requirements laid down for registration by the General Medical Council.

Satisfactory completion of the course to be recognised by a University qualification (degree or diploma).

It was resolved also that this resolution be sent to each of the Universities and Dental Boards in Australia, and to the Federal minister of Health.

4. It was resolved to recommend to all dental education bodies in Australia that a conference of representatives be arranged to consider the whole curriculum of dental students, including especially the methods to be taught. (Conference of Dental Faculties 1933)

In the space of four years (1929-33), the Adelaide Dental School had become part of a national network that would decide the future directions of training and curriculum development of dentistry in Australia. Such agreements between dental schools contributed toward a greater transmigration of staff and students, invariably leading to improvements in many aspects of dental education.

The influence of the Faculty of Dentistry at the University of Melbourne upon the Adelaide Dental School is difficult to determine accurately. Not only did Adelaide adopt Melbourne's five-year training course, but it also accepted graduates seeking careers in Adelaide. Percy Raymond Begg was one and another was a BDSc graduate applying to be admitted ad eundem gradum to the University of Adelaide's BDS degree. His name was Gordon Ord Lawrence. Lawrence's application was granted on 19 November 1929, before the interstate university agreements had become effective. 


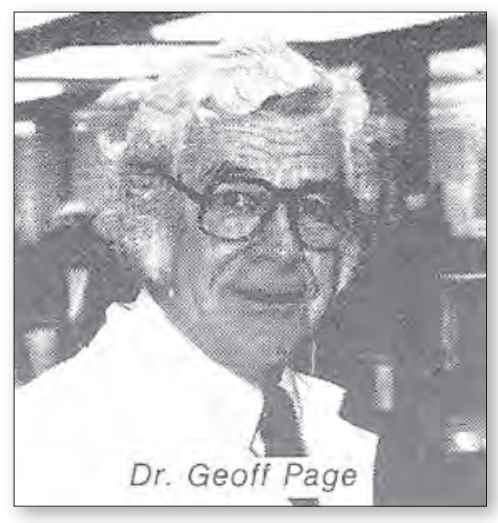

Figure 2.1 Geoffrey Page (Probe 1983, courtesy AUDSS) and GO Lawrence (left) sitting next to Campbell (ADASA Archives, courtesy of A Lake).

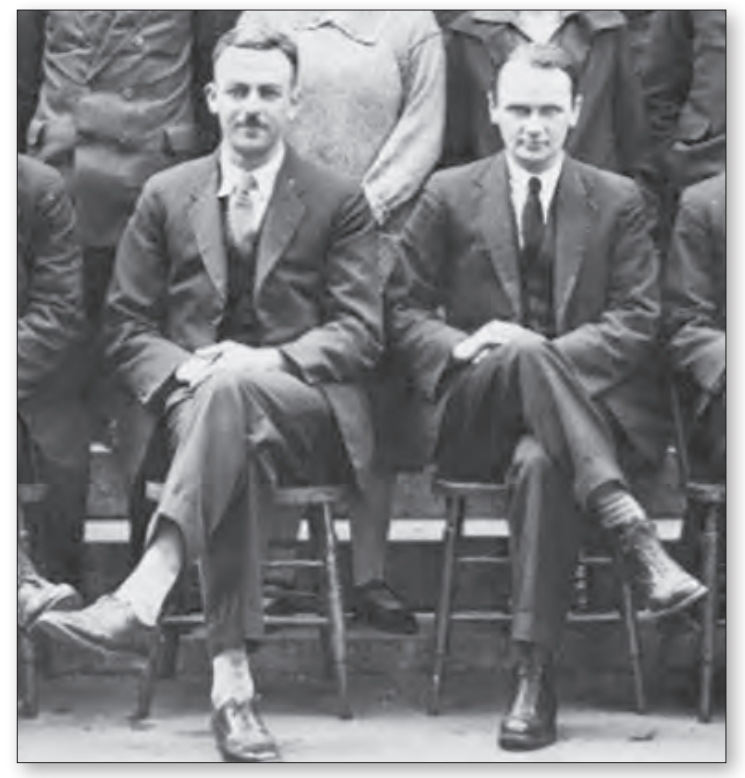

\section{GO Lawrence}

GO Lawrence had been registered with the Dental Board of South Australia since 1925 and practised as a House Surgeon at the Royal Adelaide Hospital for three years. He was in general practice at Largs Bay and later at Semaphore, South Australia. He became an instructor in restorative dentistry at the University of Adelaide's Dental School in 1937 and divided much of his life between his practice and his teaching commitments.

One of his pupils at the Dental School was Geoffrey W Page, who remembers him as

a tall, dark, impressive man, gentle and with an inquiring and inventive mind. A perfectionist, he contributed substantially to dental research and education in South Australia; his insistence upon the highest standards of clinical dentistry is remembered by his students and colleagues. His original work (1938-40) included the Lawrence Matrix, an ingenious instrument for the improved restoration and contour of compound cavities, which received world acclaim. At a time when there were few Australian studies of dental materials, and when wartime shortages and quality variation in raw materials were a problem, Lawrence did basic work on impression pastes and gels. He was awarded a Doctorate of Dental Science by the University of Adelaide in 1945 for a thesis on these matters and other studies, including the hot oil sterilisation of dental handpieces. Lawrence loved working with his hands; his hobby was the making of fine gold jewellery. (1986, p. 14)

On his death in 1960, Lawrence's widow endowed a scholarship for postgraduate studies in conservative dentistry known as the GO Lawrence scholarship (1967). 
Men of the calibre of TD Campbell, PR Begg and GO Lawrence were able replacements for those who founded the Faculty of Dentistry. Sir Joseph Verco was replaced as dean by the election of Arthur Murray Cudmore on 20 November 1928. Sir Joseph Verco's death on 29 July 1933 was recorded in the August Faculty Minutes of that year.

\section{The colour of the academic hood}

On 16 July 1929, the Faculty of Dentistry approved the colour of the academic hood for the degree of BDS. A shade of pink was decided upon, which later came to be known as salmon pink. Scarlet was chosen to be the dominant colour of the academic dress for those holding doctorates. The

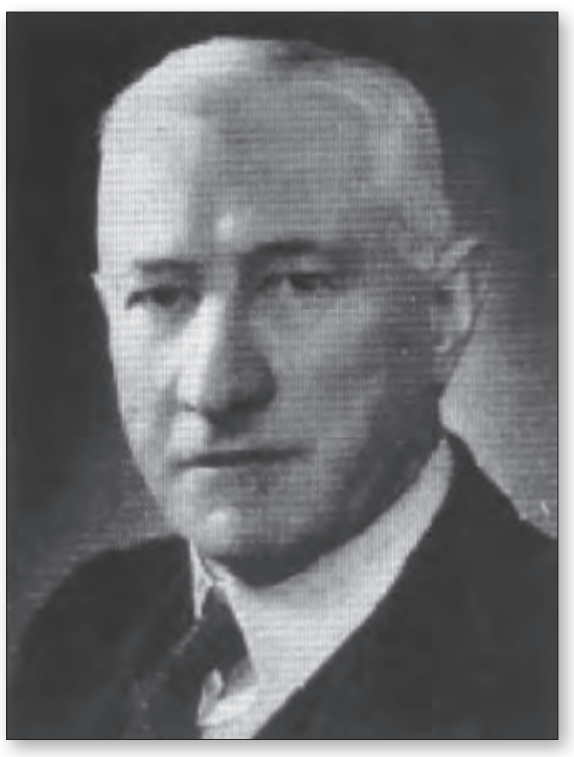

Figure 2.2 Arthur Murray Cudmore (courtesy of Adelaide Dental School). current academic dress rules state that dental PhD graduates shall wear a Cambridge-style gown faced with scarlet and, for BDS graduates, a Cambridge-style gown with an eosin pink hood - eosin being the hood colour for all graduates in the current Faculty of Health and Medical Sciences.

\section{On the faculty's agenda}

On 25 November 1931, two new topics appeared on the faculty agenda that had not been presented before. The first of these concerned the number of students who failed their examinations. In November 1931, all of the First and Second Year students failed in one or more of their subjects. This prompted questions about whether some of these students had failed subjects more than once and whether they should be allowed to continue in the course. The dean was asked to consult with the university's vicechancellor and the registrar to seek clarification about what could be done. How much advice or direction was given is unknown but, on 16 May 1932, Faculty approved in principle that those students who failed successive subject examinations in both the first and second years of their course should be precluded.

A second, more pleasing topic began in 1928 when Faculty received notification from The North Western University, Illinois, USA, that it was offering a dental scholarship with free tuition and $£ 250$ to be provided to scholarship holders. It took nearly a year before Faculty accepted the offer and recommended that graduates only apply to continue their postgraduate studies. 
In the decade preceding the Second World War, the Dental School operated much as it had done in previous years and one important issue concerned curriculum development. The Faculty Minutes of 23 August 1933 show that an application was lodged to the General Medical Council of Great Britain for approval/acceptance of both the BDS and DDSc degrees. Approval from this body would have guaranteed that graduates from the University of Adelaide holding these degrees could practise and study in Great Britain. This was a reciprocal process that, after 1948, was handled by the General Dental Council of Great Britain.

\section{The importance of the Eighth Australian Dental Congress}

The Eighth Australian Dental Congress held in Adelaide on 21 August 1933 was a landmark event during which much of what really mattered about the future of dentistry in Australia was discussed.

Of the numerous scientific papers and lectures presented at the Congress, two specific outcomes emerged: first, the promotion of greater social contact between dentists in Australia; and second, a forum to create an unrestricted exchange of ideas

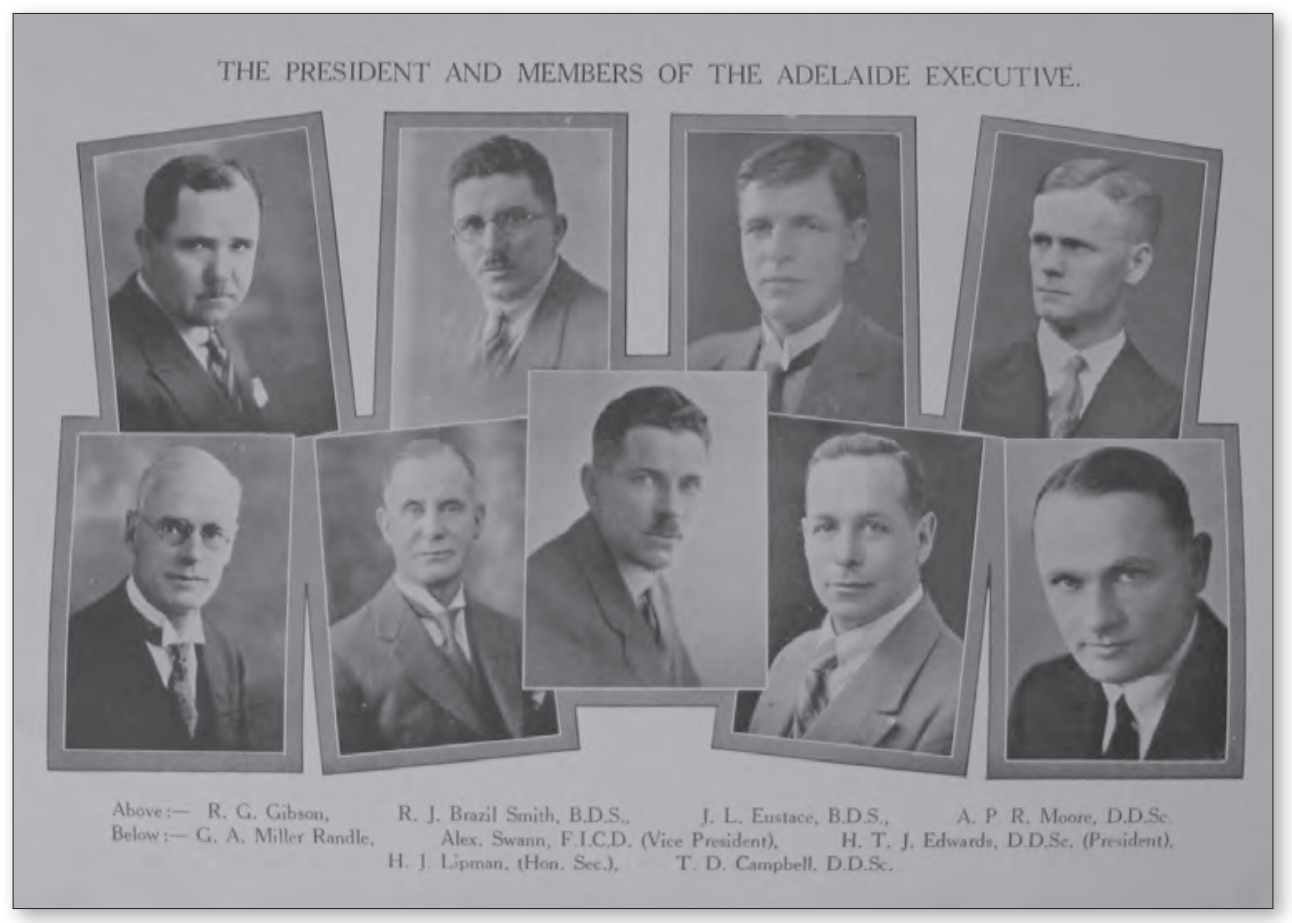

Figure 2.3 The Eighth Australian Dental Congress, Adelaide, South Australia, 21-26 August 1933 (ADASA Archives, courtesy of A Lake). 


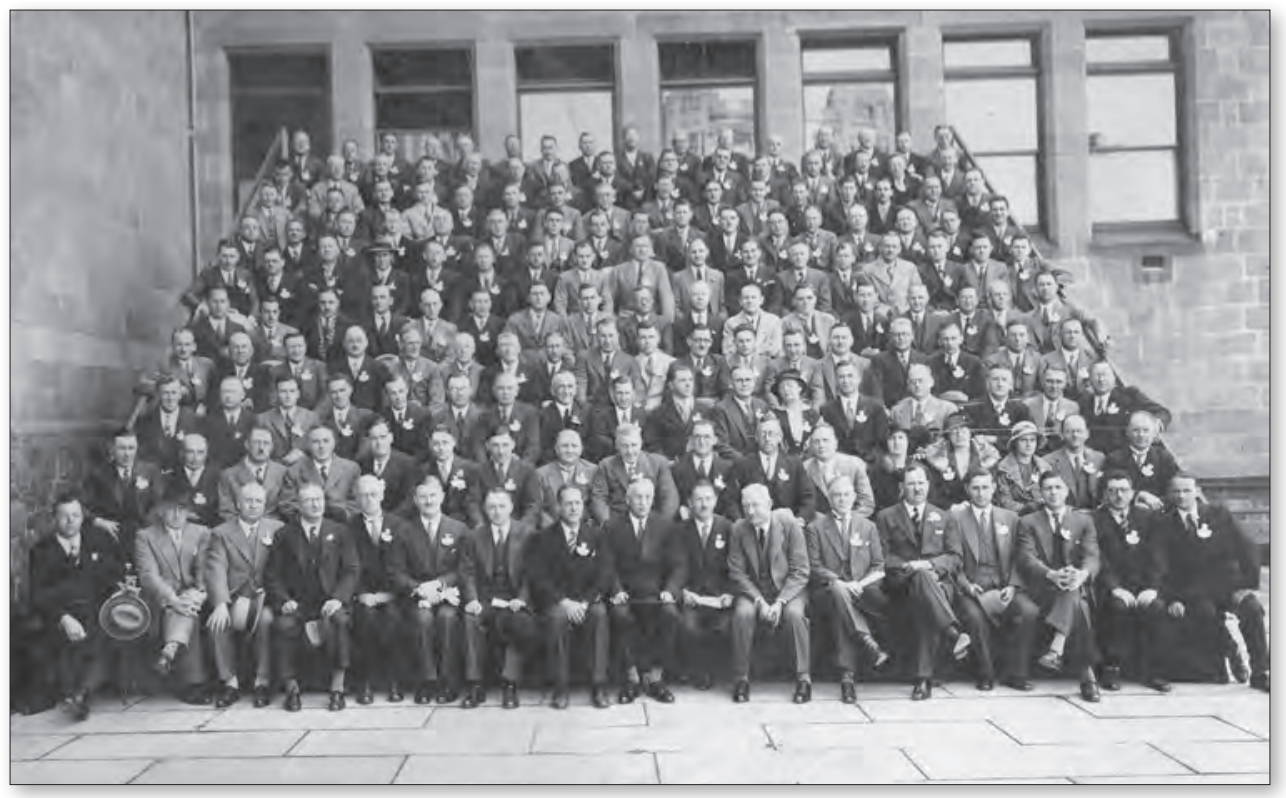

Figure 2.4 Participants at the Australian Dental Congress held in Adelaide in 1933 (ADASA Archives, courtesy of A Lake).

generated through research and experience. The conference covered a wide range of topics including dental surgery, prosthetic dentistry, odontology and economics; and the proceedings emphasise the growing importance at that time of dental science to the practice of dentistry. Some of the topics debated during the conference included the importance of public health education, the inclusion of dental hygiene in the dental curriculum, the use of the courtesy title of doctor by dentists, dentistry's identity and relationship to medicine, whether dentistry was within the reach of all Australians, and the increasing costs of dental practice (Chapman 1933). It could be argued that little has changed in the problems facing the dental profession. Also, whilst identifying what needed to be addressed, those at this congress found it difficult to come up with answers - and we still do.

As the years drew closer to the declaration of World War II, Faculty had to take action in preventing too many of its staff and students from resigning their positions and enlisting in military service. There is a note in the Faculty Minutes of 14 November 1939 requesting that the dean consult with the Faculty of Medicine to determine what action should be taken over this issue, but the outcome is unknown. The note ends with a comment that the Faculty of Dentistry will adopt whatever the Faculty of Medicine decides. 


\section{Wartime}

It is obvious from reading the Minutes of the war years (1939-45) that the Dental School was not really affected by the war. It was business as usual, with the only real worry being those of its staff and students wishing to join up for military service. On 19 June 1940, Fourth Year dental students asked the faculty whether their course could be curtailed so that they could enlist for service in military dental units. It is not surprising that Faculty failed to rule on this issue. To agree and let the students go meant that the School would lose students and possibly be accused of letting unqualified personnel into the military. However, if it did not permit the students to join the military, it could be accused of not helping the war effort.

A scan of the Faculty Minutes throughout the war years shows that there seems to be a bias against foreign students (German-speaking in particular) wishing to become students in the Dental School. One such request to join the BDS course came from a German refugee who presumably was qualified to join the course but whose case was consistently deferred for three-month periods. There is no record whether he was ever given status. Despite this apparent bias, some possible wartime refugees were admitted to the BDS course and were given credit for matriculation, plus the first two years of the course. It is assumed that these successful candidates were already trained dentists.

Another interesting situation considered by Faculty involved a student who had failed several First Year subjects. This occurred in 1942, and during the discussions concerning the student it was noted that, under the National Security Regulations, all dental students held a reserved occupation category. Should the student be excluded from the course he would lose his reserved occupation category and forfeit his chances of becoming a dentist. Considering the war had the potential to preclude him from ever returning to dentistry, he was given another chance. He passed all First Year subjects a year later.

In 1944, the Australian Dental Association corresponded with the dental schools of Australia, requesting that those dental personnel who had been involved in military service be admitted to a dental course on discharge. The association also requested that the requirements for matriculation be wavered in their cases.

The following recommendations made by the faculty on 18 July 1944 were to have a profound effect upon student numbers at the University of Adelaide in the decade following the end of World War II:

i. that applications for concessions in matriculation be considered individually on their merits;

ii. that all service personnel be eligible for concessions which should not be restricted to dental personnel only;

iii. that no student be admitted to the course unless he satisfied the Faculty that he was adequately equipped to undertake the first-year work of the degree course; and 
iv. that concessions be allowed only in the requirements for matriculation, no variation in the course for the degree being permitted except by the normal procedure of granting status for equivalent work done elsewhere. (Faculty of Dentistry 1944)

On 17 April 1945, Faculty received a letter from the Royal Australian Air Force asking for details of refresher courses that would be suitable for discharged dental officers. This letter stimulated an in-house review of the facilities that would be needed to cater for these extra dentally qualified personnel. The main difficulties that the faculty envisaged concerned the Dental Hospital, where there were limited facilities to cater for the special individual tuition of ex-service personnel. Whatever improvements were made in this regard, there was little time before the first applications from ex-service personnel were received under the Commonwealth Reconstruction and Training Scheme.

Mr OB Morgan, Mr KJ Daws, Wing Commander HA Nicholas, Mr BH Lake, Mr WA Ogden, Mr TH Pascoe and Mr KM Bowler were the first to avail themselves of a refresher course. A few months later, Mr ES James and Mr JA Waugh joined the course, with Mr HD Kennare being offered a place in First Year after being given matriculation status for his service as a flying officer.

In the decade following the end of World War II, the Dental School underwent a metamorphosis, with staff numbers increasing in line with the increasing numbers of students.

\section{Student numbers}

On 3 October 1947, a report was tabled at Faculty which outlined estimates of future student numbers. The table below is derived from the Dental Faculty Minute Book and shows the student estimates for each calendar year and each year of the course. It should be noted that attached to this report was a statement emphasising the fact that the student estimates were definitely conservative.

\begin{tabular}{|c|c|c|c|c|c|c|c|}
\hline Year & 1946 & 1947 & 1948 & 1949 & 1950 & 1951 & 1952 \\
\hline 1 & 42 & 54 & 40 & 33 & 26 & 19 & 18 \\
\hline 2 & 5 & 28 & 50 & 42 & 35 & 27 & 20 \\
\hline 3 & 5 & 4 & 22 & 44 & 42 & 36 & 29 \\
\hline 4 & 2 & 5 & 4 & 18 & 39 & 45 & 40 \\
\hline 5 & 6 & 2 & 5 & 4 & 15 & 30 & 35 \\
\hline
\end{tabular}

Table 2.1 Estimated student numbers for the years 1946-52. 
What emerged from this exercise was the knowledge that the reliance on parttime staffing could no longer be maintained. A more stable organisation was needed for the future with more full-time appointments and particular attention to areas of general administration and supervision of student work. A Faculty Sub-Committee for Staffing Requirements was formed and this committee reported regularly to the faculty. Besides the staffing matters under discussion, the sub-committee made two recommendations: one was the need to establish a chair in dental science and the other was to argue the case for expansion at the Dental Hospital.

In many ways, the Staffing Sub-Committee Report of 3 October 1947 had farreaching implications for the future of the Dental School. Some of the important recommendations made at that time were resubmitted in the following years. In 1949, for example, a Sub-Committee Report made the following recommendations and observations:

The present instructional staff on the practical side of the course is insufficient for present requirements and will be entirely inadequate for conditions in 1949 and for some years to follow.

The dental instructional staff has always been a part-time one which experience has shown to have obvious disadvantages.

The practical work of the senior years consists of continuous clinical work on patients for the whole of the hospital year. Instruction and supervision for this work will be hopelessly inadequate for some years under the present staff set-up.

Owing to the nature of their practical work, especially in senior years, students in the dental course require (with perhaps the exception of the medical course) closer and more continuous supervision than in any other Faculty. (Staffing SubCommittee Report 1949)

The report goes on to add:

The Adelaide school which is not the smallest of the five Australian dental schools, is the only one without full-time dental instructional staff and a Chair in Dentistry. The dental school is the only one in our University providing a graduate course without a Chair and the Faculty is convinced that proper direction and organisation of instruction can be adequately achieved only by the establishment of a Chair. The present arrangements cannot be continued if standards are to be maintained.

Very much less is spent on dental instructional staff here than in the other dental schools in Australia.

With the exception of Medicine, it is the longest under-graduate course in the University.

With perhaps the exception of Medicine, it is the most expensive course in the matter of fees and fees paid by the student for instruction.

The Dental Faculty realised that it could not accept every candidate who wanted to study dentistry. To establish control over who was able to enter the course and 
who was not, a committee was formed within Faculty to consider the standards and regulations imposed by the university. This committee, established in 1951, also analysed the statistical records of past and present students, and standards were set to determine Credit, Pass or Fail grades. The number of subjects acceptable for entry into the course was determined to be five subjects at matriculation level, three of which had to be of an A-grade standard. This committee also provided information about student performance and future career prospects. It was also tasked with considering what subjects should be prerequisites for those wishing to study dentistry. This was particularly relevant to prospective candidates who had difficulty with the English language. Faculty clearly placed great importance on setting educational standards that governed both whether a student should or should not be admitted into the dental course and whether a student passed or failed a subject. These standards have been maintained to the present day.

\section{The evolving BDS curriculum}

As the end of the decade of the 1940s approached, the Faculty of Dentistry began to look carefully at the content of the BDS curriculum and consider reorganisation of some of its teaching. The dean, Dr T D Campbell, stated that he 'expected to have a sum of at least 2,500 pounds available for purchase of equipment for teaching of dental students' (Faculty of Dentistry 1946) and he also informed the Faculty that he and $\mathrm{Mr}$ Eustace would be visiting the dental schools in the eastern states to look at the facilities in Melbourne, Sydney and Brisbane.

A sub-committee, comprising the dean and Messrs Lawrence, Joyner and Eustace, was formed to investigate the Fourth ${ }^{-}$and Fifth Year subjects, with a view to obtaining a better balance between the prosthetic and operative aspects of the course. There was also discussion of decreasing the amount of general surgery and general medicine in the course.

An important appointment was made in 1948. Alec Cran, a Queensland graduate who had served in Papua New Guinea during World War II, was appointed reader in oral pathology and oral surgery. Cran was a key member of the Adelaide Dental School staff throughout the period from the 1950s to the 1970s and he became dean of the Faculty of Dentistry for the period 1966-67.

At the end of the decade, there was a lecture-based subject, entitled oral hygiene, which was presented to Fourth and Fifth Years combined in alternate years. It was agreed that this course needed to be replaced by 'an adequate course in preventive dentistry'. So, even at this early stage, there was a recognition of the need to have a strong preventive focus in the curriculum.

Photographs of graduates during the 1930s and 1940s are included on the following pages from the ADASA Archives, courtesy of A Lake. 


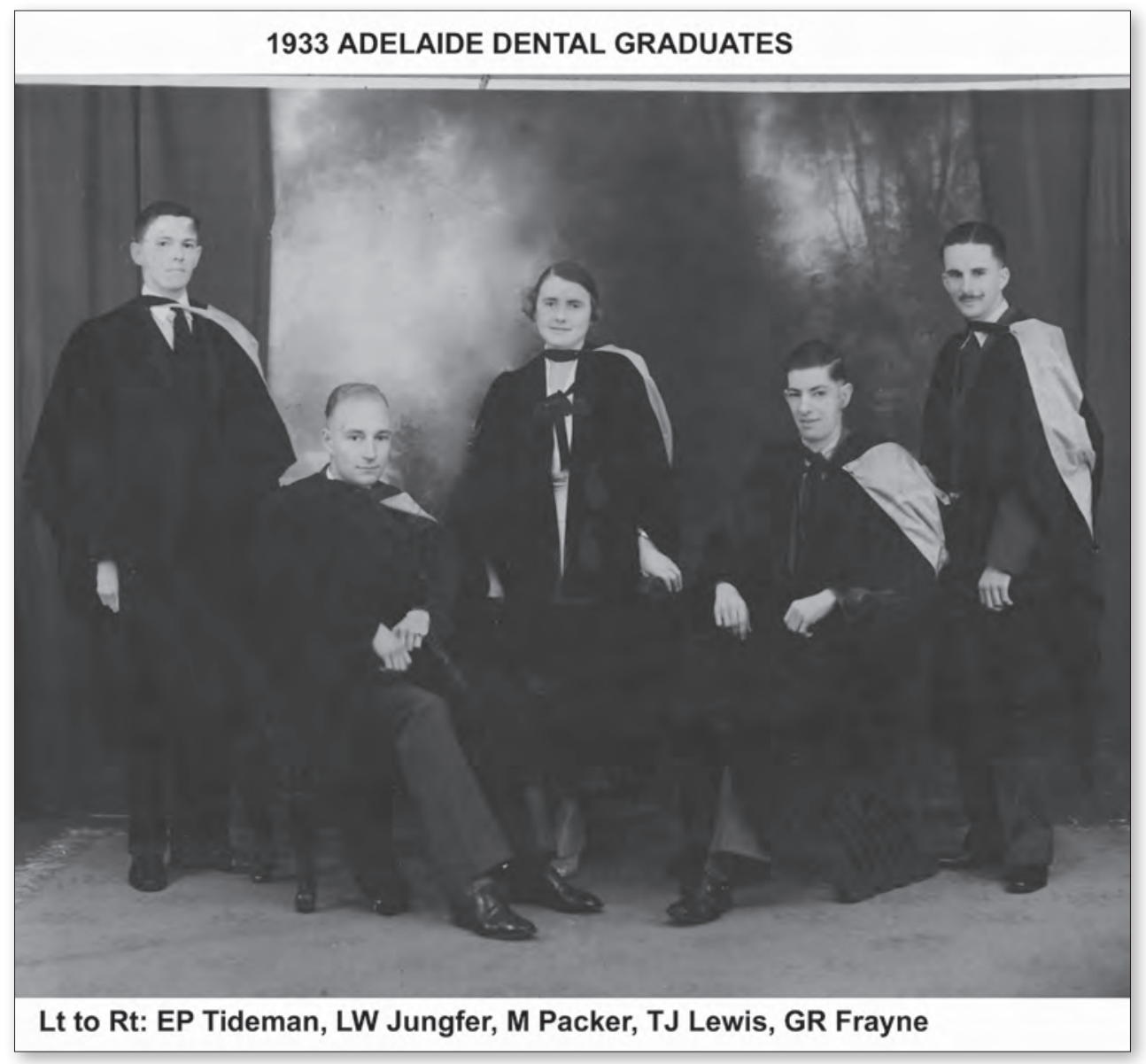

Figure 2.5 Adelaide dental graduates 1933. 


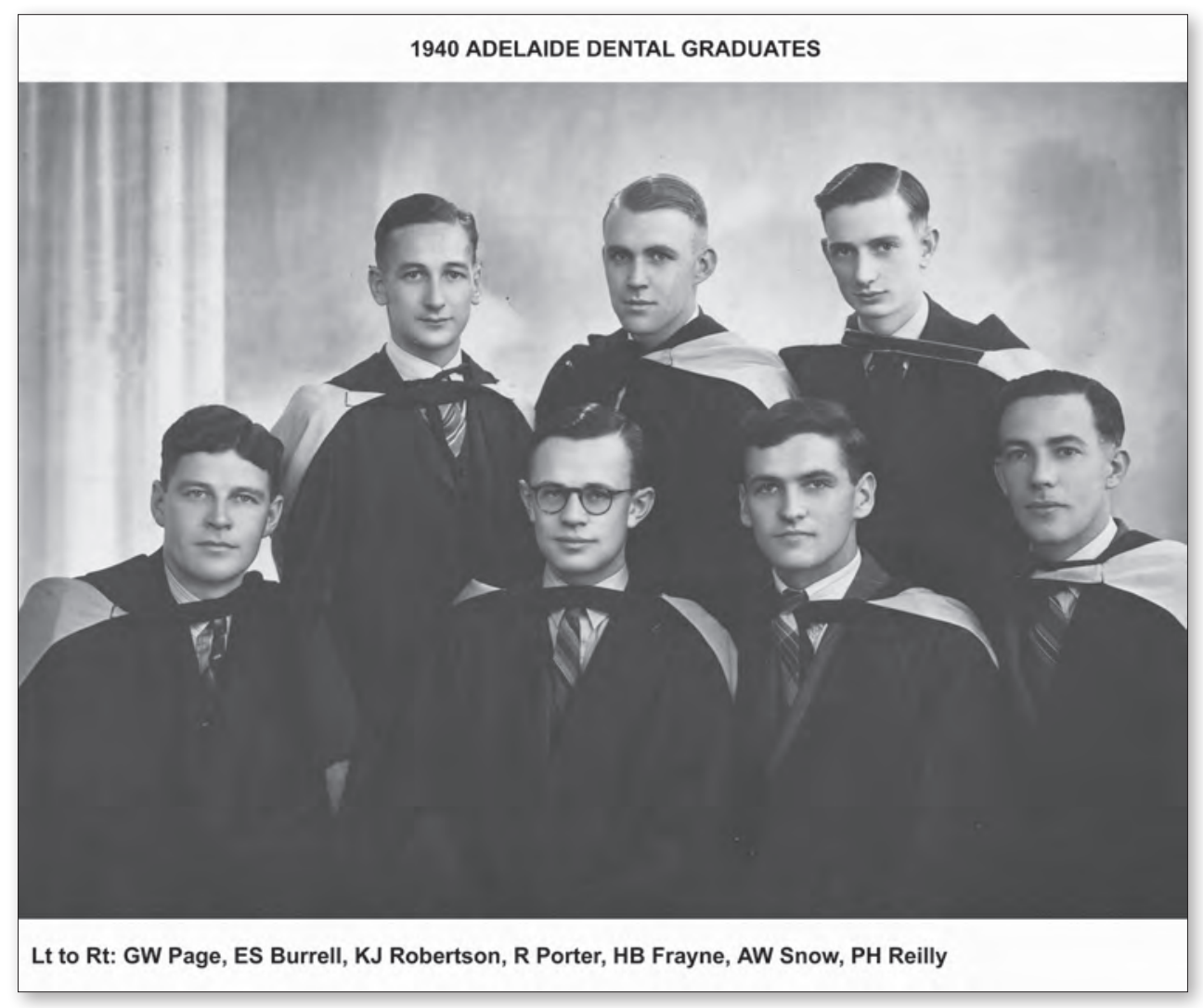

Figure 2.6 Adelaide dental graduates 1940. 


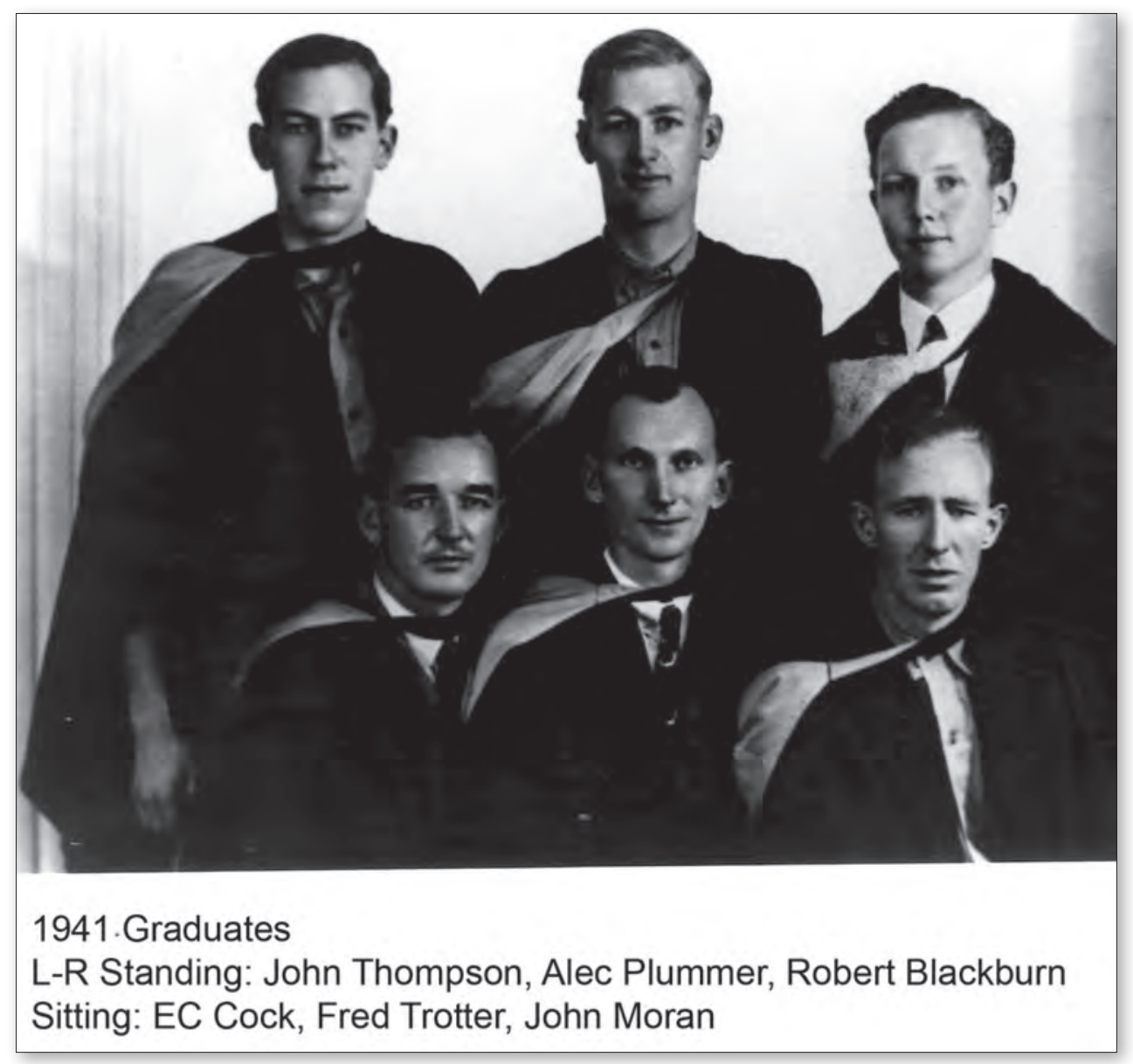

Figure 2.7 Adelaide dental graduates 1941. 


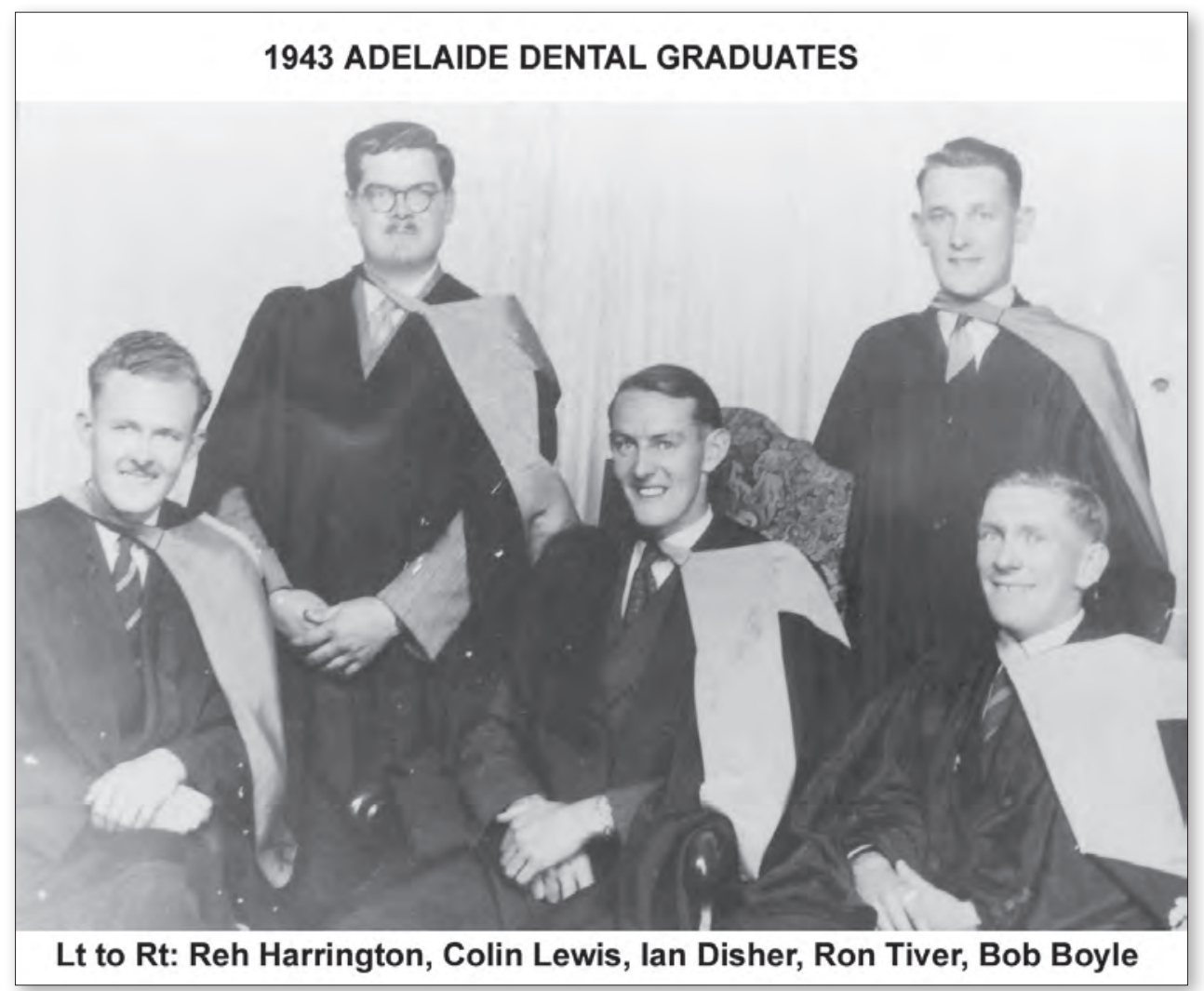

Figure 2.8 Adelaide dental graduates 1943. 


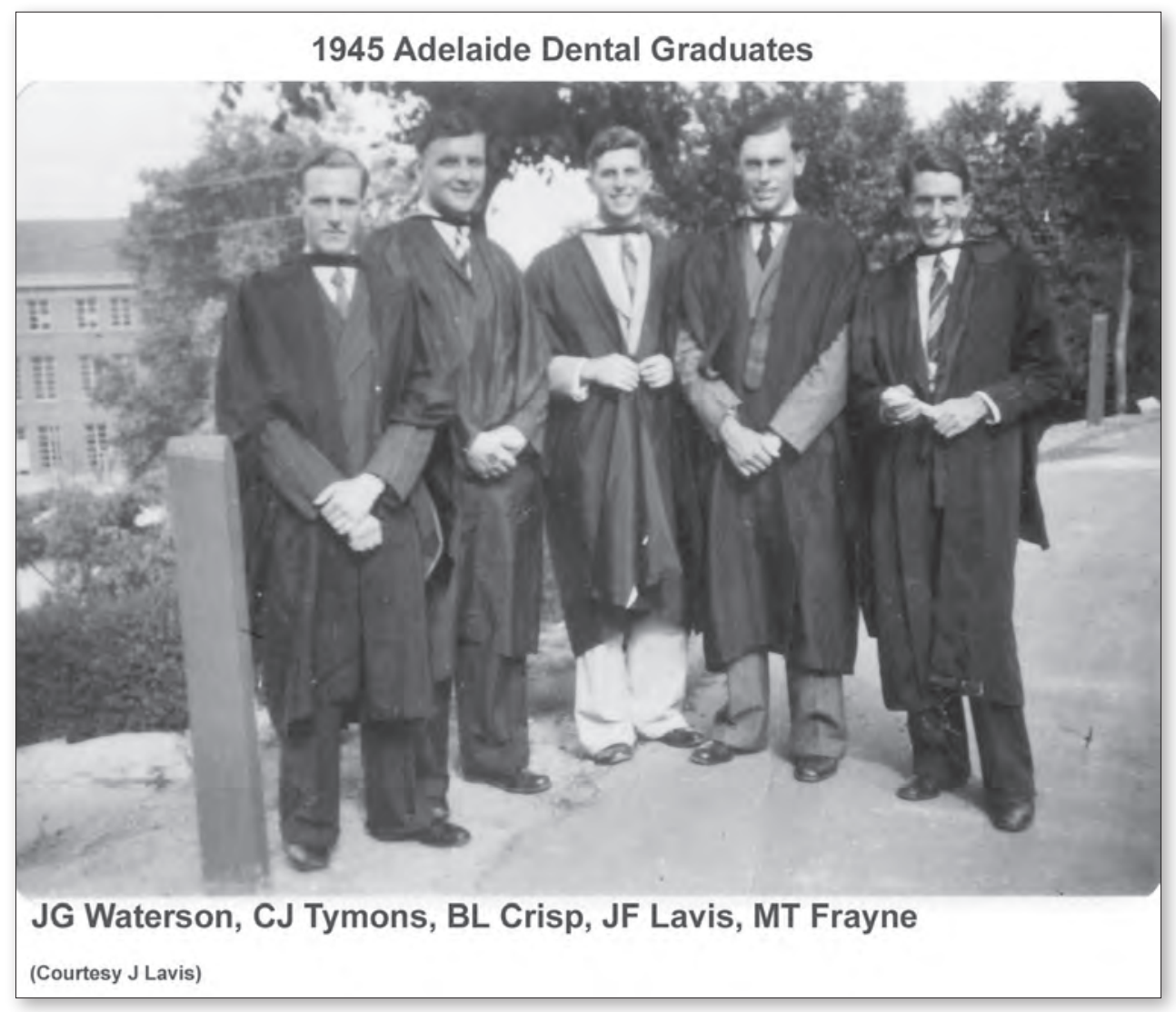

Figure 2.9 Adelaide dental graduates 1945 . 


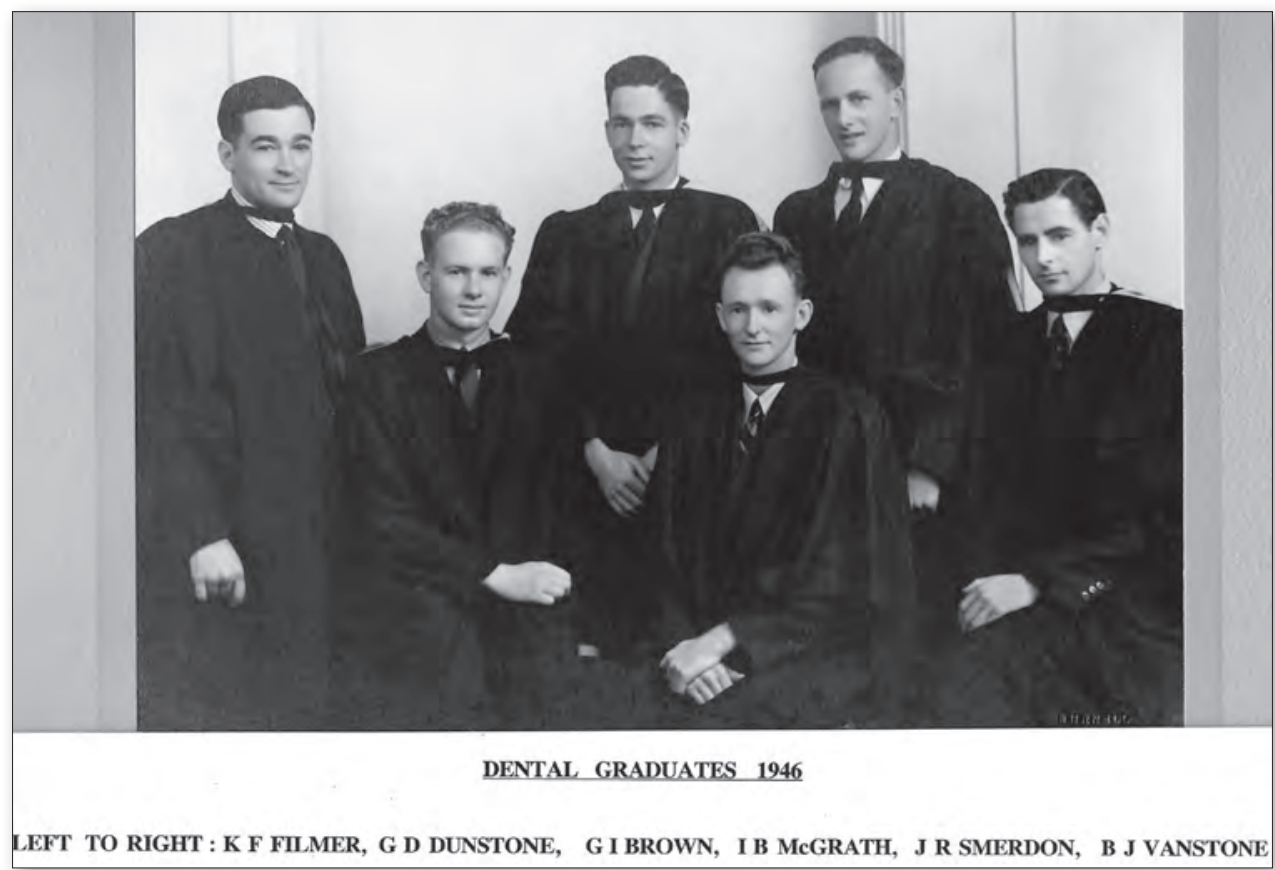

Figure 2.10 Adelaide dental graduates 1946. 


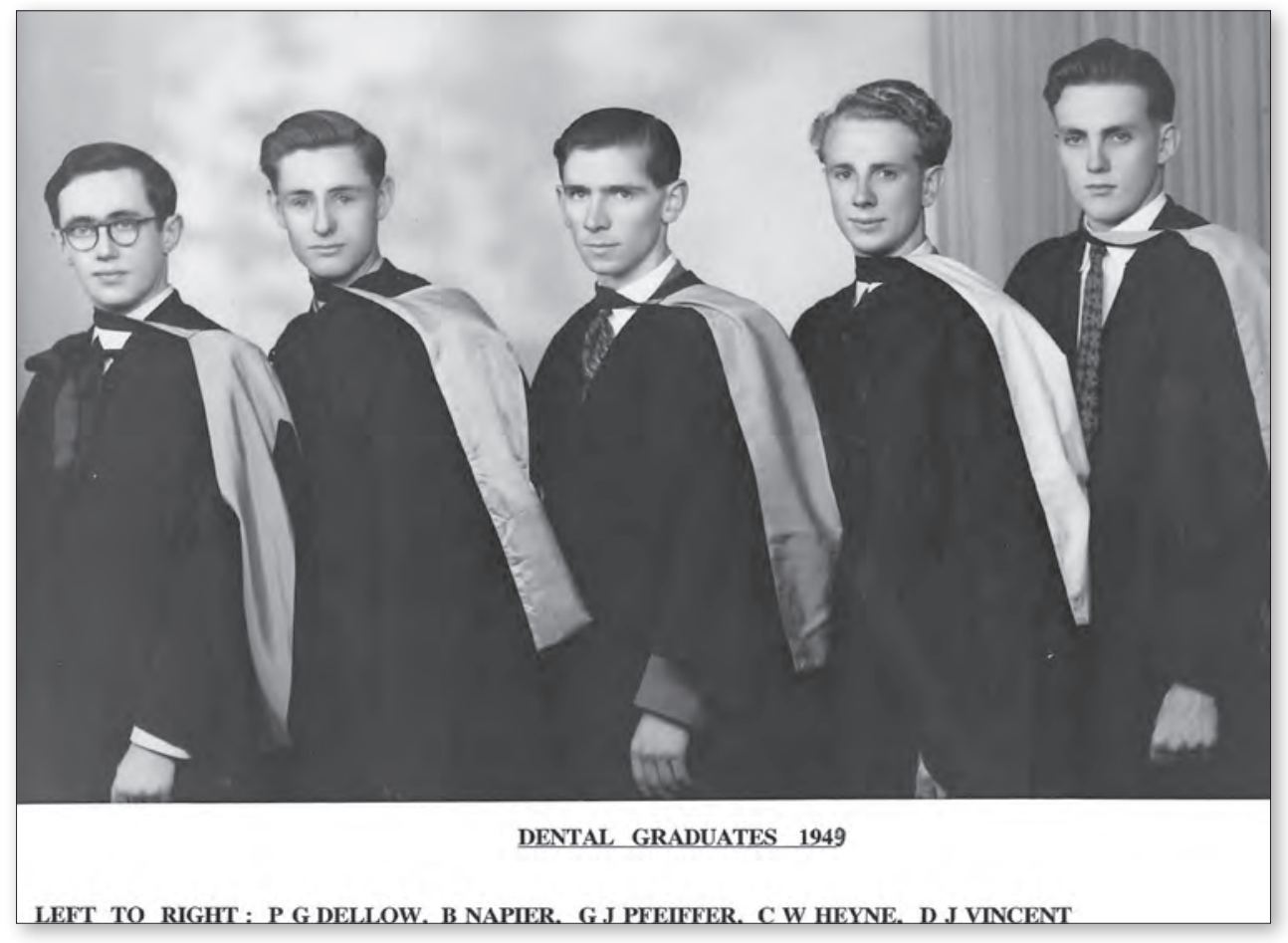

Figure 2.11 Adelaide dental graduates 1949. 


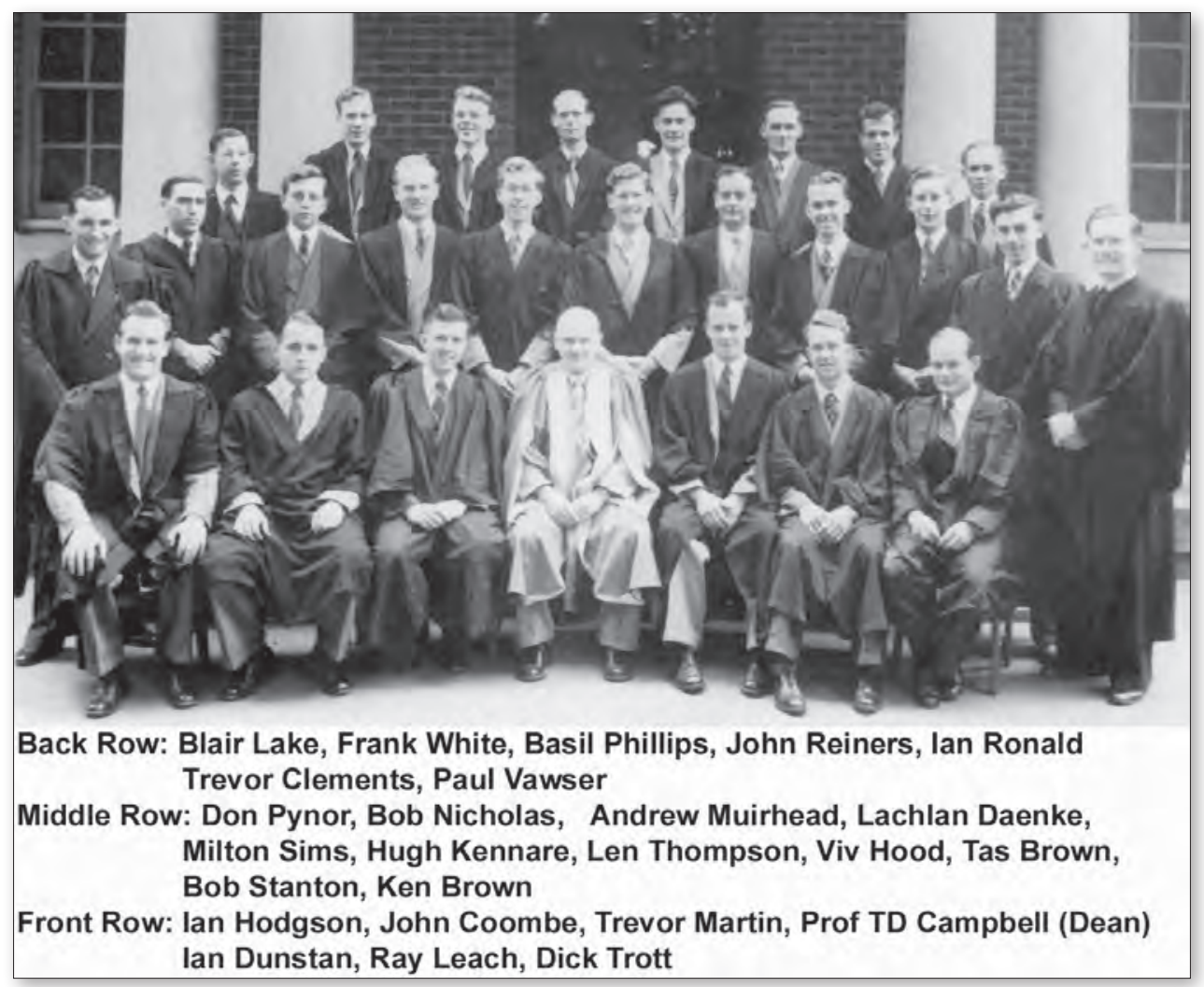

Figure 2.12 Adelaide dental graduates 1950. Returned servicemen in above photograph: BH Lake, BW Phillips, JA Reiners, ID Ronald, HA Nicholas, HD Kennare, LA Thompson and RB Leach.

\section{The Commonwealth Reconstruction and Training Programme}

The First Year intake of dental students in 1946 was the largest (totalling forty-two students) in the history of the Adelaide Dental School. This group included a number of ex-servicemen who had been accepted under the Commonwealth Reconstruction and Training Scheme (CRTS). Of these First Year students, almost half either failed or dropped out in the early years of the course, leaving twenty-five to graduate in 1950. Among these graduates, eight were the first CRTS ex-servicemen to become registered dentists in South Australia. Others were to follow in subsequent years.

\section{Fiftieth anniversary of graduates}

In the year 2000, the university arranged a fiftieth anniversary celebration for graduates from all faculties. The occasion was marked by a celebratory commemoration ceremony 


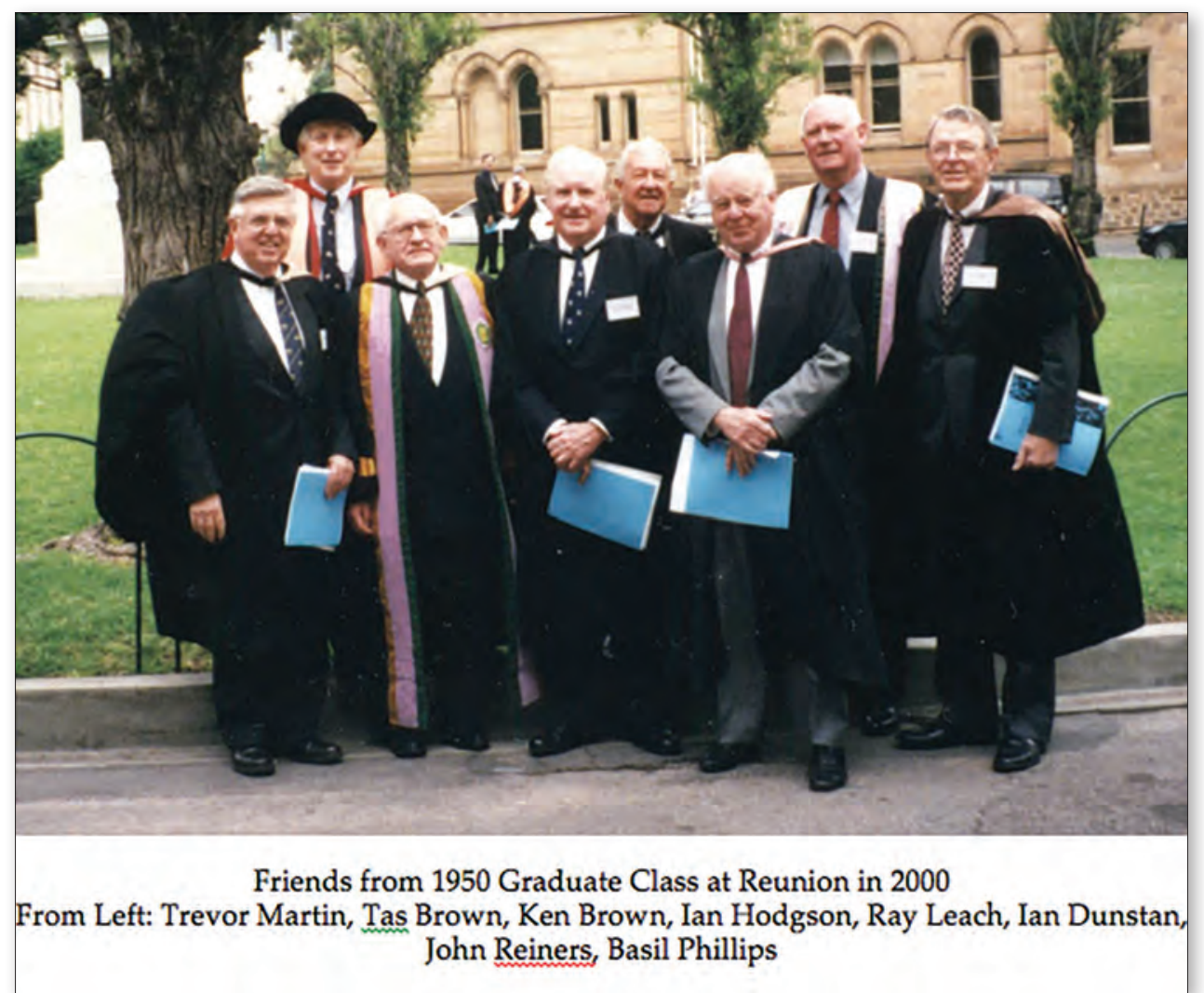

Figure 2.13 Friends from 1950 graduate class (photograph courtesy of T Brown).

in the Bonython Hall followed by luncheon in the Union Building. Eight of the dental graduates of 1950 attended the function garbed in colourful academic attire. It is of some interest that Emeritus Professor Tasman Brown was invited to deliver the commemoration address on this occasion. Similar ceremonies have been held in subsequent years.

\section{References}

Chapman A (1933) Report of the proceedings of the Eighth Australian Dental Congress. Harrison Weir, Government Printer, Adelaide.

Conference of Dental Faculties (1933) Minutes. University of Adelaide, Adelaide. August. Faculty of Dentistry (1933) Faculty Minutes. University of Adelaide, Adelaide. 23 August. Faculty of Dentistry (1939) Faculty Minutes. University of Adelaide, Adelaide. 14 November. Faculty of Dentistry (1944) Faculty Minutes. University of Adelaide, Adelaide. July. 
Faculty of Dentistry (1946) Faculty Minutes. University of Adelaide, Adelaide. March.

Page GW (1986) Lawrence, Gordon Ord (1896-1960). Australian Dictionary of Biography, Volume 10, Melbourne University Press, Melbourne, p. 14.

Schedules, Degree of Bachelor of Dental Surgery (1921) University of Adelaide, Adelaide.

Staffing Sub-Committee Report (1949) Faculty of Dentistry, University of Adelaide, Adelaide. 


\section{A period of expansion and curriculum development - 1950s and 1960s}

\section{New blood - AM Horsnell and JC Thonard}

The 1950s and 1960s was a period of substantial expansion for the Dental School. The deans of dentistry during this period were: Professor TD Campbell (1939-58), Professor AM Horsnell 1959-63, 1971), Mr MJ Barrett (1964-65), Dr AJ Cran (1966-67) and Professor JC Thonard (1968-70).

The first professor of the School, Draper Campbell, was appointed in 1954 after previously being the director of dental studies from 1949 to 1953 . When Campbell retired in 1958, Professor Arthur Maxwell Horsnell, who had been sub-dean at the Dental School, University College London, was appointed as professor of dental science. A second professorship was granted by the university in 1964 and it was filled in 1966 by John Thonard. With Thonard's appointment there was now an opportunity for the Dental School to take more charge of the co-ordination and teaching of sciencebased subjects related to dentistry. Thonard was a graduate from the Melbourne Dental School and he had gained research experience in the UK and the USA. He was professor of microbiology at the School of Dentistry, University of Pittsburg, prior to coming to Adelaide. Thonard's appointment not only opened up opportunities for dental staff to have more involvement in teaching dental students in the early years, but it also added to the research stature of the School.

The Minutes of faculty meetings from the late 1950s to the mid-1960s provide some insight into the political manoeuvring that led to Thonard's eventual appointment. In the 1950s, there was a single Department of Dental Science (with Campbell and then Horsnell as the professor of dental science) but the clinical areas within the faculty 

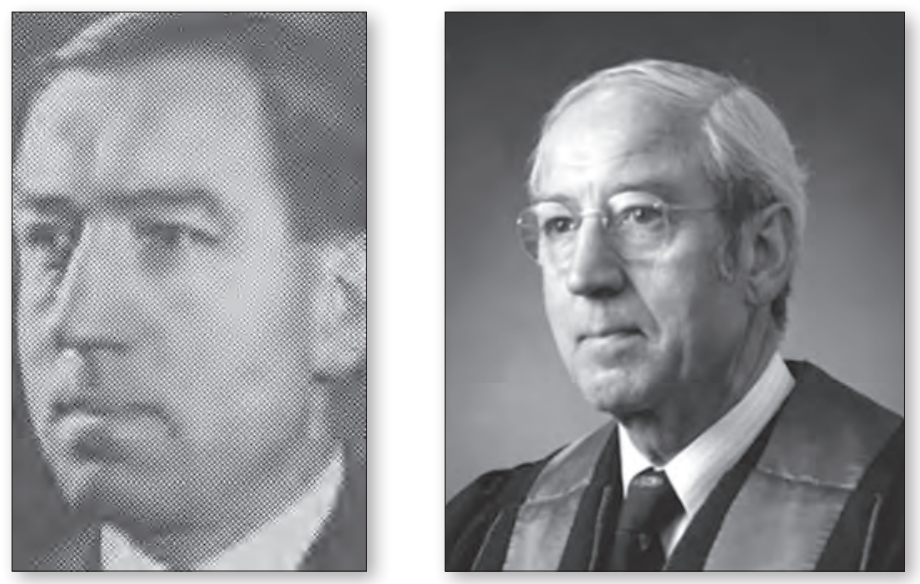

Figure 3.1 Arthur Maxwell (Max) Horsnell, on arrival in Adelaide (left) and as many will remember him (right) (Probe 1958-59, courtesy of AUDSS and ADASA Archives, courtesy of A Lake).

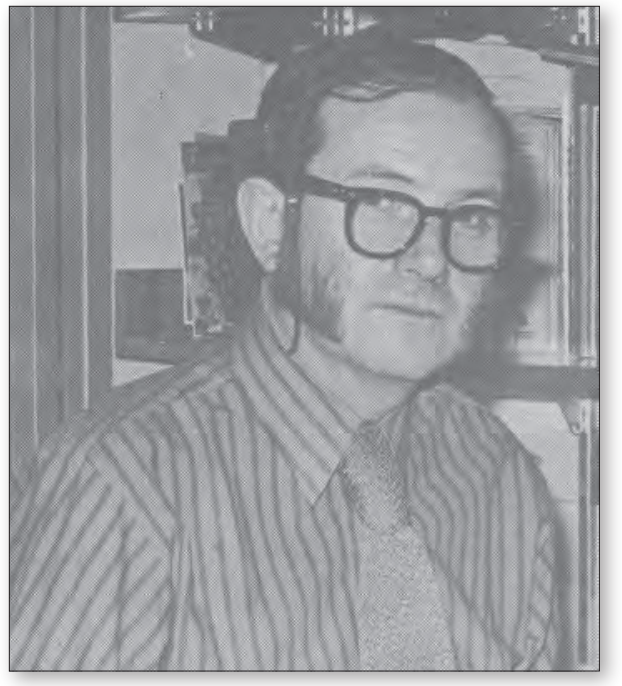

Figure 3.2 John C Thonard (Probe 1973, courtesy of AUDSS).

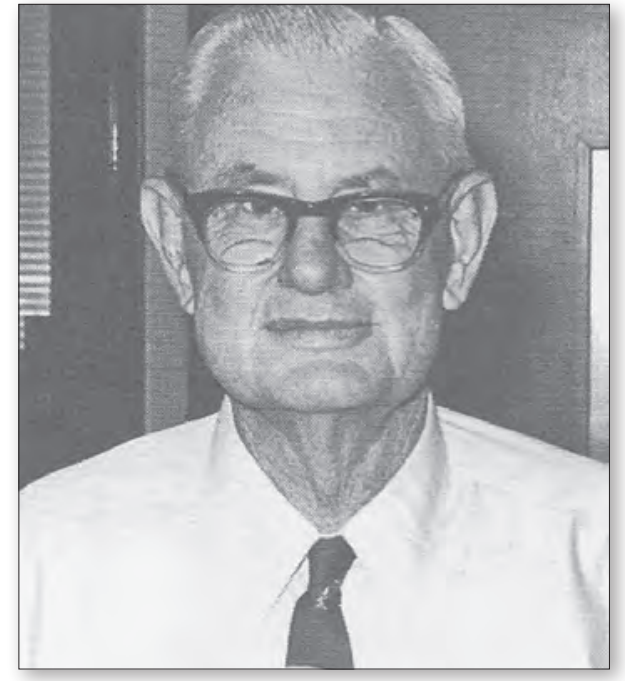

Figure 3.3 James Alexander (Alec) Cran (Probe 1973, courtesy of AUDSS).

were divided into three divisions — preventive dentistry, oral pathology and restorative dentistry — and it was agreed that each of these should be led by a professor. In 1963, Faculty proposed that two additional chairs were required urgently (one in oral surgery and oral pathology and the other in restorative dentistry), noting that a readership in preventive dentistry (to be filled by Elizabeth Fanning) had been funded by Colgate. In 1964, a senior lectureship in oral biology was listed as one of the positions approved by the university's Development Committee but the faculty said this was not adequate. In the end, the restorative chair did not come to fruition but a chair in oral biology was created that was filled by Thonard. The oral surgery and oral pathology chair was not filled at this time, either, with Cran as reader being the senior staff member in this area. 


\section{UNIVERSITY TEACHING STAFF 1968}

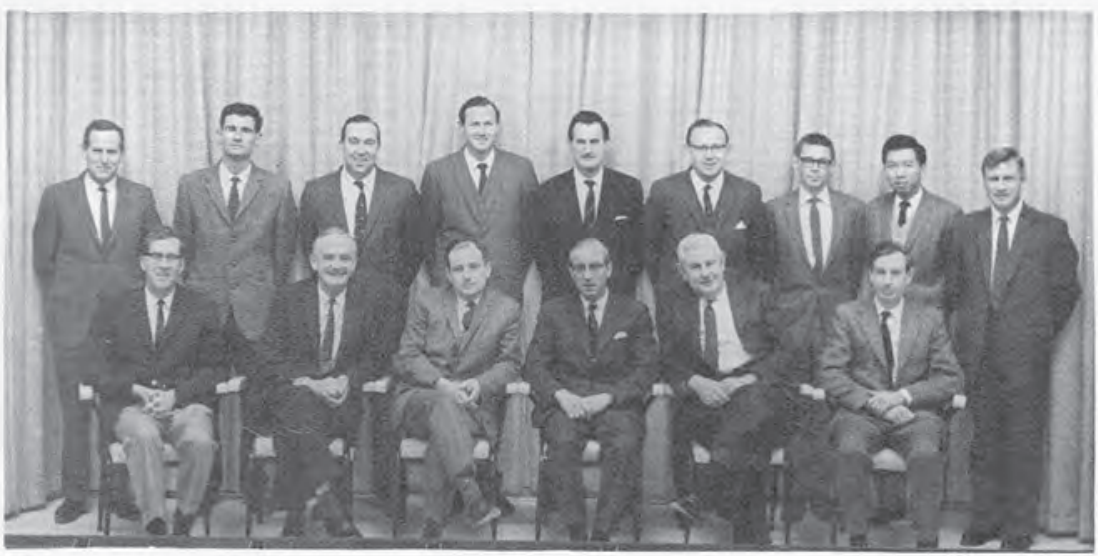

Standing L. to R.:

J. C. Waterson, Senior Lecturer in Oral Biology.

B. N. Fitzpatrick, Senior Lecturer in Oral Surgery.

P. R. N. Beasley, Senior Lecturer in Prosthetic Dentistry.

G. S. Heithersay, Part-time Lecturer in Restorative Dentistry.

J. Kirkwood, Senior Lecturer in Conservative Dentistry.

W. Joyce, Lecturer in Restorative Dentistry.

A. Rogers, Lecturer in Microbiology.

E. Chau, Lecturer in Oral Pathology.

L. E. Reynolds, Senior Teaching Technician.

Seated L, to R.:

M. R. Sims, Reader in Orthodontics.

M. J. Barrett, Reader in Prosthetic Dentistry.

J. Thonard, Professor of Dental Science, Dean of the Faculty.

A. M. Horsnell, Professor of Dental Science, Head of the Department.

A. J. Cran, Reader in Oral Pathology and Oral Surgery.

O. F. Makinson, Senior Lecturer in Conservative Dentistry.

Absent:

E. A. Fanning (Reader in Preventive Dentistry), N. Atkinson (Lecturer in Microbiology), T. Brown (Senior Lecturer in Oral Anatomy), N. G. Clarke (Lecturer in Periodontics), J. Harrison (Teaching Technician), A.

Jeriodontics), Bloomfield (Part-time Lecturer in Pharmacology),

G. J. Mount (Part-time Lecturer in Restorative Dentistry).

The Editors regret they were unable to include Clinical Tutors in the photograph.

27

Figure 3.4 Staff of the Adelaide Dental School (Probe 1968, courtesy of AUDSS). 


\section{A chair in restorative dentistry}

During the 1960s, there was considerable debate within the Faculty of Dentistry about the establishment of further professorial posts within the School, in addition to the single chair of dental science held by Professor Horsnell. Faculty eventually agreed that a chair in restorative dentistry was its number-one priority and an Appointments Committee was formed. It should be noted that then, as now, all chair appointments in the university were usually only made after an exhaustive international search had identified a short list of suitably qualified candidates. In this case, the process was varied and an appointment was made by invitation directly to John Thonard, not as professor of restorative dentistry but as professor of dental science.

Some correspondence from the registrar to the dean of dentistry is provided in Appendix 3 (Figure A3.2), for those who might be wondering how a chair in restorative dentistry, which Faculty had agreed was its number-one priority and which had reached an Appointments Committee, could then 'disappear' and be replaced by a second chair in dental science (to be called oral biology), filled by invitation from the university! While the letter does not provide all of the answers, it does confirm that there was considerable political manoeuvring 'behind the scenes' that influenced the outcome of this appointment. Certainly, the importance of politics both within and outside the School should never be underestimated when it comes to staff appointments and also curriculum issues.

The reason that this particular event was so pivotal is that it was linked to several interrelated factors that subsequently affected the long-term future of the School — for example, a desire by the School to move to a multi-departmental structure whereas the university had indicated it preferred schools to develop 'as unified wholes'; a push for the School to assume a greater role in teaching biodental sciences to dental students (supported by several of the non-dental departments at the time); and the need to find space for research laboratories and teaching laboratories in the soon-to-be-built Adelaide Dental Hospital.

\section{Staff appointments and building research}

Several academic staff members were appointed during the late 1950s and 1960s. Tasman Brown was appointed to lecture in oral anatomy; Brian Radden, a graduate from the University of Western Australia who had completed a PhD in London, was appointed to support Alec Cran in oral pathology; John Kirkwood, a Sydney graduate, came to Adelaide after spending time in Canada and the UK; Betty Fanning, a New Zealand graduate, came from the Forsyth Research Institute in Boston; Owen Makinson, a Sydney graduate, came to the School via London, Melbourne and Baghdad; Peter Beasley, another Sydney graduate, arrived from the Perth Dental Hospital; and 
Nigel Clarke arrived from Sheffield, UK, replacing Peter Reade, who accepted an appointment in the Dental School in Melbourne.

The specialty of oral surgery had started to become organised in the 1950s following the appointment of Alec Cran and then $\mathrm{T}$ Bruce (Buck) Lindsay as the senior visiting oral surgeon. They were supported by a sequential group of senior lecturers in oral surgery during the 1960 s, namely Sydney Roveda (1966-68), Barry Fitzpatrick (1968-69), John Williamson (1968-74, oral pathology) and then later John (Jock) Herd (1970-78).

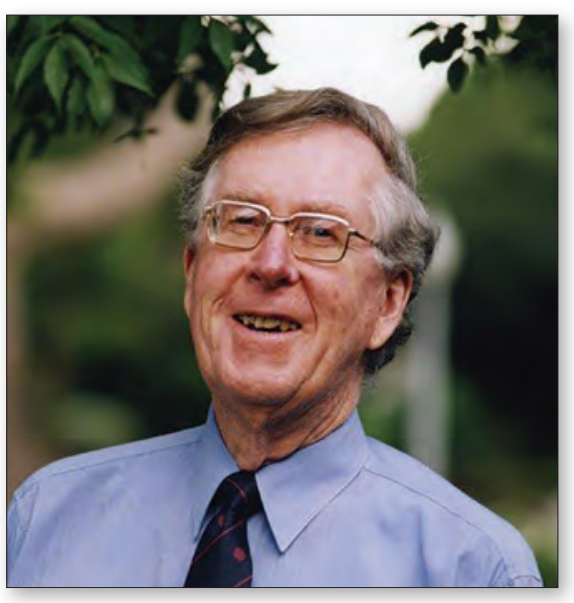

Figure 3.5 Milton Sims (courtesy of W Sampson).

Apart from oral surgery, several other clinical and research strengths of the School were established during this period, including orthodontics, restorative dentistry and endodontics, periodontics and preventive dentistry, as well as pharmacology, microbiology and immunology, and dental anthropology.

Milton Sims, a 1950 graduate from the Adelaide Dental School who completed postgraduate orthodontic training at St. Louis and Boston Universities, was appointed reader in orthodontics upon his return from the USA in 1963. Prior to this, orthodontics had been taught by Dr P Raymond Begg, who had trained with Dr Edward H Angle, commonly known as 'the father of modern orthodontics', in Pasadena, California, from 1924 to 1925 . Milton Sims introduced the two-year Master of Dental Surgery programme in orthodontics in 1969 whilst conducting extensive courses in the Begg Lightwire Technique in Australia and overseas at venues in the USA, Japan and Europe. Adelaide became a world focus of orthodontic attention due to the efforts of Milton Sims, P Raymond Begg, Geoffrey Brown and Mike Nugent. The Postgraduate Committee in Dentistry flourished during this exciting period of activity around the Begg phenomenon of the 1960s and 1970s.

The appointments of Owen Makinson and Graham Mount during this period laid the foundation for the School's emphasis on Minimally Invasive Dentistry (MID) and glass ionomer cements, with input later from other staff including Wyatt (Rory) Hume, Hien Ngo, John McIntyre and John Kaidonis.

Geoffrey Heithersay was appointed to the staff as a part-time lecturer in restorative dentistry in 1962. Heithersay graduated from the Adelaide Dental School in 1956 and then spent four years undertaking postgraduate study in the UK and Sweden, where he 
experienced the highest standards of teaching and research, principally in the field of endodontics. On returning to Adelaide, Heithersay played a pivotal role in establishing the discipline of endodontics that, until that time, had been in its infancy in Australian dental schools and had been limited to the treatment of the six maxillary anterior teeth. All other compromised teeth were extracted and prosthetic replacement was the only option. Heithersay took over the teaching of endodontics and championed an approach to the teaching of endodontics and dental traumatology that was based on a biological approach, drawing on his philosophy that 'knowing why' and 'knowing how' are of equal importance in the management of pathological or traumatic conditions encountered in most clinical fields (Heithersay 2010).

Based on Heithersay's belief that endodontic disease provided an excellent teaching model for a biological approach to patient management, together with the introduction of new dental materials and techniques, the focus of clinical teaching in the Adelaide Dental School moved away from replacement of teeth to the restoration of teeth and the need to understand the underlying biological factors involved. This approach drew on the basic sciences and interrelated disciplines, such as periodontics, orthodontics, oral surgery, general medicine and psychology (2010). Heithersay continues to provide outstanding service to the Adelaide Dental School through his teaching and research and also through his collaboration with two full-time staff members subsequently appointed to head the discipline of endodontics, Peter Cathro in 2005 and Giampiero Rossi-Fedele in 2013.

Nigel Clarke was appointed as a lecturer in periodontics in the late 1960s and, subsequently, Robert Hirsch was appointed, followed by Sushil Kaur. Mark Bartold, who completed his periodontal training in the USA, returned to Adelaide as director of the Colgate Australian Clinical Dental Research Centre in 2002 to provide a strong focus for clinical and research activities in periodontics.

Elizabeth Fanning was appointed as reader in preventive dentistry in the mid1960s and, along with Professor AM Horsnell, established a strong preventive focus in the School, including leading roles in the fluoridation of Adelaide's water supply. The appointment of AJ Spencer as professor of social and preventive dentistry in 1986 emphasised the importance placed on this field of dentistry by the School.

The discipline of oral pathology developed following the appointments of Cran and Radden, with the subsequent appointments of John Williamson, David Wilson and Richard Logan.

Pharmacology and pulp biology developed from the appointment of John Waterson, with the subsequent appointments of David Parker, Trevor Bridges, Rory Hume and Ward Massey, while the areas of microbiology and immunology grew following the appointments of Thonard, Rogers and Nancy Atkinson, followed by Neville Gully and Peter Zilm (both PhD students of Rogers). 

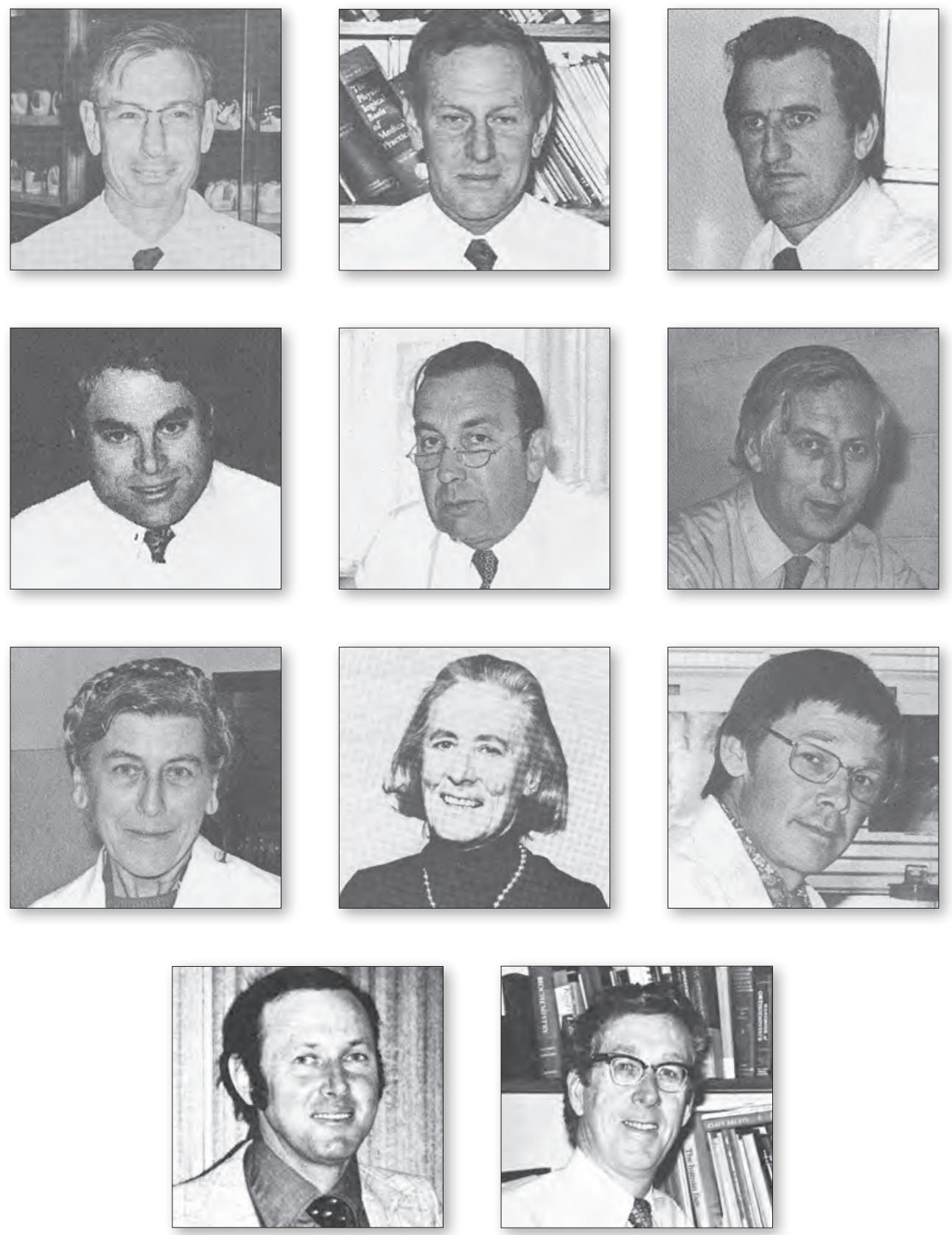

Figure 3.6 Photographs of staff from the 1960s and 1970s (Probe 1973 and Probe 1975, courtesy of AUDSS).

First row from left to right: Dr OF Makinson, Dr JG Waterson, Dr J Kirkwood. Second row from left to right: Dr NG Clarke, Dr PRN Beasley, Dr T Brown. Third row from left to right: Dr N Atkinson, Dr EA Fanning, Dr AH Rogers. Fourth row from left to right: Dr GS Heithersay, Dr MR Sims. 


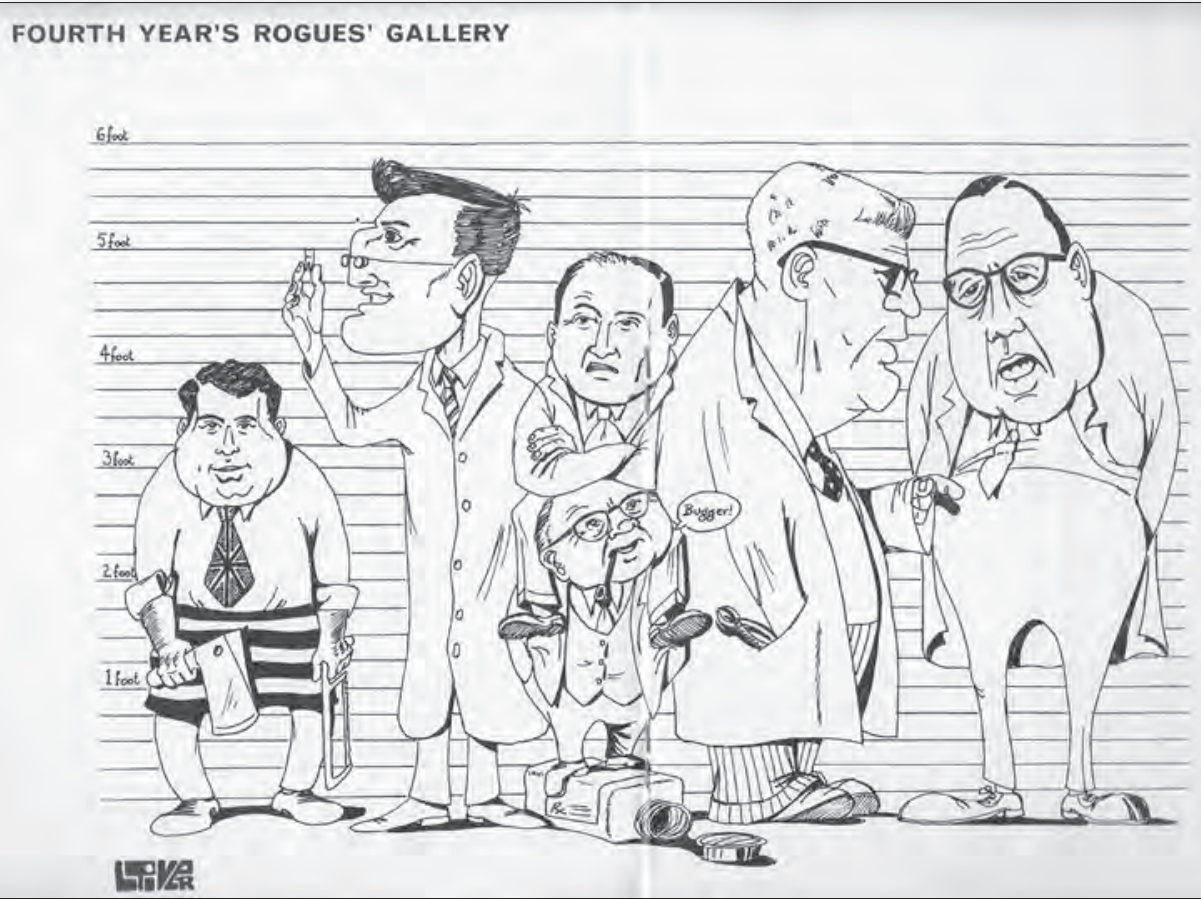

Figure 3.7 Sketches of some staff members, showing (from left to right) Nigel Clarke, John Kirkwood, John Thonard (behind), John (Jack) Bloomfield (front), Alec Cran and Peter Robert Noble Beasley (Probe 1968, courtesy of AUDSS).

The longstanding tradition of research strength in dental anthropology and human growth and development pioneered by Campbell, then Barrett and Brown, has continued with the appointments of Townsend, Richards, John Kaidonis and Toby Hughes.

\section{A preventive approach}

One of the key issues relating to the BDS curriculum during the 1960 s was to make changes to introduce a more preventively orientated course. At this time, there was considerable debate about water fluoridation. Fortunately, the leaders of both political parties in South Australia were in favour of fluoridating the water supply but there was also considerable opposition. With extensive work by staff in the Dental School, including Elizabeth (Betty) Fanning and Kevin Allen, and with the support of the Australian Dental Association (SA Branch) and the profession, the Premier, Steele Hall, reported to Parliament in 1968 that Cabinet supported fluoridation and it was introduced into the water supply in 1971. 

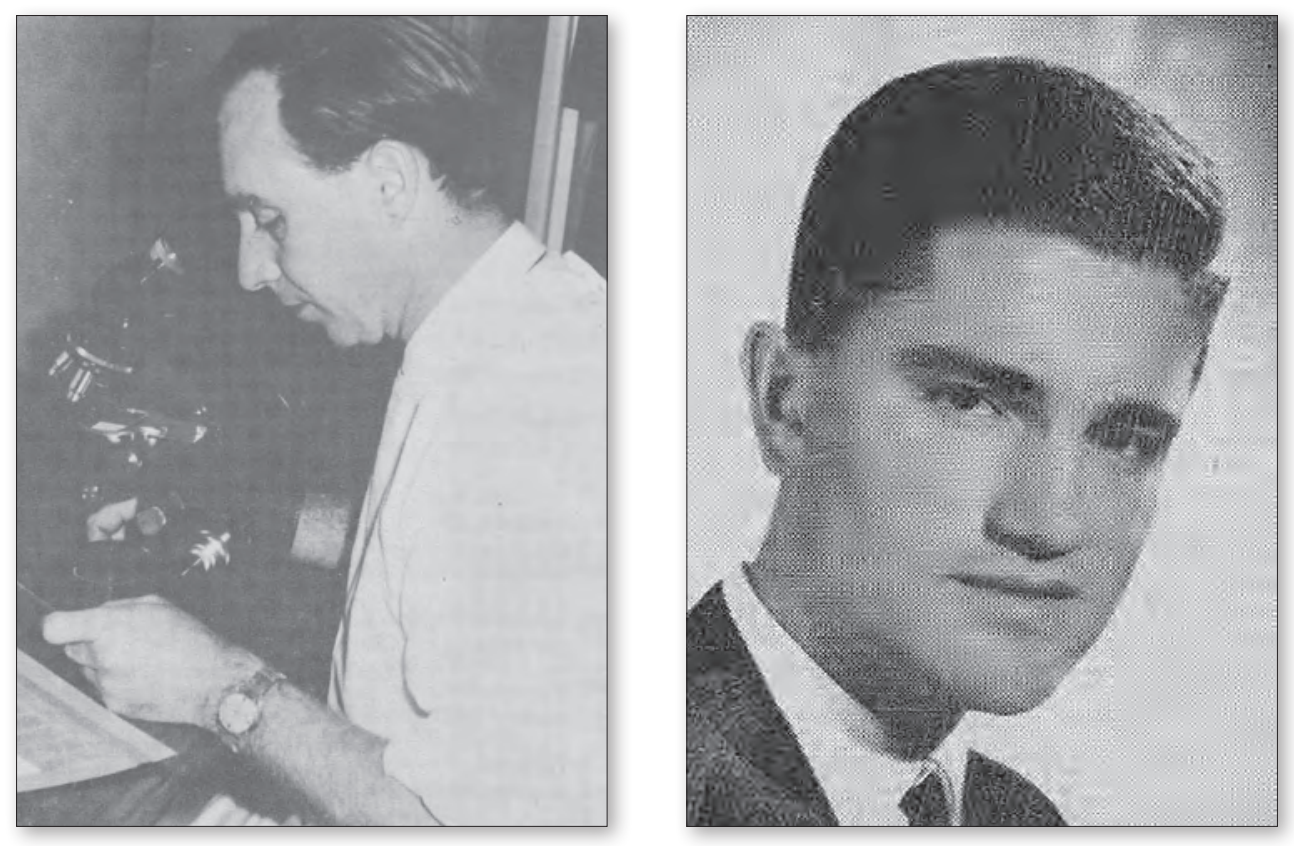

Figure 3.8 Peter Reade and Theo Gotjamanos (Probe 1965-66 and 1964, courtesy of AUDSS).

\section{Postgraduate and honours programmes}

During this time, there was also an introduction of programmes of postgraduate study. The Postgraduate Committee in Dentistry was also established - this is discussed in more detail in Chapter 7.

In 1961, an honours degree was established to enable students to undertake a research project and to serve as preparation for those intending to proceed to further postgraduate work, including masters and $\mathrm{PhD}$ degrees. The honours programme could only be undertaken at the time after the third year of the BDS programme or after graduation. The first student to enrol in this programme was RV Blanden in 1962 and then a further ten students were admitted up to 1970, including John Waterson, Stephen Wei, KK (Ed) Chau, Sven Kuusk, John Reiners, Michael Roberts, Wyatt (Rory) Hume, Bryan Kardachi, John Kearney and Harold Clark. Later on, in the 1980s, students were also offered the opportunity to undertake the honours degree concurrently with the BDS programme and this has become the most popular format for students over the past twenty years or so.

In the early 1960s, it was agreed by Faculty that appropriate candidates could enrol in the PhD degree in the Faculty of Dentistry, and Peter Reade was the first to receive a $\mathrm{PhD}$ in the faculty in 1965 for work carried out in the Department of 
Microbiology under the supervision of Professor Rowley. Two more candidates were awarded the PhD degree in the late 1960s/early 1970s: John Waterson in 1968 in the Department of Physiology and Pharmacology and Theo Gotjamanos in 1971 in the Departments of Surgery and Microbiology.

\section{Adelaide graduates' overseas study}

The 1950s and 1960s were exciting years, when a large number of young Australians travelled widely to experience other countries and cultures, particularly the UK and the rest of Europe. For recently graduated dentists, there were also excellent opportunities for work and study. In the UK, Australian dentists could gain experience in general practice under the National Health Scheme. In addition, or as an alternative, they could study specialised areas of dentistry at one of the UK dental schools, major hospitals with oral surgical units, or at The Eastman Dental Institute, which latter was the only centre for postgraduate dental training in London. At that time, there were no clinical programmes in dental disciplines available in Australia, other than orthodontics.

Mutual recognition of Australian degrees in the UK allowed an easy interchange and most graduates who pursued further study were able to supplement their educational costs by working some sessions in a National Health practice. This was important, as most intern/training positions were extremely poorly paid. Ken Kinnane (1959) noted in an article in Probe magazine that dentists were paid monthly for work completed and that patients contributed one pound toward the cost of conservative treatment and about half the cost for prosthodontic work. At the time, the cost of a full upper and lower denture was nine pounds and nine shillings.

Other graduates headed to the USA, Canada or Scandinavia, usually to study advanced restorative dentistry, including crown and bridgework, periodontics, orthodontics, paedodontics or endodontics.

The graduates who pursued postgraduate studies during this period included: Bruce Lindsay, Kevin Moore, Keith Bailey (oral surgery); Bruce Tidswell, Kevin Allen (paedodontics); Rex Wallman, Laurie Smart, Grahame Moore (orthodontics); Peter Reade (oral medicine); Fred Henning, Brenton Burfield, Norman Vowles (periodontics); Roger Willoughby, Bruce Wark, John Lavis, Graham Mount, John Myhill (restorative dentistry/crown and bridgework); John Reiners (prosthodontics); Lachlan Daenke and Geoffrey Heithersay (endodontics).

The Adelaide Dental School has indeed been fortunate to benefit from significant input to teaching and research by graduates who have studied various specialised dental disciplines overseas, as well as in Australia, and then joined the part-time staff as tutors/ lecturers. These well-qualified graduates have added an important and exciting new dimension to clinical teaching in all disciplines, including endodontics, orthodontics, paediatric dentistry, oral surgery, periodontics, prosthodontics and restorative dentistry. 


\section{The new Dental Hospital}

Although the original Dental Hospital that opened in 1923 was considered to be a state-of-the-art facility at the time and was envied by other Australian states, with the increase in dental student numbers after World War II, facilities for teaching became inadequate. A temporary building was erected subsequently on the southern side of the main building to accommodate a teaching laboratory for operative dentistry. The students' common room was also used as a classroom and temporary laboratories and offices were built on the ground floor and also on the first-floor verandas. The building was also not large enough to accommodate the Dental Department of the Royal Adelaide Hospital, with increasing demand for dental treatment.

As Barrett noted in his article in the 1967 edition of Probe, this was a particularly difficult time for hospital staff, teaching staff and students trying to function in such cramped accommodation. There was a temporary decline in student numbers after the marked increase directly after World War II but then the numbers began to rise again in the mid- to late 1950s. As Barrett explained, there were 11 First Year students in 1957 and a total of 45 students in all 5 years of the course, whereas in 1967, there were 83 students in First Year and 220 overall.

The enlargement of the Dental Hospital became an urgent matter as demand for clinical facilities increased. Plans had already been submitted to build a new wing to the existing Dental Hospital and these had been recommended by a Parliamentary Standing Committee on Public Works. Associated with this urgency was the need to modernise much of the equipment. In the Faculty Minutes there is constant mention of the progress or otherwise of the Dental Hospital expansion programme. By 1954, it was suggested that because of financial restraints only part of the proposed extensions should be constructed next to the existing building. This addition was known as the north wing and the cost totalled $£ 328760$.

The north wing extension to the original building was completed in 1962 and a south wing extension was then completed in 1964 . There were originally plans to modernise the ground and first floors of the original building but it became clear that this would not accommodate the projected increase in numbers of students. The plans were reconsidered with a view to providing appropriate space and facilities for fifty students per year. The number of fifty students per year had for some time been considered internationally to be an optimal number for a viable dental school involved in teaching, research and service. A proposal was put to the SA government that the old building should be demolished and replaced by a seven-storey building that would link the new northern and southern extensions. This submission was approved by the government in 1964.

Barrett (1967) explained that the initial planning of the new Dental Hospital was carried out by the Public Buildings Department in consultation with a small 


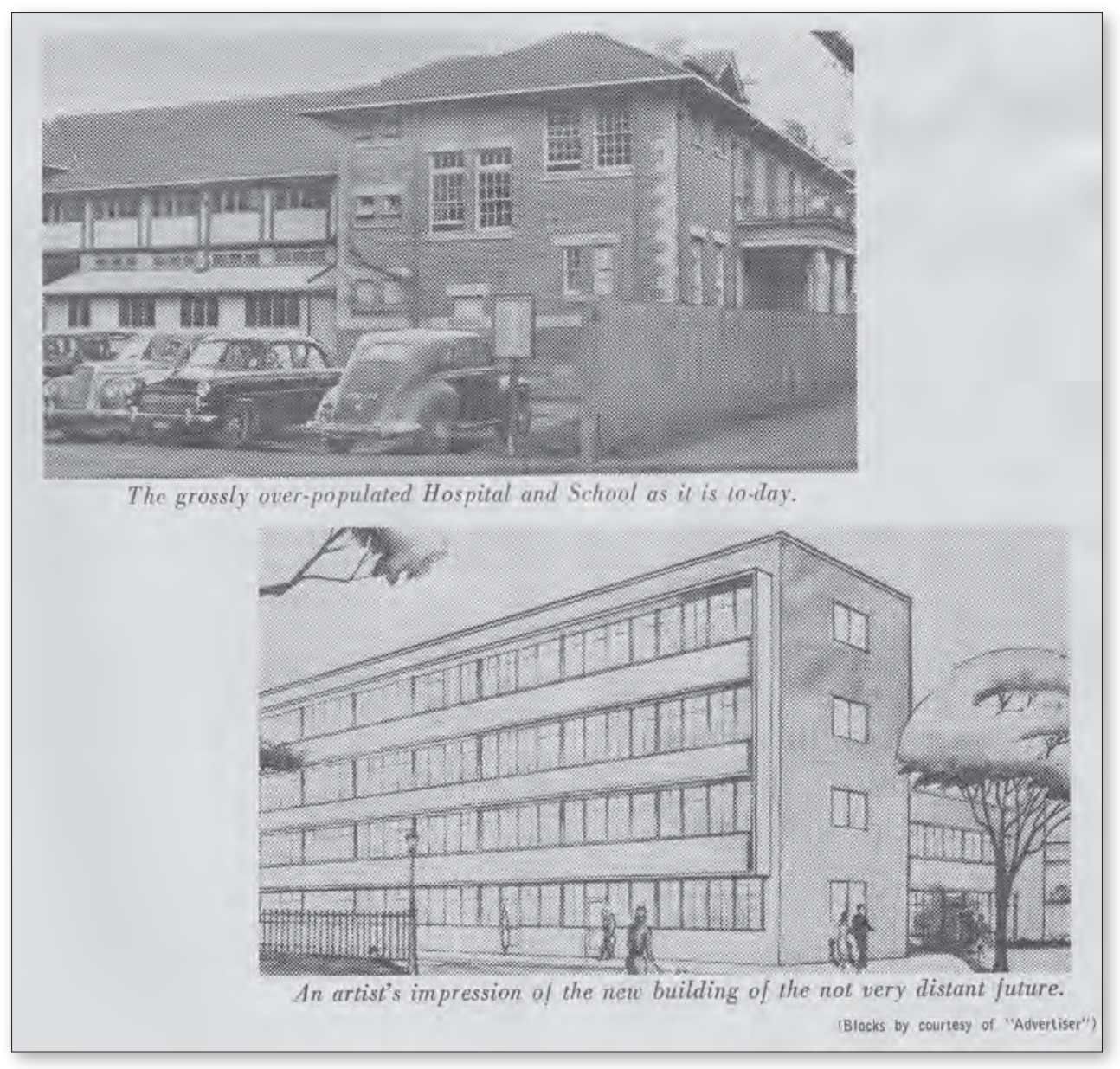

Figure 3.9 The old Dental Hospital (side view) and plans for the new building (Probe 1953, courtesy of AUDSS).

group of dentally qualified people, namely TD Campbell, GO Lawrence, JL Eustace and J Scollin. In the later stages, the planning was carried out by a private firm of architects who worked with the Public Buildings Department and a larger consultative committee was formed that included Professors Horsnell and Thonard and Drs Cran, Makinson, Scollin, Sims and Barrett. The architect was Mr PD Haddrick.

In his Probe article, Barrett listed the major objectives in planning the new building. These included: to provide better treatment facilities for patients admitted to the Royal Adelaide Hospital or eligible for treatment at the Dental Department; to provide clinical and non-clinical teaching facilities for students from Second to Fifth Year, with up to fifty students in each year; and to provide facilities for postgraduate 
research and clinical training. Barrett explained that the clinical areas had to be spread over four floors even though it was acknowledged that this would lead to some problems with communication. Clinics that were closely associated in terms of their function were placed together and facilities were planned to be shared between the Dental Department and the Dental School wherever possible.

One of the admissions surgeries on the ground floor was set aside for teaching in oral diagnosis and a tutorial room was planned for teaching oral and dental radiology. Undergraduate teaching clinics were located on three levels and each of the clinics was designed to have four teaching modules, each comprising five dental chairs. One decision made early in the planning

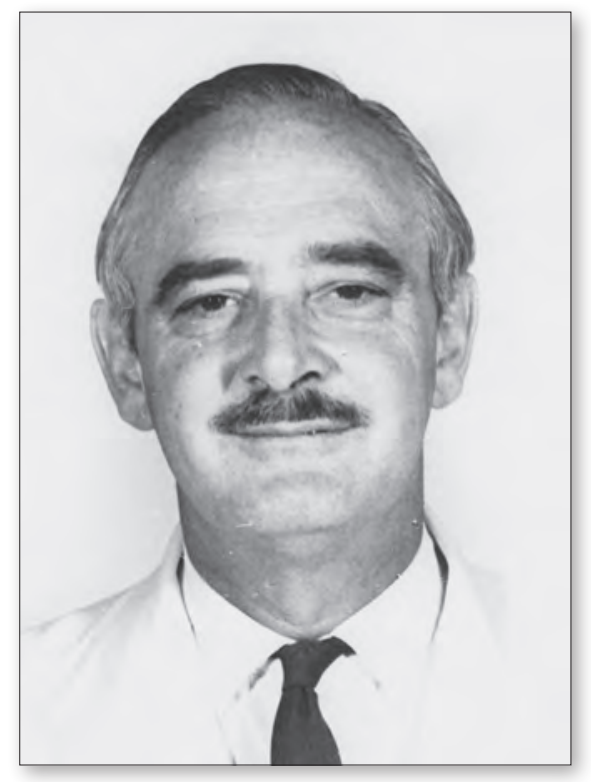

Figure 3.10 Murray James Barrett (courtesy of Adelaide Dental School). was that there would be a system of central sterilisation of instruments and supply.

It was planned that the oral biology and oral pathology teaching divisions of the Dental School would be located together with lecture rooms on the fifth and sixth floors. A large laboratory for teaching histology, oral anatomy, pathology and microbiology was also planned for the sixth floor (which was replaced by offices in the 1980s), as well as research laboratory space. Barrett (1967) commented that '[w]ith these facilities the Dental School will be able to accept a greater responsibility for teaching in basic biomedical subjects than it has in the past' (p. 6). Barrett speculated about the future and said:

Although the construction of the new Dental Hospital will eventually be recorded as another important milestone in the history of dentistry in South Australia, bricks and mortar and items of equipment will be of minor interest and significance compared with the less tangible but more lasting effects dependent on the people who use the building and the manner in which it is used. Young people now at the beginning of their careers in dentistry are those who we look to for the future progress of dentistry. The new building will be their training ground, it will be a place in which some will work after graduation, it will be a place for continuing studies. Properly used, the new building should have a tremendous impact on dentistry of the future. (p. 6) 
Given that it continued to function effectively for nearly fifty years up to mid-2017 when it was decommissioned, one must acknowledge the magnificent efforts of all those involved in designing the 'new' Adelaide Dental Hospital and its role in enabling the Adelaide Dental School to develop an international reputation for its teaching and research.

It is worth emphasising that academic staff from the Department of Dental Science, including Campbell, Lawrence and Eustace initially, and later Barrett, Horsnell, Thonard, Cran, Makinson and Sims, were all intimately involved in the planning and design of the new facility which was built to accommodate both a dental hospital and also a dental school. At the time, the Dental Hospital was a department of the Royal Adelaide Hospital with a dental superintendent, J Scollin, as well as a staff of dentists, nurses and a technician. At the time, the university staff were in a single department of Dental Science with three clinical divisions: Oral Pathology and Oral Surgery; Preventive Dentistry; and Restorative Dentistry.

Although the state government provided the funds for the new building, the university was fully involved in its planning and design. The aim was to provide an integrated facility for the reception, examination and treatment of public patients, as well as offices, laboratories and lecture theatres for the education of dental students and the training of nurses and technicians, and also postgraduate research facilities. In total, it was built to be a complete Dental School.

A document prepared by Faculty in the 1960s entitled Teaching Facilities in the Dental Hospital: Summary of Discussions and Decisions in 1964 and 1965 included a section that refers to the second report of the Australian Universities Commission Committee on Teaching Costs of Medical Hospitals. This report was presented to the Hon JG Gorton in May 1965 and recommended a capital grant in the 1964-66 triennium of 400000 pounds for the rebuilding of the Dental School within the Dental Hospital in Adelaide. Presumably, this federal government funding did not eventuate and so the Adelaide Dental Hospital has been 'owned' by the state government ever since.

In 1966, Barrett and Makinson travelled to England and Denmark to inspect clinical facilities in dental schools and to assess equipment to be acquired for the Adelaide School. Manufacturers were also contacted. Brown was on sabbatical leave in 1966 at the Royal Dental Hospital in Copenhagen and met with Barrett and Makinson during their visit.

The Faculty Minutes of August 1968 record that the dean informed Faculty that it had been agreed by the director-general of Medical Sciences SA, the acting administrator of the RAH and the vice-chancellor, in consultation with the dean and the head of the Department of Dental Science, that the new building would be called The Dental Department of the RAH and The School of Dental Science. 


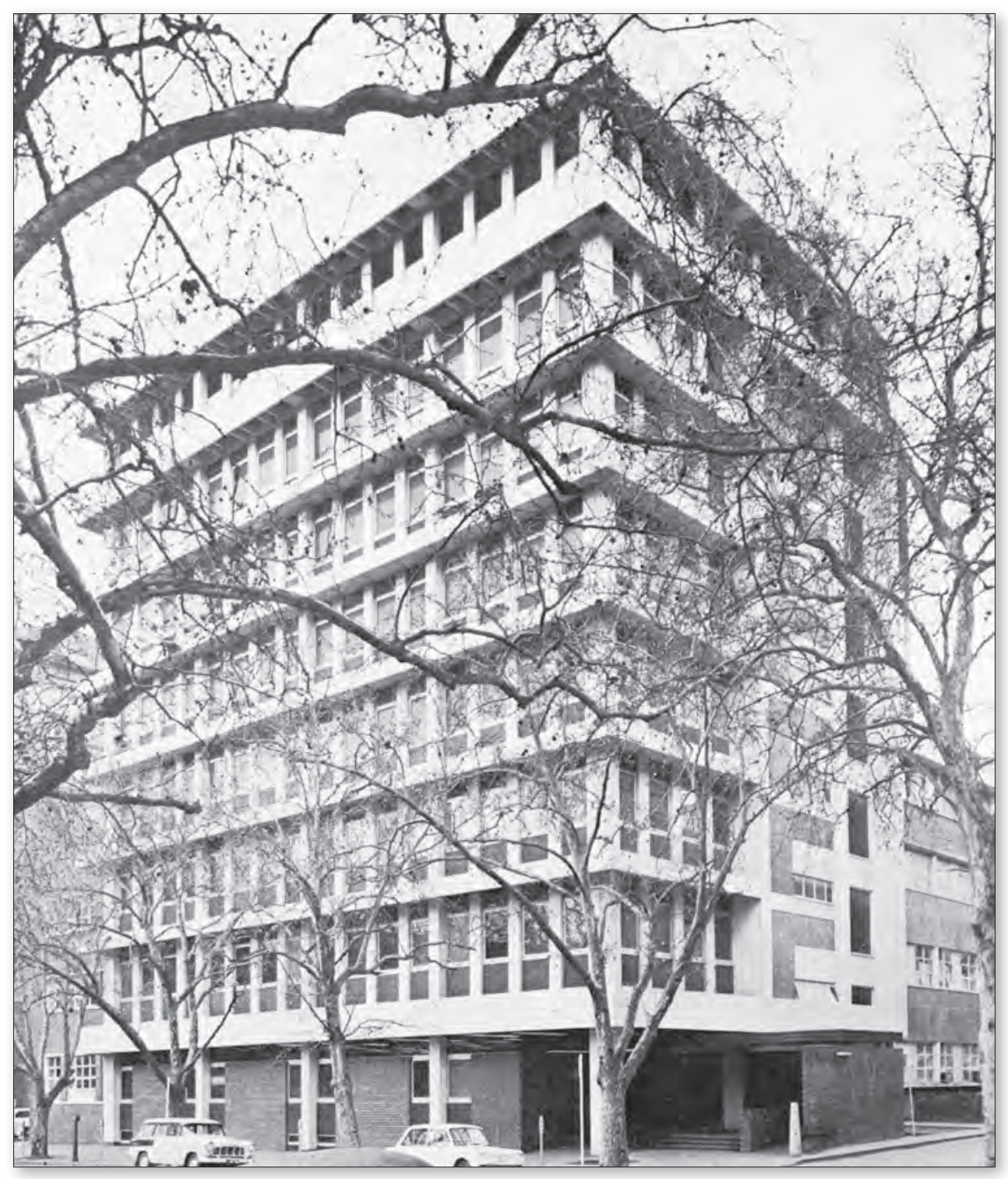

Figure 3.11 The new building for the Dental Department of the RAH and the School of Dental Science (courtesy of Adelaide Dental School).

The booklet produced to mark the opening, on Friday 29 August 1969, of the new Royal Adelaide Hospital Dental Department and the University of Adelaide School of Dental Science is reproduced in Appendix 3 (Figure A3.1). It depicts the original floor plans for the building with areas for teaching, research and service all combined into a single facility. The booklet includes a listing of staff, some notes from 
the vice-chancellor and floor plans. The new facility was estimated to cost $\$ 2750000$, including equipment.

Emeritus Professor AM Horsnell presented the third Graham Mount Oration in the Elder Hall at the University of Adelaide in 1989 and the chairman of the Postgraduate Committee at the time, Dr Ian Watson, introduced him. The topic of the oration was 'Then and now - how things have changed'. It seems appropriate at this stage to include some of the points made in the introduction to the Oration and during the lecture that provide some background information about why Horsnell came to Adelaide along with his view of some of the main events that occurred during his time at the Dental School.

Ian Watson pointed out that, following the retirement of Draper Campbell in 1958, the chair in dental science was advertised and the dean of the Eastman School in London, Professor Frank Wilkinson, and others encouraged the 'young Horsnell' to apply. He was appointed and arrived in Adelaide in February 1959 with his wife Babs and four daughters and, according to one of his peers, brought 'life and fire' into the School (Watson 1989, pp. 1-2). In reflecting on his career, Horsnell noted that his greatest appreciation of his time in dental education was the total commitment of all his colleagues and staff in their pursuit of excellence in the Dental School.

In his Oration, Horsnell recalled that, in 1959, the Dental Hospital and Dental School comprised the building on Frome Road that had been built in 1923 with a big hole on its northern side. He noted that the hole had been dug for the foundations and basement of a new north wing that had been planned in order to ease the crowding in the existing building. It was planned that construction of the north wing would be followed by a smaller south wing and then the two wings would be joined together at the east end. The proposed extensions had been based on a figure of twenty-five dental students in each year of the BDS course but there had been two committees in the UK that had recommended that, to be cost-effective, plans for any new dental school should aim for a minimum of at least fifty students in each year.

Based on staffing and accommodation issues, Horsnell and others calculated that about forty-five new students would be needed each year. However, when the university's Education Committee considered the matter, it was decided that a larger number was needed to allow for attrition and that additional accommodation would be required.

Horsnell pointed out that when the new north wing was completed and the south wing was almost completed in 1963, someone noticed that the proposed link at the eastern end had been planned without a basement. There was a full basement in the north wing (where the students' common room is located) and a partial basement in the south wing, but no link between them. This would have meant that for people to move from the north to the south wing, it would be necessary to come up to the 
ground floor and cross through a clinic and then travel down in the only lift. After this discovery, it was decided that the best solution would be to demolish the 1923 building and then incorporate the north, south and east extensions into a new central building of seven floors. This was certainly a stroke of luck for the Dental School.

Emeritus Professor Tasman Brown presented the fourth Mount Oration in 1992 and the focus of his presentation was TD Campbell, the first professor of dental science. The substance of the lecture was published subsequently in the Australian Dictionary of Biography (Brown \& Rogers 1993) under the title Thomas Draper Campbell: Pioneer Dental Anthropologist (Brown 2001), but Brown's description of the circumstances surrounding the appointment of Campbell to the first chair in the Dental School is worth recounting.

For many years, Campbell was the only full-time member of the teaching staff in the Dental School, with other part-time staff including Drs Lawrence, Eustace, Begg, Moore, Edwards and Joyner. Brown notes that the class sizes were smaller in those days, recalling that Campbell would occasionally call in a single student to his office for a personally delivered lecture.

With the increasing numbers of students after World War II, the question of a chair in dentistry was raised around 1947 and the matter was considered by the University Council, who referred the matter to a special committee. While the committee considered the matter, Campbell was appointed as director of dental studies in 1949. In 1951, with still no outcome, Faculty again proposed to the Council that a chair in dentistry should be established as soon as possible. Council agreed to consider the matter along with other issues with which it was dealing. The faculty kept pressing the matter and then an item appeared in the Minutes of the November 1952 meeting of the Education Committee as follows:

The Dean [of Dentistry] was reminded that by general consent throughout the University, it had been agreed early in the year that preference should be given in 1953 to expansion in the Faculty of Arts and that [the dental] Faculty's request had been made very late. (Education Committee 1952)

In 1954, Campbell was eventually offered the first chair in dental science in the Dental School and he held the position for four years until his retirement in 1958.

\section{Dental technology}

There was an increasing emphasis on the teaching of dental technology during this period. This had started in 1925 with Leonard Brougham being the first appointee as a Senior Hospital Mechanic, teaching Second Year students the art of laboratory procedures. The fact that three more dental technicians (as they became known) were needed illustrates the emphasis placed on students acquiring both a knowledge of dental technology and a 'hands-on approach' when handling materials and techniques used 

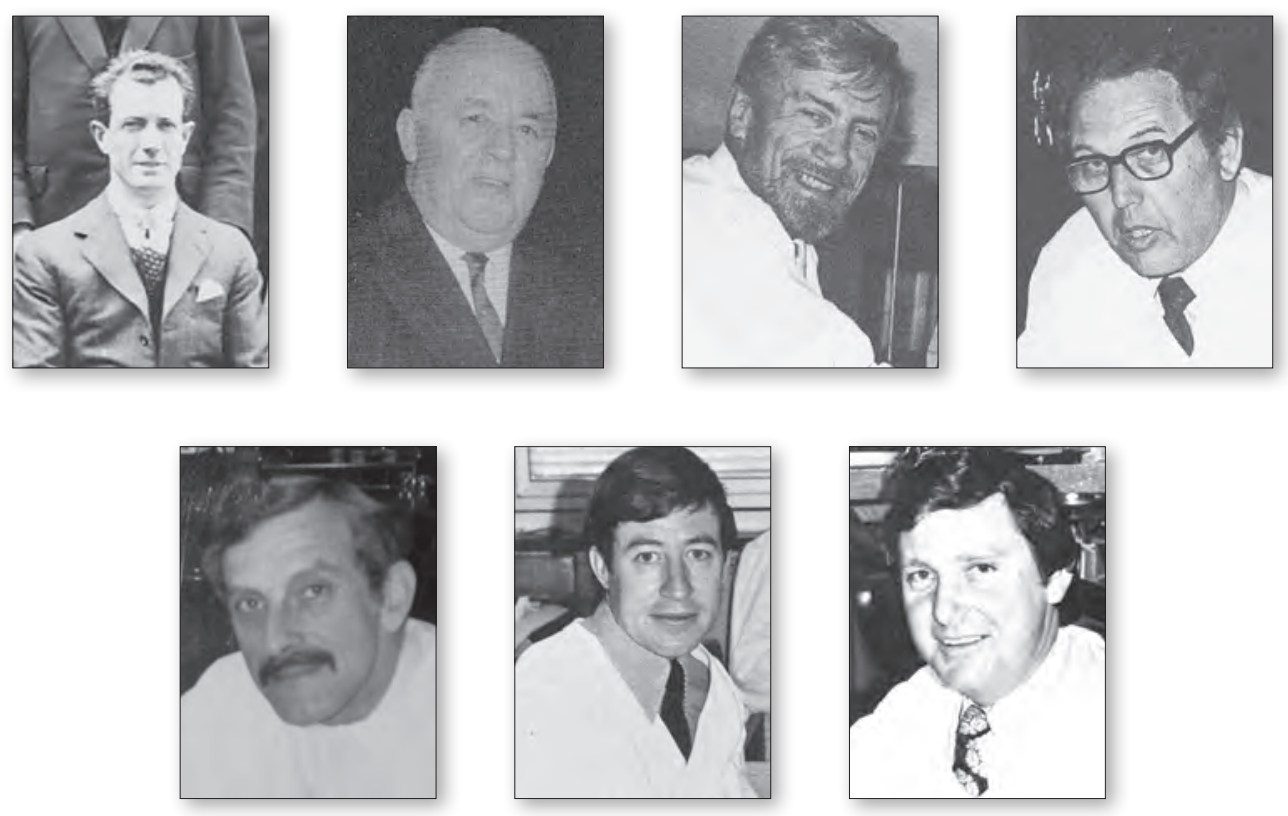

Figure 3.12 Photographs of long-serving teaching technicians in the Adelaide Dental School (ADASA Archives and Probe 1973 and 1975, courtesy of AUDSS).

First row from left to right: Leonard Brougham, Clarence (Clarrie) Whitford, Leslie (Les) Reynolds, Thomas (Tom) Rollings.

Second row from left to right: James (Jim) Rogers, Garry Briscoe, Graham Scriven.

at the chairside. Another important factor in requiring students to produce their own laboratory work for their patients was to make them more aware of the complexities in manufacturing dental appliances. Also, by being involved in the construction of dental prostheses, students would, it was felt, acquire an understanding of why an appliance was successful or why it had failed. It was also considered that, with any future work that students received from a laboratory, they would be better able to determine good from bad.

After Leonard Brougham retired in 1943, Clarence (Clarrie) Whitford carried on the technical duties. He introduced the students to methyl methacrylate resin, a great improvement on the earlier vulcanised rubber. After Whitford's appointment, the technician instructors took on ever-increasing duties until students in all years of the course came, to some degree, under their influence.

First and Second Year students were shown the rudimentary principles of dental technology, as well as being introduced to the materials and equipment used in a dental laboratory. Third Year became the year when students were introduced to the laboratory stages of prosthetic and conservative restorations, with Fourth and Fifth 
Year students becoming less involved in instruction but more often seeking advice from the instructors with their patient cases.

While students were expected to learn how to make dental appliances, they were also expected to manufacture work for their patient cases. Horsnell made a special mention in his Graham Mount Oration in 1990 of the help he received from the administrator of the Royal Adelaide Hospital (RAH), Mr Colin Rankin, who had been appointed in the same year as he had become dean (1959). There was an understanding between the two men which proved beneficial for both the RAH dental clinics and the university teaching programmes involved with operative techniques and laboratory procedures.

One big improvement for the dental students in the 1960s was the ability to hire a kit of instruments supplied by the RAH, instead of having to purchase expensive kits for themselves. Students were expected to service these instruments and to make sure they were sterilised between patients. Should any instrument be lost or misplaced the student was expected to pay for its replacement.

The co-operation between Horsnell, Rankin and the dental superintendent, William (Bill) Scollin, was such that much was accomplished in the new Dental

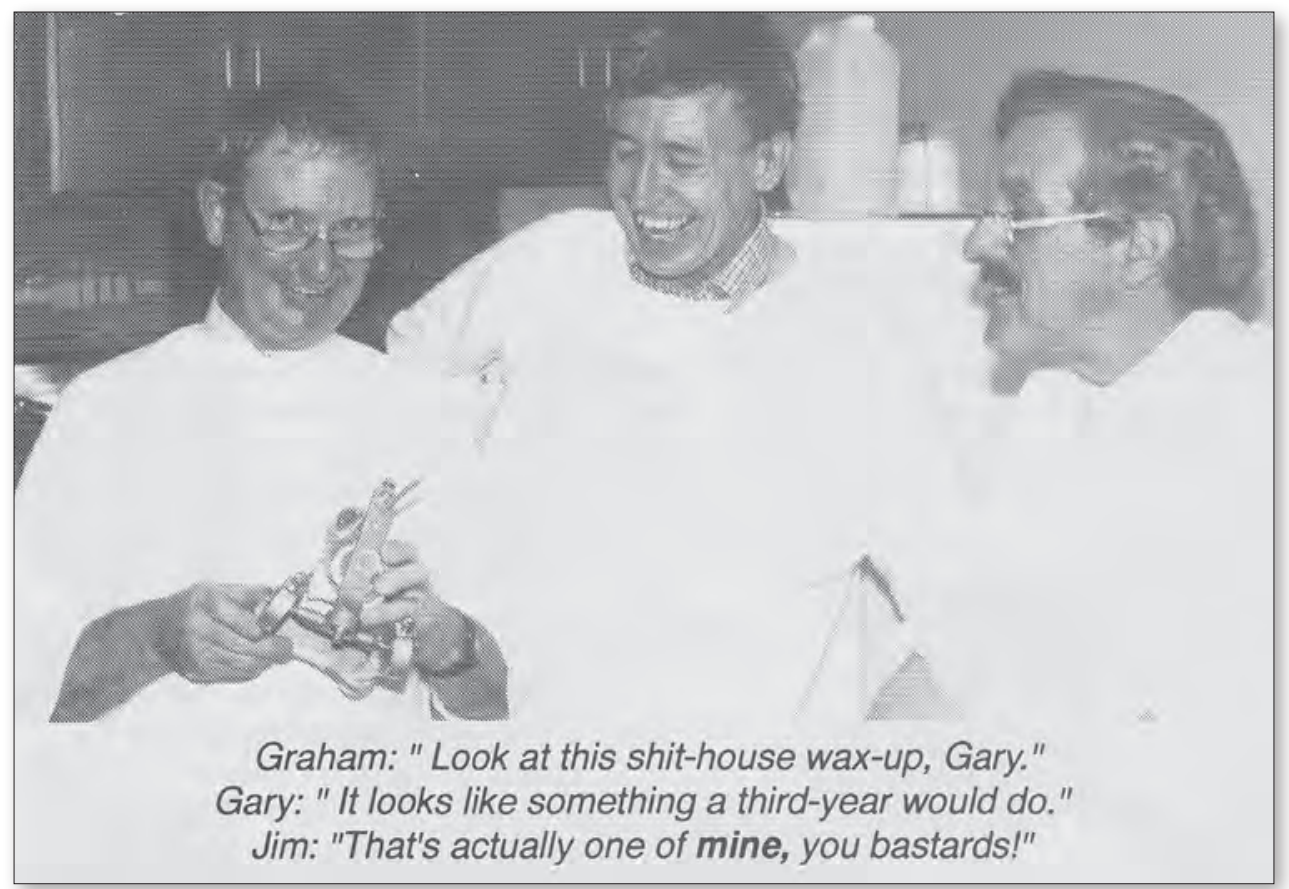

Figure 3.13 Photograph of teaching technicians and caption from Probe 1993 (courtesy of AUDSS). 


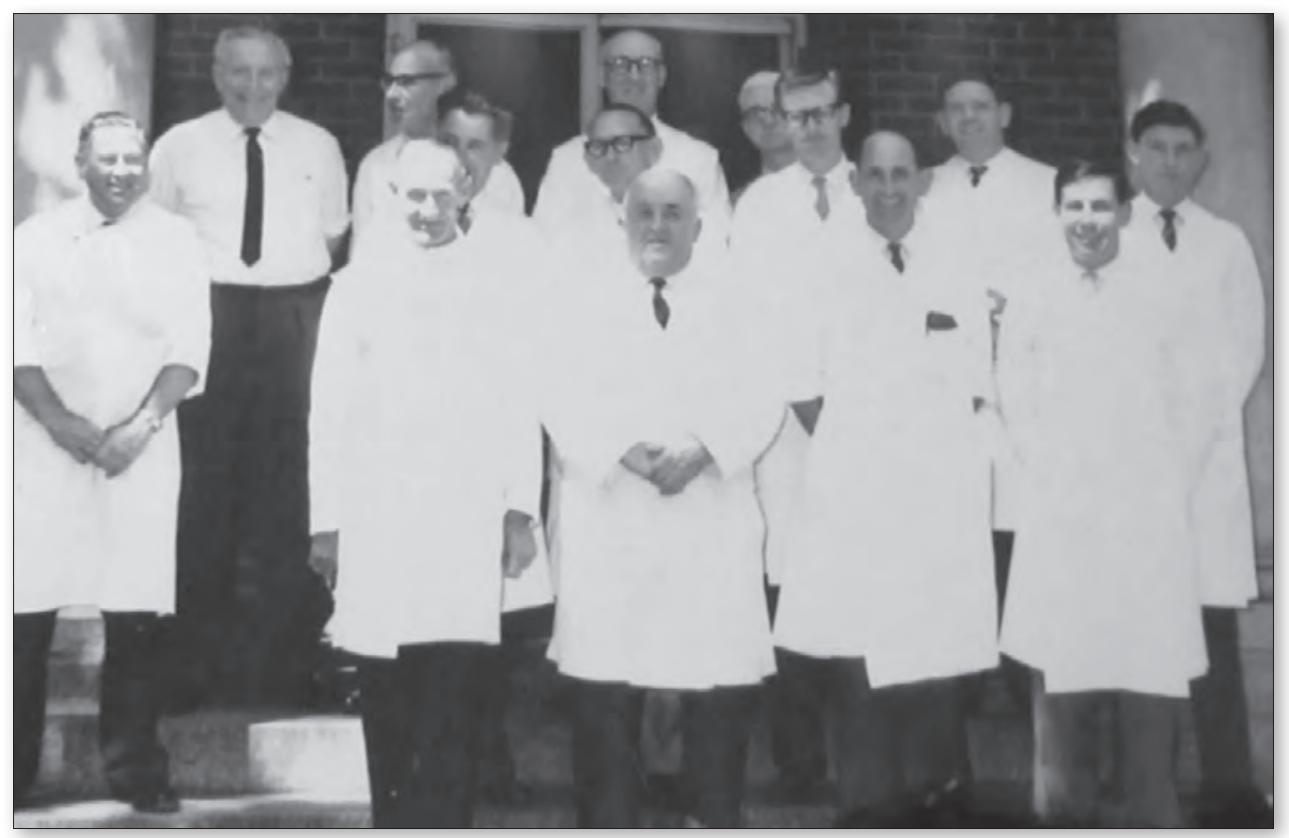

Figure 3.14 Photograph of the dental technical staff in December 1964, outside the old Dental Hospital Building, Frome Road, Adelaide (courtesy of Graham Scriven).

Back Row from left to right: James (Jim) Dunnet (Store keeper,) Frederick (Fred) Cassebohm, Oliver Headley, William (Bill) Johns (assistant store keeper), Cyril Mensforth.

Second row from left to right: Derrick Turner, Walter (Wally) Sierp, Neville Wright, Graham Scriven.

Front row from left to right: Raymond (Ray) Jones, Donald (Don) Menzies, Clarence (Clarrie) Whitford, Noel Gully, Bruce Siviou.

Hospital. Working together they made sure that the needs of all parties were catered for with particular attention to the creation of a good teaching environment as well as to the improvement of the operation of the RAH, especially the central sterilising area and supply section. Another improvement that Rankin initiated was the involvement of Dental Clinical Assistants (DCAs) to provide assistance at the chairside for dental students.

After Leonard Brougham and Clarence (Clarrie) Whitford, several technician instructors were appointed by the University of Adelaide in the following years, including Leslie Reynolds, Norman Harrison, Graham Scriven, Thomas Rollings, James Rogers, James Grey and Garry Briscoe.

The teaching of dental technology by the technician instructors was phased out of the BDS course in 2005, when Scriven and Rogers, the last of them, retired, and the emphasis moved away from students spending large amounts of time in hands-on learning of laboratory technical skills. Whether the pendulum has now swung too 
far the other way remains a debatable point. Aspects of the teaching of dental technology were transferred to selected dental technicians employed by the South Australian Dental Service and students these days do not spend much time carrying out technical work themselves. There is always pressure on a dental curriculum to fit in everything that is considered to be essential. Over the past twenty years or so, the time that was formerly spent by students 'doing lab work' has been replaced with other topics and activities.

\section{Consideration of using the courtesy title 'Doctor'}

The Dental Advisory Committee to the Victorian Minister of Health considered

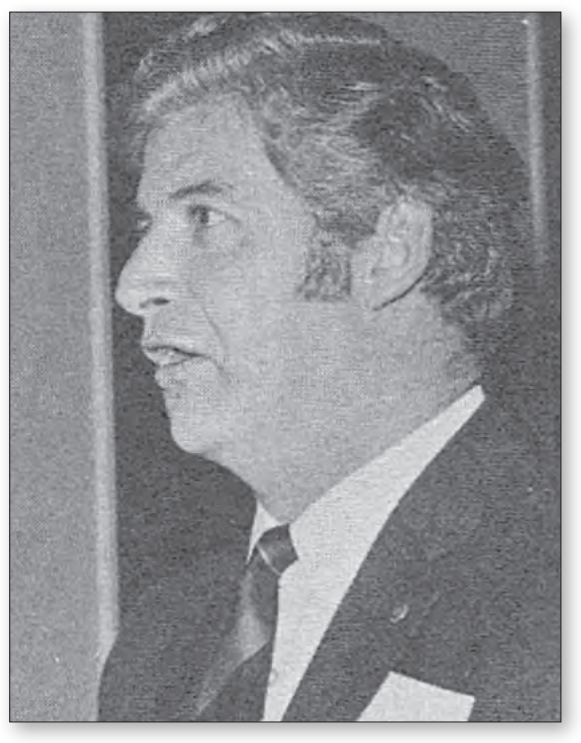

Figure 3.15 John Marriot (Probe 1970, courtesy of AUDSS). a request in 1969 from the $\mathrm{ADA}$ and the Dental Board to confer the courtesy title 'Doctor' on dentists, as it was considered that this would increase the status of the dental profession and the recruitment of dentists to the dental course. The Committee 'gave careful consideration to the suggestion ... [and] examined all of the implications and decided that it could not support the proposal that the [Dentists'] Act be amended' (p. 28). However, not long afterwards the use of the courtesy title 'Doctor' was approved in Victoria. In South Australia, the Minister of Health approved the use of the courtesy title by registered dentists in 1971 and an announcement was made in the press by the president of the ADA (SA Branch), Dr John Marriott. There was some initial criticism about the move but it was generally well accepted by the public. One 'problem' noted at the time was that some older practitioners were embarrassed to be referred to as 'Doctor' after working twenty to thirty years in practice and being referred to as ' $\mathrm{Mr}$ '. Up until this time, within the university environment, the title 'Doctor' had been reserved for those holding a doctorate degree from the university.

\section{BDS curriculum development}

At the beginning of the 1950s, Faculty considered further re-organisation of the BDS curriculum. It was decided to delete the subject elements of metallurgical chemistry from the First Year as it 'no longer served its purpose' and was 'considered unnecessary'. It was replaced by dental materials and technics I and II. (Faculty of Dentistry 1951). 
Interestingly, Mr WH Brindal, a representative of the Third Year dental students, proposed to Faculty in 1952 that the course in pathology should be lengthened to enable students to obtain lasting knowledge that they could put to practical use in their future careers. Faculty responded that it thought that there was sufficient time devoted to the course. This is surely one of the few occasions where students have asked for an increase in subject content that has then been knocked back by the faculty.

In 1954, Drs Cran and Barrett proposed that the BDS course needed to be reviewed and revised and it was agreed to wait until Dr Campbell returned from study leave. Subsequently, in 1956, the First Year course in zoology was replaced by a course in biology. Other changes occurred in the late 1950s, including the renaming of operative dentistry as conservative dentistry, dividing the subject dental surgery and pathology into two separate subjects called oral pathology and oral surgery, and transferring the local anaesthesia section of the Fifth Year subject anaesthesia to the Fourth Year subject dental materials and therapeutics.

In October 1959, the Dental Curriculum Committee presented a report to Faculty and, after general consideration of the report, the following decisions were made:

1. The Faculty approved the recommendation that an assessment be made of each Fourth and Fifth Year dental student at the end of each academic term.

2. The Faculty did not approve the recommendation that these assessments should be presented to the Faculty at the first meeting after the end of each term.

3. The recommendation that every effort should be made for a greater integration of those aspects of training associated with the clinical practice of dentistry, was supported by the Faculty.

4. The Faculty approved the recommendation that, before the beginning of the 1960 academic year, a meeting be called of all teachers of First, Second and Third year subjects in an attempt to establish a more integrated course.

5. The Faculty approved the recommendation that introductory courses be given to third-year students in the subjects Pharmacology and Periodontics. It was noted that there would be no examination in the Third year of these subjects, and that no amendment was necessary to the regulations, Schedules or Syllabuses.

6. The Faculty approved the recommendation that the existing Fifth Year courses in Dental Public Health and Services and Dental Jurisprudence be incorporated into one subject entitled 'Principles of Dental Practice', and that additional lectures on relevant topics such as Dental Ethics, Forensic Odontology, History of Dentistry etc. be also included in the new subject. The Faculty resolved to recommend that the consequent amendments be made to the Schedules and Syllabuses. 
7. The Faculty resolved that a meeting be called of all teaching staff in the Faculty to consider the recommendation that the existing written papers for the Final Year should be replaced by two papers in General Dental Practice to cover all subjects given in the course.

8. The Faculty approved the recommendation that the subject Junior Dental Anatomy in the Second year be renamed Dental Anatomy, and resolved to recommend that the appropriate amendments be made to the Regulations, Schedules and Syllabuses.

9. The Faculty resolved that the subject Senior Dental Anatomy be renamed Applied Oral Anatomy and Physiology, and further resolved to recommend that the appropriate amendments be made to the regulations, Schedules and Syllabuses.

10. The recommended re-allocation of the marks for Anaesthetics in the Fifth Year and Dental Materia and Therapeutics in the Fourth Year was referred to the meeting of all members of the teaching staff referred to in (7) above. (Faculty of Dentistry 1959)

Notably, Faculty was keen to develop greater integration within the BDS course at this time, as well as to introduce more integrated assessment, two of the key aims of the 'revised' BDS curriculum that was introduced in 2010.

In the early 1960s, with increasing numbers of students, appointments of new staff and plans for a new building to house the Adelaide Dental Hospital and the Dental School, there was an increasing focus on the content and balance of the BDS curriculum. At its meeting in March 1964, the Faculty of Dentistry asked its Dental Curriculum Sub-Committee to review the BDS curriculum and to submit a report as soon as possible.

The Minutes of the Dental Curriculum Sub-Committee from 1963 to 1973 are held in the university's archives and record in detail the various issues that were considered during this time and the decisions that were made (or in some cases not made!). While the key issue under discussion over this time was the BDS curriculum itself, and how it might be improved, the Sub-Committee also expressed its opinion on matters of staffing, accommodation and postgraduate issues. It is stimulating to read about the debates that occurred and to appreciate how many staff from within the School contributed directly to these debates, as well as other members of Faculty.

The Sub-Committee agreed to examine the BDS course and to determine its general structure, object and design, and guiding principles. It also decided to determine the context of the course in the following divisions: pre-professional, pre-clinical and clinical. Further, it decided to determine in broad terms the allocation of time between the various subjects, the distribution of subjects in the different years, as well as the sequence and continuity of individual subjects. It decided to send a questionnaire to all members of Faculty and to all teaching staff (both within the School and also in the 
non-dental departments involved in teaching dental students) to ask for views on what should be included in the curriculum.

At this time, many of the subjects, especially in the early years of the BDS course, were taught by non-dental departments. These departments ran their programmes more or less autonomously, including making decisions about content, teaching methods and assessment. For this reason, the Faculty of Dentistry and, in particular, the teaching staff within the School, had very little understanding of what was taught by the other departments.

\section{Objectives of the Adelaide Dental School}

In carrying out its review, the Curriculum Sub-Committee reviewed the aims and objectives of several international dental schools before compiling a list of the Adelaide Dental School's objectives in 1964 as follows:

The objective of the Dental School as part of the University is to provide the opportunity for the students to attain by the time they graduate the following attributes, standard of knowledge and abilities:

1. The outlook of a well-educated person

2. A highly developed sense of personal responsibility

3. Intellectual curiosity and the ability to reason

4. A state of knowledge in basic and applied physical and biological sciences enabling the exercise of proper judgement in the application of acquired skills

5. An awareness of the importance of prevention and of the significance of research in determining the causes of oral and dental diseases with the object of providing a rational basis for prevention and treatment

6. Competence in the diagnosis of oral and dental diseases, the ability to recognize oral manifestations of general disorders, and an understanding of the relationship between general and oral diseases

7. Reasonable skill in the treatment of conditions commonly encountered in general practice

8. Awareness of personal limitations in diagnosis and treatment and the need to refer patients for specialist advice and treatment

9. Competence to undertake limited specialist treatments under special circumstances

10. A realization of the need to maintain an association with fellow practitioners and the need for continuing study. (Dental Curriculum Committee 1964)

It would appear that the School was largely achieving its aims during this period of time, as evidenced by the following comments recorded in the Faculty Minutes about the 
Fifth Year students by Professor George Davies, dean of the Department of Dentistry at the University of Queensland, who visited Adelaide as an external examiner in 1964:

With one exception, all the students in this year impressed me as an excellent group of personable, intelligent, and charming young men. They were a credit to themselves, to the Dental School and to the University. Their powers of reasoning were well-developed and they could present their views logically and forcefully. (Faculty of Dentistry 1964)

It is not known who the 'one exception' was and the reference to 'men' underscores the 'maleness' of the course in those days compared to now.

\section{Key staffing and curriculum issues}

Key staffing and curriculum issues that were discussed and debated during the 1960s included the following:

1. Recommendations that two new chairs be established, one in oral surgery and oral pathology and another in restorative dentistry. Faculty had pointed out in 1964 that there was an urgent and longstanding need for these new chairs but it was not until many years later that they finally eventuated.

2. Discussion about the need to better integrate the separate subjects in the BDS course. There was general agreement that this was desirable, but no formal resolution was passed.

3. Discussion between Professor Whelan, professor of physiology, about the teaching of physiology to dental students and consideration of the appointment of a lecturer in physiology (dental) on a similar basis to the 'joint' appointments already in place in the Departments of Anatomy and Pathology. At this time, staffing requests were considered by the Faculty of Dentistry and other proposals for new staff in the basic sciences were also put forward, including a position in general and dental histology. Whelan's proposal was supported by Faculty but the irony was that Peter Dellow was already in Physiology, with a research interest in neurophysiology, so the decision meant that he remained in Physiology but occupied a staff post in Dentistry. Shortly after Dellow's appointment, the subject applied oral anatomy and physiology, which had been suggested in an earlier curriculum review, was introduced and taught jointly by Brown and Dellow.

When Dellow moved to Western Ontario as professor of physiology, John Waterson was appointed in the Dental School and then, when he accepted a professorship in Perth, Trevor Bridges filled the post. Faculty was never able to reclaim its post in physiology. However, over the years the number of dental graduates appointed to the academic staff in the Department of Physiology in the Adelaide Medical School rose to four, 

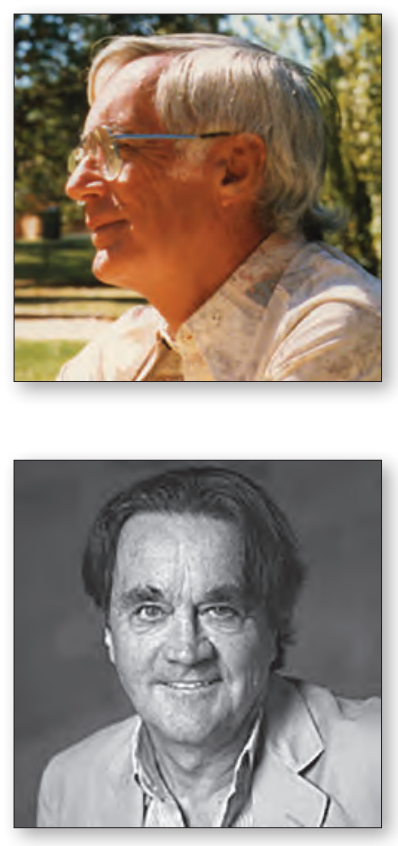

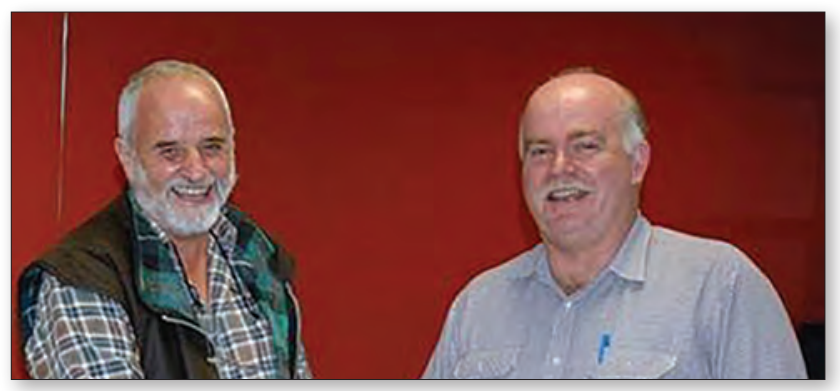

Figure 3.16 (top left) Peter Dellow (courtesy of T Brown).

Figure 3.17 (top right) Timothy Miles and Michael Nordstrom (courtesy of M Nordstrom).

Figure 3.18 (left) James Lund (1942-2009) (Montreal Gazette, 10 December 2009).

composed of Timothy Miles, Michael Roberts and Michael Nordstrom, all Adelaide graduates, and Kemal Turker a dental graduate from Turkey. This must surely have been a record for any Department of Physiology and it was a great bonus for teaching Adelaide dental students.

Dellow was a great lecturer and mentor to many Adelaide dental students, apart from those mentioned above, including James Lund and John Barker. Another Adelaide graduate who followed Dellow to Canada and became a professor at the University of British Columbia was Alan Hannam. Other Adelaide dental graduates have occupied professorial posts in Canada, including Roy Ellis, who graduated in 1926 and became dean of the Toronto Dental School, and Richard Trott, who graduated in 1950 and took office in Winnipeg, Manitoba.

4. Discussion about whether the Dental School should assume more responsibility for teaching basic and applied science topics in the early years of the BDS. The non-dental departments were concerned about the added strain on their teaching staff and facilities with increasing numbers of dental students. There were differences of opinion both within and outside the School about the extent to which the School should assume responsibility for this additional teaching.

5. Comment that the term 'oral biology' was confusing in considering which subjects might fall under the umbrella of a Department of Oral Biology and which might not. 
The Sub-Committee decided to group the relevant subjects into two groups, $\mathrm{A}$ and $\mathrm{B}$.

They included the following subjects:

Group A - basic biological sciences

General anatomy

General histology

Biochemistry

Human physiology

General pathology

General microbiology

Group B — specialised and applied biological sciences

Dental anatomy

Dental histology

Applied oral anatomy and applied oral physiology

Oral pathology and microbiology

It was considered at the time that those subjects in Group A would be best taught by the respective university departments and that the courses could either be taken with the medical students or be taken separately. With the appointments of Thonard and later Anthony (Tony) Rogers and Nancy Atkinson, it was agreed that the teaching of microbiology would logically fall within the Dental School. The School had already assumed responsibility for teaching topographical anatomy and dental anatomy with Brown's appointment, and it also assumed greater responsibility for teaching pharmacology with Waterson's appointment, but other subjects remained in their parent departments. Arguments about the term 'oral biology' persisted throughout the 1970s and the 1980s, with one academic from a non-dental department arguing that there was no more reason to have a department of oral biology than there was for a department of anal biology!

6. Discussion about the implications of the introduction of the new matriculation scheme in high schools in 1966, replacing the former final year of school known as 'Leaving Honours'. It was agreed that the university First Year subject general physics would be discontinued in 1968 and that dental students would then be required to study physics I from 1968 onwards. At this time, some medical and dental students attended the newly opened Flinders University in their first year through an arrangement with the University of Adelaide. Those medical and dental students who attended Flinders University studied physics, chemistry and biology, with one other 
subject to be chosen by the student. From the personal experience of one of the authors of this volume, who attended Flinders in First Year in 1968, it appears that those dental students who selected mathematics as their fourth subject found themselves travelling to Bedford Park.

7. An unattributed note in the Minutes of a Curriculum Sub-Committee meeting in March 1966 summarises the perennial issue relating to curriculum review: 'The lack of progress by the Curriculum Committee is causing ... much concern'.

Another comment from Professor Whelan from Physiology in 1968 emphasised a view that was repeated often in subsequent curriculum reviews in the 1970s and again in the 1990s, which was eventually addressed. Professor Whelan stated that he was of the firm opinion that the Faculty of Dentistry should advise the medical departments on the content of the courses required from them. This was a key outcome with the introduction of the new BDS programme in 1993.

Two important dental staff members involved in the biological sciences during this time were Peter Reade (microbiology and also dental medicine and clinical dentistry) and Bryan Radden (oral pathology and general pathology). They were appointed in the parent medical departments, along with Tasman Brown (anatomy and histology). One of the strengths of the Adelaide Dental School over the years has been in both teaching and research in dental sciences, with academic appointments being made of science and psychology graduates, including Tony Rogers, Trevor Bridges and, more recently, Neville Gully, Peter Zilm, Elizabeth Farmer, Toby Hughes and Vicki Skinner. The teaching contributions of staff with a variety of backgrounds located in the Australian Centre for Population Oral Health $(\mathrm{ARCPOH})$ of the Adelaide School have also greatly enriched the education of dental students.

\section{Recommendations on the BDS curriculum}

Finally, in 1967, the Dental Curriculum Committee provided a series of recommendations on the BDS curriculum. It did, however, point out that the feasibility of the recommendations had only been partly discussed and was not a matter for the present considerations by the faculty. The formulation of a timetable to give effect to the recommendations would need to be a later study by the Department of Dental Science.

The general principles underlying the recommendations were:

1. Where possible, teachers in the basic sciences and teachers in the clinical subjects should assist in teaching in other fields, to further understanding by the student of the relationship between different subjects. 
2. The final year of the course should provide a period for consolidation and co-ordination of knowledge gained from subjects taken in earlier years of the course; flexibility in teaching methods is to be encouraged. (Dental Curriculum Committee 1967)

These principles were then, and remain now, of considerable importance. However, in the absence of a definite plan about how they could be put into practice, they remained largely unfulfilled for many years. While the new Problem-Based Learning (PBL) BDS curriculum introduced in 1993 did provide a way forward, there still remains much to do before one could say that these principles have been fully met.

Apart from specific recommendations about the subjects in each year of the course, general recommendations were made for the whole course as follows:

1. that students be given continued encouragement to engage in private study (with time and facilities being made available to allow students private study)

2. that the use of teaching methods other than lectures (for example, essays, seminars and programmed instruction) be considered wherever desirable

3. that the student be encouraged to apply his/her basic knowledge in his/her clinical care of patients, with a greater emphasis on diagnosis and treatment planning

4. that consideration be given to possible alternative systems of rostering, to minimise interruption to continuity of teaching

5. that consideration be given to renaming some of the Fourth and Fifth Year subjects, as the present names did not suitably describe these subjects

6. that, since there are certain advantages in holding examinations on lecture courses soon after the courses have been completed, examinations in subjects whose courses ended before the end of the calendar year were to be held, where desirable, at the end of the course

7. that a course in oral biology be introduced near the end of the undergraduate course.

Deficiencies or omissions from the existing course were noted in the following areas: statistics, psychology, social science, special dental services (handicapped, geriatric), ophthalmic and ENT disorders, student project training (which could be in term-time or during vacations and could involve library or experimental laboratory work, and could initially be limited to selected students), genetics and forensic dentistry.

The Committee strongly recommended that there should be a pre-registration period of clinical practice of about six months, subject to two provisions: first, that there be adequate forms of guidance and assistance available during the period from members of the hospital staff; and, second, that attendance at a lecture course given 
during the pre-registration period by university staff be required. It provided three alternatives for the pre-registration period. The five-year BDS course could be followed by a pre-registration period; the lectures and direct teaching in the third term of Fifth Year could be removed, allowing clinical work under the supervision of Dental School staff plus a short pre-registration period; or the final written examinations could be held at the end of the second term of Fifth Year, followed by a longer pre-registration period.

Finally, the Committee pointed out that the facilities in the new Dental School building made such a pre-registration period feasible, and that the Dental Board of South Australia and the South Australian branch of the Australian Dental Association would have to be consulted on the introduction of any such pre-registration period (Dental Curriculum Committee 1967, pp. 1-8).

\section{Reflections on the BDS curriculum recommendations of the 1960s}

Given the above review of the recommendations about the BDS curriculum, it is remarkable how well they have served as a basis for subsequent curriculum reviews, which occurred in the 1970s, 1990s and in the 2000s. Many of the recommendations relating to greater integration and co-ordination of topics relied on goodwill between departments or individual staff but, without more concrete mechanisms to drive them forward, there was limited success initially.

After his arrival in Adelaide in 1966, Thonard became the convenor of the Curriculum Committee and continued with the curriculum review that had commenced in 1963. Apart from addressing the recommendations already made about the curriculum, many additional items were discussed, two of which are described briefly below.

Professor Ross Miller had noted that the number of Distinctions and Credits awarded to dental students seemed to be much lower than in the rest of the university. Following a review of data for the years 1966, 1967 and 1968, it was found that there were definitely fewer Distinctions, although the number of Credits was comparable to other faculties, including medicine. It was also noted that there was wide variation between subjects within the BDS course in the numbers of Distinctions and Credits that were awarded. Although the issue was noted, no clear directives were made and this issue has continued to be raised by dental students for the past fifty years. The introduction of an Assessment Strategy in 2009 provided a framework for addressing this longstanding issue but it still rears its head when the results are published each year.

Following a review of its curriculum, the Faculty of Medicine indicated in 1969 that it intended to replace the subject physics I with a new composite subject that would include biophysics, statistics and human genetics. Medicine also intended to 
introduce a new subject, behavioural science, into its First Year. It was agreed that dentistry would follow medicine in making these changes. When these changes were finally made in 1973, two new half-subjects were introduced to replace physics I physics IM and genetics.

As discussed in the next chapter, the creation of four new departments from a single Department of Dental Science in the 1970s, while heralding a recognition by the university of the growth and maturation of dentistry as a profession, tended to make it harder to achieve integration and co-ordination of subjects across departmental barriers. It was not until the four departments were combined into a single department again in the 1980s that a structure was in place that facilitated major curriculum change. Although returning to a single department structure provided the context for the School to achieve much greater control over its curriculum and greater integration and co-ordination, there were other, less desirable outcomes. These included a feeling by some staff that there had been a loss of identity of smaller groupings based on disciplines.

One important development during the 1960s that becomes apparent when reading the archived Minutes of meetings is the growing voice of the student body in commenting on curriculum issues. For example, Peter Telfer wrote to the dean in 1969 as the student vice-president of the AUDSS, informing him that a committee had been set up by the students to investigate student opinions about the BDS curriculum, teaching matters and facilities, and to make recommendations for change. At around the same time, the university had contacted its faculties, asking them to ensure that their committees included student representation. Prior to this time, there appeared to be few formal mechanisms for students to provide feedback on their perceptions of the learning and teaching environment within the School.

\section{GEOFFREY S HEITHERSAY, 1952-56}

How well did my education at the Adelaide Dental School prepare me for my future career?

My undergraduate education extended from 1952-56. There were few full-time staff in the Dental Faculty and the School relied heavily on parttime tutors from the profession. Academically the standard of lectures and supporting teaching material varied considerably. Generally, the teaching from the Medical School was of a high standard - particularly in the fields of human anatomy and pathology — but poor in physiology. Although the 
standard of lecturing/seminars in dentistry was relatively poor, in general the course provided me with a sound biological basis for my future endeavours. It is ironic that perhaps the best lectures in the Dental School were delivered by a well-known Adelaide dentist in the field of periodontics but as it turned out he did not possess a scaler in his private practice.

Clinically we received extensive training in 'conservative dentistry' even though in hindsight tooth restoration using Black's classic cavity preparations was far from conservative - but with the state of dental health at that time the teaching was appropriate. Gordon Lawrence, the head of restorative dentistry, was a poor communicator but a brilliant innovator in cavity design, matrices and conservative gold inlay preparations. Periodontal management was of a good standard under the supervision of Dr Roger Willoughby, while experience in oral surgery was appropriately wide and in addition to exodontia included mandibular and maxillary fracture management.

While we were taught the microbiological basis and pathology of pulp and periapical disease, endodontic treatment methods at the time were just evolving and applied only to maxillary anterior teeth. Endodontic surgery in the form of apicectomy was carried out on any tooth with a periapical radiolucency in excess of $5 \mathrm{~mm}$ - this was indicative of the poor understanding at that time of healing responses which can follow endodontic treatment. The obvious deficiencies in knowledge and technology in the field of endodontology in Australia led to my decision to pursue this field as my principal postgraduate endeavour.

Prosthetic dentistry, clinical and laboratory work dominated our time in the undergraduate course as the teaching at that time assumed the inevitable loss of some or the entire dentition of a significant proportion of the population at some stage of their lives. There was a philosophy that it was better to remove the entire dentition at a relatively early stage of life so that the patient could learn to adapt to dentures before old age. It is little wonder that this concept was another factor which led to my decision to embark on postgraduate studies in endodontology.

Perhaps the most significant experience I had during my undergraduate years was a serendipitous invitation to be part of a physical anthropological expedition to Haasts Bluff, west of Alice Springs, led by Professor Andrew Abbie from the anatomy department. This proved life-changing as my eyes were opened to the cultural and physical challenges facing Aboriginal 
communities at that time and also I was exposed to the world of research through this unique association with the highly distinguished members of the expedition.

\section{JUDY PACKER, 1955-59}

How well did my education at the Adelaide Dental School prepare me for my future career?

Obviously, after two clinical years we all had a lot more to learn, both about dentistry, business, research and keeping current for starters.

For women, at that stage, when one became engaged, one retired from the workforce, so having even a few working women dentists was very important. Gwen Hannon, Win Preedy and Vera Alexandravicius were real trailblazers for me.

There were also other European women who had requalified.

However, marriage and three children in three years, coupled with a spouse on a Registrar's pittance, made working unthinkable. There was of course no childcare. At my Mother's insistence I trod back into dentistry with Bill Scollin's help and understanding before the arrival of \#4 child. Working part time at the ADH was excellent. Support where needed, school holidays off and a feeling of being useful.

Three half-days a week went, one for the ATO, one for the cleaner and one for me. This gradually built to full-time (no super for part-time over almost twenty years) and eventually included some administration for which I was equally unqualified. The fact that the area of running a business was totally omitted was of no consequence to me at all.

The course was probably fairly pointless in many respects. Processing $80 \mathrm{~F} / \mathrm{F}$ 's in final year from start to finish was more to do with waiting lists than learning. I suspect in those times students were a lot less challenging than now. The task was set; you did it. No questions asked.

In retrospect, topics and tasks covered in the early years were sometimes appropriate/or not. We never worried. Learn it — pass it — do it. Whatever it took. Productive for one's future — who knew! 


\section{Curriculum}

What was learnt and what we became good at was a matter of luck. What sort of patients we gathered, needing what procedures, was the critical thing.

Staff

All very senior in our clinical years except Peter Reade, recently arrived back from overseas and with fancy new ideas like porcelain crowns.

TD Campbell retired midway through our course and we acquired the English fellow whom we needed to train in being Strine. I doubt Max Horsnell knew what had hit him!

\section{Facilities}

In one word, archaic. No operating lights, dubious suction, 'sterilisation'! reusing burs, no high speed till very late in Fifth Year. Hand-held radiographs with three-second exposures were standard.

\section{(MRS) IRENE MINKIEWIEZ}

(Mrs) Irene Minkiewiez graduated in 1961 after completing medicine in Europe. The following is extracted from an article by Dr Minkiewiez entitled 'Why Did I Take Up Dentistry' in Probe 1958-59 (p. 15).

In the Dental Faculty there are so few women students that we seem to be a constant source of curiosity to some of our colleagues.

We are often told that a woman's place is in the home and that her family will suffer if she does not give her full attention to her home. And yet there are thousands of women all over the world who combine successfully professional work with a happy family life.

I chose it [Dentistry] because it seems to me a good way to gain reasonable financial security and independence whilst carrying out interesting work. Many people will insist that in doing so, I am neglecting my duties as a wife and mother. It may be so in other cases with other 
families - I do not know. But I can say for certain that my family is not being neglected. For one thing, my mother willingly does most of the routine housework for me, including cooking and ironing — this gives her a sense of usefulness and a feeling that she is not yet too old. Secondly, as far as my husband is concerned, he does not feel that he is being neglected, and he is himself prepared to sacrifice a little for me to gain this independence, a worthwhile stopgap in the event of accident or mishap.

Having seen so many women forced into misery by widowhood, illness of the bread-winner, divorce or neglect, we would like our girl to be able to fend for herself adequately, should any of these things happen to her, or if she doesn't marry at all.

Thus, I feel that I am justified in learning a profession - if only in my own and in my family's eyes, and that is reason enough for me. Certainly, it is not easy to combine family life with hard studying, but it is a rewarding and full life. I can assure you, I have never been happier since I plucked up courage to re-enter professional life in my new country.

\section{JOHN WETHERELL}

Year of graduation

1968

Career since graduation

Worked in private practice at Henley Beach 1969-2007.

One year in Bowen, North Queensland in 1973.

Flying Doctor 1977-79.

\section{Teaching}

Started as a part-time perio tutor in 1969 through to 1977.

1978-79: Half-time lecturer in oral diagnosis, taking over from Prof Horsnell. 
Returned to teaching 1977-89 as part-time Cons tutor.

1990-2005: Half-time in oral diagnosis.

2001: Second Year Cons.

\section{Current position}

Recently sold the Henley Beach practice.

Since 2007: still work there one session per week.

Worked for Katherine West Health board in Aboriginal communities for a month a year from 2006-08.

Started with SADS working in Aboriginal areas of SA 2008-15.

A range of locums in SA - a month in Hobart.

Worked part-time for Colgate Centre and teach when needed.

How well did my education at the Adelaide Dental School prepare me for my future career?

Gaining a BDS Adel has meant everything to me. Coming from a country High School background at Mount Gambier and sitting in my first ever lecture, physics, and the lecturer saying, 'Look at the person either side of you: two of you will fail!' Eighty-five started First Year in 1964, twentyseven passed! I was one of them. Not because I was bright, just worked extremely hard.

That set the scene for the next four years, and final year in 1968 only six people gained Passes, the rest were Credits or Distinctions! Quite a remarkable outcome.

Nigel Clarke had a high influence on me as I won the periodontology prize and he wanted me to tutor perio on graduation, which I did. This started a love for teaching and learning, that has never stopped. I would consider myself having had a most privileged life. I could never have imagined, as a young person, such a fulfilling and rewarding outcome, especially 1990 to 2004, and the new curriculum. 


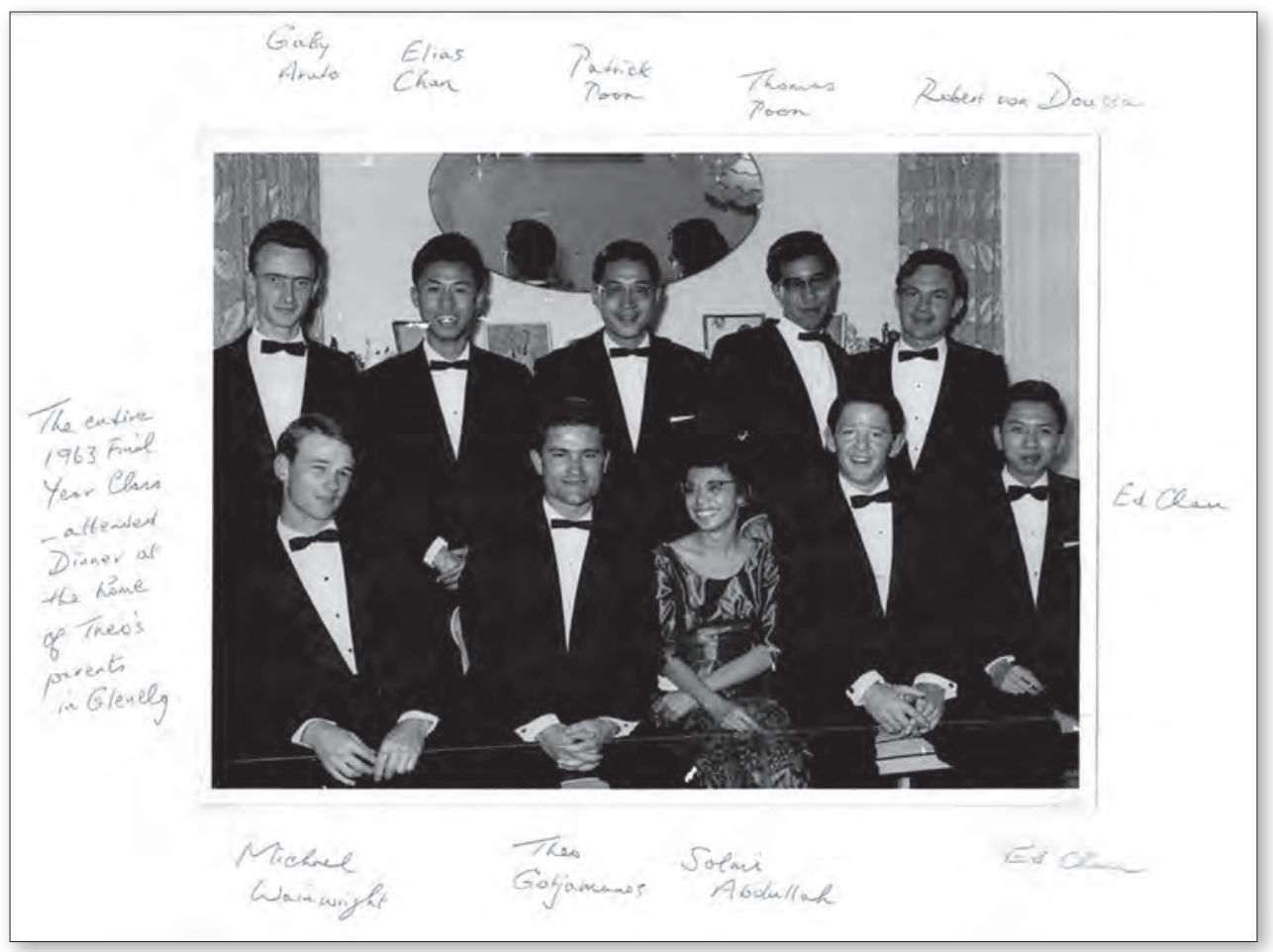

Figure 3.19 The final-year class of 1963 at a dinner at Theo Gotjamanos's parents' home (courtesy of T Gotjamanos).

\section{References}

Barrett MJ (1967) The new Dental Hospital. Probe: 4-7.

Brown T (1992) Thomas Draper Campbell: Professor of Dentistry, Anthropologist. Graham Mount Oration, University of Adelaide, Adelaide.

Brown T, Rogers R (1993) Campbell, Thomas Draper (1893-1967). Australian Dictionary of Biography, Volume 13, Melbourne University Press, Melbourne. http://adb.anu.ed.au/ biography/campbell-thomas-draper-9684 (accessed 7 March 2018).

Brown T (2001) Thomas Draper Campbell: Pioneer dental anthropologist. In: Causes and effects of human variation, ed M Henneberg. Australian Society for Human Biology, pp. 1-11.

Dental Advisory Committee (1969) Report to the Honourable Minister of Health. Melbourne, Australia.

Dental Curriculum Committee (1964) Objective of the Dental School. Faculty of Dentistry, University of Adelaide.

Dental Curriculum Committee (1967) Recommendations on the dental curriculum. Faculty of Dentistry, University of Adelaide, Adelaide.

Education Committee (1952) Minutes. University of Adelaide, Adelaide. November. 
Faculty of Dentistry (1951) Faculty Minutes. University of Adelaide, Adelaide. December.

Faculty of Dentistry (1959) Faculty Minutes. University of Adelaide, Adelaide. October.

Faculty of Dentistry (1964) Faculty Minutes. University of Adelaide, Adelaide. December.

Faculty of Dentistry (1965) Teaching facilities in the Dental Hospital: Summary of discussions and decisions in 1964 and 1965. University of Adelaide, Adelaide.

Faculty of Dentistry (1968) Faculty Minutes. University of Adelaide, Adelaide. August.

Heithersay GS (2010) Background statement for the Stephen Cole the Elder Award for Excellence in Teaching and the Vice Chancellor and President's Award for Excellence in Teaching, University of Adelaide, Adelaide.

Horsnell AM (1989) Graham Mount. Graham Mount Oration, University of Adelaide, Adelaide.

Kinnane KJ (1959) A few aspects of dentistry in the United Kingdom. Probe: 33.

Minkiewiez I (1958-59) Why did I take up dentistry? Probe: 15.

Report of the Dental Advisory Committee to the Honorable the Minister of Health (1969) Melbourne, Australia, p. 28.

Teaching facilities in the Dental Hospital: summary of discussions and decisions in 1964-1965

(1965) Faculty of Dentistry, The University of Adelaide, Adelaide.

Watson BI (1989) Introduction. Graham Mount Oration, University of Adelaide, Adelaide. 


\section{4}

\section{The Raywood workshops and BDS curriculum reform - 1970s and 1980s}

\section{Restructuring the School - one department becomes four}

The Council of the University of Adelaide approved the establishment of four departments within the Faculty of Dentistry in March 1971. These departments were: Restorative Dentistry, Dental Health, Oral Pathology and Oral Surgery, and Oral Biology. The four new departments replaced the former single Department of Dental Science with its divisions. The heads of these new departments were Murray Barrett, Arthur Maxwell Horsnell, Alec Cran and John Thonard.

The decision to expand the number of departments and to include a Department of Oral Biology showed that the university had recognised the development of dentistry as a discipline. It also acknowledged that scientific advances in understanding the biological basis of health and disease related to the oral cavity were considered to warrant the establishment of a new department, Oral Biology, to focus on biological aspects of the oral cavity.

Staffing during increasingly difficult financial times

By 1971, membership of the Faculty of Dentistry had grown from twenty-four members when the first meeting was held in 1920 to fifty-four members. The number of student enrolments had increased from eighteen to 250 and the number of teaching staff had grown from ten in 1920 to twenty full-time and eighty-eight part-time by 1971 (Brown 1971).

Professor John Thonard was dean of the Faculty of Dentistry from 1968 to 1970 and he arranged for three student members, elected by the student body, to 


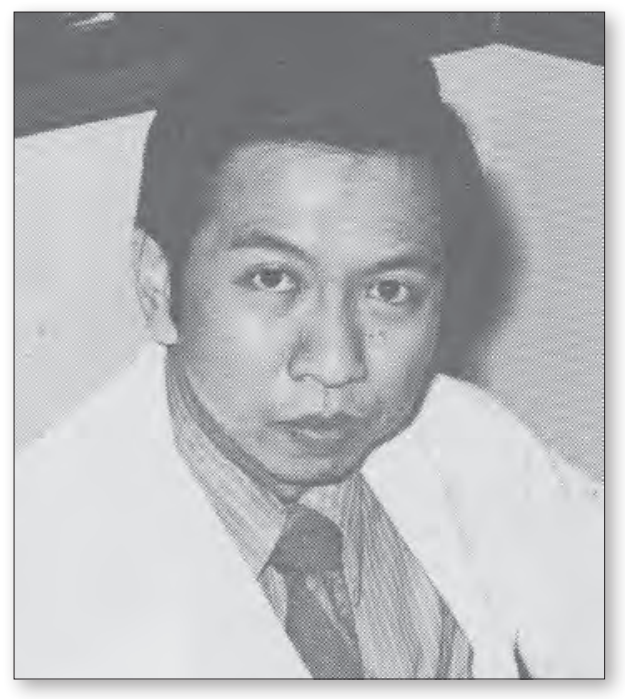

Figure 4.1 Ed Chau (Probe 1973, courtesy of AUDSS).

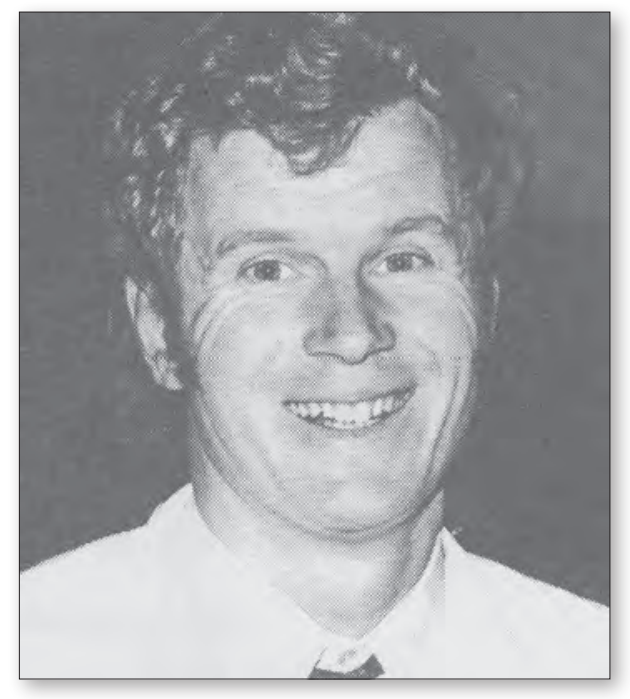

Figure 4.2 Alastair Goss (Probe 1973, courtesy of AUDSS).

be added to the Faculty of Dentistry in 1970. Over the period of the 1970s and the 1980s there were eight deans of the Faculty of Dentistry: Max Horsnell (1971-74); Peter Beasley (1975-76); Tasman Brown (1977-78); John Thonard (1979-82); John McIntyre (1983-84); David Parker (1985-86); Roger Smales (1987-88); and John Spencer (1989-90).

Many new staff were appointed over these two decades and several staff resigned. Two new staff appointed to the Department of Oral Pathology and Oral Surgery in the early 1970s were Ed Chau and Alastair Goss. Dr William (Bill) Scollin, who was appointed in 1949, retired as dental superintendent of the Royal Adelaide Hospital (RAH) in 1975 and Dr Robert (Bob) Barter was then appointed as administrator, dental services, RAH. Dr Nancy Atkinson and Dr Alec Cran both retired in 1975.

In 1975, the Universities Commission published its Sixth Report. This report indicated that there were difficult financial times ahead for universities and that there would be restrictions on expansion and development. Peter Beasley noted in his Dean's Report in Probe 1975:

The only thing clear so far is that the financial situation for the whole University is going to be a difficult one for some years and that there will be a period in which all must concentrate on maintaining existing services. To talk of immediate development is unrealistic. No doubt there will be some frustrating times ahead for both staff and students. Patience and tolerance on all sides will be necessary. (p. 5) 
Tasman Brown was acting dean in 1976 while Peter Beasley was on study leave and during this year Tom Wilkinson was appointed as a halftime lecturer and Ines Young (to become Ines Parker) as a temporary half-time lecturer. Brown (1976) pointed out in his Probe report that universities in Australia were entering a 'nongrowth' period and that meant that the Adelaide Dental School was entering a static period with respect to student intake, graduate output, staffing and facilities. In his Dean's Report in Probe in the following year (1977, p. 4), Brown payed tribute to Max Horsnell for his role in developing the faculty and 'moulding the shape of our educational programmes'. Horsnell retired in 1977 after nineteen years of dedicated service.

In 1977, Grant Townsend was appointed

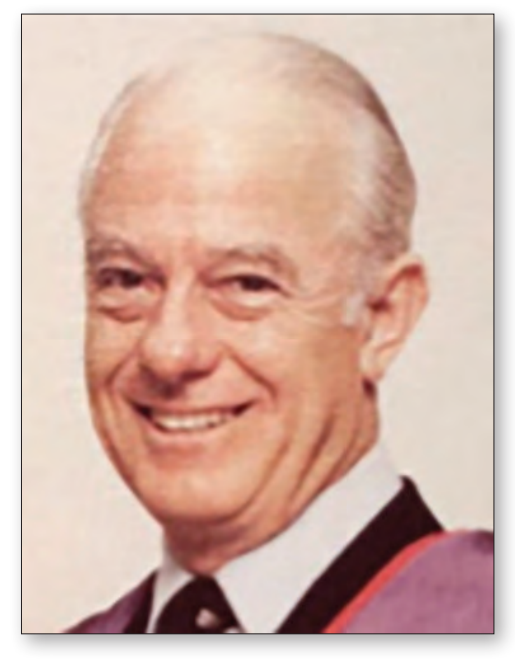

Figure 4.3 David Poswillo (courtesy of A Goss). as temporary lecturer in oral biology, replacing Brown who transferred to restorative dentistry in 1976 as the inaugural professor and head of the department.

David Wilson, who had completed his undergraduate education at the University of Otago, arrived from Canada in 1978 to take up a position in oral pathology and, in 1979, Peter Beasley resigned from the university to become director of prosthodontics in the Royal Adelaide Hospital.

In 1979, David Poswillo (who had been appointed in 1977) resigned as professor of oral surgery to take up a post at the Royal Dental School and Hospital in London. This occurred in a so-called no-growth environment and the dean at the time, John Thonard, bemoaned in his Probe 1979 report the fact that the School had been 'striving for nigh on two years to obtain from the responsible University committees release of the Chair vacated by Professor Horsnell on his retirement' (p. 41). Thonard pointed out that 'the deliberations surrounding this post have entailed us in a close examination of certain administrative and educational changes which I hope will enable the University to give us the green light to go ahead and seek a suitable replacement for the Chair in Dental Health' (p. 41). He noted that replacing Poswillo in the prevailing circumstances would not be an easy task and, indeed, it took four years before Henk Tideman was appointed.

Thonard went on to say:

Matters of staff replacement, and there are other recent cases, may seem remote from the everyday life of dental students weaving their diverse ways through the 
complexities (sometimes vagaries?) of a dental course. But they are not. Loss of two professors whose terms of employment stipulate that they are 'expected to provide academic leadership of a high order' has a stultifying effect on a small but highly specialised staff such as ours. This in turn affects new curriculum changes and students. (p. 41)

Thonard's report in Probe 1980 follows the rather pessimistic tone of his previous report, with the announcement of further staff losses. These included Dr John Kirkwood who resigned as senior lecturer in operative dentistry to become reader in conservative dentistry at the newly established School in Hong Kong; Dr KK (Ed) Chau who resigned to take up a post in Hong Kong; and Dr Peter Telfer who resigned to become the new director of admissions and clinics in the Royal Adelaide Hospital.

At this time, under the policies in place in the university, positions that became vacant were automatically 'frozen' and were not replaced. Horsnell's position remained 'frozen' but Poswillo's post was eventually released only after a 'Crisis Committee' allowed the faculty to release a Chair in Oral Pathology and Oral Surgery. Henk Tideman was appointed subsequently.

1980 saw the establishment of a half-time senior lectureship in forensic odontology funded by the South Australian government and the first appointee was Dr Kenneth Brown. The establishment of a Forensic Odontology Unit with a university-based director had been supported by Dame Roma Mitchell, a Justice of the Supreme Court of South Australia; it was the first in Australia.

In 1981, a document referred to as the '1981 Compact' was completed within the university. An outcome of this process was that the ten deans of the North Terrace campus agreed on staffing profiles that would reduce the spiralling costs of salaries. The Faculty of Dentistry agreed to a staffing profile of twenty-one full-time academic positions (or their equivalent) with a quota of eighteen full-time positions that would be reached by 1985 and would include temporary positions. This number was less than the staffing at the time, so the Compact provided some opportunity for the faculty to regain some of the six positions it had lost over the previous three years, providing opportunity for forward planning.

1983 saw the arrival of Professor Henk Tideman and Dr Ram Prabhu in the Department of Oral Pathology and Oral Surgery. Dr Rory Hume arrived from the University of California in Los Angeles to take up a senior lectureship in restorative dentistry and Dr Brian Penhall was appointed as lecturer in prosthodontics. Shortly after Tideman arrived from the Netherlands, there was a seismic shift when the whole Dental Hospital was split from the Royal Adelaide Hospital and joined to the South Australian Dental Service (SADS). This produced a conundrum of what to do with Oral and Maxillofacial Surgery. The plastic surgeons, with some support from a few nonsurgical dental staff, thought that they could do it all. Some advocated that Oral Surgery 
should stay with the Hospital and some with SADS. In the end, the state government Cabinet decided it should be a tripartite department, responsible to the $\mathrm{RAH}$, the university and SADS. Dr Lewis Mayne was appointed assistant director for SADS, with Professor Tideman as the university and RAH head. The full story of these turbulent and sometimes perfidious times has been recounted in the book Extractions to Reconstruction. The Development of Oral \& Maxillofacial Surgery in Australia and New Zealand (Goss and Linn 2015).

1984 represented the end of an era with the retirement of Leslie (Les) Reynolds as senior dental technician after twenty-four years. Reynolds was well liked by the dental students, although his dry sense of humour was sometimes intimidating to students. After his retirement he was honoured by having a teaching laboratory in the Adelaide Dental Hospital named after him. The position of laboratory manager was not filled after Reynolds's retirement, leaving Rogers, Scriven and Briscoe to continue teaching dentallaboratory-based skills.

In 1984, Professor John Thonard unexpectedly retired for health reasons after seventeen years, for seven of which he had served as dean. Edward (Ed) Gorkic was appointed by the South Australian Dental Service (SADS) as

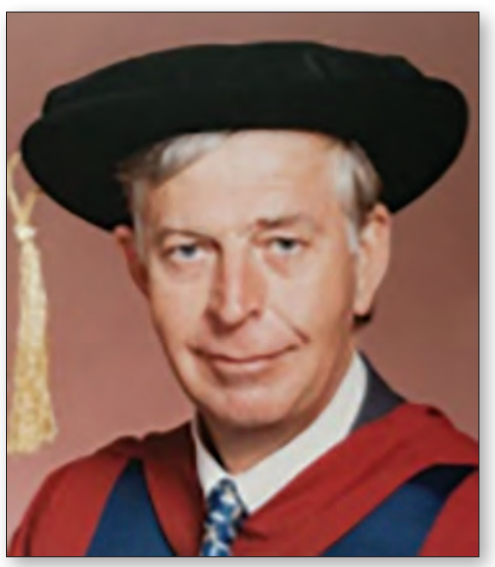

Figure 4.4 Henk Tideman (courtesy of A Goss).

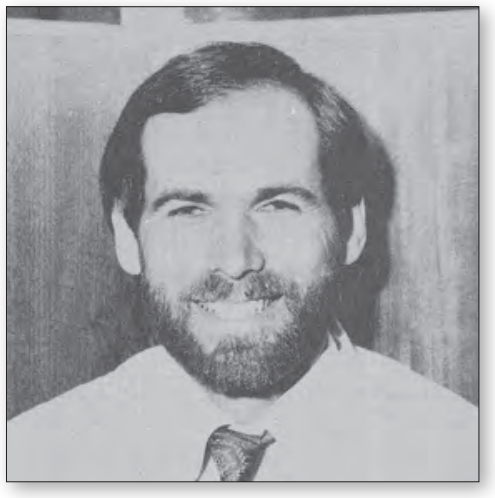

Figure 4.5 Wyatt (Rory) Hume (Probe 1976, courtesy of AUDSS). senior dentist in charge of Teaching Clinics and, in this role, he provided oversight of the General Dental Practice component of the new curriculum.

David Parker became the dean in 1985. Thirty new students entered into the BDS course in that year and Parker commented in his Probe 1985 report that, even though dental students generally have excellent academic records, there was a high failure rate in the early years of the course. Although he stated that the reasons were not entirely clear, committees were investigating possible reasons and it had been suggested that the School might accept more students who had transferred from other courses. There were also concerns about students who were having difficulties because of inability to communicate in English. 


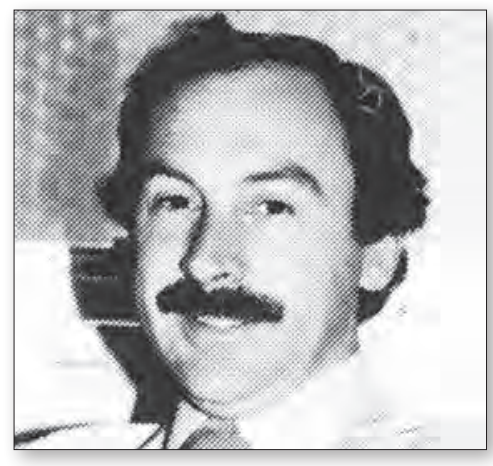

Figure 4.6 David Parker (Probe 1983, courtesy of AUDSS).
In his Probe 1986 Dean's Report, Parker noted that there were increasing political pressures for universities to provide more opportunities for students to enrol in their courses. At the same time, there were concerns about the high rate of attrition in universities, with $16 \%$ of First Year students in 1985 withdrawing from the University of Adelaide. In dentistry, 10\% of First Year students in 1985 withdrew before the end of the year, while $31 \%$ failed first year. Apart from the effects on the students themselves, the cost of these withdrawals and failures was very high. It was estimated that the cost to the university at that time to train a dental student was more

than $\$ 12000$ per year and the South Australian Dental Service estimated that it spent $\$ 1.5$ million in 1984 on undergraduate and postgraduate dental programmes.

Parker mentioned in his report that the Faculty of Medicine was reviewing its curriculum and that the physics and chemistry courses would be reduced substantially in 1988 with flow-on effects for dentistry.

John Spencer was appointed to a five-year limited-term chair in social and preventive dentistry in 1986 (replacing the chair held by Thonard, who took early retirement in 1984) and the position was then converted to a tenurable post after two years. A full-time position in periodontology was filled by Robert Hirsch, while Dr Rory Hume left the School to accept an appointment as chair in conservative dentistry at the University of Sydney. 1986 also marked the deaths of Dr Kevin Murphy, half-time senior lecturer in oral surgery at the age of forty-eight years, and the vice-chancellor Professor Donald R Stranks.

In 1987, Roger Smales became the dean. In his Dean's Report in Probe 1987 he mentioned that the establishment of a Dental Chapter of the University Alumni Association was being explored. He also mentioned that the Teaching Discipline Groups that had been recently formed included private practitioners and that this was a good move. An analysis of dental student entry and progress had been initiated.

Dr David Blaikie moved to the post of Acting Executive Director, Metropolitan Health Sector, leading to a re-organisation within SADS. Ian Stead became the chief executive of SADS and Dr Peter Telfer became the director of the School Dental Service. Dr Ed Gorkic became the Director, Clinical Services.

In 1988, severe budget cuts were imposed on the university sector by the federal government, with significant effects on the Faculty of Dentistry. There were also proposals from federal and state governments to implement major changes to the 
structure of tertiary institutions. Smales (1988) noted that

[t]he excellent national and international reputation of the Adelaide Dental School in the quality of its teaching and research appears to count for little in these largely, economicallydriven exercises ... The next few years will be very difficult; having to grapple with budget and staffing cuts, and possible restructuring as a major exercise. It is time for the profession to close ranks, and to support strongly what I believe is the best Dental School in Australia. (p. 4)

Following considerable discussion between the university, the hospital and SADS, support for a chair in oral and maxillofacial surgery was obtained to replace Professor Tideman, who had gone to Hong Kong. Alastair Goss was appointed to the position in 1989 and served

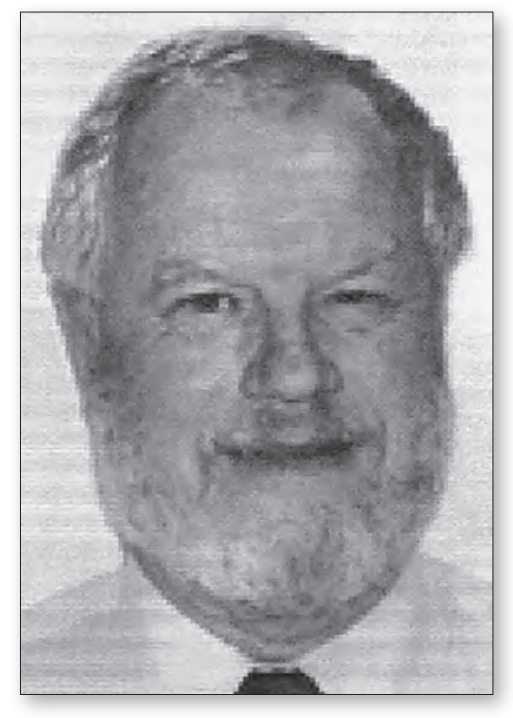

Figure 4.7 Alastair Goss. in the role until his retirement in 2014. Paul Sambrook, senior lecturer in oral and maxillofacial surgery, is the current director of oral and maxillofacial surgery at the Royal Adelaide Hospital and the Adelaide Dental Hospital, as well as the academic leader of the discipline in the School.

\section{A 'dental manpower crisis'}

In the late 1970s and early 1980s there were large meetings of dental graduates who were concerned about the growth of the School Dental Service and its effects on private practice. This was linked to a 'manpower crisis' in the profession, and the Health Commission commenced an investigation to determine the situation in dentistry. The Australian Dental Association lobbied to implement the recommendations of the Committee of Enquiry into Dental Services, which included reducing the intake into the BDS course to around twenty to twenty-five students per annum. John Thonard, who was dean of the faculty at the time, argued from the university's perspective that ' $[\mathrm{t}]$ he University must take the line (until directed by higher authorities) that a student meeting the requirements for entry to any of its manifold courses has the right to be admitted to the course of his choice within the limits of the resources of the University' (Thonard 1979, p. 63). The issue of student quotas always stimulated vigorous debate at faculty meetings but these decisions are now made at higher levels within the university. 


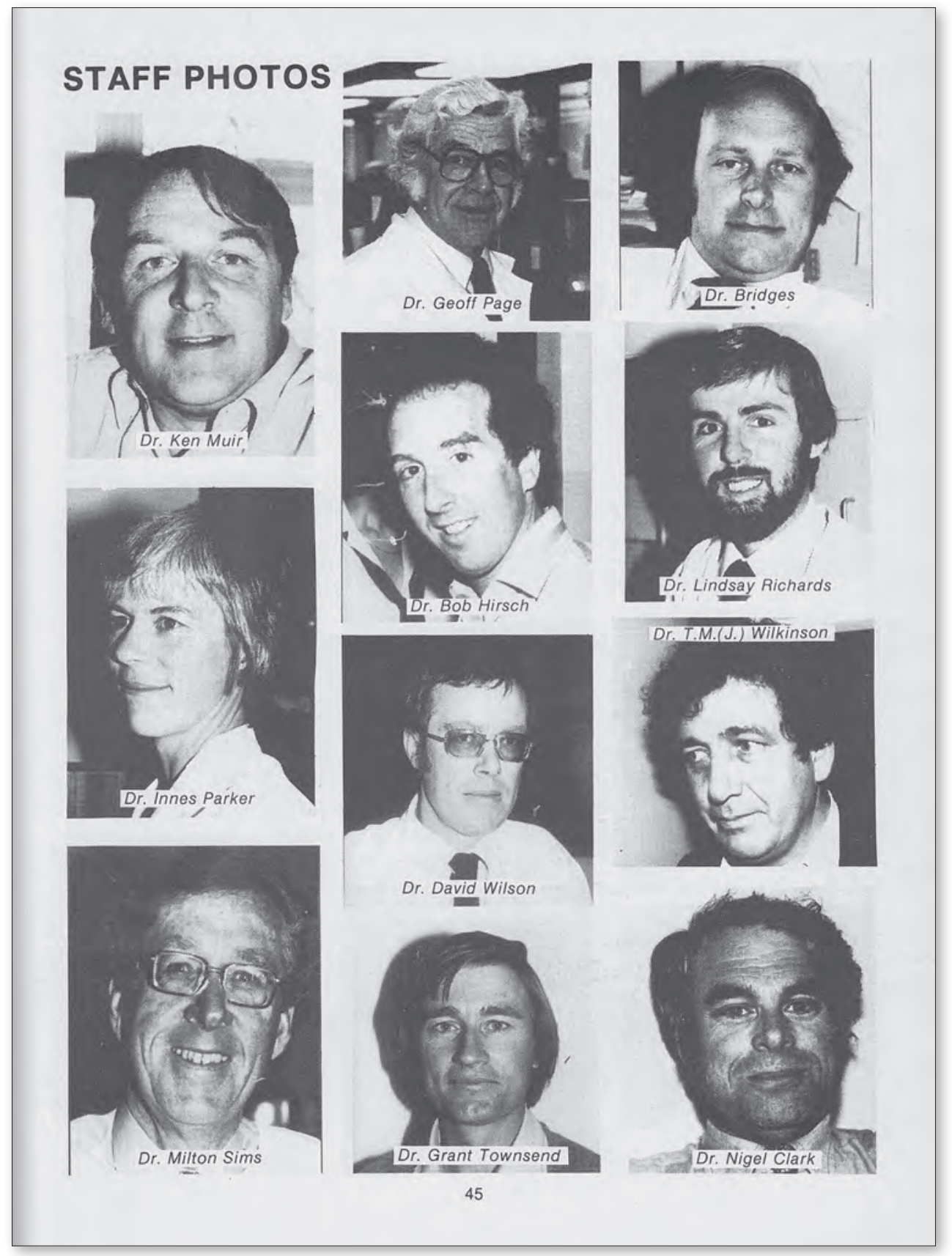

Figure 4.8 Staff photographs (Probe 1983, courtesy of AUDSS). 

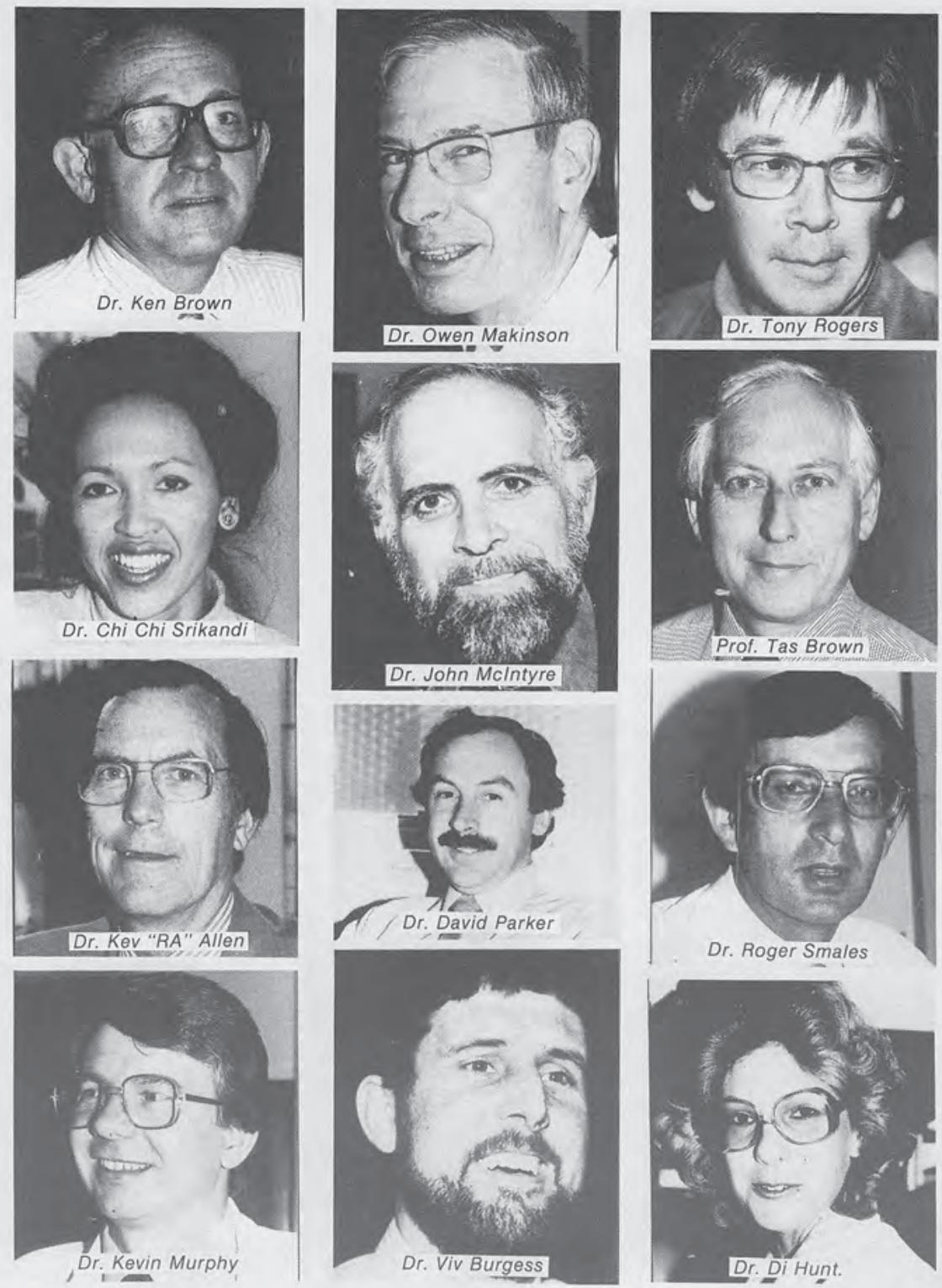


\section{Back to a single department}

It is often said that it is easier to move a cemetery than to change a curriculum, and the experience of implementing change in the 1970s and 1980s at the Adelaide Dental School certainly supports that saying. It was felt by many that the four-department structure had hindered progress in achieving a more integrated curriculum and this led to a series of meetings that considered whether the new curriculum would be best served by a structure that involved four, three or two departments, or only one. Although the Faculty of Dentistry strongly affirmed its support for a system of teaching groups in June 1982, there were concerns about how these teaching groups related to the existing departments and the Curriculum Co-ordinating Committee.

A committee, consisting of Tasman Brown (convenor), Ken Muir, Tony Rogers and David Wilson, was formed in July 1982 to consider this issue. This group reviewed existing documentation, including the proceedings of a special meeting of Faculty held at Clarendon. Although it did not specifically support any particular departmental structure, it expressed the view that if a single department structure were supported by the majority, it could be made to work. Whatever the outcome, a decision was needed as soon as possible.

As it turned out, a single department structure was adopted. In December 1983, University Council approved the recommendation of the Faculty of Dentistry that the four existing dental departments amalgamate to form one department, effective January 1984, and that the new department should be named the Department of Dentistry. The dean at this time was John McIntyre. While this undoubtedly facilitated subsequent curriculum planning and the implementation of a more integrated curriculum design, the return to a single department model was not without its problems. One of these was that some staff who were used to 'belonging to' relatively small departments with reasonable

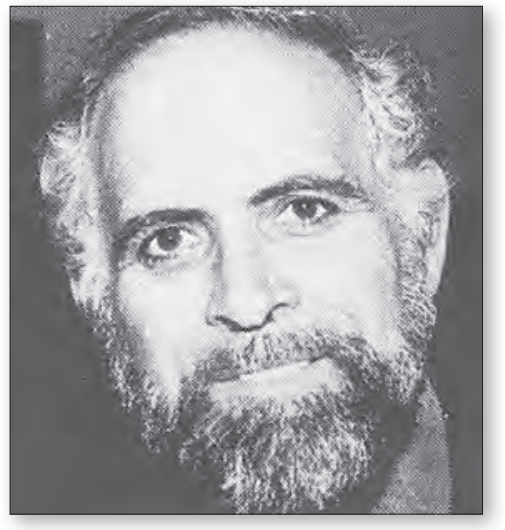

Figure 4.9 John Mclntyre (Probe 1983, courtesy of AUDSS) autonomy felt 'lost' and disenfranchised in the larger single grouping. This was a time when many dental schools worldwide were being closed down, so there was a sense that the School needed to be bold in setting up a structure that would facilitate curriculum innovation and improve its reputation for learning and teaching as well as for research.

\section{Establishment of the South Australian Dental Service (SADS)}

An important event that occurred in 1982 was the amalgamation of the School Dental 
Service and the Adelaide Dental Hospital to form the South Australian Dental Service (SADS). Given differences in the missions of the SADS and the Dental School, one principally focusing on service and the other on education, the relationship between the two organisations has waxed and waned over the years. Each organisation relies on the other, with SADS needing 'manpower' to provide general and specialist services to public patients, and the university needing access to patients and the necessary equipment to enable its students to gain clinical experience. The extent to which the two organisations have been able to work positively together has had (and will continue to have) a significant effect on the quality of the education received by students. Given the brinksmanship involved in the recent call for tenders by SA Health for tertiary institutions to establish a partnership with SADS, it would appear that the state government had decided that, at least in the existing political climate, the University of Adelaide needed it more than it needed the University of Adelaide.

One item that appears in the Minutes of the faculty meeting of July 1982 provides an early example of a dispute between the university and the hospital about space allocation within the Adelaide Dental Hospital. Faculty endorsed a statement from the heads of the four departments in the Dental School registering their 'strongest protest to the acquisition of one of the University teaching rooms through the Minister of Health' (Faculty of Dentistry 1982). The university did not pursue the matter vigorously as the vice chancellor was 'instructed' by the Minister of Health to request that the School give the space to the hospital. Further similar outcomes have occurred over the years, leading up to the present time. Despite the fact that the Adelaide Dental Hospital was designed to accommodate both university and hospital roles, it is generally accepted these days that the building is owned by the state government and it retains ultimate power in terms of its use.

\section{Amalgamation of medicine and dentistry}

A major event in late 1988 was the strong reaction from the dental profession to the proposal to amalgamate the Faculties of Medicine and Dentistry. There was overwhelming condemnation of the proposal from the dental profession and the faculty with a strong view expressed that the integrity and identity of the Faculty of Dentistry should be retained. Although dentistry may have won this 'battle', ultimately it lost the 'war' and its faculty status.

\section{The Dawkins reforms}

During the period from 1987 until 1991, John Dawkins was the Minister for Employment, Education and Training. He produced a White Paper and then a Green Paper proposing that there should be a Unified National System that removed the binary divide between universities and colleges of advanced education. It was proposed 
to merge tertiary institutions, increase student access and equity, and reduce costs. The Higher Education Contribution Scheme (HECS) was introduced, with students being required to contribute to the cost of their education.

The federal government would fund universities on a per-student basis, thereby enabling the government to put pressure on the universities to achieve greater efficiencies. As part of its requirement to reduce the unit cost of educating students, the government decided that the tiered system of tertiary institutions could not continue and the total number of institutions would have to be reduced by about $50 \%$. This led to a series of mergers. All institutions that remained after the rationalisation process could then call themselves 'universities'. The Dawkins merger plan led to the replacement of the collegial style of university governance that had existed previously with a more corporate style top-down management that was thought would enable universities to respond more effectively to government policy.

\section{Integration of dental education}

During 1988, the Department of Dentistry sponsored a workshop on 'A model for dental education in South Australia'. Participants came from all sectors of the dental profession, including dentists, dental therapists, dental hygienists and other paradental personnel. The workshop addressed the topic of greater integration of dental education across the various sectors. The outcome of the workshop was that the executive officers of the Faculty of Dentistry, Somerton Park School of Dental Therapy, Gilles Plains TAFE and the professional associations would meet to consider further the formation

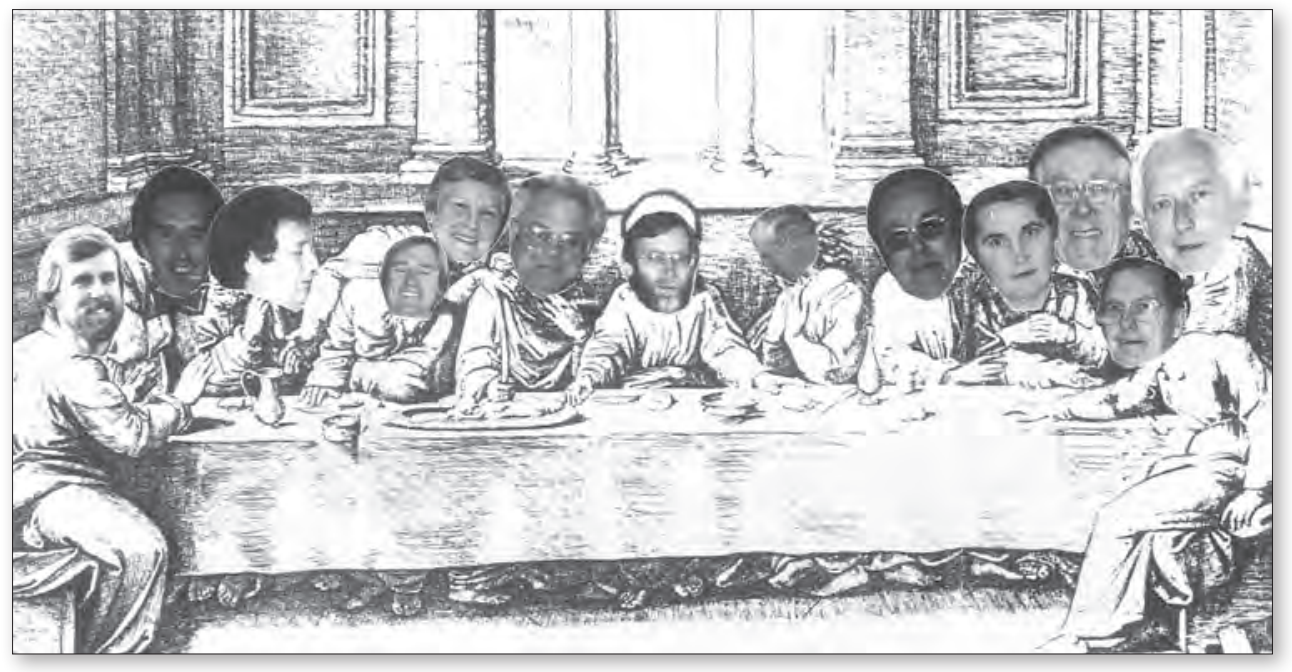

Figure 4.10 Staff at the 'last supper', showing that students at the time were well aware of the pressures faced by the School (Probe 1988, courtesy of AUDSS). 


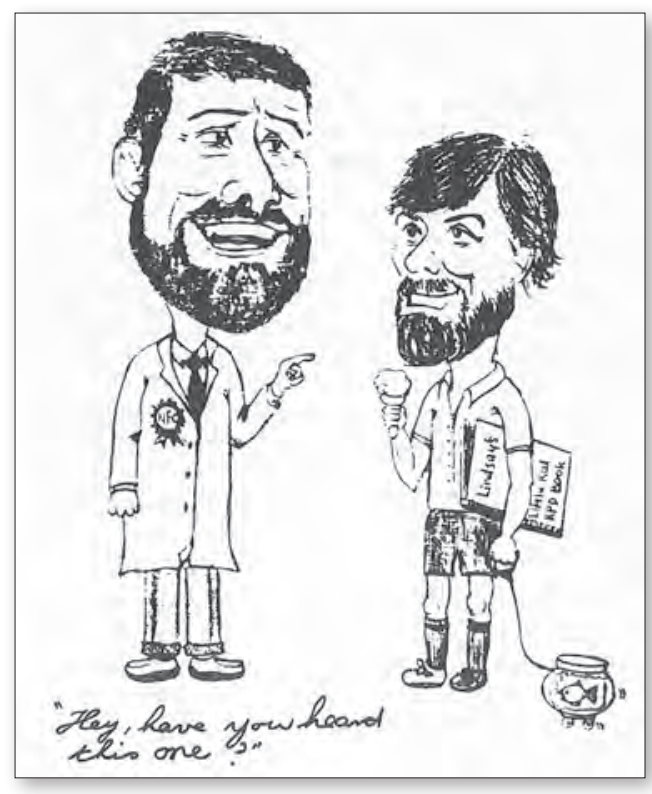

Figure 4.11 Vivian (Viv) Burgess and Lindsay Richards - two very familiar staff faces often seen together in the clinics (Probe 1983, courtesy of AUDSS). of an umbrella organisation to foster integration in dental education.

The new dean in 1989 was John Spencer and he was faced with more budget cuts that affected the School's teaching programmes. Professor Spencer pointed out in his Probe 1989 report that all faculties in the university were funded according to their student load multiplied by a factor of agreed average costs. He noted that the only way that the Faculty of Dentistry could recoup lost resources would be to increase its student numbers. In 1989, there were thirty South Australian students new to the BDS course, together with five students under the MATES scheme and three Fijians. There were also six lateral-entry students into Second Year through a Bridging programme and a further six who entered later

years, after completing a dental education overseas. The aim was to broaden the undergraduate student base to reach an average number of forty-five undergraduate dental students per year.

\section{The new BDS curriculum - 1970s version}

During the early 1970s, workshops on undergraduate dental education (1971) and also graduate and postgraduate education (1972) were held at the Raywood Centre, Bridgewater. Detailed reports of the discussions that took place were recorded, and make fascinating reading, as they document the different views of participants and the flow of thought within the various working groups. This level of documentation is a far cry from the present day where records of meetings are often cursory or non-existent.

The workshop on undergraduate education was held over a weekend and participants formed groups to consider the following topics: elective courses in dental education (chair: Barrett); topic teaching in dentistry (chair: Cran); behavioural sciences in the dental curriculum (chair: Allen); and the training of dentists using auxiliaries (chair: Horsnell).

In introducing the workshop, Horsnell made the following comments, which would be equally as applicable today: 
When we think quietly about our problems we are trying to handle a system of education which is taking place, which is being put across, organized, presented at a time when the body of knowledge available has grown enormously, when the ways of presenting this knowledge have changed remarkably — these are things which we must consider very carefully. If there is more knowledge, can we make more of it available by using different methods of presentation? Another thing which we must remember constantly is that the attitudes of students to learning have changed. Another point of some interest is that the attitude of students to their responsibility in society may be changing, or they may be appearing to change. There are changes too in the profession to its own terms of reference. (Workshop on Undergraduate Dental Education 1971, p. 3)

In relation to elective subjects, it was agreed that the dental course of the future would differ considerably from the present one. By cutting back time allocated to core subjects, it was thought that there would be time made available for elective subjects that would provide students with opportunities to gain experience in areas of special interest.

The group who considered topic teaching noted that this would involve courses where teachers from many disciplines would be involved. The topic courses could be introductory in nature or they could be in-depth courses of short duration. A third type of topic course considered was a review-type course that could be presented in the final year and could take the form of clinical scenarios - for example, a patient presenting with a toothache, with students then considering diagnosis and treatment issues.

Dental caries was considered to be one possible topic that could be covered in an interdisciplinary manner; others included occlusion, anaesthesia and radiology. Of interest were some of the hurdles identified to introducing topic courses, including the need for staff to attend each other's lectures, which would involve extra time.

The group who considered behavioural sciences in the dental curriculum considered three main areas: the study of people in society; clinical applications of behavioural science in dentistry; and communication. The group felt that it would be necessary to remove some subjects/topics from the existing First Year (perhaps physics) to enable a behavioural science component to be included. It was suggested that detailed discussions with other departments in the university should be initiated, including psychology, child health, mental health and other departments in the Faculty of Medicine. The group thought that the pre-clinical aspects of such a course should be taught by non-dental staff, but the dental aspects should be taught by dental staff. In discussing the group's findings, Tasman Brown made the following comments:

We think that there is an imbalance in the scope and nature of courses taken by dental students at secondary school level and first year university level. For example, by the time a dental student reaches his second year at university, which we regard as the time when he branches into his dental education, he may have completed six years of study of physics and chemistry but he probably has very little exposure, if any, in human sociology. In addition, he has often completed only one year of biology, yet the same student will be working in the fields of human biology and 
behavioural science for the rest of his undergraduate course and all his professional life. We feel that students should have some detailed instruction in the broad aspects of sociology. It is not our intention that students should be trained to become professional sociologists but they should know and understand man as a social organism as well as a biological organism. (Workshop on Undergraduate Dental Education 1971, p. 32)

These comments are applicable to all of the basic and applied sciences. That is, a dental curriculum is not about training students to become, for example, biochemists or physiologists or pharmacologists, but it is important for dental students and practising dental professionals to be able to apply knowledge from these areas to their clinical practice.

Thonard then reminded the group that the dental students could be included with the medical students in the new courses that were proposed to be introduced in 1973, at the same time that dental students would be coming back to Adelaide from Flinders University. The three main courses proposed for the new first year in medicine were chemistry IM, biology, and behavioural sciences, as well as physics, biophysics, statistics and genetics, which would be taken as a composite course.

Comments from students that are recorded in the archived Minutes of the Curriculum Committee in 1972 indicate their support for the proposed changes to the first year of the BDS course. They expressed concern about the large degree of repetition in the present course and suggested that there should be a greater attempt to bring the lectures and the practicals together. The students were also supportive of the move to introduce electives and agreed with ensuring some 'free time' across the five years of the course.

The fourth group looked at the training of dentists using auxiliaries. This group commented that it could see a clear trend, likely to occur within the next decade, for the general dental practitioner to delegate more of the 'straightforward, repetitivetype dentistry' to specially trained auxiliaries. However, the group stated that it was 'clear that the auxiliaries would not be expected to undertake the treatment, which we consider they will be capable of doing, unless the diagnosis has been made by a fully trained graduate dentist' (Workshop on Undergraduate Dental Education 1971, p. 40). It was considered that the dental curriculum of the future might consist of four phases: a basic science phase; a clinical introduction or 'clinical core' stage; a preregistration phase; and a graduate or post-registration phase. The group considered that the dental students' education during the second phase would be improved if there were trained assistants available to assist in the clinics.

The table that follows shows the hours allocated to different subjects in the 1974 version of the BDS curriculum (Curriculum Review Committee 1974). As can be seen, there was very little exposure to dental topics in the first year, with only twelve hours of introductory topics provided. The table also highlights the large number of separate subjects in each year, each being examined separately. 
Table 4.1 Adelaide BDS Curriculum - 1974. Arranged by Years (adapted from original source material).

Columns headed 1 and 2 are estimates of teaching hours:

$1=$ Lectures, seminars or tutorials

2 = Practicals or clinics

Teaching hours were estimated from timetables and from information provided by teaching departments.

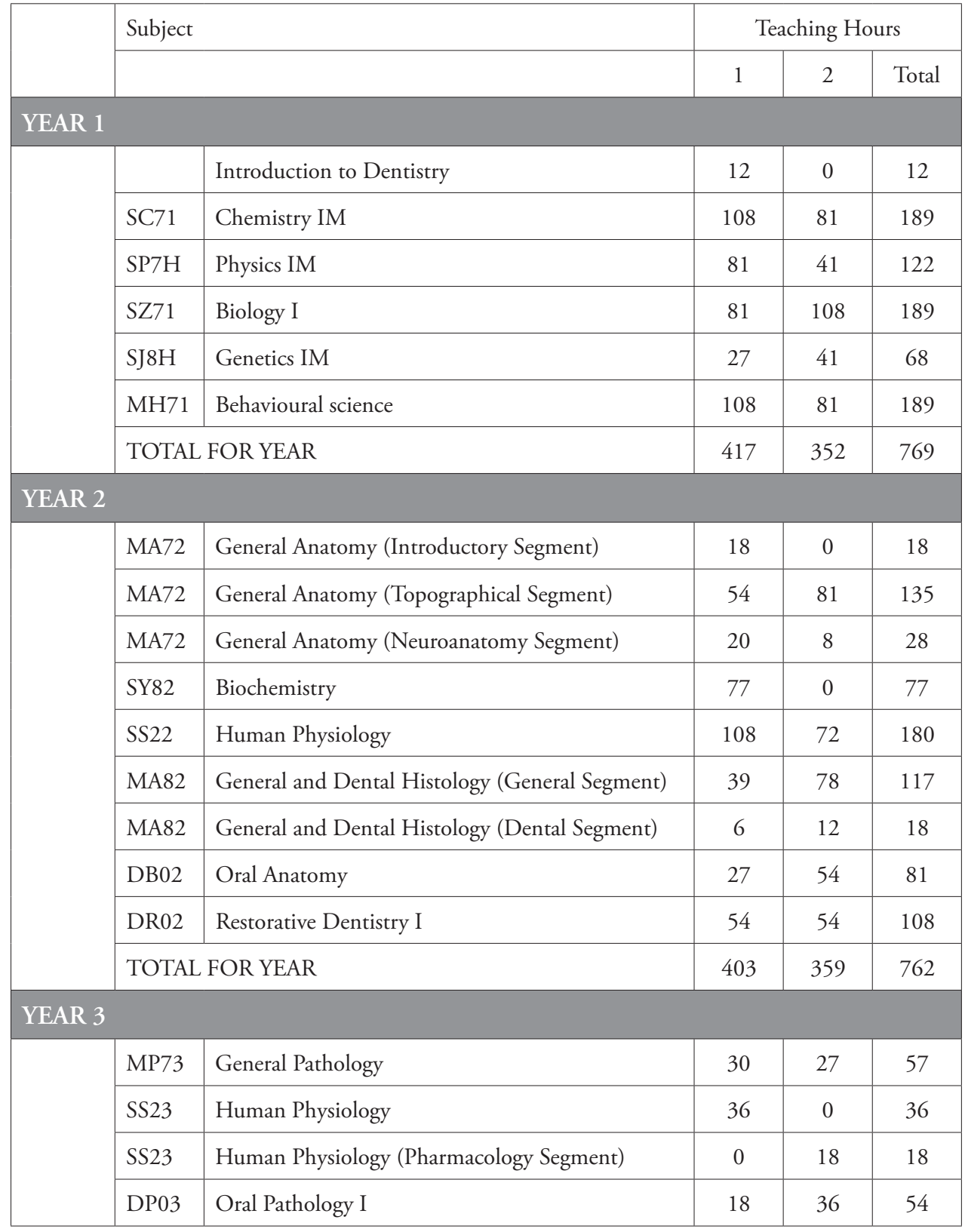




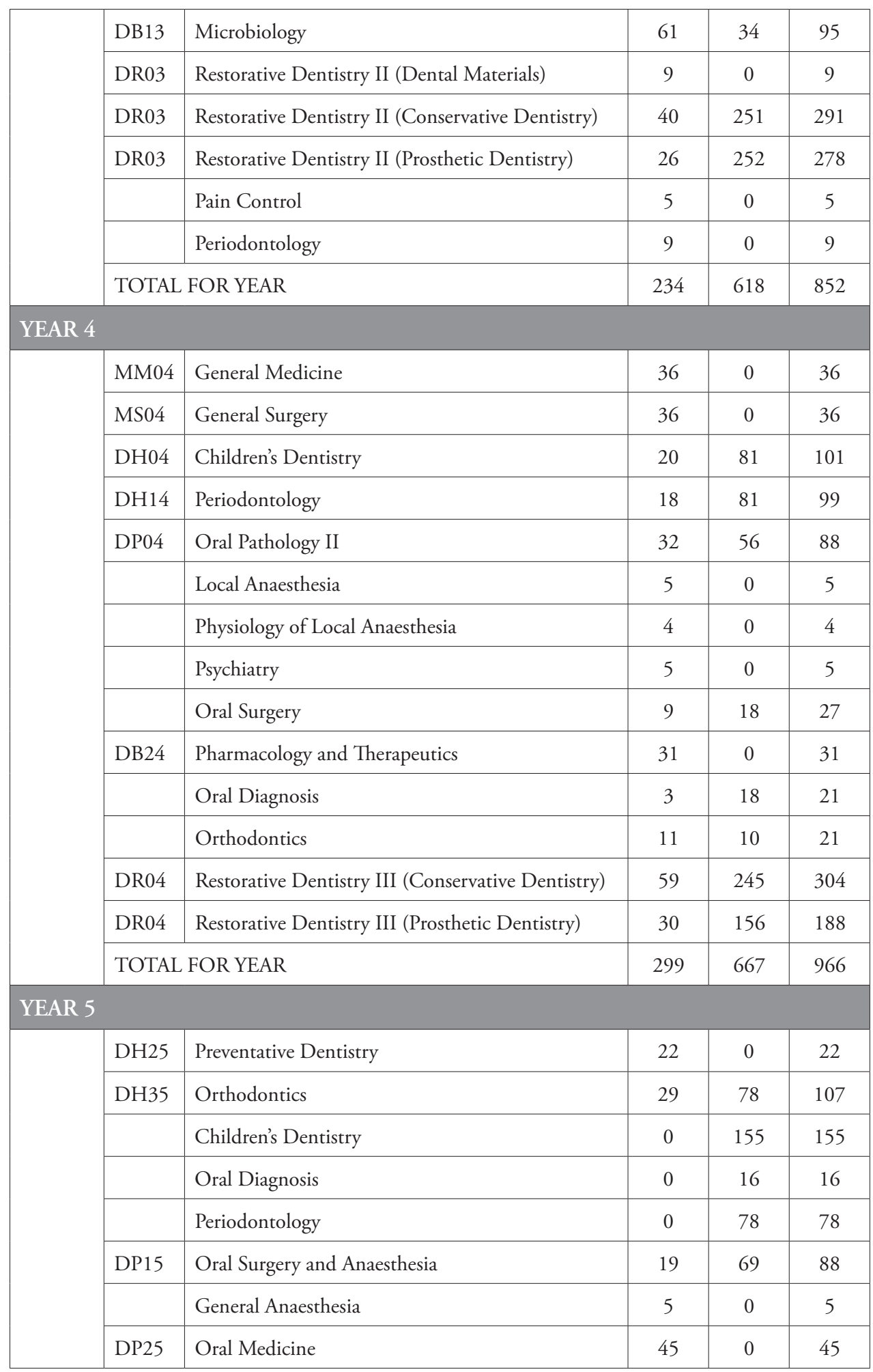




\begin{tabular}{|l|l|l|c|c|c|}
\hline & DR05 & Restorative Dentistry IV (Conservative Dentistry) & 53 & 182 & 235 \\
\cline { 2 - 6 } & DR05 & Restorative Dentistry IV (Prosthetic Dentistry) & 28 & 149 & 177 \\
\cline { 2 - 6 } & Applied Oral Biology & 9 & 0 & 9 \\
\hline & Principles of Practice & 5 & 0 & 5 \\
\hline
\end{tabular}

\section{Graduate and postgraduate education}

A Workshop on Graduate and Postgraduate Education in Dentistry was also held at Raywood Centre, Bridgewater, in May 1972. This resulted in reports from two working groups.

The first working group agreed that there was a need by both dentists and the community for continuing education. It was noted that there was a difference between needs and demands and that this should be kept in mind when planning programmes.

It was agreed that new graduates required further clinical training after graduation, associated with the increasing complexities of dentistry and a possible lack of clinical experience in the undergraduate programme. The notion of a one-year compulsory course after graduation was discussed. It was thought that such a scheme could be run in a teaching institution but not necessarily in a hospital. Government clinics or even selected general practices were suggested. Problems with providing adequate staffing and accommodation were noted.

The topic of continuing education for the general practitioner was also considered. It was not felt that compulsory attendance at postgraduate courses should be a pre-requisite for re-registration, although the awarding of certificates for attendance was raised. Further discussion about postgraduate education and research is provided in Chapter 7.

A third area of discussion was the training and education of academics. It was considered desirable that teachers in the basic sciences should hold a PhD, as well as sufficient dental knowledge to make their teaching relevant to dental situations. It was felt that clinical teachers required a broader teaching base than their non-clinical colleagues and that they needed to maintain and develop their clinical skills after appointment. There was agreement that the need for, and recognition of, this clinical expertise was not appreciated by the university and that promotion was still based mainly on publications.

The second working group made a series of recommendations:

- that the Australian Universities Commission be asked to make an allocation to the university to assist the Postgraduate Committee in Dentistry 
- that the College should share responsibility for graduate education but assume total responsibility for administering its own fellowships

- that the compulsory factor in postgraduate education for private practitioners should not be implemented at this time

- that there was a projected or future need for a part-time or full-time co-ordinator to organise postgraduate education in South Australia

- $\quad$ that in the degree structure the MDS should be the normal avenue to a specialist training qualification and for this reason should be regarded as a clinical rather than an academic qualification, and that there should be some research component

- that the normal avenue to academic achievement should be the PhD.

\section{Recommendations in the Dental Curriculum 1/74 Report}

A Report on the Dental Curriculum 1/74 was produced by the Faculty of Dentistry's Curriculum Review Committee in June 1974. The Committee comprised Tasman Brown (Chairman), Kevin Allen, David Blaikie, Hugh Kennare, Owen Makinson and Michael (Mike) Nugent. The report was submitted to Faculty for consideration and it was made clear that the proposals were submitted simply as guidelines and that considerable planning remained to be done. It was pointed out that the proposed curriculum structure differed in many respects from the traditional dental courses that had been available in Australia in the past.

Some of the key recommendations that were subsequently accepted by Faculty were:

- $\quad$ organisation of the curriculum around three teaching programmes biomedical sciences, applied dental sciences and dental care

- the inclusion of an elective programme

- the introduction of pre-requisites and co-requisite subjects to allow students to progress through the course according to their individual abilities

- the allocation of at least one session weekly as free time for all students

- the introduction of a credit point system to quantify courses according to contributions to the total curriculum

- the achievement of a dental training period of four years of university education and one year of pre-registration hospital practice

- that Faculty should maintain its interest in proposals for a School of Health Sciences and lend its support to the extent that such proposals were compatible with the proposed development of the dental curriculum.

The structure of the proposed new BDS curriculum is shown below. Innovative features included the grouping of subjects into three programmes - biomedical sciences, 
applied dental sciences, and dental care - as well as the inclusion of topic courses that covered interdisciplinary topics such as human health and disease, dental caries, oral anatomy and occlusion, and pain control.

Table 4.2 Proposed new dental curriculum showing content of the compulsory teaching programmes.

\section{PROGRAMME 1: BIOMEDICAL SCIENCES}

\begin{tabular}{|l|l|l|}
\hline General Science Group & Physiology Group & Anatomy Group \\
Chemistry & Human Physiology & General Human Anatomy \\
Biolical Physics & Biochemistry & Regional Anatomy \\
Pharmacology & $\begin{array}{l}\text { Neuroanatomy } \\
\text { General Histology }\end{array}$ \\
\hline Microbiology and Pathology Group & & $\underline{\text { Topic Courses }}$ \\
General Pathology & Human Health and Disease \\
Microbiology & Development, Growth and \\
Immunology & Ageing
\end{tabular}

PROGRAMME 2: APPLIED DENTAL SCIENCES

\begin{tabular}{|c|c|c|}
\hline $\begin{array}{l}\text { Oral Histology } \\
\text { Oral Physiology } \\
\text { Oral Pathology } \\
\text { Materials Science } \\
\text { Radiology } \\
\text { Behavioural Science }\end{array}$ & & $\begin{array}{l}\text { Topic Courses } \\
\text { Oral Anatomy and Occlusion } \\
\text { Nutrition and Dental Health } \\
\text { Dental Caries } \\
\text { Periodontal Disease } \\
\text { Forensic Odontology }\end{array}$ \\
\hline & & $\begin{array}{l}\text { Behavioural Science Group } \\
\text { Behavioural Science } \\
\text { General Sociology } \\
\text { Applied Physiology } \\
\text { Social Aspects of Dentistry } \\
\text { Preventative Epidemiology }\end{array}$ \\
\hline \multicolumn{3}{|c|}{ PROGRAMME 3: DENTAL CARE } \\
\hline $\begin{array}{l}\text { Restorative Group } \\
\text { Conservative Dentistry } \\
\text { Prosthetic Dentistry } \\
\text { Practice Management } \\
\text { Patient Management } \\
\text { Ethics and Jurisprudence } \\
\text { Endodontics }\end{array}$ & $\begin{array}{l}\text { Medicine and Surgery Group } \\
\text { General Medicine } \\
\text { General Surgery } \\
\text { Oral Medicine } \\
\text { General Medicine } \\
\text { Oral Surgery } \\
\text { Anaesthesia } \\
\text { Dental Therapeutics } \\
\text { Periodontology }\end{array}$ & $\begin{array}{l}\text { Dental Health Group } \\
\text { Preventative Dentistry } \\
\text { Community Dental Health } \\
\text { Children's Dentistry } \\
\text { Orthodontics }\end{array}$ \\
\hline
\end{tabular}




\begin{tabular}{|l|l|}
\hline & Topic Courses \\
& Introduction to Dentistry \\
& Pain Control \\
& Recent Advances in Oral \\
& Biology \\
\hline
\end{tabular}

It was proposed that the new First and Second Years should be introduced in 1976 and that detailed consideration should be given to the need for increased staff and facilities for the new curriculum, and that recommendations should be made to the university.

In terms of clinical training, it was recommended that

- clinical instruction be permitted in hospitals and clinics apart from the Royal Adelaide Hospital

- $\quad$ preventive/restorative mini-clinics be established to increase preventive dental education

- an oral diagnosis and treatment planning centre be established

- greater emphasis be given to the promotion of good oral health by the diagnosis and prevention of oral and dental disease

- the role of 'dental teams' be emphasised in the delivery of dental care.

During 1975, a Curriculum Study Committee was appointed to look at the feasibility of implementing the recommendations of the Curriculum Review Committee. It presented its report to Faculty in 1976. The original aim had been to introduce the new curriculum at First and Second Year levels in 1976 and complete the changeover for all years by 1979. As it turned out, changes only began to occur in 1980, almost a decade after the first Raywood meetings.

\section{Reports from the Advisory Centre for University Education}

Two reports from the Advisory Centre for University Education (ACUE), authored by the Director of the Centre, Robert Cannon, and Owen Makinson, provided important data derived from surveys to support the need for curriculum change. The first summarised the views of dental practitioners and students about curriculum content and relevance, as well as preparation for practice, selection of students and changes to the BDS curriculum (Makinson and Cannon 1980). A second report canvassed the views of teaching staff on the BDS curriculum and curriculum change and on the pressures in dental education. This report also explored the issues of 'system defensiveness' - that is, the tendency for non-dental departments who were involved in presenting subjects in the BDS course to defend their own interests in the face of the interests of the Dental School (Cannon 1981). 
Cannon drew on the contents of the book Innovations and Innovation Processes in Higher Education by Berg and Ostergren (1977) to highlight important principles of change, and applied them to the Adelaide Dental School and its desire to introduce an innovative BDS curriculum (Cannon 1981).

These principles included:

- Conditions of change are determined mainly by system characteristics. Cannon pointed out that the system in this case was the Dental School and that its characteristics included its membership composition, its ideology, technology, organisational structure and relations with the environment (that is, those systems outside the School).

- $\quad$ Systems tend to defend the interests of their members, their ideology, their technology, their organisational structure and the nature of their relations with the environment.

- The innovation process is a political process that takes place in a field of mutually opposing forces. Change occurs when the 'driving' forces dominate the 'restraining' forces.

Cannon's discussion in the early 1980s is just as relevant now as it was then. Innovation, whether it be in a dental curriculum or other areas within a Dental School, is certainly a political process, with the balance between mutually opposing forces determining whether change occurs or not - using the metaphor of biological punctuated evolution (relatively rapid change or stasis). The added difficulty these days is that there is no longer a reasonably autonomous faculty of dentistry in which the driving and restraining forces were debated openly and often very vigorously before decisions were made. These days, the Adelaide Dental School has very little control over its own destiny. Decisions are made at the level of the Faculty of Health and Medical Sciences or above, with very limited opportunity for meaningful consultation and open debate.

The main findings provided in these reports were published subsequently in an article in the Australian Dental Journal (Cannon and Makinson 1983). It was noted that the need for curriculum reform had been expressed by dental students, staff and dental practitioners, especially with respect to the basic sciences, some of the biomedical subjects, behavioural science, and also practice management. Staff and practitioners also expressed serious concerns about the quality of dental skills of new graduates. The authors noted that 'dental education occurs within a complex set of interacting circumstances which extend beyond the immediate confines of the Dental School and, indeed, the University' (p. 146). They explain how the slow-down in economic activity at the time had led to a direct impact on the university's ability to replace staff who left the School. The importance of prevention of disease was emphasised by many respondents to the surveys. One staff member who was quoted in the report wrote: 
'We are not teaching students well enough to realize the importance of preventing disease' (p. 146).

\section{The BDS course in the 1980s}

Following a special meeting of Faculty in 1979, a restructuring of the School was adopted in which the existing four-department structure was retained but ten inter-departmental groups were formed, each with a leader and membership from across the departments. This new structure aimed to promote group or unit teaching.

During 1979 First Year students spent time in the clinics for the first time as part of the dental care subject and this then followed on into Second Year.

The Biodental Sciences Teaching Group restructured the first year of the BDS course and introduced two new subjects into First Year — dental care I/oral anatomy, and introductory anatomy and histology. Furthermore, the hours allocated to behavioural science, biology and chemistry were reduced. Achieving these changes was by no means an easy task. Although Faculty agreed to changes in 1980, the difficulties in trying to reduce the amount of chemistry in the first year led to a special working party being formed that was chaired by Professor ES Barnes. This group recommended that the current more extensive course in chemistry should continue to be taught in 1981 but that further discussions should occur to resolve the issue. Eventually, a new chemistry ID subject was approved for 1982 .

The first and second years of the BDS curriculum for 1982 comprised the following subjects:

\section{First Year}

- Behavioural science (162 hours)

- Biology ID (163 hours)

- $\quad$ Chemistry ID (89 hours)

- $\quad$ Genetics IM (68 hours)

- $\quad$ Physics IM (83 hours)

- Introductory anatomy and histology (81 hours)

- Dental care/oral anatomy (81 hours)

Total: 727 hours.

\section{Second Year}

- $\quad$ Biochemistry (75 hours)

- Regional Anatomy (including Neurobiology) (131 hours)

- $\quad$ Systematic histology and embryology (99 hours) 
- Human physiology (116 hours)

- Oral anatomy (54 hours)

- $\quad$ Restorative dentistry II (108 hours)

- Dental care II (126 hours)

Total: 709 hours.

Further changes flowed on over the next few years, some linked to changes in the medical curriculum; however, many of the more far-reaching aims arising from the Raywood meetings were not achieved.

By 1985, the subjects in third, fourth and fifth years were:

\section{Third Year}

- $\quad$ Biology of disease IIID

- Human physiology IIID

- Oral pathology III

- Pharmacology and therapeutics III

- Conservative dentistry III

- Dental materials science III

- Removable prosthodontics III

- $\quad$ Periodontology III.

\section{Fourth Year}

- General medicine IV

- General surgery IV

- Oral pathology IV

- Periodontology IV

- Conservative dentistry IV

- Removable prosthodontics IV

- Orthodontics IV.

\section{Final year}

- Oral medicine and applied oral pathology V

- Oral surgery V

- Oral diagnosis and dental radiology V

- Children's dentistry and orthodontics V

- Pain control V 
- Community dentistry V

- Conservative dentistry $\mathrm{V}$

- Removable prosthodontics $\mathrm{V}$

- General dental practice $\mathrm{V}$

- $\quad$ Electives V.

Overall, there were thirty-nine separate subjects in the BDS course in the 1980s, each largely presented as discrete entities and each examined separately.

\section{MEREDITH FANTHAM}

Year of graduation

1972

Career since graduation

1973 House Dentist Adelaide Dental Hospital

1974-2007 Dentist, SA Dental Service mainly based in school dental service Rural Mallee, Port Pirie, Whyalla and Peterborough, suburban Adelaide.

\section{Current position}

Retired and enjoying caravan travel and volunteering with non-dental organisations, church, private hospital, local library service and support of intellectually disabled holiday groups. I have also been privileged to volunteer with Experience Adelaide 2014-15.

How well do you believe your education at the Adelaide Dental School prepared you for your future career?

Excellent clinical grounding and education. Practical and theoretical experience. Great group of fellow students, teachers and clinical tutors. Enjoyed paediatric dentistry and Professor Horsnell, Dr Betty Fanning and Hugh Kennare (tutor) both lectures and clinical. Guided me to a career in government health services dealing with children and adolescents. 


\section{KARIN ALEXANDER}

Year of graduation

1982

\section{Activities since graduation}

After completing my BDS degree in 1982, I worked as a part-time employee of both my mother, Dr Vera Alexander, and my godmother, Dr Dagmara Krumins, in their respective practices. I then worked parttime for my mother in her suburban practice while I had my two children, Alyssa and Paul, before deciding to go back to full-time work. It was then that I purchased a practice in Adelaide and, several years later, the associate practice on my associate's retirement. I have, and still do, employ several other dentists and an oral health therapist in the city practice. While I enjoy general dentistry, one of my special interests is delivering dental care for residents of several aged care residential facilities.

Concurrently I became involved in the activities of the South Australian Branch of the Australian Dental Association (ADASA), starting with work on committees, notably the Practice Management and Members' Services Committee and then the Review Committee, before moving on to the Branch Council and ultimately becoming Branch President in 1999.

This initiated an interest in actively participating and influencing the direction of our profession so I nominated for Federal Council of the ADA. This led to election to the Federal Executive in 2004 culminating in the position of Federal President in 2012. During this time I also chaired the Continuing Professional Development Committee and sat on various other committees and external stakeholder committees. I was also privileged to be Chair of the Local Organising Committee (LOC) for the 2005 Australian Dental Congress in Adelaide.

Amongst my current commitments, I chair the Federal Dental Education and Workforce Committee, am a member of the ADASA Branch Council, and am Chair of the LOC for the 2019 Australian Dental Congress.

I was inducted to Fellowship of the Academy of Dentistry International (2003), the International College of Dentistry (2003) and the Pierre Fauchard Academy (2005). I am also an Honorary Life Member of the ADASA (2012) and the ADA (2014). 


\section{How did my education prepare me for my future career?}

My education at the Adelaide Dental School equipped me well for the path I have travelled. It gave me a robust foundation and inspiration to continue my quest for knowledge, a strong sense of the history of our profession and the strength to continuously strive for the betterment of our profession and our patients. The guidance and mentorship of lecturers and tutors gave me the confidence to keep pushing my own boundaries and learn the many new skills needed for life outside the shelter of the School.

\section{SIMON READING MOORE}

Year of Graduation

1985

\section{Activities since graduation}

During my fourth year at Dental School, I signed up as an officer cadet with the Australian Defence Forces (Army) and, on graduation at the end of 1985, was posted to Wagga Wagga (Kapooka) as a dental officer. I served for five years in NSW and Townsville before being discharged in 1991. I spent the first part of 1991 teaching at the Adelaide Dental School before moving back to Wagga where I established an Aboriginal Dental Clinic for the NSW Department of Health. I studied in Melbourne from 1993-95, obtaining a theology degree, before returning to Adelaide in 1996. At this time I commenced teaching at the Dental School and also began my postgraduate studies, being awarded an MDS (Oral Pathology) in 1999. I continued teaching at the university until relocating to Brisbane in 2004. Since that time I have worked in specialist private practice (oral medicine and oral pathology) in Brisbane and the Sunshine coast.

How did my education prepare me for my future career?

I have many recollections of my time as a student at the Adelaide Dental School. Our cohort 'pioneered' a new dental curriculum with the 
introduction of basic clinical practice (dental care I \& II) in the early years of the course. Teachers including Dr John McIntyre, Dr Rory Hume and Prof Grant Townsend were pivotal in this transition. An additional benefit was the small number of students in our year group. We commenced in 1981 with only twenty-five students and the final graduating class was closer to twenty. The smaller class size meant a much closer relationship between the students, increased opportunity for clinical practice (in my final year I removed over 300 teeth) and also greater access to the teaching staff.

We were required to carry out extensive pre-clinical laboratory training in addition to doing much of our own clinical laboratory work, e.g. pouring impressions, articulating models, setting teeth, waxing and casting gold crowns. The cheerful support of the laboratory dental technicians (Jim, Garry and Graham) was tremendous in addition to providing important insights into the interface between the dental laboratory techniques and clinical situations - I feel that the demise of this experience in contemporary dental training courses has been a significant loss for younger dentists. Another positive memory I have of the senior clinical years was the opportunity to undertake electives. A wide range of clinical and researchbased topics were offered and this allowed students to 'try out' research endeavours and/or further develop their clinical skills. I have many fond memories of my time at the Adelaide Dental School and, overall, found my undergraduate training in the early 1980 s to be a great preparation and springboard for my subsequent dental career.

\section{References}

Beasley PRN (1975) Dean's report. Probe: 4-5.

Berg B, Ostergren B (1977) Innovations and innovation processes in higher education. National Board of Universities and Colleges, Stockholm.

Brown T (1971) The University of Adelaide, Faculty of Dentistry, a short history. University of Adelaide, Adelaide.

Brown T (1976) Dean's report. Probe: 4-5.

Brown T (1977) Dean's report. Probe: 3-4.

Cannon RA (1981) Advisory Centre for University Education Report. University of Adelaide, Adelaide. 
Cannon RA, Makinson OF (1983) Dental education at The University of Adelaide: An evaluation. Australian Dental Journal 28: 143-148. https://doi.org/10.1111/j.1834-7819.1983. tb05269.x.

Curriculum Review Committee (1974) Report on the Dental Curriculum 1/74. Faculty of Dentistry, University of Adelaide, Adelaide.

Curriculum Study Committee (1976) Report on the Dental Curriculum 1/76. Faculty of Dentistry, University of Adelaide, Adelaide.

Faculty of Dentistry (1982) Faculty Minutes. University of Adelaide, Adelaide. 1982.

Goss AN, Linn R (2015) Extractions to Reconstruction. The Development of Oral \& Maxillofacial Surgery in Australia and New Zealand. Historical Consultants, Cherry Gardens, South Australia.

(The Full Archive of the History of 'Surgery-Oral \& Maxillofacial' is housed in the National Library of Australia, Canberra, 2017.)

Makinson OF, Cannon RA (1980) Advisory Centre for University Education Report. University of Adelaide, Adelaide.

Parker DAS (1986) Dean's report. Probe: 4-5.

Smales RJ (1987) Dean's report. Probe: 4-5.

Smales RS (1988) Dean's report. Probe: 4-5.

Spencer AJ (1989) Dean's report - 1989. Probe: 3-4.

Thonard JC (1979) Dean's report. Probe: 41, 63.

Thonard JC (1980) Dean's report. Probe: 28-29, 41.

Workshop on Graduate and Postgraduate Education in Dentistry (1972) Raywood Centre, Bridgewater, 6-8 May, University of Adelaide, Adelaide.

Workshop on Undergraduate Dental Education (1971) Raywood Centre, Bridgewater, 8-9 May, University of Adelaide, Adelaide. 



\section{A new Problem-Based Learning curriculum - 1990s to 2000}

The context

In his Dean's Report in Probe 1990, John Spencer discussed the increasing emphasis being placed on performance indicators in universities and also innovations being adopted to try to cope with the frequent budget cuts. He raised the issue of needing to consider what, when, where and how we teach. He noted that the faculty was beginning the process of curriculum review and reform and encouraged students to actively participate in the process.

\section{Staffing matters}

New appointments in 1990 included Drs John Wetherell, Christopher Eldridge, Michael Stacey and Robert Jones. Two new course proposals were also working their way through university committees: the Graduate Diploma in Forensic Odontology and the Diploma in Dental Therapy. A new director of continuing dental education, Dr John Abbott, was also appointed. In 1991 a separate Faculty of Dentistry still existed, with John McIntyre as the dean. There was a single department within the faculty, with David Wilson as the head of the department and Grant Townsend as his deputy head. There were three professors, Tasman Brown, professor of restorative dentistry (appointed in 1976); John Spencer, who was appointed to a continuing position as professor in social and preventive dentistry in 1991; and Alastair Goss, who had been appointed professor in oral and maxillofacial surgery in 1989.

December 1993 marked the retirement of Owen Makinson and Kevin Allen and, in mid-1994, John McIntyre and Nigel Clarke retired. 


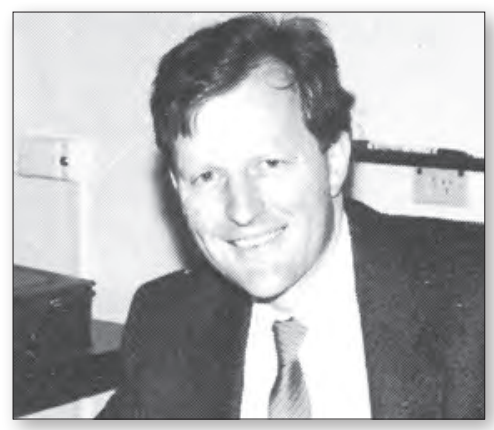

Figure 5.1 Andrew John Spencer (Probe 1989, courtesy of AUDSS).

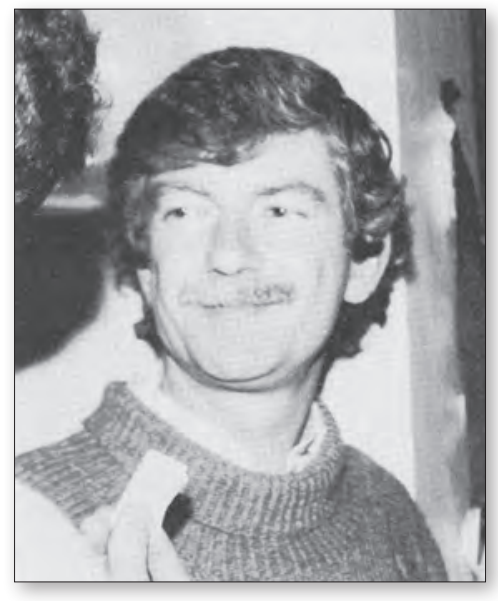

Figure 5.3 Wayne Sampson (Probe 1987, courtesy of AUDSS).

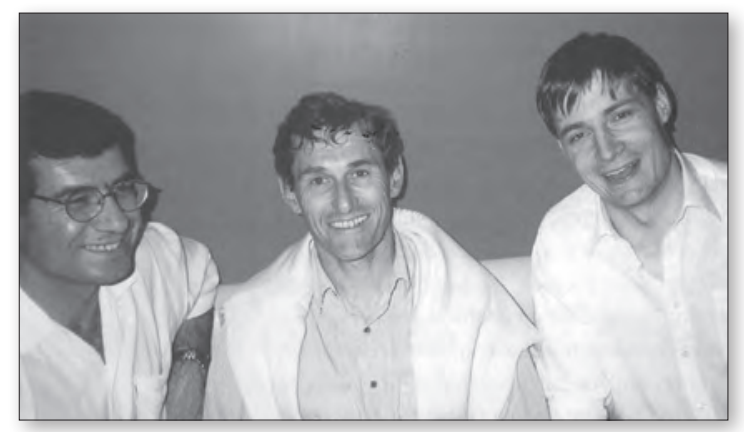

Figure 5.2 (From left to right) John Kaidonis, John Wetherell and Simon Moore (Probe 1996, courtesy of AUDSS).

After the retirement of Professor Brown in 1991, Mathilda (Tilly) Peters from Nijmegen in the Netherlands accepted the appointment as chair in restorative dentistry and took up the post in January 1994. Offers were also made in 1994 for a chair in dental science and the Begg Chair in Orthodontics, with these positions being filled by Grant Townsend and Wayne Sampson respectively. Once these positions were in place, it was intended that the School would begin a restructuring process.

\section{Upgrading of facilities}

Upgrading of facilities in the $\mathrm{ADH}$ was also planned at a cost of \$6-7 million over five years. This included the development of a lecture theatre/seminar room on the ground floor, an upgrade of Clinic 1.4 and the building of a bridge from the third floor of the Adelaide Dental Hospital over to the Old Medical School (Medical School South). In 1999, new clinical facilities were built on the second floor of the $\mathrm{ADH}$ and the lecture theatres on the sixth floor were upgraded. Redevelopment of the orthodontic clinic on the fourth floor followed with substantial support of $\$ 400000$ from the Variety Club Children’s Charity.

\section{Establishment of SAFDER}

The South Australian Foundation for Dental Education and Research (SAFDER) was established in 1990 to provide support for clinical dental research and education. 
SAFDER played an important role in supporting new developments within the School during the 1990s and into the 2000s. It raised over \$1 million to endow the P Raymond Begg Chair in Orthodontics, which was filled by Wayne Sampson from 1995-2014 and then, more recently, by Craig Dreyer; it funded a Clinical Centre for Continuing Dental Education involving refurbishment of Clinic 1.4 on the first floor of the ADH; and it contributed $\$ 2$ million to the establishment of the Colgate Australian Clinical Dental Research Centre (Chapter 7). Support for the School continues through the Dental Education and Research Foundation (DERF), chaired by Dr Helen McLean.

\section{Australian Centre for Oral Health}

Also during the mid-1990s, a proposal for an Australian Centre for Oral Health $(\mathrm{ACOH})$ was put forward by the dean, Vivian Burgess. This included a combined approach to dental education between the university, SA Health and TAFE. The proposal was presented to the university in 1997 and eventually it was endorsed by all parties. The final contracts were ready for signing in February 2002 when the SA Dental Services seemed to lose interest in the initiative, so the vice-chancellor decided that the university would not pursue the issue, even though the School and the faculty were very positive about it. Interestingly, the concept was adopted subsequently for the Western Australian Centre for Oral Health (WACOH).

\section{Restructuring in the university}

During 1995, the restructuring of the university began to take shape. In his Probe 1995 Dean's Report, Vivian Burgess noted that 'preservation of the history, identity and external relationships of the two Faculties [dentistry and medicine] is regarded as essential' (p. 6).

The dean also noted in his report to the Department of Dentistry in 1995: 'Each year it seems that the task becomes harder and there are less resources at hand. While that may only be a perception generated by difficult times, 1995 has certainly been a hard year for all concerned in the work of the Faculty' (p. 6). In 1996, the existing eleven faculties in the university (of which Dentistry was one) were grouped into six new divisions. This was part of a restructuring process to establish a more corporate style of management within the university. It was agreed at the time that the Faculties of Medicine and Dentistry would initially retain their two separate existing structures but it was anticipated that over the following few years there would be increased co-operation and a new entity, the Division of Health Science, would emerge. However, the statutes of the university were not amended at the time to include the new divisional structure, so, in 1998, a proposal was put to the Academic Board of the University of Adelaide (the highest decision-making committee apart from the Council) to rename the divisions in the university as faculties, with executive deans instead of heads. The faculties would then be re-named schools that would be headed by deans or heads of schools. 
The Faculty of Dentistry rejected the proposal, as there was concern that the Department of Dentistry and the Faculty of Dentistry would cease to exist and be replaced by a school. After further discussion, and despite our concerns, dentistry became a school within a Faculty of Health Sciences at the beginning of 1999. This marked the end of the Faculty of Dentistry, which had existed since 1920. Dentistry became a school and, along with the Medical School, we were located within the Faculty of Health Sciences. This type of structure was now in place across all of the dental schools in Australia. The number of schools in the Faculty of Health Sciences was initially two: a Medical School and a Dental School. The number has varied over the years but there are currently five schools within the faculty: the Adelaide Dental School; the Adelaide Medical School; the Adelaide Nursing School; the School of Psychology; and the School of Public Health. The Faculty of Health Sciences was renamed the Faculty of Health and Medical Sciences in 2016 and is one of five faculties in the University of Adelaide, the others being the Faculty of Arts; the Faculty of Engineering, Computer and Mathematical Sciences; the Faculty of the Professions; and the Faculty of Sciences.

\section{Accreditation}

In 1996, the Australian Dental Council (ADC) conducted the first accreditation round of dental schools in Australia after the General Dental Council (GDC) system was abandoned. The last British GDC accreditation visit to Adelaide occurred in the 1970s when two senior British academics, Professors Darling and Hopper, visited the School. The story goes that the visit was timed to co-incide with the Adelaide cricket test between Australia and England and the quality of the report was not greatly helpful to the School in terms of providing a well-informed, critical review of its curriculum. It seemed that these visits had become more of a 'tick the box' exercise than a worthwhile educational process.

\section{A new Problem-Based Learning BDS curriculum}

During 1991 and 1992, many meetings were held to plan a new BDS curriculum. The dean, Vivian Burgess, and the associate dean (academic), Grant Townsend, met with the heads of other non-dental departments to explain what was planned and to invite them to participate in the new curriculum.

A new PBL-based curriculum was introduced to the first year of the BDS programme in 1993 and then incrementally, one year at a time over five years. A considerable amount of planning went into this major revision of the BDS programme and many publications and presentations were made before, during and after its implementation with a view to evaluating its effectiveness.

The term Problem-Based Learning (PBL) has been interpreted in many different ways. In Adelaide, it was decided to use Dental Learning Packages (DLPs) to provide 
students with exposure to clinically relevant problems, preferably before they were exposed to formal study or reading. Over time, this approach was modified as it became very difficult to timetable activities so that the DLPs always preceded more formal class meetings. Essentially the DLPs involved exploration of a new situation, followed by interpretation of what was going on and the development of a list of problems or issues. The possible causes and consequences of these problems were then explored and further information that might be needed to refine the causative hypotheses clarified. This then led to the development of learning issues or research questions that were explored either individually or in groups.

The steps in a DLP mirrored those in the clinical process, as well as the scientific research method.

Table 5.1 Link of DLP steps to clinic and scientific methods.

\begin{tabular}{|c|c|c|}
\hline Clinic steps: patient attending & DLP steps: DLP patient & Scientific research method \\
\hline $\begin{array}{l}\text { 1. Obtain history/examination } \\
\rightarrow \text { list issues }\end{array}$ & $\begin{array}{l}\text { 1. Key information } \rightarrow \text { list of } \\
\text { priorities to consider }\end{array}$ & $\begin{array}{l}\text { 1. Key information } \rightarrow \text { define } \\
\text { the problem }\end{array}$ \\
\hline $\begin{array}{l}\text { 2. Develop explanations } \\
\text { - provisional diagnoses } \\
\text { - provisional prognoses }\end{array}$ & $\begin{array}{l}\text { 2. Suggest explanations } \\
\text { - possible reasons } \\
\text { - possible effects }\end{array}$ & $\begin{array}{l}\text { 2. Develop hypotheses } \\
\text { - explanations and causes } \\
\text { - implications and conse- } \\
\text { quences }\end{array}$ \\
\hline $\begin{array}{l}\text { 3. Further information needed? } \\
\text { - e.g. further history; radi- } \\
\text { ographs, other diagnostic } \\
\text { tests; consult colleagues, } \\
\text { literature search re un- } \\
\text { familiar condition, new } \\
\text { treatment options }\end{array}$ & $\begin{array}{l}\text { 3. Further information needed? } \\
\text { - e.g. further history; radi- } \\
\text { ographs, other diagnostic } \\
\text { tests; consult colleagues, } \\
\text { literature search, other } \\
\text { learning classes (e.g. lab } \\
\text { session, clinic, Class } \\
\text { meeting) }\end{array}$ & $\begin{array}{l}\text { 3. Further information needed? } \\
\text { - further facts about obser- } \\
\text { vations } \\
\text { - what is currently known - } \\
\text { literature search and review }\end{array}$ \\
\hline $\begin{array}{l}\text { 4. Learning needs } \rightarrow \text { research } \\
\text { questions }\end{array}$ & $\begin{array}{l}\text { 4. Learning needs } \rightarrow \text { research } \\
\text { questions }\end{array}$ & $\begin{array}{l}\text { 4. Learning needs } \rightarrow \text { research } \\
\text { questions }\end{array}$ \\
\hline $\begin{array}{l}\text { 5. Obtain, analyse and apply } \\
\text { information } \rightarrow \text { definitive } \\
\text { diagnosis } \rightarrow \text { treatment options } \\
\rightarrow \text { discuss with patient }\end{array}$ & $\begin{array}{l}\text { 5. Develop search strategy; } \\
\text { collect, analyse and interpret/ } \\
\text { apply data } \rightarrow \text { test suggested } \\
\text { explanations for patient } \rightarrow \text { class } \\
\text { summary }\end{array}$ & $\begin{array}{l}\text { 5. Design research study; } \\
\text { collect, analyse and interpret/ } \\
\text { apply data } \rightarrow \text { test hypotheses } \rightarrow \\
\text { publish results }\end{array}$ \\
\hline $\begin{array}{l}\text { 6. Reflect and evaluate } \\
\text { - strengths, limitations, } \\
\text { improvements and further } \\
\text { learning and development }\end{array}$ & $\begin{array}{l}\text { 6. Reflect and evaluate } \\
\text { - strengths, limitations, } \\
\text { improvements and further } \\
\text { learning and development }\end{array}$ & $\begin{array}{l}\text { 6. Reflect and evaluate } \\
\text { - strengths, limitations, } \\
\text { improvements and further } \\
\text { learning and development }\end{array}$ \\
\hline
\end{tabular}


A key point to make in relation to the process of introducing the 1993 BDS curriculum is that it was initiated by dental academics for educational reasons and was based on existing evidence for best practice in dental education. The existence of a separate Faculty of Dentistry certainly facilitated the process and it would be fair to say that such a major change to the curriculum, with its financial implications, would be much more difficult in today's climate. In the early 1990s there was a sense of real excitement and anticipation to be initiating such an innovative new programme.

The account provided in this text about the 1993 BDS new curriculum is drawn mainly from the book Problem Based Learning in Dentistry: The Adelaide Experience by Gerry Mullins et al. (2003), as well as papers published in various journals (for example, Winning \& Townsend 1998; Greenwood et al. 1999a, b; Winning \& Townsend 2007).

Some of the changes that were eventually made to the Adelaide BDS course in 1980, even though recommendations had been made in 1974, have been detailed in a previous chapter. These changes included the introduction of dental subjects early on in the course, the development of topic courses and the introduction of a general dental practice subject in the later years. However, as tends to be the case, not all of the original proposals for curriculum reform that were commenced in 1980 actually came into being. Refinements were made over the years but these tended to involve inclusion of more material rather than reductions. This led to a very overcrowded curriculum and one that lacked balance by the time the 1990s were reached.

The heavy contact hours for different subjects in the first three years of the BDS programme in 1992 are shown below.

Table 5.2 Contact hours of Adelaide BDS course in 1992 - first three years (Townsend \& Burgess 1993). These figures are based on a keynote address by Townsend at the Australasian Association of Schools in Dentistry, Adelaide, September, 1992. The high number of hours spent in conservative dentistry and removable prosthodontics reflects the fact that students spent considerable time in the teaching laboratories.

\begin{tabular}{|l|c|}
\hline Subjects & Contact hours (approx.) \\
\hline First Year & 182 \\
\hline Behavioural science & 78 \\
\hline Genetics & 58 \\
\hline Medical physics & 64 \\
\hline Organic chemistry & \\
\hline
\end{tabular}




\begin{tabular}{|c|c|}
\hline Anatomy and histology & 106 \\
\hline Biology & 156 \\
\hline Dental science & 90 \\
\hline Total & 734 \\
\hline \multicolumn{2}{|l|}{ Second Year } \\
\hline Biochemistry & 98 \\
\hline Regional anatomy & 104 \\
\hline Systematic histology and embryology & 91 \\
\hline Human physiology & 130 \\
\hline Dental care & 130 \\
\hline Conservative dentistry & 104 \\
\hline Dental science & 78 \\
\hline Total & 735 \\
\hline \multicolumn{2}{|l|}{ Third Year } \\
\hline General pathology & 81 \\
\hline Microbiology and immunology & 44 \\
\hline Human physiology and occlusion & 78 \\
\hline Pharmacology and therapeutics & 84 \\
\hline Oral pathology & 53 \\
\hline Conservative dentistry & 208 \\
\hline Removable prosthodontics & 202 \\
\hline Dental materials science & 78 \\
\hline Periodontology & 104 \\
\hline Oral diagnosis and dental radiology & 24 \\
\hline Pain control & 20 \\
\hline Orthodontics & 13 \\
\hline Total & 989 \\
\hline
\end{tabular}




\section{Some reasons for change}

Apart from the overcrowded nature of the curriculum, several other factors led staff to consider revising the BDS curriculum.

These other factors included:

- $\quad$ an explosion of knowledge in the biodental and biomedical sciences that generated new philosophies and controversies in patient care

- major changes in oral health in the Australian community, with marked reductions in dental caries in younger children but an increase in middleaged and elderly patients requiring dental care, as well as medically compromised patients

- $\quad$ significant technological advances, including new restorative and implant materials that provided a broader range of treatment options

- $\quad$ an increased focus on, and a greater understanding of, student learning

- major advances in the field of teaching methodology, including the availability of computer-assisted learning (CAL) and multimedia technology

- consistent negative feedback from students about the balance of the existing BDS course, with complaints about too many contact hours, duplication of material and lack of relevance of material.

\section{Broad goals of the new BDS curriculum}

The broad goals of the new BDS curriculum (1993 version) were:

- to develop a more flexible curriculum structure that could respond more rapidly to developments in the science and practice of dentistry.

- to provide a core experience to all students, with the addition of options (referred to as 'Selectives') that would enable each student to customise their degree course to some extent. It was thought that this was important given the increasing numbers of international students who would return to their own countries after graduation where dental needs were likely to differ to those in Australia.

- to reduce the number of formal contact hours for students and to provide more opportunities for self-directed, experiential learning throughout the course.

- to facilitate greater opportunities for contextual learning and a greater integration, balance and flow of basic and applied science material throughout the programme. 
There was a deliberate decision to move away from the traditional model of dental education where most of the basic and applied science subjects are presented in the early years of the course, followed by the clinical subjects in the later years. In this traditional model, the basic and applied science topics are often not reinforced later, when the students are in the clinics and when their relevance would be more apparent.

It was decided to introduce Problem-Based Learning throughout the course, so that the students would be required to integrate material and apply their knowledge and also to develop their skills in clinical reasoning and communications. It was also intended to make greater use of advanced educational technology, including computer-assisted learning. Most importantly, there was a key aim to develop a course that students would find stimulating and enjoyable, as well as one that engendered a desire for lifelong learning. The desire was to produce graduates who could practise as 'oral physicians', with the ability to communicate effectively, self-evaluate, diagnose and formulate treatment plans of varying complexity, as well as provide a range of treatment procedures for their patients.

The degree to which all of these aims were achieved is open to debate but there are many indications that the outcomes of this major change in the BDS curriculum were positive overall. Indeed, Adelaide was the second dental school to move to a PBLbased programme, following Malmö in Sweden. This early adoption of PBL and the extensive evaluation of the outcomes of the new curriculum have led to the Adelaide Dental School being recognised as a world leader in dental education as evidenced by the large number of invitations to staff to present keynote presentations at national and international conferences and to act as consultants at dental schools around the world.

\section{The process of curriculum review in the 1990s}

It is of interest to reflect on the process that was undertaken to review the BDS curriculum back in the early 1990s. Following endorsement of the major objectives of the review by the Faculty of Dentistry, a series of curriculum workshops was held at which there were participants from all of the different stakeholders.

At the request of the Curriculum Co-ordinating Committee, the head of the Department of Dentistry, Viv Burgess, wrote to all of the departments in the university that were providing courses for dental students. This correspondence provided information about the review process and asked for feedback. Based on the information

gathered by this process, working groups of the Curriculum Co-ordinating Committee considered alternative models for the new BDS curriculum that could enable the broad objectives to be met.

The various options considered included:

1. the possibility of a Bachelor of Health Science degree followed by a dental degree 
2. a 'general' first year of study followed by four years leading to a BDS degree, in which students could be selected either before or after the first year

3. a five-year course consisting of fully integrated streams in each year which would replace the large number of subjects that at the time were separately presented and examined.

Although the Curriculum Co-ordinating Committee noted some benefits in moving to a postgraduate model — for example, a dental degree following a BSc or BHSc degree - it considered that this option was still some years away. At this time there were moves to make medicine a postgraduate degree programme at the University of Sydney, University of Queensland and Flinders University. However, the dean of medicine at the University of Adelaide had stated that he would prefer to see how the new model progressed elsewhere before making major changes at Adelaide. As it turns out, the dental schools in Sydney, Melbourne and Perth have all since moved to graduate-entry models.

\section{The model for the new BDS curriculum - 1993}

Eventually, the Curriculum Co-ordinating Committee adopted a model with a small number of integrated 'streams' replacing the existing large number of separate subjects. These streams were designed to be integrated both horizontally and vertically. There was also a reduction in formal contact hours and improved co-ordination in the presentation and assessment of material. A key feature of the new programme was that students were introduced to dental scenarios (in the form of PBL dental learning packages, abbreviated to DLPs) from day one at Dental School, and they had handson experience in the clinics during their first year. These were major changes from the previous traditional model of dental education.

Another important change in terms of management of the course was that staff from the Dental School now co-ordinated all of the streams in the new programme, including being responsible overall for assessment. This did not mean that dentistry staff took on all of the teaching and assessment themselves. Active participation by staff from other non-dental departments was encouraged, and there continued to be input from staff to the relevant streams from many other departments, including physics, genetics, anatomy, physiology, pharmacology and pathology. But there were no longer separate subjects run by non-dental departments. The Dental School had assumed control of its BDS curriculum and its educational philosophy now ran throughout the entire course.

After the Faculty of Dentistry accepted the general structure of the proposed new BDS curriculum in 1991, meetings were held with teachers from all of the non-dental departments that presented subjects to dental students and a more detailed outline was developed. 


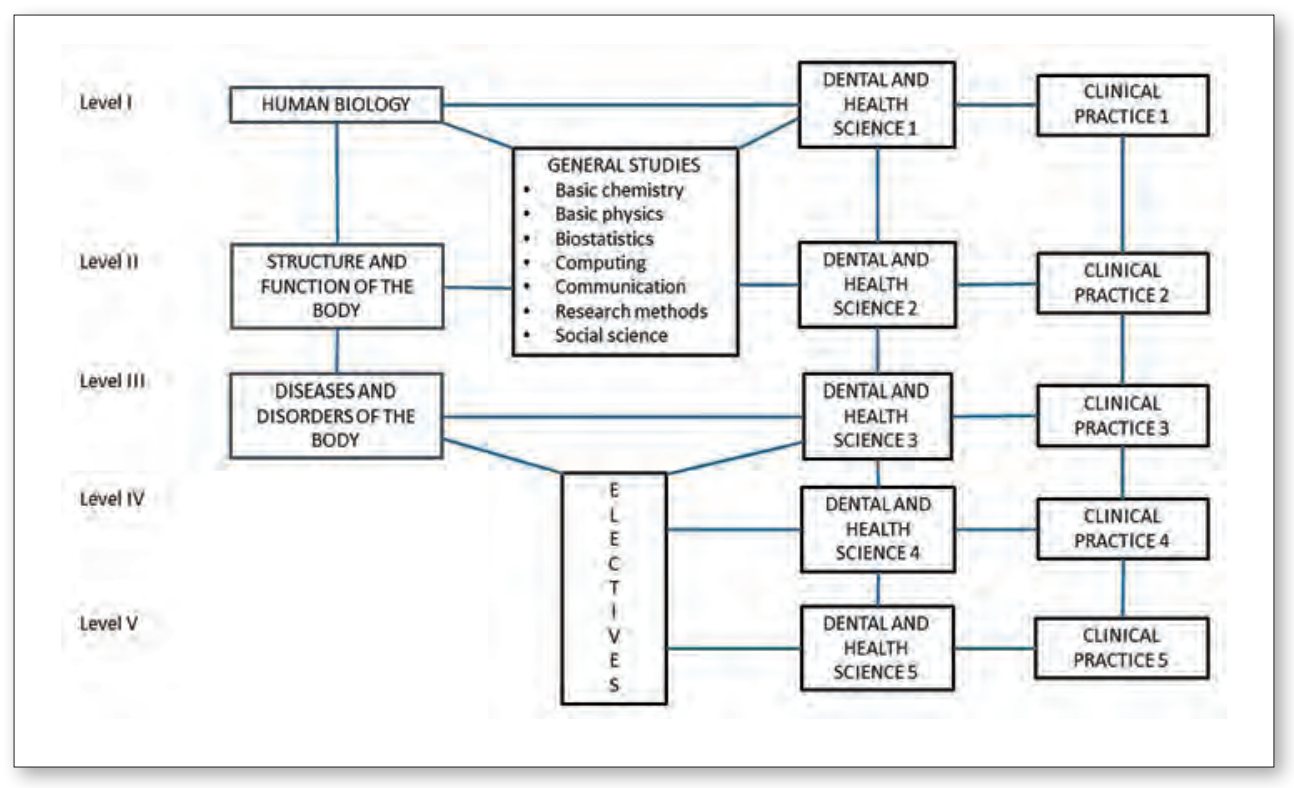

Figure 5.4 Major streams proposed in the 'new' Adelaide BDS curriculum and their relationship to each other (Townsend and Burgess 1993, p. 241, courtesy of Australian Dental Journal).

\section{Features of the PBL BDS curriculum}

More detailed features of the new PBL BDS curriculum are listed below.

- There was an approximately equal distribution of contact hours between the different streams, with seven hours per week for each of the major streams, giving a total contact time of twenty-one hours per week (plus a General Studies stream).

- The proposed model in First Year had an emphasis on Problem-Based Learning and self-directed learning and included class meetings (a term preferred to 'lectures'), tutorials and learning laboratories. The Clinical Practice stream included clinic, laboratory and tutorial sessions.

- Academic staff from either dental or non-dental departments presented particular aspects of the different streams, but the overall co-ordination of each stream became the responsibility of dental staff. The key co-ordinating staff (referred to as 'stream co-ordinators') were supported by a team of academics who taught in each stream, as well as professional staff within the School. This local professional staff support within the School ceased with the implementation of the Professional Services Review in 2016, an administrative decision that led to the centralisation of professional staff within the Faculty of Health and Medical Sciences. 
- Assessment was co-ordinated by stream co-ordinating committees and linked to the objectives of the stream to provide a more co-ordinated approach.

In a paper in the Australian Dental Journal, Townsend and Burgess provided some observations about the process undertaken (1993). They noted that an existing faculty/departmental structure can either facilitate or cripple curriculum review. The Dental School in Adelaide had moved to a single department structure in 1984 and the authors stated that they believed that this enabled the curriculum review process to occur quite rapidly. The time interval from planning to implementation was only two years. Nevertheless, not all staff supported the move to a single department and this did affect the extent to which the curriculum changes could be implemented, particularly in the later years of the programme. This is discussed further in the section on the revised BDS curriculum (2010 version).

The prevailing attitudes toward the introduction of innovative curricula were quite positive within the university in the early 1990s. There was a concentration on academic arguments for curriculum change in dentistry, with support sought initially for the general objectives; subsequently, ways in which these objectives could be met were explored.

Every effort was made to provide opportunities for broad input into the review process from the beginning. There was a unity of purpose from the Department of Dentistry with strong support and advocacy from the head, and this united front underpinned discussions with non-dental departments which were difficult at times.

Townsend and Burgess (1993) noted that any discussions about curriculum content can ultimately become very personal. Most academics think that what they teach is very important and they are usually not keen to 'give up time' allocated to their particular area of interest. This is especially so if it appears that someone else is going to 'pinch' the time for their topic. It is also common for academics to resort to the argument that they are the expert in their particular discipline and therefore they must know what is best for that subject.

In the 1993 revision, a structure was developed that removed all of the existing subjects from the curriculum. In this sense, everyone was disenfranchised. No-one was left with their own little patch and so there was a tendency to concentrate on the broader issues. This strategy was particularly relevant in dealing with the non-dental departments that had previously run their own separate subjects for dentistry students, often combined with other student groups.

Townsend and Burgess noted that it is very important for dental schools to have control of their own undergraduate curricula. In saying this, they acknowledge that this does not mean that dental staff should teach everything. They observed that it is important to have input from other non-dental departments, but stressed that it is unacceptable to require dental students to undertake subjects provided by other 
departments when the Dental School might be unaware of what is in the course or how the dental students are being treated.

It is clear that the success or otherwise of any curriculum relates to the commitment and ability of the teaching staff and the Adelaide Dental School has been fortunate in building a strong staff profile over the years.

It is important to acknowledge that the process was not without its costs, both financially and on staff. It had been assumed, rather naïvely in retrospect, that the finances that flowed to non-dental departments for teaching dental students would be returned to the Dental School when dentistry staff took over most of the teaching, including administration and assessment. However, this never occurred.

One of the key issues with major curriculum change is whether momentum can be maintained. Unfortunately, the momentum built in the first three years did not extend into the final two years of the BDS programme, which tended to run in a more compartmentalised fashion.

\section{Dental Learning Packages}

Dental Learning Packages (DLPs) formed the foundation of the 1993 new BDS curriculum, providing an overall philosophy of Problem-Based Learning throughout the curriculum. That is not to say that all good ideas translate smoothly and effectively into practice.

It is always sobering to receive feedback from students about their perceptions of new curriculum initiatives and the following comments from one of the students in Probe (1997) about the new curriculum were both humorous and worthy of reflection.

\section{D.L.P. (DAM LONG-WINDED PROCESS)}

Five years ago, the 1993 first years were introduced to the 5-year BDS course and were soon informed that the dental faculty had introduced a new, updated curriculum. Initially, this was greeted by [sic] much excitement and joyfulness (especially as the contact hours had been decreased by about half). Over the proceeding five years we were subject to all the new ideas that were proposed in the new curriculum.

As usual when anything new comes along, every man (and woman) and his dog wants to get involved and put across their ideas, and we were definitely subject to that. 
Over the years we've been made to fill out those forms which try to evaluate the course so that they can make improvements for future years. Usually these are done at the end of lectures and are filled out in haste and not much thought is put into them (we are also all too nice to say what we really think because they really do have everyone's writing style 'on file' and do know who writes what. (N.B. despite introducing the title 'class meeting' rather than 'lecture' in the new curriculum, the old term still lived on largely because the style of teaching of some staff did not change.)

THIS IS what we really think!

- Dental Learning Packages (need we say more!?)

- Self-assessment process and the amount of criteria you're supposed to use (they might have it right by the time we are finished).

- $\quad$ Self-directed learning (we pay HECS fees so someone can direct us to look up books and learn it ourselves)

- Journals of Reflection (if you didn't know, most of us filled them out the night before we had to hand them up and made most of the stuff up, anyway.

Fortunately, the comments of this rather cynical student were not reflected in the overwhelmingly positive feedback from the first class to graduate from the new curriculum in 1997. But they do highlight the need for staff always to appreciate that students form their own perceptions of the learning environment and the learning processes that are being encouraged within a curriculum and then they will develop their own approaches to coping with that environment.

\section{Evaluation of the BDS curriculum}

Chapter 8 of the book Problem Based Learning in Dentistry: The Adelaide Experience provides a summary of the process that was followed to evaluate the new PBL-based Adelaide curriculum. The chapter summarises one of the few examples worldwide of where a rigorous and comprehensive approach was used to evaluate outcomes from an entire new five-year dental curriculum. Although many evaluations have been published about outcomes of new initiatives in discrete subjects or topics from various dental schools, the evaluation carried out at the Adelaide Dental School during the 1990s and early 2000s still stands out in dental education literature. 
Mullins and colleagues have pointed out that there is a certain irony in the fact that innovative approaches to a curriculum are challenged to demonstrate that they are effective in achieving their desired goals, whereas conventional approaches to teaching are generally not subjected to the same scrutiny (2003). Nevertheless, proponents of PBL have risen to the challenge and there is now an extensive literature on the evaluation of PBL programmes, although, as mentioned above, few of these span a whole curriculum.

Evaluation is necessary as a quality control measure at all stages of a curriculum, but it is particularly important at the beginning and the end. At the beginning it is essential to determine what issues the new or revised curriculum is aiming to address and, at the end, it is very important to determine whether the curriculum is producing graduates who have achieved the desired learning and curriculum goals (although this latter evaluation is rarely done).

Prior to the 1990s there were a few publications relating to evaluation of the Adelaide BDS curriculum and its graduates. Smales (1977) reported in the Australian Dental Journal that First Year graduates were finding practice management difficult and were also experiencing difficulties in managing interpersonal relationships. There were also reports of lack of competence in several clinical skills. Cannon and Makinson (1983) also reported the results of surveys in the Australian Dental Journal indicating that Adelaide graduates lacked understanding of community and individual attitudes to dental care, lacked an ability to develop rapport with patients, and had difficulties in administering a practice efficiently.

Prior to the introduction of the new BDS curriculum, a seventeen-item questionnaire was administered to students in the first year of the 'old' curriculum and then repeated in 1993 and subsequently for First Year students in the 'new' curriculum. The replies indicated that there was:

- a more acceptable workload

- a better balance between theory and practice

- clarification among staff of their teaching roles

- $\quad$ improved staff/student relationships for students

- a significant improvement in perceived clarity of assessment criteria

- resolution of a frequent criticism of the 'old' course that there were too many topics.

Other evaluation methods that were used to assess the Adelaide PBL course were:

- $\quad$ questionnaire surveys of final-year students from 1992 onwards addressing competence in various areas

- comparison of Adelaide graduates with those from a conventional dental course at Toronto 
- $\quad$ surveys of academic staff teaching final-year students comparing graduates of the new and old curricula

- $\quad$ analysis of journals kept by graduates in their first six months of professional practice

- $\quad$ surveys of graduates and their employers in the first twelve months of practice.

While there were many positive outcomes identified from this comprehensive evaluation of the new PBL curriculum, there were also many areas where further improvements were still clearly needed. Some of these are discussed in Chapter 6.

One aspect of the 1993 curriculum that built on earlier proposals of the 1970s was the introduction of electives, or Selectives, as they were termed. However, there were some difficulties that arose in terms of the types of topics that were considered to be acceptable for students to undertake, and also whether or how they should be assessed. Indeed, formally recognised Selectives were removed from the BDS curriculum in the 2010 revised version. Recently, however, the university has circulated a new policy stating that all undergraduate programmes must have at least nine units of broadening electives across the programme that must be outside the discipline (in the BDS, this would equate to approximately nine weeks) — so the Dental School will need to assess this policy to consider how it should proceed.

\section{Admission to the BDS course}

Up until 1996, admission to the BDS course had been on the basis of secondary school academic achievement (more recently referred to as a TER or ATAR score) for school leavers or on the basis of previous tertiary achievement for non-school leavers (Credit level). There was a quota in place that was discussed (usually robustly) each year at a Faculty of Dentistry meeting when the number of new students was set for the following year. There were always more applicants than places and, because of the competitive nature of the process, school leavers required high aggregate marks to be accepted.

In the 1980s, staff and members of the dental profession began to raise concerns about the process of admission being based only on prior academic results (Cannon \& Makinson 1983). Although the students in the BDS course all had strong previous academic records, there was a high failure rate in the early years of the programme. It was suggested that an admission interview could improve the process, with an assessment being made of various attributes, including motivation to study dentistry.

With the implementation of a new PBL-based BDS curriculum in 1993, and in concert with changes in the admissions process being sought by the Faculty of Medicine, the Dental School moved to introduce a new admissions process in 1996 for entry in 1997 . The overall aim of this new process was to select applicants who were 
highly motivated to study dentistry and who displayed attributes that would enable them to succeed in a PBL environment and in dental practice after graduation.

Specific reasons for wanting to change the selection process into dentistry were:

- It was believed that motivation to become a dentist should be an important selection criterion. The South Australian Tertiary Admissions Centre (SATAC) system had led to a large proportion of First Year dental students being 'second preference dentists' whose first preference was to study Medicine.

- There was a need for dental students to possess good problem-solving abilities, logical reasoning and communication skills.

- The ever-increasing cut-off score for entry was resulting in a 'bunching effect', with many applicants all ranked together on very high matriculation scores. Many applicants with high matriculation scores were not successful in their applications.

- In a course such as dentistry, with its high costs, withdrawal or failure of only a few students leads to significant resource implications (Mullins et al. 2003).

In the 1990s there was a growing body of evidence to support alternative systems of selecting students into health professional courses. The Faculties of Medicine and Dentistry followed the model that was already in place at the University of Newcastle.

The new selection process was based on three components:

1. performance in a written test referred to as UMAT (Undergraduate Medical and Health Sciences Admissions Test)

2. performance in a structured interview (oral assessment) for the top performers in the UMAT

3. achievement of a final high school result in the tenth percentile for school leavers or a Credit-level average for tertiary transfer students.

Although medicine has modified its admissions process over the years since the new three-step process was introduced, the Dental School had, until the process was taken over recently by the Faculty of Health and Medical Sciences, retained a system that was very similar to the original version for admission to the BDS programme. There has been pressure placed on the university to abandon the interview system for medicine but there have been relatively few complaints relating to dentistry.

Key findings of a PhD thesis by Dr Dimitra Lekkas (2009) relating to the characteristics and performance of students in the BDS programme after the introduction of the new admissions process were:

- Most of the students entering the programme had chosen dentistry as their first career choice, contrasting with applicants under the previous system. 
- Achieving good secondary school academic results, having previous educational experience and being a local (Australian) student predicted good academic performance in the first year but not in subsequent years.

- Performance on an admission interview had some predictive ability for subsequent academic success.

When the $\mathrm{BOH}$ was introduced in 2002, a similar method of selection was used for its applicants, although changes have been made subsequently, including dropping the UMAT as a requirement.

The topic of what is the best approach for selecting medical and dental students continues to provoke controversy, with the different methods each having advantages and disadvantages (Lekkas 2009).

\section{SUE TAJI}

Year of graduation

1999

Career since graduation

Federal Vice President ANZSPD 2015-current Federal Secretary AAPD 2013-15 Federal Councillor (Qld) ANZSPD 2012-current Paediatric Dental Specialist 2010-current Dental Conference Organiser 2005-current General Dental Practitioner (Private Practice) 1999-2007

\section{Current position}

Director, Queensland Dental Group for Kids Federal Vice President ANZSPD 2015-current Federal Councillor (Qld) ANZSPD 2012-current Paediatric Dental Specialist 2010-current

How well did my education at the Adelaide Dental School prepare me for my future career?

Looking back over the time that has elapsed since graduation highlights the solid foundations the Adelaide Dental School provided in shaping my career path. Having completed various undergraduate dental research projects encouraged diversification and established strong links with the research teams involved. Fundamental to what one learns at university is the underlying premise that those who graduated yesterday, who stop 
taking note of changes within their profession today will be out of touch by tomorrow. Much of the undergraduate training at the Adelaide Dental School emphasised this and inspired me to pursue further education in the form of dental specialisation in the field of paediatric dentistry and continue beyond this with conferences, specialist dental societies and continuing professional development. Reflecting back on the five years spent as an undergraduate dental student at the University of Adelaide Dental School, I always consider these to have been a wonderful few years primarily because of the unified and positive approach that the professors, clinical and research staff took to developing and empowering the next generation of clinicians. Such a positive and encouraging approach in turn created a cohort each year of like-minded clinicians, researchers and health professionals to promote the better good of oral health and society in general.

NORMALIZA AB. MALIK

Year of graduation

1998

Career since graduation

Dental Officer, Dental Specialist, Senior Lecturer

\section{Current position}

Senior Lecturer, Conservative Dental Specialist

I am really pleased and honoured to have been given the opportunity to contribute some comments as part of the book currently being put together to celebrate 100 years of education at the Adelaide Dental School. Adelaide Dental School certainly provided me and, I believe, many others, with a solid foundation for our career. The School has prepared me really well to equip myself with the knowledge and clinical expertise required to be a successful dental practitioner. Obtaining a Bachelor of Dental Surgery (BDS) degree from the prestigious Adelaide Dental School of the University of Adelaide 
had always been my childhood's dream. The School also provided me with valuable experience and benefits which I draw upon even in my present career. In addition, the engaging campus life experience helped me a lot in preparing me, both physically and mentally, to render my services to the society. Ours was only the second batch of the then newly introduced dental curricula, namely, Problem-Based Learning (PBL). PBL is a process of education and learning that enabled me to view things out of the box. Problem solving and being independent, besides being taught and groomed to be able to communicate and discuss issues, are all assets which I apply in dealing with working environment today. The teaching and coaching by the experienced and caring lecturers and staff of the Adelaide Dental School exposed me to new ideas, and most importantly prepared me to excel in my chosen career. I learned about good time management, seeking proper information and handling tasks. I also benefited a lot from self-assessments, held from time to time, during the practical session. The process enabled me to self-assess my daily work and build my confidence over the years. More, the Australian education taught me to become involved in the community, and it inspired me to make a contribution back to communities, particularly in my home country, Malaysia.

In conclusion, the BDS degree obtained from the University of Adelaide was a stepping stone to my present career in dentistry. Overall, it was an extremely precious educational experience provided by the Adelaide Dental School, made possible by the opportunity given by the Malaysian Government. I would like to thank all who have helped me progress and excel in my career, especially my lecturers for their support, patience and dedication. 


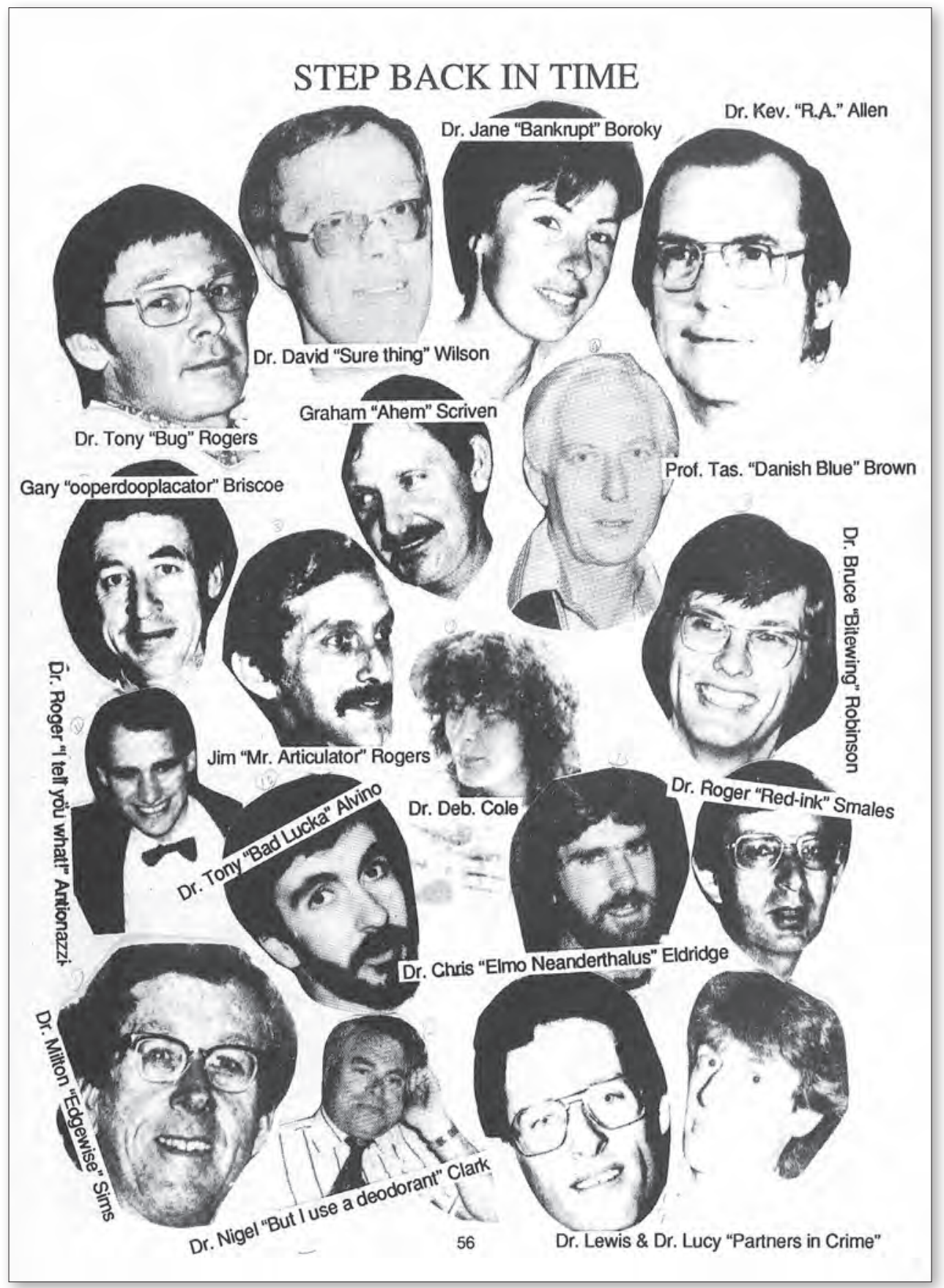

Figure 5.5 Some of the Dental School staff in the 1990s (Probe 1991, courtesy of AUDSS). 


\section{References}

Burgess VB (1995) Dean's report. Probe: 6.

Cannon RA, Makinson OF (1983) Dental education at the University of Adelaide: An evaluation. Australian Dental Journal 28:143-148. https://doi.org/10.1111/j.1834-7819.1983. tb05269.x.

Greenwood F, Mullins G, Townsend G, Wetherell J, Winning T (1999a) Evaluation of the performance of graduates from a PBL dental course. In: HERDSA Annual International Conference Proceedings, 'Cornerstones: What do we value in higher education?' Melbourne, pp. 1-13.

Greenwood F, Townsend G, Wetherell J (1999b) Self-perceived competency at graduation: A comparison of dental graduates from the Adelaide PBL curriculum and the Toronto traditional curriculum. European Journal of Dental Education 3:153-158. https://doi. org/10.1111/j.1600-0579.1999.tb00085.x.

Lekkas D (2009) Becoming a dentist: Characteristics, experiences and performance of students in the early years of the Adelaide dental course. PhD thesis, University of Adelaide, Adelaide.

Mullins G, Wetherell J, Townsend G, Winning T, Greenwood F (2003) Problem-Based Learning in dentistry: The Adelaide experience. David Lovell Publishing, Ringwood.

Smales RJ (1977) The Adelaide undergraduates dental curriculum: An appraisal by recent graduates and final-year students. Australian Dental Journal 22(1): 23-26. https://doi. org/10.1111/j.1834-7819.1977.tb04439.x.

Spencer AJ (1990) Dean's report. Probe: 7.

Townsend G, Burgess V (1993) New curriculum developments at the University of Adelaide. Australian Dental Journal 38: 238-242. https://doi.org/10.1111/j.1834-7819.1993. tb03071.x.

Winning TA, Townsend GC (1998) Problem-based curricula and dental education: Facilitating change for teachers and learners. European Journal of Dental Education 2: 143-148. https:// doi.org/10.1111/j.1600-0579.1998.tb00050.x.

Winning T, Townsend G (2007) Problem-Based Learning (PBL) in dental education: What's the evidence for and against ... and it is worth the effort? Australian Dental Journal 52: 2-9. https://doi.org/10.1111/j.1834-7819.2007.tb00458.x. 


\section{6}

\section{A revised integrated BDS curriculum and a $\mathrm{BOH}$ programme - 2000s to the present}

Quo vadis, dentistry? (Where are you going, dentistry?)

Over the past fifteen years or so there has been an increasing tendency for universities in Australia and around the world to move to a more corporate style of management. The University of Adelaide is no different and the effects of this move have been felt by the Dental School in many ways. Rather than comment at length about the many changes that have occurred under this increasingly corporate style, and their impact on the Adelaide Dental School, in this chapter we briefly describe some important events as dispassionately as possible. Readers are left to make up their own minds about what this all means for the future of dental education and dentistry in general. A paper by Orr and Orr (2016) entitled The Death of Socrates: Managerialism, Metrics and Bureaucratisation in Universities is recommended for those who wish to explore this topic further.

\section{The context of the School}

Vivian Burgess, in his Dean's report in Probe 2000, pointed out that national surveys among new graduates and employers had, for the third year in succession, ranked the Adelaide Dental School highest in Australia and amongst the highest of all university programmes generally. The Teaching and Learning portfolio produced by the School was ranked first within the University of Adelaide and the School received a \$25 000 award from the deputy vice-chancellor, education. 
Restructuring of the graduate programmes in the School continued in 2000, with the introduction of the doctorate in clinical dentistry. This was a first for Australian dental schools. The School was also involved in fostering a series of international development projects, including the redevelopment of dental services in East Timor.

The Foundation Dental Studies Unit, which was formed in 1999, extended the scope of the graduate certificate and graduate diploma programmes offered by the School and there were more than eighty dental graduates from around Australia enrolled in these programmes in 2000 and taking them by external study.

In 2001, the number of graduate students within the School rose to seventythree, a record high. This led to the formation of a Graduate School led by an associate dean. In his Probe 2001 report, Dean Burgess also pointed out that the Adelaide Dental School had the largest number of international students of any dental school in Australia.

\section{Joint ventures}

By the mid-2000s, the Dental School had managed to implement some of the initiatives in the original $\mathrm{ACOH}$ (or $\mathrm{AIOH}$ as it became known) package. For example, a Joint Operating Agreement was signed with SADS for the running of the Adelaide Dental Hospital. However, this was not renegotiated when it lapsed. Opportunities arose for the commercialisation of curriculum material and the School's curriculum was sold to Sharjah for $\$ 5$ million. The Health Education, Development and Innovation (HEDI) Unit was formed to package curriculum materials for Sharjah but it closed in 2012. A joint venture was initiated with the University of Tasmania to enable Adelaide students to receive some of their education in Tasmania, but it, too, was not renegotiated, and other universities are now involved.

\section{Staffing matters}

Professor Mark Bartold was appointed as the director of the Colgate Australian Clinical Dental Research Centre in 2001. Bartold graduated from the Adelaide Dental School in 1978 and had been professor of periodontology at the University of Queensland prior to his appointment.

Several staff retired at the beginning of 2002. They included Associate Professor David Wilson, Dr David Parker and Dr Thomas Wilkinson. Mr Gary Briscoe, one of the School's teaching technicians, also retired in 2002.

Following the resignation in 2005 of Vivian Burgess, who had been the dean of the School for twelve years, Lindsay Richards became dean for a short period before Johann de Vries was appointed as full-time dean in 2006. De Vries had been the dean at the University of Manitoba and was the first dean of the School to be appointed from 


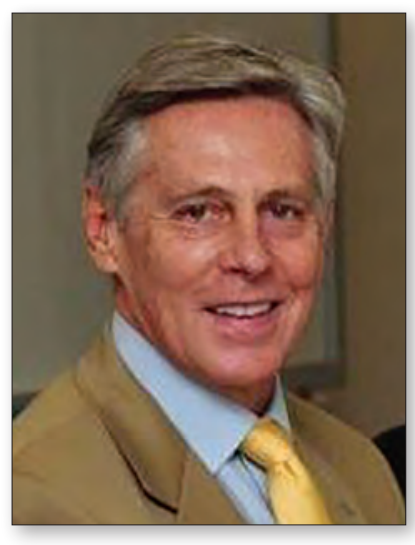

Figure 6.1 Johann de Vries.

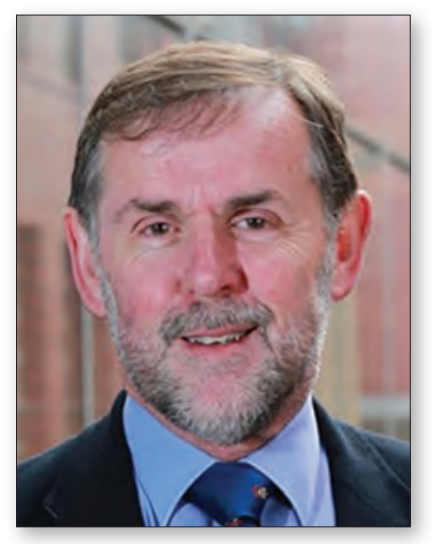

Figure 6.2 Lindsay Richards.

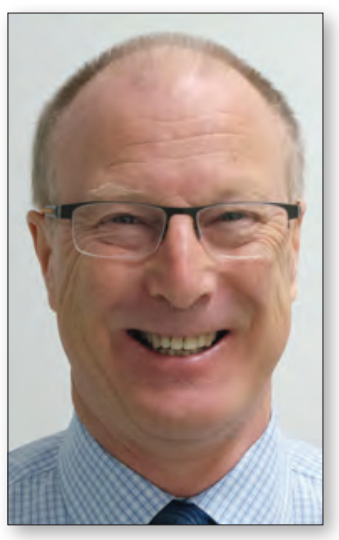

Figure 6.3 Craig Dreyer.

outside the University of Adelaide with a role that was mainly managerial, without teaching responsibilities. He served as dean for seven years before leaving to take up a post in Qatar. After de Vries's departure, Kaye Roberts-Thomson served as interim dean from 2013-15 before Lindsay Richards was appointed dean in 2016 for a fiveyear term following an international search.

\section{Loss of professorial positions}

During the past decade, several professors in the Dental School have retired, with all of them transitioning to emeritus or honorary roles, including Vivian Burgess, John Spencer, Alastair Goss, Wayne Sampson, Kaye Roberts-Thomson, Mark Bartold and Grant Townsend. In addition, Johann de Vries resigned and is currently in Qatar, while Gary Slade resigned from his professorial position in ARCPOH to take up an appointment in North Carolina, USA.

Only two new professorial appointments have been made during this time, namely Marco Peres (who has resigned recently) and Craig Dreyer (following on after Wayne Sampson as the PR Begg Professor of Orthodontics). Others who have been promoted to Level E (professorial level) are Richard Logan, David Brennan and Lisa Jamieson, while honorary professorial appointments have included Geoffrey Heithersay, Alan Brook and Peter Anderson.

In 2016 there were forty-seven academic staff in the School who were involved in teaching in the $\mathrm{BDS}$ and $\mathrm{BOH}$ programmes and/or supervising honours and higher degree students, with twenty-one continuing full-time staff and the remainder on fractional or honorary appointments. There were 386 students in the BDS programme (First Year: 71, Second Year: 75, Third Year: 73, Fourth Year: 80, Fifth Year: 87) and 102 students in the BOH programme (First Year: 37, Second Year: 36, Third Year 29). 


\section{Accommodation issues}

Prior to 2000, staff in the School were all located within the Adelaide Dental Hospital on Frome Road or in the Medical School South (now named the Helen Mayo South building) next door. The construction of a bridge connecting the third floors had facilitated movement of staff and students between these two buildings. In 2000, due to increasing numbers of research staff within $\mathrm{ARCPOH}$, and also the need to free up more teaching space within the $\mathrm{ADH}, \mathrm{ARCPOH}$ agreed to move from the $\mathrm{ADH}$ to university-leased accommodation at 122 Frome Street.

In late 2009, several staff, including those from the dean's office, moved from the $\mathrm{ADH}$ to 233 North Terrace. Other staff remained in the ADH. The move offered some opportunity to expand and provided access to more teaching space, but the teaching space at 233 North Terrace was held mainly by the Business School and was only released to Dentistry in 2011. Even then, the actual space available to the School was much less than originally thought. In 2013, when the university decided not to renew its lease at 233 North Terrace, dental staff moved from there to the Oliphant Building. No teaching space was allocated in the move. Recently, ARCPOH moved to the ninth floor of the new AHMS building alongside Public Health; the rest of the dental staff have been relocated to an open-space, 'paperlite' environment on the tenth floor in June 2017. The Simulation Clinic has remained on the main campus and the School's research accommodation, considerably reduced from the dedicated space previously available in the Adelaide Dental Hospital and the John Thonard laboratories, is on the third floor of the Medical School South on Frome Road.

The fragmentation of the School over time has had a significant effect on the face-to-face interactions between staff, which are critical for teaching, research and collegiality. With each move, the School lost space and this has made it difficult to continue with some of its academic activities. The fragmentation has also affected the branding of the School and the provision of a clear point of contact for staff, students and the profession. It is hoped that the recent relocation to the AHMS building will address some of these issues.

\section{A new simulation clinic}

In 2013, the then executive dean of the Faculty of Health Sciences, Professor Justin Beilby, together with the then dean of the School of Dentistry, Professor Johann De Vries, opened a new Dental Simulation Clinic in the central part of the university. Constructed at a cost of $\$ 6$ million, this state-of-the-art facility enables students to practise real-world patient care procedures in a technologically integrated environment. The Dental Research and Education Fund (DREF) was also launched at this event, carrying forward the work of the discontinued South Australian Foundation for Dental 


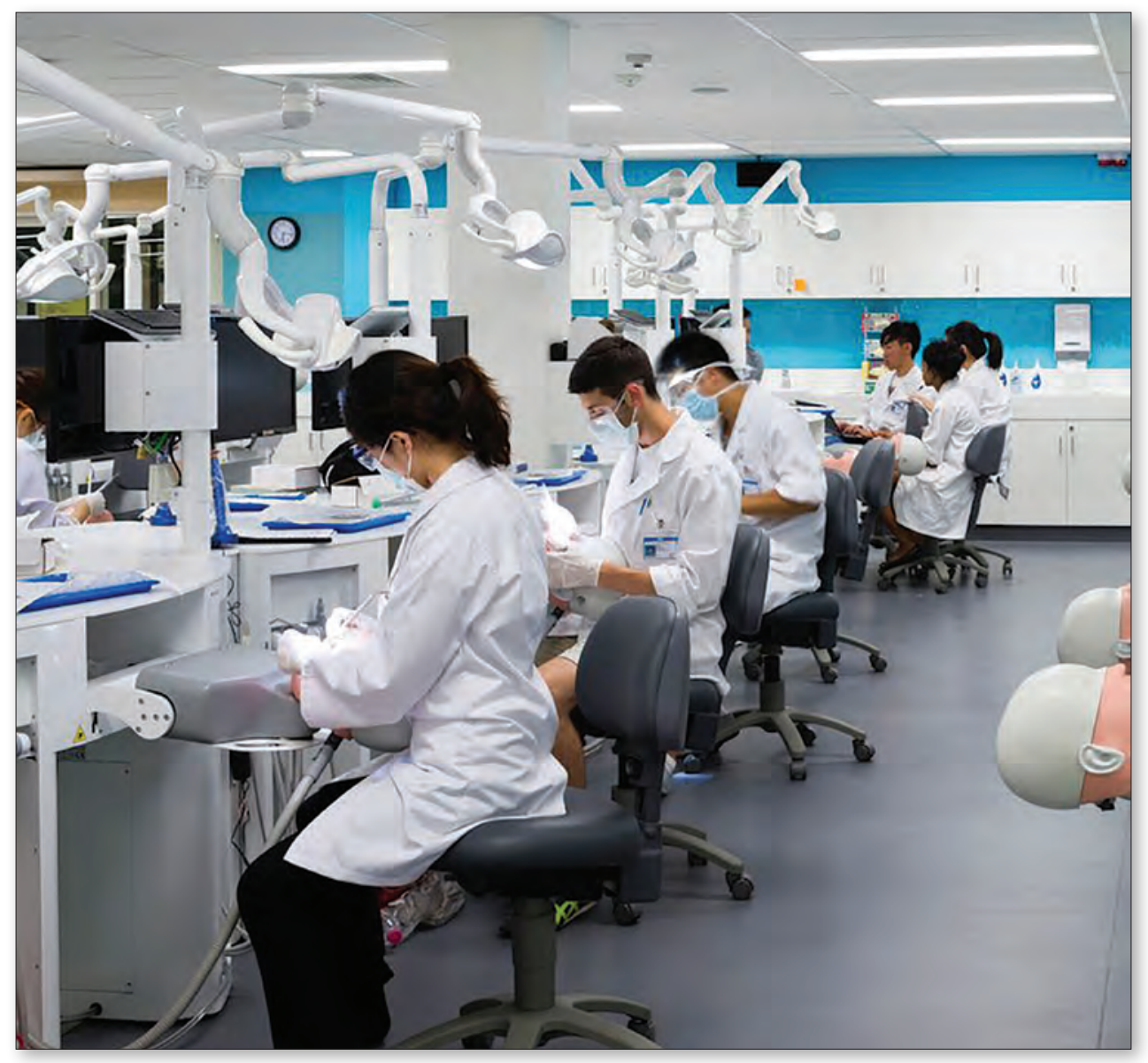

Figure 6.4 The new simulation clinic in the Barr Smith South building on the North Terrace campus (courtesy of Adelaide Dental School).

Education and Research (SAFDER). DREF has been established by the University of Adelaide to manage fundraising initiatives and administer an advisory board to support the School of Dentistry.

\section{The tender}

When SA Health publicly sought registrations of interest from universities to enter into a partnership, by the end of 2014, to deliver an integrated dental teaching program and SA Health operated public dental service, students, staff and graduates of the Adelaide Dental School were shocked. The School had always been in the University of Adelaide and surely it always would be? While it is not the purpose of this book to explore the background to this situation, it is fair to say that the School found itself in a position 


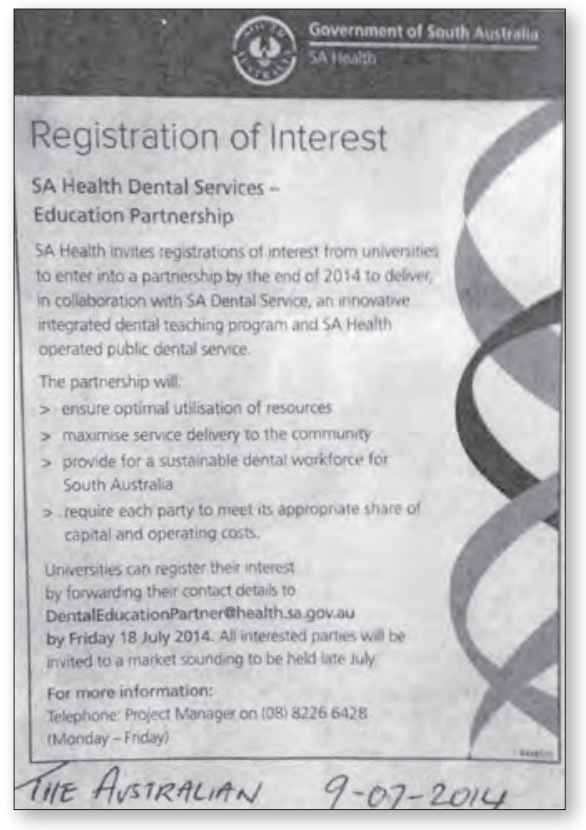

Figure 6.5 The announcement from the government of South Australia seeking registrations of interest from universities to enter into a partnership with the South Australian Dental Service.

of great uncertainty, caught in the middle of a game of high-stakes brinkmanship that was being played out by the university and SA Health.

With the move of the Royal Adelaide Hospital to the West End planned for 2017, the question of what would happen to the Adelaide Dental Hospital building and also the future of the Adelaide Dental School suddenly loomed large within the university. Countless meetings were held between the Senior Management of the university and SA Health, and the ADA and the School did their best to provide informed comment, but no agreed resolution was found and so SA Health decided to put the matter out to tender.

Once news of this spread around Australia and internationally, it was interpreted that the Adelaide Dental School was going to close. Indeed, the School's reputation took a battering and this led to a decrease in the number of applicants for both undergraduate and postgraduate courses. At one stage, the university announced that it would build its own $\$ 30$ million dental clinic on Kintore Avenue.

The University of Adelaide put in a bid that included a proposal to fund an Adelaide Dental Clinic within its new Health and Medical Sciences building at the West End. This seems to have clinched the bid, and the University of Adelaide won the tender ahead of the University of South Australia.

The vice-chancellor at the time, Professor Warren Bebbington, was quoted in the press as saying:

I am pleased that the very long-standing partnership in dentistry between the University of Adelaide and SA Health will now be renewed for a further 30 years. The School will also modify its current dental clinical practice model to provide an enhanced year-round service to public patients. (ABC News)

The modification has involved rostering of final-year BDS and $\mathrm{BOH}$ students across forty-eight weeks of the year to provide dental care for public patients. While this change can be viewed positively, it provides an example of a political decision having a direct and significant impact on the way the BDS and $\mathrm{BOH}$ programmes are delivered, including supervision of students. 
There are only forty dental chairs available for undergraduate dental and oral health students in the new Adelaide Dental Clinic at the West End. This compares with the approximately ninety chairs that were available in the 'old' Adelaide Dental Hospital on Frome Road. Students are now rostered to various community clinics for their clinical experience and students in First and Second Year access the new facilities in the evening.

\section{A review of the Faculty of Health Sciences and a Professional Services Review (PSR)}

Early in 2015, all staff in the Faculty of Health Sciences received a memo from the executive dean outlining proposed major organisational changes within the faculty. This followed a review of the structure and governance of the faculty in 2014 during which various perceived problems were identified, including duplication of administrative functions between schools and between schools and the faculty. The review process occurred in two phases, with the first phase covering senior Faculty management roles and responsibilities, Faculty governance, and the number of schools in the faculty. As part of this phase, the number of schools in the faculty was reduced from eight to five. While the School of Dentistry remained as a separate school, the number of groups within the School was reduced from seven to five.

The second phase of the reorganisation process involved a professional staff restructure across the faculty and this was referred to as the Professional Services review (PSR).

The Dental School had reasonably recently undertaken a major review of its professional staff structure in a process referred to as 'Blueprint 2000'. This led to the formation of teams of professional staff and academic staff, in order to support teaching and learning activities and other functions within the School. Despite considerable pain during the process and the need to allow some time for the structure to settle down, most staff in the School felt that the system was working well. No-one was ready for the shock of the PSR proposal, in which nearly all the professional staff positions in the School were disestablished and replaced by a smaller number of more centralised positions in a new faculty structure.

The concerns of staff in the Dental School were summarised in a petition that was signed by 145 staff members and submitted to the senior managers and Council members of the university in October 2015 during the period of time when feedback was being sought.

Receipt of the petition was acknowledged by the executive dean but then, in November 2015, with no reference to the petition, he sent a further email to all staff in the faculty in which he noted that a large amount of written feedback had been received and that the feedback showed general support of the proposed change. In the email, staff were then provided with the Final Change Plan in accordance with 
clause 7.9 of the enterprise agreement in place at the time, the University of Adelaide Enterprise Agreement 2014-2017. (This agreement has since been superseded by the University of Adelaide Enterprise Agreement 2017-2021.)

Implementation of the PSR led to ten professional staff from our School accepting redundancy packages, with their extensive knowledge and expertise (representing well over 100 years of accumulated experience) being lost from the School and the university. The new structure has only been operating for a short while and the wider implications for the School in the longer term are unclear, but academic staff have had to assume many additional administrative functions.

\section{Other factors impacting the School}

Apart from the events described above, many other factors have impacted the School over the past decade or so. There was a massive increase in student numbers in the early 2000s, peaking with over 100 students in the first year of the BDS programme in 2005. There has also been an increasing number of international students, with approximately half of the First Year BDS cohort in 2016 from overseas. There are now also new requirements for academic staff to fulfil specified criteria relating to their performance in teaching, research and administration, including the use of Individual Academic Profiles (IAPs) and workload models.

Despite the difficulties faced by the School in recent times, there have still been many achievements. The following list from Professor Richards, previous dean of the School, highlights some of the recent 'achievements' of the School in relation to both external and internal matters during the period 2015-16:

In terms of the external environment, the School has

- $\quad$ established a Partnership Agreement with SA Health

- completed a restructuring of the Faculty Executive

- maintained our Excellence in Research for Australia (ERA) 5 ranking for research

- improved our relative ranking in relation to the other Australian dental schools

- $\quad$ established completion dates for the new Adelaide Dental Hospital and Riverland Oral Health Centre

- gained some understanding of how the PSR will impact on the School

- begun to gain an understanding of the principles driving the Phase II infrastructure project for the faculty.

Internally, as a School we have

- $\quad$ restructured our governance and management systems

- been through some positive review and accreditation processes 
- $\quad$ successfully introduced the new Graduate Certificate in Oral Health Science

- $\quad$ successfully added Port Lincoln to our network of clinics

- $\quad$ achieved the transition milestones defined in the Partnership Agreement on or ahead of schedule.

A new Riverland Oral Health Centre at Berri opened in December 2016. The $\$ 6$ million centre, funded by the federal government, provides public dental services to eligible patients and children and provides rural training places for dental students from the University of Adelaide. The clinic includes ten dental chairs and is operated by the South Australian Dental Service under the thirty-year Dental Education Partnership Agreement between the University of Adelaide and SA Health. Final-year dental students spend forty-eight weeks at the Centre on a rotational basis under the supervision of qualified dentists and academic staff.

Another initiative of the School, supported by grants from the ADA, the Wrigley Foundation and the Commonwealth Government, has been the establishment of a Community Outreach Programme, managed by Ms Margie Steffens. This includes a dental clinic in the Common Ground Project's facility at Light Square in Adelaide, where students, staff and volunteer dentists provide oral healthcare services for Adelaide's homeless community.

\section{The Australian Dental Council (ADC) and the Dental Board of Australia (DBA)}

A short section is provided here about the ADC and the DBA, as these two bodies play central roles in the regulation of dental educational programmes in Australia and the registration of oral health professionals.

The ADC was formed in 1993 and, on the formation of the DBA, was confirmed as the independent accreditation authority for the Australian dental professions. The DBA is the registration body for the dental professions and it is supported by the Australian Health Practitioner Regulation Agency (AHPRA). An important innovation since July 2010 has been the requirement for all oral health practitioners to maintain a record of continuing professional development (CPD) activities to enable them to be registered. The Registration Standard sets out the minimum requirements of the Board and this involves the need to complete a minimum of sixty hours of CPD activities over a three-year cycle.

Two of the main functions of the ADC are to develop standards, policies and procedures for dental practitioner programmes of study and to assess programmes of study that lead to both general and specialist registration in Australia.

As indicated on their website, the purpose of accreditation by the ADC is to protect the public by ensuring that only health practitioners who are suitably trained and qualified are eligible to register with the DBA, and to facilitate the provision of high-quality education and training of health practitioners. 
All of the programmes accredited by the ADC are assessed against the ADC/Dental Council (NZ) Accreditation Standards for Dental Practitioner Programs, which were developed in 2014. The Accreditation Standards include five domains: public safety; academic governance and quality assurance; programme of study; the student experience; and assessment. Each of these domains has a standard statement that is supported by a set of criteria. These criteria set out what is expected of an ADC-accredited programme to meet each standard statement. In consultation with the dental profession, the ADC has developed professional competencies of newly qualified dental practitioners. These describe the professional competencies at the point of graduation from an ADC-accredited programme.

The development of formal standards and competencies by the ADC has been an important development in recent years to try to ensure that the quality of graduates from existing dental schools is satisfactory. They are also important for universities when considering the introduction of new programmes in dentistry or oral health therapy.

\section{ADC reports}

Accreditation visits by the ADC for the Adelaide BDS programme have occurred in 1996, 2001, 2009 and 2016. In its 2009 Accreditation Report, the Accreditation Review Team noted positively:

The School has an emphasis on innovation in dental education with a clearly stated intent of producing a modern curriculum based on evidence-based educational principles and good international educational practice. The success of the curriculum development is supported by the University of Adelaide's recognition of the School's endeavours in education. (Australian Dental Council 2009, p. 12)

However, the Team was concerned about some of the facilities in the Adelaide Dental Hospital and noted that the general laboratory facilities and preclinical laboratories on the third floor of the $\mathrm{ADH}$ were old and required urgent redevelopment. The establishment of the new Simulation Clinic in 2013 addressed these concerns.

The School has received full programme accreditation for its BDS programme following each of these visits. The outcomes of the most recent 2016 ADC visit, including some comments, are provided below:

The ADC has determined that the University of Adelaide Bachelor of Dental Surgery (BDS) program is accredited until 31 December 2023.

The ADC has determined that as a monitoring requirement for the BDS program:

1) a visit be undertaken to review the new Adelaide Dental Hospital to confirm that its clinical and other facilities are appropriate to allow the program to meet its objectives. The visit is to take place no later than 31 December 2017.

2) the School of Dentistry provides an update in its 2017, 2018 and 2019 ADC Annual Reports on developments in the following areas: 
a. The impact of the agreement with the South Australian Dental Service (SADS) on involvement of the School in tutor allocation following credentialing by SADS

b. The range of patients available to students in the program, specifically those requiring removable prosthodontics, endodontics, fixed prosthodontics and opportunities for complex treatment planning

c. The impact of the Professional Services Reform on timetabling and management of student outplacements and tutors

d. The impact of the university's new budget model on the number of casual staff available to support the program. (Australian Dental Council 2016, p. 8)

As part of its key findings, the ADC noted:

The School is going through a period of significant change with the recently signed agreement with SADS and imminent move to the new Adelaide Dental Hospital. A recent Professional Services Reform (PSR) has impacted on professional staff support available to the School.

The School is well served by an experienced and very committed staff group who appear to work well with each other and have good working relationships with the students. The School's academic governance structure is clear and robust and utilises a good range of stakeholders to inform programme review and development.

The curriculum is strong with a particular emphasis on case-based learning in all years through 'Integrated Learning Activities'. Clinical experience is gained entirely in public clinics which, while providing access to a large number of patients, potentially limits the range of patient types available to students. The new Adelaide Dental Hospital is scheduled to open in mid- to late 2017 and will have less chairs available to undergraduate students which will result in more clinical experience being gained at outplacement clinics. (p. 7)

\section{ADC recommendations}

The following recommendations and commendations were made by the Site Evaluation Team (SET) following its evaluation of the programme:

A recommendation refers to an action or a course of actions that should be considered by the provider to improve the delivery and/or outcomes of the program.

A commendation refers to a particularly significant achievement by the education provider with regard to the program.

\section{Recommendations}

It is recommended that the School of Dentistry:

1. Continues to investigate opportunities for strengthening interprofessional learning (IPL) in line with the Faculty IPL strategy 
2. Investigate opportunities for joint treatment planning between students at various year levels

3. Explore opportunities to expose students to private practice as part of their clinical experience

\section{Commendations}

The School is commended on:

1. The enthusiasm and commitment of its staff team, particularly during a time of significant change

2. The leadership provided by the program co-ordinator, year co-ordinators and the Learning and Teaching Committee in managing the program

3. The innovation of integrated program delivery through case-based learning in all years

4. The robust nature of assessments aligned with learning activities and outcomes. (2016, p. 30)

As mentioned in the section in this chapter on the $\mathrm{BOH}$ programme, both ADC reports for accreditation of the $\mathrm{BOH}$ have also been very positive.

\section{Revised BDS curriculum (2010 version)}

The new PBL BDS curriculum was introduced during the 1990s when class sizes were much smaller than in the 2000s and the School's facilities, though showing their age, were still reasonably functional. In the early 1990s, the School had a student to staff ratio (SSR) of about 6:1 and most students were selected using only Year 12 results. As described in Chapter 5, from 1997 onward students were selected based on a threestage process that included academic results, performance in a UMAT, and outcome of an oral assessment (structured interview).

In the 2000s graduating class sizes grew from around 50 to nearer to 100 (peaking at over 100 in 2005) and staff numbers declined, giving an SSR of over 12:1. Fewer clinical chairs were available in the $\mathrm{ADH}$ and extra-mural programmes were introduced. Funding levels fell in real terms and funding not only for research but also for aspects of teaching became more competitive.

These changes were occurring within the context of students being required to make increasingly greater contributions toward the cost of their education. Between $25 \%$ to $40 \%$ of undergraduate classes comprised international students, and this figure has now risen to around 50\%. There was also a developing crisis in the dental workforce in the Western world that made recruiting staff very difficult. Furthermore, there was rapidly changing technology in both dentistry and education. Against this background it was acknowledged that there was a need to review the BDS and $\mathrm{BOH}$ curricula, and to plan programmes that would provide students with an education that would give them the skills and knowledge needed for practice into the middle of the twenty-first century. 
One of the main impediments to doing this was that the overwhelming workloads associated with increasing student numbers meant that few staff had the enthusiasm to face further change. In addition, those staff who had been involved in curriculum review previously knew that the processes involved are time-consuming, challenging and not without a degree of pain, as assumptions and previous practices and decisions are challenged and criticised.

\section{The Australian Universities Quality Agency (AUQA) commendation}

Although the Adelaide Dental School has an acknowledged international reputation for its research and educational programmes, in order to ensure that it retained its leadership position in dental education it was decided to employ an international expert in health professional education to lead a curriculum review. This approach, and the process adopted, were commended as areas of excellence within the University of Adelaide in a report by the Australian Universities Quality Agency (AUQA) in 2008.

The AUQA commends the University of Adelaide for the innovative, integrated curriculum in dentistry .... The University has several examples of excellence in curriculum design. The School of Dentistry recently has undertaken a thorough review and redevelopment of its curriculum, assisted by an external specialist consultant, and informed by international trends. The process, which is documented and has engaged internal stakeholders, is regarded by the Audit Panel as an example of good practice that could be used for other disciplines. (pp. 28-29)

As a result of the review, the School decided to commence a process to modify the existing BDS curriculum so that it would both meet the university's Learning and Teaching Plan and enable it to retain its position at the forefront of international best practice in dental education.

\section{Proposed changes to the BDS programme}

The main proposed changes were based on a recognition of the broadening role of dentists in general healthcare and the Australian healthcare system.

They included:

- a clearer outcome focus represented by specifically defined outcome objectives (graduate attributes)

- a higher degree of horizontal and vertical integration throughout the programme

- $\quad$ an increased emphasis on communication and professional behaviours

- $\quad$ expanded and increased opportunities for clinical experience

- the introduction of a comprehensive integrated assessment strategy

- an improved central management system for curriculum implementation. 
The revised BDS curriculum was designed to align with the university's Strategic Plan and the review process took into account current international best practice in dental education. It built on previous innovations with a focus on an 'outcome-based approach' that is one of the current major trends in professions education. This approach aimed to ensure that the knowledge and skills acquired by the students would meet the needs of the community.

It was envisaged that students would spend significantly more time in nonhospital-based clinical settings, both in private and public practice, ensuring a greater appreciation of the dental and broader healthcare needs of the community. It was an aim of the new BDS curriculum that all students should develop an increased appreciation of research through a 'Scientific Basis of Dental Practice' component of the Dental Sciences theme which was designed to run through all years of the programme. Staff were also encouraged to further their international links to other dental schools to enable students to undertake electives overseas.

The Dental School had been very successful previously in repackaging its curriculum for overseas use (for example, the Sharjah project) and it was hoped that an upgraded curriculum would prove to be equally attractive.

The overall aims and the specific outcome objectives remained very similar to those of the existing course but were reviewed in relation to Curriculum Vision Statements. The objectives were revised and reframed under a fully integrated stream named 'Dental Science and Practice' which was planned to run through all five years of the programme.

\section{Appointment of an educational consultant}

To facilitate the process of curriculum review, the School decided to employ an educational consultant, Professor David Newble, who had been involved in several previous reviews of medical and dental curricula, to lead the process. He organised curriculum conferences involving a broad mix of participants to develop a consensus about the way forward.

The First Curriculum Conference was held in the Art Gallery of South Australia on 5 July 2007. The event was attended by 117 participants, comprising academic staff, tutors, students, practising dentists from the wider community, SADS staff and general community representatives (many of whom were involved in helping the School with its admissions interviews).

In opening the conference, the dean of dentistry, Professor Johann de Vries, introduced Professor David Newble, the School's educational consultant, who then gave an outline of international trends in dental education and details of the process of curriculum development that he was following. A high priority was given to consulting all those with a stake in the outcome of the School's educational programme, and 
the wide representation among participants provided evidence of the success of this strategy. De Vries then introduced the main activity of the evening - to review a set of discussion points dealing with the key issues on which the vision for the revised curriculum would be based. These were considered within small groups and suggested modifications were reported in a plenary session. More detailed reports were submitted to the School. These were collated and considered by the Curriculum Review Task Force chaired by Professor Wayne Sampson.

Recommendations from the task force were forwarded to the School Executive. Once ratified, the Vision Statements for the curriculum were posted on a special Curriculum Development website.

\section{Vision Statements}

The Vision Statements are summarised below:

1. The dental curriculum was to be outcome-focused, with the aim being to produce graduates able to commence their role as general dentists in the Australian healthcare system. An holistic approach to the delivery of patient care was to be adopted, capable of having a strong influence on the oral health of all Australians. Graduates should also possess the graduate attributes expected of the University of Adelaide.

2. The program should ensure substantial opportunities to learn and practice in a variety of hospital and community settings, both public and private.

3. The program should demonstrate a high degree of integration.

4. The program should expect students, with the support of staff, to take responsibility for identifying, implementing and monitoring their learning goals.

5. The program should enable students to understand the principles of research and scholarship, to undertake evidence-based practice and quality assurance activities, and to explore topics in depth.

6. The program was to be structured throughout to provide clinical experiences that would be of increasing complexity throughout the program, ensuring that graduates would be competent to commence independent general dental practice.

7. The program should place emphasis on interpersonal skills, communication and team working skills, appropriate professional behaviours and personal development.

8. The scientific components of the program should underpin and integrate with the clinical components of the program. 
9. The instructional approach should consist of a variety of integrated learning activities complemented by a range of other learning and teaching activities.

10. Information and communication technology should be used to enhance student learning and should be integral to the design and delivery of the curriculum.

11. Student assessment, both formative and summative, should be matched closely to the integrated learning and teaching activities and to their clearly defined outcomes objectives.

12. The curriculum should be managed by a multidisciplinary team, including experts in education and educational technology; representatives of the dental health service (hospital and community), the wider profession and the students; and a senior dental school administrator.

13. Students, healthcare providers and other stakeholders should have meaningful opportunities to provide input regarding the design, implementation and evaluation of the program.

14. A quality assurance system should monitor the implementation and evaluate the outcomes of the curriculum.

These statements were the main drivers for designing the revised BDS curriculum and for the educational methods that were adopted. As mentioned, an outcome-focused approach to curriculum development was adopted to ensure both that the content of the curriculum would be relevant to current dental practice, and that students would acquire the underpinning scientific knowledge and the high level of clinical competence expected of our graduates.

Further opportunities for comment and participation were offered at regular intervals during the review process.

At a second Curriculum Conference, Professor Newble presented a report on the activities undertaken following the previous July meeting. These included the development of a detailed set of Outcome Objectives and a Core Curriculum Database structured around a set of Dental Presentations and a set of Medical and Healthrelated Problems. This database could be entered into a searchable computer-based system that was initially named 'Athena' after the Greek goddess of wisdom and ethical behaviour, but was later renamed 'Ngutto', the local Aboriginal Kaurna people's word for 'knowledge'.

\section{Ngutto: A web-enabled core curriculum database}

The word 'ngutto' means 'knowledge' in the language of the local Aboriginal Kaurna people and the name was decided after consultation with Kaurna elders and with strong support from staff in the School. The core curriculum database was designed to 
store all of the competencies and knowledge-based outcome objectives that comprised the revised core curriculum. The database was developed with a web-based front end, so that it could be available to School staff and students from any internet-enabled computer. The concept was modelled on a database created for the medical programme at the University of Sheffield in the UK, but Ngutto was designed and developed independently.

The revised BDS programme was developed with a focus on the outcome objectives of the programme. This involved defining the clinical competencies and related underpinning dental science knowledge that graduates would be expected to have acquired upon completion of the programme.

A set of 'Dental Presentations' and a set of 'Medical and other Health-related Problems' faced by dental practitioners within the Australian healthcare system was also developed. The presentations and problems identified what students need to know or be able to do at the time of graduation in order to practise as a general dentist. For each problem/presentation, a blueprint of the specific clinical competencies and knowledge that students need to acquire, in order to understand and manage each problem or presentation, was constructed by teams of clinicians and scientists. The clinical competencies were coded to show how the overall objectives related to the specific instances that comprised the problem and presentation blueprints.

The development of a core curriculum database was one of the innovative initiatives linked to the 2010 revised BDS curriculum. Unfortunately, mainly due to a lack of resources, this database has not been implemented and remains in its pilot form.

\section{A School Assessment Strategy}

A School Assessment Strategy was also developed, with Professor Newble providing leadership. This strategy was endorsed by the School's Academic Advisory Committee and is now used as a basis for assessment in both the BOH and BDS curricula. The key features of the Assessment Strategy are quoted here (Newble 2009, p. 8):

- $\quad$ assessments will be closely matched to purpose, program objectives and intended teaching and learning activities

- $\quad$ regular opportunities for formative and self-assessment, remediation and counselling will be evident throughout the program

- $\quad$ summative assessments will all be integrated

- $\quad$ assessments of clinical competence (including professional behaviours) will be included in all phases of the programme

- the concept of progressive testing will be incorporated into all end-of-course summative assessments (i.e. a proportion of material from previous phases of the program will be included in all subsequent assessments) 
- $\quad$ assessment methods will be limited to those on an approved evidence-based list

- $\quad$ assessments will conform to a standardised format to ensure familiarity to students, to aid staff training, and to simplify test development and administration

- $\quad$ summative assessments will meet expected internationally-credible standards of validity and reliability

- $\quad$ students will be fully informed of all assessment procedures at the beginning of each year of the program

- $\quad$ university graduate attributes will be assessed

- $\quad$ assessments will comply with University examination policies and regulations.

\section{Key aspects of the revised BDS curriculum - 2010 version}

The proposed five-year Curriculum Plan included a five-phase structure. Within each phase there were several longitudinal components. The two academic themes were Dental Sciences and Clinical Competencies, reflecting the planned highly integrated approach as defined in the Vision Statements. There was also a longitudinal programme of Integrated Learning Activities (ILAs) that could be conducted in a variety of formats and would require the students to integrate Dental Sciences and Clinical Competences. In addition, there was a Personal Development stream to provide support for students throughout the programme. Opportunities for electives were also planned but, due to various reasons, these were not implemented.

A key aspect of the revised BDS curriculum was for the School of Dentistry to implement a highly integrated curriculum in line with international best practice in the education of health professionals. It should be noted that changes to the School's assessment policies were introduced, as defined in its Assessment Strategy, including a change to a criterion-referenced grading system and the requirement that students would be required to pass all components of the year before progressing to the next year of the programme.

In addition, failing the end-of-year integrated examination in the revised BDS curriculum now required students to repeat all of the components of that year. This was considered necessary because of the highly integrated nature of the programme and the need for students to constantly be relating the clinical components of the programme with the dental sciences components (this approach is aligned with that of medicine).

The revised programme adopted a hybrid approach, combining a variety of integrated learning activities (inquiry-focused learning in large and small groups, and individually), class meetings, practicals (laboratory and clinics), assignments and selfdirected learning. There was an increased use of simulations in practical sessions and a wider range of clinical attachments in the community. This required an increase in use 
of 'blended learning' that involves a range of e-learning strategies. Most class meetings are now recorded and there is a move by the university to prerecord lectures.

During the planning and implementation of the revised BDS curriculum staff made contact with overseas institutions with an interest in innovation and educational development. It was hoped that strategic alliances would develop, providing opportunities both for students to undertake international electives and for staff to participate in exchange and study leave activities. This has occurred to a limited extent, with interchanges with dental schools in Japan, Malaysia, the Netherlands and the UK, and also with the Dental School at the University of Queensland.

Learning and teaching activities throughout the revised BDS programme require students to analyse, evaluate and discuss international publications. Group activities involve students from diverse ethnic and cultural backgrounds, including those from overseas, enabling them to consider oral health from an international perspective.

There is a longitudinal research component built into the curriculum referred to as the 'Scientific Basis of Dental Practice'. This incorporates features such as critical scientific thinking, evidence-based practice, principles of research, bio-statistics, research-based projects, and elective opportunities to undertake more extensive research. It was expected that the School's research groups would take a leading role in developing this component and in providing a range of research attachments so that students could experience leading-edge research activities. Although students have the opportunity to undertake summer vacation research projects with academic staff and also enrol in concurrent honours programmes, this aspect of the revised BDS curriculum has not been fully implemented.

As mentioned earlier, the School has developed and ratified an Assessment Strategy. This has been implemented within the revised BDS curriculum. The procedures outlined aim to ensure that assessments closely match the stated outcome objectives for the overall programme and for each phase within the programme. Innovative strategies such as 'progressive integrated assessments' (or PIAs) aim to ensure that students do not adopt a 'learn and forget' strategy for summative examinations. Most assessments are integrated to match the single stream structure of the curriculum and are designed to ensure that students always have to apply the theoretical science content within a clinical practice context.

It was recognised that the financial situation within the School could preclude the immediate implementation of all aspects of the planned curriculum. However, it was indicated to the university that most of the proposed changes could be introduced within the existing funding of the School and the Faculty of Health Sciences through the achievement of efficiencies and reallocation of resources in management, administration and teaching. External consultancies helped to identify how best to achieve these things. The changes did not substantially alter the content of the material in the curriculum but consisted mainly of varying the mode and timing of delivery. 


\section{Management of the revised BDS curriculum}

The management of the revised curriculum was placed initially in the hands of a Curriculum Implementation Committee (CIC) responsible to the School Board through the School Executive. The CIC consisted of a chair, the main theme directors and co-directors, the director of assessment, the director of personal development, the co-ordinator of Integrated Learning Activities, two student representatives, a representative of the South Australian Dental Service, a senior School administrator and an educational adviser. The previous curriculum continued to be managed by the Curriculum Committee and this committee. The CIC was disbanded once the first cohort of students completed the revised curriculum and the last cohort of the previous curriculum had graduated.

\section{Integrated Learning Activities in the revised BDS curriculum}

As Newble explained during the planning phase of the revised BDS curriculum, a major focus of the 2010 curriculum change was to improve horizontal and vertical integration. This was consistent with the international literature and accreditation guidance documents in Europe and North America.

Horizontal integration is reflected usually in a breakdown of disciplinary boundaries within a year or phase of the curriculum. For example, in the early years of the programme, separate courses in basic sciences such as anatomy, physiology and biochemistry might be replaced by a system-based course or by Problem-Based Learning. Vertical integration is intended generally to introduce more clinical input early into the programme. This can be achieved through Problem-Based Learning; by clinicians taking part in joint teaching sessions with basic scientists; by incorporating a range of early real and simulated clinical experiences within the teaching hospital environment or out in the community; and by teaching basic clinical skills during the early part of the course. Another aspect of vertical integration that is often advocated is incorporating the concept of a spiral curriculum with basic sciences being revisited in the later years of the course.

The vision for the revised Adelaide dental curriculum incorporated a desire that it should demonstrate a high degree of integration and that this would be achieved through various integrated learning activities complemented by a range of other teaching and learning activities.

With an outcomes-focused approach, it is fundamental that students are required to integrate the learning of dental sciences with their developing clinical competencies in a way that ensures that they can be applied to the patient problems they will encounter as general dentists when they graduate. The most common instructional strategy to achieve such integration is Problem-Based Learning (PBL). However, many schools, including some of those who have most strongly advocated PBL, have 


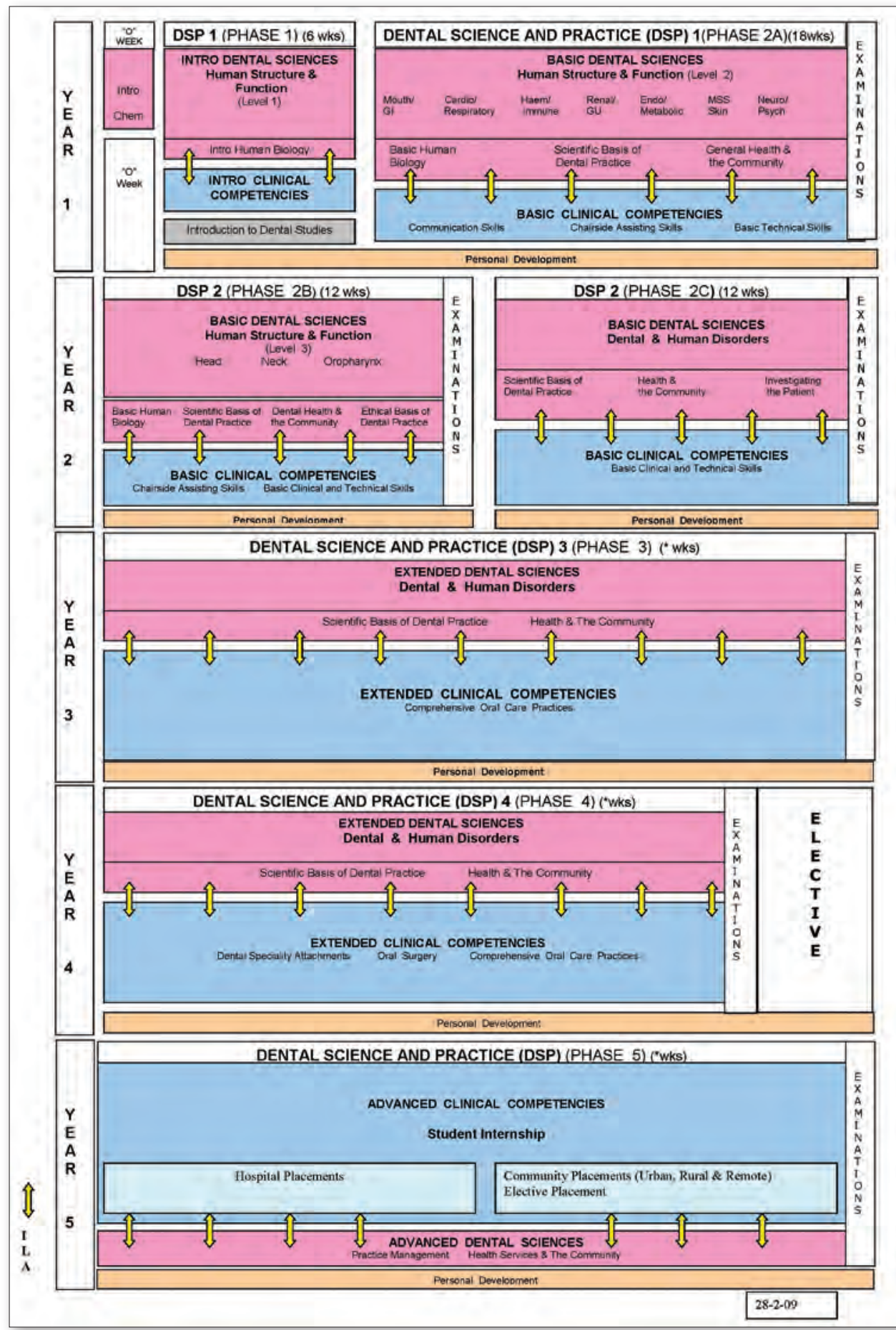

Figure 6.6 The proposed outline of the revised BDS curriculum - 2010 version. 
re-evaluated the small-group approach and adopted more flexible hybrid approaches. Nevertheless, the fundamental aims and principles behind PBL remain essential to the achievement of high levels of integration, even though the range of teaching formats might be more varied.

The ILAs form a vertical spine of teaching and learning activities alongside more traditional didactic formats in the revised BDS curriculum. Fundamentally, they are designed to help students integrate the two major academic themes of the curriculum - Dental Sciences and Clinical Competence. While the format varies both within and across phases, the criteria for classifying an activity as an ILA are the same. The features of the ILAs are that they should

- be authentically case- or patient-based

- include relevant aspects of all the underpinning dental sciences (basic, clinical, behavioural and population health)

- $\quad$ relate to the outcome objectives and the core curriculum database developed from the dental presentations and the medical and other health-related problems.

- $\quad$ relate to both academic vertical themes

- $\quad$ require students to engage in a process involving

o clinical situation/problem analysis

o identification of learning needs

o guided and self-directed learning activities

o application of new information to the situation/problem

- collation/presentation of outcomes

o identification of areas requiring immediate or later learning

o application of new knowledge and understanding to other related clinical situations/problems.

\section{The stages of implementation of the revised BDS curriculum}

The Dental School made changes to its organisational and administrative structure to facilitate implementation of the revised BDS curriculum. Two key appointments were made specifically to facilitate implementation of the revised curriculum - Paul Sambrook accepted the position of theme director for Dental Sciences and Peter Cathro accepted the position of theme director for Clinical Competences. Both worked closely with the School's educational adviser, David Newble, and with the chair of the Curriculum Committee, Tracey Winning. The School established a Curriculum Implementation Committee (CIC) that took over the leadership role for the review from the Curriculum Task Force. The CIC was chaired by Cathro until he returned to an academic position in New Zealand. In association with the Academic Advisory 
Committee, the CIC arranged a series of meetings to discuss the various components of the proposed Curriculum Plan.

The School's proposal to the University's Programs Approval Committee was accepted in 2009 and the revised BDS curriculum commenced in the first year in 2010. A feature of the revised programme is its highly integrated nature. The whole programme is organised as a single stream in each year, referred to as Dental Science and Practice I through to Dental Science and Practice V.

\section{Reflecting on the revised BDS curriculum}

As with the previous major changes to the BDS curriculum (1974 and 1993 versions), not all of the aims of the 2010 revised BDS curriculum have been achieved. For example, the curriculum database, Ngutto, has never been implemented. Furthermore, it was decided not to proceed with a Selectives (electives) stream, mainly due to the difficulties in defining appropriate options and then resourcing them adequately. Major advances have been made in terms of assessment but there is still much to do, especially in the later years of the programme.

The main changes implemented in the revised BDS curriculum (2010 version) have been the introduction of a single stream, referred to as Dental Science and Practice, in each year of the programme, with a greater degree of co-ordination and integration within and between years than previously. Indeed, the Adelaide BDS programme is one of very few programmes in the world to implement this model, along with the dental school in Malmö in Sweden. In addition, following the School's Assessment Strategy, there is a more co-ordinated and integrated approach to assessment, one that follows 'best practice' and is more transparent than previously.

The pressures exerted on the School from outside over the past few years have limited its ability to fully implement the revised BDS programme and, under the conditions flowing from the outcome of the tender with SA Health, timetabling within the programme has needed to be modified considerably, as a result of the move to a forty-eight-week clinical year. The BDS and $\mathrm{BOH}$ curricula are now being driven to a considerable degree by the need to find enough dental chairs (in various venues) for the students to practise their clinical work and to save money.

As mentioned earlier, the university is now requiring all faculties to include a certain proportion of elective topics in their programmes, so the School will need to revisit this issue.

Linked to recent changes in the arrangement of committees in the Faculty of Health and Medical Sciences, Associate Professor Dimitra Lekkas became the BDS co-ordinator in 2016 and now has a very important role in overseeing all aspects of the BDS curriculum. For the BOH programme, Associate Professor Cathy Snelling took over from Dr Jenny Miller as co-ordinator in 2016. 
In reflecting over the past seventy years or so, the process of curriculum change in the Adelaide Dental School has shown a pattern of 'punctuated evolution' with three periods of major change separated by periods of relative stasis. It is intriguing to speculate on when the next major change will occur in the Adelaide BDS and $\mathrm{BOH}$ programmes and what the principal drivers will be.

POPPY ANASTASSIADIS

Year of graduation

2009

Career since graduation

Private Practice and Academia

Current position

General Dental Practitioner \& Lecturer, the University of Adelaide

How well did my education at the Adelaide Dental School prepare me for my future career?

My education at the Adelaide Dental School taught me to question every aspect of my practice as a dentist, to place my patients at the centre of all decisions, and to ensure that the aim of my clinical practice was to improve patient health outcomes. I was taught by inspiring academic staff and dedicated tutors who led by example and shared their passion for oral health and the practice of dentistry. My experiences were enhanced by a support network of stable academic staff who valued their students as aspiring professionals, and by a diverse range of tutors who were able to facilitate our learning in a supportive but rigorous manner.

Throughout my education I was supported by my peers and together we were treated as colleagues by staff and older students from the day we entered the Dental School. This collegiality, professionalism and respect has been a key resonating feature of how I have wished to engage in the dental community. This has subsequently inspired me to be a co-learner in my academic career, and I have continued to participate in mentoring opportunities to proliferate the culture of support that I experienced as a student. 


\section{HELEN CLARE MCINNES}

Year of Graduation

2015

Career since Graduation

Public Dentistry, South Australian Dental Service

\section{Current Position}

Dental Officer, Special Needs Unit \& Community Clinics, South Australian Dental Service

How well did my education at the Adelaide Dental School prepare me for my future career?

I am still very early in my practising career, with a mere eighteen months' 'real world' experience under my belt. However, I am already aware of subtle ways in which the Adelaide Dental School has shaped both the type of dentist I want to be and the sort of work I want to do in the future.

The Adelaide Dental School offered me a perfect balance of background sciences, technical skills and the human side of dentistry. Its strong relationship with the Australian Research Centre for Population Oral Health and with the South Australian Dental Service gave me opportunities to develop my interest in public dentistry. When I graduated, I was lucky enough to earn a place in the Voluntary Dental Graduate Year Program, which included a year of public service in metropolitan and rural locations. From my interest in General Dentistry I am now developing a passion for Special Needs Dentistry — working with patients who require care beyond that which can be offered in general practice.

It is too early to know exactly where my career will take me, but I do know that the Adelaide Dental School gave me not just a strong education but a strong set of values - both of which will shape my future as a dentist. 


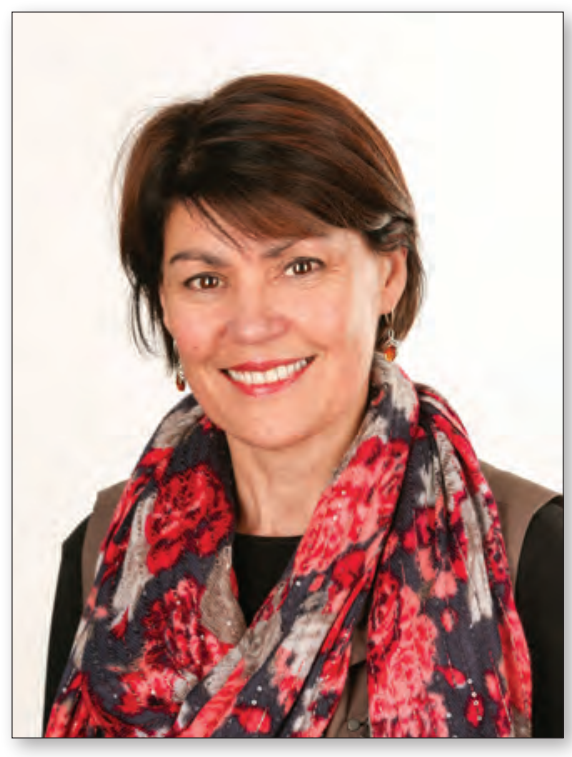

Figure 6.7 Dr Jenny Miller.

\section{The Bachelor of Oral Health $(\mathrm{BOH})$ programme}

The following section has been provided by Dr Jenny Miller, co-ordinator of the $\mathrm{BOH}$ programme from its introduction until 2016, when Associate Professor Cathy Snelling took on the role. The Bachelor of Oral Health programme, established in 2002, was derived from the dental therapy and dental hygiene programmes. These were two separate programmes, offered by different organisations, and separate disciplines within oral health.

\section{Dental therapy}

From the early 1900s, there were concerns about the oral health of children, and a school dental programme was established.

The dental service programme was staffed by publicly funded dentists. During the late 1950s and early 1960s, the NHMRC Dental Health Committee explored the concept of an operative dental auxiliary. It was recommended that training should be undertaken under the auspices of the appropriate government rather than university dental schools. The role of the auxiliary was seen as complementary to the dentist rather than as a substitute, and employment would be restricted to government services. The training should be cost-effective but ensure competence, with a requirement to provide a two-year tertiary course of education comprising 1500-2100 hours. South Australia established a School of Dental Therapy School in 1967.

Dental therapy education was conducted under the authority of the SA government, to train dental therapists to provide general dental care to children. Initially the care was limited to children up to the age of twelve years but the age range was extended to children and adolescents up the age of eighteen years during the 1980s. The programme began as a Certificate in Dental Therapy, a two-year programme consisting of a full-time study, over thirty-five hours per week, for forty weeks.

In 1991, the education and training of dental therapists was included as one of the undergraduate programmes offered by the University of Adelaide as the Diploma in Dental Therapy. The majority of the teaching was provided by SA Dental Service, with additional teaching from staff of the School of Dentistry at the University of Adelaide. 


\section{Dental hygiene}

Dental hygienists initially developed from the role of dental assistants, providing assistance to the dentist and some cleaning services under the direction of the dentist. The South Australian dental hygiene programme was based on the UK and USA dental hygiene curricula.

In 1974, South Australia was the first state to develop and deliver a dental hygiene training programme as an initiative between the Department of Further Education, the University of Adelaide and the Adelaide Dental Hospital. Over time, the programme developed and evolved from a twelve-month certificate programme, to fifteen months, to an eighteen-month associate diploma and then a two-year advanced diploma. The TAFE SA Dental Hygiene programme has been an important cornerstone for dental hygiene education and practice.

\section{Bachelor of Oral Health}

In 2001, staff from SA Dental Service and TAFE SA worked together to combine the curricula from the Associate Diploma in Dental Hygiene and the Diploma in Dental Therapy to form a new programme, the Bachelor of Oral Health, which would be offered through the School of Dentistry at the University of Adelaide. The scope of practice of the new oral health therapist would incorporate the knowledge and skills of both the dental therapist and the dental hygienist. The graduate would have a primary care role, providing routine dental care and health promotion, working in conjunction with dentists. Skills would include examination, diagnosis, treatment planning, restoration and management of teeth, prevention, scaling, health education and promotion. The result would be a multiskilled oral health professional who could provide care across the age-range but with age-specific skills.

The three-year university programme offered an opportunity for a broader education for oral health therapists, with increased study of biological and dental sciences, along with the inclusion of evidence-based dentistry and research skills, thus enabling students to demonstrate an enhanced ability to synthesise and apply knowledge. This was important in order to ensure a strong, effective and balanced learning environment with a well-conceived structure. An important factor was that the graduate would be equipped to be responsive to the contemporary oral health needs of the Australian population. The programme philosophies and structure were designed to align with the existing Adelaide BDS programme. In addition, there was an opportunity to incorporate integrated sessions with dental students. The aim was to adopt an integrated approach to education of the dental team that would promote co-operation and understanding, and ultimately enhanced patient-centred oral healthcare. 
The Bachelor of Oral Health $(\mathrm{BOH})$ programme aims to be a stimulating, challenging and enjoyable experience for the students, incorporating a social approach to learning where students learn collaboratively through problem solving, groupbased learning and a range of other social learning methodologies. The students are introduced to a diverse range of learning technologies that further enhance the concept of establishing a supportive and trusting learning community that provides a positive learning environment.

Throughout the $\mathrm{BOH}$ programme the School aims to stimulate a desire to develop the skills necessary for lifelong learning with an overall educational philosophy based on student-centred learning - in particular, small-group discovery and ProblemBased Learning (PBL). Both are used to develop a systematic approach to problem and clinical investigation, self-directed learning skills and development of an ability to self-assess. As a result of these beliefs, the School endeavours to facilitate and guide both students' learning in the discipline of oral health therapy and their development as independent learners, along with associated generic skills.

The first year of the programme focuses on a general introduction to oral health, basic sciences, professional and clinical practice. The second year extends the understanding and application of the dental sciences, together with an increased focus on simulation and clinical skill development, and an exploration of community health and health promotion. The final year consolidates and extends clinical skills and practice, explores population health, and introduces a research project. An overarching principle of the curriculum has been the focus on exploratory learning, which provides underpinning skills and approaches in order to enable deeper learning. Students are encouraged in a patient-centred and team approach to oral healthcare.

\section{$\mathrm{ADC}$ accreditation of the $\mathrm{BOH}$ programme}

The Australian Dental Council is responsible for the accreditation of dental programmes across Australia. It is a requirement that all of the undergraduate and postgraduate programmes in dentistry undergo the accreditation process. The Adelaide $\mathrm{BOH}$ programme has received full accreditation in each of the accreditation processes in 2004, 2009 and 2014.

From the 2014 ADC report (p. 7), it was noted:

The University of Adelaide, School of Dentistry, should be commended for the quality of its $\mathrm{BOH}$ program.

The enthusiastic staff utilise contemporary teaching and assessment practices as evidenced by the low attrition rate and recent teaching awards.

The University of Adelaide conducted a review of the School of Dentistry in 2015. The Bachelor of Oral Health was included as part of the review. The panel concluded: 
Delivery of the Bachelor of Oral Health $(\mathrm{BOH})$ curriculum was proceeding smoothly. Student comments were favourable and interviews with $\mathrm{BOH}$ staff demonstrated a level of operational focus and dedication to learning outcomes that the Panel considered to be impressive. (Site Evaluation Team 2016, p. 24)

The panel also noted the positive attitude of staff and students and their engagement in the programme. It highlighted the opportunities to develop integrated clinic time between the Bachelor of Oral Health and Bachelor of Dental Surgery cohorts.

A key strength of the programme has been a core team of dedicated academics, enhanced by the inclusion of additional discipline experts and the leadership to assist the implementation of the new degree. The development of the degree has been complex in navigating the university systems, local politics and resource issues. It has required interaction with a range of key personnel across different educational and service organisations. It has been important to work closely with many university and service staff to articulate the vision of the $\mathrm{BOH}$ and the possibilities for a multidisciplinary team working together to provide a different approach to teaching and service delivery.

The success of the $\mathrm{BOH}$ programme has been based on enlisting support and co-operation from multiple groups of people on an ongoing basis. The $\mathrm{BOH}$ programme has generally been greeted with enthusiasm and has fostered unique commitment and co-operation from a wide range of people. The success of the programme is dependent upon the staff who have been involved in developing and delivering the programme. They are the cornerstone of the programme: their commitment, diversity and abilities. The programme has continued to evolve with reflection from the staff and students, developing new teaching and learning methodologies and tools, particularly in the area of student-centred and online learning.

The culture within the $\mathrm{BOH}$ group and the university has been an important part of the development of a network to share ideas, and to learn from each other. There was incredible enthusiasm and willingness to contribute and support the development of the programme, which has continued over the past fourteen years. From these core staff, there are now two associate professors within the programme, the School of Dentistry Assistant Dean for Learning and Teaching, as well as the Faculty of Health Sciences Assistant Dean for Gender and Equity. In addition, four staff members have completed a Bachelor of Science in Dentistry (Honours) degree and two have completed a Doctorate of Philosophy (PhD). As the programme has developed, the intake numbers and the number of graduates have increased, and a number of the graduates of the $\mathrm{BOH}$ programme have been appointed as academic and casual teaching staff. This is an important stage of development, both of the programme and the profession. These staff offer a unique perspective for our students, in being able to provide recent experience of the broader scope of practice for patients of all ages across both public and private sector. 
In 2002, the Bachelor of Oral Health programme had its first intake of twenty students. The intake increased to twenty-five places in 2004, and later to thirty-five students per year. The programme is available to international applicants; however, there have only been a handful of international students across the fourteen years, predominantly from Botswana. Demand for places in the programme has increased steadily over time: an initial applicant pool of 250 has since increased to around 800 applicants.

In total, there have been over 300 graduates from the $\mathrm{BOH}$ programme since its inception. These graduates have worked in Australia and overseas. The majority of graduates are female; however, there has been an increase in the number of males since the inception of the $\mathrm{BOH}$, with forty-five males (15\%) completing the programme. Students who enter the programme have varied backgrounds, with a relatively even split between school leavers, tertiary transfers and mature entries. The majority of the graduates remain in South Australia for employment, with most working within the private sector. However, graduates often have multiple employment locations or work across both the private and public sector.

Students are encouraged to continue their learning and pursue postgraduate studies. A number of graduates have continued studies, with three completing the Bachelor of Science in Dentistry (Honours) and one completing the Doctorate of Philosophy. Four graduates have continued with undergraduate studies and completed the Bachelor of Dental Surgery and six have completed the Graduate Certificate in Oral Health Science. Currently, there are an additional four $\mathrm{BOH}$ graduates who are undertaking the Bachelor of Science in Dentistry (Honours) programme part-time.

\section{Graduate Certificate in Oral Health Science}

The Graduate Certificate in Oral Health Science was developed in early 2015 to provide an educational programme to allow dental and oral health therapists to provide simple restorative care to adults. The one-semester programme is offered as a combined face-to-face and distance approach to learning, allowing students a flexible style of learning to meet their clinical and personal circumstances. The programme was designed to add to the knowledge and skills from the students' base qualification, utilising a self-directed and small-group collaborative approach to learning based on context-rich scenarios.

The School of Dentistry aims to educate all members of the dental team in an integrated fashion and to promote co-operation and understanding between oral health and the rest of the healthcare system. The School of Dentistry promotes the use of innovative educational approaches to provide the Australian and international community with responsible, adaptable and skilled oral health practitioners who can apply science to the practice of oral health. 


\section{MEGHAN ARMITAGE}

Year of graduation

2015

Career since graduation

Full-time Dental Therapist within the Western Australia Dental Health Services

\section{Current position}

Full-time Dental Therapist within the Western Australia Dental Health Services

How well did my education at the Adelaide Dental School prepare me for my future career?

The education that I received during the Bachelor of Oral Health at the University of Adelaide was fundamental in the development of my skills in preparation for my future career as an Oral Health Therapist. The research components, which formed a basis for many of the subjects, encouraged self-directed education. Through this our ability to seek knowledge and discover information was emphasised, creating an increased awareness for the opportunities that present throughout our careers for professional development.

Beyond the academic aspects of this degree, the clinical components, in both the simulation clinics and the South Australian Dental Services, enabled the development of skills which have formed the foundation for my work as a dental practitioner. In addition to the core clinical skills, working in these settings emphasised the importance of team work and developed communication skills which have aided my progression into the workplace. Working with fellow students and tutors during these years provided the confidence and necessary communication skills that would later underpin the relationships formed with my colleagues. The University of Adelaide has provided me with not only the skills necessary to succeed but also the enthusiasm to participate in the pursuit of excellence. 


\section{SAHBA KAZERANI}

Year of graduation

2011

Career since graduation

Dental Therapist (adult/children) at Noarlunga SA Dental Service, Dental Hygienist at Minda, Dental Therapist/Hygienist at Coast Dental

\section{Current position}

Dental Therapist at Noarlunga SA Dental Service, Extended Care Dental Therapist (ECDT) at Noarlunga SA Dental Service, Special Needs Dental Hygienist at Minda

How well did my education at the Adelaide Dental School prepare me for my future career?

First and foremost, the practical and theoretical training that I received as part of my studies at the Adelaide Dental School has afforded me the opportunity to gain entry into variety of career pathways following my graduation in 2011. Fortunately, I was immediately offered positions as both a Dental Therapist and Dental Hygienist in the Public Sector, where I have remained working ever since. Not only did the Adelaide Dental School provide me with a vast academic knowledge through lectures and tutorials, but it also, through clinical placements, shaped my understanding of the practicalities of working in the dental profession.

More recently, I was provided with the opportunity to extend my qualifications at the Adelaide Dental School as a postgraduate student. The Graduate Certificate in Oral Health Science extended my career opportunities and pathways and provided me with a secure position within the dental profession. The Adelaide Dental School has provided me with high-quality education and training, something which is most important to me. I look forward to future opportunities within the Adelaide Dental School and further progressing with my career. 


\section{References}

ABC News (2014) Adelaide dental school and public clinic to be part of new North Terrace medial precinct. http://www.abc.net.au/news/2014-12-02/dental-school-and-publicclinic-rah-precinct/5934210 (accessed 7 March 2018).

Burgess VB (2000) Dean's report. Probe: 9.

Burgess VB (2001) Dean's report. Probe: 6.

Orr Y, Orr R (2016) The death of Socrates: Managerialism, metrics and bureaucratisation in universities. Australian Universities' Review 58: 15-25.

Australian Dental Council (2009) Report of an evaluation of University of Adelaide Bachelor of Dental Surgery Program. Melbourne, Australia.

Australian Dental Council (2014) Report of an evaluation of University of Adelaide Bachelor of Oral Health Program. Melbourne Australia.

Australian Dental Council (2016) Report of an evaluation of University of Adelaide Bachelor of Dental Surgery Program. Melbourne, Australia.

Australian Universities Quality Agency (2008) Report of an audit of the University of Adelaide. Canberra, Australia.

Newble D (2009) School of Dentistry Assessment Strategy. University of Adelaide, Adelaide.

Site Evaluation Team (2016) Report of a review of the School of Dentistry. University of Adelaide, Adelaide. 



\section{Postgraduate education and research}

\section{The beginning}

Soon after the establishment of the Adelaide BDS degree, there were moves made to introduce a higher degree in dentistry.

The question of whether a Doctor of Dental Science (DDSc) degree should be offered was considered by Faculty in 1921 and there was debate about whether it should be referred to as a Doctor of Dental Surgery or a Doctor of Dental Science. In 1922 a recommendation was put by the faculty to the Council of the University to establish a DDSc degree. This recommendation was accepted and it was agreed that the degree would be awarded to successful candidates who had submitted an original thesis or who had passed advanced examinations (Brown 1971, pp. 14-15).

The first two graduates to be awarded the DDSc were TD Campbell and HTJ Edwards, both in 1923. The thesis by Campbell, entitled Dentition and Palate of the Australian Aboriginal, was subsequently published by the Hassell Press in 1925 with support from the Keith Sheridan Foundation for Medical Research following a recommendation by the Faculty of Dentistry. Campbell was later awarded the DSc degree in 1939 for his research in dental anthropology — the only dental graduate to receive this award.

Brown (1971, p. 15) notes that only a few admissions to the DDSc degree were made over the next twenty years or so and then the masters degree became available in the late 1940s. For the MDS degree, candidates needed to complete a thesis or pass examinations or both. The first person to be awarded the MDS degree was RL Boyle in 1947. A further twenty-one admissions were then made up until 1971.

Peter Reade (1953) noted that both the popularity of the MDS degree and the fields of study increased steadily. Following the award of an MDS degree to MJ Barrett 
in 1949, HB Frayne, KJ Robertson and RG Willoughby were all awarded the MDS degree in 1953, while Mrs E Saulite, JD McKinnon, FR Henning, PC Reade (all studying physiology) and RH Wallman (anatomy) commenced their courses in that year. In responding to the question 'Why are you doing your MDS?', Reade (1953) said that it was to gain 'a greater knowledge and therefore understanding of our everyday tasks as dentists, which must lead us to rendering our best possible service to our patients' (p. 51).

By the late 1950s there were two main avenues for graduates to undertake postgraduate education. One was via the various study clubs (described further below), under the auspices of the Postgraduate Committee in Dentistry. The other was by enrolling in the MDS programme. The examination for the degree was divided into two parts. Candidates were able to present for the first part at any time after admission to the BDS, but they could not present for the second part until at least two years after graduating from the BDS and completing satisfactorily the first part. Part 1 consisted of either anatomy, physiology, general pathology and bacteriology, or physics, chemistry and metallurgy. Part 2 comprised advanced dental surgery and pathology and another topic of dentistry chosen by the candidate.

The MDS degree then became the usual prerequisite for the DDSc degree. Since then, the DDSc degree, the highest degree in the faculty, has been awarded for a thesis or compilation of published work that, in the opinion of the examiners, makes an original and substantial contribution to dental science.

Two DDSc degrees were awarded in the 1960s (to Alec Cran and Tasman Brown). An ad eundem gradum DDSc degree was awarded to Roy Ellis, an Adelaide graduate who had become dean of the dental school in Toronto, as part of the fifty-year celebration of the faculty in 1971 .

DDSc recipients up to 1971 were as follows:

$\begin{array}{ll}\text { TD Campbell } & 1923 \\ \text { HTJ Edwards } & 1923 \\ \text { JA O’Donnell } & 1924 \\ \text { CB Maddern } & 1926 \\ \text { APR Moore } & 1926 \\ \text { PR Begg } & 1935 \\ \text { MW Evans } & 1943 \\ \text { GO Lawrence } & 1945 \\ \text { JA Cran } & 1961 \\ \text { T Brown } & 1968 \\ \text { RG Ellis } & 1971\end{array}$




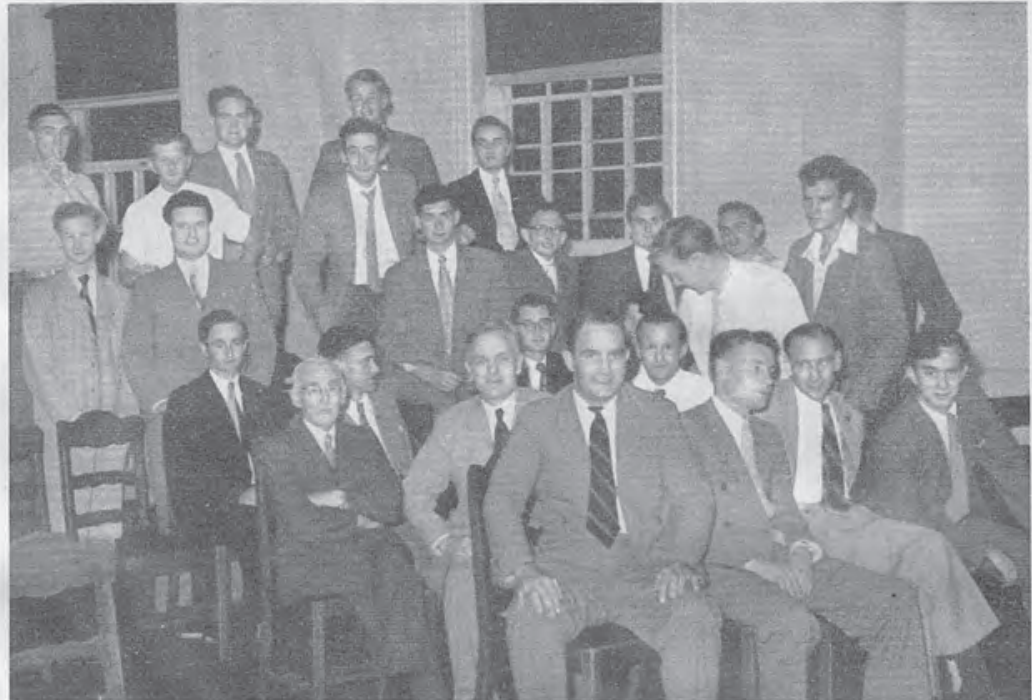

\section{M.D.S. CANDIDATES}

\begin{tabular}{lllllll}
\multicolumn{9}{c}{1953} & & & \\
& \multicolumn{9}{c}{ Part I } \\
Mrs. E. Saulite & $\ldots$ & $\ldots$ & $\ldots$ & $\ldots$ & $\ldots$ & Physiology \\
Mr. P. C. Reade & $\ldots$ & $\ldots$ & $\ldots$ & $\ldots$ & $\ldots$ & Physiology \\
Mr. F. R. Henning &. & $\ldots$ & $\ldots$ & $\ldots$ & $\ldots$ & Physiology \\
Mr. J. D. McKinnon & $\ldots$ & $\ldots$ & $\ldots$ & $\ldots$ & Physiology \\
Mr. R. H. Wallman & $\ldots$ & $\ldots$ & $\ldots$ & $\ldots$ & Anatomy \\
Mr. L. L. Daenke & .. & $\ldots$ & $\ldots$ & $\ldots$ & $\ldots$ & Chemistry
\end{tabular}

Part II

Mr. J. F. Lavis

Advanced Dental Surgery and Pathology Conservative Dentistry

\section{2}

Part II

Mr. H. B. Frayne .. . . . . Advanced Dental Surgery and Pathology Prosthetic Dentistry

Mr. K. J. Robertson

Advanced Dental Surgery and Pathology

Mr. R. G. Willoughby .. .. Advanced Dental Surgery and Pathology

Prosthetic Dentistry

Mr. K. A. Brown

Preventive Dentistry

Figure 7.1 Dentists and students in 1953, including candidates enrolled in the MDS degree (Probe 1953, courtesy of AUDSS). 
Others to have been awarded the DDSc degree at the University of Adelaide since 1971 include David Roder, Rory Hume, Grant Townsend, Graham Mount, Geoffrey Heithersay, Milton Sims, Mark Bartold, Kenneth Brown, Michael Burrow, Alan Brook and Peter Anderson.

As research programmes in the School gained momentum, more students enrolled in higher degrees, either in masters degrees, which were the usual method for gaining specialty recognition, or in $\mathrm{PhDs}$, which were the usual pathway for those planning to go on to academic positions.

\section{BDS honours degree}

In 1961, an honours degree was established that could be completed as one extra year of full-time study any time from the end of the third year of the BDS programme. The first person to enrol in the honours degree was RV Blanden in 1962, and then a further ten candidates enrolled up to 1970 .

Initially, the usual way of undertaking this degree was to intermit studies in the BDS course and to spend one year full-time studying for the honours degree after the end of Third Year or, alternatively, to enrol after completing the BDS course. It was also possible, and still is, for BSc or BA graduates with appropriate backgrounds to enrol in the honours programme, which is now denoted as the BScDent (Hons) degree. In the 1990s, a concurrent honours degree was introduced that enables students to undertake the BScDent (Hons) programme over two years while also enrolled in the BDS programme.

\section{PhD degree}

The Doctor of Philosophy degree $(\mathrm{PhD})$ became available to dental graduates who had completed the honours degree in the early 1960s. The PhD was initially administered by the Board of Research Studies and the first candidates from the Faculty of Dentistry to be awarded the PhD degree were Peter Reade (1965), John Waterson (1968) and Theo Gotjamanos (1971).

\section{MDS and DClinDent degrees}

In 1996 the Senate approved changes to the Regulations to enable the single masters course in dentistry that had exisited up until that time to be replaced by thirteen named degrees. As explained in the Senate agenda papers, the Faculty of Dentistry had offered the single degree of Master of Dental Surgery for many years to meet the continuing education needs of dental practitioners. However, in response to requests from graduates and changing community demands, Faculty decided to introduce 
named degrees that would lead to specialist registration with the Dental Boards across Australia. It was stated that the courses would provide graduates with expert knowledge and specialised skills in specific disciplines, as well as skills for leadership roles within the profession.

The named masters courses were in the following disciplines: community and preventive dentistry; dento-maxillofacial radiology; endodontics; forensic odontology; general dental practice; gerodontics; oral and maxillofacial surgery; oral pathology; orthodontics; paediatric dentistry; periodontology; prosthodontics; and tropical oral pathology.

At the time, it was agreed that, except for oral and maxillofacial surgery, orthodontics and prosthodontics, the courses could be undertaken over two to three years full-time or four to six years half-time. Orthodontics and prosthodontics required three to four years full-time study and research or the part-time equivalent. Oral and maxillofacial surgery (OMS) would be taught part-time over four years in conjunction with the Royal Adelaide Hospital and candidates would be required to be qualified in both medicine and dentistry. This arrangement for OMS was soon discontinued and all candidates were then required to complete programmes in dentistry and medicine as well as gain their fellowship in oral and maxillofacial surgery from the Royal Australasian College of Dental Surgeons. The requirement for OMS students to complete a masters degree was dropped on the grounds of relevance to surgery and the added cost of an additional university degree.

In 1999 the ADC reviewed all postgraduate programmes in the School leading to specialist qualifications. As an outcome of the review, all programmes were restructured and the professional doctorate or DClinDent was then introduced. Adelaide was the first school in Australia to make this introduction. Acceptance of the DClinDent as a Higher Degree by Research (HDR) qualification meant that it was eligible for government funding and that candidates did not have to pay upfront fees. However, in 2012 the university reconsidered its position on the DClinDent and the School was required to rebadge the qualification as a coursework degree. This now means that applicants must pay upfront fees (AUD\$40 000/year for domestic students and AUD\$50 000/year for international students in 2017).

It is important to realise that postgraduate education in the different dental specialities occurs largely within the dental schools, although some specialties follow the College route (that is, through the Royal Australasian College of Dental Surgeons). There are also now some private providers offering postgraduate qualifications (not at clinical doctorate level) in orthodontics and implantology. In medicine, specialisation falls under the umbrella of the specialist colleges - for example, the Royal Australasian College of Surgeons and the Royal Australasian College of Physicians - not the universities. 


\section{Postgraduate Committee in Dentistry}

The first meeting of the Postgraduate Committee in Dentistry (PGCD) was held in the Dental School on 5 July 1958. Professor TD Campbell convened the meeting and the other participants were: JB Day (ADA President), JF Burrow (ADA Secretary), G Millhouse (Chairman, Oral Surgery Study Group), M Sims (Australian Society of Orthodontists, SA Group), L Smart (Australian Society of Orthodontists, SA Group), CM Somerville (Chairman, General Dental Practice Group), PC Reade and JA Cran (University of Adelaide).

According to the Minutes of this first meeting, Campbell outlined the purpose and aims of the Committee as follows:

- to tie together the study groups, $\mathrm{ADA}$ and other activities

- to ensure that the groups should retain their autonomy

- $\quad$ to prevent overlapping of activities

- to establish itself along the same lines as the Postgraduate Committee in Medicine, with the university being expected to assist in any way possible, including financially

- to appoint a part-time secretary ultimately, who would co-ordinate activities of all groups

- to appoint representatives of each body.

Campbell further noted that

- approval had been granted by the university for an interstate lecturer in October

- there should be co-operation between groups and the university on bringing over interstate lecturers.

Campbell also suggested that Dental School staff could assist by contributing lectures on basic subject material.

It was agreed that Campbell act as chairman of the Committee and Cran as secretary and that each group nominate two representatives (Postgraduate Committee in Dentistry 1958).

\section{GJ Mount}

The Postgraduate Committee in Dentistry sponsored the first Mount Oration in 1985, twenty-three years after the Committee's first meeting in 1958, in order to recognise the tremendous contribution that Graham Mount had made to the Committee over many years. In this inaugural oration, Mount provided further details about the history of the Postgraduate Committee in Dentistry (Mount 1985). Mount noted that prior to World War II and for some time afterwards, continuing dental education in South 
Australia was the responsibility of the ADA. The ADA held monthly meetings that often included a scientific component and every year there was a full-day programme of continuing education.

Mount pointed out that by the early 1950s there was a group of young practitioners who felt that more should be done in the area of continuing professional education. Roger Willoughby, Brian and Ray Leach, Max Stain and others formed the General Practice Study Group in 1954 and this led to some conflict with established leaders in the profession who were concerned that this group might form a breakaway group from the ADA. There was a period of political turmoil during which Roger Willoughby was forced to resign as vice-president of the ADA (SA Branch) but eventually the issue was resolved and

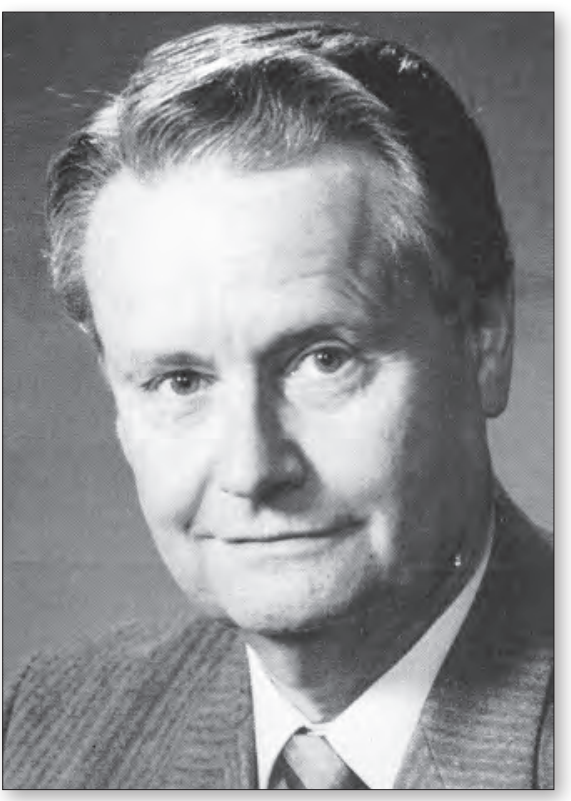

Figure 7.2 Graham Mount (Probe 1985, courtesy of AUDSS). the General Practice Study Group was formally accepted. Several other groups were then formed, including the Oral Surgery and Oral Medicine Study Club, the Periodontology Society, the Prosthodontic Society, the Australian Society of Orthodontists (SA Branch) and the Endodontology Society.

After one year as the chair of the Postgraduate Committee in Dentistry, Campbell retired and Horsnell then became the chair of the Committee. Horsnell ensured that the Committee was officially recognised by the university, and had it set up as a sub-committee of the university rather than of the faculty. In 1959, courses were presented in nutrition and physiology and the first overseas guest lecturer was Dr George Hollenbach of Hollenbach's carver fame.

Horsnell remained as chair of the Committee until 1964 and then Barrett, Cran and Horsnell each served for shorter terms. After several lay secretaries, Rene Scantlebury, later to become Rene Thonard, was appointed in 1967. Graham Mount was appointed as a member of the Committee in 1960, and served as chair from 1971 to 1983 .

By the 1970s, the Committee was finding it increasingly difficult, due to financial and resource limitations, to expand its activities to meet the demands of the profession. It made several submissions to various bodies seeking funding without success and then, in the early 1980s, due to the efforts of Brian Wheeler and Graham Mount, received the promise of $\$ 5000$ in seed funding from both Coca Cola Bottlers and 
the Colonial Sugar Refinery to help establish a position of director of continuing education in dentistry. The dean at the time, John McIntyre, then facilitated further negotiations that led to additional support from the university, SADS and the Dental Board, enabling a director of continuing education position to be created with secretarial support - John Abbott was the first appointee as director. With his typical enthusiasm, Graham Mount noted in his 1985 Oration that, with these appointments and the purchase of a new Apple Macintosh computer, the future of the Committee seemed assured.

Apart from organising continuing education programmes for the profession, the PGCD also acted as a leader in the area of peer review (which has subsequently led to a mandatory system of continuing professional development as a condition of registration by the Dental Board of Australia). The PGCD also introduced a Graduate Certificate in Clinical Dentistry programme.

With the loss of Dentistry's faculty status, together with the abolition of the University Senate, the PGCD was restructured and then eventually disbanded. Its CPD activities were then taken on by the Colgate Australia Clinical Dental Research Centre (CACDRC), with Professor Mark Bartold as director. With the recent closure of the CACDRC, a new model for the delivery of CPD courses in South Australia is currently being developed.

\section{A tradition of research in the School}

The Adelaide Dental School has a strong tradition of excellence in research that dates back to the early 1900s, with Draper Campbell's pioneering work in the field of dental anthropology. This research gained national and international recognition and, with further anthropological investigations and clinical innovations by orthodontist Percy Raymond Begg, established Adelaide as an international centre for studies of the human dentition. The strong tradition of studies in human growth and development, especially of the craniofacial region, has continued, with a series of internationally recognised researchers, including Barrett, Brown, Townsend, Richards, Kaidonis and Hughes (Brown et al. 2011; Townsend et al. 2015).

The appointment of John Thonard in the late 1960s, together with the formation of a Department of Oral Biology and the appointments of Anthony (Tony) Rogers and John Waterson, and later Trevor Bridges, added further strength to the School in the fields of oral microbiology, immunology and pharmacology. These developments provided research projects and academic staff to supervise honours, masters and $\mathrm{PhD}$ projects. One honours graduate in the 1960s, John Kearney, completed a PhD in immunology at the University of Melbourne in 1973 and was then appointed as professor of microbiology at the University of Alabama at Birmingham, USA. Later on, three of Thonard's honours students in the 1980s who were all in the same cohort, 
Mark Bartold, Christopher Overall and Nicholas Boyd, went on to become leading dental researchers and academics.

Other research strengths within the School that are described later in this chapter can also be traced back to academic staff who were appointed in the 1960s or earlier, including Cran (oral surgery), Horsnell and Fanning (preventive dentistry), Sims (periodontal ligament and orthodontics), Makinson and Mount (dental materials), Clarke (periodontology) and Heithersay (endodontics and pulp biology).

\section{Excellence in Research for Australia (ERA)}

Excellence in Research for Australia (ERA) is a research quality and evaluation system developed by the Australian Research Council. ${ }^{1}$ It measures the quality of research produced by Australian universities against world standards, using metrics focused on researchers, research outputs, research income, esteem and applied measures. A 'report card' is provided to each university, in which discipline areas are rated on a scale of 1 to 5 :

5 rating — well above world standard

4 rating - above world standard

3 rating - at world standard

2 rating — below world standard

1 rating - well below world standard

Results for the third round of ERA were made available in December 2015, providing a comprehensive assessment of the University of Adelaide's research outputs for the period 2008-13.

More than 18600 individual research outputs by academic staff and affiliates of the university were assessed, including published papers, authored and edited books, book chapters, conference papers, and creative works. The results confirmed many of the university's fundamental research strengths, in areas including geology, ecology, oncology, nutrition, civil engineering, astronomical sciences, macromolecular chemistry, soil sciences, philosophy and dentistry. In fact, dentistry at the University of Adelaide has been ranked ERA 5 in the last two rounds, underlining its recognised strength in research internationally.

\section{QS worldwide ranking}

Rankings of dental schools around the world are now published and the Adelaide Dental School has performed very well in the three published lists to date, being ranked twenty-fifth in the world in 2015, twenty-ninth in 2016 and thirty-first in 2017.

1 For more information about ERA and the ARC, see: http://www.arc.gov.au. 
These rankings are based on several factors including academic reputation and employer reputation based on global surveys, as well as research impact, comprising research citations per published paper and $\mathrm{h}$-indices. These latter metrics are sourced from Elsevier's Scopus database, the world's most comprehensive research citations database, spanning a five-year period. The four components are combined to produce the overall results.

The h-index is a means of measuring both the productivity and impact of the published work of a scientist or scholar. The index is based on the set of the scientist's most cited papers and the number of citations that she/he has received in other publications. The h-index can also be applied to the productivity and impact of a group of scientists, such as a department or university or country, as well as a scholarly journal. The index was proposed by Jorge E Hirsch, a physicist at the University of California, San Diego, as a tool for determining theoretical physicists' relative quality, and is sometimes called the Hirsch index or Hirsch number.

\section{The research-teaching nexus}

The solid research foundation to the Adelaide Dental School has meant that there has always been an appreciation of the importance of maintaining strong links between teaching and research within the School. There are many ways in which the university and the School seek both to inform and enhance learning and teaching through the research that its staff carry out, and to draw on the research literature.

The university's current strategic plan, entitled the Beacon of Enlightenment (University of Adelaide 2012), includes four key themes. The first theme is the centrality of small-group discovery. The aim of this aspect of the strategic plan is to return research to undergraduate teaching. 'While content will be increasingly delivered in other formats, every student, in every program, should experience small group-discovery as a key part of their learning experience' (p. 9). Second, '[a]n Adelaide Student Experience Charter will set out the kind of campus experience we shall commit to providing' (p. 10). Third, the strategic plan sets out how the university will increase its international research standing: 'In 2013-15 we will enhance our research capacity by adding at least 10 more internationally high-impact research professors in fields of our research strength' (p. 12). Fourth: 'We will also need to reanimate and re-energise the support the University has traditionally enjoyed from external stakeholders' (p. 14).

The 'Small-Group Discovery Experience' places importance upon collaboration between students and researchers, and upon working together in small groups to make new discoveries. The School's BDS and BOH curricula include several examples of this approach, including ILAs in the BDS programme and small-group learning in several subjects in the $\mathrm{BOH}$ programme. 


\section{Australian Research Centre for Population Oral Health (ARCPOH)}

The following historical account of the development of ARCPOH has been provided by Emeritus Professor John Spencer.

In 1984, the Faculty of Dentistry proposed that a new professorial post be established in the fields of social and/or preventive dentistry. The faculty recognised and accepted that emphasis was shifting from the provision of reparative services for the individual to the delivery of preventive and dental care programmes at community and national levels. In a letter to the chairman of the Staffing Sub-Committee, Tasman Brown (1984) advised that the areas of greatest significance to the future dental care delivery in Australia were:

- $\quad$ information on the oral health of the community (oral epidemiology)

- the identification of special priority groups, their dental problems and the subsequent formulation of appropriate dental care programmes

- the need for radical changes in dental education to meet rapidly changing community needs and expectations

- the development of a closer liaison between academic, government and private sectors of the dental workforce in planning future initiatives in education and dental care

- more intense research into the prevention of oral diseases and the diagnosis of genetic abnormalities of the craniofacial structures.

The professorial position in social and preventive dentistry was also expected to increase the opportunities for research in the Faculty of Dentistry and to provide leadership and cohesion across many disciplines within the faculty.

Professor John Spencer was selected for the position in 1986 and took up the professorship in early 1987. The appointment had an almost immediate impact on teaching and research in the faculty. In teaching, expanded coursework in community dentistry was introduced and major changes were made in dental science I in the new curriculum in 1989. Coursework postgraduate teaching was introduced in an elective in the Master of Public Health that many public dentists were to undertake over the next few years. At the same time, the first few of what became a strong stream of PhD research training students commenced projects in social and preventive dentistry. Such PhD students included Gary Slade, who went on to win a chair in oral epidemiology at the University of Adelaide and subsequently the John Stamm Distinguished Professor in the Department of Dental Ecology at the University of North Carolina.

The research programme in social and preventive dentistry was stimulated by the establishment of the Australian Institute of Health and Welfare Dental Statistics and Research Unit at the University of Adelaide. The AIHW DSRU serves as a national 
focus for improving the range and quality of information available on oral health status, dental workforce, dental practice and the use of dental services. The agreement for the AIHW DSRU to be at the University of Adelaide provided a 'core' of data managers and experienced researchers who lead a range of grant-funded research projects, including the Longitudinal Study of Dentist Practice Activity and the South Australian Dental Longitudinal Study. Colgate Oral Care became a supporter of research by Dr Louise Brown on the provision of periodontal services in general practice. This $\mathrm{PhD}$ research led to the development of the Dental Practice Education and Research Unit (DPERU), which has been continuously funded from the beginning of the 1990s by Colgate Oral Care.

Towards the end of the 1990s the research and administrative staff associated with social and preventive dentistry had grown to the extent that the area applied to the University Research Committee for recognition as a University of Adelaide research centre called The Australian Research Centre for Population Oral Health (ARCPOH). The Australian Research Centre for Population Oral Health (ARCPOH) was established in November 2001, after endorsement from the University of Adelaide's vice-chancellor, with the aim to undertake research and associated research training of the highest quality in population oral health, through the collaborative efforts of those having relevant expertise within the university, other universities, industry, government bodies and the profession.

At the heart of the formation of ARCPOH was the Dental School's academic area of social and preventive dentistry, the Australian Institute of Health and Welfare's Dental Statistics and Research Unit (AIHW DSRU) and the Dental Practice and Education Research Unit (DPERU) funded by Colgate Oral Care, and the Professorial Unit in Oral Epidemiology. In 2008, ARCPOH expanded to include the Oral Health Promotion Clearinghouse, followed by the Indigenous Oral Health Unit (IOHU) in 2011, and the Health Services Research Unit (HSRU) in 2012.

The new unit within ARCPOH, the Indigenous Oral Health Unit (IOHU), formalises ARCPOH involvement over many years in documenting the oral health of Australia's Indigenous population. The IOHU has been highly successful in obtaining research grants to pursue its programme, which has tended to focus on the investigation of interventions on improving the oral health of Indigenous people. The IOHU is led by Professor Lisa Jamieson.

ARCPOH is Australia's pre-eminent population oral health research body undertaking dental research and provides a broad range of dental and oral health statistics for Australia. The highest level of population oral health activity is the conduct of national oral health surveys. ARCPOH has achieved a national and international recognition through the development of a strong competitive research grant performance, a substantial research-only higher degree training programme and 


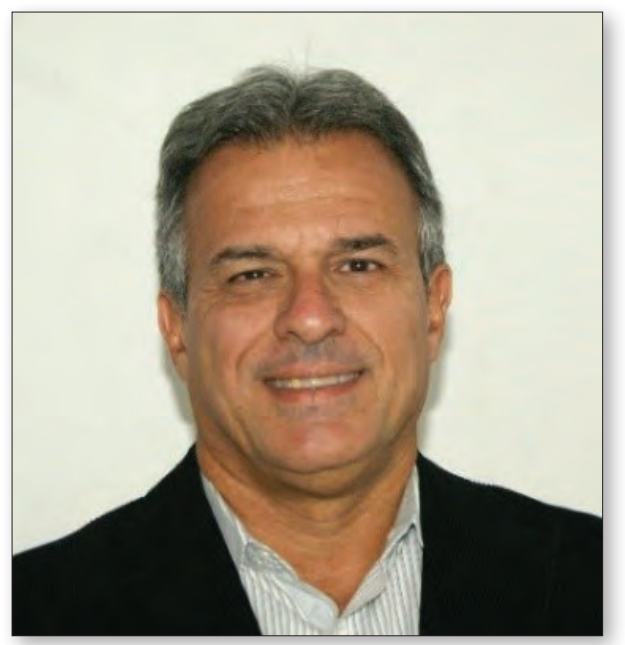

Figure 7.3 Marco Peres.

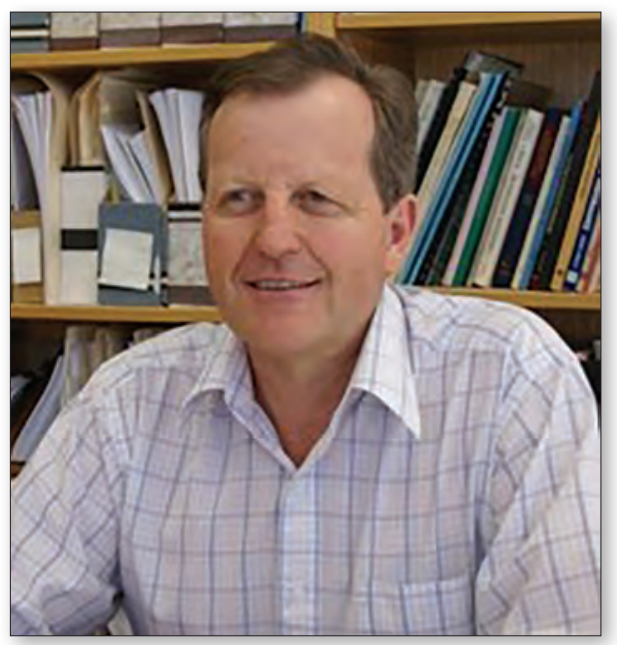

Figure 7.4 John Spencer.

a set of stakeholder relationships that reflect the importance placed on translation of research into public policy and dental practice, including the provision of public dental services.

With the retirement of Professor Spencer in 2011, a new professor of population oral health, Professor Marco Peres, was appointed.

\section{Establishment of the Colgate Australian Clinical Dental Research Centre (CACDRC)}

Planning for the CACDRC began in 1996 when the South Australian Foundation for Dental Education and Research commenced fundraising to build a dedicated clinical dental research centre in order to provide up-to-date information to the dental profession. An extensive campaign sought support from South Australian dental practitioners who provided the initial finances for building of the Centre to commence. Naming sponsorship was obtained from Colgate Palmolive in 1997 and additional support was provided by the dental industry. The CACDRC was officially opened on 8 April 1998 by the Minister for Human Services, Mr Dean Brown.

Colgate Palmolive continued their sponsorship of the Centre on five-year terms, with the final term expiring in 2017. Research within the Centre was supported by competitive grants and contract research. In addition to its research activities, the Centre operated a busy six-chair private dental clinic, staffed by general and specialist dentists treating private patients. These clinical facilities were also utilised for research projects by staff and students of the Centre and the School of Dentistry. The funds raised by the clinical practice supported the research activities of the Centre. 


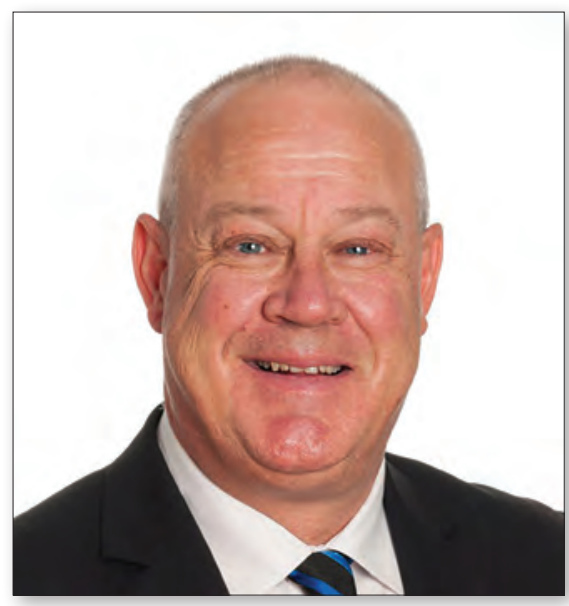

Figure 7.5 P Mark Bartold.

The mission of the CACDRC was a commitment to dental research, education and service that was focused on clinical relevance and oral health. Through these activities, the CACDRC extended, evaluated and transmitted knowledge in oral health for the particular benefit of the people of South Australia as well as the wider national and international community. The Director of the CACDRC until February 2017 was Professor Mark Bartold.

With the de-commissioning of the Adelaide Dental Hospital and the move of clinical services to the Adelaide Health and Medical Sciences Building at the West End, university managers decided that the Colgate Clinic located on the second floor of the Adelaide Dental Hospital would not be relocated and would close at the end of May 2017. All of the staff of the CACDRC, including research staff as well as clinic staff, were to cease their employment with the university by June 2017. In addition, the director was offered a contract renewal from 25 February to 2 June 2017, even though the contract with Colgate was not due to expire until 31 December 2017. In light of these developments, Professor Bartold decided to retire and has been awarded an Emeritus professorial title to enable him to continue some of his research and academic pursuits.

\section{Centre for Oro-facial Research and Learning (CORAL)}

In 2007, the Faculty of Health Sciences Research Committee confirmed that an application to establish a recognised research centre within the Adelaide Dental School had been successful and it provided some 'start-up' funding. The centre was named CORAL and it comprised four major units that all pursued multidisciplinary research. The four groups were periodontal pathology, craniofacial biology, mucosal research and dental education.

The Centre for Orofacial Research and Learning (CORAL) was a multidisciplinary centre that brought together nationally and internationally recognised research leaders, basic scientists, clinicians and translational researchers in oral health and disease. CORAL had four priority areas of research activity that represent clear national leadership and are internationally recognised. These included periodontal pathology, craniofacial biology, mucosal research and dental education. CORAL was also developing a fifth area around an existing nucleus of research strength in dental 
materials where there is the opportunity for development of new dental technologies and substantial commercial earnings from licensing.

CORAL was very successful in bringing together staff with diverse research interests, and the inclusion of dental education as one of its major groupings was unique. In 2008, members of CORAL published fifty-two papers in top-ranking journals and then in 2009 members were successful in receiving \$2.5 million for a new five-year NHMRC Centre for Clinical Research Excellence in Oral Health. CORAL continues to promote interdisciplinary research within the School. With reorganisation within the School following the implementation of the recommendations of the PSR, CORAL's activities have lapsed.

\section{Research groups within the School}

There have been several research groups within the School that have pursued various research initiatives, including the three already described with formal recognition from the university. These groups and their memberships (obtained from the School's 2015 Research Report, published in 2016) are listed below, with the names of the leaders of the groups denoted in bold.

Support for the School's research initiatives has been provided through competitive grants from various funding agencies, including the Australian National Health and Medical Research Council and the Australian Dental Research Foundation. The School has also received outstanding long-term support for its research activities from Colgate Oral Care.

It is also important to recognise the outstanding support to research within the School that has been provided by professional staff over many years, both research officers and general administrative staff. These School-based positions supporting research were disestablished with the implementation of the recommendations of the Professional Staff Review (PSR) in 2016 and the structure and leadership of groups is now in a state of flux. The names of research group members in 2015 are provided below.

\section{Australian Research Centre for Population Oral Health}

- Professor DS Brennan

- $\quad$ Professor M Peres

- $\quad$ Professor KF Roberts-Thomson (Adjunct)

- $\quad$ Emeritus Professor AJ Spencer

- Associate Professor J Armfield

- Associate Professor LG Do

- Professor LM Jamieson 
- Associate Professor K Peres

- Dr N Amarasena

- Dr P Arrow (Adjunct)

- $\quad$ Dr L Crocombe (Visiting)

- Dr D Ha

- Dr J Harford

- Dr K Kapellas

- Dr D Keuskamp

- Dr R Lalloo (Adjunct)

- Dr L Luzzi

- Dr G Mejia (Adjunct)

- Dr E Parker

- Dr H Tan

- Ms J Aldis

- Mr M Balasubramanian

- $\mathrm{MrS}$ Chrisopoulos

- Ms A Ellershaw

- Mr E Gnanamanickam

- Ms J Hedges

- Ms S Islam

- $\mathrm{Ms} X \mathrm{Ju}$

- Ms C Koster

- Ms J Miller

- Ms H Mills

- Ms D Teusner

Population oral health is concerned with the community's oral health, access to dental care and the provision of dental care. It focuses on the population as the patient. ARCPOH includes research units in oral epidemiology and health services research, including the Australian Institute of Health and Welfare Dental Statistics and Research Unit (AIHW DSRU), the Colgate Oral Care funded Dental Practice Education Research Unit, the state-and-territory-supported National Oral Health Promotion Clearinghouse, the Indigenous Oral Health Unit and the Health Services Research Unit. Additional support for ARCPOH is received through DSRU from the Australian Government Department of Health, and the South Australian Dental Service. Several competitive grants (for example, NHMRC, ADRF) and contract 
research/consultancies are held by ARCPOH staff. ARCPOH has local, national and international collaborations and receives advice from an Expert Advisory Committee.

ARCPOH is pursuing a broad strategy of co-ordinating the relevant research activities of the contributing organisations and units to enhance progress in the following main areas:

- burden and impact of oral disease

- distribution and determinants of oral health

- effectiveness of population oral health interventions

- health services research

- oral epidemiology

- labour force research

- $\quad$ oral health policy analysis

- behavioural sciences and population oral health

- oral health promotion data warehouse and information clearinghouse

- Indigenous oral health

- $\quad$ geriatric oral health

ARCPOH staff are involved in national and international expert groups, such as Nutrient Reference Values - Fluoride Expert Working Group and the Australian Burden of Diseases 2011 - Oral Health expert group. ARCPOH is also responsible for conducting National Oral Health Surveys among children and adults in Australia and overseas, for developing randomised clinical trials to test different measures of preventing dental caries and periodontal diseases, and for participating in large multidisciplinary health studies.

\section{Craniofacial Biology}

- Professor P Anderson

- Professor A Brook

- Professor F Greenwood

- Professor G Townsend

- Associate Professor T Hughes

- Associate Professor J Kaidonis

- Associate Professor T Winning

- $\quad$ Emeritus Professor T Brown

- Dr P Anastassiadis

- Dr J Berketa 
- Dr H James

- $\quad$ Associate Professor D Lekkas

- Dr S Mihailidis

- Dr R Phillips

- Dr S Ranjitkar

- Dr C Redwood

- Dr V Skinner

- Dr I Tomo

- Dr S Tomo

- Dr R Ueno

- DrT Wilkinson

- $\quad$ Dr R Yong

- Ms C Bennett

- Mrs S Pinkerton

- $\quad$ Mr J Rogers

- Mrs R Rogers (Honorary)

- Mr G Scriven

- Ms Michelle Bockmann

- Ms Karen Squires

- Mrs A White

The Craniofacial Biology Research Group is involved in several areas of research activity, including craniofacial genetics and development, tooth emergence and oral health, tooth wear, forensic odontology and masticatory anatomy. Analysis based on a large collection of records of Australian twins and their families obtained over the past thirty years is enabling the group to elucidate the contributions of genetic, epigenetic and environmental influences to variation in facial and dental features, and childhood oral health. Clinical and experimental studies of tooth wear are clarifying how processes such as corrosion, abrasion, attrition and abfraction can lead to loss of tooth structure. Professor Peter Anderson, director of research at the Australian Craniofacial Unit, Women's and Children's Hospital is an active member of the Craniofacial Biology Research group and supervises honours and postgraduate students involved in programmes relating to craniofacial growth and development, including craniofacial abnormalities.

Members of the Forensic Odontology Unit also belong to the Craniofacial Biology Research Group and, with the recent retirement of Helen James, Denice Higgins has 
become the director of the Unit. Previously, Jane Taylor served as director after the retirement of Kenneth Brown.

As well as its collaborations with colleagues in Australia, the group is working with other researchers in the USA (Pittsburgh; Albuquerque; Reno), UK (Queen Mary University of London), Finland and Japan, and is actively involved as part of the International Collaborating Network in Oro-facial Genetics and Development with Professor Alan Brook, who holds an adjunct professorial position within the Adelaide Dental School. New collaborations have been established recently with the J Craig Venter Institute (USA) and the Murdoch Children's Research Institute, Early Life Epigenetics group.

Members of the group recently edited and contributed to a special issue of the Australian Dental Journal entitled The Face, the Future, and Dental Practice: How Research in Craniofacial Biology Will Influence Patient Care. This looks at developments in the field of craniofacial biology and how they relate to dental education and practice (Townsend \& Brook 2014). Collaborative projects involving international teams of researchers, including members of the Craniofacial Biology Research Group, have led to two papers being accepted for publication in the prestigious journal Nature during 2016 (Evans et al. 2016; Weyrich et al. 2017).

\section{Dental Education Research}

- $\quad$ Professor G Townsend

- Associate Professor J Kaidonis

- Associate Professor T Winning

- Associate Professor D Lekkas

- Dr C Redwood

- Dr V Skinner

- Associate Professor S Karanicolas

- Associate Professor C Snelling

The research being undertaken by the Dental Education Research Group is focused on the investigation of students' experiences and outcomes during their undergraduate education, in relation to collaborative learning, communication and motor skills, interactive learning technologies to enhance face-to-face teaching, admission processes and sessional teacher development. This research involves postgraduate students, and institutional, national and international collaborations with colleagues in the Australian Catholic University and Universities of Melbourne, Tasmania, Otago, Hong Kong and Manitoba. 


\section{Endodontics and Pulp Biology}

- Associate Professor N Gully

- Associate Professor G Rossi-Fedele

- Clinical Professor G Heithersay

- Dr D Parker

- Dr P Zilm

The Endodontics and Pulp Biology Group is active in a number of research projects including splinting of teeth, resorption and bleaching studies, and formulation of dental trauma guidelines. In collaboration with the Restorative Dentistry and Oral Microbiology and Immunology Groups, research interests include pulp neurophysiology, endodontic biofilms and the effect of irrigation and medication on endodontic pathogens. Victor Marino provided outstanding research support to this group and many others over a long period of time.

\section{Forensic Odontology}

- Dr J Berketa

- Dr G Cirillo

- Dr D Higgins

- Dr A Lake

- Dr C Sims

- Dr L Stow

Forensic Odontology focuses on legal aspects of human identification and oro-facial trauma. Current research is related to practical applications, including maximising data from incinerated remains, obtaining DNA from teeth at varying post-mortem intervals and expression of dental features to aid identification; education, including real and perceived value of dental records, and online education for the dental profession; and anthropology, including pathology and wear in ancient Aboriginal remains.

\section{Oral and Maxillofacial Surgery}

- Professor A Goss

- Professor R Logan

- Dr M Doddridge

- Dr P Duke

- Dr P Sambrook

The Oral and Maxillofacial Surgery (OMS) Research Group primarily investigates problems related to the practice of OMS and related medical issues. These follow a 
number of themes, with the longest-duration studies being conducted by the Japan Australia Temporomandibular Disorder Research Group. Other areas relate to orthognathic surgery, benign jaw pathology, pharmacotherapy and multidisciplinary management of head and neck cancer. In the past few years the group has been an international leader on bisphosphonate associated osteonecrosis of the jaws.

\section{Oral Microbiology and Immunology}

- Associate Professor N Gully

- Associate Professor A Rogers

- Dr E Farmer

- Dr P Zilm

The Oral Microbiology and Immunology group is involved in research into the physiology, interactions between, and ecology of bacteria found in dental plaque. Members have a particular interest in the biofilms of bacteria implicated in the aetiology of caries and periodontal diseases. Many of the investigations undertaken involve the growth and subsequent proteomic analysis of one or more bacterial species under continuous cultural conditions.

\section{Oral Pathology}

- $\quad$ Professor A Goss

- Professor D Keefe

- Professor R Logan

- $\quad$ Professor K Roberts-Thomson

- Associate Professor R Gibson

- Associate Professor L Jamieson

- Dr J Bowen

- Dr S Liberali

- Dr J McIntyre

- Dr P Sambrook

A major focus of the Oral Pathology Group is toxicity of cancer treatment, particularly with respect to the pathogenesis of mucositis. This is often a severe side effect of chemotherapy and radiotherapy, with important implications for patients who are undergoing cancer treatment. The group is interested in looking at the changes that occur, not only in the oral mucosa, but also throughout the entire alimentary tract, along its length and in different compartments of the mucosa. Other areas of interest include the oral health of homeless populations (particularly with respect to oral 
pathology), and the epidemiology of oral cancer in both Asia and Papua New Guinea, including education and awareness about oral cancer.

\section{Orthodontics}

- Professor C Dreyer

- Dr Esma Dogramaci

- $\quad$ Emeritus Professor W Sampson

- Associate Professor S Gue

- Dr W Cheung

The research activities of the orthodontic group have included investigations into the tissue responses of the periodontal ligament to osteo-inductive stimulus (ankylosis) and orthodontic tooth movement, evaluation of candidate cranio-metric planes in orthodontic diagnosis and treatment planning, and analysis of tooth wear as it interacts with dental arch development. Collaborations with the Institute of Medical and Veterinary Science, dental anthropology, periodontics, neurophysiology at Flinders University, and the physiology and orthodontics departments of the National University of Singapore and the University of Hong Kong have been productive and valuable.

\section{Paediatric Dentistry}

- Professor P Anderson

- $\quad$ Professor A Goss

- $\quad$ Professor D Keefe

- Professor R Logan

- Associate Professor S Gue

- Associate Professor T Revesz

- Dr W Cheung

- Dr M Malandris

The Paediatric Dentistry Research Group is involved in several areas of research activity. Much of the focus has been centred on clinical retrospective and prospective research on oral mucositis in paediatric oncology, resulting in several publications in this field. Other areas include paediatric oral pathology, odontogenic infections and craniofacial biology. Current projects include assessment and validation of a diagnostic scale; oral care protocol, prevention and treatment of oral mucositis in a paediatric population receiving cancer therapy; a retrospective analysis of oral and maxillofacial pathology in a paediatric tertiary referral hospital over fifteen years; a nine-year retrospective audit of severe odontogenic infections at the Women's and Children's Hospital; and oral features of Crouzon and Pfeiffer Syndromes. 


\section{Periodontics}

- Professor PM Bartold

- Associate Professor N Gully

- DrT Fitzsimmons

- DrS Kaur

- Dr P Zilm

- Mr R Bright

The periodontal research group has research projects focused on the role of periodontal ligament stem cells in periodontal regeneration, the molecular mechanisms of bone resorption, periodontal disease and systemic health (including low birth weight, diabetes and rheumatoid arthritis), and the interactions of dental implants with hard and soft tissues. Collaborators include staff from the School of Medical Sciences, Department of Pathology, Royal Adelaide Hospital, Repatriation Hospital and several overseas institutions.

\section{Restorative Dentistry}

- Professor L Richards

- Associate Professor J Kaidonis

- Associate Professor J Dudley

- Dr J McIntyre

- Dr S Ranjitkar

- Dr L Rupinskas

The broad interests of the Restorative Dentistry Research Group include clinical and survey- and laboratory-based studies in implantology, fixed and removable prosthodontics, operative dentistry, dental materials, minimum intervention dentistry, and tooth wear cariology. Current projects include accuracy of fit of implant-retained frameworks; implant abutment screw loosening; surveys of the practice of implant dentistry amongst general and specialist practitioners; alternative techniques for crown preparations amongst undergraduate dental students; accuracy of fit of crowns fabricated using digital scanning; review of implant treatment carried out in a public hospital over fifteen years; investigations of the influence of restorative materials and commonly used preventive agents on enamel and dentine remineralisation; wear studies involving enamel, dentine and restorative materials including strategies for wear prevention; minimum intervention dentistry; the Atraumatic Restorative Technique; and glass-ionomer cements. 


\section{References}

Brown T (1971) The University of Adelaide, Faculty of Dentistry, a short history. University of Adelaide, Adelaide.

Brown T (1984) Letter to Dr PD Mayer, Chairman, Staffing Sub-Committee, University of Adelaide. 1 August.

Brown T, Townsend GC, Pinkerton SK, Rogers JR (2011) Yuendumu: Legacy of a longitudinal growth study in Central Australia. University of Adelaide Press, Adelaide.

Evans AR, Daly ES, Catlett KK, Paul KS, King SJ, Skinner MM, et al. (2016) A simple rule governs the evolution and development of hominin tooth size. Nature 530: 477-480. https://doi.org/10.1038/nature16972.

McIntyre JM (1989) Proposal to convert the limited-term Professorship in Social and Preventive Dentistry to a tenured chair. Faculty of Dentistry, University of Adelaide, August.

Mount GJ (1985) The Inaugural Graham Mount Oration. Postgraduate Committee of Dentistry, University of Adelaide, Adelaide.

Postgraduate Committee in Dentistry (1958) Minutes. University of Adelaide, July.

Reade PC (1953) MDS notes. Probe: 51.

Townsend GC, Brook AH (2014) The face, the future, and dental practice: How research in craniofacial biology will influence patient care. Australian Dental Journal 59 (1 Suppl): 1-5. https://doi.org/10.1111/adj.12157.

Townsend GC, Pinkerton SK, Rogers JR, Bockmann MR, Hughes TE (2015) Twin studies: Research in genes, teeth and faces. University of Adelaide Press, Adelaide.

University of Adelaide (2012) Beacon of Enlightenment: Strategic Plan 2013-2023. https:// www.adelaide.edu.au/VCO/beacon/beacon-of-enlightenment.pdf (accessed 8 March 2018).

Weyrich LS, Duchene S, Soubrier J, Arriola L, Llamas B, Breen J, et al. (2017) Reconstructing Neanderthal behavior, diet, and disease using ancient DNA from dental calculus. Nature 544: 357-361. https://doi.org/10.1038/nature21674. 


\section{8}

\section{Where to now and in the future - dental education and practice?}

Having considered in previous chapters the major educational changes that have occurred over the past century at the Adelaide Dental School, as well as the context in which these changes have taken place, this chapter explores the future of dental education and practice, both locally and more broadly at national and international levels. In setting the scene for the comments that follow, excerpts from two published papers are provided.

Leadership, governance and management in dental education - new societal challenges

The abstract and recommendations of the Working Group that considered the topic of Leadership, Governance and Management in Dental Education - New Societal Challenges at the Global Congress on Dental Education held in Dublin, Ireland in 2007 are presented below (Townsend et al. 2008).

The Working Group emphasised that many of the problems faced by dental schools are similar around the world and that there needs to be better co-operation between schools to ensure we have the resilience not only to survive but to grow and prosper in the future.

Dental schools around the world face new challenges that raise issues with regard to how they are governed, led and managed. With rapid societal changes, including globalisation and consumerism, the roles of universities and their funding have become intensely debated topics. When financial burdens on universities increase, so does the pressure on dental schools. This is exacerbated by the relative expense of running dental schools and also by the limited understanding of both university 
managers and the public of the nature and scope of dentistry as a profession. In these circumstances, it is essential for dental schools to have good systems of leadership and management in place so that they can not only survive in difficult times, but flourish in the longer term. This paper discusses the concept of governance and how it relates to leadership, management and administration in dental schools and hospitals. Various approaches to governance and management in dental schools on different continents and regions are summarized and contrasted. A number of general governance and leadership issues are addressed. For example, a basic principle supported by the Working Group is that an effective governance structure must link authority and responsibility to performance and review, i.e. accountability, and that the mechanism for achieving this should be transparent. The paper also addresses issues specific to governing, leading and managing dental schools. Being a dean of a modern dental school is a very demanding role and some issues relating to this role are raised, including: dilemmas facing deans, preparing to be dean and succession planning. The importance of establishing a shared vision and mission, and creating the right culture and climate within a dental school, are emphasized. The Working Group advocates establishing a culture of scholarship in dental schools for both teaching and research. The paper addresses the need for effective staff management, motivation and development, and highlights the salience of good communication. The Working Group suggests establishing an advisory board to the dean and school, including lay persons and other external stakeholders, as one way of separating governance and management to some extent and providing some checks and balances within a dental school. Several other suggestions and recommendations are made about governance, management and leadership issues, including the need for schools to promote an awareness of their roles by good communication and thereby influence perceptions of others about their roles and values. (pp. 131-132)

\section{Recommendations made by the Group were:}

1. Schools must establish and maintain a clear vision, mission and a strategic plan which encourage broad ownership. Each school should nurture a culture and climate that are congruent with its vision and mission. It is important to stress that students form an integral part of the dental school community and that they should have input into the governance and management processes.

2. Despite differences in geopolitical factors, university structures and types of school, all dental schools (including new schools) should ensure that systems of governance and management are put in place that display the following features:

- Everyone in the school needs to understand what success means for their school.

- There needs to be good leadership in place and a planned cascade of leaders within the school to facilitate succession planning.

- Appropriate internal organizational structures must be in place, allowing appropriate delegation and empowerment. 
- Clear, equitable and regular systems of appraisal, performance review and evaluation must be in place.

- Individuals and teams within the school must be supported to enable them to achieve desired outcomes.

- $\quad$ Processes must be transparent, effective, quality-assured and validated.

- Clear lines of communication should exist within the school and with external stakeholders.

- Innovative ways to achieve recruitment and retention of excellent academic, support and administrative staff should be identified.

- $\quad$ Governance and management systems within a school should be in harmony and co-ordinated with those of the parent university.

3. Schools should become more pro-active in explaining modern concepts of oral health, dental education, training and research to stakeholders, including university officers, hospital administrators, politicians, the profession and the public, to ensure that their circumstances and visions are better understood.

4. The Working Group believes there are advantages to be gained by dental schools in setting up advisory boards as a means of improving engagement with the lay community and external stakeholders and to provide balance in their governance structures.

5. Schools should consider using Boyer's broad concept of scholarship when they define the nature of the work performed by their academic staff. They should also consider developing group-centred outcomes when evaluating performance rather than focusing purely on individual achievements.

6. Schools should work towards more collaborative involvement at local, regional, national and international levels, both in terms of their scholarly activities and also in their interactions with governments, the profession and the public. (Townsend et al. 2008, pp. 145-146)

\section{Strategic management and organisational behaviour in dental education}

A second paper of relevance to the theme of this chapter was written by American dental academics and is entitled Strategic Management and Organizational Behaviour in Dental Education: Reflections on Key Issues in an Environment of Change (Dunning et al. 2009). These authors consider the economic challenges facing dental schools in the United States and note that the word 'crisis' is appropriate. They also raise the need for deans and other dental school leaders to display the highest levels of ethical decision making and behaviour in these times of economic constraints and internal and external pressures faced by dental schools. They caution that 'the tendency to "lord it over" others in order to achieve public and hidden agendas could not be more tempting for people in authority — namely, deans and other administrators 
above and below them in the mystery of hierarchy' (p. 691). They go on to state that ' $[t]$ hose in authority must counter the tendency for power to corrupt and, instead, be guided by uncompromising ethical principles expressed in part by relationships of trust. If ethics become compromised in leaders, so do credibility and, ultimately, effectiveness' (p. 692).

Their observation that " $[t]$ he dean is sandwiched between the institutional levels within his or her own school and the reporting levels above (in the larger university system) and the political intrigues beyond the confines of academia' (p. 693) would resonate in many dental schools.

\section{Comments from previous deans and leaders of the Adelaide Dental School}

Former deans and leaders of the Adelaide Dental School were asked to respond to the following question:

Where to now and in the future - dental education and practice?

Responses are provided from:

- Adjunct Professor Kaye Roberts-Thomson

- Emeritus Professor John Spencer

- Professor Wyatt (Rory) Hume

- Emeritus Professor Alastair Goss

- Emeritus Professor Wayne Sampson

- Clinical Professor Geoffrey Heithersay

- Dr John McIntyre (published comments)

- Other dental academics (published and unpublished comments)

\section{Adjunct Professor Kaye Roberts-Thomson}

Dental education has changed markedly in the last fifty years and could take a number of different directions in the future. These directions are largely variations of emphasis rather than wholesale differences. However, the changes may affect a number of aspects of dental education, including curriculum, personnel and means of delivery.

\section{Curriculum and teaching focus}

Role of simulation and virtual reality and technical approaches

There has always been a focus on technical skills in dentistry; in fact, that is one reason some people enter the profession. However, with the increased availability of simulation 


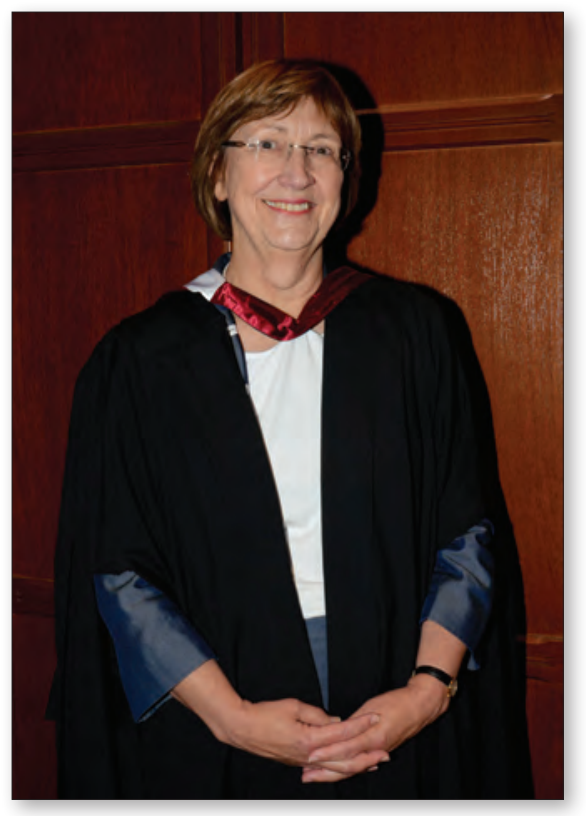

Figure 8.1 Kaye Roberts-Thomson. and virtual reality technology there is a tendency for that emphasis to increase. The choice for the future is whether technology becomes the main focus of dental training or whether an academic/health emphasis is retained and developed.

Simulation and virtual reality have great potential for the development of technical skills, and can provide a more realistic training than previous techniques. The risk, however, is that the emphasis on these skills will increase to the detriment of other essential knowledge and skills. The consequence of that direction means that dentistry becomes a technical course in which students are trained rather than an academic course in which students are educated for lifelong learning.

In the longer-term, computerenhanced technical interventions may reduce the technical skills required by dental professionals, but they are less likely to reduce the diagnostic and treatment-planning skills.

\section{Evidence-based dentistry}

Dental schools in Australia rely heavily on clinical tutors whose primary employment is in private practice. This has many advantages but some problems. The advantages are that these tutors bring emphasis and experience to students as to what they might expect in the dental workforce. The problems are that these tutors may not be familiar with recent research and practices. With the explosion in knowledge and research, much is known about which treatments are effective and which are less effective or not at all, and also about those treatments for which there is little evidence. It is very important that students understand these issues and know how to evaluate evidence for treatments and products, and that they are encouraged to practise evidence-based dentistry wherever possible. This is sometimes undermined by pressure from dental companies strongly promoting their products within dental schools or by non-academic tutors who may not be up to date with the latest research. What 'always works for me in this situation' or the promotion by a dental company is not a sufficient rationale today and will be less so in the future. It is also confusing to students. Mitigating these influences requires significant time and energy by academic staff and relies on a 
willingness of tutors to spend the time and energy to engage with the relevant academic staff. This continues to be is a major issue for clinical teaching in dental schools.

The explosion in research that is likely to continue means that graduates will need to continue to update their knowledge including rationales for treatment approaches. The scientific basis for oral health diseases and disorders and for their remediation and prevention should form the solid basis of dental education, as should the skills for evaluating evidence both in the research literature and in the commercial field.

\section{Public and personal health focus including patient-centred care}

Scambler et al. (2015) have described a model of healthcare for individual practitioners as patient-centred care, which should be the primary focus of dental care into the future. They have described a hierarchy of patient-centred care ranging from providing, at a minimum, information to the patient, to information and choice, to information, choice and the tools to make an informed decision, through to full patient control. This patient-focused care relies on good communication between the practitioner and the patient and results in a more satisfied patient and operator as dental care becomes a partnership. The increase in the teaching of communication skills in dental curricula is a welcome development, and it should remain an emphasis into the future. In an increasingly litigious environment, patient-centred care is to the advantage of the practitioner as well as the patient.

Patient-focused care requires the practitioner to discuss with the patient what outcome the patient desires and what are the risks and benefits of any treatment or no treatment. It requires an open conversation. Students need both modelling of this approach and support and encouragement to practise it. The increase in distance education raises issues for the teaching of communication and patient-centred care, however. If students do not spend sufficient time with teaching staff, tutors and patients, their ability to interact positively with patients may be compromised.

Another desirable focus for the future is an emphasis on public health, particularly in comprehensive health promotion, as outlined in the Ottawa Charter (WHO 1986) and the Jakarta Declaration (WHO 1997). One public health intervention that will require well-informed and committed graduates into the future is the threat of abandonment of water fluoridation by governments, either for supposedly economic reasons or in response to anti-fluoridationists. Students need a solid understanding of the benefits, costs and any risks of water fluoridation so that they can both discuss the issues in an informed way with patients and colleagues in the health professions and be a resource to their communities. This will assist in the maintenance of the oral health gains that have been made through this community preventive intervention.

Another aspect is the understanding and awareness of costs of care to the community and/or to the individual and the influence these costs have on access to 
care for disadvantaged persons. A disturbing feature of tertiary education, at least in Australia, is increasing student fees. Students will want and need to recover these costs, and this will result in high dental fees or, even worse, unnecessary treatment. Both of these outcomes are detrimental to the community. High student fees also discourage students from following a research or academic career, and this threatens dental schools in the long term, both in viability and quality. Thus it also threatens dentistry as a health profession.

\section{Personnel focus}

The decisions made on the direction of the dental curriculum have obvious implications for teaching staff. Dental schools are under increasing pressure from university administrations to cut budgets. These cuts result in an increased proportion of the time allotted to academic staff to teach, with a decrease in time allotted to research and other academic pursuits. This problem is confounded by the reduction in the availability of research funding, at least from government sources. This again threatens the quality of teaching and the future of dentistry.

One of the possible outcomes of high student fees and the increase in costs of dental education is a move by practising dentists to use members of their dental team who have fewer years of training to undertake basic dental care. In many countries the use of dental therapists for the treatment of children has been a longstanding practice. This approach is now being used for adults in some places. This direction will be accelerated if the costs of training dentists, either to universities or to the community, continue to increase. This move would mean that dentists become the specialists in the dental system with additional training in a specialist area. This is already occurring in a number of countries (Reinders et al. 2016). Thus the nature of the dental team as it is currently understood would change significantly. The implications of such changes for dental education are far-reaching, both in terms of student populations and undergraduate and postgraduate curricula.

A focus on both health, rather than technology, and person-centred practice should result in more interaction with other health professionals. This would be facilitated by more interprofessional education. As healthcare in Western countries is now dominated by people with chronic diseases, many of which have oral health implications, more informed interactions between health professionals could be improved by educating health professionals together, at least for parts of their education. This would enhance patient care.

\section{Conclusion}

Basic decisions need to be made about the future direction of dental education. Is the emphasis to be on technology or on healthcare? The implications of that decision 


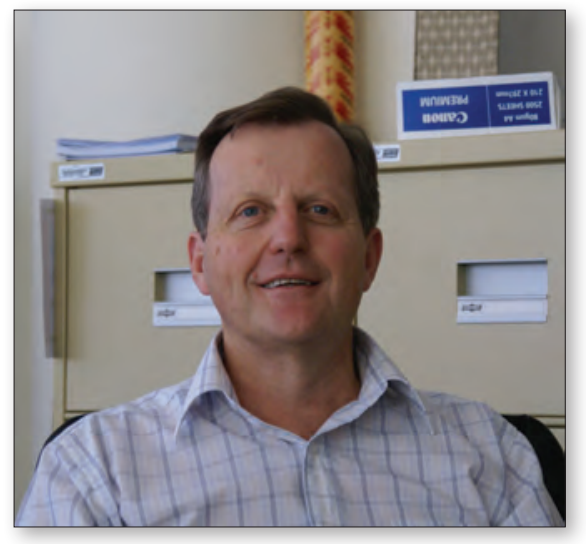

Figure 8.2 John Spencer.

relate to the future oral health of both individual patients and public health. It is not sufficient only to treat existing disease with highly technical skills — good oral healthcare involves much more, including current knowledge, communication skills and an understanding of public health. Dental education will be further challenged by the changing nature of the dental team, a process that has already begun.

\section{Emeritus Professor John Spencer}

The challenges facing dental education at the University of Adelaide are multiple. Some come about from the unique nature of the tender that the university recently won both to provide the infrastructure for the clinical education of dental practitioners and to act as the central hub for the South Australian Dental Service in return for a guaranteed service income to the university. The challenge in minimising capital and operating costs is to maintain the quantum in the output of dental services to public dental patients while using a reduced dental chair capacity and finding ways to reduce operating costs. Maintaining service output from a reduced chair capacity can only be achieved by decoupling the calendar for the academic year and the clinical year for students. Undergraduate BDS and BOH students will continue in a five-year and three-year programme with similar academic year start and completion dates and therefore a similar academic year length. However, the clinical year will be extended to a forty-eight-week year, with students rostered in blocks for of the clinical year. This can be achieved through the division of the student body into groups that will see approximately two-thirds of the groups active in the clinical training at any one time. This basic structure can allow students to schedule their clinical involvement across the forty-eight weeks of the clinical year, and so it maintains use of student clinical facilities at full capacity for the forty-eight weeks of the year.

Overlaid on this fundamental change in the clinical year is a model of dispersed clinical facilities. This basically takes the form of a 'hub and spokes' model. The hub remains a CBD-located facility accommodating student clinical facilities, some specialist clinical facilities, SADS general practice and sub-specialty/specialty clinician facilities. The spokes are a dispersed set of outer metropolitan and rural clinical facilities that are a combination of university and SA Health GP Plus centres. A limited number of special-care spokes will be established focused on student opportunities to engage with the homeless, institutionalised older adults and others. The basic model would see 
Fifth Year BDS students spend the whole of their clinical year in the dispersed spokes of this model on placements. Some of the third year of the $\mathrm{BOH}$ would also be spent on placements. A consequence of this structural change is that the hub can be reduced in size. But it also satisfies the need to make dental services more accessible to those people eligible to use the public dental services.

A further set of major organisational changes has been suggested in order to introduce efficiencies in the involvement of students and academic staff in the provision of clinical services to public dental patients across South Australia. These organisational changes are aimed at gains in efficiency and quality of the provision of clinical services. They flow on from new and innovative ways of conceptualising and managing clinical training. There are three concepts that are at the core of the proposed innovations in clinical training:

- $\quad$ patient-centred dental care

- dental homes or practices

- $\quad$ monitoring and feedback of system performance.

\section{Traditional student-centred clinical teaching}

To appreciate the value of these new and innovative ways of conceptualising and managing clinical training, it is first necessary to describe more traditional approaches to clinical training.

Traditionally, educators have approached clinical training as a parallel activity to the academic learning of students. It is a student-centred approach to clinical training. The success of clinical training has been focused on students achieving competencies in the practice of clinical dentistry in a phased manner across the years of their degree programme. This has meant that clinical training has been organised around the students' needs. Skills to be acquired and competencies to be developed have been mapped across the degree programme.

Thus the organisation of the provision of clinical services to patients has been largely determined by student needs. This has begun with the selection of patients with treatment needs that match the competencies the students need to develop, and the allocation of patients for that treatment to individual students. In this scenario patients with a range of treatment needs may be allocated to a number of students at different stages in their skills development, in order for all their treatment needs to be met. This creates a fragmented, silo-type circumstance in which services are delivered with numerous points at which the movement of the patient between silos can break down. Efforts to match the students' and patients' needs are generally conducted at the level of whole years of the degree programmes and by co-ordinators. The result can be a lack of co-ordination in the provision of care, which draws out treatment time and, not infrequently, does not deliver a comprehensive treatment plan. It invites inefficiencies 
such as failure to attend appointments, as there is a lack of continuity in the offering of appointments, time of appointments and clinics in which those appointments are offered. When patients move to another student for a different component of their treatment plan, they are re-examined and their needs reconsidered, duplicating earlier diagnostic and treatment-planning efforts. There is a challenge to build a better system for students to deliver dental services.

\section{Patient-centred dental care}

The University of Adelaide should place the patient at the centre of service provision. Patient-centred care is respectful of, and responsive to, the needs and values of patients. Patient-centred care seeks an improved understanding of the patient's needs, and it seeks to manage patients' treatment in an integrated, co-ordinated and efficient manner, with appropriate emphasis on disease prevention and promotion of oral health, and continuity of care including review. It is not student-, treatment-, or clinic-centred.

\section{Dental homes or practices}

Placing the patient at the centre of care is only possible if the unit at which patients and students are managed is small enough that there can be effective management of all needs. The University of Adelaide needs to organise clinical training around dental homes or practices. A dental home is both an expression of the type of relationship between a patient and students and a functional entity that seeks to maximise comprehensive and co-ordinated care for patients. For convenience, it can be viewed as a group dental practice within the clinical facility.

Just as with a group dental practice, there should be 'principals' whose responsibility it is to manage and co-ordinate the treatment that patients need and the clinical experiences that students need.

The University of Adelaide introduced 'practices' some years ago. However, there is an opportunity to greatly extend this concept. The key issues in extending this concept are:

- Dental practices need to be modest-sized enterprises, reflecting a larger group dental practice. It is envisaged that a dental practice will have a sizable total staff, but that with rotation of students through the practice its effective size at any moment would be small.

- $\quad$ Each practice would have several principals who will give leadership to the practice, will manage all patient and student scheduling and will be active in service provision. Such individuals will also provide input into case-reviewbased clinical teaching for the members of the practice. 
- $\quad$ Principals could be a mix of university academic staff, SADS general dental staff, and some jointly appointed staff. It would be the long-term goal that all practice principals would be jointly appointed staff.

- $\quad$ Each practice would have a range of members:

○ several principals

o a registrar - a university-funded recent graduate whose role is clinical service provision with some minor role in student demonstrating

o several SADS 'specialist' clinicians and several postgraduate students who are pursuing DClinDent degrees in clinical specialty areas, who will provide sessional input into student supervision and specialist care to patients of the practice

o varying numbers of $\mathrm{BDS}$ and $\mathrm{BOH}$ students from each year of each degree programme - students from each year level of each programme will be engaged in clinical activities that are commensurate with their skills development and competency. These would sequentially build from chairside assisting for BDS First Year students, to hygiene and preventive treatments for Second Year students, simple restorative treatments and full dentures for Third Year students, more straightforward specialist services within exodontia, endodontics and single unit crowns for Fourth Year students, and general treatment for Fifth Year students. Similarly, BOH students will engage in treatments that are commensurate with their skills development and competencies for each year level. This will sequentially build from chairside assisting through to hygiene and preventive treatments for First Year students, restorative treatments on children for Second Year students, and periodontal and restorative treatments for adults for Third Year students.

- It is a crucial aspect of the dental practice that it would operate as a co-ordinated team around the needs of patients.

- Dental practices will be involved in the provision of dental services for fortyeight weeks of the year. Principals, registrars and postgraduate students will be involved across all forty-eight weeks. While there will be some fluctuation in the members of the practice engaged in service provision across the year, there will be a core of members always available and utilising clinical infrastructure. This will be achieved by the 'block' rostering of BDS and $\mathrm{BOH}$ students across a forty-eight-week period of the year. 


\section{Monitoring and feedback of system performance}

An innovative aspect of the dental homes or practices concept is the development of a rigorous programme of monitoring and feedback in the 'management' of the practice. Together with the SADS Evaluation and Planning Unit, it is intended to use the management information systems capabilities as operated by SADS to produce a range of reports that will be both crucial to assessing the performance of each practice and to co-ordinating the care of each patient who is allocated to a practice. Monitoring and feedback is therefore seen as both a management tool and an educational tool for all levels of dental student.

Monitoring and feedback will be organised around several different levels of analysis. As the primary function of the dental practice is the co-ordination of dental services to patients, there will be a reporting structure developed that focuses on the patient. This reporting will track the treatment planned within 'service areas' against treatment delivered. This will be used in the day-to-day co-ordination of services to be provided against students available to provide them. Second, reporting on a monthly basis will focus on the activities of the practice. A number of 'output' indicators will be available on each practice. These will include indicators of efficiency in terms of throughput of patients, numbers of appointment, numbers treated, numbers whose dental treatment has been completed, numbers of patients with different types of treatment yet to be provided, and provision of services overall and by service areas. These can be discussed in practice meetings. Additional information would be collected from samples of patients to gather patient-reported indicators.

All these indicators will be used to develop periodic reporting that comments on the dental practice as a whole and compares across practices. This will be used in a form of feedback that encourages further innovation and continuous improvement in service provision.

A second level of reporting will be developed around each student working within the practice. This is necessary in order to document the amount and type of services students are involved in providing, so that acceptable levels of activity can be confirmed. It needs to be recognised that the University of Adelaide, through the presence of a substantial Dental Simulation laboratory, is in a position both to greatly alter the preparation of students for clinical tasks and to reduce the need for repetition of the clinical task to gain competency. Therefore, the programme of study should not be too prescriptive of 'quotas' of particular services to be provided by students in each year of both BDS and $\mathrm{BOH}$ programmes. However, there is an expectation that every student would experience the provision of multiple services in a range of service areas, and that total clinical time will remain at levels established in the past while total output will reflect a commitment to building competency. 
An innovative aspect of the monitoring and evaluation activities extends beyond the functional co-ordination of patient care, management of patient needs and students' requirements for experience, and the accountability of students for a level of clinical engagement. It is the opportunity to turn such monitoring and evaluation data into a student learning activity. The discussion of these data at practice meetings will provide a forum for the education of staff and students in aspects of dental health services research and practice improvement. Research staff from the NHMRC Centre for Health Services Research Excellence with ARCPOH will play a role in facilitating Problem-Based Learning around the activities of each practice and the provision of services through the clinical training facilities as a whole. These activities will be guided by accepted frameworks for understanding health systems performance such as the 'health system performance domains' from the National Health Performance Framework (National Health Performance Committee 2002). These domains are Effective, Appropriate, Efficient, Responsive, Accessible, Safe, Continuous, Capable and Sustainable.

\section{Value-adding to the role of dental practices}

Several innovative developments could be linked into the dental practices. These include medical student consultations, case-work counsellor consultations and community engagement.

\section{Medical student consultations}

Each dental practice meeting could be attended by several Sixth Year medical students. The expectation is that this would provide a two-way learning opportunity: medical students will learn about oral diseases and their management, including medically necessary dental treatment; and dental students will learn about possible medical complications to the management of their patients, including pharmacologic complications. This is seen as a necessary development in preparation for the steadily growing proportion of older adults and their increasing demand for dental services across a period of their life with potential chronic illness.

\section{Case-work counsellor consultations}

Psychology students or Master of Clinical Psychology students at the University of Adelaide could be asked to attend the same dental practice meetings. The expectation is that behaviour management issues ranging from adherence, to recommended preventive actions, to failure to show for clinical appointments will be discussed and remedial actions involving the student members of the practice formulated. Again, this is seen as a two-way interaction providing an opportunity for application of cognitive therapy into preventive dental behaviours and a practical counselling input into the 
dental students' management of patient visits. Failure to attend appointments is a substantial drain on efficiency in student clinical sessions. Anything that can be learned to reduce this problem would assist in both increasing the productivity of student clinical sessions and placing the patient at the centre of the dental care process.

\section{Community engagement}

Two novel extensions of the dental practice outside the central hub could be developed. There will be a direct relationship of each dental practice within the hub in metropolitan Adelaide and a spoke or rural dental clinic. This would link clinical experience outside the hub into the philosophy and practices adopted in the hub. This is also a feature adding the recruitment of graduates into areas that are less well serviced, as described below. The very nature of the under-serviced community will be a focus of the dental practice meetings and discussions.

A second aspect of community engagement is the allocation of a population oral health promotion function to the dental practices. Every dental student needs to be prepared for an active role in the lives of potential patients for most days of the year when those people are not in a dental surgery. While this is one of the responsibilities of the didactic curriculum, it also needs to become part of the clinical teams' activities and to be a natural component of 'clinical' work, and to be seen as a fundamental responsibility of all dental practitioners. Each dental practice could be allocated a geographic region that has a high proportion of health concession card-holders. The dental practice will be expected to adopt an oral health promotion role for preschool children, youth employment services, community organisations and residential aged care facilities within their area. The dental practice would be expected to conduct oral health promotion activities centred on mid-course students, led by later-year students from both the BDS and $\mathrm{BOH}$ programmes. An advantage of this approach is to carry the 'practice of dentistry', at least preventive measures and oral health promotion, into non-traditional settings. The principals of the dental practice in consultation with academic staff and researchers associated with the Oral Health Clearing House within ARCPOH could help guide the development of these activities as part of Health Promotion and Community Dentistry.

\section{Professor Wyatt R Hume, professor and dean, University of Utah School of Dentistry, USA}

The move of medical and then dental education from stand-alone trade schools, or from hospital-based schools, into the research and university environment began about 100 years ago. As was the case with the Adelaide Dental School, early dental school affiliations were often with hospitals only, and were in essence apprenticeshipbased. Increasingly, various societies required their healthcare professionals to be 
both educated and trained in a scientific, research-based academic setting.

The change first to university-based education and then to education and care integrated with active research was largely complete in many places (including South Australia, at the Adelaide Dental School) by the mid-twentieth century, and has had profound, beneficial effects since then on both general and oral health, and the nature of dental practice. The University of Adelaide provided both the material support and the overt requirement for its Dental School also to become a strong and active member of the community of research scholars. Sometimes in active partnership with its medical counterpart, and sometimes acting alone, the School developed research programmes in at first

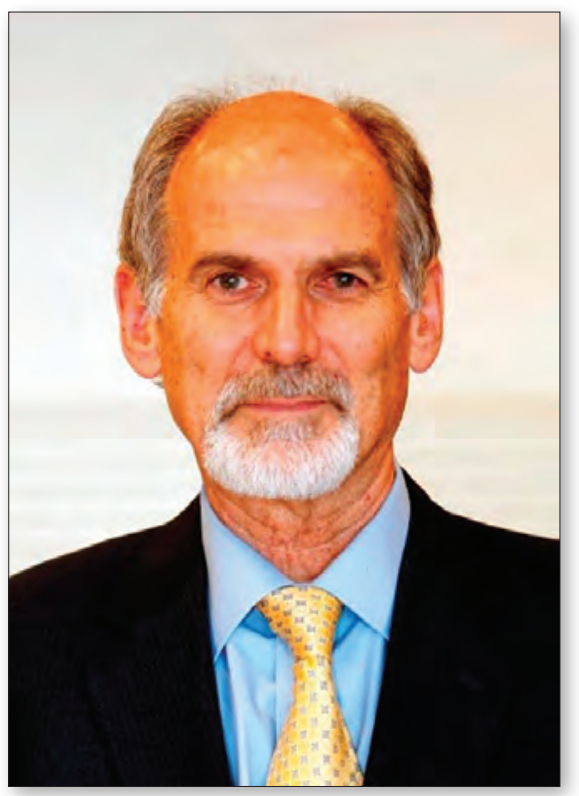

Figure 8.3 Wyatt R (Rory) Hume. a few, and then many, of its discipline areas.

The School increasingly integrated the substantial benefits of its own and other research into its teaching, clinical care and healthcare advocacy activities, providing valuable support, as it did so, for more effective educational and clinical programmes that were each responsive to community needs.

Prior to the integration of dental education into the research environment, the three main oral diseases - caries, periodontal disease and oral cancer - were each understood and managed primarily in terms of surgical intervention. The surgical removal of diseased oral and dental tissue, and in the great majority of cases teeth themselves, followed by the fabrication of removable prostheses, were the cornerstones of the dental profession. Dentists were in fact, as well as in name, principally dental surgeons.

However, research into the nature of caries and periodontal disease, conducted primarily by dental professionals working within research university environments, led over a period spanning most of the twentieth century to a profoundly different approach to care. As the understanding of the nature of the diseases improved, the following became possible: increasingly predictable and effective prevention; disease management with minimal surgery; and, finally, predictable and enduring cure of the two diseases without surgery. Increasingly effective reparative and tooth replacement technologies were also developed and validated, also through systematic research, in 
part by dental professionals based in research universities, and in part by dental and other research scientists working with industry.

Research into the nature and causes of oral cancers, which has been and is conducted in a broad partnership with medical and public health colleagues worldwide, also led to an increasing understanding of their prevention, and to the benefits of early detection and intervention. That process is ongoing, as it is for many other forms of cancer.

The knowledge created by research into oral and dental diseases changed both teaching and, in time, clinical care.

The University of Adelaide can be justifiably proud of its close association with one of the world's most successful community-wide interventions to improve oral health, the South Australian School Dental Service. By applying relatively simple oral health education and clinical preventive interventions beginning in the early 1970s in a school-based, publicly funded setting, the Service reduced dental disease rates dramatically across an entire population of children and adolescents, at very low cost. Many improvements also occurred in the dental private practice setting, through improvements in both initial and continuing dental education, aided by changed expectations and behaviour among patients.

These changes were profound. Oral and dental care is now much less focused on the delivery of tooth-extractive surgical services and the fabrication of prostheses, or on caries debridement and restoration placement as a primary mode of dealing with the disease, and much more focused on disease prevention and cure, supported by very conservative restorative services when these are required. Increasingly, dentists are also able to prevent the initiation and to halt the progression of periodontal disease, and able to guide the regeneration of supporting bone and soft tissue when that is required.

The principal challenge that remains in the area of dental and oral health is now how best to deliver these preventive, curative and, when needed, tooth- and supporting -tissue reparative and replacement services to populations at reasonable cost, both in publicly funded and in private, fee-for-service settings, in a way that provides appropriate incentives and rewards for care providers without the risk of overservicing. It is likely that this challenge will best be met by research conducted by an active and engaged dental profession working in close partnership with other healthcare colleagues, focusing largely on evaluating care outcomes relative to cost. To be successful, such research will most probably draw on the capabilities of research scholars in a broad range of disciplines.

The benefits of such research will, as it has throughout the last half-century, reach populations largely via the dental profession both through initial and continuing dental education, using an increasingly broad range of teaching and learning modalities. 
Dental schools might now design their curricular structures and their research and clinical service components with such goals in mind.

Increasingly, the oral health of populations will be positively influenced by health education, early diagnosis, intervention and monitoring services delivered not only by focused dental professional teams, but also by other health service providers in some form of partnership with dental teams. For example, it has been well recognised that the monitoring of blood pressure by dental teams can be a cost-effective way of improving general health, and such monitoring is now widely practised as an accepted standard of care. It is very likely to become increasingly clear that, for instance, costeffective oral health education services can be provided in partnership with medical care teams, including physicians, physician's assistants and nurse practitioners, for patients of all ages.

Recent data indicate strongly that relatively simple prior interventions to improve periodontal health reduce subsequent costs of medical care substantially in patients with diabetes, patients who have suffered cardiac infarct and women who have suffered complications after childbirth. Other close links between oral and general health may well become clear in the future. It will be in the interests of patients and communities increasingly to integrate oral and general health service provision, and to integrate the financing of such services.

These benefits of integration between research, teaching and clinical care will most probably continue to accrue in dental practice settings if oral and dental health education, research and service continue to be primarily managed and delivered by dental professionals, but if they are also organised in such a way as to be closely integrated into general healthcare in education, research and care delivery.

Finding the best balance between the unique nature of the dental professions and their close integration into healthcare as a whole in education, research and care delivery will not be simple, but it will most probably be one key factor determining the future value and effectiveness of the services that we provide. The other key factor influencing the future of our profession will be our continuing ability to find the most cost-effective ways of delivering high-quality preventive, curative and reparative services, through research linked with practice and care outcomes.

\section{Emeritus Professor Alastair Goss}

In the seventies I recall David Poswillo, the Inaugural Professor of Oral \& Maxillofacial Surgery (OMS), saying that 'education was a pendulum'. You could always find somebody in the world who was enthusiastic about a new educational concept; then you could find somebody else who was applying it now; and finally you could find somebody who had tried it but found that it had failed, and so they were moving on to the next educational concept! So the pendulum swings. Around the same time, Dick 


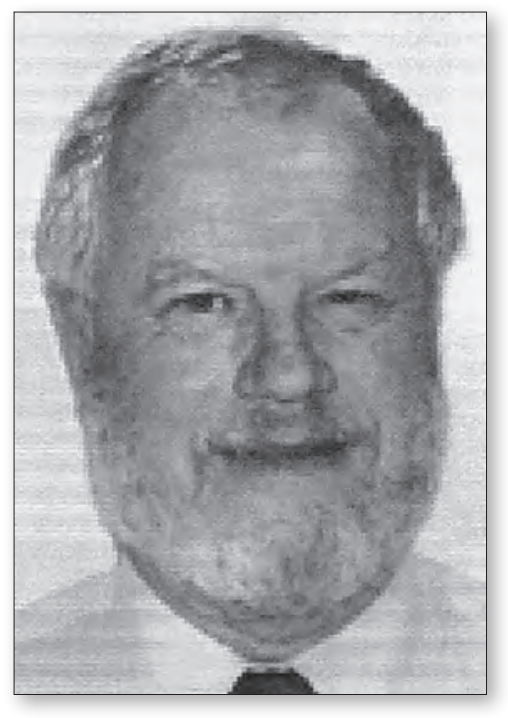

Figure 8.4 Alastair Goss.

Trott, an Adelaide graduate based in Winnipeg, was reviewing the then new curriculum. His advice was that the only real way to change the curriculum was to sack all the existing staff, as otherwise they just rebadge their old course and continue! Wise words.

I had the privilege in the early sixties of studying dentistry at the University of Otago in New Zealand. It was then, and is now, the best School in Australia and New Zealand (based on the world rankings of dental schools). We were the first class into the brand-new Dental School under the leadership of the brash Australian, Sir John Walsh. We had a very traditional education. The basic sciences were taught first: anatomy, physiology and pathology. These were taught fully and thoroughly, so that we worked our way through the principles and the applied material in a logical fashion. This was followed by general medicine, surgery and pharmacology. All courses were taught by qualified experts in the subject, commonly in shared classes with medical students. In parallel, we did hands-on dental technology, making all our own dentures, inlays and crowns. These were searchingly examined, so that early in the course both the weaker and the uninterested students were weeded out.

On graduation I furthered that experience with house surgeon jobs and then a Rotary fellowship - first, at the Royal College of Surgeons of England and then at the University of Michigan in the United States of America. This meant that when I arrived in Adelaide in 1970 on a one-year contract, I fitted in well as a junior lecturer. You learn a lot from hands-on teaching of undergraduates and postgraduates. Concurrent with that, I completed my research doctorate on embryology and in particular, cleft palate, and passed my fellowship examinations in oral and maxillofacial surgery. If anybody had told me in the early seventies that I would still be here forty-seven years later, I would have said that they were dreaming!

So, where are we now and what does the future hold?

To analyse that, one needs to look at a number of issues, namely:

- What are we educating dental students to do?

- What are the strengths and weaknesses of current teaching methods?

- How can teaching be improved?

- Assessment — are we assessing students optimally? 
- Dental School Staff issues

- $\quad$ Facilities

- Conclusions.

The fundametal issue is: What are we educating dental students to do?

That's very simple: the great majority of students are being trained to be clinical dental practitioners who will practise hands-on dental treatment for individual patients one at a time. Most will remain as general dental practitioners but with a wide variety of practice locations, styles and interests. About 20\%, at most, will undergo formal specialist training and qualifications. That doesn't include three-day courses to become an orthodontist or an implantologist, so don't get me started on that!

Importantly, only about $1 \%$ will become scientists, academics or educationalists. Hence clinical training led by expert clinicians must predominate.

\section{What are the strengths and weaknesses of current teaching methods?}

For the last two decades or so, the teaching in the early years of the dental course has been primarily by dental learning packages (DLP). It is worthwhile first to look at how learning packages in education developed. The original concept was that, in the first years at American colleges, students had a formal education in the building blocks of their subjects, whether that education was in the arts, biology or the health sciences. They would then go on to Graduate School, where they could assemble their knowledge with learning packages in a multidisciplinary way, under the guidance of trained specialists in the disciplines. This works well, as they have the fundamentals to apply. If, however, you start with the learning package, particularly if it is not taught by currently practising teachers, then there is a problem. The students get small snatches of information but lack the basics or the big picture.

I have long known that current dental students don't have a detailed knowledge of anatomy. If you are going to diagnose dysfunction, pathology or surgically cut people, you need to know where the 'bits and pieces' are. 'Terra nullius' appears to start about $5 \mathrm{~mm}$ from the tooth apex for most. This is not confined to dental students, in fact. Recently, I was discussing an oral cancer resection and reconstruction with a senior medical student. He had no idea of anatomy of the arm which was involved in a radial forearm flap. He advised that anatomy was elective these days and he'd never studied the arm but he'd done an elective on the knee. He knew quite a lot about the knee but one would hope that one's medical practitioner knew where all the body bits were and what they did.

Another example is the teaching of diabetes to dental students. First, it is very much overpresented as a medical topic. Over $50 \%$ of the initial exam bank of 
questions submitted for the Australian Dental Council had diabetes as the medical stem, whereas diabetes only affects $7 \%$ of the community. Students are taught early on that all diabetics have problems with healing, when in fact it is only patients with poorly controlled diabetes who have healing problems. To test this in 2009, I set up a study in the university extraction clinic to determine the incidence of dry socket and non-healing problems amongst diabetic patients who were on oral hypoglycaemic medication and were having extractions. The control group were fit and well. The findings of my study showed that, in fact, the control group had a much higher incidence of healing complications, probably mainly because the incidence of tobacco smoking in the fit and well public dental patient was much higher than in the diabetic patient (Huang et al. 2013).

So why, in 2016, when the evidence has been published and the students have been told about it, do the final-year students all trot out the statement that diabetics have healing problems? Probably because they remember what they were incorrectly taught in the early years — or do they ignore evidence-based articles?

\section{How can teaching be improved?}

A tempting answer to this question is to say that the curriculum could be 'flipped' - a current education term that I have purposely misused! My meaning is that the basic sciences could be taught traditionally, and some DLPs could be programmed in the clinical years, when the students have the basic building blocks.

Clearly, lectures are pointless as students don't attend. About eight years ago, all the OMS lecturer material was converted to an online lecture series. The students methodically go through the principles, basics and then the applications. There are eight modules with forty 'lecturettes', all illustrated. Indeed, we had this in place before the vice-chancellor announced that teaching should be online with small-group teaching (that is, in the clinics). This works well, so currently there is a series on general medicine for dental students and another in progress on oro-facial pain.

The only problem is that there was no money set aside by the university to produce this online material, so we have done it ourselves by a combination of the Australian and New Zealand Association of Oral and Maxillofacial Surgeons (ANZAOMS), Royal Adelaide Hospital and personal funds. It gives the students a solid basis for the clinics.

\section{Assessment - Are we assessing students optimally?}

Teaching and assessment within the major clinical disciplines remains mandatory. One of Sir John Walsh's many wise sayings was: 'We will teach you how to do things properly so you know how far you have fallen!' True then and true now. A variety of assessment methods should be used. The practice of dentistry involves just the dentist and the patient, and the patient expects the dentist to know all the answers now. There 
are no group sessions and no shooting the breeze. That's one of the reasons I use cards with the student's names on them to be picked to answer the questions. I'm infamous for it, but one-on-one is what happens in the real world.

One of the assessment learning experiences of my career has been as a long-term member of the Assessment Committee of the Australian Dental Council for foreign dentists. Over the last two decades we have developed psychometric testing, using specialist expertise, of a very large examination bank to a high degree of accuracy and predictability. Another assessment experience was as chairman of the Education Committee of the International Association of Oral \& Maxillofacial Surgery. The Committee developed the concept of an International exam in Oral \& Maxillofacial Surgery for the specialty worldwide. My initial attempt failed, but it has now been implemented successfully under the team leadership of Paul Sambrook. Again, a highly sophisticated, internationally validated exam.

Clearly, the current multiple-choice examinations at Adelaide Dental School need to be upgraded to these international standards. This is beyond the current skill and time availability of the staff, however, and the university doesn't appear to have such a specialist group to help.

An alternative would be to join with the Australian Dental Council (ADC) who have such expertise. In a recent pilot Adelaide Dental Students did well; however, students from some of the newer rural schools fared poorly. If they were from an overseas school, then one-third would be rejected from dental registration. I made a similar finding when I evaluated the teaching of Oral and Maxillofacial Surgery in Australia and New Zealand dental schools. For some, the sole teaching was simple extractions taught by general dental practitioners in a general clinic. Nothing else (Goss 2018).

Face-to-face viva exams also have a role, not the least of which is to encourage and train students to be able to interact sensibly, one on one with their patients. In these days of 'Dr Google', often patients believe themselves to be well briefed, and you need to be able to help them sort out the wheat from the vast amounts of chaff that you can find on the internet.

\section{Dental School staff issues}

The Dental School staff has changed significantly over the years. Generally, there has been a progressive reduction in numbers and a decline in those who are experienced, hands-on clinicians. For example, in the mid-seventies there was a 4.5 FTE of university teachers in oral pathology and oral surgery. Currently it's about 1.5 FTE with some of the numbers being made up by hospital appointees. They are all part-time, but, on the positive side, they have high clinical skills. 
The greatest loss in the staff, however, has been in the technical and administrative support areas, as the Professional Development Review (PDR) of 2015/2016 has resulted in a large number of Dental School staff being disestablished.

\section{Facilities}

There is no doubt that the current facilities are old and tired. So, a new School is a great idea. Is it wise to put it on the top floors of a high building? The current size of the new facility actually matches the size of the current staff and a class of no more than forty-five. Is it a good idea to have all the staff in a single large room with no space or privacy? Time will tell.

\section{Conclusions}

It has always been the fate of elders to be concerned about the problems of the young. But as a born optimist, I don't despair. Indeed, having remained on the Dental School staff, full-time for forty years and then for a further seven years as an unpaid emeritus, and having experienced the challenges of the eighties with the OMS Unit, I feel that I need to be an optimist.

Poswillo's pendulum does need to swing, not to remain stationary. Trott's mandate that there needs to be major changes in the staff is occurring, with the retirement of many of the senior clinical staff, myself included. Provided the profession is aware of the challenges and acts on objective analysis rather than dogma, then the Dental School will flourish. However, I believe that the clinicians, not the administrators or educators, need to regain some measure of control of the Dental School. If they don't, the Barbarians are at the gates!

\section{Emeritus Professor Wayne Sampson}

Over the past 100 years the Adelaide Dental School has earned a proud international reputation for excellence in education, research and clinical achievement. This book has followed many of the events and individuals who have made outstanding contributions to the perception that dental graduates from the University of Adelaide are amongst the best in the world. But what of the future?

My perspective from fifty years in dentistry is that there have been many changes - particularly with regard to technological advances and the ever-expanding improvements in equipment and materials that have led to sophisticated management of our patients' oral health and wellbeing. The concept of 'patient' has meant the provision of appropriate care that is in the person's best interests and we, as professionals, should always put the patient's needs first. With the increasing commercialisation of our lives, it is disappointing to witness the apparent erosion of these professional ideals through 
aggressive marketing. In orthodontics, for example, there are now many courses available which claim to teach dentists how to perform appliance therapies that were once regarded as the province of specialist orthodontists. Particularly of concern is the commercial emphasis placed upon the practitioner's income potential from providing services to meet a claimed increase in demand from the public. The demand seems to be more a product of clever advertising than genuine health benefit. Is this really meeting the patients' needs or are we simply providing a service to a 'client'? It is of concern that the leading medico-legal issues now involve dental

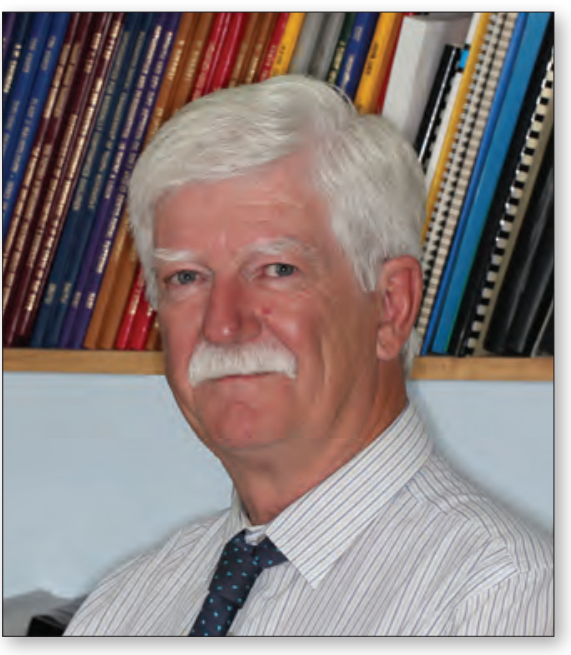

Figure 8.5 Wayne Sampson. implants and orthodontics. Undergraduate programmes have never included sufficient curriculum time for a newly graduated dentist to be proficient in clinical orthodontics beyond basic recognition of dentofacial patterns and some developmental variations.

With the introduction of mandatory continuing education, where 'points' are accumulated for registration purposes with the regulatory bodies, a very fertile field of opportunity has been exploited by predominantly private entrepreneurs and dental supply companies to meet the increased need and demand for 'education'. However, there seems to be precious little effective regulation regarding standards or competency of the newly acquired skills. The growing spectre of a Pandora's Box of privately run educational institutions might pose significant challenges for the more traditionally accepted university-based programmes. The stringent accreditation checks on university programmes would also need to be applied to the alternative options, but will the regulatory bodies be able to deliver the necessary evaluations to monitor competencies and high standards?

Universities have also evolved. When I decided to join academia in 1976, there was a strong perception of the virtue of scholarly pursuit and there was what I found to be a largely satisfying level of collegiality. Over time, the business model has prevailed, with emphasis upon output performance indicators and mostly financially driven expectations. The measures of academic success now seem to me to be how many students have completed their programme and how much money has been generated from teaching and research. Academic life has become very competitive and I find it difficult to see where the dental teachers will find sufficient time to teach increased 
student numbers, manage burgeoning administrative loads and pursue research, with diminished access to secretarial assistance.

Time will tell whether government decisions to increase the number of dental schools, and thereby the number of dentists, have been in Australia's best interest. Perhaps the notion that increases in the number of locally trained dentists, along with the acceptance of many overseas-qualified dental migrant dentists, would lead to greater competition and control of the cost of dentistry will more likely encourage provision of services beyond tested competencies and ultimately lead to greater expense. As yet, these are still early days.

Despite such challenges, I'm still optimistic, because dentists are a resilient, innovative and dedicated group of professionals who seek the highest standards of treatment for their patients. This translates into educators who always want to encourage future dentists to achieve excellence in their chosen profession - but the pressures placed upon maintenance of this noble aspiration have perhaps never been greater.

\section{Clinical Professor Geoffrey Heithersay AO}

During my fifty-six years of involvement in the education of dental students, specifically in the discipline of endodontology and dental traumatology, I have witnessed some significant changes within the Adelaide Dental School, but none can compare with the educational challenges that the School now faces as it enters its second century.

This valuable history of the evolution of the Dental School at the University of Adelaide over the first 100 years reveals the truth of the old saying that 'history repeats itself'. Dentistry at the University of Adelaide was first established under the umbrella of medicine and it was not until the 1950s that it emerged with faculty status only to then lose its independence in 1999, when again it was broadly brought under the control of medicine within the Faculty of Health Sciences. While the apparent economic advantage for the amalgamation of disciplines was the driving force for the university's decision, it nevertheless had important implications for the School of Dentistry and its future educational development.

An early administrator (superintendent) of the Royal Adelaide Hospital's Dental Hospital was a remarkable member of the dental profession - James (Bill) Scollin, who had survived as a Japanese prisoner of war. A man of great integrity and clinical ability, he and the university's Faculty of Dentistry worked well together with remarkably little conflict - it was truly a dental school/hospital with a common purpose of educating dental students. In 1975, upon the retirement of Bill Scollin, the Board of Management appointed an administrator to replace him. The first appointee resigned after a very short period, and Robert Barter then became administrator, a role he filled with similar collegiate understanding of a combined Hospital/University School of 
Dentistry. Bill Scollin, in a Foundation Day address in 1984, concluded with the following words: 'My history of the Dental Hospital closes on, for me, a sad note. The Health Commission decided to amalgamate the School Dental Service and the Dental Hospital. In June 1982, the new organisation, [the] South Australian Dental Service came into being and $\mathrm{Mr}$ Barter returned to Royal Adelaide Hospital' (Scollin 1984).

Thus began a new era in which state government control of the Dental Hospital became the new norm and the symbiotic relationship embodied with the previous administration slowly, but inevitably,

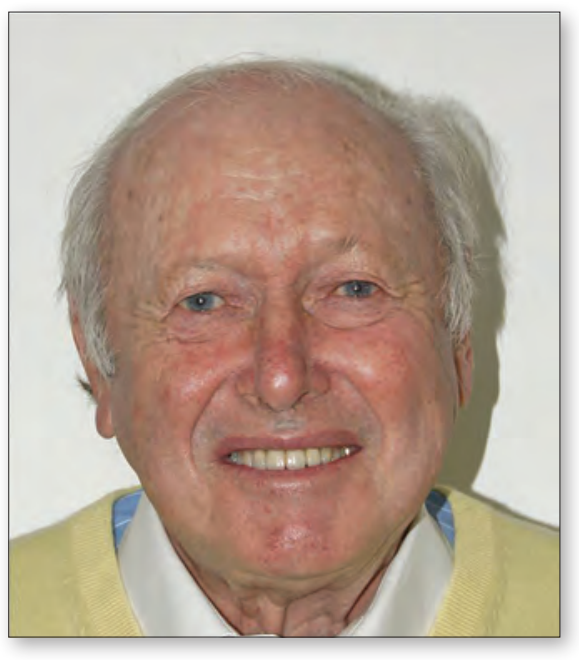

Figure 8.6 Professor Geoffrey Heithersay. changed, with the result that the South

Australian Dental Service became the dominant player and the university's School of Dentistry became reliant on the generosity, but also the control, of the SADS administration.

The predicted closure of the Frome Road Dental Hospital in 2017 created a major challenge for the Dental School. Due to a breakdown in negotiations between the University of Adelaide and the state government, the School was forced to bid for the right to access government patients via the South Australian Dental Service, in direct competition with other Australian and overseas institutions. Considerable concessions were made in the successful University of Adelaide bid, which included the relocation of the South Australian Dental Service Clinics and academic staff to the new University of Adelaide Medical and Nursing School. The agreement between the state government and the university envisaged a reduction of student numbers, which, if fully implemented, will compound the financial state of the Dental School. In respect to the BDS dental degree, it is predictable that the University of Adelaide will follow the example of the University of Melbourne and the University of Western Australia, both of which have implemented a graduate programme for dentistry with entry dependent on the completion of a suitable undergraduate degree. Such a change would provide dental graduates with the broader education commonly experienced by graduates in the USA and many European countries.

The scene has been set for significant new physical and educational challenges for the Adelaide Dental School, and my comments regarding the future directions of dental education will be confined to the BDS programme, where I have had a lifetime involvement. While I am aware of the many fine and dedicated dental educators in the 
$\mathrm{BOH}$ programme, I lack sufficient knowledge of their curriculum and training to be able to comment on the future directions of their discipline.

The physical challenges that will have an impact upon the education of dental students relate to the diverse locations for teaching — the Simulation Clinic is remaining in the main university campus, while clinical teaching will be divided between the new clinical facility with forty-eight chairs and various community clinics which have been established by the South Australian Dental Service and the University of Adelaide. The theoretical and practical components of the Dental course have evolved significantly over the past decades and it could be anticipated that this pattern will continue into the future. The challenge will be to maintain a high level of clinical teaching and supervision in the various locations. It would be expected that there will be benefits in dental students experiencing rural dentistry and possible social interaction with diverse communities. Clearly, the exposure of final-year students to advanced teaching by specialists in various disciplines - for example, periodontics and endodontics — will need to be addressed within the new framework if students are to be equipped with sufficient theoretical knowledge and practical experience consistent with the demands of modern dental practice.

Adequate staffing of the Adelaide Dental School will be critical to meeting the educational challenges posed by the new facilities and state government requirements, but with the financial restrictions currently being experienced within the university this is likely to be a slow path. Attracting dedicated teachers to an academic career will be an ongoing challenge. The creation of more attractive 0.2 FTE or 0.4 FTE teaching positions at levels commensurate with postgraduate qualifications could provide attractive employment for those who wish to expand their experience and personal academic advancement while maintaining private practice. Reliance on the many dedicated part-time tutors will continue and probably increase with the enforced forty-eight-week academic year.

With the shift of most academic staff to the new University of Adelaide's Health and Medical Science building in the west end of North Terrace, restrictions on space and facilities may have potentially unfortunate consequences. Almost all staff will be accommodated in a common area, with little or no privacy. However, it is hoped that this physical arrangement might lead to greater collegiality, and being housed in the Health Sciences building may lead to greater interaction with other medical/ nursing disciplines. The facility will be largely bookless, with reliance on internet access to literature. The concept of academics without their personal collection of textbooks, theses and research material seems to me unthinkable but this trend is not confined to the University of Adelaide. Corporatisation within universities seems to me increasingly to be the norm. The likely result may well be that many academics will need to work from home or in alternative facilities if they are to maintain their 
standard of teaching and research for which the Adelaide Dental School has developed worldwide recognition.

Research and excellence in teaching go hand in hand, and the maintenance of active research groups will be essential to the educational health of the Dental School. With the disestablishment of many key research support staff in 2015-16, readjusting to new facilities and sharing centralised support staff will pose major challenges both for academics and for honours and graduate students. The doctorate of clinical dentistry programmes in all disciplines will remain essential for the health and reputation of the Adelaide Dental School. Candidates also provide valuable undergraduate teaching and their research injects valuable academic stimulation.

Technology in teaching will inevitably increase, with a greater use of online lectures, simulated clinical scenarios, interactive diagnostic programmes and other innovative teaching modules. While the use of these technologies may free up lecture time for academic staff, the preparation time and updating of online modules may negate the apparent advantages. The re-establishment of a university audiovisual production team to develop teaching material will be essential. For online teaching to be effective there must also be direct contact with academic staff, either in small-groupteaching or class meetings, where recording facilities should routinely be employed by all staff to supplement any online material.

With the increasing sophistication of clinical dental practice, undergraduate teaching will need adjustment. The present broad and excellent teaching in general and oral physiology, pathology, immunology, microbiology, and pharmacology must remain as essential basic biological sciences, while oral diagnosis including advances in oral radiology must continue as a cornerstone of clinical dentistry. While 'preventive dentistry' has been taught for over sixty years, an extended concept of preventive dentistry should have as its aim the maintenance of a healthy and functional dentition, and should embrace broader methods of disease management, including periodontics, endodontics and restorative dentistry. Hence there will be a need for broader teaching in these and related disciplines, but students should also be made aware of clinical situations where referral to a specialist would be required. When tooth loss is inevitable, prosthodontic replacement with implants, bridgework or removable prostheses will necessitate expertise in overall management, either within general practice or in referral for specialist treatment. Inevitably, full denture prosthodontics will be phased out from the undergraduate curriculum, as there will be little demand in general practice, since, increasingly, that field becomes the domain of the clinical prosthetic technician or a specialist prosthodontist. The existing high level of teaching and clinical supervision in oral surgery will also face new challenges in its new environment, as outlined earlier by Emeritus Professor Alastair Goss. 
In an era dominated by social media, the basic aim of the teaching of dentistry remains to graduate well-educated and clinically competent health professionals who will become ethical and empathetic members of the dental profession. There has been an explosion of new and exciting advances in dental technology and materials over recent decades and it could be anticipated that future developments will prove equally stimulating for dental students in the future. Beyond technology, the teaching of social interactive skills, both at a personal and community level, will be of increasing importance.

During the past 100 years the Dental School has faced many challenges which it has met with positivity. It is my hope and belief that the School will rise again to meet the unique challenges it now faces as it enters its second century. It has been a privilege and pleasure to have been involved in dental education within the University of Adelaide for over half of the first 100 years.

\section{Published comments by Dr John McIntyre}

Dr John McIntyre has addressed the 'crisis in funding and support for dental education' in a recent opinion paper in the ADA News Bulletin (2015).

In this paper, McIntyre acknowledges that many factors are involved, but he points to an important initiating cause as occurring in 1991-92 when the federal government reduced the funding of BDS training programmes. McIntyre was the dean at the Adelaide Dental School at that time and he notes that, up until then, funding for courses was based on their assessed cost. For example, in the 1970s, it was determined that the cost of training a medical student was about $\$ 12$ 000/year, whereas the cost for a dental student was $\$ 32000 / y e a r$. The difference in cost reflected the fact that medical students had little 'hands-on', small-group teaching, and most of this was provided by hospital staff. As McIntyre points out, much of the 'hands-on' training of medical students occurs after graduation during their internship and is subsidised by the federal government. In contrast, dental students must be competent to provide a wide range of clinical services upon graduation, and this requires high staff/student ratios for clinical training that is not subsidised.

McIntyre notes that following the introduction of the Dawkins reforms to higher education in the late 1980s, the funding formula to universities was simplified so that medicine, veterinary science and dentistry were all grouped together in a single block for funding, resulting in a reduction of funding of around $60-70 \%$ for dentistry.

Although increasing the number of international students has brought more money into the universities, the proportion of this money retained by the university has been high (up to $70 \%$ for dentistry at Adelaide in 2005), meaning that relatively little has flowed through to the School. As McIntyre describes, universities have 
tended to use funds from overseas fee-paying students 'as a "cash cow" to prop up ever expanding administrations and compensate for constant reduction in federal funding' (p. 26). This is likely to be one of the reasons why universities have commenced new dental schools in recent times.

McIntyre discusses several approaches to dealing with the funding crisis. He notes that most dental schools are looking for lower-cost approaches to teaching, including students spending more time in the simulation laboratory than in treating real patients. The clinical years have also been extended (to forty-eight weeks in Adelaide as an outcome of the recent tender process). Some Australian schools have moved to graduate-entry fee-paying models, as Professor Geoffrey Heithersay mentioned earlier, but the issue of equity looms large, as does the question of what the effects of large debts will be on graduating dentists and how these debts may influence the type of dentistry practised - something that is yet to be determined.

McIntyre notes that if deregulation of university fees comes into effect, it is very likely that there will be large increases in fees for dentistry. He asks for 'widespread discussion within the profession as to the different approaches to our educational programs, to ensure the quality of dental education is not further diminished and that it is a viable option to all bright students seeking to enter it' (p. 27).

Some options and issues for consideration raised by McIntyre are:

- the involvement of students in public clinics over the whole year to ensure a 'ready supply of teaching cases at an undergraduate level'

- the restructuring of curricula into a four-year course, followed by a one- or two-year 'internship' in public health dental clinics or possibly accredited private practices

- the importance of ensuring that, with likely increases in the number of overseas fee-paying students, universities provide a sufficient proportion of the fees that are paid to dental school budgets 'to ensure their costs are totally neutral to both university and DOH costs in training them' (p. 27).

It is worth noting that the Voluntary Dental Graduate Year Program (VDGYP) in dentistry that was introduced in 2013 was terminated by the federal government in 2015.

\section{Comments by other dental academics}

Comments made in the Australian Dental Journal by three leaders of the dental profession in Australia are also included to stimulate thought:

- $\quad$ Professor Mark Bartold

- $\quad$ Professor Eli Schwarz

- Professor Terence Freer 


\section{P Mark Bartold, Adelaide Dental School, editor, Australian Dental Journal}

The words below were originally published in an article in the Australian Dental Journal entitled 'The dumbing down of dentistry' (Bartold 2009). They are reproduced here with permission from the Australian Dental Journal.

I have written about this before and I am sure I will write about it again. The dental schools are in trouble and, therefore, dentistry is in trouble. The experts tell us we need more dental schools - especially in rural areas to not only retain, but also attract dentists, to these regions. While an admirable goal, at what cost will this be achieved? The established dental schools in Australia have a solid, sound and proud tradition of academic excellence involving teaching, research and service. Some of the 'new-age' dental schools, often with affiliations to less traditional academic institutions, appear to have no such ethos. A recent article published in Campus Review quoted one senior Australian academic as advocating the concept of moving away from full-time academic appointments in dental schools to mixed or blended appointments of hiring local dentists to do most, if not all, of the teaching. While on the surface this may seem reasonable, I am concerned over the qualifications and experience of these new wave academics for university teaching and research and service. While local dentists may have considerable clinical experience, how can we be sure they are at the cutting edge of knowledge and expertise we would expect of a 'real academic'? I suspect the answer could be debatable but I doubt the majority of these new wave teachers will have been reading current top ranking and high impact journals in their supposed fields of expertise encompassing all fields of clinical and scientific dentistry. I have my reservations as to when some of them may have last attended a serious clinical update course to improve their knowledge base and clinical skills in any of the specialist areas of dentistry. While I suspect I will get 'howled down' for such inflammatory statements — the truth hurts and we must accept the simple reality of the situation. These schools are likely to be staffed by technical experts but by no stretch of the imagination true academics at the forefront of the science and art of their specialized field. A more sensible alternative to opening up a plethora of new-age dental schools, as suggested by another senior academic, would have been to utilize the existing expertise of the existing schools and rotate students to rural settings under the guidance and supervision of mainstream academics.

The time has come for the profession at large to consider the real ramifications of the dumbing down of dentistry. The dental schools, both traditional and new age, are suffering from a staffing crisis. There are very few young academics in training and even fewer appropriately qualified individuals available and willing to step into academia. The obvious sequelae to this is that in the not-too-distant future academic positions will be filled by under-trained and under-qualified staff who will not be able to compete and survive in the overall university environment. We run the risk of returning to the apprentice training scheme of eons ago. I strongly believe that a dental school may well be clinically strong but without a 
strong research base it will be nothing. Think of the 'great dental schools' in the world and you will quickly see that their reputation comes from their research not their clinical excellence. The clinical excellence comes as a secondary factor to the research excellence. With the demise of academics capable of undertaking serious research, clinical work at the forefront of each discipline and providing service to the profession by way of postgraduate training and continuing education, it is obvious that this has the potential to lead to the dental schools being sequestered off from traditional universities as they will no longer be able to fulfil their obligations to warrant status as bone fide university departments. Who will take them? The only options available will be to either privatize the dental schools, realign them with the so-called 'new-age universities' or see them engulfed by technical training colleges. None of these should be palatable options for our profession.

I hope the future proves me wrong. However, if my predictions are correct then the dumbing down of dentistry will be a fact and something that we will all have been responsible for allowing to happen.

\section{Professor Eli Schwarz, former dean of the Dental School in Sydney}

Professor Schwarz wrote the following response to the article above (2009) and it is reproduced here with permission from the Australian Dental Journal:

I take exception to almost every statement in the Editorial published in the March issue of the Journal.

I find the Editor's premise ('The Dumbing Down of Dentistry') offensive, wrong, and lacking in evidence.

In contrast, I find the government's decision to invest almost $\$ 150$ million in new dental education infrastructure invigorating and empowering for the communities in which they are being established and, hopefully, they will create new opportunities for dental education and access to dental care overall. Of course, I would have loved to receive tens of millions of dollars to improve our infrastructure in Sydney, but the fact that our new dental schools have been placed in regional areas, which the metropolitan dental schools have ignored for decades, is a testament to a failure of the 'solid, sound and proud tradition' of the established dental schools.

The characterisation of these new dental schools and their academics as 'new-age' is arrogant and disrespectful in the extreme and completely ignores the fact that they have all been through the ADC's rigorous accreditation process.

I don't think the Australian dental community has ever experienced such a concentrated recruitment of highly-qualified dental academics from institutions across the world in such a short period of time. The Editor's a priori assumption that these new colleagues of ours are any less serious about serving our universities and communities than the existing ones is completely baseless. The Editor's reference to our use of practising colleagues in the clinical training programme as 'dumbing down dentistry' is nothing but appalling. Since the days of Gies in the early 1900s, 
training of dentists has been implemented through the use of dental practitioners from the community, either in a hired or an honorary capacity, balanced by contributions from faculty staff whose priorities could be in the research or in the learning and teaching arenas.

Clearly, it is the responsibility of the dental school to ensure that the purpose of this collaboration is well defined and that appropriate quality assurance is established through calibration and training of the staff who are providing student supervision. No dental school that I have ever visited had its entire clinical training done by full-time research staff.

The fact that we are now attempting to expose our students to a community-based clinical experience is entirely consistent with our realisation that the teaching hospital is a poor proxy for what happens in the real world and that that experience needs to be complemented by community experience to produce a well-rounded dental graduate. The lack of trust in our community-based colleagues is like shooting ourselves in the foot. Neither research nor clinical training takes place in a vacuum. The greatest dental schools in the world are great because, among other things, they are excellently supported by their alumni - most often community-based dental practitioners - who assist in the clinical education part, thus leaving the full-time staff more time to pursue research or university service and curriculum planning tasks. No dental school would survive by only doing research because it would have no purpose unless there was a strong connection to the clinical activities. In fact, the whole notion of the development of evidence-based dentistry, to which most dental education aspires, rests on a premise of an ongoing exchange between identified clinical problems and researchers' continuous attempts to solve them.

In conclusion, it was depressing to find such a biased and deprecating piece about the relationship between the dental academic institutions and the dental profession in the profession's own research outlet. We definitely need a broad debate about the status of Australian dental education including all factors impacting on the situation in the dental schools including government and university funding, staffing, competencies of the graduates, relationship to the profession and to the surrounding dental care systems and so on. But without a strong and trusting relationship between those two parties, neither the old nor the new dental schools in Australia will succeed.

Bartold's response was noted in an Editor's note as follows:

Editor's note: I thank Professor Schwarz for his comments regarding my Editorial published in the March issue. This Editorial generated considerable interest. Professor Schwarz's letter was the only negative letter received. Numerous letters (too many to publish), telephone calls and conversations received provided positive feedback on the subject matter. 


\section{Professor Terence (Terry) Freer, University of Queensland}

Selected aspects of a paper in the Australian Dental Journal by Emeritus Professor Terry Freer from the University of Queensland also provide a very insightful commentary on contemporary issues in dental education in Australia (2010).

In the abstract of his article Freer states:

Australia has witnessed a proliferation of dental workforce training opportunities over the last 15 years, including dentists, dental therapists, dental hygienists and prosthetists. The reasons for this have not been examined critically. Universities have welcomed the opportunities to increase the student base but do not seem to have examined the advisability of continued expansion or its impact on the delivery and costs of health services. Nor have they enquired expressly whether they have any responsibility in these matters. Public health benefits should constitute a significant element of curriculum design. There seems to have been a general acceptance of the premise that more is necessarily better. Ironically, these developments have occurred in the face of significant recurrent cost increments and serious academic staff shortages. The schools have responded with alterations to curriculum content. Student cohort composition, course structures, educational focus, postgraduate training and research have been affected. (p. 20)

Freer argues that some of the current issues that are driving workforce training and curriculum content should be re-examined and that defined common objectives need to be set for Australian dental schools.

He lists nine developments that he believes are needed to prevent a decline in dental educational standards in Australia:

1. The implementation of stable sustainable funding models for dental schools and public examination of the establishment of any new training facilities.

2. Insistence on university accountability for facilities, funding and staffing profiles.

3. Sensible curriculum progression which mitigates the constant burden of major disruptive change imposed by individual preference and university policies.

4. Transparent governance structures and a national school database.

5. National definition of dental competencies and how to assess them.

6. Transparency of dental curriculum objectives with accountability to all stakeholder groups.

7. Re-evaluation of the team concept including dentists, dental technicians, dental therapists and dental hygienists in terms of education and efficient health delivery.

8. Clear definition of the role of the Australian Dental Council in setting standards. 
9. Establishment of a standardized national clinical academic training scheme supported by accurate national records. (p. 26)

\section{The growth of new dental schools in Australia}

There has been a rapid growth of dental schools in Australia over the past decade or so. Up until 1946 there were only four dental schools in Australia, located in Adelaide, Melbourne, Sydney and Brisbane. Then, in 1946, the Dental School at the University of Western Australia was opened. This situation was stable until 2004 when the first of the so-called 'new age' dental schools, using Mark Bartold's words, was opened at Griffith University on the Gold Coast. Since then, several new dental schools or schools of oral health have commenced at Charles Sturt, LaTrobe, James Cook, Newcastle, Curtin and Central Queensland University, without any national regulation. Clearly, there are differences of opinion about the advantages and disadvantages of this rapid increase. However, whatever your view, it has produced a seismic shift in the landscape of dental education in Australia.

Advertisements have now appeared in the media for 'Australia's newest dental school'. The Postgraduate School of Dentistry, marketed as Australia's first private dental school, was established in 2014 'to provide state of the art, accredited post graduate qualifications for the practitioner of tomorrow' (Postgraduate School of Dentistry 2016). The promotional material states that the curricula on offer are aimed at 'niche areas of dentistry, principally for general dentists around the world to gain further qualifications and to sub-specialise'. It is claimed that dentists can remain in general practice yet offer specific treatments and services that are beyond the realm of their undergraduate degrees. The promotional material states that students will obtain a 'prestigious, government accredited Level 8 qualification (between a Degree and a Masters) and post-nominals which distinguishes [sic] yourself in your area of subspecialty'. The programme is described as being 'self-paced, self-directed, all online, your own patients, your own practice, state-of-the-art content, highly practical with unique e-learning platform, and one-on-one mentoring'. Could this be the way of the future?

\section{Concluding comments by the authors}

In the previous chapters, the evolution of the Adelaide BDS curriculum over the past 100 years has been described, together with factors, both within and outside the School, that have driven change. The Adelaide Dental School has earned an international reputation for the excellence of its teaching and research, but it has reached a critical point in its history.

As was noted in the Preface of this book, the University of Adelaide's previous vice-chancellor, Professor Warren Bebbington, has stated that there will be far-reaching 
changes in the tertiary education sector across Australia in the next few years that will 'sorely test the resilience of the University's mission and values as it faces new circumstances on every front' $(2017$, p. 1). We have learnt from our history that financial and other pressures on the university are quickly reflected in pressures on the Dental School, given that educating oral health professionals is complex, expensive and very demanding. Moreover, the process is rarely understood by those not directly involved.

We have also noted previously that the loss of full faculty status for dentistry in 1999 led to a loss of control over our own destiny, with the loss of a formal forum for robust, collegial debate and decision making. We believe that maintenance of its reputation in teaching and research into the future will depend on how effectively the Adelaide Dental School, and the dental profession at large, are able to advocate and negotiate their way forward in an environment with many competing interests, where control resides in a Faculty of Health and Medical Sciences functioning within a corporate style of university management.

In this chapter, several senior dental academics have provided their views about the future of dental education and dental practice for readers to contemplate. Clearly, the quality of dental education in the future will have a direct bearing on the quality of dental practice and, given the 'hidden nature' of much of what we do, it is likely to take a long time before any falling standards are recognised by the public and even longer before remedies can be found.

While it is unclear what the future may bring, we wish the Adelaide Dental School every success in maintaining, and hopefully improving, the outstanding national and international reputation it has built for excellence in teaching and research over its first 100 years.

\section{References}

Bartold PM (2009) The dumbing down of dentistry. Editorial. Australian Dental Journal 54(1): 1. https://doi.org/10.1111/j.1834-7819.2008.01096.x.

Bebbington W (2017) Facing the winds of change. Lumen (Alumni Magazine, University of Adelaide), Autumn Issue: 1.

Dunning DG, Durham TM, Lange BM, Aksu MN (2009) Strategic management and organizational behaviour in dental education: Reflections on key issues in an environment of change. Journal of Dental Education 73(6): 689-695.

Freer TJ (2010) Contemporary issues in dental education in Australia. Australian Dental Journal 55(1): 20-27. https://doi.org/10.1111/j.1834-7819.2009.01184.x.

Goss AN (2018) The teaching of oral and maxillofacial surgery in Australian dental schools in 2016. Australian Dental Journal Supplement: 'Contemporary Oral \& Maxillofacial Surgery' (in press). 
Huang S, Dang H, Sambrook P, Goss A (2013) The healing of dental extraction sockets in patients with Type 2 diabetes on oral hypoglycaemics; a prospective cohort. Australian Dental Journal 58:536-543. https://doi.org/10.1111/adj.12029.

McIntyre J (2015) A personal perspective on the crisis in funding and support of dental education. ADA News Bulletin, February (439): 26-27.

National Health Performance Committee (2002) National report on health sector performance indicators 2001. Queensland Health, Brisbane.

Reinders JJ, Krijnen WP, Onclin P, van der Schans CP, Stegenga B (2016) Attitudes among dentists and dental hygienists towards extended scope and independent practice of dental hygienists. International Dental Journal 67(1): 46-58. https://doi.org/10.1111/idj.12254.

Scambler S, Gupta A, Asimakopoulou K (2015) Patient-centred care - what is it and how is it practiced in the dental surgery? Health Expectations 18(16): 2549-2558. https://doi. org/10.1111/hex.12223.

Schwarz E (2009) Dumbing down dentistry. Letter to the Editor. Australian Dental Journal 54(3):281. https://doi.org/10.1111/j.1834-7819.2009.01136.x.

Scollin J (1984) 1984 - A history of dentistry in South Australia. Address delivered at the Sixth Foundation Day Ceremony held at the Royal Adelaide Hospital on 11 July 1984. http://www.healthmuseumsa.org.au/menu/foundation-day/1984-a-history-of-dentistryin-south-australia (accessed 8 March 2018).

Postgraduate School of Dentistry (2016) World class education for world class dentists. www. pgdentalschool.edu.au (accessed 24 January 2018).

Townsend GC, Thomas R, Skinner V, Bissell V, Cohen L, Cowpe J, et al. (2008) Leadership, governance and management in dental education - new societal challenges. European Journal of Dental Education 12 (Suppl. 1): 131-148. https://doi.org/10.1111/j.16000579.2007.00495.x.

WHO (1986) The Ottawa Charter for Health Promotion. First International Conference on Health Promotion, Ottawa, 21 November. www.who.int/healthpromotion/conferences/ previous/ottawa/en/ (accessed 24 October 2016).

WHO (1997) Jakarta Declaration on Leading Health Promotion into the 21 st Century. Fourth International Conference on Health Promotion, Jakarta, 21-25 July. www.who.int/entity/ healthpromotion/conferences/previous/jakarta/en/ - 31k (accessed 21 October 2016). 
Section II:

Personal reflections 



\section{Dental student (1941-45) - John Lavis}

\section{Some recollections}

These recollections were originally set down following a request from Dr Mervyn Evans for material for a history of the University of Adelaide Dental Students Society which he planned to write. For the most part I was too slow for Dr Evans's needs, but I enjoyed it so much that I kept on.

Perhaps I should have taken more notice of Lennie Brougham's advice about soldering investment: 'Cut it away until you think you have ruined it, then remove half of what remains'.

JFL, December 1987

\section{Finding a path}

At about seven or eight I was taken to Mr Roy Sims for treatment. These visits meant a trip by tram to the corner of Wakefield and Hutt Streets, then an endless walk to South Terrace. After the visit, the slog was reversed and I came to dislike Hutt Street intensely. But the dreary journey was forgotten once I was in the waiting room. I liked the goldfish and the smell of antiseptic and eugenol, and even then I was aware that everything was spotless. Although treatment was unpleasant, Sims was not: he was kind and gentle; and when later I began to think about dentistry as a career I was strongly influenced by the image of Roy Sims as a professional gentleman. The image did not dim in the light of later experiences. 


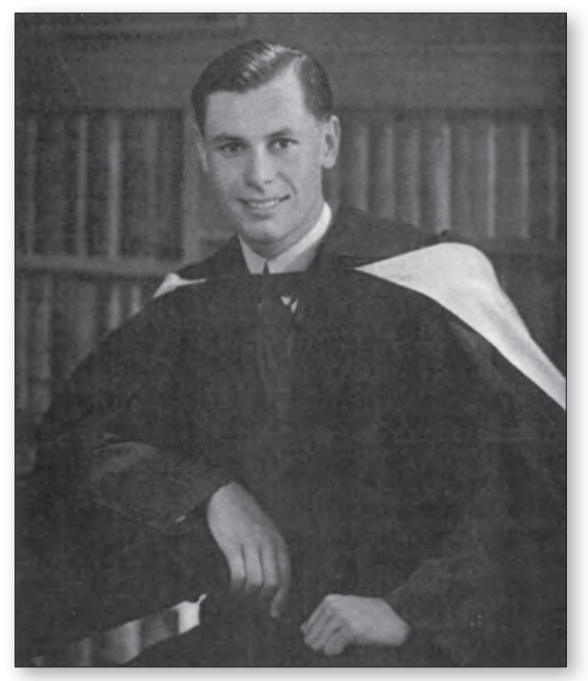

Figure 9.1 John Lavis AM MDS FRACDS FICD FADI.

In 1938 I was sent to C Rex Forder for treatment and saw modern dentistry practised in modern surroundings. For the first time I had a local anaesthetic for cavity preparation, experienced an electric dental engine, and had a matrix placed for amalgam. Quiet in manner, Rex Forder was efficient, up to date, and interested in his patients as people. Here was another example which I later followed when I set my sights on a North Terrace practice like Forder's.

Meanwhile, my father had suggested a university course and I decided that the choice would be between dentistry and medicine. I cannot remember sitting down and thinking it out logically for myself but one Saturday, after the evening meal, we sat around the table and decided on dentistry. I chose it because I would not require Leaving Latin and because I should not have to handle viscera as I had seen my Uncle Arthur Haynes do when dressing rabbits. I think that a shorter course also came into my thoughts. Since then I have added the fictitious reason that I would rather place my hands in the mouth than in other orifices which would present in medical practice.

My father agreed readily, doubtless supported in his mind by the fees which he had paid to Forder. The likelihood of an assured and adequate income mattered a great deal in the 1930s. Matriculation presented a language problem. Languages were not taught at Adelaide Technical High School (ATHS), but I had received wise advice to attend a special course in French which was available to a few students who might wish to matriculate. I went to Prince Alfred College (PAC) to do my Leaving with Intermediate French, but still required Latin. The school provided a class for Leaving students who still needed Intermediate Latin, where our master was Alex Yule, a kindly and very patient man and the head's son-in-law. I wasted my time and had no hope of passing the subject in one year.

My attitude then to study was academic suicide, and I repeated the year. Fortune favoured me, for in 1939, Alex Yule's Latin class gave me an enduring friendship. I sat next to John Waterson, who was also heading for dentistry and who also required Latin. We soon became friends and I admired his wit and courage in regularly misspelling his name at the head of his Latin exercises. His ruse was soon noted but allowed to persist until Yule had enough ammunition to suggest quite strongly that 'Friend Waterson should learn to spell his name'. He did. 
Common sense and work prevailed in 1939, and I matriculated. This achieved, I slacked off again in 1940 and passed no Leaving Honours subjects. I have regretted deeply since that I did not hear then the advice to find the fun and joy of learning. Not until nearly fifty years on did I realise what I missed through such an antagonistic attitude to Latin.

To begin with, I did not come from a bookish home. School was for passing exams, and reading was guided but little. The exception was my father's encouragement to read Dumas and Hugo, but as this took the generous and overwhelming gift of a complete set of books of each author, few were read. They are still there in the same order (he had them numbered to keep me to that order) on the same shelf of the same secretaire. Nor did the doors of learning open for me at secondary school. The attitude at ATHS was that one had to get it right and to correct it in red ink until it was so. I paid dearly for this as, at PAC, I could not see any reason to drink of my own accord when I had been led to water. But it was not all the fault of others; I am sure that I was a late developer.

\section{Sub cruce lumen}

\section{A wartime student}

The War had been waging for sixteen months when I turned eighteen just after leaving school. I was discouraged from enlisting by my parents and it seemed quite normal to start at the university as planned. The War was far away but by the end of First Year I was worried about what I should do and volunteered to join some of the older students who were called up for the Citizen Military Forces (CMF). We entered camp at Woodside on 8 December 1941 when the War had suddenly become real for Australia. We were sent back to the university in February 1942 with my doubts unresolved, despite the discharge.

The advice from new and old soldiers alike was to complete my course, for the country needed dentists, but supportive as this was, in the end it was one's own decision; there was no directive. It was not until years later that I learned that we had been assessed by the authorities, who decided that we should stay at the university, and that we would be refused if we attempted to enlist during a successful course. It would have been reassuring to have known that at the time.

I decided to continue, and was able to maintain my resolve despite the emotional battering it took when friends left for the War, and, later, when some were killed. But tears did not change arguments, and I kept going with the support of my parents and those friends. They still have my gratitude.

University life took on a more sombre note. Extracurricular activities almost vanished, sport was limited to local competition, and I cannot recall anything of the Students' Union apart from sport and the refectory. After only one year we took it all 
for granted and did not feel deprived. Nor were we much aware of staff shortages and of difficulties with equipment and supplies until our clinical years. We took it all as more or less normal and the compelling drive was to pass the examinations. Failing an examination would be a failure in one's War effort.

Passing became an end in itself, and the price was that we saw no further than the Final Examination. There was a consequent delay in the revival of formal postgraduate studies, so essential to every discipline.

\section{First Year}

I was taken to enrol by my father one Saturday morning. We saw Mr VA Edgeloe in a small office on the eastern side of the now Mitchell Building and were received in the kindly and helpful manner which he retained always as he rose in the administration of the university. I looked through the window to the lawns as he picked up the telephone and uttered the first convincingly university words to reach my ears, 'Good morning, Mr Dean'. Dr TD Campbell, at the other end, answered some questions; I signed; my Father paid; and I was an undergraduate.

Basil Hetzel and other students took some 'Freshers' on a tour of the buildings and grounds and made us feel welcome; I donned my new sports coat and green shirt; and that first awesome walk down the main drive began. I was not frightened, but I was aware of a great unknown ahead of me, a feeling which stayed with me in some degree until I had passed the year.

At the end of that walk was the first lecture in physics I and Professor Kerr Grant, the best-known figure both in fact and fable at the university. He set out to make physics entertaining and he succeeded, but he was never given a fair hearing by some of the students. Consequently, the demonstrations took first place, and to keep up with the subject some of us attended the evening lectures by George Fuller, who gave priority to the lecture. Fuller made sure that we were told the facts while Kerr Grant let us see it all happen, in our own hands where possible. He was a kindly man who took much ragging in good spirit. The only time I saw him angry was on discovering a student using many more figures than were significant in a practical exercise. His anger was justified.

Chemistry came to life for the first time for me that year. Dr SW Pennycuik presented a lecture series based on the Periodic Table supported by immaculate demonstrations prepared by Leslie Frahn. Unlike Kerr Grant's lectures there was no theatre here, and all went like clockwork; and for the first time I understood inorganic chemistry. Organic chemistry, from an unknown, became a series of enthralling but all-too-short hours from Professor A Killen Macbeth, far and away the best lecturer I have ever heard. We paid close attention, for he was a disciplinarian with a remarkable 
ability for throwing a piece of chalk hard and accurately to any part of the lecture theatre where there was a late arrival or an inattentive student.

Practical chemistry classes were well planned also by $\mathrm{HH}$ Finlayson and Frahn Finlayson, who had lost an eye and a hand in a laboratory experiment and was known as Lord Nelson. He had a distinctive style of speech and a sonorous voice which I can still mimic with, 'Take as much as will liberally cover a threepence. On no account are you to use three pennies'.

In contrast, Professor T Harvey Johnston's zoology lectures were frantic dictation sessions when our pens raced as we tried to write it all down. In the practical we were terrified of Pat Mawson, Madeleine Angel and Margaret Davey. Margaret has since become a good friend whom I now tease about my earlier fear. They had as good a reason to be stern with us as we had to fear them, for we were not good students. With hindsight I blame the poor lectures and their not relating to the practical classes. Many of the diagrams in my practical notebook were copied from the textbook viewed in a mirror, and preparation for the final examination was by studying earlier papers and calculating the pattern in which topics were allegedly set. It was a sorry state of affairs for a subject in which most of us had absolutely no previous experience. It was also my first experience of a viva voce examination and I found myself unable to speak at first. Pat Mawson must have noticed my predicament, for she gave me an easy time and a Pass.

There were other signs of understanding in the Zoology Department, such as the tolerance with good grace of a churchwarden's pipe which Bill Bray brought into the practical class when we were given permission to smoke while dissecting rabbits. Professor Johnston delayed his lecture on one occasion to allow students to attend a contentious union meeting. Feeling had been running high, but I was never sure of the reason other than objections to the Leftish, perhaps Communist (in fact, they were pacifist) views of the president, Elliot Johnson, and some others including Max Harris, then an undergraduate. The chancellor attended a meeting at which he repeated the inadequate epigram that the union should be a forum and not an arena; otherwise, he said nothing useful and the arguments continued. It was suggested that the unliked ones be thrown in the River Torrens at lunch time, and a large crowd of students gathered at the footbridge. Exciting in prospect, it was less so in the event, when a few who stood by their views were manhandled into the river by superior numbers. Johnson escaped the ducking, having threatened legal action.

The closest we came to dentistry was in Elements of Metallurgical Chemistry with lectures by RAL (Reggie) Laughton and practicals by Eric (Billy) Hughes, two stalwarts of the School of Mines. One of the exercises was the refining of gold, which at one stage was a fine precipitate. Margaret Dunstone, our only female member, dropped this dark-coloured material on to the floor of the laboratory. While the rest 
of us stood back trying not to laugh at her problem, Billy Hughes showed us how a gentleman should behave when he knelt and painstakingly picked up the gold from the floor with a small spatula. Hughes later became a patient and a friend who reacted with great modesty when I recalled the incident.

Reggie Laughton's lectures were given in the Dental Hospital, which meant that once a week we felt like real dental students as we walked into the building with hissing steam, white coats, dental smells, and the main clinic. I can recall seeing the Fifth Years in the ommon room and marvelling at John Thompson's immaculate white coat and his knowledge of general anaesthesia about which they were talking.

After two happy terms the end of the year rushed upon us. I had learned my lesson about study and worked harder than ever before. The papers were satisfactory and I found myself enjoying the practical chemistry examination, circumstances previously undreamed of. My cup ran over when Macbeth, prowling around the laboratory, praised my efforts. I had also some success in picking the zoology paper and Pat Mawson had been kind, so there was a chance.

While the examiners met in the late afternoon we waited in the saloon bar of the Richmond Hotel and then, suitably fortified, crossed North Terrace to the foyer of the Mitchell Building. After we had waited for an eternity, the examiners drifted down the stairs, giving no hint of what was to come. At last Vic Edgeloe, typewriter under one arm and results sheets in his hand, appeared on the landing with the dean and, descending to the foyer, crossed to the notice board and pinned up the results, still holding the typewriter. I believe that he deliberately avoided making us wait while he took the typewriter to an office.

We crowded around and there it was: eleven of us had become five, and I was one of them; I had passed! Brian Crisp, Max Frayne, Clem Tymons and John Waterson had also passed. Of the others, Bartley Vanstone repeated the year, while Ray Leach and Ian Ronald enlisted, returning to graduate after the war.

\section{Initiation}

Early in the first term of 1941, we faced initiation into the Dental Students Society. We were apprehensive of what lay ahead of us, but it turned out to be tolerable, if humiliating. The plans were curtailed to some extent when one victim received a drop of eugenol in his eye as an initiator was endeavouring to paint a silver nitrate moustache on his upper lip. We were dressed in theatre gowns and vulcanising flasks were hung from our necks, and we waited outside the lecture theatre in the care of Alec Plummer until we were called in. Ted Cock was the inquisitor, asking one's full name, why one chose dentistry, the name of one's girlfriend, 'What's she like?' and so on. All had to be answered with care, as Ted was skilled in turning the answer back on one. John Waterson let it slip that his second name was Gabriel and was at once asked if 
he could show them his horn. He looked as if he was about to die. Ted Cock did not press the question.

By this time Cock was in full flight, after having all of us wriggling beneath his questions; then Waterson had his revenge. When asked if he had a girlfriend, Waterson replied, 'Yes'.

'Is she nice?'

'Yes'

'What's her name?'

Prompted outside by Plummer, Waterson gave the name of Cock's fiancée, Bronny Donaldson. Cock's moment of glory was gone, and the ceremony was over. Ridicule and teasing were behind, and we were made to feel part of the Society.

In retrospect, initiations were not the great occasions we thought them to be, and it was a good thing when the arrival of the Commonwealth Reconstruction and Training Scheme (CRTS) students caused them to be abandoned. However, one incident is still talked about. In 1940 Max Stain approached his initiation boasting that he knew all the hoaxes he would face. When shown a dish of live worms he was not afraid, for he knew that he would have spaghetti placed in his mouth. He boasted too loudly and underestimated his seniors; blindfolded, he nonchalantly swallowed a worm from the sewerage farm.

\section{The Battle of Woodside}

At the end of First Year, I went into camp at Woodside Barracks, a defence establishment in the Adelaide Hills, with some of the older students and found that even recruitment required some ingenuity. At the medical examination I breathed, hopped and coughed as requested, but could not supply a sample of urine and the more I tried the less likely it became. After many fruitless attempts when the medical orderlies were becoming heartily sick of me, I selected a container which had just been used by a recruit whose form, I noted, was marked 'NAD' ('no abnormality detected'). There were one or two cubic centimetres of the previous sample remaining which I handed to the orderly, and I too was NAD, thanks to the anonymous donor.

My fellow soldiers were Clem Tymons and Bart Vanstone from First Year, John Day and Max Stain from Second, and Ian Disher, Ken Filmer and Ron Tiver from Third Year. There were no males in Fourth Year, while the Fifth Years had graduated and would appear in another role. We were assigned to the 101st Australian General Hospital and seconded to the Dental Centre attached to the Camp Hospital. Outside the Dental Centre we were commanded by Arthur Welch. The man on the spot for the Colonel, Dr De Crespigny CSM, was George Walters, to become the Honourable Mr Justice Walters and now a friend. 
Some of us were technicians and the others, including me, were orderlies chairside assistants today. To our delight the Dental Officers were our former Fifth Years, Bob Blackburn, John 'Polly’ Moran, Alec Plummer, John Thompson and Fred Trotter. Sam Burrell was there and, for all too short a time, Bob Taylor. My first introduction to clinical dentistry was as Polly Moran's orderly, where I learned many lessons, not the least of which was how to keep working with a monumental hangover - Polly's, of course. Such a morning would begin with head in hands and: 'John, I feel terrible'. The reviver was a Starboard Light at lunch. With Polly I saw my first intravenous anaesthetic, which was the first also for the anaesthetist, the dentist, and probably for the hospital.

We had a lot of fun in the Dental Centre but we all felt that the CO, Major Alec Wotton, took himself far too seriously. Trouble was inevitable, and it came when Wotton was seated in the lavatory, which was below the plaster room window. Reaching out with a broomstick, Disher caused the cistern to flush, while Tymons poured a plaster bowl of water on to the occupant. The Major was very cross and the story became widely known, with all of us basking in reflected glory.

With the AGH we learned drill and saw Ron Tiver stand up to the bullying Sergeant and earn himself the name Cisco Kid. He wore his slouch hat with the brim neither up nor down and the chin strap hanging well below his chin. We also mixed with the other soldiers and learned the great lesson of a wide society.

For some reason we did not visit the wet canteen (perhaps it was out of bounds) and therefore pressure was put on the dental officers to order a route march on Saturdays. These always went to Woodside or Oakbank, where we were fallen out near the hotel. The homeward march was usually less orderly.

We entered camp on the day after Pearl Harbour amid much uncertainty about the future. None of us wanted to stay where we were, yet there seemed no alternative in the Army. Dow Pflaum was at Woodside with an AIF artillery unit and I put it to him that he might claim me to join his unit. He politely declined and advised me to return to the university if possible. In the end we had no option; we were discharged shortly before the first term of 1942 began, and found ourselves back at the university.

Thereafter we saw ourselves as having been members of the 3rd AIF: 'Hasn't fought yet'.

\section{Teeth at last}

February 1942 found me a member of the establishment. I was no longer a Fresher, and before me lay truly dental subjects and those concerned with human biology, an exciting prospect.

The great unknown was anatomy, about which I felt an apprehension close to fear, causing me to have nightmares about corpses. When the moment came and the 
covers were lifted from those shapes, all was well for, like those before me, I saw the cadaver as material for dissection and not as a human being. We were not required to dissect the arm as was usual for dental students, but started directly on the head and neck. This abbreviated course was not as advantageous as it first seemed, as the region is complex for beginners and we made a poor fist of dissection. It meant also that we were not in step with our medical contemporaries and kept to ourselves in the Anatomy Department, making our own fun and a little progress.

Over the body we set up the 'Second Year Social Club', which was to provide for an end-of-year dinner. John Waterson collected our weekly dues and kept the record in a notebook from PAC days. He was a good treasurer and in due course we dined in style at the Hotel Adelaide in Pirie Street. In those days John could be persuaded to do other things. An elaborate wager was devised by Clem Tymons in which John was required to kiss the body and this he did, then to find that Clem had found a flaw in the agreement so that payment was not made. John reacted in the theatrical manner for which he was to become renowned, which would make him the subject of many practical jokes.

We were taught by Professor Goldby and by Hugh Gilmour as tutor. We probably so disillusioned Hugh about anatomy that he became a specialist physician. Still, anatomy was the dominant subject and there were enough others to make this the busiest year of the course. Histology came from Dr Karl Poesner and was done with the medical students for most of the subject. For physiology we had our own course given by Dr Franz Lippay, who later resumed a career in opthalmology. It was an interesting subject, but we wasted much time in the practical classes where once again John Waterson was the victim. During an experiment on respiration when he was the subject with a tube around his chest and attached to a recording device we managed to start him laughing. Lippay came up and roared, 'Thees ees no laughing matter'. Waterson said, 'I am not laughing, sir', which made Lippay even angrier as he pointed to the evidence of mirth recorded as respiratory movements on the smoked paper.

Mitchell lectured us and the physiotherapists, a group of women who did not join us in the unsupervised practical classes. He sucked Life Saver peppermints continuously, taking them from an attaché case packed with cigarettes and peppermints. We looked enviously at that case; now, I wonder about his rate of caries.

On the other side of Frome Road, I felt that we were getting somewhere towards becoming dentists, for we were in the Dental Hospital where we studied dental subjects. We drew and carved teeth for Draper Campbell and carried out prosthetic exercises for Lennie Brougham. Campbell's teaching was good, as he introduced us to manipulative skills with a series of models which demonstrated the stages in carving teeth. The models showed that the curved surfaces of a tooth could be represented as a series of 
flat planes and also illustrated Campbell's maxim that, with any task, one should first determine what is to be done, how it is to be done and only then set about doing it.

In the Prosthetic Laboratory we mixed plaster of Paris and, with the exception of the more conscientious Crisp, added salt as an accelerator and threw the excess plaster to adhere to the ceiling, both of which actions were forbidden. We made rubber moulds and models of edentulous jaws, and then vulcanite baseplates for them, and we broke and repaired countless dentures. German silver was shaped and soldered into pyramids and gave rise to the fashion of making initials for the handbags of girlfriends. Tymons had the only success with initials, as his was the only established romance; the rest of us did not have the same motivation.

Our time was spent happily, and the end of the year raced upon us, with its heavy schedule of examinations. These were better than expected until the prosthetic practical, when my repaired partial denture caught in the woollen polishing wheel and was wrenched from my hands. I repaired it again, which took a long time with vulcanite, and so I left the hospital well after the others, resigning myself to repeating the year. When Vic Edgeloe pinned the results to the board a week or so later my gloom vanished, for I had passed with Credit, second to Brian Crisp.

I had never known such success and a few heady days followed when my mother spread the news through a large family. Then I went to work as a farm hand for Jim Ellis at Mount Compass and spent a wonderful vacation in his dairy and behind his tractor, planting potatoes and being scared out of my wits one night when his wife seemed about to give birth to her first baby. I was left with her while Jim went for the doctor. It turned out to be a false alarm but by then I had several terror-filled hours with plenty of boiling water and no idea of where to put it.

Third Year began in dramatic fashion with the sudden illness of Lennie Brougham, who was never to return to work. We had lost a teacher and the hospital a technician, but there were unexpected benefits for us. Brougham's duties were taken over by Clarrie Whitford, until then full-time technician to the hospital; he was to become a teacher and lifelong friend of mine. He taught us well and was responsible for our being able to carry out all laboratory procedures, and in due course I was able to do all my own work during the early years of practice.

As there was no replacement of Brougham due to the War, we Third Years were given the task of carrying out all the repairs and all the flasking, packing and finishing of the hospital dentures. We felt the continual pressure of the work, but this was no bad lesson in the demands of the world nor in using our hands, and was more beneficial than the then obsolete swaging exercises which it replaced.

Clinical dentistry came a step closer with operative techniques — 'op tec' during which we prepared cavities in large plaster teeth and then in extracted natural teeth, into which we placed restorations. The bête noir was malleted tin foil, which I 
at last condensed into a simple cavity. It was inspected by Rex Forder with the words, 'The future of the profession is in good hands'. The comment was as reckless as it was generous, but it was inspiring to one facing a subject which at the time represented dental practice.

In Third Term we began pathology ('path.') and bacteriology and met a great gentleman, Professor JB Cleland ('Bertie'), who was one of the last of the naturalists. He was interested in every living and growing thing, knew much about many of them, and in some areas was an authority. We attended path. with the medical students, whom we saw remove Jim Bonnin's trousers as we stood in a tightly packed group around the Prof. 'Bertie' must have known what was happening but ignored it, winning the day and more of our esteem.

Bertie also saw to it that we learned some bacteriology, which had been neglected by the appointed lecturer. In both subjects he was assisted by Dr Charles Swan, a brilliant man who had achieved international fame for his research into rubella, and by the loveable demonstrator, Ted Rogers. Ted was a friend to all, and his pre-examination tutorial ensured that we passed the practical. His son, Anthony (Tony) Rogers, has become one of the great men of Oral Biology.

I finished the year sharing top Credit with Brian Crisp.

\section{Clinical years}

These were what we had been waiting for, now we were dentists — or so we saw ourselves. With blunt burs and foot-engines we treadled our way towards the muchrespected 'minimum requirements'. For clinical teaching we relied heavily on Jackie Clark and the Fifth Years. It was not until we were in Fifth Year that I received help in the clinic from a full-time private practitioner. Malcom Joyner showed me how to cut a Class III cavity easily and quickly, after which I never looked back in that field.

In contrast, we were closely supervised when we began to extract teeth. This took place in Local Anaesthetics, or 'LAs', as the sessions were known. I was lucky to have Dr Arthur Moore providing support during my first attempt at a mandibular block local. Like Forder and the tin foil a year earlier, Moore's words of reassurance have remained with me.

Another time of encouragement came with crown and bridgework. We had come to regard Mervyn Evans as one of us when he sat with us as a candidate for a DDSc at the 1943 annual examinations, and we could say, 'Good luck, Merv!'. In 1944, as our demonstrator in crown and bridgework, he was 'Sir' with no loss of respect, and he raised our sights at last beyond the restricting horizon of 'Aurocast'. Students were required to use this poor substitute for gold and had little confidence in the lost wax technique. Aurocast was difficult to cast, did not fit well and could not be burnished, so that our inlays were each a sorry compromise and left us disheartened. Merv Evans 
made his own demonstration crowns using natural teeth and the correct casting gold, and with a Cast Base Davis Crown opened my eyes to the possibilities of cast gold. This was another major encouragement, for while we went on using Aurocast there was some hope for the future. Two serious restrictions in our course were the insistence on Aurocast and the prohibition of local anaesthetic for cavity preparation. Both restrictions have since been removed.

We were watched over by three women, Sister Marion Wilson in LAs and GAs (General Anaesthetics) downstairs, Sister Molly Lawson in the upstairs clinic, and Miss Champion in the office, who cared for our welfare and that of the patients. Sister Wilson once gave me a set of instruments to see a patient in a ward in the RAH and sent me off with the advice: 'They will be watching you, Mr Lavis. Be sure to wash your hands, and if you drop an instrument, PLEASE DON'T PICK IT UP!' Meanwhile, in 1945, the Sisters joined some of us in queueing in the early morning for tickets for the gods to see Gladys Moncrieff in a season of musical comedy at the Theatre Royal.

The Student's Society functioned steadily with regular monthly meetings and supper supplied by Mr TA Brown. Dr RHG Taylor became president as a direct result of the Woodside days and Brian Crisp and I contested an election for secretary which Brian won. The contest represented a division which existed for several years in the student body but never between Brian and me. It was the turn of our Year to provide the secretary and we were nominated by the opposing factions.

The Society held an annual Dental Ball in aid of War charities and in 1945 we reached new heights. We held a pre-Ball sherry party at my house to which we invited senior members of staff, including Dr and Mrs Campbell and Mr (later Dr) Lawrence, and possibly some others. I can clearly recall their pleasure at being asked and I now wonder if it had happened before, as I wonder how I persuaded my parents to agree. The highlight of the decorations in the refectory was a plaster reproduction of Max Frayne's face, painted a deathly colour and bleeding continuously and realistically from the mouth. The pump was a saliva ejector borrowed from the hospital, fed with soapy water plus phenol phthalein through the saliva inlet and oxygen through the water jet. I have never made a better mouse trap; Max bled all night. Plaster heads of all of us Fifth Years were there and are possibly still in existence somewhere. Malcolm Bills led an excellent band which was named 'Moonface Bills and his Heavenly Bodies' for the occasion.

\section{Some people}

We were in the care and sometimes control of a wide range of people, some of them colourful, all of them interesting and concerned about our welfare. Here are some of them. 


\section{Percy Raymond Begg}

Begg fitted neither the picture of an Honorary nor a full-time member of the hospital or university. He had a theatrical, sinister appearance which still shows in Hannaford's portrait painted nearly forty years later. His lectures were no more conventional, delivered while seated in a portable dental chair and chain-smoking American cigarettes. Democracy prevailed and the students smoked, too, envying all the while those Chesterfields.

\section{Leonard Arthur Morris Brougham}

We were a little frightened of 'Lennie', due to his stern manner and reputation when we met him in Second Year as senior hospital mechanic (now he would be called a technician) and demonstrator in prosthetic dentistry to the students. He would limp to the end of the laboratory, rest one hand on the flask clamp and call out instruction or reprimand. Beneath the stern mask was a kindly, understanding man, the first of four great technician instructors who have taught me. His kindness supported me in my disastrous practical examination, and his humanity on other occasions won me over. From Lennie we learned the basics of plaster, vulcanite and metal work. There was deep sorrow when he suffered a stroke in 1943 and did not return to the hospital.

\section{Thomas Draper Campbell}

Campbell was a talented man who could walk with a wide range of brilliant people. He was a competent musician and had studied at the conservatorium of the university under Professor Harold Davies (from whom, he said, he had learned the maxim, 'First, decide what is to be done ... ') and enjoyed classical music. His tastes were wide and he wrote the music for The Moon Dream, produced by the Repertory Theatre. It is likely that he was involved in the production as he was an expert on stage lighting. His interest in the arts must have extended to literature, for I discovered years later that he was a member of an avant-garde which included Norman Lindsay when he visited Adelaide. He belonged also to a group of musical intellectuals, the Savages.

By the time we met him, Campbell was recognised internationally for his anthropological work with Indigenous Australians; he, too, was one of the last of the naturalists, interested in and recording observations of natural phenomena.

This remarkable man must have had a brilliant undergraduate course and in 1923 he became the first dental house surgeon of the Dental Department of the Adelaide Hospital, then lecturer in dental anatomy in 1924. There he stayed, becoming superintendent and dean of the faculty.

The Campbell we met in 1942 had become bored with the limited scope for his intellect in his day-to-day life. He seemed remote, probably due in part to shyness, and 
appeared to us to spend most of his time doing very little in the 'Kiosk'. But as soon as he taught us, his genius showed. As mentioned earlier, his system of tooth carving was a masterpiece of the understanding of form; later, his lectures in comparative dental anatomy (senior dental anatomy) provided a unique basis for dentistry.

He did not smile much, and so one day we were surprised on being greeted with a smile as one after another we entered the GA theatre. The surprise heightened as our smiles to him were returned with a frosty stare above the still smiling mouth. Then we understood: the dean had a new upper denture and the incisors were too long. Next day he was back to the old one.

At a party on VJ day ${ }^{1}$, staff and students celebrated together and we saw the fun in his make-up for the first time, revealed less shyly than ever before. In 1948 he invited me to join the part-time tutoring staff; I began in 1949 and began also a friendship with him which lasted until his death. During this time I came to appreciate the stature of the man and his enormous contribution to dental education.

\section{John Francis Clark}

The other full-time dentist in the hospital, 'Jackie' Clark, was as gregarious and garrulous as Campbell was shy and reserved. He would come into the laboratory, roll a cigarette, light it in a small black holder, and, with his foot on the seat beside a student, talk on and on. Without losing any respect from us he would argue on anything and never admit defeat, although we sometimes found him boring and sometimes irksome, for we thought his politics a bit to the Left. Then at lunchtime he would stoke the homemade gas producer and climb into his old Dodge car to disappear for an hour where to, we never knew. Clark, too, had his share of mystery.

If he was a know-all in argument, Clark was a knowledgeable friend in the clinic, where he was almost the sole, and certainly the best, teacher we knew. He was always there when we needed him, rough in his manner but understanding of our and the patients' needs. There are many of us who owe our start in clinical dentistry to Jack Clark.

\section{John Burton Cleland}

Cleland was a great man: a naturalist, pathologist, teacher and a friend to dentistry and to all students. He took an interest in dental pathology beyond what would have been expected of him and was solely responsible for its establishment in the university. 'Bertie' went to great pains to produce sections for us despite the difficulties in preparing hard tissues and with his assistant, Ted Rogers, gave us some excellent specimens to be examined under our microscopes.

1 Victory of Japan Day, 1945. 
His enthusiasm was matchless; of a slide of a gastric ulcer, for instance, he said, 'O what a wonderful picture. Look at it, Ted, the artery which caused death!' On looking at a dental section: 'What a beautiful specimen! I really don't know how I can give you gentlemen such a lovely slide.' And at a post-mortem, 'A duodenal ulcer, and look, Ted, I can put my thumb in it!'

Above all, he was a truly gentle person, courteous and just, always interested in the world around him. One day some of us walked with him across the old Jubilee Oval on the way back to Frome Road after lunch. He took a lens from his pocket, stooped and picked a weed, examined it through the glass and said, 'Look gentlemen, this is a ...' He then identified the plant, gave its botanical name and talked to us about it as we walked back to work.

\section{Hurtle Thomas Jack Edwards}

We used to think that Jack Edwards was not interested in us and that he was passé until one morning, seated in the Students' common room, he waxed up two bite rims to the occlusion provided by an anatomical articulator with a dexterity that I had never seen before. A respect was born then which grew into friendship in later years.

Edwards had the best mind that I have met in dentistry. I now think that he had no peers here and that life must have been lonely for him, so that he put on a rough veneer to hide the intellectual solitude.

\section{John Leonard Eustace}

With Campbell, Edwards and Moore, Bob Eustace was one of the Alpha Group, the first dental graduates from Adelaide. Ill health had given him a sallow complexion and a cadaverous appearance, and as if to complement these he had the boring job of lecturing in a boring subject, materia medica and therapeutics. He did this by reading from notes while we followed from our own copies which had been taken from those of earlier students. As happens in the party game 'Pass the secret', there must have been some wild inaccuracies in those notes after generations of transcribing.

Eustace had a sonorous voice to go with his appearance and was known for his utterance of a description of the synergistic effect of epsom salts and senna, 'Rapid and drastic purgation!' I came to know later of the considerable influence of Bob Eustace behind the scenes.

\section{Gordon Ord Lawrence}

Gordon Lawrence had a half-time appointment and took us for operative techniques in Third Year and then became a teacher in all things now called restorative dentistry. He was a kindly man, but his intense interest, sometimes amounting to an obsession, in 
dental materials prejudiced our learning of clinical skills. We had to make up our own hydrocolloid and impression paste, the latter having to be weighed on an ingenious balance in an incredibly messy procedure. Lawrence Paste had good physical properties but these were lost on us by the time we had made and weighed it and then coated the denture bases, the patient and ourselves with the sticky material; we could not see the wood for the trees.

A competent craftsman - perhaps he should have been an engineer - he made many devices, the most famous being the Lawrence Matrix. To this day it remains the only scientifically designed matrix but, alas, quite impractical for general use. He designed and made every part including the dies, and in the end he must have made dozens which he gave to students. Years later he gave me his own matrix with his initials engraved by hand, which is now in the Dental Museum. His ingenuity did not end with matrices; his home boasted a washing machine and an evaporative air conditioning unit which serviced most of the house, both his own work.

Gordon Lawrence gave me his support and guidance as a graduate and it was his influence which played a large part in my MDS. We became good friends and he came to me as a patient, one of the great compliments of my career. He died when I was in London and I have long regretted the lost opportunity of sharing that postgraduate experience with him.

\section{Arthur Pariss Reading Moore}

There were no jokes about Arthur Moore nor any nicknames for him; he was above them. There was not much of him physically: his small frame had been wracked by illness but his fine mind had not been dulled nor his great spirit quenched. He was unfailingly kind and courteous, and quietly spoken; he impressed us with his wisdom and delighted us with his wit. He left us alone to answer an examination paper and dealt with our cheating by saying nothing but giving us each $99 \%$, a very clear message. His kindness to me at my first extraction was a milestone of my course.

\section{Clarence William Whitford}

When Brougham retired in 1943 and was not replaced, Clarrie Whitford took over all his duties, which included teaching, and so began one of the legendary eras of the Dental School. He appears in old photographs of the hospital staff and probably started there as an apprentice, but once in charge of the laboratory he soon became a great teacher. Shortish, plump and genial, he had our respect and affection.

Clarrie took us into the exciting new world of methyl methacrylate, a major advance in dentistry. The improvement from vulcanite was stunning and we were eager to use the new material, nagging all the while to be allowed to make the change. But the resin was in short supply and the technique was still being learned; teeth cracked, 
moulds had to be lined with foil, and thick sections became porous, so that Clarrie was under some pressure. He overcame the problems, gave us as much material as he could and taught us to handle it, never losing his cheery manner.

Clarrie Whitford tolerated all sorts of student behaviour and technical errors with good humour even when I caused him to be sprayed with molten Aurocast, muttering only a little as I lifted metal fragments from his scalp. Later, when one who was expected to know better transgressed, we saw him angry for the only time. Brian Crisp was working late one evening towards the end of Fifth Year trying to complete his requirements and needed some Aurocast, which was kept in a locked cabinet in Clarrie's room. He tried unsuccessfully to pick the padlock, then found that the cord of the dental lathe would just allow the grindstone to reach the lock if he nursed the lathe in his arms while kneeling beside the cabinet. Displaying great skill in this awkward position Brian removed the heads from the rivets of the lock, which he then dismantled to reach the Aurocast. After replacing the unused metal he re-assembled the lock, restored the rivet heads with minute pieces of solder, and touched up the lock with paint. We thought it to be sheer artistry, but as soon as Clarrie inserted the key next day the lock fell to pieces. I think that he felt that his trust had been betrayed by the most trustworthy of his students and he was most upset. For the first time an incident could not be laughed off, and our behaviour was impeccable for the remaining few weeks.

Some years later he joined the university staff, where he continued to fill a unique position in bridging the gap between clinic and laboratory with dignity and authority. I have been fortunate in knowing four such men, Brougham, Whitford, EA Dennison at Eastman and Les Reynolds, who followed Whitford.

\section{Golden interlude}

University life had begun under the grey clouds of war but by 1945 they were lightening. The War was being won by the servicemen and we had achieved our goal so far. Once in Fifth Year we felt as though we were bathed in sunlight. We were likely to pass at the end of the year and meanwhile we were 'top dogs' in the Dental School, with enough confidence in our own abilities to enjoy our work so much more. We would tackle anything, such as immediate insertion cantilever bridges. I was so carried away with my imagined skill that I omitted to consider the occlusion on the pontic of one such device. By the next appointment the contact with the opposing tooth had rotated the abutment tooth better than any orthodontic appliance.

We extracted many teeth and felt that we had mastered oral surgery. Gordon Lawrence showed us how to make the forerunners of immediate full dentures, and we learned to live with Aurocast inlays. We were to find out later in the outside world the true limits of our skills. 
These happy days were further enriched by the friendships amongst ourselves and the teachers, the staff and the WAAFs and technicians of the Dental Section of 4 STT (School of Technical Training) of the RAAF. The Dental Ball, the theatre parties, Clarrie's padlock, the Victory party were all part of a life that could not end. The examinations came, and we all passed, and it still seemed part of the same golden days, celebrating our own victory. We started work as soon as we could, and were admitted to the degree of BDS. Christmas came and went, and then we were in another world.

\section{Departure platform}

\section{A postscript fifty-six years on}

I am grateful to $\mathrm{Mr} \mathrm{DH}$ Laidlaw $\mathrm{AO}$ for stimulating me to revisit the original manuscript of 'Dental Student' and to include the few photographs I have of those days. Valuable assistance has been given to me by Mrs Anne Maree (Annie) Hutchins and the State Library of South Australia, whom I thank.

I have used for my postscript the title of Lady Violet Powell's third and last volume of her autobiography. Two prostates, diabetes, emphysema, failing eyesight and heart disease amongst the three of us who remain make the title appropriate. Of the five who graduated together, John Waterson died in 1994 and Clem Tymons in 1998. Three of the five gained postgraduate qualifications, the highest proportion since the Alpha Group in 1921 (four out of six). In particular, John Waterson held chairs in the University of Western Australia and the University of Melbourne and became dean of the Faculty of Dentistry in each.

In the final paragraph of 'Dental Student' I referred to the others who made up life in the Dental Hospital. I should have mentioned those outside the hospital, our families, friends and sweethearts, all of whom supported us and helped make those days so golden.

John Lavis, February 2002 


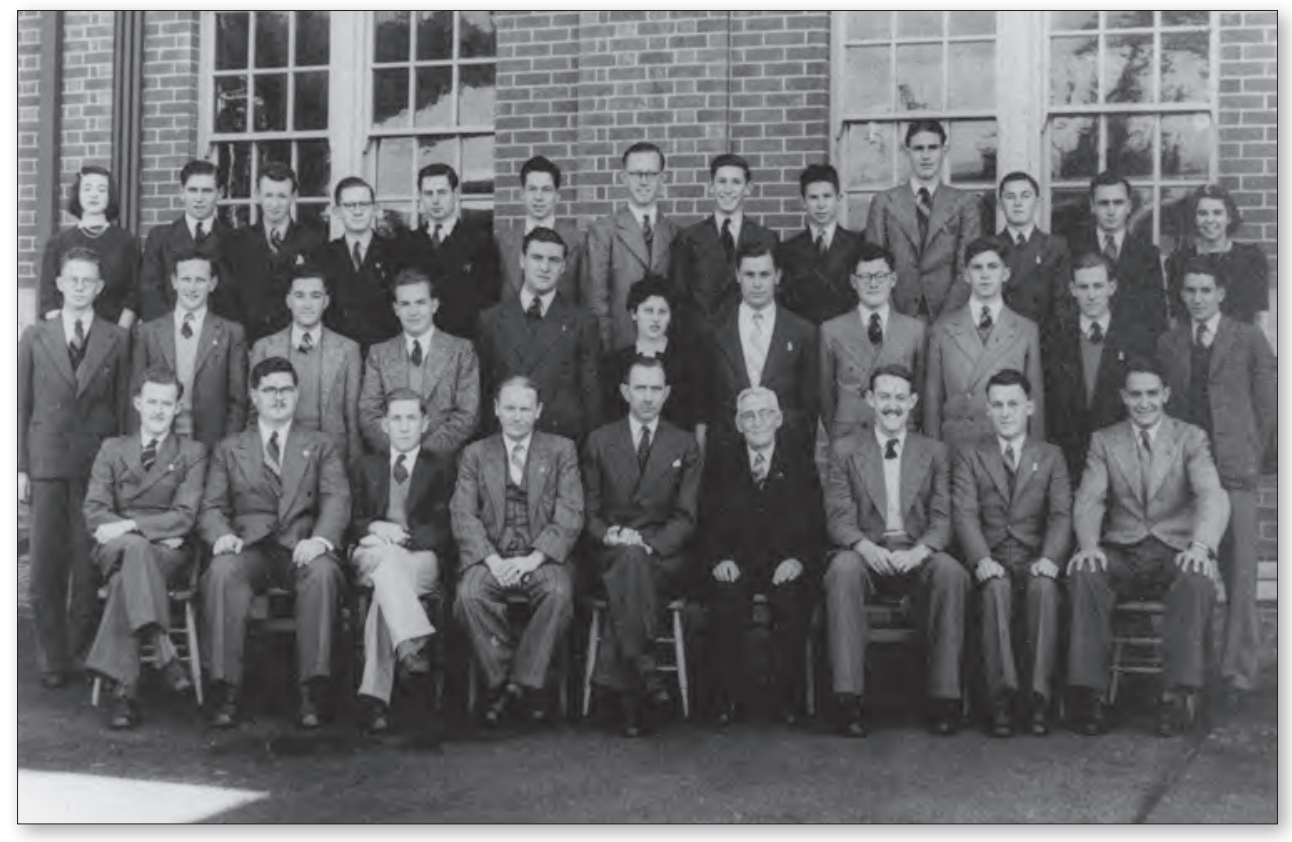

Figure 9.2 The University of Adelaide Dental Students' Society 1943.

Back row from left to right: M Dunstone, GJ Pfeiffer, IS McGrath*, KA Brown, BJ Vanstone*, GJ Brown, MB Bills, DW Quinn, JB Leach, JAF Stevens, RJ Mybill, ED Morgan, FS Westerman.

Middle row from left to right: GD Dunstone, JR Smerdon, KF Filmer*, MW Stain*, CJ Tymons*, NJ Edwards, JF Lavis, RS Tanko, BC Crisp, JG Waterson*, MT Frayne.

Front row from left to right: RF Harrington*, CH Lewis, LR Boyle*, Dr TD Campbell (dean), Dr RHG Taylor * (president), Mr TA Brown* (patron), IM Disher* (vice-president), RW Tivet, JB Day* (secretary).

* deceased 


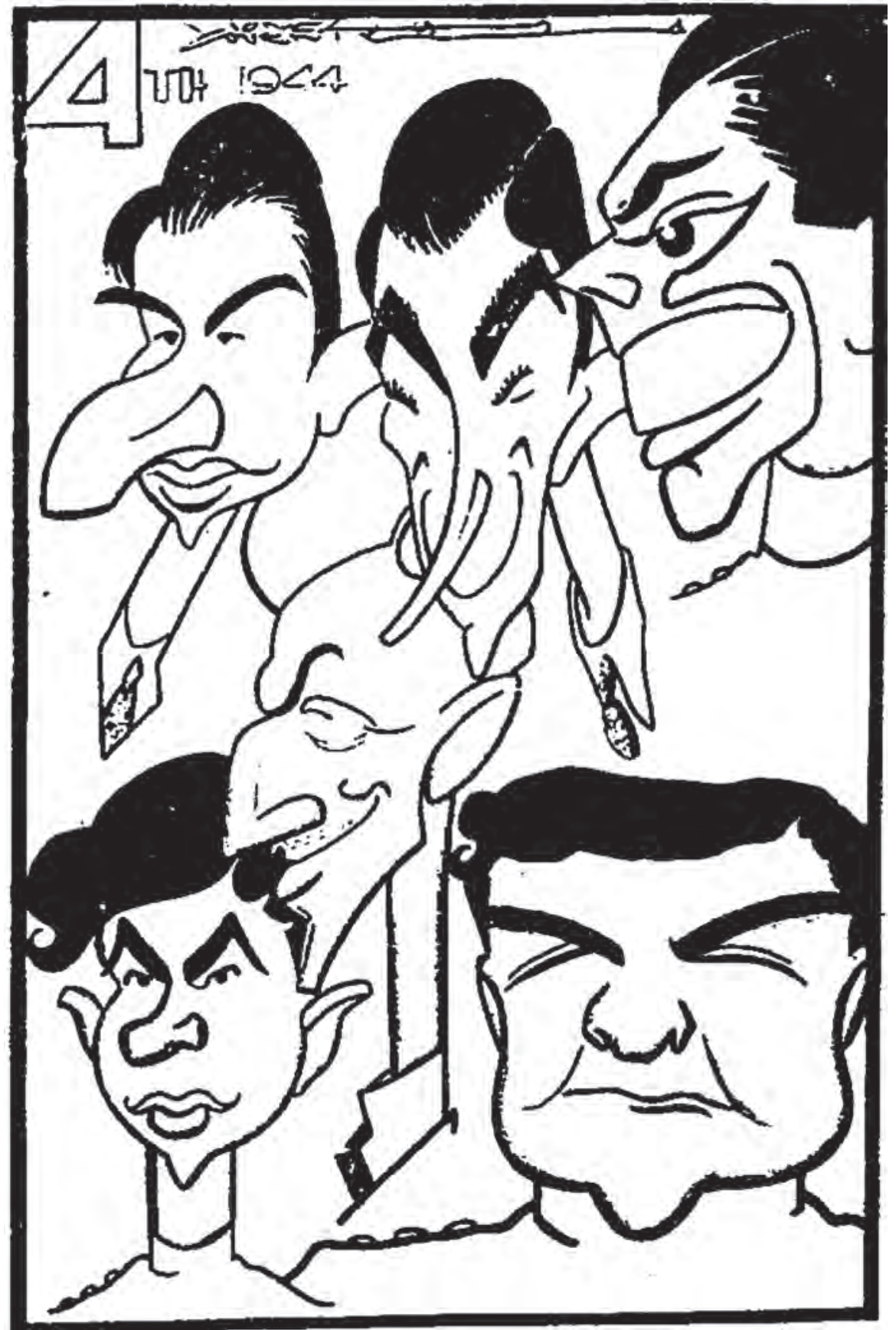

Figure 9.3 As Lionel Coventry saw us in 1944: Max Frayne, Ken Filmer, John Lavis, Brian Crisp, John Waterson, Clem Tymons. Ken Filmer held the record, still unbroken, for taking eleven years to complete the five-year BDS course. We caught up with him in 1944, then left him to graduate in 1946. He later drowned at Waikerie. 


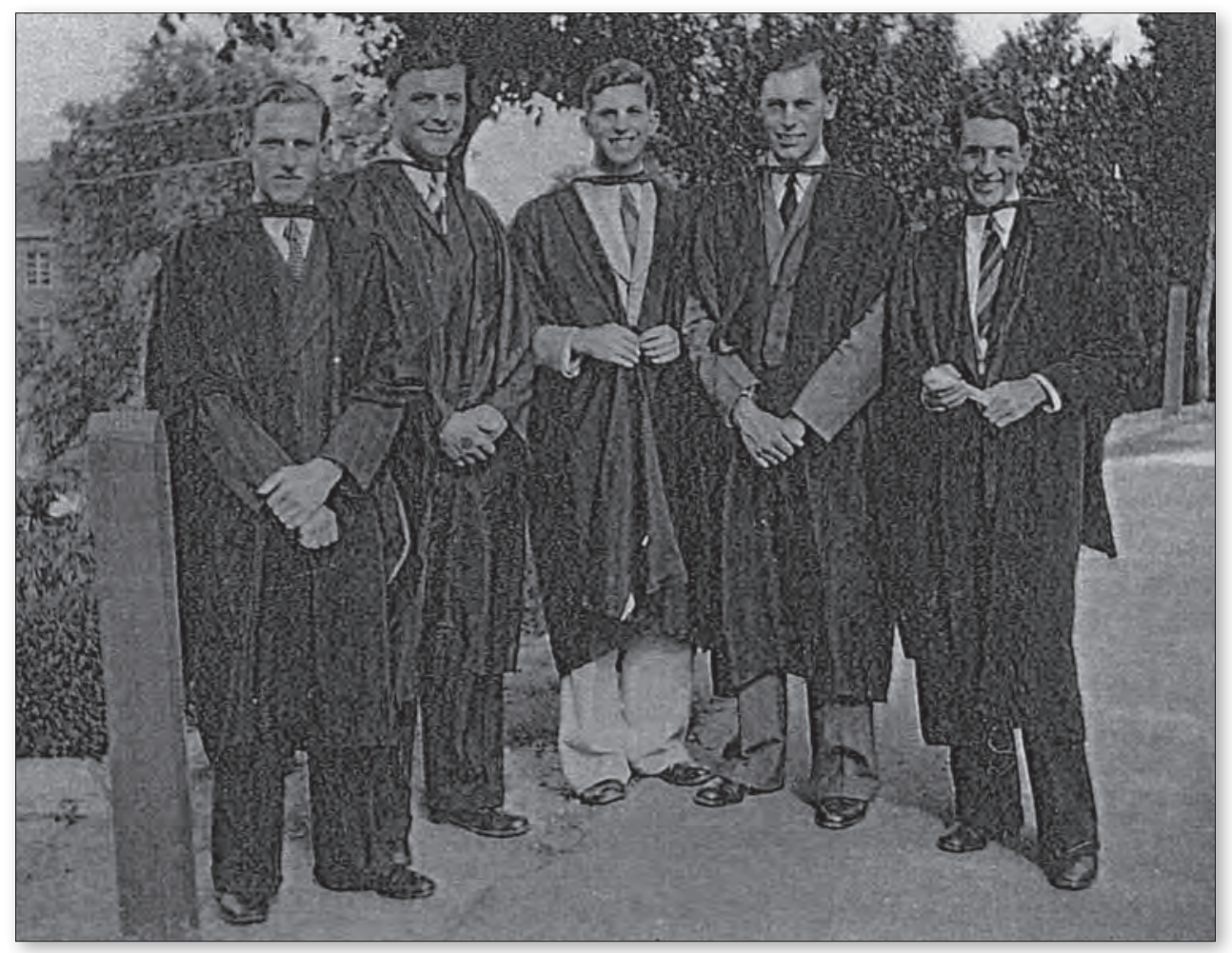

Figure 9.4 Graduation Day, 12 December 1945. From left to right: John Waterson, Clem Tymons, Brian Crisp, John Lavis, Max Frayne. 


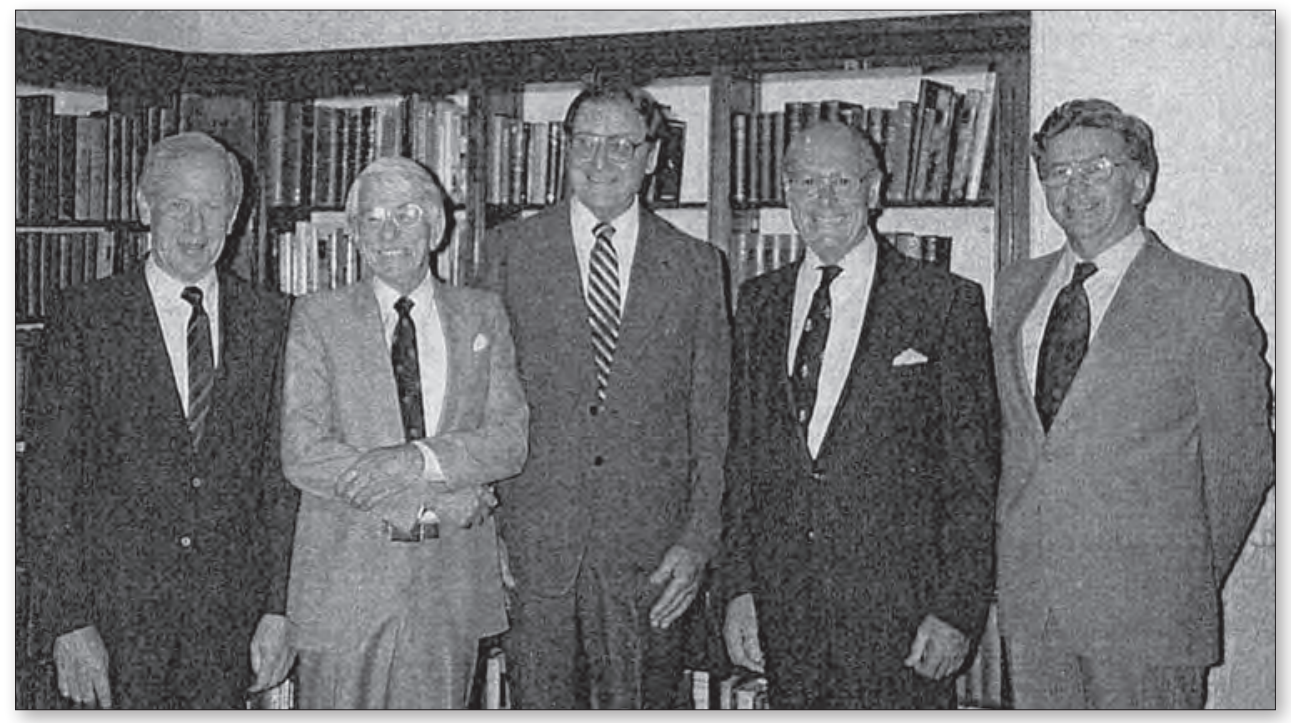

Figure 9.5 Forty-year reunion, 13 December 1985. From left to right: John Waterson, Max Frayne, Clem Tymons, John Lavis, Brian Crisp. 


\section{0}

\section{Learning to be a dentist (1946-50) - Tasman Brown}

This chapter is the revision of a section of personal recollections written in 2005 for family members only. Immense changes in dental education, dental practice and the composition of the student body have occurred in the three-quarters of a century since the author of Chapter 9, John Lavis, and I were undergraduate students. Students now benefit from new teaching methods such as Problem-Based Learning and greatly advanced dental practice with technologies and materials that could not be imagined in earlier years. The maleto-female ratio has changed radically from an overwhelming majority of male students to a more even distribution, with sometimes more females than males. Chapters 9 and 10 emphasise the striking changes that have taken place in the Adelaide Dental School over the intervening years.

One of the most difficult decisions of my life was to decide whether I wished to enter university for tertiary studies and if so, which course to pursue. My parents were a little uncertain at first and encouraged me to take an examination for entry to the Savings Bank of South Australia as a junior banking trainee. A good friend of mine from Unley High School, Max Barton, had done this, and I suppose my parents saw banking as a respectable and secure future career. For a while my father thought that an electrical trade was the way to a prosperous future, and occasionally my mother would offer the opinion that it would be 'nice' if her son entered the ministry. Unfortunately, she didn't survive to see her grandson, Peter, do precisely that.

None of the above options appealed to me greatly. My preferences at that stage were music, medicine or dentistry. For a number of reasons, dentistry finally won and 


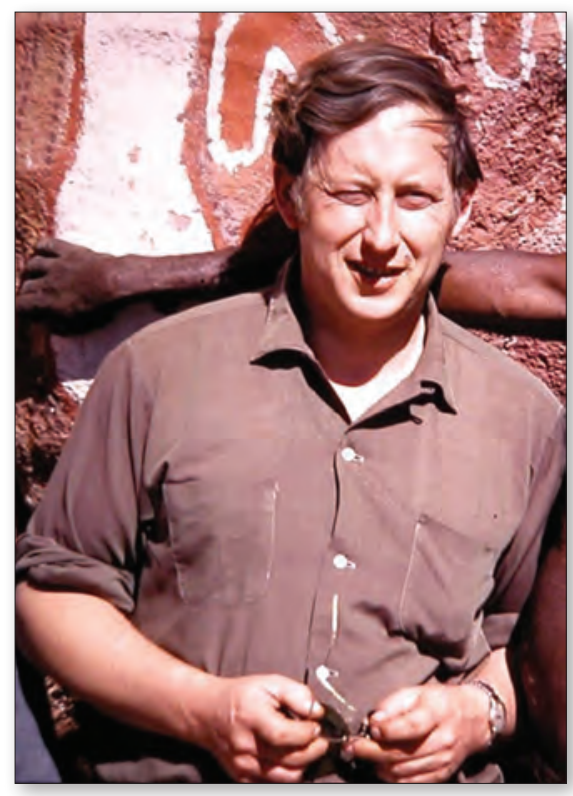

Figure 10.1 Tasman Brown at Yuendumu during one of his field trips. the registrar, Mr AW Bampton, enrolled me as a matriculated student of the University of Adelaide on 7 January 1946. My parents gladly accepted my decision and to my knowledge they never expressed any disappointment, in spite of the financial burden they were about to undertake for at least five years. At age seventeen, I did not fully appreciate the extent of the family sacrifices that would be made to keep me at university.

My first memory of entry to the University of Adelaide is the excitement of starting a new phase of my life and apprehension about how I would handle the next five years. Compared with Unley and Adelaide High Schools, the University of Adelaide seemed to me to be a vast complex of buildings, lecture theatres and laboratories that occupied much of a large city block bounded by North Terrace, the

River Torrens, Frome Road and Kintore Avenue. In the first weeks of the year, new students wandered around looking somewhat lost and confused as they met others in the same boat seeking information on venues and timetables. At that stage we didn't know many of the buildings and it was somewhat of a trial finding one's way around the grounds. Having consulted the university calendar, however, we knew the courses set for the first year of dentistry as well as the required textbooks, which we purchased from the university bookshop, then a small concern on the eastern side of the main drive in from North Terrace.

Lectures started in March and continued until just before the final examinations in November. The First Year course in dentistry consisted of science subjects chemistry, physics, zoology and elements of metallurgical chemistry. Chemistry and physics were very similar in content to what I had experienced the previous year at Adelaide High School, but the other two subjects were new to me. Attendance at practical classes in all the subjects was also required.

In those days each lecturer had to 'sign off the students at the end of the year, attesting that they had attended at least three-quarters of the lectures and had satisfactorily completed the prescribed practical work. I never heard of any student failing to be 'signed off' and not being allowed to sit the final examinations, but I dare say there were a few recalcitrants from time to time. 
I quickly got to know my fellow dental students and, as they were to be my constant companions at classes for the next five years, close friendships that remained for the rest of our lives were forged. There were forty-five of us in First Year dentistry, including a few repeating students, three or four women and a number of returned servicemen, who were enrolled under the Commonwealth Reconstruction and Training Scheme. Unfortunately, not all of us were successful in our efforts to become dentists and the original forty-five fell to twenty-five on graduation five years later, most of the failures occurring in the first two years of the course. There were no women in the group of graduates.

Studying at university was certainly different from studying at high school. There was no teacher to pressure students and no overnight homework to complete, although there were set exercises from time to time. Lecturers would appear in the theatre, speak for the allotted lecture time of one hour and then disappear. Tutors supervised practical

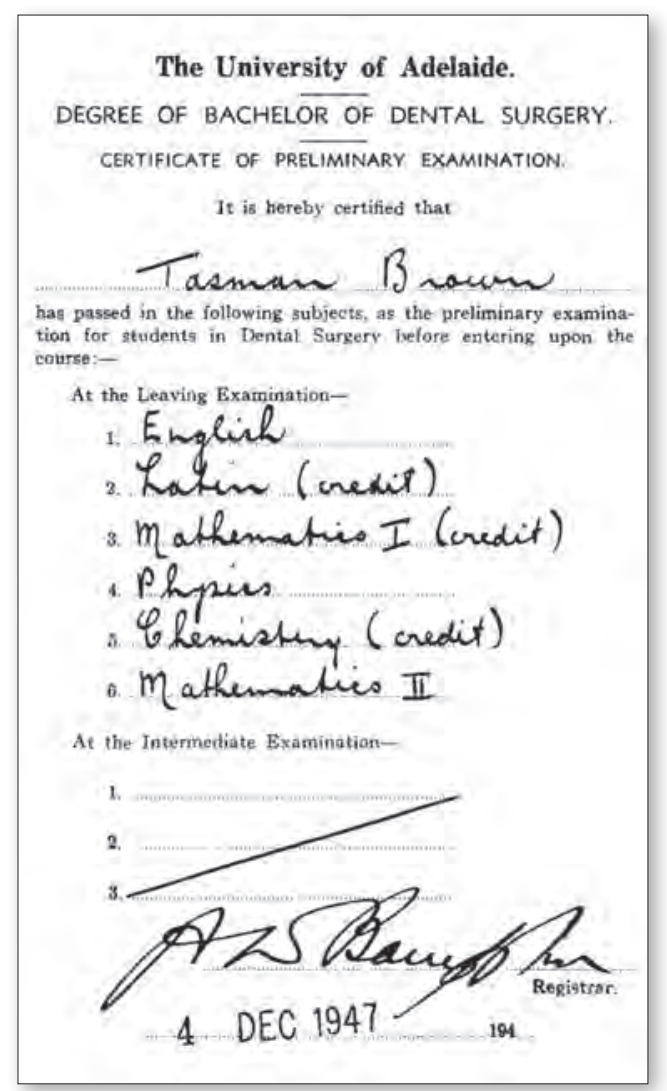

Figure 10.2 Certificate listing the results of the Leaving examination taken in 1944 and showing that I had matriculated for entry to the university. classes, and on these occasions there were opportunities for students to ask questions. Generally, however, we were left on our own and our future progress depended on hard study.

The quality of the lectures varied immensely as did the dedication, enthusiasm and knowledge of the lecturers. During our five-year course we experienced many lecturers and lecturing techniques. Some teachers were obviously very learned and they impressed us immensely; others had the ability to keep a lecture alive, humorous and interesting; and others, at the other end of the scale, considered a lecture to be an hour of reading from a textbook or notes. During the latter type we scribbled even more furiously than usual to keep pace with the recital. Fortunately, I began to enjoy the university environment and the challenges of learning new subjects and techniques. 
In retrospect, I believe that these early days at university were instrumental in my later choice to become an academic and return to the university for my daily work.

I found physics and chemistry enjoyable, but not to the extent that I had at high school. The subject matter was somewhat more advanced than at Leaving Honours level and it required a degree of mathematical knowledge. The chemistry practical classes were always entertaining, particularly the sections dealing with chemical analysis and recognition of unknown substances. Organic chemistry was new to me and I never quite felt at home with the carbon, oxygen and hydrogen compounds and formulae. This feeling of unease with organic chemistry continued the following year when we studied biochemistry.

The professor of chemistry was A Killen Macbeth, a well-known university personality. Demonstrations during his lectures were always enthralling. I was intrigued when the assistant would drop flowers or a sausage into liquid air or liquid nitrogen and then, with a flourish, like a magician, the demonstrator would remove the object and smash it into a thousand pieces with a mallet. The assistants were usually students themselves who had been awarded cadetships that enabled them to study at university.

Likewise, the physics lectures usually involved a demonstration of some type - for example, tesla coils, electromagnetism, or pulley principles. We had a rather taciturn lecturer, George Fuller, who gave humourless but still confident lectures to a class of dental and medical students. It was a feature of the physics programme that the professor, Sir Kerr Grant, who was a well-known university eccentric, would recite Kipling's poem 'If' at the final lecture of the year. On that occasion, the lecture theatre would always be overflowing and students from various faculties would be packed in for the occasion. Kerr Grant always took it in good spirit and gave a stirring performance of the famous poem.

Kerr Grant was a legend in the university and numerous stories about him abound. I shall relate only one such story. It was Kerr Grant's practice to demonstrate the power of electromagnetism by using a large electromagnet on a pulley to raise an iron ball high in the lecture theatre. He would cut the current and the ball would drop with a thud onto a sand tray that had been aligned to a chalk-mark on the floor. One day, according to the story, students moved the chalk-mark slightly and, of course, the ball crashed onto the lecture floor, missing the tray but causing much merriment. Not to be fooled a second time when the lecture was repeated, Kerr Grant moved the tray away from the chalk-marks, but the ball still crashed onto the floor, as the tray had been positioned correctly. It's a good story, which may or may not be true, but it is indicative of some of the pranks that students played on their professor.

Zoology was entirely new to me, as I had not taken any biological subjects prior to university. Lectures were given by Patricia Mawson and the practical sessions involved the dissection of creatures such as frogs, stingrays and, I think, a rabbit. We were a bit 
squeamish at first, but soon learned the art of dissection and drawing — just as well, because later I would spend about twenty years teaching human anatomy to dental students using the dissection of cadavers. Zoology classes also introduced us to the micro-world of pond water, where we met the amoeba, paramecium and many other strange creatures. We also learnt to use a microscope. Zoology appealed to me, and I think at that stage I realised that biology could replace the physical sciences as a main interest of mine in the future. Many years later when I was on the staff of the university, I once again met my chemistry teacher from Adelaide High School, Stan Edmonds, who had always been a favourite teacher of mine. He had since studied zoology, gained his doctorate and become a member of the staff of the Zoology Department. That was a change of career for Stan who, incidentally, was an accomplished Gilbert and Sullivan performer in earlier days.

The fourth subject in 1946 was Elements of Metallurgical Chemistry, taught by a lecturer from the South Australian School of Mines, Mr Reginald 'Reggie' Laughton. Reggie lectured us on the properties of various metals, their melting points, alloys and so on. The practical classes required us to undertake various quantitative analyses as we melted metals in crucibles placed inside furnaces. One such exercise involved the assay of gold, and, to this end, we were asked to bring some unwanted article of gold such as an old locket, piece of gold chain, brooch or earring. Success with the exercise varied when the assay results informed us that some students had brought along fragments of brass, gold-plated silver or other metals with a gold appearance.

It is indicative of my interest in metallurgical chemistry that I scarcely remember anything about the subject. This may be due at least in part because, in the company of similarly minded truants, I would sometimes skip the metallurgy class in favour of a game of snooker at Brady's billiard saloon, a famous establishment on the first floor above the Rundle Street Arcade. It is a pity I didn't learn more from 'Reggie's' course, because I later enjoyed working with metals and alloys as part of our dental studies.

We spent most of our days on the western side of Frome Road in the university proper, and would catch the occasional glimpse of well-known university personalities as we moved around the grounds. Kerr Grant was one such person, but the most famous was the Antarctic explorer Sir Douglas Mawson. He was the professor of geology and it was not unusual to see his tall and imposing figure walking in the university grounds. Unfortunately, I never had the opportunity to hear him lecture.

At the end of the year, when lectures were finished, there was a free period of a week or so before examinations commenced. This was called 'Swot Vac', a period marked by furious last-minute revision of coursework and perusal of previous examination papers in the hope of guessing what would be set that year. Having been 'signed off as eligible examinees, we all sat the final examinations, usually a three-hour written paper in each subject. These examinations were stressful affairs, particularly as, like students of other 
subjects at the time, we crowded into the examination room, sat at our assigned desks and anxiously waited for the test paper to be distributed. We were usually informed that we had five minutes to study the paper before the examination would commence. Thereafter we scribbled in our booklets under the eagle-eyed supervision of invigilators. The head supervisor would advise when the three hours were almost exhausted and then at the exact moment would announce in a loud voice, 'Please cease writing now' The completed papers would then be collected and we would leave the examination room and gather outside for a post-mortem discussion. The smiles or frowns on the students' faces would indicate how the paper had been received.

We dental students usually shared a large examination room with students from other faculties, and it would always amaze me that some of those students would rise from their desks and leave the examination room well before the allocated time. Did this mean they realised that the paper was beyond their ability and therefore it was not worth staying any longer? Or did it mean that they were so knowledgeable in the subject that they did not require the full time to do justice to the questions? I can't recall any of the dental students leaving an examination early. Like me, most seemed to be scribbling until the very end.

When all examinations were finished, there would be an anxious wait until the results were placed on notice boards in the foyer of the main university administration block in the Mitchell building. My student record book reveals that I received a Credit for the first year's coursework (there were only three grades in 1946 - Credit, Pass, Fail). I was very pleased indeed, as this was the first quantitative measure of how I was coping with tertiary study.

I made many new friendships during this first year at university. They were reinforced over the next four years as we shared the fun times of student life as well as the trials of coursework and the anxiety of the examinations. From Unley High School days, Ian Hodgson and Peter Dellow were close friends, and many others, such as Paul Vawser, Ian Dunstan and Ken Brown, soon became good friends also.

It was usual for students to seek employment during the long summer break from about late November through to the following February or March, when the next year's lectures started. A variety of jobs were undertaken and on one occasion Ian and I were employed at Barker Brothers, a dry-cleaning establishment that was then located at the northwest corner of the Unley and Cross Road intersection. Initially we were given the onerous task of chopping wood for the boilers that generated steam for the presses. We also emptied the massive tumble-drying machine, a job we always looked forward to in case a few forgotten coins had tumbled out of pockets. In pursuing this quest, we faced the pungent fumes of dry-cleaning spirit. In due course, when we had served our time in the woodyard, we were promoted to the shop area of the premises, where the pressing took place and customers brought and collected garments 


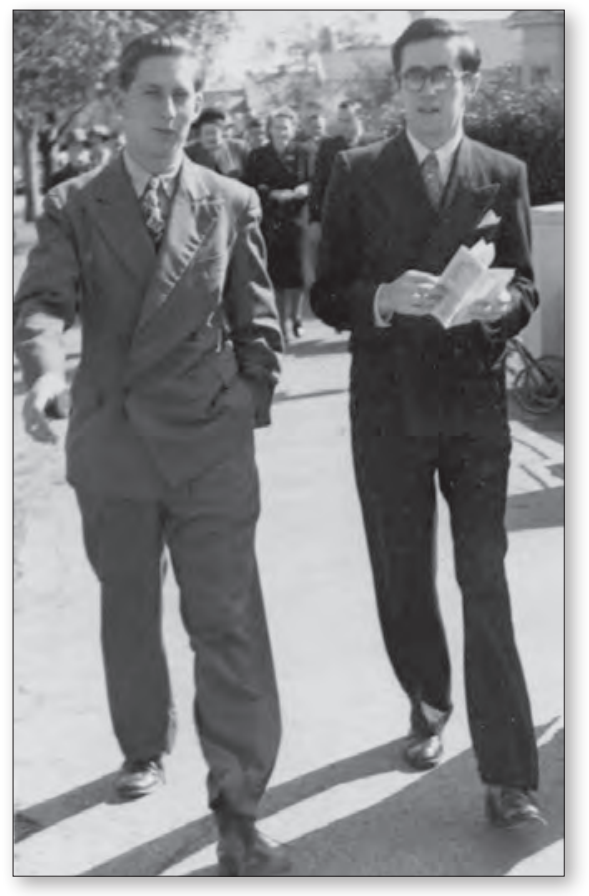

Figure 10.3 Tas Brown and Peter Dellow on their way to a Sturt football match in 1947.

for cleaning. I even learnt how to operate the steam presses for ironing trousers and jackets, a skill I have rarely put to good use since. For these services we were paid the generous wage of $£ 2$ per week, an amount that was subsequently deducted from the Commonwealth Scholarship that I received. Who said, 'Honesty pays?'

We regrouped the following March for the Second Year courses, although in somewhat depleted numbers. At last we felt like real dental students, since some subjects were taken in the Dental School building on the eastern side of Frome Road. The basic biomedical subjects in second year were anatomy and histology, physiology, biochemistry and our introduction to dentistry was through dental histology, junior dental anatomy and prosthetic dentistry, the latter being essentially laboratory techniques.

The anatomy course consisted of lectures on general anatomy, given by Professor Andrew Arthur Abbie, along with lectures on the topographical anatomy of the head and neck, delivered by Dr Ross Adey. Abbie's lectures were entertaining, mainly because he often drew on the blackboard with a chalk in each hand. We were most impressed with this display of ambidexterity, and many years later when I was teaching anatomy I used the same trick. (It is simple to draw symmetrical objects, such as spinal cord sections, using left and right hands simultaneously.) Abbie, however, was an extremely knowledgeable man and a very good artist in his own right, as was demonstrated in the textbook on general anatomy that he had written and illustrated and that we students had to study.

Ross Adey's lectures were a different story altogether. We dental students joined the Third Year medical students, who had already completed a year's anatomical study of the thorax, abdomen and limbs. Adey made no concession whatsoever to us and in the first lecture I remember him going at fast pace into the posterior triangle of the neck with all its musculature and branches of the complex cervical plexus. All of this was accompanied by colourful blackboard diagrams and a continuous dialogue. At that stage, we knew absolutely no detailed anatomy whatsoever and didn't even know the common terms used. After that first lecture, we looked at each other wondering what 
we had struck. In all honesty I don't think that any of us had understood one word. Horror of horrors! Was this subject going to be our nemesis?

We were about to start our dissection classes at that stage. Dissecting a human body was a strange experience — rather horrifying, at first — but we soon adjusted and took it in our stride. Armed with our Cunningham's Manual of Practical Anatomy Volume 3 - Head and Neck, we entered the dissection room, took in the overpowering smell of formalin and were allocated in groups of five or six to a cadaver. The dissecting room was located at the end of the main university drive in a building that later became the staff club. Later still, it was demolished to become part of the new library complex. Today the Security Office stands in this location. The aim of the dissection classes was to encourage us to find, recognise and remember all the various structures in the head and neck and their relationships to each other. That included the muscles, their attachments, the morphology of bones of the skull, the veins and arteries and the nerves. Needless to say, that was an unrealistic expectation. Structures in a dissecting room never look like the glossy colour illustrations in an anatomy atlas. We were lucky to locate only a small fraction of all the structures listed in the manual, and those that we did locate were fairly obvious. Nonetheless, we painstakingly pursued the exercise throughout the year. We were assisted for a while by Brian Crisp and Bruce Lindsay, dental graduates who were themselves studying anatomy for the first part of the MDS (Master of Dental Surgery) degree.

It was the practice of the anatomy department that each group of students was required to take a 'viva' or viva voce examination at regular intervals during the year, according to the region of the head and neck just dissected. These 'vivas' could be interesting and worthwhile or a cause of alarm, depending on how well the anatomy had been learnt and which tutor was booked for the 'viva'. Ross Adey was a formidable examiner and because he was a brilliant anatomist himself he expected students to be almost perfect in their answers. We always tried to avoid Ross for our 'vivas', but this was not always possible. Drs Dudley Packer, Trevor Dinning and Russell Barbour were other tutors who sometimes took our 'vivas'. They were more considerate, probably as they made allowances for the poor anatomical expertise of dental students. A rather unfair (we thought) aspect of 'vivas' was the rule that all in the group passed or all failed. This put a fair amount of pressure on the weaker students to learn their anatomy because they knew that if they didn't do this the other group members would fail with them and consequently need to repeat the examination at a later date. The examiner signed each completed 'viva' on special cards that we all carried. It was a great relief to see the number of signatures gradually increasing as the year progressed.

For a considerable time anatomy was a mystery to us and the only way to success was to memorise the complex structures and their relationships. Thus we could name the cranial nerves in order and likewise the branches of the external carotid artery and the muscles of mastication. Even so, we did not fully understand what we were 
memorising. It was common practice for us to use mnemonics or maxims to help us remember anatomical relations and the branches of arteries and nerves. One such aid that I recall was the 'chemical' formula LR6(SO4)3 for the cranial nerves supplying the muscles of the eyeball - lateral rectus supplied by the sixth cranial nerve (abducent), superior oblique by the fourth (trochlear) and all the rest by the third (oculomotor). There were many other such aids, including a few that do not bear repeating.

Many years later, when I taught anatomy to dental students, I soon realised that one required at least two or three years to become a confident lecturer or demonstrator Then, with a better understanding of functional anatomy, embryology, and the somatic and autonomic nervous systems, one could usually explain topographical anatomy without resort to a capacious memory.

As far as our lecturers and tutors were concerned, Abbie remained professor of anatomy until his retirement. Later, I enjoyed many years as a staff member in his department, when I got to know him and Dudley Packer well. The brilliant Ross Adey specialised in neuroanatomy, moved to the United States and became a leading figure in the Space Program. Russell Barbour was a prominent surgeon, and Trevor Dinning was one of Adelaide's leading neurosurgeons who, many years later, attended an emergency call to my wife Cerry, who was suffering intolerable headaches and vomiting with a suspected brain haemorrhage. Fortunately, it turned out to be a stressrelated condition, brought about by driving a fastidious visitor around Adelaide on a very hot day while he looked for accommodation. All the while, Cerry had been inhaling the exhaust fumes from our car. We found out later that she is very sensitive to petrol and car fumes and even today she feels ill if she gets a whiff of petrol.

The Department of Anatomy also conducted the histology course. The lectures, read slowly from notes by Enid Ashby, dealt with the microscopic anatomy of the various organs and tissues of the body, and during the practical classes we peered at structures through a microscope. I found it to be quite a fascinating subject, as it supplemented our study of gross anatomy, giving more meaning to the concepts of form and function. If I remember correctly, our textbook was Schafer's Histology, which contained numerous photographs of cells and tissues as seen through the lens of a microscope. Before long, we learnt to recognise structures such as nerve cells and fibres, blood vessels and the various cell types in different organs. Towards the end of the year we were given spot tests, during which we were expected to recognise an unknown section. This type of test later became part of the final examination in histology.

Some years later, when I first joined the staff of the Dental School, I was asked to tutor in the general histology class in addition to my other duties. During my first week, the histology staff gave me a slide and asked me if I could identify the tissue thereon. I examined this unknown tissue for some time and could not make any 
final diagnosis, although I recognised almost every cell type - there were pieces of cartilage, muscle tissue, fibrous tissue, a few cross-sections of vessels and various other amorphous objects. I described the section but, feeling an ignoramus, admitted that I could not identify the tissue. They burst into laughter and told me that it was a slice of salami. Apparently this was a joke they played on all new members of staff? They later became good friends of mine.

The Department of Anatomy also taught dental histology. During this course we learnt all about the microstructure of human teeth, including the various hard tissues and the central pulp tissue that contained all the blood vessels, nerves and cells that kept the tooth alive. Practical classes involved examination of ground sections of teeth as well as decalcified and stained sections of teeth and their supporting structures. We also learnt about the development of teeth, their growth within the jaws, and their eruption into the mouth. However, there was relatively little emphasis placed on the study of embryology. In retrospect, I now know that this was unfortunate, because knowledge of embryology of the head and neck region helps substantially in the understanding of gross anatomy and developmental pathology. This omission was remedied in later years.

Dr Franz Lippay, who elucidated his subject in a rather thick Central European accent, delivered our physiology lectures. He appeared to be an authority on the cardiovascular system and would introduce his lectures by walking into the lecture theatre, placing his notes on the lectern with a thud, and peering at the assembled students. He would then announce in a loud voice something along the lines of 'Blut - today ve vill study blut'. During the year, we learnt the fundamentals of cardiac and respiratory function and perhaps a smattering of alimentary tract physiology, but the subject never really appealed to me as much as anatomy. It was an essential subject, however, as we realised later on in the course, particularly as it was the basis for understanding serious illnesses that might affect dental patients, as well as the systemic and local actions of various agents we needed to use. Some years later, when I was completing the first part of my MDS studies, I was required to spend a year part-time with physiology tutorials and practicals under the supervision of Professor Bob Whelan. The difference with these tutorials was that my fellow dental students and I had to present them periodically to the entire physiology department staff - a terrifying experience for Ken Brown, Judy Packer and myself. Franz Lippay was still on the staff then, and attended our tutorials regularly.

Biochemistry, the other biomedical subject in second year, remains a mystery to me today as it was during the course of lectures delivered by Professor Mark Mitchell. As we were instructed on such esoteric topics as carbon rings, sugars and their metabolism, or the Krebs cycle, Mitchell kept us amused and puzzled as he kept popping what appeared to be tablets into his mouth. I learnt many years later that the 
tablets were only peppermints, so I guess he can be excused from being the drug addict we had sometimes suspected him to be.

The class of Second Year dental students was introduced to Dr (later Professor) Thomas Draper Campbell in his course entitled, for some strange reason, Junior Dental Anatomy. This subject consisted of lectures given by Campbell and practical classes also supervised by him with occasional help from others. He was the director of dental studies and later became the first professor of dentistry. He came to be well known to all of us over the next four years. His lectures were predominantly descriptions of the human dentitions, primary and permanent, on a tooth-by-tooth basis. As budding dentists, we

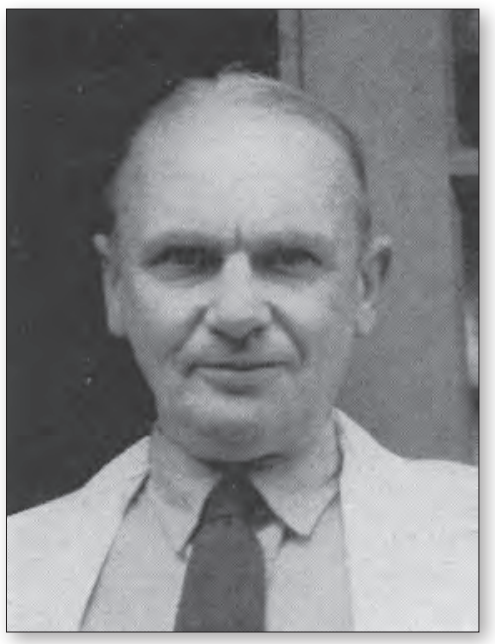

Figure 10.4 T Draper (TD) Campbell. were expected to know every cusp and groove on every tooth intimately. Draper Campbell was a well-known physical anthropologist as well as a competent dentist, and a reasonable oral surgeon. He had a world reputation for his pioneering studies in dental anthropology. His doctorate thesis, published in 1925 and entitled Dentition and Palate of the Australian Aboriginal, became a classic in the field of dental anthropology. Not only was it one of the first studies of this nature, but it also served as a model for numerous studies of a similar nature that followed from many parts of the world.

Campbell never missed an opportunity, then or later in the course, to bring a discussion around to his favourite topic. He would always draw our attention to the excellent teeth and well-formed dentitions of Australian Aboriginals, a characteristic that he told us was related to their vigorous chewing and well-balanced diets. In stark contrast were the rotting dentitions of white Australian children and adults in the 1940s. Draper Campbell held the Aboriginals in very high regard. He had devoted many years of his life leading field trips to Central Australia in the 1920s and 1930s and making contact with nomadic tribes for the first time. He always maintained this interest, and in later years he produced many excellent films depicting Aboriginal crafts and way of life. His best-known movie, which was titled So They Did Eat, depicted the daily search for food and water within a group of nomadic Aboriginals. This film was shown in many countries around the world. Campbell was also one of the first investigators to point out the relationships between diet, function and dental disease.

In the practical classes, we found ourselves doing something that was connected with dentistry at last, namely learning to make models of teeth by carving them out 
of wax and plaster and, later in the year, filing them from blocks of hard casein. We made large-scale plaster teeth by constructing sectional moulds and casting them with plaster of Paris. Campbell was of the firm opinion that digital dexterity was an essential attribute for success as a dentist. He went to great pains to ensure that we became digitally dextrous through the endless carving of teeth, first on a large scale and later in natural size. Today, opinions would vary on whether this approach is the best way to teach theoretical knowledge and technical ability, especially with the refinement of teaching methods like enquiry-based learning and the introduction of simulation clinics such as the one operated by the Adelaide Dental School.

In the first practical class with Campbell, we all received a block of wax with the instruction to carve anything we liked with our newly purchased wax knives and LeCron carvers. Weird and wonderful were the objects we carved - they included cars, houses, aeroplanes and various other objects. The exercise was designed to test our ability to think and carve in three dimensions. The student seated next to me as a consequence of alphabetical proximity was Kenneth Aylesbury Brown, a member of an esteemed family of Adelaide dentists, the dynasty founded by his still-living (at that time) grandfather, Thomas Aylesbury Brown. Ken exceeded all expectations in the carving exercise by producing an anatomically perfect replica of a human ear. I think he also surprised Draper Campbell, but he was later rewarded for his competence by being asked to produce a model for a prosthetic ear that was required for a patient. This must have been one of the first examples in Adelaide of the prosthetic replacement of a facial structure.

After many years in private dental practice, Ken Brown returned to the university, founded the Forensic Odontology Unit and became a leading expert in this field. Over the years, Ken was involved in many forensic cases in Australia and abroad - the most famous being the disappearance of baby Azaria Chamberlain on 17 August 1980 at Ayres Rock (also known as Uluru) in Central Australia. Ken remains a good friend to this day.

Tooth identification was another feature of the practical classes. Campbell would expect us to identify any tooth that he gave us using our recently acquired knowledge of dental anatomy. There was never a shortage of human teeth to identify, as this was in 1947 in the days before fluoride, when teeth were not regarded as highly as they are today. Consequently, a steady stream of patients entered the Dental Hospital and left after the extraction of one or more teeth, which eventually found their way to Campbell's boxes or tins for identification and sorting by his students.

To assist in our study of teeth, we were also required to build our own collections, which we did by asking a friendly neighbourhood dentist to save his extracted teeth for us. Again, there was no shortage of extracted teeth, and most students eventually acquired a reasonable set, although some collections included some rather horrific- 


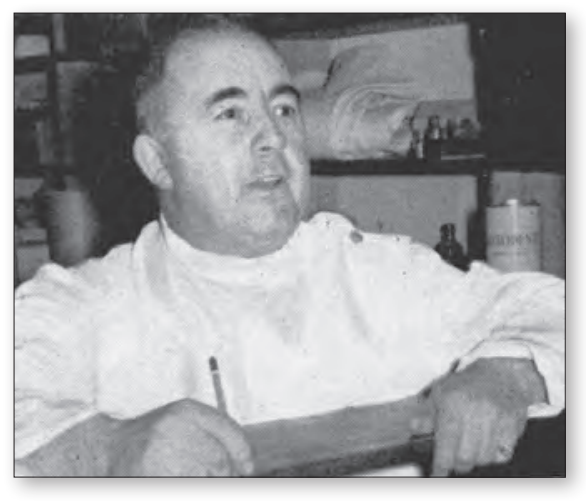

Figure 10.5 Clarrie Whitford - our technician instructor and mentor. looking specimens. A swap system usually helped to locate a desirable tooth to enlarge the collection. We were encouraged to build our own miniature chest of drawers from matchboxes: the teeth were placed correctly inside these matchboxes, which were then neatly labelled 'drawers'.

When I became an academic in the Dental School, my interests in anatomy, anthropology and the life and oral health of Australian Aboriginals led me to a greater appreciation of Campbell's work and to an admiration for his scientific writings. I came to realise that he had a brilliant mind and had influenced a whole generation of dental anthropologists with his earlier writings. In his later years, he would visit the Dental School now and again, and if we were lucky he would spend a short time chatting to Murray Barrett and myself. At that stage he was working on his films depicting Aboriginal customs and crafts. I had the privilege of writing accounts of Campbell and his work and made him the subject of the fourth Graham Mount Oration in 1992. He also figured prominently in two of my later publications (Brown 1998, 2001).

The other dental subject in second year was prosthetic dentistry, supervised by a prominent Adelaide dentist, Dr Hurtle Jack Edwards, one of the early Adelaide DDSc graduates. We rarely saw Dr Edwards in Second Year, but he was to play an increasingly important role as we progressed through the course. Most of the instruction in prosthetic dentistry in this and in later years was given by the head technician, Clarrie Whitford, who became a friend and mentor to most of us during our years of contact with him. Clarrie had his laboratory in a separate room divided off from the main student laboratory on the southern ground floor of the Dental Hospital, and from this room he dispensed materials, advice and friendly chats. We sat at benches for our dental anatomy and prosthetic dentistry sessions, the instruments we used being kept in drawers under the benches. These instruments were purchased by the students according to a list distributed at the beginning of the year. They were closely guarded and often stamped with the owner's initials, but inevitably an instrument or two from one's kit would 'go missing'. It was a lucky student who completed the year with his instrument kit intact.

Practical work in prosthetics was essentially a series of exercises to familiarise us with dental laboratory materials — plaster of Paris, metals, vulcanite rubber and, in later years, acrylic resins. We learnt basic techniques such as mixing and pouring plaster of 
Paris, melting and casting metals, and drawing silver wire through successively smaller drawing holes until the correct diameter was reached. Metal casting was performed by the relatively simple, but effective, method of swinging a small bucket at high speed to force the molten metal into the heated mould by centrifugal force. This was potentially dangerous, as the student laboratory was usually filled with students. There is a story that, on one occasion, a student's bucket became detached from its swinging chain and was hurled with its load of molten metal right across the laboratory. I did not witness an incident such as this, but I have no doubt that it did happen. Soldering techniques were learnt by constructing a length of chain from the drawn silver. We also became adept at wielding a wax knife and modelling the sheets of pink boxing wax in various ways for numerous laboratory procedures. Unlike dental students today, we were expected to undertake all of our laboratory procedures - a distinct advantage in later dental practice if a dental technician was unavailable.

I enjoyed this part of the course immensely, probably because there is always pleasure in completing a task satisfactorily, particularly if it involves manual construction. This experience with metalwork served me well many years later, after I retired and took classes in silversmithing for a few years.

Second Year studies eventually finished with the final examinations, and I was very pleased when I was again rated a Credit. I was really enjoying university life by now.

After the summer break, which included a period of work plus as many days as possible lolling around on one of the Adelaide beaches with friends, we returned for Third Year studies. At last, we had entered a year when dental subjects dominated the course.

The two medical subjects in Third Year were general pathology and bacteriology (now called microbiology). Pathology was taught by Dr Ord Poynton from the Institute of Medical and Veterinary Science. He amazed me by delivering his course over two terms without any lecture notes that I can remember. Now there was a man who knew his subject! Poynton later became a director of the Institute. General pathology was a natural extension of anatomy, histology and physiology, as we learnt to recognise diseased tissues both macroscopically and microscopically. Lectures covered the fundamentals of inflammation and healing, tumour pathology, heart and lung infarction, haemorrhage and blood clotting. The characteristics of inflammation were considered very important and we were taught to remember the so-called five cardinal signs of inflammation. They are often remembered by their Latin names - rubor (redness), calor (heat), tumor (swelling), dolor (pain) and functio laesa (loss of function).

Practical work in pathology involved examining sections under the microscope and attending sessions when various sections were projected onto the screen. Another requirement of the course was attendance at a few post-mortems. I can see little reason 
for this, except that it was thought to round out a dental student's appreciation of human disease. I can remember vividly my first post-mortem. It was a harrowing experience. Even though we had dissected cadavers in the anatomy department, they had hardly seemed human, as they had been infused with formalin and then stored for some time. However, the post-mortem was a different matter altogether, as the subject lying on the table was all too real, having been deceased for only one or two days.

I did not attend very many post-mortems, but one I remember well. It was the practice to record the findings of the examinations in a book, this being before the days of tape-recordings. Usually it was a medical student who was given this task if there was no official recorder present to take the dictation from the pathologist performing the post-mortem. On this occasion, all the medical students suddenly left the room to attend a lecture, whereupon the record book was passed to me, the next student in line. I did the best I could, but never knew if it was adequate or not.

The dental pathology section of the course was taken by the professor, the eminent Sir John Burton Cleland who, like many learned men of his era, displayed a sound education in classics and science. He was an excellent pathologist, botanist, naturalist and environmentalist. Needless to say, his lectures were confident and well received. During my early years on the university staff I got to know 'Bertie' Cleland, but not very well, as he was too exalted a person for a lowly lecturer like myself. It was the practice of the few Dental School staff members to dine in the old staff club (mentioned earlier), and Sir John would often join the table for a chat. My late friend and colleague Murray Barrett always had his luncheon meat pie there and he and Cleland were both members of the Board of Aboriginal Research. Later, I was to become a member and even chairman of the Board, but by that time both Murray Barrett and Sir John had passed away.

'Bertie' had a wicked sense of humour. On one occasion, he informed us that a reporter had contacted him for his views on the scarring of the Adelaide hills face from quarrying. There was considerable public concern at this disfigurement and comment from the well-known naturalist would make good reading for his paper. 'Bertie' thought for some time and then in all seriousness said, 'I suggest that they be painted green'. Apparently this was duly reported as a serious proposal.

Dr Nancy Atkinson taught bacteriology, or microbiology, to us in Third Year. It was a companion subject to pathology and we learnt about the main classes of bacteria - the streptococci, staphylococci, gonococci, pneumococci, lactobacillus and so on and how to recognise them by their staining properties (gram-positive or gram-negative) and morphological appearance. For the first time we learnt to use oil immersion lenses on our microscopes in order to get the required magnification. Practical sessions involved recognising the various bacteria from provided samples. The course gave us a good introduction to general and specific diseases. 
Nancy Atkinson later transferred to the staff of the Dental School after a lengthy tenure in the Department of Microbiology. Her position was in the Department of Oral Biology, established under the leadership of Professor John Thonard. Dr Atkinson was a very experienced microbiologist with a long and distinguished career. Previously, she had been involved in researching salmonella organisms as well as plants with antibacterial properties. She was also the first South Australian to produce penicillin, and she was instrumental in establishing the Australian Society for Microbiology. Nancy was a collector of Australian art and published a book on the subject. She was also a very keen winemaker and after retirement established her own winery in the McLaren Vale region, where she marketed her excellent products.

Our Third Year course introduced us to real dentistry for the first time, although the treatment of patients was postponed until the following year. Lectures in drugs and prescriptions were given by a Dr John Leonard 'Bob' Eustace, a gentle and charming man, who later tutored in the clinic and called each of us 'laddie'. In return he was affectionately referred to as 'Uncle Bob'. His subject went under the imposing title of Dental Materia Medica and Therapeutics, and the lectures were based on a series of notes we received at the beginning of the course. In 1948 the drugs available to dentists were very limited compared with the vast array today. I doubt if the course was of much use, as the most common drugs used by dentists and students were zinc oxide, eugenol, oxyphosphoric acid, silver nitrate, local anaesthetics and some common analgesics and mouth rinses. I never became a competent writer of prescriptions, even though we were shown how to do. It always seemed strange for a dentist to write a script, but these days dentists can legally prescribe numerous pharmaceuticals from a broad range of drug classes.

Our skills in laboratory techniques improved as we were taken through the intricacies of packing and curing vulcanite dentures, repairing them, investing wax patterns and casting metals for inlays, mixing plaster of Paris and investment materials, and more soldering. We also learnt about various impression materials. After we had mastered the handling of vulcanite, we were introduced to the methacrylates. Later, I was intrigued when I commenced dental practice at Gawler to find that the technician had hoarded a vast supply of vulcanite rubber with the suspicion that it would soon be hard to get. At first I wondered why, but I soon found out the answer, as an endless procession of country folk presented — either personally or by post — their broken vulcanite dentures for repair.

Occasionally, a student — all of whom, by Third Year, were male — would volunteer to be the subject for a facial model, whereupon he would suffer the indignity of having an impression material spread over his face and then strengthened with layers of plaster of Paris. When all had set, the mould was removed and a casting of the face was made from plaster. All these fascinating laboratory exercises were carried out under 
the eagle-eyed supervision of Clarrie in the downstairs student laboratory, amid much merriment and comradeship. Sometimes we would hone our casting skills by investing a dead insect or some such object, burning it out in a furnace and casting it in metal.

Operative techniques was the other clinically oriented practical subject. Dr Gordon Ord Lawrence was in charge of this course. He was a very talented man, a superb clinician and a skilled craftsman who manufactured quite intricate articles in his home workshop. His practical course centred around cavity design according to the principles of GV Black, the great American guru who is arguably the father of modern dentistry. Black had proposed five basic cavity designs for excavating decay from teeth and cutting (drilling) a suitable cavity into which the filling material would be placed and retained. The surface and the tooth on which the carious lesion was present determined the cavity design. The policy of 'extension for prevention' was drummed into us - that is, the operator should always extend the cavity preparation into small grooves and fissures in order to prevent decay commencing in those areas.

We became quite skilful in preparing these various cavities, first on large plaster models of teeth and then, when our skills were enhanced, on natural teeth which were mounted on plaster blocks. Students had to learn the use of numerous hand instruments to supplement the dental drill in producing a perfect cavity. There were instruments to chip enamel away, instruments to bevel an edge on the left or right side of a tooth and instruments to smooth a prepared cavity. After a lining had been placed in the prepared cavity, the tooth was filled with a suitable material, usually an amalgam alloy for posterior teeth or a white-coloured silicate cement for anterior teeth, where the filling would show. Gold was often used as a filling material in anterior teeth, not only because of its durability and strength, but also because it was obvious evidence of the owner's wealth. This precious metal was also used to construct crowns in posterior teeth, for bridgework and even as the base for partial dentures. We had to learn the special techniques for making gold restorations by waxing a pattern, investing it, burning it out and then casting it, but we were not trusted with real gold in Third Year. In its place, Clarrie Whitford distributed a cheap imitation gold alloy called Aurocast for our use.

Mention should be made of the Lawrence matrix. This was a device, designed and constructed by Dr Lawrence himself, which facilitated the placement of amalgam restorations in what were called Class II cavities. In this case the prepared cavity encompassed both the chewing surface of a posterior tooth and a surface facing an adjacent tooth — an impossible task without some matrix or forming device to hold the filling material in place. The Lawrence matrix was far superior to any of the commercially available matrices, but use of it was time-consuming because the operator needed to construct a specially moulded strip that was unique for the tooth being filled. The commercial matrices were universal and no prior fitting was required. For 
these reasons, the Lawrence matrix never achieved the recognition it deserved, even in South Australia. Modern views on preventive dentistry, concepts of conservation, the use of fluoride treatments, minimal tooth preparation and an abundance of improved dental materials have changed operative dentistry radically.

The director of Dental Studies, Dr Thomas Draper Campbell, returned to us in Third Year as our lecturer in senior dental anatomy, a course that was concerned with the morphology of animal dentitions and the relationships between dietary and eating habits and craniofacial morphology. We learnt about the teeth of herbivores, insectivores, carnivores, rodents and omnivores. We learnt why the sabre-toothed tiger had become extinct, why the dentition of dogs differs from that of cats, and why New World monkeys have more premolars than both Old World monkeys and the anthropoid apes. The course also included interesting aspects of human evolution and theories of dental evolution. The latter included complex topics such as the tritubercular theory and the strange names for features on teeth such as hypocone, paracone, hypoconulid and so on.

Campbell was the ideal teacher for the subject. Interesting as the course was, the worst aspect was having to memorise the dental formulae of various animals and animal classes. Our textbook was written by a famous person in the field of dental anatomy and histology, Charles Tomes. He even had a microscopic feature of human dentine named after him — Tomes Fibres.

At last Third Year was complete, and we looked forward to the long summer break before returning for our final two years of the course, when at last we would be let loose on real patients. Most of us undertook some form of employment during the vacation period in order to earn a little welcome money. For one of these vacation jobs a few students, including Ian Hodgson, Trevor Clements and myself, became fruit-fly sprayers for the government. Each day we would be taken to a suburban area by truck, given our knapsack sprays and told to progress down the street, enter houses and spray anything on a tree that looked as if it might be a suitable home for the destructive fly. If I recall correctly, we were well paid, with the princely sum of $£ 6$ per week considerably more than the $£ 2$ per week we earned at Barker Brothers Dry Cleaners.

The final two years of our course provided most of the clinical teaching, as well as lectures, practical classes and at last patient treatment sessions. We were seniors in the Dental School now; we wore white clinical gowns; we knew our way around the building, spoke to nurses and were regarded in awe by the preclinical students. Friendships within our group were well established and they remained for life.

Fourth Year studies introduced us to the specialities of dentistry, which were taught by some of the most respected and well-known Adelaide practitioners. In our student days, clinical teaching was almost entirely undertaken by honorary staff; they were unpaid and considered it to be a privilege to devote time to university teaching. 
This concept was to change and by the 1960s, when there was an expansion of fulltime staff, practitioners who were paid a sessional rate according to their experience, status and years of service undertook much of the clinical teaching.

Our clinical lecturers and tutors included APR Moore (dental surgery and local anaesthesia), Hurtle J Edwards (prosthetic dentistry), Malcolm Joyner and John Bloomfield (crown and bridgework), Percy Raymond Begg (orthodontics), Mervyn W Evans (periodontics) and Cecil Maddern (prophylaxis and oral hygiene). We still benefited from the ministrations of Dr Campbell for oral surgery, Gordon Lawrence for operative dentistry, and Bob Eustace, who now gently guided us through the trials of clinical restorative dentistry. Other tutors who attended on a sessional basis to supervise our clinical work included Graham Mount, John Lavis, Roger Willoughby, Max Stain, Bruce Frayne, Harold Clarke, Phil Wesslink, Wesley Marshman and Fanny Westerman. All of these were outstanding practitioners and were or would shortly become leaders of the profession.

For example, Graham Mount became a talented dental educator who travelled widely, lecturing on clinical dentistry - particularly the use of glass ionomer materials. He was instrumental in establishing the university's Postgraduate Committee in Dentistry. John Lavis, who held many senior positions in the Dental Association and the Royal Australasian College of Dentists, also wrote an account of his years as a dental student, which is included in this book. We did not have Roger Willoughby with us for very long after we graduated. He was an extremely fastidious clinician who inspired many of us, but unfortunately he died prematurely with a brain tumour. Harold Clarke, Max Stain and Bruce Frayne were typical practitioners who were much liked by the students, as they brought a practical approach to clinical problems no doubt based on much experience in private practice. Phil Wesslink was also a down-to-earth clinician who, besides being a good teacher, kept us amused with his stories of earlier dentistry along the River Murray towns, where he would often perform emergency treatment with the patient seated on the running board of his car. My memory of Wesley Marshman is outlined below. Two house dentists at the time, Jack Clark and Bob Boyle, took an interest in our progress and were very helpful. They seemed to spend most of their time downstairs in the surgical areas. In 1947, Bob Boyle became the first graduate to gain the MDS (Master of Dental Surgery) degree. All these tutors became our friends, and I am sure that the students of my year would agree that we owe a great deal to their enthusiasm, dedication and knowledge.

Apart from the dental classes and clinics, we were required to attend lectures and ward rounds in general medicine and general surgery. We had senior clinicians such as Drs Chinner and McPhee guide us through the principles of medicine and the elements of diagnosis. We even learnt to listen to heart sounds, to tap a chest and to use a stethoscope. Russell Barbour (mentioned earlier) was in charge of our surgery course, 
but the rounds were usually taken by a surgical registrar, who would shepherd us in small groups through the wards of the Royal Adelaide Hospital. On these occasions we would be shown nasty conditions such as advanced and untreated carcinomas of the head region. At times like this, I was pleased that I had chosen dentistry instead of medicine for my future career. We also had instruction in sterilisation, infection control and the healing of wounds.

The clinical lecturers became very familiar to us, and their idiosyncrasies and habits were often recalled on later occasions. Dr P Raymond Begg was a well-known orthodontist — in fact, he was the only orthodontist in Adelaide at the time. His lectures seemed to me to be most obscure and I think we graduated with only a smattering of the subject, no doubt because Dr Begg encouraged the idea that his speciality was beyond the likes of us (or at least that was what we thought). Nonetheless, during final year we were invited to visit his North Terrace surgery in small groups to watch and admire the great man at work. He was one of a kind. He would bend an arch wire into shape in a flash, tie it to bands on the teeth and clip the ends of the wire, which he then flicked accurately into the corner wastepaper basket in one smooth action. He had a very dry sense of humour and sometimes he would ask a child patient not to look at the light, as it used too much electricity.

Another of Dr Begg's favourite jokes made fun of the well-known rivalry between two of Adelaide's elite boy's schools, St Peter's College and Prince Alfred College. Dr Begg would ask a boy from St Peter's College how he enjoyed being a student at Prince Alfred College. The lad, wearing the blue-and-white blazer of 'Saints', would look most confused and would correct Dr Begg. The good doctor would confirm that the uniform was indeed a 'Prince's' uniform and would enlist the opinion of the nurse, who was in on the joke to support him. Thus the charade would continue while the appointment progressed.

Stories of Percy Raymond Begg are, in fact, numerous. He was an enthusiastic smoker of Temple Bar cigarettes and would deliver his lectures to the class while seated in a chair smoking his cigarettes. Many years later I got to know Dr Begg much better; in fact, when I tutored in children's dentistry for a while, he was also on duty as the orthodontic consultant. On almost every session, he would draw me aside to show me various testimonials to his excellence, which he had received from patients and other orthodontists from overseas. He was certainly a world figure; a journal was even established that dealt exclusively with Begg Orthodontics. He was always very witty and, being of the older school, would dismiss new-fangled techniques such as radiographic cephalometry with words along the lines of, 'You don't need those things when you have my experience', or, 'You shouldn't use X-rays; they cause the roots of teeth to resorb - I've seen it on films'. 
In our senior years, Dr Hurtle Jack Edwards supplemented the practical and clinical classes in prosthetic dentistry with a series of lectures which he gave seated in a corner of the lecture room, usually while smoking Craven A cigarettes. In his own account of his years as a dental student (earlier in this book), John Lavis describes Dr Edwards as having had 'the best mind that I have met in dentistry'. Unfortunately, my group of students missed most of the lectures, as we were often rostered in the clinic at the time of presentation. It didn't seem to matter much, as we had the standard American Textbook of Prosthetic Dentistry to help us understand the subject. Murray Barrett, one of the first Adelaide graduates to gain the MDS (Master of Dental Surgery) degree, joined the staff around the time of our final year and gave some clinical instruction in prosthetic dentistry.

Dr Malcolm Joyner gave the crown and bridgework lectures, with Dr John Bloomfield as his offsider. Joyner was a leading Adelaide dentist who was popular with the students, not necessarily for his lectures but on account of his generous entertainment of final-year students at a party each year. Unfortunately, his lectures were less inspiring than the parties and consisted of each student reading aloud in class from the standard text on crown and bridgework, which, if I recall, was written by Stanley Tylman. We didn't complete much crown and bridgework on patients, but our operative technique exercises gave us experience in constructing post crowns, jacket crowns, three-quarter crowns and three-part bridges. One such crown was known as the 'Cast-base Davis' crown until John Lavis, a great enthusiast and executor of crown work, decided that the 'Cast-base Lavis' crown was a more appropriate term.

Gold, being a precious metal and therefore very costly, was guarded by the hospital authorities with a vigour that reminded one of Fort Knox. However, it was occasionally sanctioned for use by clinical students when we were constructing inlays or bridgework. In these instances, Clarrie Whitford would dispense it from his downstairs laboratory. He regarded this requirement as a very solemn duty as he filled in the necessary requisition form and issued pennyweights of gold to the student. After the inlay or bridge component was cast, the student was required to return the residue in the form of a casting button to Clarrie, who duly weighed it carefully before attending to the necessary documentation. It was a very time-consuming event to approach Clarrie for a gold issue, because one might endure a detailed description of the Whitford holiday house at Christies Beach, including even the colour of the walls. Our gold issuer was always ready for a lengthy chat and a bit of leg-pulling on both sides of the conversation.

Wesley Marshman, another well-known Adelaide dentist, supervised children's dentistry clinics. A screaming kid or two and an anxious student calling for assistance usually marked the afternoons with 'Marshy' in attendance. Assistance came in the form of 'Marshy' practising his towel technique, whereby the poor kid, towel over 


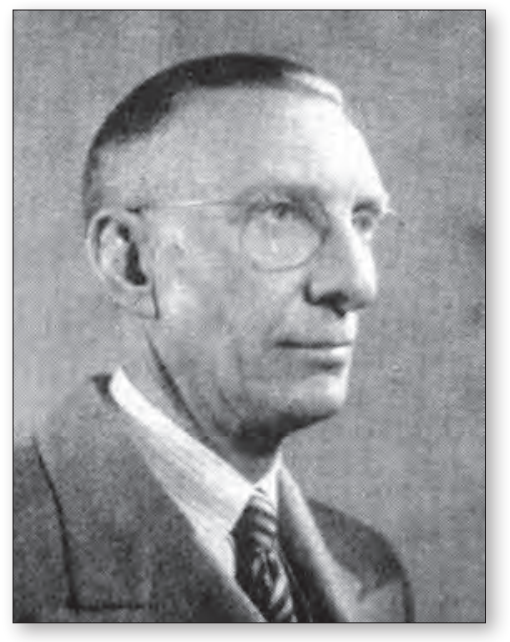

Figure 10.6 Wesley Marshman.

the mouth, was told the dental work would be completed, no matter whether it was done the dentist's way or the patient's way! Marshman was also the silver nitrate 'king', who encouraged us to paint every carious primary tooth in sight with a solution which resulted in black teeth and often a blackened student and a blackened gown, bib and any other fabric that had absorbed a few drops of the magic fluid. Most of us did not relish 'Marshy's' afternoons, although I must say that they were never dull.

By final year we were introduced to extractions and anaesthesia. We attended in small groups of a few students at a time. I imagine that we were all rather apprehensive approaching oral surgery, even on a small scale. I know that I was.

My first patient was a child requiring extraction of a carious primary tooth. This was not a difficult task and it proceeded smoothly enough to give me confidence for more demanding tasks. Before the end of the year we were all reasonably competent in routine extractions but were only allowed to observe the more difficult removal of impacted teeth.

There was never a shortage of teeth to extract in the 1940s, and by the time we had graduated most of us had filled our extraction requirement cards to overflowing with the signatures of tutors. I wonder how much experience of tooth removal the student of today has.

Occasionally, we would have the opportunity to attend the general anaesthetic sessions on the ground floor of the Dental School. Dr James 'Bill' Scollin, who was superintendent of the Dental Hospital and no amateur when it came to surgery, would carry out a difficult impaction or multiple extractions while he calmly whistled away and we looked on in admiration. Meanwhile, we were expected to be taking in the principles of the general anaesthesia administered by a specialist from the Royal Adelaide Hospital. This instruction didn't quite prepare me for my first experiences as a new graduate at Gawler working with Hedley Schoff. Hedley was a master extractor, as were most of the dentists who gained registration after an apprenticeship training. Hedley seemed to take multiple extractions in his stride while the patient lay 'etherised' in the backroom surgery. There was no shortage of extractions in those days!

To round out the year, Dr Max Wilson gave us a few lectures in a subject called Ethics, Economics and Jurisprudence. I can't recall much about this subject, but its title certainly was imposing. Personal economics was uppermost in our minds at that 
stage, because most of us were impecunious to the extreme and could hardly wait to earn some decent money after five years of study. In addition, Dr Mervyn Evans gave us a brief course in periodontology, but all I can remember are the descriptions of rather horrible gum conditions such as fulminating pyorrhoea and the miracle of Liquor Arsenicalis, Mervyn's cure-all for oral soft tissue diseases. Merv Evans was another of our DDSc (Doctor of Dental Science) holders; he knew a great deal about another magical fluid, saliva, which featured prominently in our lectures, on account of its great curative properties - dogs discovered this before we did.

A set of requirements had to be met by each student to satisfy the demands of the clinical curriculum. We were expected to complete a minimum number of fillings of each type, as well as dentures and extractions. A smaller number of the more difficult procedures such as root canal fillings, inlays and partial dentures were also expected. In the 1940s, dental decay was rampant and the protective properties of fluoride were not yet recognised. Hence there was no shortage of patients on whom to sharpen our skills so that we could slowly get our requirement lists signed off. Some less common procedures were hard to come by, and a certain amount of trading of patients took place in an effort to complete requirements. With examinations looming, patients were forgotten as people and became regarded more as a Class II amalgam or a Class IV inlay or another extraction or whatever procedure was needed to fill requirements. Fortunately, dental education today has progressed past these practices.

Apart from our lecturers and tutors, most of the students would remember other hospital personalities or patients who invaded our lives from time to time. Sister Wilson was a kindly soul who looked after our interests as she supervised her team of nurses. Alf Williams, the cleaner, and Mr Troubridge, the gentleman who staffed reception, were people we encountered during our student years. Alf was definitely a character, an affable returned army man with a wooden leg. He was forever offering stories of doubtful morality to any student who was willing to listen. Alf seemed to be permanently redolent of Fisher's polishing wax but, in what we thought of as classic Public Service mode, he spent as much of his time leaning on his mop and gossiping as he did cleaning floors. He, too, liked a joke, as evidenced by a crudely written notice he once placed in the toilet block - 'Please don't throw your butts in the urinal — they become soggy and hard to light'. Mr Troubridge was a jovial man not given to much lateral thought. According to Dental School legend, on one occasion, a distinguished professional visitor from the USA approached the reception desk and informed Mr Troubridge that he wished to see Dean Campbell. Our reception officer looked through his hospital records and responded, 'I'm sorry sir, there is no one here by the name of Dean Campbell'.

Life as a dental student in the years 1946-50 was generally happy, marred by the periodical examinations and the apprehension they occasioned. Comradeship increased 
year by year, as we spent most of our days in close proximity sharing the same trials and jokes together. As our First Year class of about forty-five was whittled down to the final twenty-five who graduated, our friendships were deepened and cemented for life.

We younger students who came to university direct from secondary school were very fortunate to share our course with many returned servicemen, some of whom were already married. They were anxious to succeed and set a cracking pace in their studies that we tried to emulate. They were a happy lot and brought much humour to the group when we were working side by side in the laboratory or clinic. The warm glow of nostalgia is always a common feature when those times are recalled during meetings of those of us who remain.

Being a very large class, our group brought major problems to the faculty, particularly in the logistics of providing clinical and laboratories space. The group was rostered for clinical sessions, as there was an inadequate number of dental chairs to accommodate all of us together. We didn't have the luxury of electric dental engines before we reached final year, having to persevere with our foot-operated treadle engines before then. Pity the patient who endured an extensive cavity preparation at the hands of a student operating a treadle drill which tended to gradually slip away from the operator as the drilling progressed.

The treadle-operated dental drills revolved at a much slower speed than the electric drills and of course the marvellous air rotors were not introduced until about ten years later. Students were required to buy all clinical hand instruments that were kept in our instrument cabinets, carried into the clinic for each session and set alongside the allotted dental chairs. There was no central sterilising facility in the Dental Hospital and the students were responsible for sterilising their own instruments after use by placing them in the boiling-water sterilisers lining the wall of the clinic. Some instruments were cold-sterilised in glass trays filled with a solution such as Zephiran. When I think of the conditions in the student clinic in the late 1940s, I realise that they were primitive indeed. The students of the twenty-first century would have difficulty in recognising our 1950s clinic as a dental surgery.

The larger groups of post-War dental students (there were usually only a handful in each year prior to the War) demanded better student facilities. Accordingly, during our course a common room appeared on the southern side of the Dental School. This prefabricated hut became our refuge from the rigours of study, a place where we could eat lunch, swap yarns, play table tennis and act as all students do. Many a game of table tennis was played in this room to the cheers of onlookers. I remember that one of our class, Andrew Muirhead, was a greatly admired and talented player.

Our friendships also extended into our social lives, as we tended to spend time with each other at weekends and on special occasions such as the annual dental ball or the annual picnic. In my case, I spent a great deal of time with my friends Ian 
Hodgson, Ian Dunstan, Paul Vawser, Peter Dellow, who was in a class ahead of us, and Kevin 'Gubby' Allen, who was in the year behind. During my final year, I was becoming more involved in playing jazz, and this led to my friendship with Kevin, who was a talented pianist and saxophonist. Peter Dellow and Kevin Allen were best man and groomsman respectively for my first wedding, while I was a groomsman at Paul's wedding.

As students, we became members of the Dental Students' Society of the University of Adelaide. This society had been established many years previously in 1919 by a few students in order to provide a means for regular meetings to further common interests. An official lapel badge was designed, with the Greek letters Delta and Sigma (D and S) upon a shield. We were proud to receive and wear our badges. The Society met regularly to discuss dental matters and to hear invited guest speakers from time to time. In later years, students were elected to represent their fellows if any negotiations with staff or university administration were required. They were known as the 'year reps'. Dr Mervyn Wyke Evans, our lecturer in periodontology, published a history of the society in 1988 covering the years 1919-79 (Evans 1988). This excellent publication contains numerous stories about students of earlier years and gives a good account of life at the Dental Hospital. As for me, after my retirement in 1991, I was very pleased to be made an honorary member of the Dental Students' Society and have my name placed on a plaque in the common room alongside those of Professor Max Horsnell and Mr Les Reynolds, each a friend of mine.

Another student endeavour was the magazine published at the end of each year by the Dental Students' Society. It was called Probe and was launched in 1949, with Peter Dellow as the first editor. Due largely to Peter's efforts, the magazine was a great success and was eagerly anticipated each successive year. Probe contained both serious and light-hearted articles, photographs of the year's activities, humorous profiles of students and cartoons. Sometimes staff members would contribute articles. The cartoons were usually very good. Peter Dellow was a talented artist and he contributed cartoons for the magazine somewhat in the style of Walt Disney, whom he admired greatly. Harold Austin was also a good cartoonist and his work appeared in several editions of Probe. Peter Dellow graduated a year ahead of me, but after a very brief sojourn as a house dentist he enrolled for a medical course, graduating with his MB BS in 1957. He wished to further his studies in surgery but ironically found that he had a heart condition preventing him from doing so; it had been brought on by a childhood bout of rheumatic fever. He then joined the staff of the Department of Human Physiology, developing a special interest in neurophysiology. In the mid-1960s, Peter accepted a professorial position at the University of Western Ontario in London, Ontario. He continued his work as a neurophysiologist and attracted many of his earlier Adelaide students to Canada for postgraduate studies with him. 


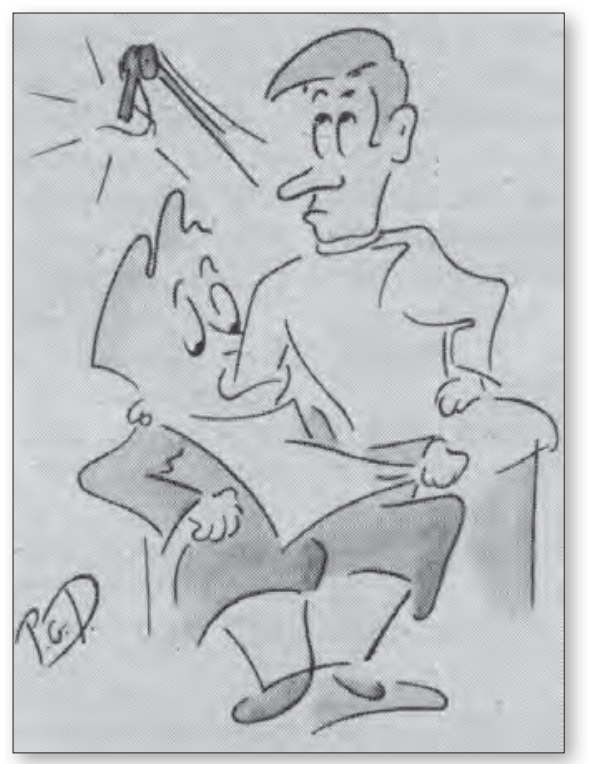

Figure 10.7 Peter Dellow's cartoon in the first Probe magazine, 1949. Courtesy of AUDSS.

Figure 10.8 Prosh Day 1947 with Tas Brown (clarinet), Ken Brown (violin) and Milton Sims (leading).
The annual student procession held to raise funds for charity on 'Prosh Day' ('Prosh' being a colloquial term for 'procession') was a great occasion for all. Students from the various faculties would try to outdo each other with elaborate floats or other displays. Many had a political theme related to a topical situation of the day and most of these were witty. Other students would comment on a local event or some current item of interest. The dental students usually managed to make a firstclass contribution to Prosh Day. During my time, one of the students, the unforgettable Lloyd Twartz, wheeled a barrow of horse manure with the sign 'Bernborough Souvenirs 6 ${ }^{\mathrm{P}}$ per Bag'. (Bernborough was a star racehorse at the time.) Another stunt in which I was involved drew its inspiration from an unfortunate accident suffered by our state governor, Sir Willoughby Norrie, who managed to fall off a camel during a visit to the north of the state. We made a

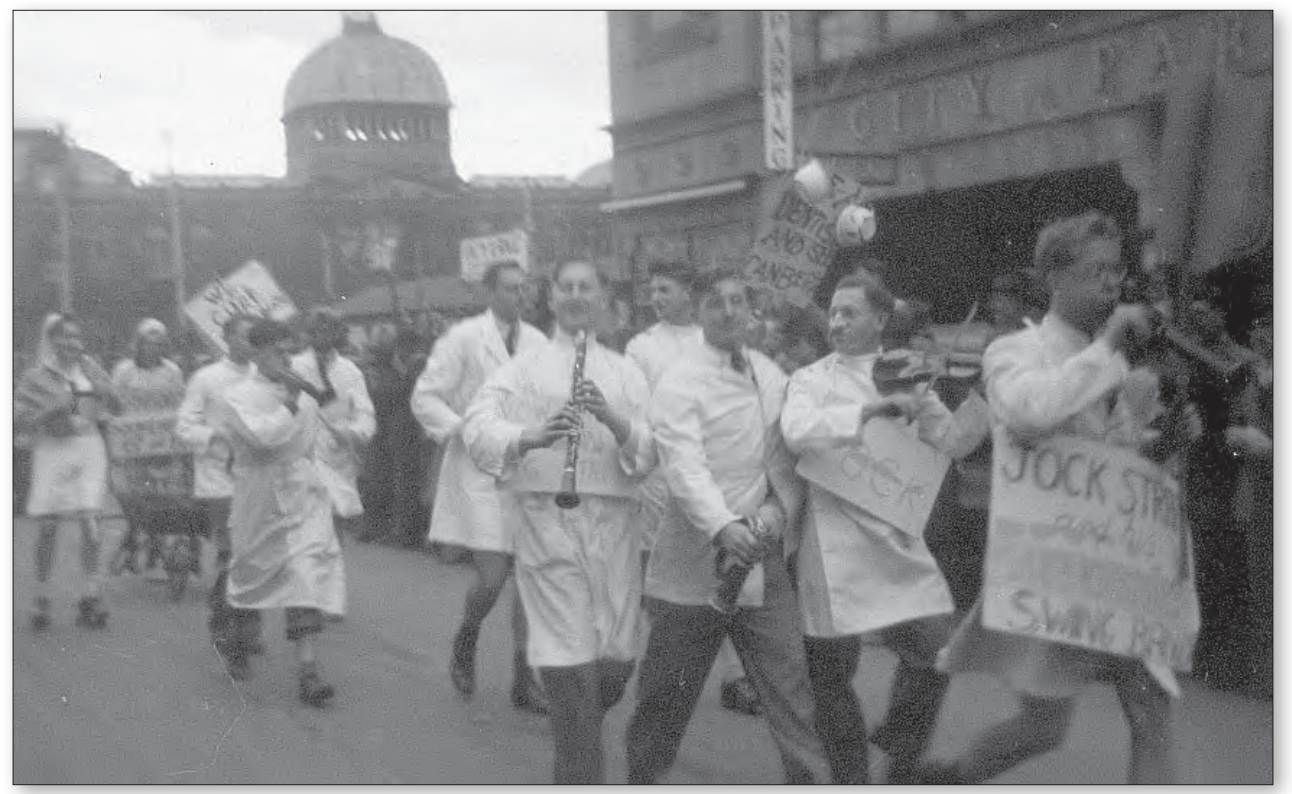


look-alike camel with students inside at either end. Ken Brown was the camel driver, dressed as an Afghan, and I was one of the two stretcherbearers following the camel. Above the camel was a sign advertising a new book — 'How to Ride a Camel by Willie B. Sorrie — Best Seller 7/6'.

Prosh Day was well supported by the public, who donated money for charity to student collectors. On the whole, the processions, escorted by the local constabulary, proceeded without too much trouble. The police kept the students under control and had the power to ban any

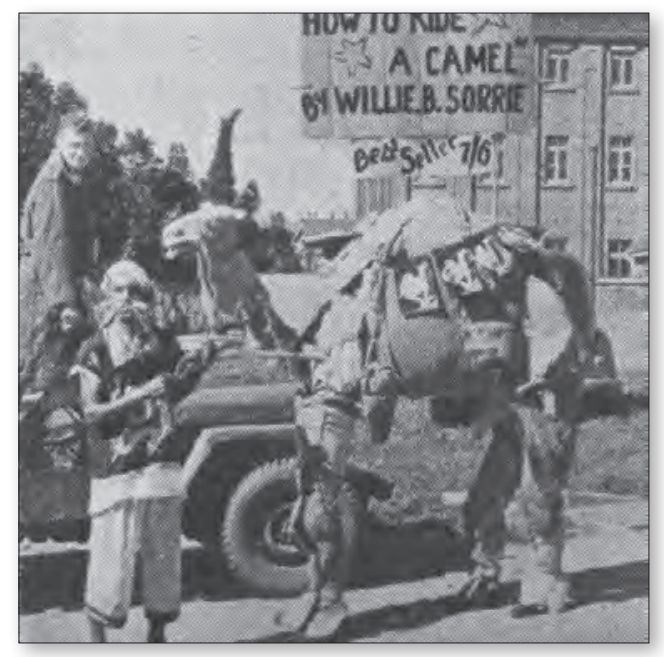

Figure 10.9 Prosh Day 1948 - 'How to ride a camel'. float considered offensive to $1940 \mathrm{~s}$ morality. Occasionally, a student riding on the floats would bombard the watching public with water bombs or, even worse, flour bombs. This activity was frowned upon, but the unfortunate victims usually suffered with good grace. I don't know if the students of today have a similar event, given how much student life has changed over the years.

As the examination period drew near towards the end of 1950 we final-year students found much to discuss about our futures. Jobs were not all that easy to come by, and there was some competition for suitable positions. However, the immediate task was to take the final theoretical and clinical examinations and do the very best we could. The clinical examinations were rather frightening, as they required the presentation of selected patients to display our restorative and prosthetic skills. It was up to us to select the patients who showed our talents to the best advantage and convince them to take part in the examination (which did not involve any actual further treatment). There was great apprehension on examination day until the patient appeared at the appointed time. Sighs of relief could be heard throughout the clinic. Happy was the day when the examination results were published and we learnt that all twenty-five of us had passed. I am certain that there were many celebrations that day which marked the end of five years of hard study and also five years of wonderful companionship. Shortly afterwards, we officially graduated at a ceremony held in the Bonython Hall on Friday 15 December 1950, when we gowned up and received our official BDS (Bachelor of Dental Surgery) certificates. Now that we were 'proper' dentists, we were registered by the Dental Board of South Australia, were given our certificates of registration, and were then free to practise dentistry anywhere in South Australia. 
It seemed sensible to most of us to find an assistantship with an established dentist so that we could gain additional experience before we commenced to practise on our own. Most of us found such positions either in Adelaide or in country areas, but a few soon went overseas, and one or two may have established practices of their own. In my case, I worked for a couple of weeks in a Kensington Road practice operated by Mr Maurice McCarthy before I secured a job as assistant with Mr Hedley Schoff in Murray Street, Gawler. However, that is another story.

\section{Acknowledgement}

I am extremely grateful to Dr Ian Hodgson, who read an earlier draft of this chapter, corrected a few mistakes and sharpened my memory of some personalities.

\section{References}

Brown T (1998) A century of dental anthropology in South Australia. In: Human Dental Development, Morphology and Pathology, A Tribute to Albert A. Dahlberg, ed JR Lukacs. University of Oregon Anthropological Papers Number 54, pp 421-441.

Brown T (2001) Thomas Draper Campbell: Pioneer dental anthropologist. In: Causes and Effects of Human Variation, ed M. Henneberg. Australasian Society for Human Biology, University of Adelaide, Adelaide, pp 1-11.

Evans MW (1988) The history of the Dental Students' Society of the University of Adelaide 1919-1979. Published by the author. 


\section{1}

\section{Learning to be a dentist (1968-72) - Grant Townsend}

\section{First Year}

During my years at Norwood High School, I had not spent much time thinking about what I might do after matriculating. If pressed, I would usually say that I might become a teacher. In my final year, our class teacher, Mr John McDonald (who was later to become the Foundation Chancellor of the University of South Australia), asked me whether I had considered dentistry as a career. I hadn't, but a neighbour, David Burrow, was studying dentistry, so I spent some time with David looking at the calendar entry for dentistry and listening to his description of the course. It seemed interesting, so I listed dentistry as my first preference for university entrance and medicine as my second.

I was accepted into the Adelaide Bachelor of Dental Surgery course to commence my First Year studies in 1968 and I also received a Commonwealth Scholarship, which was very welcome as it eased the financial burden on my parents. At that time, dental students who chose to study mathematics as one of their First Year subjects were 'sent' to Flinders University. Flinders had only opened two years before and was seen very much as the 'new frontier', being located some distance from Adelaide in the suburb of Bedford Park. Studying chemistry, physics, biology and mathematics along with medical and science students was challenging but enjoyable, and I remember spending a lot of time in the library going over lecture notes and reading associated textbooks. I also remember the biology practical sessions, where we cut up frogs and looked down microscopes, something that was new and exciting. In fact, we had many practical sessions in non-dental subjects throughout our course that I found interesting generally but which took up a large amount of our timetable. With the increasing pressures to 
also complete laboratory and clinical work in dentistry, it was clear that something would have to 'give' at some stage in the future.

Many young, enthusiastic academics had taken up appointments at the new Flinders University and they generally presented high-quality lectures. Among our lecturers were physicist Professor Max Brennan, who later became head of the Australian Research Council in the 1990s, and mathematician Professor Brian Abrahamson, who became a pro-vice-chancellor and deputy vice-chancellor at Flinders in the late 1980s and early 1990s.

Two of my other classmates from Norwood High were also commencing their studies at Flinders in 1968, and so we travelled together by car to and from the university every day and spent that time talking about all the new topics that we were learning. Robert Hirsch was also studying dentistry and went on to become a senior lecturer in periodontics at the Adelaide Dental School, while Ralph Scicchitano was studying medicine and went on to become a respiratory physician. Sadly, both Robert and Ralph have since passed away.

I vividly remember sitting in a packed introductory lecture on the first day of term and being asked to 'look to the right' and 'look to the left' and then being told that 'only one of you three will pass at the end of the year'. I'm not sure whether that prediction was accurate across all of the First Year courses, but it was true for the 1968 group of dental students. At that time there was no quota on places in the BDS programme, but the first year of study served as a rather brutal but very effective exercise in 'survival of the fittest'.

My recollection of the last lecture for the year in one of our subjects was the lecturer coming into the lecture theatre wearing a laboratory coat and being bombarded with tomatoes, eggs and various other objects. Throughout his lecture, paper planes glided down from the back of the theatre. I remember, though, that this last lecture consisted entirely of tips about what would be in the final exam, so I was glad I was able to maintain reasonable concentration and benefit from his advice.

My main disappointment about this first year at Flinders was that there was absolutely no mention of dentistry made at all and no contact from the Dental School. I felt isolated from the other dental students who were not studying mathematics and who were located at the North Terrace campus of the University of Adelaide. The results of First Year medical and dental students from the University of Adelaide, as well as those for dental students who attended Flinders University, are presented in Figure 11.1. At that time, results were published in the local newspaper for all to see.

\section{Second Year}

Second Year commenced with functions in the students' common room in the basement of the Adelaide Dental Hospital (yes, it was in the same place as it is now!). 


\section{Medicine, Dentistry Results}

Results of the examinations in first year medicine and first year dentistry conducted by the University of Adelaide, were released yesterday.

Distinetions and eredit. ave shown in order of merit and passes in alphabetical order.

YACUITY OF MEDICINE

EXAMINATIONS FOR THF MEDICINE AND SURGERY Preliminary Examination

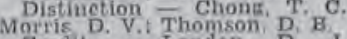
Credit London. D. J. Kwitko, A.: Gaetjens; G, T. Passed - Armilase, M. H. Primela B.: Hart, M.: Role. P. B.: Saunders, G, M,: SWanson. Pamcin C. not classiffed, drews. D. W.: Crowhurst.; J. A. Prost. L: P. Garrett, $P$. B Gilchirist. $P$. $N$. Graham $F$ C.: Lake, $P$. B.: Manare, $M$. Smith R. D.: Thompson. P. V. worthey, cis.

for The Elder Prize - Chons. T, C. Middle FACUITY OP DENTISTRY ORDINARY DEGRE THE BACHEIOR OV DENTAL SURFirst Annmal Examination Passed Anderson T.: Eirk P. P. G. Classitied Brigden. J. L. Callachan p. Choimes.

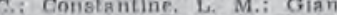
ropoulos. $\mathcal{A}_{\text {f }}$ Hancook. R. D: Manos G. P.; Packer, J. W.

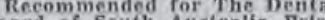

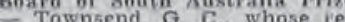
sults have neen published sep grately by the Finders Univerarately by
sity of SA

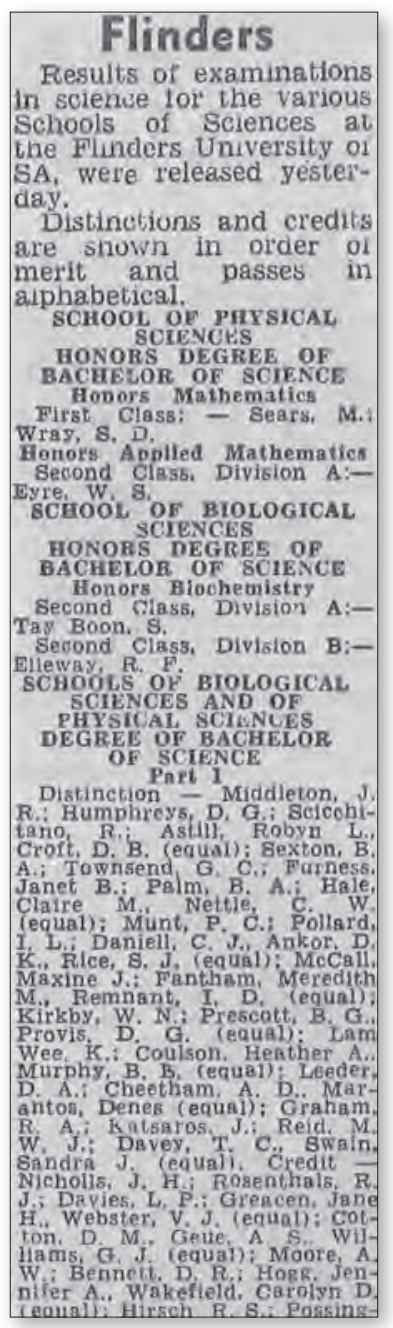

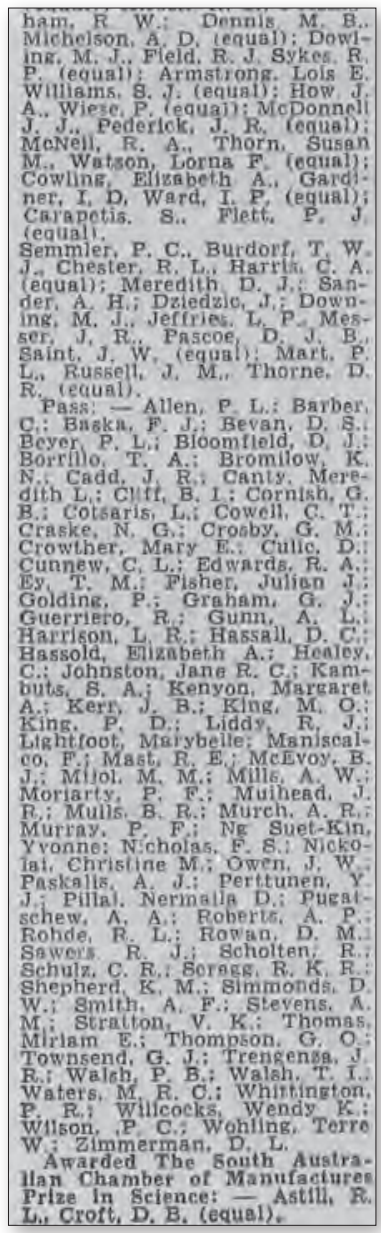

Figure 11.1 The University of Adelaide and Flinders University First Year medical and dental student results, 1968.

The Flinders group soon made friends with those who had studied at the University of Adelaide campus, and we now all felt much more part of the Adelaide Dental School and the Adelaide University Dental Students' Society. Our subjects consisted of general anatomy, general and dental histology, biochemistry, oral anatomy, and dental materials and techniques, and the first three of these were presented to both the medical and dental students in the Hone or Stirling Lecture Theatres in the Medical School South. Although being in lectures with the medical students did lead to some social interaction outside class times, any mention of the relevance or application of topics by lecturers was always directed to the medical students. There was never any 
mention of dentistry or dental applications in the lectures and there was a feeling that we were 'second-class citizens'.

In those days, the Stirling and the Hone Lecture Theatres faced the opposite way to their current arrangement and were sharply tiered, with cramped wooden bench-type seating. We often had three or four lectures in a row, with what seemed to be an endless stream of new words and concepts flowing from the lecturers' mouths, supplemented with sketches or important points written in chalk on the large blackboards at the front of the theatres. There were no PowerPoint presentations or slides, very few printed notes, and certainly no recordings of lectures or iPads or iPhones. My approach to capturing this mass of information was to take down notes and diagrams that were as detailed as possible and then to spend each evening trying to make sense of them. This included looking up in dictionaries or textbooks the spelling and meaning of many new technical terms that I had never heard before but had spelt phonetically during the lecture (there was no Google to help me).

Our lecturers and demonstrators in anatomy and histology included Dr Robert Barbour, Dr Ram Tulsi, Dr Dudley Packer and Judy Schroeder. Dissection sessions extended over the whole year and followed Cunningham's Manual. Histological slides were examined using microscopes, with the tutors having a special eyepiece with a small arrow to point at structures of interest. While we learned to use a microscope, it seemed that a lot of time was wasted trying to identify various cells and microscopic structures ourselves and then asking a tutor to point them out: 'Is this what you mean?' 'No, the pointer is aimed at that purple-coloured structure!' Technology now allows a whole class to look at photomicrographs without needing to look down a microscope, just as it allows for areas of interest to be clearly indicated.

The biochemistry course ran for the entire year, with three lectures a week. The first lecture was presented by Professor Deller, who discussed biochemistry in medicine (no reference to dentistry). Our lecturers were all research-active academics, including Drs Wells, Rogers, Keech, Symons, Wheldrake and Egan. A page of my notes from a dental materials lecture is shown below as a tribute to the dying art of note-taking. The examinations have changed substantially over the years, and one wonders how students of today would cope with the questions that were asked in examinations back then, or indeed the staff in the School. Of course, the overriding question should be: 'Is this important for a dentist to know?' I note all of this in order to highlight an important question that needs to be kept in mind when designing a dental curriculum - 'What is it that students (and future dentists) really need to know and what would be nice to know?'

I enjoyed the biochemistry course and I passed the exams - but how much of it was really necessary and how much would dentists use in their practice? This question often comes up in curriculum discussions when the balance between time allocated to 


\section{Dento Mate.}

Mondan

$$
\text { Eutecties - Miquid } \rightarrow S_{\alpha}+S_{\beta}
$$

pust belaw $800^{\circ} \mathrm{C}$ hequid gives 2 thase $\alpha, \beta$

$\alpha, \beta$ - each do an solid solin

$$
\begin{aligned}
& \beta \text { thase contais } 10 \text { \% Silver } \\
& \alpha \text { - } 102 \text { copper at } 800^{\circ} \mathrm{C} \text {. }
\end{aligned}
$$

* Hypeentectric allay - say $202 \mathrm{Cu}$
What haptens during solidi

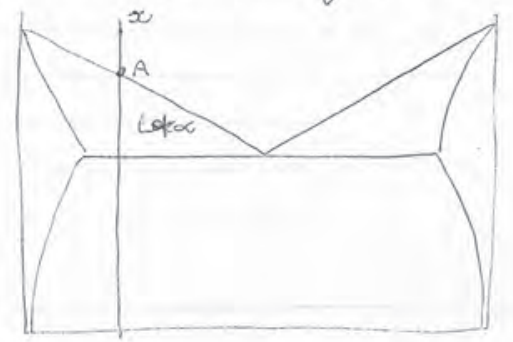

$$
\begin{aligned}
& \text { at } A, \alpha \text { there fint appears. } \\
& \text { monc a mave } \alpha \text { placer otpears }
\end{aligned}
$$

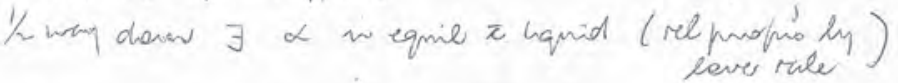

jut alove entertic cempo $\alpha+$ ergmind

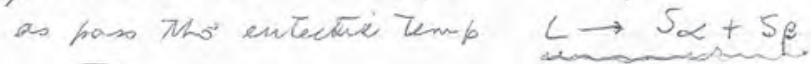

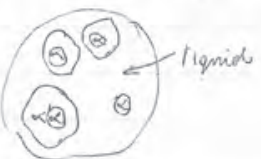

Get altemate platelets of the 2 phases prom hiquid

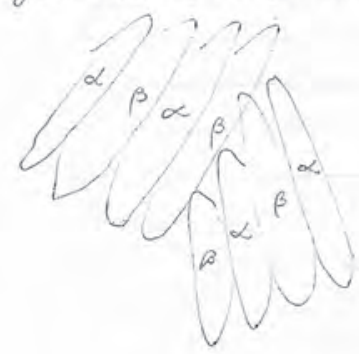

Figure 11.2 A page from my lecture notes on dental materials. 
the basic and biological sciences is considered, in comparison with the time for dental topics and clinical practice.

A colleague, Professor Charles (Chuck) Shuler, former dean of the Dental School at the University of British Columbia, uses the biochemical example of the Kreb's cycle when discussing the application of knowledge in clinical contexts. He asks his audience to consider one clinical example for which a knowledge of the Kreb's cycle is essential. Needless to say, I am yet to be in one of Chuck's audiences when someone has been able to provide an example. And yet, we all 'know' about the Kreb's cycle even though most of us could not provide any detail about it! My experience in biochemistry made me realise how important it is to present basic and biological science topics to dental students in context, and to make sure they understand the basic concepts and why they are important, rather than getting bogged down in the fine detail. After all, we are educating oral health professionals, not biochemists.

Dental Materials was covered by Dr Owen Makinson, who concentrated on the clinical use of different materials and their manipulation, while Professor Ross Miller covered materials science. Given that we had not seen any of the materials described or had a chance to use them, the significance of Dr Makinson's lectures was often lost on me. Professor Miller was entertaining and we spent much time on eutectics, peritectics and phase diagrams, as well as testing some materials in the laboratory. I managed to break the device used to assess the forces exerted during condensing (packing) of amalgam, gaining recognition from Professor Miller for my apparent strength!

Oral anatomy, presented by Tasman Brown, was a favourite subject for me. Our lectures were held in Lecture Theatre 1 on the sixth floor of the Adelaide Dental Hospital and Tas would use his skills at sketching teeth and explaining dental morphology in a very interesting and relevant way. The laboratory sessions gave us a chance to draw and carve teeth and also to set up natural teeth in dental arches in preparation for restorative dentistry in Third Year.

One of our tutors in oral anatomy was Professor Tadashi Ozaki, who was on study leave from the Nippon Dental University at Matsudo, Japan. Tadashi's visit and collaborative research with Tas Brown and Murray Barrett formed the basis of ongoing exchanges of staff and collaborative research initiatives between our two dental schools that have continued to the present time.

Toward the end of Semester 2 we had our first introduction to Dr John Kirkwood. We had heard from students in later years that Dr Kirkwood could be difficult on occasions and he certainly did not disappoint when he arrived at the last laboratory session of Oral Anatomy to check the placement of natural teeth we had arranged in manikins ready for operative technique exercises in Third Year. I can still remember the long queue of students fronting up to Dr Kirkwood to have their natural teeth, which had taken weeks to set up in wax, checked for correct alignment and contacts. It is not 
easy (in fact, it's impossible) to arrange twenty-eight teeth from different individuals into perfectly aligned dental arches but that did not deter Dr Kirkwood. He would only accept perfection, and this meant that each student's work was criticised, with teeth being pulled out of the wax, and then we were sent back to rearrange them. This approach to 'teaching and learning' had a profound effect on me.

We had now met two of the so-called terrible trio (a name gained as the three men struck fear into the hearts of many dental students during their time in the Dental School) - Makinson and Kirkwood. There was still Dr PNR Beasley to come!

One Tuesday afternoon that is fixed in my mind was when Tas Brown wheeled a television monitor into Lecture Theatre 1 on the sixth floor of the Adelaide Dental School and then tuned in to the first landing of a human on the moon. I can remember the grainy black and white pictures that showed Neil Armstrong climbing down the ladder from Apollo 11, then placing his foot on the moon's surface with the words: 'One small step for a man, one giant leap for mankind'. That was certainly an inspiring dental anatomy class!

Another tradition that developed and grew amongst our class was playing cards in the common room, especially Bridge. Many happy hours were spent between classes (and sometimes during classes for some of our group) honing our skills.

\section{Third Year}

One consideration that weighed heavily on our minds when we reached twenty years of age was whether we would be 'called up' or conscripted for National Service and sent to fight in Vietnam. Fortunately, a marble with my birthdate was not drawn in the lottery but other students were called up. Sometimes I wonder how I managed to sit through so many lectures in restorative dentistry I, where GV Black's principles of extension for prevention in cavity preparation were espoused, without thinking and asking: 'Could this not be done more conservatively?' Maybe it was partly due to the person instructing us and our fear of being made to look silly. Mind you, we rarely raised any criticisms of our course as a class - we just accepted that this was the way it was. Those were the times.

Third Year was the first time we were exposed to operative dentistry and clinical activities. Although most of our class seemed to cope reasonably well, there were always students who reached this stage of the course and then decided that dentistry was not for them. It always seemed to me that there would be advantages in an earlier exposure to clinical dentistry and this was one of the outcomes of subsequent curriculum reviews. I remember vividly one of the early clinical sessions in Clinic 1.3 on the first floor when I was looking at a receptionist in the nurses' station, Maxine, who smiled at me. That interaction became the start of a long-term relationship that continues to this day (about which, more later). 
Apart from restorative dentistry, we also studied human physiology, where one of our outstanding lecturers was Derek Frewin, later to become the executive dean of the Faculty of Health Sciences. The lectures in general pathology were less inspiring, with Jo Fanning reading chapters from our recommended text by Walter, Hamilton and Israel to the class. I do recall examining the pathological specimens or 'pots' in the Department of Pathology. Oral pathology I was presented by Ed Chau and John Williamson and was very interesting.

Microbiology was presented by Professor John Thonard and Dr Tony Rogers, with some input from Dr Nancy Atkinson. John Thonard presented a completely different style of lecturing to any we had experienced previously. His lectures were much more conversational and apparently unstructured, and were interspersed with words such as 'inter alia', 'ad hoc' and 'milieu interieur'. Thonard stimulated us to think and encouraged discussion and debate in class. I even remember one session where he had a rather heated discussion with Tony Rogers about a controversial microbiological topic in front of the class - this was quite an eye-opener for us.

One of the initiatives that built a strong bond between the members of our class was the production of a series of films by Rob Hirsch that involved both students and staff. These films were shown at social events, including the annual dental dinner, and they were enjoyed by all and considered hilarious (although they would be judged as highly politically incorrect today and would cause offence to some viewers). Staff were generally eager to appear in the films and we will never forget the images of Professor Horsnell pulling up outside the School on a Harley motor bike (to the music of 'The leader of the pack'), or 'Fancy' Nancy Atkinson dancing to the Fanta song — 'There's real orange in Fanta'), or John Thonard with his mischievous expression tucking into some agar (and bugs?) from a Petri dish.

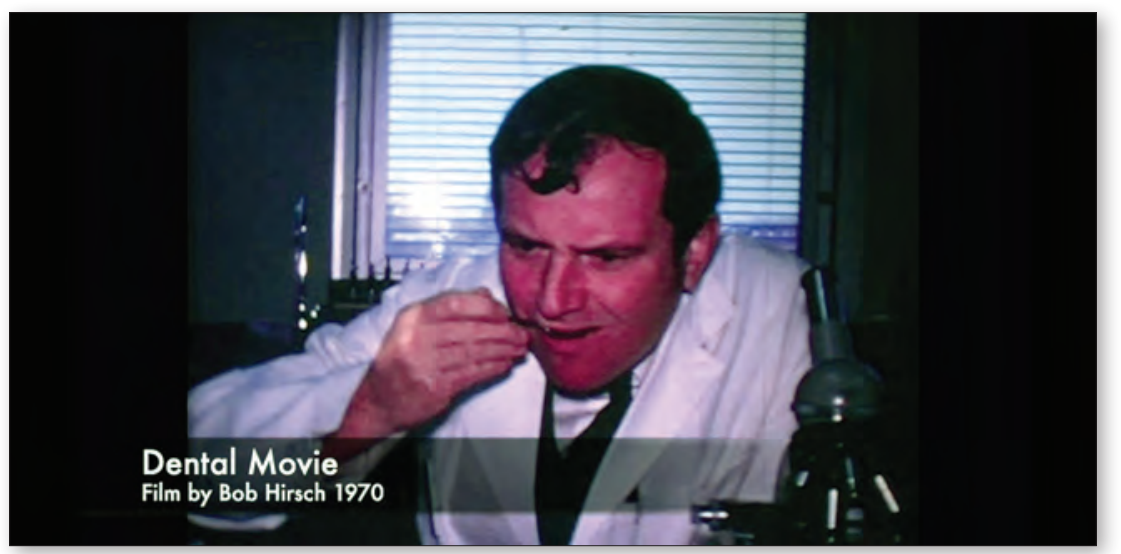

Figure 11.3 Professor John Thonard hamming it up for the camera in the 1970 dental movie produced by Robert Hirsch. 

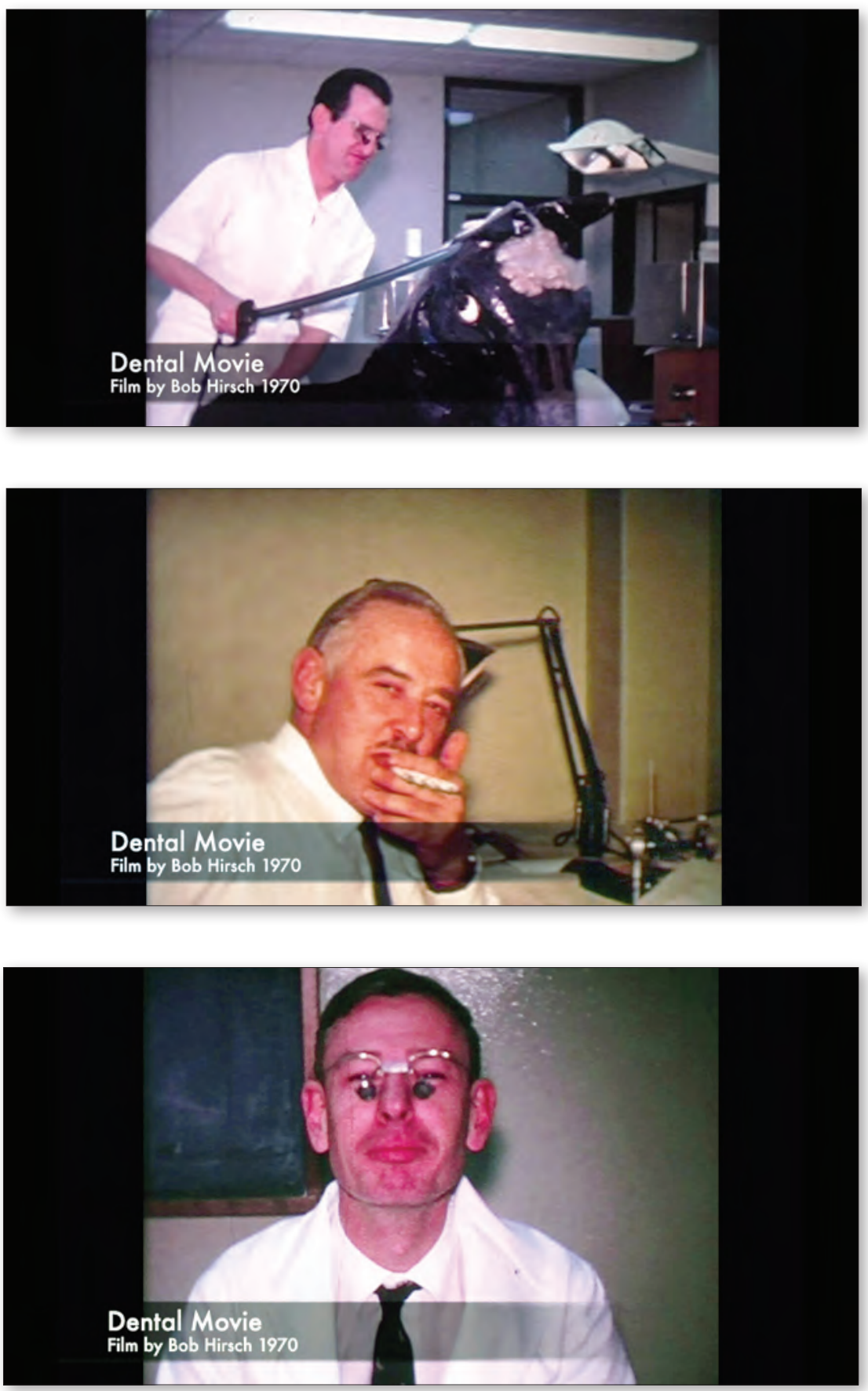

Figure 11.4 Some more 'wanna-be' actors from Robert Hirsch's 1970 film. a. John Kirkwood riding a horse in the clinic.

b. Murray Barrett having his daily nicotine fix.

c. Owen Makinson feeling very smug after winning a game of poker against the students. 
It was during this year that I had the opportunity to accompany a team of researchers from the Dental School, including Barrett, Brown, Williamson and Reynolds, who travelled to Yuendumu in the Northern Territory of Australia, where they were carrying out a longitudinal growth study of Indigenous children living at the settlement. My role was to act as a recorder for Dr John Williamson, who was carrying out an oral health survey of the school children as part of the larger study. This was a wonderful experience for me and it made me realise that being an academic in a university was not only about teaching students but also about carrying out research. I decided that I would like to continue doing research in the field of human growth and development and subsequently completed an honours degree in 1973 and a PhD during 1974-76, with Tas Brown as my supervisor.

\section{Fourth Year}

Fourth Year was a busy year, with increasing exposure to different clinical disciplines. Restorative dentistry II, including restorative dentistry and prosthodontics, meant that many of our class came face to face with Peter Robert Noble Beasley. However, I was not rostered in his clinic group and I learnt clinical prosthodontics from Dr David Parker. Apart from Roger Smales and John Kirkwood, we had a large number of clinical tutors, including Peter Applebee, John Blum, Geoffrey Hall, Ian Hodgson, William (Bill) Joyce, Trevor Martin, Pat Martin, John Myhill and Chris Somerville.

John Kirkwood was prominent in the crown and bridge clinic sessions, and I recall one session where I had spent a couple of hours adding gold foil very carefully to a Class V cavity preparation and then Dr Kirkwood 'appeared' to check the restoration. He produced his own explorer with the tip sharpened to a fine point and then proceeded to work around the margins of the restoration, trying to force the explorer down between the margins of the cavity and the gold foil. Needless to say, the foil was dislodged and I was instructed to start again. This was one of many examples of the 'character building' that we were subjected to throughout the course.

Nigel Clark taught us periodontology and he also stimulated discussion and thought about various topics. John Wetherell was one of our tutors and I went on to work with John and Ian Dingle after graduation. Theo Gotjamanos was another of our tutors and I have maintained contact with Theo ever since then, including collaborating on research projects related to dental development and oral health in twins. Meanwhile, Kevin Allen was in charge of children's dentistry, and Margaret Bevan and John Burrow were also involved.

General medicine and general surgery lectures were presented by a variety of specialists and we also had ward rounds at the Royal Adelaide Hospital. A case that I still remember was a man who was suffering from Von Recklinghausen's Disease, a genetic condition characterised by growth of tumours that led to this patient being 

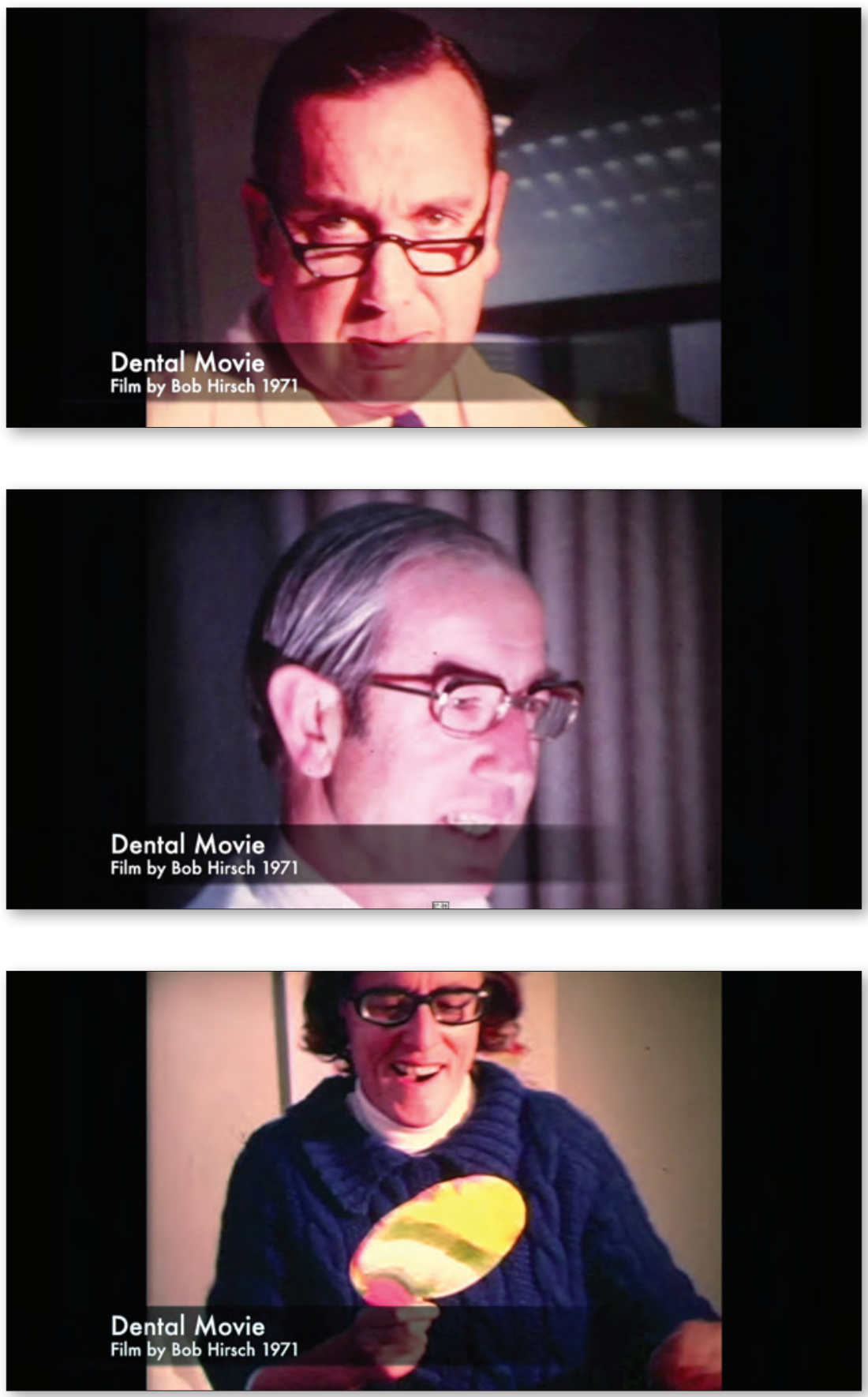

Figure 11.5 Some more staff members in the 1971 dental movie by Robert Hirsch.

a. Dr Peter Robert Noble Beasley (smiling).

b. Professor Max Horsnell giving a lecture.

c. Dr Betty Fanning about to get stuck into a rather large lollipop. 
covered in lumps all over his body. I also remember attending some autopsies as part of these subjects. Seeing patients in hospital suffering from severe diseases or illnesses, or attending autopsies, was confronting, and some of my peers queried the relevance to their dental studies. In retrospect, I think that these subjects provided important insights into how medical and surgical care is provided in a hospital setting and also into the important links between oral health and general health.

Oral pathology II was presented by Alec Cran and John Williamson, while pharmacology and therapeutics was presented by John Waterson with a cameo appearance by Dr Bloomfield, who amused us with some colourful language in a lecture about penicillin.

Another 'learning activity' that has stayed with me were the sessions in oral diagnosis with Professor Horsnell. A small group of us would be rostered to spend time with Prof Horsnell, who showed us how to examine a patient from the front and how to use two mirrors to retract the lips and cheeks and examine the oral cavity. In retrospect, I think these sessions were very valuable, but most of our class felt that they were a waste of time and that we should be doing something other than just looking and talking - like restoring teeth. This attitude persists in dentistry and is common in the general community, too. When will it be accepted that the key roles for oral health professionals are communicating with our patients, examining carefully and then thinking and diagnosing accurately? We don't always need to pick up the handpiece.

\section{Fifth Year}

Our subjects in Fifth Year included preventive dentistry with Betty Fanning; orthodontics with Milton Sims and Mike Nugent; oral surgery and anaesthesia with Alec Cran, John (Jock) Herd, Kevin Moore, Bruce (Buck) Lindsay (father of Keith Lindsay, one of our classmates) and Barry Fitzpatrick; oral medicine with Ed Chau and Alastair Goss who both arrived in Adelaide in 1972; and restorative dentistry III with various staff members and part-time clinical tutors. All of our clinic sessions were held in the Adelaide Dental Hospital and we gained considerable clinical experience over the year.

My most vivid recollections of Fifth Year are watching John Locke give a maxillary block to a patient in oral surgery via the greater palatine canal — and going to the Botanic Hotel on Friday nights, where Jock Herd would always be propping up the bar!

During 1972, William Proffit visited Adelaide to spend a period of study leave with Tas Brown and Murray Barrett examining lip and tongue pressures in the Aboriginal Australians living at Yuendumu. Proffit brought with him a device for recording intraoral pressures that involved pressure transducers built into intra-oral appliances, and he needed a 'guinea pig' to test the equipment. I was keen to be involved and I still remember vividly spending time with Proffit in one of the research laboratories on the 


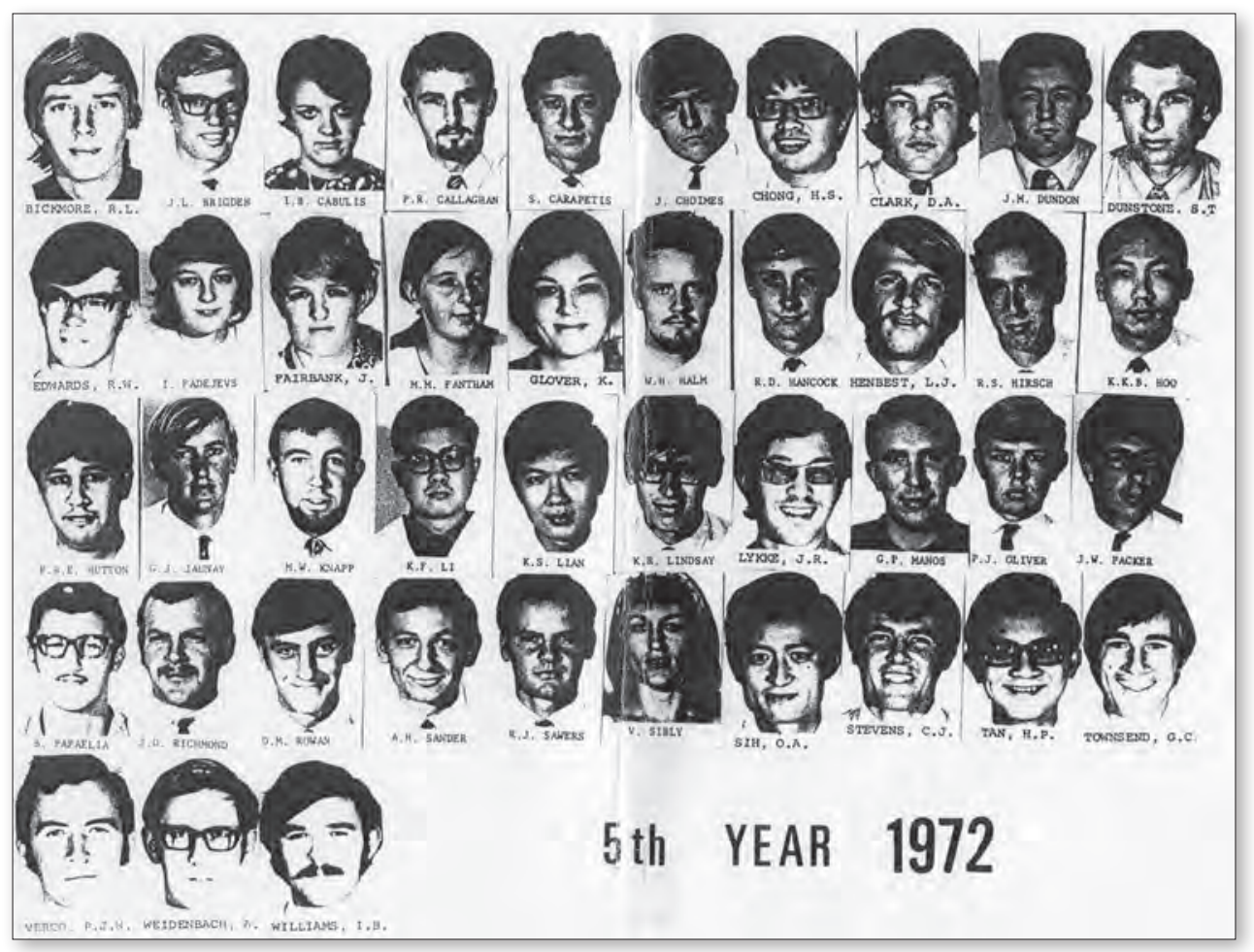

Figure 11.6 Class of 1972.

third floor of the Adelaide Dental Hospital as he worked methodically through each of the transducers in his American drawl - 'Pressure transducer number 1, pressure transducer number 2' and so on. Proffit has maintained a strong connection with the School over the years and two of our graduates, Neo Douvartsidis and David Peters, undertook their orthodontic postgraduate programmes with Proffit in North Carolina.

I recall the relief when we finished the last session of Fifth Year. For me, there was also anticipation ... as I married Maxine on the day after!

Reflecting now on my time as an undergraduate student, I certainly learnt a lot and I was very proud of my overall results, topping each year with overall Distinctions in every year. Some of the staff were inspirational and I felt well prepared for practice. I had also been exposed to research during my undergraduate years and had decided I wanted to pursue an academic career. However, my overwhelming feeling was that it could have been so much better. There was very little attempt to link the basic and biological sciences to clinical practice; there was very little integration between any of the subjects; we had very little exposure to clinical dentistry until Third Year; and the learning environment in the clinics was generally not positive or supportive. Many of 
the students in my year and those graduating around this time could not wait to get out of the School.

I decided that if I ever had the opportunity to improve the University of Adelaide dental curriculum, including developing a more supportive learning environment, I would try to do so.

Reflecting overall, I feel privileged to have received a university education at the Adelaide Dental School. Many of my memories of my time as a student are still vivid and many of the friendships made continue forty-five years after graduation. 
Section III:

Appendices 



\section{Appendix 1: Adelaide Dental School staff}

\section{Deans of dentistry}

Sir Joseph Cooke Verco 1920-28

Sir Arthur Murray Cudmore 1929-38

Professor Thomas Draper Campbell 1939-58

Professor Arthur Maxwell Horsnell 1959-63 and 1971-74

Dr Murray James Barrett 1964-65

Dr James Alexander Cran 1966-67

Professor John Charles Thonard 1968-70 and 1979-82

Dr Peter Robert Noble Beasley 1975-76

Professor Tasman Brown 1977-78

Dr John Malcolm McIntyre 1983-84 and 1991-92

Dr David Alan Scott Parker 1985-86

Dr Roger Joseph Smales 1987-88

Professor Andrew John Spencer 1989-90

Professor Vivian Brian Burgess 1993-2005 (Deanships changed from elected positions to appointed positions during this period)

Professor Johann de Vries 2006-13

Professor Kaye Roberts-Thomson 2013-15

Professor Lindsay Clem Richards 2005-06 and 2016-17

Professor Richard Martin Logan 2017-

\section{List of staff 1921-2016}

The lists of staff from 1921 until 1994/95 are reproduced in the same format as they appear in the Calendars of the University of Adelaide. The professors of non-dental departments were members of the Faculty of Dentistry ex officio. More recent listings of staff were obtained from various sources. 
1921

1922

The Professors of Anatomy, Chemistry. Physics, Physlology, and Pathology.

Lecturer on Dental Prosthesis:

ARTHUR IRWIN CHAPMAN, D.D.S.

Lecturer on Dental Metallurgy:

FREDERICK WILLIAM REID, B.SC,

Lecturer on Surgery:

BRONTE SMEATON, M.B, B, S.

Lecturer on Dental Moteria Medica and Theropeutics

WILLAM THEODORE SHANASY D.D.5.

Lecturer on Dental Histology:

WILLAM FULLER.

Lecturer on Operative Dentistry:

FRANK, MARTIN SWANN, L.D.S.

Lecturer on Medicine:

ALBERT RAY SOUTHWOOD, M.D.

Lecturer on Dental Surgery and Dental Pathology:

HERBERT GILL WILIAMS, L.D.5., R.C5.

Lecturer on Orthodontics:

PERCIVAL RAY NEWLING, D. D.S.

Demenstrator in Anotomy:

LEWIS WIEMER JEFFRIES, M.B., B.S.

ARTHUR IRWIN OHAPMAN, 0.0.5:

FREDERICK WILIAM REID, B.SC,

BRONTE SMEATON, M.B., B.S.

LEONAROW. TROTT, D.D.S

WILLIAM FULLER.

FRANKMARTIN SWANN, L.D.S.

ALEERT RAY SOUTHWOOD, M.D.

ERNEST JOSEPH MILHOUSE, D.D.S.

PERCIVAL RAY NEWIING, D.D.5.

KENNETH STUART HETZEL, M.8, B.S.

1923

1924

The Professors of Anotomiy, Physiology, Pothology, and Zoology

Lecturer on Dental Prosthesis:

ARTHUR IRWIN CHAPMAN, D.D.S,

Lecturer on Dentol Metolluingy:

FREDERICK WILLIAM REID, B.SC

Lecturer on Surgery:

BRONTE SMEATON, M. B. B.S.

Lecturer on Dentol Materia Medica and Therapeutics:

LEONARD W. TROT, D.D.S.

Lecturer on Dentol Histology:

WILLIAM FULLER.

Lecturer on Operative Dentistry:

PERCIVAL RAY NEWLING, D.D.S.

Lecturer on Medicine:

ALBERT RAY SOUTHWWOOD, M.D.

Lecturer on Dental Surgery and Dental Pathalogy:

ERNEST JOSEPH MILLHOUSE, D.D.S.

Lecturer on Orthodontics:

HURTLE THOMAS JACK EOWARDS, B.D.S.

Demonstrator in Andtomy:

CEOL SILAS MEAD, B.A., M. B., B.S.

Demonstrotor in Orown and Bridge Work:

HURTLE THOMAS JACK EOWARDS, E.D.5.

ARTHUR IRWIN CHAPMAN D.D.S.

FREDERICK WILUAMM REID, BSC,

BRONTE SMEATON, M.B., B.S.

LEONARO W. TROTT/ D.D.5

WILLIAM FULLER.

PERCIVAL RAY NEWUNG, D.D.5.

ALBERT RAY SOUTHWOOD, M.D.

ERNEST JOSEPH MIUHOUSE, D.D.S.

HURTLE THOMAS JACK EDWARDS, B.D.S.

CECIL SILA5 MEAD, B.A., M.B., B.S.

HURTLE THOMASIACK EDW ARDS, B. Q.5.

1925

1926

The Professors of Anafomy, Chemistry, Physies, Phisiology, and Pathology

Lecturer on Dentol Prosthesis:

ARTHUR IRWIN CHAPMAN, D.DS.

Lecturer an Dental Metallurgy:

FREDERICK WILLIAM REID, B.SC.

Lecturer on Surgery:

BRONTE SMEATON, M. B, B.S.

Lecturer on Dentol Materia Medica and Thenapeutics:

LEONARD W. TROTT, O.D. 5 .

Lecturer on Dentot Anatomy

THOMAS ORAPER CAMPBELL, D.D.SC.

ARTHUR IRWIN CHAPMAN, D.DS.

FREDERICK WILLIAM REID, B.SC.

BRONTE SMEATON, M.B, BS.

LEONARD W: TROTT, 0.0.5.

THOMAS QRAPER COMPBELL, D.D.SC 
Lecturer on Dental Histology:

WILLAM FULLER.

Lecturer on Operative Dentistry:

PERCIVAL RAY NEWLING, D.D.S.

Lecturer on Medicine:

ALBERT RAV SOUTHWOOD, MD

Lecturer on Dentol Surgery and Dentai Pathology:

ERNEST JOSEPH MILLHOUSE, O.DS.

lecturer on Orthodontics:

HURTLE THOMASIACK EOWAROS, D.D.SE

Demonstrotor in Anotomy:

CEOL SILAS MEAD, B.A., M.B., Q.S

Lecturer in Crown and Bridge Work

HURTLE THOMASIACK EOWARDS, D.D.SC.

Demonstrator in Qperative Technique:

ARTHUR PARISS READING MOORE, B.D.S.

Demonstrotor in Prosthetic Technique:
L.A.M. BROUGHAM

WILLIAM FULLER.

PERCIVAL RAY NEWUNG, D.D.S.

ALBERT RAY SOUTHWOOD, M.D.

ERNEST JOSEPH MILLHOUSE, D.D.S.

PERCY RAYMOND BEGG; B.D.SC, (Melb.)

CECIL SILAS MEAD, B.A., M.B., B.S.

HURTLE THOMAS IACK EOWARDS, D.D.SC.

ARTHUR PARISS READING MOORE, B.D.S.

L. A. M. BROUGHAM.

1928

The Professors of Anatomy, Dhemistry, Physics, Physiology, and Pathology

Lecturer on Prosthetic Dentistry:

ARTHUR IRWIN CHAPMAN, D.D.5.

Lecturer on Dental Metalliray?

FREDERICK WILLIAM REID, BSC.

Lecturer on Surgery:

BRONTE SMEATON, M.B., B.S.

Lecturer on Dentol Materia Medica and Therapeutics:

LEONARD W. TROT, D. D.5.

Lecturer on Dentol Anatomy.

THOMAS ORAPER CAMPBELL, D,D,5C.

Lecturer on Dentol Histology:

WILLLAM FULLER.

Lecturer on Dperative Dentistry:

FRAN\& MARTIN SWANN, L.D.S

lecturer on Medicine:

ALBERT RAY SOUTHWOOD, M.D. M.S

lecturer on Dentol Surgery and Dental Pathology:

ERNEST JOSEPH MILUHOUSE, D.D.S

Lecturer an Orthadontics:

PERCY RAYMOND BEGG, B.D.SC (Melb.)

Demonstrator in Anatomy:

CEECIL SILAS MEAD, B.A., M.B., B.S.

Demonstrator in Operative Technique:

ARTHUR PARISS READING MOORE, D.D.5

Demonstrator in Dental Mechanics:

LEONARD ARTHUR MORRIS BROUGHAM

Instructor in Prosthetic Dentistry:

ROBERT JAMES BRAZIL-SMITH, E.D.S

\section{9}

ARTHUR IRWIN CHAPMAN, D.DS.

FREDERICK WILUAMM REIO, B.SC.

BRONTE SMEATON, M.B., B.S.

LEONAROW. TROTT, D.D.5.

THOMAS DRAPER CAMPBELL, D, D,SC

WILIAM FULLER.

FRANKMARTIN SWANN, L.D.S. M.A.CD. (Melb)

ALBERT RAY SOUTHWOOD, M.D M.S.S.

ERNEST JOSEPH MILHOUSE, D.D.S.

PERCY RAYMOND BEGG, B.D.5C: (Mèlb.)

CECIL SILAS MEAD, B.A. M.B, B.S.

ARTHUR PARISS READING MOORE, D.D.S.

LEONARD ARTHUR MORRIS BROUGHAM.

ROBERT JAMES BRAZIL-SMITH, B.D.S.

1930

The Professors of Anatomy, Chemistry, Phisics, Physiology, and Pathology:

Lecturer on Prosthetic Dentistry:

HURTLE THOMAS IACK EDWARDS, D. D.SC

Lecturer on Dentai Metallurgy:

FREDERICK WILLIAM REID, B,SC,

Lecturer on surgery:

PHILLIP SANTO MESSENT, M.B., M.S, F.CS.A

Lecturer on Dental Materia Medico and Thenpeutics:

IOHN LEONARD EUSTACE, B.D.S

\author{
HURTLE THOMAS JACK EOWARDS, D.D.SÉ. \\ FREDERICK WILUIAM REIO, B,SC. \\ PHILLP SANTO MESSENT, M.8, M.S, F.C..A. \\ JOHN IEONARD EUSTACE, B.D.S.
}


Lecturer an Dentol Anatomy:

Lecturer on Operative Dentistiv.

FRANK MARTIN SWANN, L.D.S, M.A.C. D. (Melb)

ALBERT RAY SOUTHWOOD, M.D., M.S.

Lecturer on Dentol Sumgery and Pothology:

ARTHUR PARISS READING MOORE, D. D.SC

lecturer on Orthodontic:

PERCY RAYMONO BEGG, B.D.Sc (Melb.)

lecturer on Anatomy:

CEOL SILAS MEAD, B.A., M.B., B.S.

Demonstrator in Operative Techmique:

ARTHUR PARISS READING MOORE, D, D.SC

Demonstrator in Dental Mechanics:

LEONARD ARTHUR MORRIS BROUGHAM.

Instructor in Prosthetic Dentistry:

ROBERT IAMES BRAZIL-SMITH, B.D.S

1931

1931 The Professors of Anatomy Biachemistry, Chemistry, Pathology, Physics,

Lecturer on Prosthetic Dentistry

HURTLE THOMAS IACK EDWARDS, D,DSC.

Lecturer on Dentai Metallurgy:

FREDERICK WILLIAM REID, BSC.

Lecturer on Surgery:

PHILUIP SANTO MESSENT, M.B., M.S. F.C.S.A

Lecturer on Dental Materia Medica and Theraputics:

OHN LEONARD EUSTACE, B.DS.

Lecturer on Dental Anatomy:

THOMAS ORAPER CAMPBELL, D.D,5C.

Lecturer on Operative Dentistry:

FRAN\& MARTIN SWAN, LD.5, M.A.CD, (Mel6)

Lecturer on Medicine:

ALBERT RAY SOUTHWOOD, M.D., M.S.

Lecturer on Dentol Surgery and Dental Pathology:

ARTHUR PARISS READING MOORE, D. D.SC

lecturer on Orthodontics:

PERCY RAYMOND BEGG, B.D.SC (Melb.)

Lecturer an Anatomy:

CECLL SILAS MEAO, B.A., M.B., B. S

Demonstrator in Operat/ve Technique:

GORDON ORD LAWRENCE, B.D.SC.

Demonstrator in Orthodontic Technique:

PERCY RAYMOND BEGG, B.D.5C: (Melb.)

Demonstrator in Prosthetic Technique;

LEONARD ARTHUR MORRISS BROUGHAM.

Lecturer in Prosthetic Dentistry:

ROBERT IAMES BRAZIL SMITH, B.D.S.
THOMAS ORAPER CAMPBELL, D.D.5E

Lecturer on Medicine:

THOMAS DRAPER CAMPBELL, D, D,SÉ

FRANK MARTIN SWANN, L.D.S, M.A.C.D. (Melb)

ALBERT RAY SOUTHWOOD, M.D. M, S.

ARTHUR PARISS READING MOORE, D.D.SE

PERCY RAYMOND BEGG, B.D.SC (Melb.)

CECIL SILAS MEAD, B.A., M.B, B.S.

GOROON ORD LAWRENCE, B.D.SC.

LEONARD ARTHUR MORRIS BROUGHAM.

ROBERT JAMES BRAZIL-SMITH, B.D.S

HURTLE THOMAS IACK EOWAROS. D.D.SC.

FREDERICK WILUAM REID, B.SE.

PHILLIP SANTO MESSENT, M.B. M.S. F.C.S.A.

JOHN LEONARO EUSTACE, B.D.S.

THOMAS DRAPER CAMPBELL, D, D,SE

FRANK MARTIN SWAN, LD.5, M.A.CD. (Melb).

ALBERT RAY SOUTHWOOD, M. D, B.S.

ARTHUR PARISS REA DING MOORE, D,D,SC.

PERCY RAYMOND BEGG, B.D.SC(Melb.)

CECIL SILAS MEAD B. A, M.B. B.S.

GORDON ORD LAWRENCE, B.O.SC,

PERCY RAYMOND BEGG,B,D.SC.(Melb.)

LEONARD ARTHUR MORRISS BROUGHAM.

ROBERT JAMES BRAZIL SMITH.

Instructor in Andesthetlos

GILBERT BROWN, M.B., Ch.B. (Liv.)

1934

The Professors of Anatomy. Biochemistry, Chemistry, Pathology, Physics Physiology, and Zoology.

The Professors of Anatomy, Bioch
Lecturer on Prasthetic dentistry:

HURTLE THOMASIACK EDWARDS, D.D.SE.

Lecturer on Crown and Bridgework:

HURTLE THOMAS JACK EDWARDS, D.D.SE

Lecturer on Dental Metallurgy:

FREDERICK WILLIAM REID, B.SC.
HURTLE THOMAS JACK EOWAROS, D.D.SC.

HURTLE THIOMAS JACK EDWARDS, D.D.SC.

FREDERICK WILUAM REID, B.SC. 
Lecturer on Surgery:

PHILLIP SANTO MESSENT, M.B., M.S, F.C.S.A.

Lecturer on Oral Surgeny.

THOMAS DRAPER CAMPBELL, D.D.SE.

Lecturer on Dentol Mareria Medica and Theraputics:

IOHN LEONARO EUSTACE, B.D.S.

Lecturer on Dentol anatomy:

THOMAS ORAPER CAMPBELL, D.D.SC

lecturer on Operative Dentistry:

(No appointment)

lecturer on Medicine:

ALBERT RAY SOUTHWOOD, M.D. M.S

Lecturer on Dental Surgery and Dental Pathology:

ARTHUR PARISS READING MOORE, D, D.SC

Lecture on Orthodontics:

PERCY RAYMOND BEGG, B.D.Sc. (Melb.)

Lecturer on Prophylaxis and Oral Hygiene:

CEOL BOASE MADDERN, D.D.SC.

Lecturer in Anatomy:

CEOL SILAS MEAD, B.A., M.B.,B.S

Demonstrator in Operative Technique:

(No appointment).

Demonstrator in Orthodontic Technique:

PERCY RAYMOND BEGG, 8.0.5C (MElb.)

Demonstrator in Prosthetic Technique:

LEONARD ARTHUR MORRISS BROUGHAM.

Demonstrater in Crown and Bridge Work:

ROBERT JAMES BRAZL SMITH, B, 0.5 .

Instructor in Prosthetic Dentistry:

FOBEFT JAMES BRRAZL SMITH, B.0.5.

Instructor in Anaestherics:

GILBERT BAOWN, M.B., Ch.B. (Liv.)

\section{5}

The Professors of Anatomiy, Blachemistry, Chemistry, Pathology Physics, Physialogy and Zoalagy.

lecturer on Prosthetic Dentistry:

HURTLE THOMAS IACK EDWARDS, D.D.SE

lecturer on Crown and Bridge Wark:

HURTLE THOMAS IACK EQWARDS: D.D.SC.

Lecturer an Dental Metallurgy:

FREDERICK WILLIAM REID, B.SC.

Lecturer on Surgery:

PHILUP SANTO MESSENT, M.B., M.5., F.C.S.A.

Lecturer on Oral Surgeny:

THOMAS DRAPER CAMPBELL, D.D.5C.

Lecturer on Dental Materia Medica and Theraputis:

IOHN LEONARD EUSTACE, B.D.5.

Lecturer on Dentol Anatomy:

THOMAS DRAPER CAMPBELL. D.D.SC.

Lecturer in Operative Dentistry:

JOHN ANDREW O'DONNELL, D.D.SC.

Lecturer on Medicine:

ALBERT RAY SOUTHWOOD, M.D., M.5.

Lecturer on Dental Surgery and Dental Pathology:

ARTHUR PARISS READING MOORE, D.D.SC

Lecturer on Orthodontics:

PEACY RAYMOND BEGG, B.0.5C (Melb).

Lecturer on Prophylaxis and Oral Hygiene:

CECL BOASE MADOERN, D.D.SC.

Lecturer on Ethics, Economics and Dental furisprudence:

HURTLE THOMAS JACK EOWARDS, D, D,Sc.
PHILLIP SANTO MESSENT, M.B, M. S. R.C.SA.

THOMAS DRAPER CAMPQELL, D.D.SC.

JOHN LEONARDEUSTACE, B.0.5.

THOMAS GRAPER CAMPEELL, D.D.SE

JOHN ANDREW OODONNELL, D.D.SC.

ALBERT RAY SOUTHWOOD, M.D, M.S

ARTHUR PARISS REAOING MOORE, D.D.SC..

PERCY RAYMOND BEGG, B.0.5c (Melb.)

CECIL BOASE MADDERN, D,D.SC

CECILSILAS MEAD, B.A., M.B., B.S.

THOMAS DENNIS HANNON, B.D.5.

PERCY RAYMOND BEGG, B.D.5c(Melb.)

LEONARD ARTHUR MORRISS BFOUGHAM.

ROBERT JAMES BRAZIL SMITH, B.D.5.

ROBERT JAMES BRAZIL SMITH, B.0.5.

GILBERT BPOWN, M. B, Ch.B. (Liv.)

1936

HURTLE THOMAS IACK EOWAROS: D.D.SE

HURTLE THOMAS IACX EOWAROS D.D.SE.

REGINALD ALFRED LAMPIER LAUGHTON, A.S.A.S.M.

PHILUP SANTO MESSENT, M.B., M.S., F.C.S.A.

THOMAS DRAPER CAMPEELL, D.D.SC.

JOHN LEONARD EUSTACE, B.D.S.

THOMAS DRAPER CAMPBELL, D.D.SC.

JOHN ANDREW O'DONNELL, D.D.SE.

ALBERT RAY SOUTHWOOD, M.D., M.S.M.R.C.P.

ARTHUA PARI55 READING MOORE, D,O,SC,

PERCY RAYMOND BEGG, D.D.SC

CECIL BOASE MADDERN, $0.0 .5 \mathrm{C}$

HURTLE THOMAS JACK EDWARDS, DOST: 
Lecturer on Anatoniy:

CECIL SILAS MEAD, B.A., M.B., B. S.

Demonstrator in Dperative Technique:

THOMAS DENNISHANNON, B.D.S.

Demonstrotor in Orthodontic Technique:

PERCY RAYMONO BEGG, B.D.SC (Melb)

Demonstrotor in Prosthetic Technique;

LEONARD ARTHUR MORRIS BROUGHAM:

Demonstrotor in Oown and Bridge Work:

ROBERT JAMES BRAZLL SMITH, B.D.S.

Instructor in Anoesthetics:

GILBERT BROWN, M. B, Ch. B. (UV)

instructor in Prosthetic Dentistry:

(No appointment).

\section{7}

The Professors of Anotamy, Bioct

Lecturer on Frosthetic Dentistry:

HURTLE THOMAS JACK EDWARDS, D. D SC

Lecturer on Crown and Bridge Work.

HURTLE THOMAS JACK EDWARDS, D.D.SC

Lecturer on Dental Metalliuray:

REGINALO ALFREO LAMPIER LAUGHTON. A.5.A.5.M

Lecturer on Surgery:

PHILUP SANTO MESSENT; M.B.,M.S

Lecture an Oral Surgery:

THOMAS DRAPER CAMPBELL, D.D.5C.

Lecturer on Dentai Materia Medica and Therapeutics:

JOHN LEONARD EUSTACE, B.DS

Lecturer on Dental Anatomy:

THOMAS ORAPER CAMPBELL, D.D,5C

Lecturer on Dperative Dentistry:

IOHN ANOREW O'DONNELL, D.D.SE

Lecturer on Medicine:

ALBERT RAY SOUTHWOOD, M. D., M.5, M.R.CP.

Lecturer on Dentol Surgery and Dental Pathology:

ARTHUR PARISS READING MOORE, O.D.SE.

lecturer on Orthodontics:

PERCY RAYMONOBEGG, D DSC.

Lecturer on Prophylaxis and Orai Hygienes

CECLL BOASE MADDERN, D.D.SC.

Lecturer on Ethics, Economics, and Dental Jurispruderice:

HURTLE THOMASIACK EDWARDS, D.D.SC.

Lecturer on Anatomy:

CEOL SILAS MEAD, B.A.M.B., B.5

Demonstrator in Operative Technics:

THOMAS DENN IS HANNON,B.D.5.

Demonstrator in Orthodontic Technics:

PERCY RAYMOND BEGG, D.D.SC

Demonstrator in Prosthetic Tecinics:

LEONARD ARTHUR MORRIS BROUGHAM.

Demonstrator in Crown and Eridge Work:

MALCOLM STEWART JOYNER, B,D.S

Instructor in Prosthetic Dentistry:

GORDON ORD LAWRENCE, B.D.5C. (Melb),

Instructor in Anaesthetics

GILBERT BROWN, M.B., Ch. B. (LIV)
CECILSILAS MEAD, B,A, M.B, BS.

THOMAS DENNIS HANNON, B:D.S.

PERCY RAYMOND BEGG; O.O.SC.

LEONARD ARTHUR MORRIS BROUGHAM.

MALCOM STEWART JOYNER, B.D.5

GILBERT BROWN, M.E, Ch.8. (LV).

GOROON ORD LAWRENCE; B.D.SC. (Melb).

1938

HURTLE THOMAS JACK EDWAROS, D. D.SC.

HURTLE THOMAS IACK EDWARDS, D.D.SC.

REGINALO ALFRED LAMPIER LAUGHTON, AS.A.SM

ALAN HARDING LENCON, M.B, MS, F.R.CS, (ẼÉ)

THOMAS CRAPER CAMPBELL, D. D,SE

JOHN LEONARD EUSTACE, B.D.S.

THOMAS DRAPER CAMPBELL, D, D,SE.

JOHN ANDREW O'DONNELL, D.D,SE

ALBERT RAY SOUTHWOOD, M D M M.S, F.R.C.P.

ARTHUR PARISS READING MOORE, D.D.SE

PERCY RAYMONO BEGG, D.DSE

CECIL BOASE MAODERN, D.D.SC

HURTLE THOMAS JACK EDWARDS, D.D.SC.

CECIL SILASTMEAD, B.A., M.B., B.S.

THOMAS DENNIS HANNON, B.D.S.

PERCY RAYMOND BEGG, D.D.SC

LEONARD ARTHUR MORRIS BROUGHAM.

MALCOLM STEWART JOYNER, B.D.S.

GORDON OAD LAWRENCE, B.D,SE (MeIb)

GILBERT BPOWN, MiB, B,Ch.B. (Melb). 
1939

1940

The Professors of Anatomy, Bacteriology, Biochemistry, Chemistry, Pothology, Physics, Physiolagy and Zoology: Lecturer on Prosthetic Dentistry:

HURTLE THOMASJACKEDWARDS, D.D.SE.

Lecturer on Crown and Bridge Work:

HURTLE THOMAS JACK EDWAROS, D, D,SC,

Lecturer on Dentai Metalluray:

REGINALD ALFRED LAMPIER LAUGHTON, A.5.A.5.M.

Lecturer on Surgery:

ALAN HAROING LENDON, M.B, B.S., F.R.CS.

Lecturer on Dental Materia Medica and Theroputics:

JOHN LEONARD EUSTACE, B.D.5.

Lecturer on Anatomy:

THOMAS ORAPER CAMPBELL, D,D,SE

Lecturer on Operative Dentistry:

GORDON ORD LAWRENCE, B.D.5C, (Melb)

Lecturer on Medicine:

ALBERT RAY SOUTHWOOD, M.D. M.S. M.R.C.P. (Lond)

Lecturer on Dental Surgery and Dental Pathology:

ARTHUR PARISS READING MOORE, D,D,SC

Lecturer on Orthadantics:

PERCY RAYMONO BEGG, OD.SC.

Lecturer on Prophylavis and Oral Hygiene:

CEOL BOASE MADDERN, D.DSC.

Lecturer on Ethics, Economics and Deoral Jurisprudence?

HURTLE THOMAS JACK EDWARDS, D, D.5E

Lecturer on Anatomy:

(No appointment)

Demonstrator in Operotive Techeics.

THOMAS DENINIS HANNON, B.Q.S.

Demonstrator in Orthodantic Tecfinics:

PERCY RAYMOND BEGG, D.D.SC

Demonstrator in Prosthetic Techinics:

LEONARD ARTHUR MORRIS BROUGHAM

Demonstrator in Crown and Bridge Workt:

MALCOLM STEWART JOYNER, B.D.S

Instructor in Prosthesic Dentistry:

GORDON ORD LAWRENCE, 8.D.5C. (Melb).

Instructor in Angesthetics:

GILBERT BROWN, M. 8, Ch 8. (Liv)

HURTLE THOMAS JACK EDWARDS, D.D.SE.

HURTLE THOMAS JACK EDWARDS, O,D,SC.

REGINALD ALFRED LAMPIER LAUGHTON, A.5.A.S.M.

ALAN HARDING LENDON. M.B, B.S, F.R.C.S.

JOHN LEONARD EUSTACE, B,D,5.

THOMAS CRAPER CAMPBELL, D.SC, D.D.SE.

GOROON ORD LAWRENCE, B, D,SC, IMeIB).

ALBERT RAY SOUTHWOOO, M.D. M.S, M.R.C.P. (LONd).

ARTHUR PARISS READING MOORE, D.D.SC,

PERCY RAYMONO BEGG, O.D.SC

CECIL BOASE MADDERN, D,D,SC

HURTLE THOMAS JACK EDWARDS, D.OSE

KARL JOSEF POSENER, M.D. (BENIII).

THOMAS CENNIS HANNON, B.D.S.

PERCY RAYMONO BEGG, D.D.SE

LEONARD ARTHUR MORRIS BROUGHAM.

MALCOLM STEWART JOYNER, B.O.S.

GORDON ORD LAWRENCE, B. O.SC. (Melb).

GILBERT BROWN, M.B., Ch.8. (Liv)

1941

1942

The Professors of Anatomy Bacterialogy, Biochemistry, Ohemistry, Pathology, Physics, Physiologk, and Zoology.

Lecturer on Prosthetic Denitistry:

HURTLE THOMAS JACK EDWAROS, D, D,SC:

Lecturer on Crown and Bridgework:

HURTLE THOMAS JACK EOWARDS. D.D.SC.

Lecturer on Dental Metall uraY?

REGINALD ALFREO LAMPIER LAUGHTON. A.S.A.M.

Lecturer on Surgerv:

ALAN HARDING LENDON, M, B, B, S, F.R.C.S, (ENR).

ALAN THOMAS BRITTEN JONES, M. B, B, S.,F.R.CS, (Edin).

Lecturer on Oral Surgen:

THOMAS ORAPER CAMPBELL, D.SC, D.D.SC

Lecturer an Dentai Materia Medica and Theraputics:

IOHN LEONARO EUSTACE, B.D.S.

Lecturer on Dentol Anatomy?

THOMAS ORAPER CAMPBELL, D.SC, O.DSC

Lecturer on Operative Dentistry.

GORDON ORD LAWRENCE, B.D.5c. (Melb).

HURTLE THOMAS JACK EDWARDS, D,0,SC.

HURTLE THOMAS IACK EDWARDS. D OS. C.

REGINALD ALFREO LAMPIER LAUGHTON, AS.A.M.

ALAN HARDING LENDON, $M, 8,8, S, F, R, C, S$ ALAN THOMAS BRITTEN JONES, M.B.B.S.F.R.CS. (Edin).

THOMAS DRAPER CAMPBELL, D, SC, D. D, SC

JOHN IEONARD EUSTACE, B.D.S.

THOMAS DRAPER CAMPBELL, DSC, O.DSC

GOROON ORD LAWRENCE, B.D.SC, (Melb). 
Lecturer on Medicine:

MELVILLE ERNEST CHINNER, M D., M.R.C.P. (Lond) Lecturer an Dental Sutgery and Dental Pathology

ARTHUR PARISS READING MOORE, D. D.SC.

Lecturer on Orthadontics

PERCY RAYMONO BEGG, D. D.Se

Lecturer on Prophylaxis and Oral Hygiene:

CEOL BOASE MADDERN, D.D.SC.

lecturer on Ethics, Economics and Dental jurisprudence:

HURTLE THOMASIACK EDWARDS, D. O.SC.

lecturer on Anatomy:

KARL JOSEPH POSENER, M. D. (Berlin)

Demonstrator in Qperative Technics:

THOMAS DENNIS HANNON, B.D.S. (Military Service).

GORDON ORDLAWRENCE B.D.Sc, (Melb) (Acting),

Demonstrator in Orthodontic Techinics:

PERCY RAYMOND BEGG, D.D.SC

Demonstrator in Prosthetic Technics:

LEONARD ARTHUR MORRIS BROUGHAM

Demonstrator in Crown and Bridge Work

MALCOLM STEWART JOYNER, B.D.S, (OD militaryservice).

ALAN JOHN BLOOMFIELD, B.D.S., (ACtinE).

Instructor in Prosthetic Dentistry:

GORDON ORD LAWRENCE, B.D.5C. (Meilb).

Instructor in Angesthetics:

GILBERT BROWN, M.B., Ch.B, (LIV).

1943

The Professors of Anotomy, Eacteriology, Biochemistry, Chemistry, Pothology, Physics, Physiology and Zoology. Lecturer on Prasthetic Dentistry:

HURTLE THOMAS IACK EDWARDS, D.D. $5 \mathrm{C}$

Lecturer on Crown and Bridge Work:

HURTLE THOMAS JACK EDWARDS; D, D,SC

Lecturer on Dentol Metallurgy:

REGINALD ALFREQ LAMPIER LAUGGTON, A.S.A.S.M.

lecturer on Sungery:

ALAN HARDING LENCON, M.B. B.S., F.R.C.S. (ENG)

(On military service).

WALTER JOHN WESTCOTT CLOSE, M. B., E.S, F.R.CS. (EdII)

(Acting).

Lecturer on Oral Surgery:

THOMAS DRAPER CAMPBEL, D.Sc, , D. D.SC.

Lecturer on Dental Materia Medica and Theraputics:

IOHN LEONARD EUSTACE, B.D.S.

Lecturer on Dental Anatomy:

THOMAS DRAPER CAMPBELL, D.SE., D.D.SC.

Lecturer on Operative Dentistry:

GORDON OROLAWRENCE, B.D.5C. (Melb).

Lecturer on Medicine

MELVILLE ERNEST CHINNER, M.D. M.R.CP. Ilond)

Lecturer on Dental Surgery and Dental Pothology:

ARTHUR PARISS READING MOORE, D.D.SC.

Lecturer on Orthodontics:

PEACY RAYMOND BEGG, D.D.SC.

Lecturer an Prophylaxis and Oral Hygiene:

CECIL BOASE MADOERN, D.D.5C.

Lecturer on Ethics, Economics and Denta) furisprudence;

HURTLE THOMAS JACK EDWARDS, D.D.5C.

Lecturer on Anatomy:

KARL JOSEF POSENER, M.D. (Ber $\|$ in).
MELVILLE ERNEST CHINNER, M.D. MR.C.P. (Lond)

ARTHUR PARISS REAOING MOORE, D.D.SE.

PERCY RAYMOND BEGG, OIDSC.

CECLL BOASE MADDERN, D.D.SC

BURTLE THOMAS JACK EOWAROS, D.D.SC.

KARL JOSEPH POSENER, M D., (Bertin).

THOMAS DENNIS HANNON, B.D.S. (Military Service). GORDON ORD LAWRENCE, B.D.SC. (Melb) (ACtinE).

PERCY RAYMOND BEGG, D.D.SC

LEONARD ARTHUR MORRIS BROUGHAM

MALCOLM STEWART JOYNER, B. O.S., (On military service), ALAN JOHN BLOOMFIELD, B.D.5, (ACtinE).

GORDON ORD LAWRENCE, B.D.SC. (Melb).

GILBERT BROWN, M.B., Ch.8. (LIV)

HURTLE THOMAS JACK EDWAROS, D.D.SC.

HURTLE THOMAS JACK EOWARDS, D. D. SC.

REGINALD ALFREO LAMPIER LAUGHTON, AS.ASM

ALAN HARDING LENDON, M.8.8.5, F.R.C.S.(Eng)

(On military service).

WALTER IOHN WESTCOTT CLOSE, M.B. B.S.F.R.C.S. (EdII). (Acting).

THOMAS DRAPER CAMPAELL, D.SC., D.D.SE

JOHN LEONARO EUSTACE, B.D.S.

THOMAS DRAPER CAMPBELL, D.SC., D.D.SC.

GORDON ORD LAWRENCE, B.D.SC. (Melb).

PATRICIA LESLEY BIDSTRUP, M. B., B.S. (Acting).

ARTHUR PARISS READING MOORE, D.D.SE

PERCY RAYMOND BEGG, D.D,SC

CECIL BOASE MADDERN, D.D.SC.

HURTLE THOMAS JACK EDWARDS, D.D.SC.

KARL JOSEF POSENER, M. D. (Berlin). 
Demonstratar in Operative Technios:

THOMAS DENNIS HANNON, B.D.5. (On military service) GORDON ORD LAWRENCE, B.D.SC, (Meib), (ACting)

Demonstrotor in Orthodontic Technics:

PERCY RAYMONDBEGG, D.D.SC

Demonstrator in Prosthetic Technics:

LEONARD ARTHUR MORRIS BROUGHAM.

Demonstrator in Crown and Bridge Work:

MALCOLM STEWART JOYNER, B.D.S. (On milisary service).

MERVYN WYKE EVANS, B.D.S (ACting)

instructor in Prosthetic Dentistry.

GORDON ORD LAWRENCE, 8.D.SC. (Melb).

Instructor in Andesthetics:

GILBERT BROWN, M.8. Ch.B. (UV).

\section{5}

The Professors of Anotomy, Bacteriology, Biachemistry, Chemistry, Pothology. Phvsics. Physiaogy and Zoology.

Lecturer on Prosthetic Dentistry:

HURTLE THOMAS JACK EDWARDS, D, DSC

Lecturer on Crown and Bridge Work.

HURTLE THOMAS JACK EDWARDS, D.D.SC

Lecturer on Dentai Metalluray:

REGINALO ALFREO LAMPIER LAUGHTON.A.S.A.S.M.

Lecturer on Surgery:

ALAN HARDING LENDON, M. B, B.S., F.R.C. S. (Eng):

Lecturer on Oral Surgeng:

THOMAS ORAPER CAMPBELL, D.SC, D.D.SC,

Lecturer on Dentoi Materia Medica ond Theraputics:

JOHN LEONARO EUSTACE,B.D.S.

Lecturer on Dental Anatomy:

TTHOMAS DRAPER CAMPBELL, D.SC D.D.SC

Lecturer on Operative Dentistry:

GORDON ORD LAWRENCE, B D.S, (MEIG)

Lecturer on Medicine:

MELVILLERINEST CHINNER,M.D.

Lecturer on Dental Surgery and Dental Pathology: ARTHUR PARISS READING MOORE,D.D.SC:

Lecturer on Orthodontics:

PERCY RAYMOND BEGG, D.D.SE

Lecturer on Prophylaxis and Dral Hygiene:

CECIL EOASE MADDERN, D.D.SC.

Lecturer on Ethics, Economics and Dental Jurisprudence;

HURTLE THOMASJACK EOWAROS, 0.0.5C

Lecturer on Anatomy:

KARL JOSEF POSENER, M.D. (Berlin).

Demanstrator in Operotive Technics:

THOMAS DENNIS HANNON, B. O.S. (On military service)

GORDON ORD LAWRENCE, B.D.SC (Melb). (Acting)

Demonstrator in Orthodontic Technics:

PERCY RAYMOND BEGG, D.D.SC.

Demonstrator in Prosthetic Technics:

C. WHITFORD

Demonstrator in Crown and Bridge Work:

MALCOLM STEWART JOYNER, B.D.S

Instructor in Prosthetic Dentistry:

GORDON ORD LAWRENCE, B. D.5C, (Melb).

Instructor in Anqesthetics:

GILBERT BPOWN, M.B,Ch,B. (LIV).

Instructor in Radiagraphy:

JOHN FRANOS CLARK, B.DS.
THOMAS DENNIS HANNON, B.D.S. (On military service), GORDON ORD LAWRENCE, B.D.SC. (Melb) (ACting).

PERCY RAYMOND BEGG, D.D.SC

LEONARD ARTHUR MORRIS BROUGHAM.

MALCOLM STEWART JOYNER; B.D.S. (On military service). MERVYN WYYE EVANS, 8.D.5 (ACting).

GOROON ORD LAWRENCE; B.D.SC.

GILBERT BROWN M. B., Ch.8. (LIV):

1946

HURTLE THOMAS JACK EDWAROS, D.D.SC.

MALCOLM STEWART JOYNER, B.D.5.

REGINALO ALFRED LAMPIER LAUGHTON, AS.A.SM

ALAN HARDING LENCON, M.8., 8,5, F, R.CS, (ENG)

THOMAS CRAPER CAMPBELL, D.SC. D.D.SC.

JOHN LEONARO EUSTACE, B.D.S.

THOMAS DRAPER CAMPBELL, D,SC. D, D,5C.

GORDON ORD LAWRENCE, B. D,5, (Melb)

MELVILE ERNEST CHINNER, M.D. (ON military service) JAMES GARNET SLEEMAN, M.D.

ARTHUR PARISS REAOING MOORE, D.D.SC:

PERCY RAVMOND BEGG, D.D.SC.

CECIL BOASE MADDERN, D.D.SC.

JOHN FRANCIS CLARK, B.D.S

KARL JOSEF POSENER, M. D. (Berlin).

GORDON ORD LAWRENCE, D.D.SC.

PERCY RAYMOND BEGG, D.D.SC

C. WHITFORD.

ALLAN JAMES BLOOMFIELD, B.D.5

GORDON ORD LAWRENCE, D.D.SC:

JOHN DAVIO RICE, M.8.,B.5.

JOHN FRANCIS CLARK, B.D,S. 
Instructor in Gilidren's Dentistry: CHARLES REX FORDER, B.DS. instructor in Periodantics

MERVYN WYKE EVANS, D.D.SC

CHARLES REX FORDER,B.D.S

MERVYN WYKE EVANS.D.D.SC

1947 Complete staff listing

1948

The Professors of Anatomy, Bacteriology, Biochemistry, Chemistry, Pothology Physics, Physiology, and Zoology. Lecturer on Prosthetic Dentistry:

HURTLE THOMAS JACK EDWARDS, D, D, 5C.

Lectarer on Cown And Bridge Work:

MALCOLM STEWART JOYNER, B.D.S,

Lecturer on Dental Metallurgy

REGINALD ALFRED LAMPIER LAUGHTON A.S.A.S.M

Lecturer on Surgery:

ALAN HAROING LENDON, M.B.B.S.E.R.C.5 (EnR)

Lecturer on Oral Surgery:

THOMAS DRAPER CAMPBELL, D.SC, O.D.SE

Lecturer on Operotive Dentistry.

GORDON ORD LAWRENCE, O.D.SC.

Lecturer on Dental Moteria Medico and Theropeutics:

JOHN LEONARD EUSTACE, B.D.s.

lecturer on Dental Anatomy.

THOMAS ORAPER CAMPBELL, D.SC, O.DSC

Lecturer on Operative Dentistry

GORDON ORDLAWRENCE, D.D.SC,

Lecturer on Medicine:

MELVILLE ERNEST CHINNER, M.D.

Lecturer on Dental Surgery and Dental Pathology:

ARTHUR PARISS READING MOORE, O.D.SC

Lecturer on Orthodontics:

PERCY RAYMOND BEGG, D.OSE

Lecturer on Prophylawis and Oral Hygiene:

CECIL BOASE MADDERN, D.OSC.

Lecturer on Ethics, Economics, and Dentai Jurisprudence:

IOHN FRANCIS QLARK, B.D.S.

Lecturer on Anotomy:

WILLAMM ROSS ADEY, M.B, B.S.

Demonstrator in Operative Technics:

GORDON ORD LAWRENCE, D.D.SC

Demanstratar in Onthodontic Technics

PERCY RAYMOND BEGG, D.D.SC

Demanstratar in Prosthetic Dentistry:

Demonstrotor in Prosthetic Teclinics

C WHITFORD.

Demonstrator in Crown and Bridge Work

ALLAN JAMES BLOOMFIELD, B.D.S.

Instructor in Prosthetic Dentistry:

GORDON ORD LAWRENCE, D.D.SC.

Instructor in Angesthetics:

JOHN DAVID RICE, M. B.,B.5.

Instructor in Radiology:

JOHN FRANOS CLARK, B.D.S.

Instructor in Oilldren's Dentistry.

THOMAS BRUCE LINDSAY,B,D,S,

Instructor in Periodontics:

MERVYN WYKE EVANS, D.D.SC

Senior Supervisor:

JOHN LEONARD EUSTACE,B, D,S.

Prosthetic Dentistry:

Lecturer

HURTLE THOMAS JACK EDWARDS, D.D.SC

instructor

GORDON ORO LAWRENCE, D.D.SC.

Seniar Demonstrator:

MURRAY JAMES BARRETT, B.D.S

Demonstrators:

BRIAN CORRELL CRISP, B.D.S.

HAROLD BRUCE FRAYNE,B,D.S.

Operative Dentistry:

Lecturer:

GORDON ORD LAWRENCE, D.O.SC:

Instructor:

GORDON ORD LAWRENCE, D.O.SC̈.

Tutars:

ROGER GEORGE WULOUGHBY, B.D 5

HARRY MAX WILSON B.DS.

PHILUP MUROOCH WESSLINK, B.OS.

Demanstrators?

PHILLP MURDOCH WESSUNN, B. OS. (SYd).

FRANKLINNA SISLEY WESTERMAN, 8.D.5

Crown and Bndge Work:

Lecturer:

MALCOLM STEWART JOYNER B.D.S

Demonstrator:

ALAN JAMES QLOOMFIELD, B.D.S

Dental Anătomy:

Lecturer:

THOMAS ORAPER CAMPBELL, D.SC, D.D.SC.

Demonstrator.

ALEXANDER PHILLIP PLUMMER, 8.D.5

Orthodontics:

Lecturer:

PERCY RAYMOND BEGG, D.D.SE

Demonstrator:

PERCY RAYMOND BEGG, D.D.SC

Periodontics

Lecturer:

MERVYN WYXE EVAN5, D.D.SC.

Demonstrator:

LESTER ROBERT BOYLE, M.D.S.

Lecturers.

Dental Metallurgy:

REGINALD ALFRED LAMPIER LAUGHTON, A.5.A.5.M.

Surgery:

ALAN HARDING LENDON,M.8, B.5.,F.R.C.S.(Eng)

Mediane;

MELVILLE EANEST OHINNER, M.D.

Oral Surgery:

THOMAS DRAPER CAMPBELL, D,SC, D,D,SC 
1948 (cont)

Dental Moteria Medica and Theraputics:

IOHN LEONARD EUSTACE, B,D.S

Dentai Surgery and Pathologv:

ARTHUR PARI5S READING MOORE, D,D.SC

Prophylowis and Dral Hygiene:

CEOL BOSE MADOERN, D. O.SC

Ethics, Economics and Dental Jurisprudence:

HARRY MAX WILSON,8,0.5.

instructors:

Angesthetics

JOHN OAVID RICE,M.B.B.S.

Rodlography:

THOMAS BRUCE LINDSAY, B, D, S

Children's Dentistry:

THOMAS BRUCELINDSAY, B.OS

\section{9}

The Professors of Anotomy, Bacteriology, Biachemistry. Chemistry, Pothologv. Physics, Physiologr, and Zoology Director of Dental Studies:

THOMAS ORAPER CAMPBELL, 0,5c, 0,0.5C

Senior Tutor

JOHN LEONARD EUSTACE, B.D.S.

Ptosthetic Dentistry

Lecturer:

HURTLE THOMAS IACK EDWAROS, D, D,SC

instructor and Assistant Lecturer

MURRAY JAMES BARRETT, M D.

Tutars:

KENNETH JAMES ROBERTSON. B.DS.

HAROLO BRUCE FRAYNE B.DS.

PHILUP MURDOCH WESSUNK, B,D,5. (SVId).

Demonstrators:

ROBERT STEWART BLACKBURN, B.D.S.

JOHN BICE DAY, B.D.S.

GLEN MILLHOUSE, B.D.5

CLEMENT JAMES TVMONS, B.D.S.

Operative Dentistry

Lecturer:

GORDON ORD LAWRENCE, D.D.SC

instructor:

GORDON ORDLAWRENCE, D.D.SC,

Tutors:

HAROLD VERNON CLARK, B.D.S

BRIAN CORRELL CRISP, B.DS.

MERVVN WYKE EVANS, D.O.SC

IOHN FREDERICK LAVIS, B.DS

ROGER GEORGE WILLOUGHAY, B.0.5.

HARRYY MAX WILSON, B.D.S.

Tutor in Children's Operative Dentistry:

WESLEY MELVYN TILLER MARSHMAN, 8.0.5.

Demonstrators:

BRIAN CORRELL CAISP, B.D.S

RONALD FRANK PORTER, B.D.S

PHILUP MURDOCH WESSUINK, B. D. S. (SVI)

FRANKLINNA SISLEY WESTERMAN, B D. S/
1949 (cont)

Lecturer:

MALCOLM STEWART JOYNER, B.D.S

Demonstrotors:

ALLAN JAMES BLOOMFIELD, B D.S

ERIC DESMOND MORGAN, B.D.S.

Dental Anatomy

Lecturer:

THOMAS DRAPER CAMPBELL, D.SC,, O.D.SE.

Demanstrators:F

ALEXANDER PHILLIP PLUMMER B.DS.

RONALD FRANK PORTER, B.D.S

Grthodontics

Lecturer

PERCY RAYMOND BEGG, D.D.SC

Demanstrator

PERCY RAYMOND BEGG; O.D.SC

Periodontics

Lecturer:

MERVYN WYKE EVANS, O.D.SC

Demanstrator:

ROGER GEORGE WILLOUGHBY, B,D,5

Lecturers

Dental Metaliuray

REGINALD ALFRED LAMPIER LAUGHTON, AS.A.5 M

Surgery:

ALAN HARDING LENOON, $M .8,8,8,5$, F, R.C.S, (Eng)

Medicine:

MELVILLE ERNEST OHINNER, M O.

Oral surgery:

THOMAS DRAPER CAMPBELL, D.SE. D. D.5C

DentalMaterio Medica and Therapeutics

JOHN LEONARDEUSTACE, B.D.S.

Dental Surgery and Pathology:

ARTHUR PARISS REAOING MOORE, D.D.SE.

Prophyiaxis and Oral Hygiene:

CECIL BOASE MADDERN, 0.0.5C.

Ethics, Economics, and Dental Jurisprudence:

HARRY MAX WILSON, B.DS

\section{0}

Where the new staff/ position changes are minot.

only the new names and their appointments are listed. Staff change since 1949 was:

Surgery:

ALAISTAIR CAMPBELL MCEACOHERN, M. B., B.S.,F.R.C.S. (ENG).

1951

Staffing was little different from the past two vears, with the main change occurring in teaching subject

matter, e.p., a new subject was:

Dental Public Heatth ond Services

CECIL BOASE MADDERN, D, D, 5C,

Prosthetic Dentistry:

HUGH DALEY KENNARE, B.DS.

In Medicine:

JOHN MILROY MCPHIE, M B, B.S 
1952

The Professors of Anotomy, Bacteriology, Biochemistry. Chemistry, Patholagy Physics, Physiology and Zoalagy: Director of Dental Studies:

THOMAS DRAPER CAMPBELL, D.D.5C.

Senior Tutor:

JOHN LEONARD EUSTACE, B.D.S

Prosthetic Dentistry

Reoder:

MURRAY JAMES BARRETT, M.D. 5

Lecturer:

HURTLE THOMAS JACK EDWARDS, D.D.SC

Tutars:

KENNETH JAMES ROBERTSON, B.DS.

HAROLD BRUCE FRAYNE, B.D.S.

JOHN BICE DAY, B.D.5.

ROBERT STEWART BLAOKBURN, B.OS.

Demonstrators:

CIEMENT JAMES TYMONS, B. D.S

HUGH DALEY KENNARE, B.D.S.

KENNETH AYEESBURY BROWN, B.D.S.

Operative Dentistry

Lecturer:

GORDON ORD LAWRENCE. D.D.SC.

instruetor:

GOROON ORDLAWRENCE, D.O.SE.

Tutors:

HAROLD VERNON CLARKE, B.D.S.

BRIAN CORRELL CRISP, B.D.S

MERVYN WYKE EVANS, D.D.SC.

JOHN FREDERICK LAVIS, B. DS

GLEN MILLHOUSE B.OS

GRAHAM MOUNT, B.D. S.(SVd).

ROGER GEORGE WILLOUGHBY, B. D.S

HARRY MAX WILSON, B.D.5

PHILLIP MURDOCH WESSLINK B D.S. (SVd).

Tutor in Children's Operative Dentistry

WESLEY MELVYN TLLER MAPSHMAN B.D.S.

Demonstrotors:

GRAHAM MOUNT; B. D.S. (svd).

Gown and Bridge Work

tecturer:

MALCOLM STEWART JOYNER, B.D.S

Demonstrotors:

ALLAN IAMES BLOOMFIELD B.0.5

ERIC DESMOND MORGAN, B. D.S.

Dental Anatomy

Lecturer:

THOMAS DRAPER CAMPBELL, D.D.SC

Demonstrator:

KENNETH AYLESBURY BROWN, B.D.S.

Qithodontics

Lecturer:

PERCY RAYMOND BEGG, D.D.SE

Demonstrotor:

PERCY RAYMOND BEGG, D.D.SC

Lecturer, Periodontics:

MERVYN WVKE EVANS, D.D.SC.

Demonstrotor:

ROGER GEORGE WILLOUGHBY; B.D.5
1952 (cont)

Lecturers:

Derital Metallurgv:

WILLIAM THOMA5 OENHOLM, B.Met.E (Meib).

Surgery:

ALASTAIR CAMPBELL MCEACHERN, M.B., B.S., F.R.C.S. (ENE).

Medicine:

MELVILLE ERNEST CHINNER, M.D

Oral Surpery:

THOMAS URAPER CAMPBELL, D,SC,, O.D.SC.

Dental Materia Medica and Theraputics.

JOHN LEONARD EUSTACE, B.O.S.

Dental Surgery and Pathology:

ARTHUR PARISS REAOING MOORE, DID SE.

Dental Public Health and Services:

CECIL BOASE MADDERN, D.D.SC

Children's Dentistry:

WESLEY MELVYNTILIER MARSHMAN B.D.S.

instructors:

Anaesthetic:

JOHN DAVID RICE, M.B., 8.5

Radiography:

JAMES ALEXANDER CRAN, B.D.SC, (Q'ld).

Tutors:

In Medicine:

JOHN MILROY MCPHIE M, B, B.S.

in Surgery:

DONALDSTUART KIDD, M.B., B.S. (SYd)

\section{3}

Changes in personnel from 1952 were

Prosthetic Dentistry

Demanstrators

JOHN FRANCIS BURROW,B.D.S

ROBERT ANTHONY STANTON, B.D.5

REX HORTON WALLMAN, B.D.S.

Operative Dentistry?

Demanstrators:

IAN HAROLD HODGSON, B.D.5.

Dental Metallurgy:

W.KRYSKO,

in surgery:

JAMES DON SIDEY, M.8, B.5. (Lond) F.R.C.S.

\section{4}

Changes in persannel from 1953 were:

Prosthetic Dentistry:

Demonstrators:

FREDERICK RUDOLPH HENNING, 8.D.5

PETER CLARENCE READE, B.DS.

CHRISTOPHER MALCOLM SOMMERVILLE B.D.S

Surgerv:

JAMES ESTCOURT HUGHES, M.B.M.S

Anaesthetic:

FRIEDRICH BERTHOLOLEDITSCHKE, M.8.8.S.

in Surgery:

OONALD BARTON MCLEAY, M.8,8.5. 
1955

Changes in personnel from 1954 were: Demonstrator:

NORMAN STUART WALMSLEY, B.D.S.

Operative Dentistry.

Demenstrotor:

JOHN FRANOS BURROW, B.D.S.

\section{6}

Tutors/Demonstrators was introduced

Prosthetic Dentistry:

Port-time Demionstrators:

MrS ELFRIDA SAUUITE, B.D.S

REUBAN JOHN MYHILL, B. O.S.

BRUCE GOODMAN WARK, B,D.5

REGINALD FRANK HARRINGTON, B.D.5

Dental Anatomy:

Port-time Demonstrotar:

MrSELFRIDA SAULITE, B.D.S

\section{7}

Changes in personnel from 1956 were:

Periodontics:

Part-time instructor:

PETER CLARENCE READE, B.D.5.

Dental Metallurgy:

Port-time lecturer:

FRANTISEK VNUK, B.SC

\section{8}

New appointments from 1956 were:

Dental Anatomy:

Part-time Demonstrator:

KEVIN READING MOORE, B.0.5

in Medicine:

Part-time Tutors:

ROBERT BECXER, M.D., M.R.CP, M.R.A.CP.

D.T.M. and $\mathrm{H}$.

1959 Complete staff listing

Professor of Dental Science:

ART HUR MAXWEU HORSNELL, L.D.S. R.C.S. (EnP.),

F. D.S, R.C., M.R. C.S, (Eng) L R.C.P. (tond).

Prosthetic Dentistry:

Reader:

MURRAY JAMES BARRETT. M.D.S.

Port-time lecturer:

HLRTLE THOMASIACK EDWARDS, D.0.5C

Part-time Assistant Lecturer:

KENNETH JAMES ROBERTSON, M.D.S

Port-time Tutors:

ROBERT STEWART BLACKBURN, B.D.S

JOHN BICE DAY, B.D.S.

HAROLD BRUCE FRAYNE, M.D.S.

KENNETH JAMES ROBERTSON, M.D.S

ROBERT ANTHONY STANTON, B.D.S.

Port-time Demonstrators:

JOHN BLUM, B.D.S.

KENNETH AYLESBURY BROWN, B.D.S.

REUBEN JOHN MYHILL, B.D.S.
1959 (cont)

Part-time Demonstrators (Cont)

CHRISTOPHER MALCOLM SOMERVILLE, B.D.S

BRUCE ALLISON TIDSWELL, B.D.S.

JOHN ALEXANDER REINER5, B.D.S.

Conservative Dentistry:

Port-time lectures:

GORDON ORD LAWRENCE, D.D.SC

Part-time Tutors:

HAROLD VERNON CLARKE, B.D.S

BRIAN CORRELL CRISP, B.D.S.

HUGH DALEY KENNARE, B,D,S

JOHN FREDERICX LAVIS, M.D.

GLEN MILL MOUSE, B.D.5.

GRAHAM MOUNT, B.D.5. (SWd)

PHILLP MURDOCH WESSLINK, B.DS. (SVI)

ROGER GEORGE WILLOUGHBY M.D.S.

Part-time Tutor in Children's Dentistry:

WESLEY MELVYN TILLER MARSHMAN, B. D. 5

Part-time Demenstrators.

JOHN FRANCIS BURROW, B.D.5.

REGINALD FRANK HARRINGTON, B.D.5.

Crown and Bridpe Work:

Part-time Lecturer:

MALCOLM STEWART JOYNER, B.D.S.

Part-time Tutor:

ALLAN JAMES BLOOMFELD, B.D.S.

Part-tme Demonstrotoe:

ERIC DESMONO MORGAN, B.D.5.

Dental Anatomy:

Part-time Demanstrator:

LACHLAN LEWIS DAENKE, B.D.S.

Dental 5urgery and Pathology:

Reoder:

JAMES ALEXANDER CRAN, B.D.SC, (Q'Id,) M.D.S.

Part-time tutors:

KEVIN READING MOORE, B.D.5.

JOHN LEONARD EUSTACE, B.D.S.

Orthodontics:

Part-time Lecturer:

PERCY RAYMOND BEGG, 8.0.5. (Mel6), D.D.SC

Part-time Demanstrator:

PERCY RAVMONO BEGG, 8.D.5. (Melb), D.D.SC

Peniodoritics:

Lecturer

PETER CLARENCE REAOE, E.D.S., E.D.S. R.C.S. (Eng)

Part-time lecturers:

Dental Metallurgy:

FRANTISEK VNUK, B.A.B.SC

Surgerv:

JAMES ESTCOURT HUGHES, M.B., M.S.

Medicine:

JOHN MILROY MCPHIE, M.B., E.S, M.R.CP

Dental Materia Medica and Therapeutics:

ALLAN JAMES BLOOMFIELD, B.D.S.

Dental Public Health and Services:

ROGER GEORGE WILLOUGHBY, M.0.5.

Children's Dentistry:

WESLEY MELWN TILLER MARSHMAN, B.D.S, 
1959 (cont)

Port-time Assistant Lecturer:

Dental Materia Medict and Therapeutics:

ALLAN IAMES BLOOMFIELD, B.D.5.

Port-time Lecturer and Instructor:

General Anaesthetics:

FRANCIS CALLUM ARCHIBALD, M. B. B.5

Part-time Tutors:

In Medicine:

ROBERT HECKER, M.D., M.R.CP., M.R.A.C.

D.TM. and $H$.

in Surgery:

DONALD BARTON MCLEAY, M.B., BS

in Children's Conservative Dentistry:

WESLEY MELVYN THLLR MARSHMAN, B.D.S.

1960

Changes in personnel from 1959 were:

Demonstrator:

LORIMER JUDITH KAY, B.D.S.

Dental Anatomy:

TASMAN BROWN, 8.D.5

Dental Surpery and PathologV:

Senior Lecturer:

BRYAN GRAY RADDEN, B. D, SC, (W.A),

F.D.5.R.C.5. (Ene). Ph.D.

Anapsthesia:

ROBERT JAMES SWEENEY, M.B. B.S

\section{1}

Changes to postion / personnei from 1960 were: Prosthetic Dentistry:

Part-time Demonstrators:

THOMAS EGON KRASSAY.

To First Year Studerits:

HAROLD BRUCE FRAYNE, M.D.S

KENNETH AYLESBURY BROWN, B.D.5.

1962

New positions/ personnel from 1961 were: Temporary Lecturer.

JOHN KIRIKWOOD, B.D.S (SYd), D.D.S. (Tor)

F.D.S.R.C.S. (Eng),

Conservative Dentistry:

Temporary Senior Lecturer.

ELIZABETH ANN FANNING, 0.0.5, (N.Z)

Port-time Tutors:

GEOFFREY SINCLAIR HEITHERSAY, B. D.5.

In surgery:

RICHARD ENGLISH DUNSTAN, M.8.8.5.

Teaching Repistrac:

ROBERT VINCENT BLANDEN, B.0.5.

\section{3}

Changes in personnel from 1962 were:

Temporary Lecturer.

5IDNEY IVOFI LUIGI ROVEDA, B. D,5c, (QId), D.D.5.(Dal).
1964 Complete staff listing

In this year the Faculty of Dentistry was

organized into three divisions with changes in

teaching positions and personnel from 1963.

Professor of Dental Science:

ARTHUR MAXWELL HORSNELL, F.D.S R.C.S M.A.C.5, (ENR).

L.R.C.P. (Lond)

Seniar Lecturer in Dental Anatamy:

TASMAN BROWN, M.D.S.

Teaching Registror.

Temporary Lecturer:

SIONEY IVOR LUIG) ROVEDA, 8, D, Sc, (Q $Q^{\prime}(d), D, D, 5$, (Dal).

Part-time Lecturers:

in Surgery.

JAMES ESTCOURT HUGHES, M.8.8.S

in Medicine:

JOHN MILROY MCPHIE, M.D. M.R.A.C.P.

In Pronciples of Dental Practice:

ROGER GEORGE WILLOUGHBY, D.D.5. (Northwestern).M.D.S.

Part-time Tutors:

in Surgerv:

RICHARD ENGUSH DUNSTAN M B. B S

ERNEST ALFRED DAVID RUSSELL, M. 8. B.5, F.R.C.S (ENE) F.R.A.C.A.

In Medicine:

ROBERT HECXER, M. D. M.R.CP, M.R.ACP O.TM and H

RICHARD JOHN BURNS, M.B., B.S

To First Year Students:

KENNETH AYIESBURY BROWN, B.D.S

FREDERICK RUDOLPH HENNING, M. D.S. F. D.S.R.CS. HAROLD BRUCE FRAYNE, M.D,S.

Division of Preventative Dentistry

Reader in Preventative Dentistry:

EUZABETH ANN FANNING, D,D,S, (N.Z)

Reoder in Orthodontics:

MILTON REGINALO SIMS, B.D.5.

Lecturer in Periodiontio

PETER CLARENCE READE, M.D.5, F.D. S. R.C. (ENB).

Part-time Tutors:

in Preventative Dentistry:

NORMAN JOSEPH VOWLES, B. D.5.

BRUCE ALUSON TIDSWEU, B.D.5.

in Orthodontics:

BRIAN CORRELL CRISP, M.D.S

In Children's Dentistr:

BRUCE ALLISON TIDSWELL, M.D.S,

MURRAY LYALL KRANZ, B.D.S

Division of Oral Surgery and Oral Pathology

Reoder in Dental Surgery and Pathology:

JAMES ALEXANDER CRAN, B.D.SC., (Q'dd,) D.D.Sc.

Senior Lecturers:

In Oral Pathology:

BRIAN GRAY RADDEN, 5.D.SC, (W.A.), F. D.5. R.C.5. (Eng)

PhO. (Lond).

in Oral Surpery:

BARRY NILAND FITZPATRICK, M.D.SC., (W.A.), F.D.S. R.C.5. (Eng) 
1964 (cont)

Port-time Lecturers:

In Dental Materia Medica and Therapeutics:

ALLAN JAMES BLOOMFIELD, B.D.S.

In Anaesthesia:

ROBERT ERNEST STEELE, M.B. B.S. F.E.A.R.C.S.

Port-time Tutors:

in Oral Surgery:

THOMAS BRUCE UNDSAY, M. B, 8.5, M.D.5

KEVIN READING MOORE, B.D. 5

in Anaesthesia:

ROBERT ERNEST STEELE, M B, B.S, R.F, A. R.C.S

Divisian of Restorative Dentistry

Reader in Prosthetic Dentistry:

MURRAY JAMES BARRETT, M. D.5

Senfor Lecturer in Conservative Dentistry:

OWEN FRANCIS MAKINSON, B.D.5.(5Yd),

D.D.5. (Northwestern). F.D.S. R.C.5. (Eng)

Lecturers:

In Prosthetic Dentistry;

PETER ROBERT NOBLE BEASLEY, B.D.S. (SWd)

in Conservative Dentistry:

IOHN KIRKWOOD, B. D, S (SYd), D. D. S, (Toronto),

F.D.SR.C.S. (Ena).

Part-time Lecturers:

in Conservative Dentistry:

FREDERICK RUDOLPH HENINING, M. D.5., F.D.5, RLC.5.

In Dental Materials:

FRANTISEK VNUK, B.A., B.SC

Port-time Assistant Lecturer/Instructor in Conservative Dentistry:

GRAMAM JAUNEY MOUNT, B.D.S. (Syd).

Port-time Tutors:

In Prosthetic Dentistry:

JOHN BLUM, B. D.5.

KENNETH AYLESBURY BROWN, B.D.S

HAROLD BRUCE FRAYNE, M.D.S

JOHN ALEXANDER REINERS, B.D.S.

In Conservative Dentistry:

ALLAN JAMES BLOOMFIELD, B.D.S.

JOHN FRANCIS BURROW, B.D.S.

HAROLD VERNON CLARKE B.D.5.

REGINALO FRANK HARRINGTON B, 0,5 .

GEOFFREY SINCLAIR HEITHERSAY, B, D, S, F, D.5, R.C. (Edin.)

JOHN FREDERICK LAVIS, M D, 5

IOHN BRIAN LEACH, B.0.5.

GLENN MILLHOUSE, B.D.S.

CHRISTOPHER MALCOLM SOMERVILLE, B,D,S

ROGER GEORGE WILLOUGHBY, D.OS. (Northwestem), M.D.5.

In Dental Materials:

FRANTISEK VNUIK, B. A, B.SC

Part-time Assistant Tutors in Prosthetic Dentistry:

THOMASEGON KRASSEY, B D, S

BRIAN HEYLEN SOUTER, B.D.S.

\section{5}

Changes in personnel from 1964 were:

Lecturers:

PETER GIYNNN DELLOW, B.D.S. M.E, B.S

JOHN GABRIEL WATERSON, B.D.S.
1965 (cont)

Teaching Registrar:

STEPHEN WEI HON YIN, B. D.5.

Part-time Tutors:

MELVILE LIONEL CARTER, M.B., B.5.

GEOFFREY CHARLES HALL B.D.S.

JUSTIN HERBERT MILLER, M B. B.5

JOHN PETER RICE, M B., B.S

FRANOS RICHARD WHITE, B.D,S.

Part-time Tutors.

KEITH CYRIL GRAVE, B.D.S.

GORDON JAMES PFEIFFER,B.DS.

\section{6}

Changes in personnel from 1965 were:

Professor:

JOHN C. THONARD, B. D, SC. (Melb), Ph.D. (Rochester)

Teaching Registrar:

BAREY JOHN GAUDRY B D.5. (5yd), F. O.5. R.C.S

Part-time Tutors:

ROBERT MATHESON DOUGLAS M.8. B.S

Port-time lecturers:

PAUL MALCOLM RAINSFORD, M. B., Ch.B. (Birm): D.A.F.F.A.R.ACS

Port-time Tutors (Restorative Dentistry)

JAMES IAN WUKE, B. D.5

1967

Changes in personnel from 1966 were:

Part-time Tutors:

JAMES HUDSON BEARE, M.8.8.5.

THEO GOTJAMANOS, M.D.S.

DONALD CAMPBELL MCKINNON, M.B, B. S., F.R.CS, F.R.A.CS. JOHN FR.ANCIS ANTHONY WALSH, M.B., B,S, F.R.C.S, F.R.A.C.5 ERROL GLEN WILMHURST, M.B., B.5., M.R.A.C.P.

Division of Oral Pathology and Oral Surgery:

Part-time Tutars:

RALPH EDWARD ANNELS, B.D.S

KEITH WILLIAM BAILEY, B.D.S

PETER DE PAUL MCDONALD, B.D.5

Division of Restorative Dentistry:

Lecturer:

WILLIAM EDWARD JOYCE, B,D,S.(SYd),

Part-time Tutars:

PETERRONALD APPLEBEE, B.DS.

RICHARD VOULES BARTHOLOMAEUS; B.D.S.

JOHN D CHEETHAM, L. O.S. F.C. 5.

GEOFFREY GORDON LLEWELLYN EVANS, B.D.S.

DAVID MICHAEL FOX, B. D.5.

JOHNN EDWARD MARRIOTT, B.D.S.

PATRICK LAWRENCE MARTIN, B.D.S

TREVOR WALLIS MARTIN, B. OS.S.

GREGORY JOHN ROHAN B.D.S.

RICHARD ADRIAN WILFRID SNOW, B.D.S

JOHN RONALD THOMPSON, B.D.S.

ROBERT LOUIS VON DOUSSA, B.D.S

ROBERT FRANK EOISON WELCH, B.D.S. 
1968

In this year the Faculty of Dentistry was organized into Four divisions with the new division being Oral Biology Changes in personnel from 1967 were: tecturer;

CHAU KAI KIN B.D.5., F.A.C.D.S

Teaching Repistrar:

5VEN KUUSK, B. D.5., F.A.C.D.5

Port-time Tutors:

GEOFFREY ERIC GIBSON. M.B. B.S.

Divisian of Oral Biology.

Reader:

NANCY ATKINSON, 0.8.E, M.SC, (Melb), D.D.5C

Division of Preventative Dentistry:

Seniar Lecturers:

MICHAEL ANTHONY CAROL NUGENT, B, D,5C. (QId)

D.Orth.R.CS

EDWARO CONROY MONULTY, B.S D.M.D. (HaTV)

lecturer:

NIGEL GORDON CLARKE B.D.5. (tond). L.D.S.R.C.S.

Part time Lecturer/Instructor:

KEVIN REGINALD ALLEN B D S

Part-time Tutor:

GEOFFREY IVAN BROWN. M.D.S.. F.A.C.D.S

CIVE MICHAEL DURNEY

RODNEYLEWIS MOORE

BASIL WRIGHT PHILUIPS, M. D.SC, (MEID), B. D.S. FA.CD.S

ROBERT WILUIAM WENZEL

Division of oral Pathology and Oral Surgery:

Part-time Tutors:

JOHN FREDERICK HOWELL-PRICF, B.DS. (SYd)

DAVID JOHN RUGLESS, B.D.S

Division of Restarative Dentistry:

Part-lime Tutors:

ARTHUR FRANCIS DAVV, B.D.S

BRUCE HENDERSON DUNSTAN, B.D.S.

GLEN DONALD DUNSTONE, B DSS

MAX THORLEY FRAYNE, B.D.S.

DADID RUTHERFORD SMERDON, 8.0.5.

BRIAN NEIL WALKER,B.D.S. (N.Z)

JEFFREY JOHN WRIGHT, B.D.S

1969 Changes in personnel from 1968 were Part-time Tutors:

PAUL GRAHAM CARNEY M B., 8.5

MARY CEDLLAA GIBBERDM.B. B.S. B.D.5,

TADASHI OZAKI, D.D.S, D.M. SC. (TokvO)

GRAHAM ROBERT SINCLAIR, M B., 8,5

ADRIAN NEIL VORBACH, $M$ B, BS.

RICHARD LYALL WILUNG, M.B, B.S., M.R.C.P. (Glas. Lond.). Division of Preventative Dentistiv:

MARGARET JEAN BEVAN B. D.SC. (Mellb)

IOHN OLUIVER BROOK, B.5C, B.D.

PETER MATHEW CADOY, B.D.S

NEIL HUNTER, B.D.5.

JOHN MICHAEL SCHULZE B. O.5

JOHN DIGBY WETHERELL B. OS.

Division of Oral Pathology and Dral Surgery

Senior Lecturer:

JOHN JOSEPH WILUAMSON, B. D.SC, (Q'id), M.D.Sc, W.Aust) ED.S.R.CS (Eng), FA,CDS
1969 (cont)

Part-time Lecturer:

PAUL MALCOLM RAINSFORD, M.B., Ch.B, (B)

Part-time Tutors:

JAMES PETER MORECROFT, I. D.5 (ManC).

GRAHAM STEVEN PATER, B.D 5.

Divisian of Restorative Dentistry

Lecturer:

DAVID ALLAN SCOTI PARIEER, M.D,SG, (Melb), F.A.C,D,5,

Part-time Tutors:

WILLIAM HENRY HOLMES B.D.S.

ANDREW MACKINNON MUIRHEAD, B.D.5.

BRUCE NAPIER, B.D.5.

GRAHAM SIDNEY PARRY, 8D, 5

IAN ARTHUR STEAQ, 8.D.S.

1970

Changes in personnel from 1969 were:

Teoching Registrar:

ALASTAIR NORMAN GO5S, B.D.S. (OtaRo)

Holf-time Lecturer:

GERVASE HENRY LEES, B. D.5 (LiV.)

Part-time Tutors:

FRANKLIN HERBERT GRIFFIN BRIOGEWATER, M. B.S

ANTHONY WILUAMM LAKE, B.D.5.

MARI LLOYD STRATTON SADDLER M.B. B.S

Divisian at Oral Biology:

Lecturer:

ANTHONY HOWARD ROGERS, Ph. D, (Leeds), M.SC

Division af Preventative Dentistry:

Part-tine Tutars

JOHN FRANCIS IRWIN, B.D.S. (Restorative Dentistry)

PAUL RAYMOND DUKE, B.D.S

RODNEY LEWIS MOORE, B.DS

PAULL RIGAY STEWART, B.D.5.

Divisian of Oral Pathology and Oral Surgery?

Senior Lecturer:

JOHN ROSS HERD, M.D.SC (Melb), F.A.C.D.S.

Part-time Tutors:

KEITH WILUAM BAILEY, B.O.S.

DAVID CARYL BLAIKIE, B D.5

JOHN HARVARD LOCKE, B.D.S. (5yd), M. \&. B.S. (Lond), M.R.C.S. Eng),

Division of Restorative Dentistry, lecturer

ROGER IOSEPH SMALES, M. O.S. (Otaga). FD. R. R.C.

Part-time tutors:

IAN RIOGEWAY DINGLE, B.D.S.

RICHARD CLARENCE STEVENS, B,D.5.

ROWLAND JAMES KDD, B.D.S

1971

Changes in personnel from 1970 were:

Oral Biolopy:

Part-time Tutor:

PAULL ANTHONY HENSCHKE, B.SC.

Oral Pathology and Oral Surgery.

Part-time Lecturer:

SALCY ELZABETH DREW, M.B., BS.

Part-time Jufars in General Medicine and General Surgery?

RATOMIR ANTIC, M. B., B,S

JAMES QUET KONG HO. M B., B.5

KENNNETH EDGAR TREIOAR LTTLE, M.B, B.S. 
1971 (cont)

Hestorative Dentistry:

Lecturer:

ROBIN DEREK MUARAY, B. D.S (LOND.), F.D.S. R.C.S

Half-time Serior Lecturer:

JOHN OSBORNE, M.D.S. (Birm), Ph.0. (Sheff), F.D.S A.C.S.

Restorative Dentistry:

Port-time tutors:

JAMES FREDERICK BALL, B,D,5.

MALCOLM BRUCE BILLS, B.D.S.

GUISEPPE CERAVOLO, B, DS

ANDREW SAMUEL COTTELL,. B.D.S

ANTHONY IELASI, B.D.S

PETER IAMES TELFER, B.DS

\section{2}

Ohanges in personnel from 1971 were:

Teaching Registrac:

JOHN MALCOLM MCINTYRE, B.DS. (Q'Id), Ph,D.

Port-time Tutors:

BRENTON GRAMAM BURFIELO, M.D.S

DAVIO VICTOR BURROW, B.D.S.

CHENG CHUNG KWONG PETER, B,DS

HAROLD TEMPLE CLARK, B. O.S.

5COIT RAVMOND DAVIES, 8, D.5

MARGARET ALINE EVANS, B DS

DAVIOMILES B.D.5

BRUCE DEREX NOBLE, B.D.S.

PETER RONALD NOBLET, B.D.S

ANTHONY MCKINNON SEOSMAN, B.D.5.

PALAM SIVAPATHA SUNDRAM, B.D,S. (BOmbay) LD,S.R.CS. ANGELO RALPH VARTULL, B.D.S

part-time Tutors in General Medicine and General Surgery: OHRISTOPHER ALFRED SWITAIEWSKI, M.B., B.5. Restorative Dentistry:

Half-ome Lecturer:

JOHN MOSS BOOTH, B.D.5. (Manc), O.D.S. (Tor)

Part-time Tutors:

WARWICK GRANT DOOLAND, B.D.S.

RICHARD JOHN EDWARDS, B.D.5.

KEITH WALTER GROTE, B DS.

DIANE ROSEMARY HUNT, B.D.5.

WILIAMM KYROS, B.D.5

JOHN EDWARD MARRIOTT, B.D.S

BRIAN OHARLES SHEPHARD, Q.D.5.

\section{Complete staff listing}

Dental Health:

Head of the Department Professor A.M.HORSNELL

Professor:

ARTHUR MAXWELL HORSNELL, FD, S. R.S. M.R.CS (ENg) L.R.C.P. (land), F.A.C.O.S.

Readers:

EUZABETH ANN FANNING, D.D.S (NZ), F.A.C.D.S

MILTON REGINALD SIMS, M.S.D. (Boston)، B.D.S., F.A.C.D.

Senior Lecturer:

NIGEL GORDON CLARKE, B.D.S. (Lond), F.D.S. R.C.S.

Part-time Lecturer/Iinstructor:

KEVIN REGINALD ALLEN, B.D.SC.
1973 (cont)

MARGARET JEAN BEVAN, B.D.SC. (Melb)

GEOFFREY IVAN BROWN, M.D.S, F, A, C.D.S

JOHN OLLIVER BROOK, B.5C., B.D.S.

DAVID VICTOR BURROW, B,D.S.

JOHN FRANCI5 BURROW, B., D.5

GIUSEPPE CERAVOLO, 8.DS

CHENG CHUNG KWONG PETER, B. D.

HAROLD TEMPLE CLARKE, B.D.S,

BAIAN CORRELL CRISP, M. D.S., F.A.CD.S.

SCOTT RAYMOND DAVIES, B DS

CLIVE MICHAEL DURNEY, 8.D.5.

MARGARET AUINE EVANS, B,OS.

FREDERICK RUDOLPH HENINING, M. D.S. F.D.S.R.CS

NEIL HUNTER, B.D.S.

JOHN DAVID JENNER, B.D.S.

DAVID MILES, B.D.5,

RODNEY LEWIS MOORE, B.D.S

BRUCE DEREK NOBLE, B.D.5.

PETER RONALD NOBLET, BD. 5

MICHAEL ANTHONY CAROL NUGENT, MS S(Roch), D.OTh, R.C.S. F. A.C.D.5 BASIL WRIGHT PHILUPS, M.D.SC. (Melb).B. D.S. FA.CDS

PALAM SIVAPATHA SUNDRAM, B.D,S (BOmbay), L.D,5, R.C.S. (EnR).

VALEPIE JEAN TOMPSON, B.D.S.

ANGELO RALPH VARTULI, B.D.5.

BRUCEIAN WATSON, B.OS

ROBERT WILLIAM WENZEL, B O,S

INES YOUNG, B.D.5

Oral Biology:

Head of the Department: Professor ICTHONARD

Professar:

JOHN CHARLES THONARD, B.D.SC. (Melb), Ph.D. (Rochester)

Readers:

NANCY ATKINSON, O.B.E, M.SC.(Melb), D.SC

TASMAN BROWN, D.D.SC, FA.C.D.S

JOHN GABRIEL WATERSON, Ph. D. F.A.CDS

Lecturer:

ANTHONY HOWARD ROGERS, Ph. D. (Leeds). M.SC

Part-time Tutors:

KENNETH AYLES BURY EROWN, \& D.5

PAUL ANTHONY HENSCHKE, B.SE

NEIL RUNTER, B.D.S

SVEN KUUSK, 8.D.5, F.A.C.D.5

Oral Pathology and Oral Surgery:

Head of the Deportment:

Dr I.A.CRAN.

Reader

JAMES ALEXANDER CRAN, B.O.SC (Q'ld), D.D.SC, F.C.Path, F.A.CD.S.

Senior Lecturer:

JOHN ROSS HERD, M.D.SC (MEIb), F.A.C.D.S.

tecturers:

ALASTAIR NORMAN GOSS, B. O.S. (Otago).

CHAU KAI KIN, M.OS, FA.COS

Part-time Lecturer/instructor:

SALCY ELIZABETH OREW, M.B., B.S.

Part-time Tutars

KEITH WIULAM BALLY, B.D.S.

DAVID CARYL BLAIKIE, B. D.S.

JOHN HARVARD LOCKE, B.D.S. (SYd), M.8, B.S. (Lond), F.D.S. R.CS.(Eng).

F.A.C.D.S. M.R.CS. (Eng), L.R.CP, (Lond). 
1973 (cont)

IAMES PETER MORECROFT, L. D.S. (MaNC).

Part-time Tutors in General Medicine and General Surgery: JOHN KEITH FREEMAN M.B., B.S.

KEITH MUGFORO M.B., B.5.

ADRIAN JOHN PORTER, M.B., B.5

ROBERT MAXWEL REED, M. B, BS

Restorative Dentistry:

Head of the Department:

MrM.J.BARRETI

Reader:

MURRAY JAMES BARRETT, M.D.5, F.A.C.D.5.

Senior Lecturers:

OWEN FRANCS MAKINSON, B.D.S. (SYd) D.D.5.

(Northwestern), F, D.5.R.CS., D. Orth.R.C.S. M.S (Mich)

F.A.CD,S

JOHN KIRKWOOD, B. D.S. (SYd), 0.0,5, (TOr), F.D.S. R.C.5. (Eng),

F.A.C.D,S.

PETER ROBERT NOBLE BEASLEY, B, D.5. (SYd)

DAVID ALAN SCOTT PARKER, M. D.SC. (MElb), F.A.CD.S.

Lecturer:

ROGER IOSEPH SMALES, M.D.S. (OTARO), E.A.CDS

Half-time Lecturer:

HENRY JOHN ELSEY B.0.5. (Birm). F.D.S. R. C.5. (EdIn)

Part-time Lecturer/Instructors:

GRAHAM JAUNAY MOUNT, B.DS. (SYd)

GEOFFREY SINCLAIR HEITHERSAY, M.D.S. F.D.S. R.C.S (Edin).

F.A.CD.S

Port-time Tutors:

PETER RONALD APPELBEE, B.O.S

JAMES FREDERICK BALL, B.D.S.

JOHN BLUM, B.D.S.

JOHN DESMONO CHEETHAM, L.D,S, R.C.S

HAROLD VERNON CLARKE, B.D.S.

ANTHONY JOHN COATES, B.D.S.

LACHLAN LEWIS DAENKE, B.D.S, F.A.CDS.

GRAHAM JOHN DAV, B.D.S.

SUSAN IENNIFER DOOLAND, B.D.S

WARWICK GRANT DOOLAND, B.D.S

PAUL WILLAM DRUMMOND, B D.S

RICHARD JOHN EOWARDS, 8. D.5.

GEOFFREY GORDON LLEWELLYN EVANS, B.D.S.

MAX THORLEY FRAYNE, B.D.S.

KEITH WALTER GROTE, B.D.S.

REGINALO FRANK HARRINGTON, B.D.S.

DIANE ROSEMARY HUNT, B. D.5.

ANTHONY IELASI, B.D.S.

WILLIAM EDWARD JOYCE, B.D.S. (SYd)

HLIGH DALEY KENNARE, B.D.S.

ANTHONY WILLIAM LAKE, B.D.S

IOHN FREDERICK LAVIS, M.D.S, E.A.C.D.S

PETER ANTHONY LEANEY, B.D.S

IOHN EDWARD MARRIOTT, B.O.S

PATRICK LAWRENCE MARTIN, B.D.S

TREVOR WALLIS MARTIN, B.D.S

GLEN MILLHOUSE, B.D.S.

REUBEN JOHN MYHILL, B.D.S.

BRUCE NAPIER, B.D.S.

GEOFFREY WILTON PAGE, B.D.S

GORDON IAMES PFEIFFER, B.D. 8

GREGORY JOHN ROHAN, B.O.S.
1973 (cont)

BRIAN CHARIES SHEPHERD, B. D.5.

DAVID RUTHERFORD SMERDON, B.D,5.

IAN ARTHUR STEAD, B.D.S.

RICHARO CLARENCE STEVEN5, 8.0.5.

PETEP JAMES TELFER, B.D.S

DUDLEY WILUAM TROTT BDS

ROBERT LOUIS VON DQUSSA, B.D.5

BPIAN NEIL WALKER, B,D,5.

PETER MORRIS WARNER, B.DS.

ROBERT FRANK EDISON WELCH, B.DS.

DAVID WILLIAM ROBERT WRIGHT, B.D.S

\section{4}

Changes in personnel from 1973 were:

Dental Health:

Tutors (part-time):

LESTER MILTON DUTHY, M.O.5.

EDWARO GORKIC, B. D.5.

ROBERT STEVEN HIRSCH, B D.5.

JOHN ROBERT LYKKE, B D. S

GUY MAURICE NEWCOMBE, B.D.5C, (Otago.). M.S.C. (Lond).

BARAY PAPAELIA, B.D.5,

BRIAN PENHALL, L.D.S., R.C.S. (ENg), F.D.5. IEdin. L

YUEN WAI KEUNG TERENCE, B.D.S. F.A.CD.S.

aral Biology:

Tutors (Part-time):

DALE COURTNEY GERIEE, B D.5

MALCOLM ROSS MCDONALD, B.D.S.

GRANT CLEMENT TOWNSEND, B. D.5. B.5C, Dent.

Oral Pathology and Orat Surgery

Tutors (Port-time):

ROBERT HILLARY BOUCAUT JONES, B, D, S, B, SC.

DONALD KENNETH CHANDLER, B.D.5, F.D. S. R.C. P.S. (Glas.)

Tutors in Generol Medisine and General Surgery (Part-time)

DOUGLAS VICTOR HANDLEY, M. B, B.S.

DAVID RIOHARD HILL, M.B., B.S.

MARR ALEXANDER BERTRAM JOLLEY, M.B., 8.5

SPERO RAPTIS, M.B., B.5.

Restorative Dentistry:

Lecturer:

WYATT RODERICK HUME, Ph.D.

Tutors (Part-tinie):

SVEN OLA TRYGGVE AXELSON, Tandl (Sweden).

ELIZABETH ANN COATES, B.D.S.

RUSSELLLLESUE MILLS, B.D.5.

PETER STRAZDS, B.D.5.

ROBERT NAPIER GEORGE WEIDENHOFER, B.D.S.

1975

Changes in personnel from 1974 were.

Dental Health:

Tutors (Part-time) I:

ROBERT LESLE BICKMORE, B.D.S

SIH ON ANDREW, B.D.S.

PETER JOSEPH WILLIS VERCO, B.D.S

BRIAN CHARIES WHEELER, B.D.S.

Oral Biolofy:

JOSEPHINE MARGARET BERTRAM.

ROGER WILLIAIM EDWARDS, B.D.S 
1975 (cont)

Qral Pathology and Oral 5urgerv:

Senior Teaching Reqistror:

LEWIS HARPER MAYNE, B.SC, B,D.SC. (Q'ld), E.R.A.C.O.5

Tutors (Port-dime):

LAM KUI PO, WILLIAM, M.D.S

Restorative Dentistry:

Lecturers:

MAX WERNER ROHR, PH.D. (Z,Ur)

Tutors (Part-time)

MICHAEL PHILLIP ADAMS, B.D.5

STUART ASHTON BRASTED, B. D, S

IAN CHARLES DANGERFIELLD, B.D.5.

GDOFREY DAVID EVANS, B.D.5

NELSON SAI FONG GOW, B.D.S. (Syd).

MAXIM MANFRED GREBNEFF, B.D.S.

DESMOND ANDREW HAVES, B.DS

DAVID ROBERT HENDERSON, B.D.S

DAVID WINFIELD NOTTAGE, B.Q.5

R.CS:

JOHN WILLIAM PACKER, B DS,

IEFFREY ROSS PARHAM, B.D.S

MALCOLM JOHN SMITH, B.D.S

VALDIS TOMANIS, B.D,5,

ANDREW STEPHEN TROTT, B.D.S.

INTA BAIBA WARNER, B.D.S

THOMAS MAYNARO WILKINSON, B.D.S.

\section{6}

Changes in personnel from 1975 were:

Dental Health:

Lecturer:

WAYNE JOHN SAMPSON, B. Sc.Dent, M.D.S.

Tutors (Part time):

IAMES FREDERICK BALL, B.D.S

JOHN REGINALD GOOOHARDT, M. SC., (Lond), B.D. S.

WORO PURWANINGSIH NEWCOMBE, B,D.S.

COLIN FRANK O'DONNELL, B. D.5

Oral Biology:

Tutors (Fart-time)

MARGARET ISABEL MCKINNON, B,SC,

Restorative Dentistry:

Tutors (Port-time)

JOHIN RUSSELL ABBOTT, B. D.5., B.SC.Dent.

NEIL CLAUDE BEAGLEY, B.D.5.

IAN TEMPLE CLARKE, B.D.5.

MARTIN BRYN DOOLAND, B.D.S

PAUL ERIC GOWARO, B. O.5, (LiV)

CATHERINE JANENKO, B.DS

JOHN ISGAR JARRETT, B.D.5. (5Vd)

GREGORY JOHN JAUNEY, B.D.S.

JOHN ALVIC KIBBLE, B D,S

KOW CHOON CHAN, B.D.S.

LIANG KENG SENG B.D.5.

WIGI LIPPIS, B.D.S

WAYNE JOHN LOWE, B.D.S.

IAN ANDREW MCKENZZE, B.O.S

JOHN DAVID RICHMOND, B D. 5 .

COLIN PETER ROBERTSON, B.D.S., B.SC DENT

BORIS SOAVE, B.D.S.
1977

Changes to personnel from 1976

Dental Health:

Deputy Chairman:

D. E.A. FANNING

Teaching Registrar:

KENNETH HAREFIELD WRIGHT, B.COM, D.D.S. (MCG).

Tutors (Part-time):

PETER TILBURY BURGESS, B.D.S. (SYd), F.M.A.C.0,S., F.D.S. R.C.5. (Edin). GEORGE PETER MANOS, B.D.S

CRAIG PERRY MOFFAT, B.DS.

ANOREW PALL ALEXANDER TOTH, B DS

COUN CHOFT TWELFTREE, M.D. 5

Gral Biology:

Lecturer:

TREVOR EDWIN BRIDGES, B.Phäm, Ph.D (Lond).

Oral Pathology and Oral Surgery.

Professor:

DAVID ERNEST POSWILLO, D.D.5 (NZ) D.SC. (OtagO), F.D.S.

F.R.A.C.S. Fi.Biol, M.R.CPath

Restorative Dentistiv:

JOHN KINGSLEY DENTON, B.D.S

ADRIAN PATRICK GAFFNEY, E.D.S.

RICHARD DUNCAN HANCOCK, B.DS.

ANTHONY DAVID HOBEY, B.D.S.

KONG YEE CHEW ANDREW, B.D.S

PETER CAREY MUGGLETON, B.0.5.

RODNEY BARRINGTON ROACH, B.D.S.

JONATHON PERCY HOWARD ROGERS, 8.D.5.

RICHARD CLARENCE STEPHENS, B.D.S

WILLIAM TENNYSON WEEKES, 8 . D. 5

1978

Changes in personnel from 1977 were:

Dental Health:

Tutors (Part-time):

MICHAEL ROMILLY HARRY, B.D.S, B.SC Dent:

SVEIN BIARNE JOHANSEN, B D.5

ANTHONY IAN KINGSTON, B.D.5

GRAMAM JOHN MOORE, MOTh, (WaSh), B,D,S

Restorative Dentistry:

Lecturer:

JOHN MALCOLM MCINTYRE, B.DSC, (Q'Id), Ph D

Tutors (Port-time):

DYMPHINA JANE CUDMORE, B DS

MALCOLM GEDOES, B.DS.

JACQUES MESOMEMBERG, 8 DS 5

SIMON PAUL NAYLOR, BDS

GEOFFREY STUART ROBSON, B. D.S

MARK FREDERICK WOTZKE, B.D.S.

OLEG ZARUOXI, B.D.S.

\section{9}

Changes in personnet from 1975 were:

Dental Health:

Tutors (Part-time):

VIVIAN BRIAN BURGESS, B.D.S.

JOHN GARTH DEVER, M. D. S. (Otago).

BAYON JOSEPH ROSS KARDACHI, B.DS. 
1979 (cont)

LESUIE KAASSOVICH, B. D.S

4 PETER KU-FONG, B.O.S

Oral Biology:

NICHOLAS MICHAEL BOYO, B.APD.SC.

CHEAYL BOVLE,

MEGAN COOPER

LORETA RUPINSKAS, B. D.5

Oral Pathology and Oral Surgery:

DAVIO FRANCIS WILSON, M.D.s. (Otága)

Restorative Dentistry:

Tutors (Part-time):

ZOLTAN JOSEPH BARONYI, B.D.S

IAN GREGORY BILLS, B.D.5.

CARMINE CAMERLENGO, B.D.S.

DAVID ANTHONY CLARKE, B.DS

LINOSAY ALLEN DYSON, B.D.S.

KEITH CYRIL GRAVE, M D.S. F.R.A.CD.S

DALE FRANCIS HEINRICH, B.D.S.

BRIAN ARTHUR LANGE, B.D.5.

SHIRLEY LIM, B.D. S. (Sing), D.D.P.H. (Tor).

DAVID SINCLAIR MANN, B.D.5.

BASILE MAVROUDIS, B.D.S.

LINDSAY CLEM RICHARDS, B.D.S.

RICHARD JAMES SAWERS, B.D.S.

MICHAEL WATSON SHEARER, B.D.S

BHAJAN SINGH SIDHU, B.D.S. (Sing.)

ROBERT WILLIAM SOUTH, A.U.A., B.D.S.

FRANK JOHN VAN DER UINOEN, B. O.S.

\section{0}

Chànzes in persannel from 1979 were:

Dental Health:

Tutors (Part-time)

GEOFFREY RUSSELL PITOHER, M.SE.(Lond)

MAREK ROHOZINSIO, B.D.5.

Oral Biology?

Visiting Research feliow:

MALCOLM OHARLES HAU, M.SE., Ph.D.

Oral Pathology and Oral surgery:

Lecturer

DAVORLOVORO ANTE HRIEAR, B.D.SC (WA), M.D.S. F.R.A.C.D.S

Tutors (Part-ime):

KENNETH WILLIAM FRVER, B.D.S. (Br(S), F.D.S. R.C.S.

Restoratue Dentistry:

Tutors (Part-sime)

JOHN KEVIN ADAMS, B.D.S. (Syd)

PETER MARK BARTOLD, B.D.S., B.SC.Dent

WILIAM KYROS, B.D.S.

PAUL DAVID MARIN, B.D.S.

JEFFREY DOUGLAS MOUNT, M.SC.(Lond, B, B.D.S

ANGELA MARY PIERCE, B.D.S.

SEOW WAN KIM, B.D.S.

1981

Uniable to find any staff listings in the University calendar for the year 1981 . To compensate for this omission a complete staff listinp is piven for 1982
1982 Complete staff listing

Dean of the Faculty: Professor J.C.THONARD. Assistant Registrar ( Dentistry). Mrs J.A. PIERCE Dental Health

Chairman of the Department:........

Deputy Chairman: Mr R. SIMS

Professor:

Reoder:

MILTON REGINALO SIMS, M.SC.D, 6.D.S., F.R.A.C.D,S

Senior Lecturers:

NIGEL GORDON CLARKE, B, D.S, (Lond) Ph.D, L.D.S. R.CS KENNETH FORRESTER MUIR, B. D.S. F.D.S. R.C.S, (Edin-).

Seniar Lecturer (haif-time):

KEVIN REGINALD ALLEN, B.D.S.

Lecturer

WAVNE JOHN SAMPSON, B.SE Dent, M.D.S.

Lecturer (Haif-time):

WORO SRIKANDI, B. O.S.

Turors:

PETER MARK RARTOLD, B.D.S., B.SC Dent

MARGARET JEAN BEVAN, B.D.S. (MeIb.)

GEOFFREY IVAN BROWN, M.D.S. FR.A.CD.S.

PEIERTILAURY BURGESS, A.D.S. F.R.A.CD.5. F.D.S.R.C.S.

D. Orth R.C.S. (Eng.)

JOHN FRANCIS BURROW, B.D.S.

GUY JOHN BURNETT, B.D.5.

HAROLD TEMPLE CLARKE, B.D.S.

CHENG CHUNG KWONG PETER, M.Q.5.

BRIAN CORRELL CRISP, M.D.S. F.R.A.C.D.S.

CLIVE MICHAEL DURNEY, B.D.S

LESTER MILTON DUTHY, M.D.S. F.R.A.CD.5

MARGARET AUNE EVANS B. D.S. Dip. Ed., B.SC. Dent,

MICHAEL ROMILLY HARRY, B,SC.DENT. M,D,S

ROBERT STEVEN HIRSCH, 8.SCDEn, M.D.S.

JOHN DAVID IENNER, M.D.S.

SVEIN BJARNE JOHANSEN 8 D.5

BRYON JOSEPH ROSS KARDACHI, M D.S

CRAIG PERRY MOFFAT, B OS

GRAHAM JOHN MOORE, M Orth. (Wash), B.D.S.

BASIL WRIGHT PHILLIPS, M.D.SE, B.D.S. F.R.A.CD.

GEOFFREY RUSSELL RITCHER, M SE/Land, B.OS

MAREK ROHOZINSKI, 8.0.5.

BRUCE ALLUSON TIDSWELL, M.S.D. (Wash); B.D.S

VALERIE IEAN TOM PSON, B. O.5.

PETER JOSEPH WILLIS VERCO, B.SC.DENT, B.D.S.

NORMAN JOSEPH VOWLES, B.D.5.

PEUNG CHUNGHON STEPHEN, B.D.S

VUEN WAI KEUNG TERENCE, B.D.S. F.R.A.C.D.S.

Oral Biology

Chalman of the Department Dr A.H. ROGERS.

Deputy Chairman.

Professor:

JOHN CHARLES THONARO, 6.D.SC, Ph. D. (Roch), F.R.C. Path Senior Lecturers:

ANTHONY HOWARD ROGERS, Ph, D., M.SC, M.A.S M

TREVOR EDWIN BRIDGES, B.Pharm, Ph. D, (Lond). 
1982 (cont)

Senior Lecturer (Half-time)

KENNETH AYLESBURY BROWN, B.D.S.

Lecturet:

GRANT CLEMENT TOWNSEND, B. 0.5, , B., SC, Ph.D.

Visiting Research Fellow:

MALCOLM OHARLES HALL, M,Sc, Ph.D. (Melb)

Tutors:

VIVIAN BFIAN BURGESS, B.D.S

TREVOR RALPH ELLOT, B.5C

STEPHANIE MARY HOCKING, BS Sc, Ph.D.

LORETA RUPINSKAS, B.D.S.

MAUREEN GLENYS TREMAINE, B.5C

Oral Pathology and Oral Surgery

Chaimin of the Department:

Depury Chairmart: Mr D.F. WILSON

Professor:

Senior Lecturers:

ALASTAIR NORMAN GOSS, D.D.S, (OtagO,) F.R.A.CO.S, D.O.S.R.A.CDS

DAVID FRANOS WILSON, M. D.S (Otago.)

Senior Lecturer (Half-time):

KEVIN JOHN MURPHY, B.0.5. (OtaCO.), M.8.8.5. (R.C.P,

(Lond), F.D.S. R.CS. F.F. D.R.C.S.I

Tutors:

KENNETH WILUAM FREYER, B.D.S. (Brist.), F.D.5. R.C.S.

JOHN HARVARD LOCKE B.D.S.(SYd. )M.D. B.S (Lond), F.D.S.

R.CS., F.R.AC.D.5.

LAM KOI.PO WILLIAM, M.D.S. F.R.A.C.D.S. D.O.S.R.A.CD.S

KEVIN JOHN MURPHY, B. D.S. (QtaEO.), M. B., 8.5. LRCP (Lond.),

R.D.S.R.C.S. F.F.D.R.C.S.I, M.R.C.S. (EnR.)

Restorative Dentistry

Chaiman of the Department: Professor T. BROWN

Deputy Chairman:Dr D.A.5. PARIKER

Professor:

TASMAN BROWN, D.D.SC, F.R.A.C.D.S

Reader:

OWEN FRANOS MAKINSON, B.D.S, (Syd.), D.D.S. (Northwestern)

F.D.S. R.C.S., D Orth. R.C.S. M.S (Mich.), F.R.A.C.D.S

Senior lecturers:

DAVID ALLAN SCOTI PARIER, M.D.SC. (Melb), Ph.D., F.R.A.C.D.5

ROGER JOSEPH SMALES, M.D.S.(Otago.), F, D.S, R.C.S.

JOHN MALCOLM MCINTYRE, B.D.SC, (Q'ld.), Ph.D.

Lecturel:

LINDSAY CLEM RICHARDS, B.0.5. B.5C Dent.

Lecturers (Half-time):

THOMAS MAYNARD WILKINSON. M.56. (Lond. I, B.D.5

INES PARKER, B.D.S., F.R.A.C.D.5.

GEOFFREY WILTON PAGE, B.D.5.

DIANNE ROSEMARY HUNT, M.D.S

VIVIAN BRIAN BURGESS, B.D.S.

Lecturer/Instructor (Part-time):

GEOFFREY SINCLAIR HEITHEASAY, M.D.5. F.A.C.D., P.D.S. A.C.5.

(Edim.) F.R.A.C.D.S

Tutors:

IOHN KEVIN ADAMS, B. D, 5. I5 V .

NEAL CLAUDE BEAGLEY, B. 0.5.

PETER ROBERT NOBLE BEASLEY, B. D. S, (SYd.)
1982 (cont)

THOMAS LOUI5 BEREIKALLY, B.D.5.

IAN GREGORY BILLS, B.O.S.

JOHN JAMES BLUM, B.D.S.

ROBYN MARGARET BOASE, B.D,5.

JOHN MOSS BOOTH, L.D,S, (Manc.), D, D, S, (Tor)

VIVIAN BRIAN BURGESS, 8.0 .5

DAVID VICTOR BURROW, B.D.S.

CHEUNG NING HOI, D,M.D. Philippines).

DAVID ANTHONY CLARKE, B.D.5.

IAN TEMPLE CLARKE, B.D.S.

ANTHONY JOHN COATES, B.D.S. F.R.A.CD.S

HELEN DIANA COLLLER,B.D.S

JOHN KINGSLEY DENTON, B.D.S

IAN RIDGEWAY DINGIE, B.D.S.

WARWICK GRANT DOOLAND,B.D.S.

ISAIA DOUNARTZIDIS,B.DS.

ADRIAN PATRICK GAFFNEY, B.DSC (MeIb)

JOHN REGINALD GOODHAROT, M.O.SC, B.D.S. F.R.A.C.D.S.

KEITH CYRIL GRAVE, M.DS. F.R.A.C.D.S.

ANDREW PAUL HARMS, B.OS.

DIANNE ROSEMARY HUNT, M. D.S.

DALE FRANCIS HEINRICH B.D.S.

CATHERINE JANENIKO, M.D.S. F.R.A.C.D.S.

JURIS ANSIS KAIMINS, B.D.5.

HUGH DALEY KENNARE, B. D.S.

JOHN ALVIC KIBBLE, B.D.S., B.SC Dent.

KONG YEE CHEW ANOREW, B.D.S.

KOW CHOON CHAN, B.OS.

WILLIAM XYROS, B.D.S

ANTHONY WILOAM LAKE, B.D.S.

BRIAN ARTHUR LANGE, B.D.S. B.SC. Dent.

LIKU-FONG PETER, B.D.S

LIAN KENG SENG, B.D.S,

MALCOLM ROSS MaCDONALD, B.D.S., F.R.A.C. .S.S

IAN ANDREW MACKENZIE, B.D.S

DAVID SINCLAIR MANN, B.D.S

JOHN EOWARD MARRIOTT, B.D.S., F.IC.D.

PATRICK LAWRENCE MARTIN, B.D.S.

TREVOR WALLIS MARTIN, B,D.S., F.I.C.D.

BASILE MAVROUDIS, B. D.S.

JACQUES MESCHEMBERG, B.D.S

RUSSELL LESUE MILLS, B.D.5.

PETER CAREY MUGGLETON, B.D.S.

REUBEN JOHN MYHILL, B, D, 5 .

GEOFFREY WILTON PAGE, B,D.S

JEFFREY ROSS PARHAM, B. D.5.

GORDON JAMES PFIEFFER, 8.0 .5

ANGELA MARY PIERCE, B.D.S.

RALPH JOHN REID, B.D.S: (Q'Td)

JOHN ALEXANOER REINERS, B.D.S, F.H.A.C.D.S.

LINDSAY CLEM RICHARDS, B.D.5., B.5CDEN

RODNEY BARRINGTON ROACH, B.D.S

COUN PETER ROBERTSON. B.D.S., B.SC Dent:

JONATHONPERCY HOWARO ROGERS, B.D.5.

BHAJAN SINGH SIDHU, 8.0.5.(Sine). F.R.A.C.O.S

DAVID RUTHERFORD SMERDON, B.D.S. 
1982 (cont.

BORIS SOAVE, B.D.S.

ROBERT WIUUAM SOUTH, A U.A., B.D.S

FICHARD CLARENCE STEPHENS, B. D.5.

PETER STRAZDS, B.D.5.

KIM MAXWELL THOMAS, B.D.S.

ANDREW STEPHEN TROT, B.DS

ROBERT LOUIS VON DOUSSA, B.D.S.

IAN KENNETH WADDELL SMITH, B, D.5. F.R.A.C.D.5

PETER MORRIS WARNER. M.SC. (Lond.), B.D.S.

ROBERT NAPIER GEORGE WEIDENHOFER ${ }_{t i}$ M.DS.

MARK FREDERICK WOTZKE, B.D.S.

\section{3}

Changes in personnel from 1982 were

Dental Health:

(Mich.).

Tutors (Port-time):

CHRISTOPHER MARK OVERALL, B.D.S.

Oral Patholozy and Oral Surgery:

Senior Teaching Fellow:

5. RAMANANDA PRABHU, M.D.S. (BOIn)

BRUCE WAYNE ROEINSON, M.D.S., B.SC.Dent:

Restorative Dentistry:

PER ANDERS HUGO BLOMBERG, B.0.5.(Q\%)

ROBERT ASHLEY FENTON,B, D, S. (SYd.)

COSIMO MAIOLO, B.0.5.

KIM MAXWELL THOMAS, B, 0,5.

\section{$1984 / 1985$}

From this time onwards, the University Calendar published only personnel holding the tisle of

Lecturer and above. Tutor names were not included but Technical Officer and Clerical Officer names were included. Also, University Calendars were published every two vears. Dental Staff were now listed under the heading of The Faculty of Dentistry.

Changes in title and personnel irom 1983 were: Professor:

HENK TIDEMAN, D.D.S. (Utrecht). M.D. (Nijmegen.),

Ph. D. (Amst)

Technical Officers:

GARY BRISCOE

NEVILLE JAMES GULLY, B,SC

ROONEY JAMES HENOERSON

LORRAINE ELIZABETH MCMAHON

SANDRA KAY POWELL

JAMES ROBERT ROGERS, B.A. B. SC, Dent., Dip Ed

GRAMAM EOWIN SCRIVEN

PETER STEPHEN ZILM, B.SC (FIII)

Clerical Officen:

WENDY SOHWEROT

OHERYL MARGARET POMEROY

BRENOA CECILIA PURDIE

WINIFREO MARY PIERCE

MARIE FLORENCE CUMMINGS

MARGARET JOHNSTONE ARMSTRONG THONARO

5HIRLEY IRENE HASTINGS

\section{$1986 / 1987$}

Changes in personnel from $1934 / 1985$ were:

Assistant Registron

MS5. WALKER

Lecturer:

MICHAEL JOHN STACEY, B.5C, B.DS

Visiting Research Fellow:

SVEN FREDERICK LINDSKOG, D.D.5., Ph. O. (Karolinska ins.) Research Officer:

GEORGE RAYMONO TRAVAN. B.S. G, (Flin.). M.SC (Texas.).

derical officer:

ANGELA HELEN KEANE

\section{$1988 / 1989$}

Changes in personnel from 1986/1987 were: Professor:

ANDREW JOHN SPENCER, M.D.SC, Ph.D.(MElb.), M.P.H

Senior Lecturer.

GRAHAM ALLAN WOOD, B. D.5. (Glas.), M.B., Ch.8. (Dund), F,D.S.R.C.P.S.(Glas).

Lecturers:

CRAIG WILLIAM DREYER, M.D.S. F.R.A.C.D.5.

PETER BARDSLEY HAWKER, B. 0.5.M.SC. (Lond.)

Technical Officers:

NORMAN JOSEPH LEE, JP.

VICTOR MARINO, B.SC. (FIII.).

Administrative Officer:

JENNIFER PENECH

\section{$1990 / 1991$}

Channes in personnel from 1988/1989 were:

Assistant Registror:

MrM.R.KOORNDVK

Research Officer:

FEARNLEY STEFAN PYM SZUSTER, B.A.(Flin.). M.IS

Lecturers:

CHRISTOPHER DAVID ELDRIDGE, B.D.S.

KAYE FRANCES ROBERTS-THOMSON, B.D.S. (MEIb.) L.D.S.

STEPHEN TIMOTHY DUNSTONE, B.SC B.D.S,

KARIN BLUMENTHAL, B.D.5.

INGRID LOUISE WHITE. B.D.S.

SIMON READING MOORE, B.D.S

Visiting Research Fellow:

GRAEME PRETTY, B.A, DIP Ed. (N.S.W.)

Glinical Lecturer:

LORIMER JUDITH PACKER, B.D.5.

Research Olficer:

DAVID ANDERW WEBSTER, $8.5 \mathrm{C}$

Technical Officer:

RAOUL ANGELO PIETROBON,

Adiministrative 5 ervice Officer:

PAMELA ANNE KEILY

Neil Hamilton Fairley Fellow:

LOUISE FRANCES BROWN, M D.SC (Melb). 
$1992 / 1993$

Changes in personnel from 1990/1991 were:

Lecturer:

KARIN ELIX, B.D.5

Visitiog Riesearch Feliow:

Assistont Professor MASATSUGU HASHIMOTO

KAZUTAKA KASAI, D. D.5Ph Di (Nihon)

\section{4/1995}

Dental staff changes to this edition of the Universitv Calendar.

Dnly members of Faculty of Dentistry are listed. The

following list records the members of the Dental School with

full-time and half-time academic positions only.

Please note: no siven names, positions or qualifications are listed in

the University Calendar from this time onward.

Changes in personnel from 1992/1993 were:

Ms 2 Fuss

Professor M.C.R. B. PETERS

D.T. WINNING

MrIXAIDONIS

MTP HEIJKOOP

MT A SMEROON

Mr HIEN NGO

MSI.A.TAYLOR

The lists of staff below have been derived from submissions of the Adelaide Dental School to the Australian Dental Council

\section{$1996 / 1997$}

Department of Dentistry

Head

Mr Vivlan Brian Burgess, M. D.5, F.A.D.1., F.L.C.D., F.A.A.D.M.E.R.

Deputy Head

Assaciate Professor Lindsay Clem Richards, B.D.5., B.5c Dent., Ph.D

Academic staff

Dr Trevor Edwin Bridges, B.Pharm, Ph. D.,(Lond.), M.P.S., C.Eiol, M.1.Biol, M.L.A. Biol.

Mr Anthony John Coates, B.D.S, F.R.A.C.D.S.

Mr Craig William Dreyer, M.D.S, F.R.A.C.D.S

Ms lanet Fuss, 8.0.5y G.SC. Dent. (Hans), Grad.Dip.Clin.Dent, M.SC

Professor Alastair Norman Goss, D,D,S.JOtago), F. R.A.C. D.S, D, O.S.R.A.C. O, S.

Mr Paul Heljkoop, B.D.S, M.D.S., F.R.A.C.D.S

Dr Robert Steven Hirsch, 8. Sč.Dent, M. D.S. Ph. D.

Ms Diane Rosemary Hunt, M.D.S.

Mr Robert Hilary Boucaut Jones, B.SC.Dent, M.D.S, F.R.A.CDS, F.R.A.C.D, S, (O.M. S.)

Dr John Kaidonis, 8. D. S., B.SC.Dent, Ph.D.

Mr Kevin Reading Moore, B.D.5. 
Di David Alan Scott Parker, M. D.Sc.(Melb.), Ph. D., F.R.A.C. 0.5

Ms ines Parker, B.D.5, M. O.5, F.R.A.C.D.S.

Mr Brian Penhall, LD,S.R. C.S.(Eng), F.D.S.R.CS, (Edin.)

Professor Mathilde CR B Peters, D.M.D.(NIjmegen), Ph.D.(N)ijmegen)

Dr Angela Mary Plerce, Ph. D. (Katolinska inst.). M.D.S., F. . A. CD.S.

Mrs Kaye Frances Roberts-Thomson, B, D, S., Me/b.), L.D.S,

Dr Anthony Howard Rogers, Ph.D. (leeds), M.Sc., M.I.Biol, F.A.S.M.

Professar Wayne John Sampson. B.Sc.Dent., M.O.S.

Dr Roger Joseph Smales, M.D.S, D.D.Sc(Otago), F.D.S.R.C.S, (on leave)

Professar Andrew John Spencer, M. D.SC, Ph. D. (Melb), M.P.H.(Mich.)

Ms Jane Amelia Taylor, B.D. S. M.Sc. Dent.

Professor Grant Clement Townsend, B.D.S., B.SCDent, Ph. D, D.D.SC.

Mr John Dlgby Wetherell, B.D.5.

Ms ingrid touise White, 8.0.5.

Mr Thomas Maynard Wilkinsan. M. Sc/(Lond), M.D.S.

Associate Professor Oavid Francis Witson, M.D.S.(Otago)

Dr Tracey Winning, B.D.S.(Hanis), Ph. D.

Honorary Visiting Research Fellow

Emeritus Professor Tasman Brown, M.D. S, D.D.S., F.R.A.C.D.S, FIC. D

Visiting Alesearch Fellow

Mr Paul William Drummand, M.D.S, F.R.A.CD.S.

Mr Mark S A Earl, B.D.S., M.SC. (Lond.), M.A.S.H. F.R.A.C.D.5.

Mr John Reginald Goodheart, M.SC (Lond), B.D.S. F.R.A.C.D.S

Dr Malcoim Charles Hall, M.Sc., Ph.O. (Melb, )

Assistant Professor Masatsugu Hashimoto,

Mr Peter Bardsley Hawker, 8.0.5. M.5c. (Land)

Dr Sven Fredrik Lindskog, D.D.S., Pls.D. (Katolinska inst.)

Dr Graham Jaunay Mount, B.D.S.(Syd), D.D.SC, F.R.A.CD.S., F, C.CD., F.A.DI

Mr Hien Ngo, M.D.S.

Mr Henricus Wilheimus Poort, M. Eng, se (Eind dhoven)

Mr Graeme Pretty, B.A., Dip.Ed.(N.S.W.)

Mr Brian Walker, B.D.S.

Visiting Associate

Mr Brian Nell Walker, B.DS. (N.Z)

Clinical Senior Lecturer

Mr Peter James Telfer, M.D.S

Mr Peter Burgess, M.D.S. 
Clinical Lecturer

Mr Edward Gorkic, Dip. T, B.D.S.

Mr John Alvic Kibble, 8.0.5., 8,5c.Dent,, Grad. Dip.F.E.

Mr Tony Mavrokokkl, B.D.5

Affiliate Lecturer

Ms Maureen Gwenyth soyce, Cert Dent Ther, B.T. (U.5.A.)

Ms Catherine Anne Snelfing, Cert Dent Ther.

Ms Karen Hasenaht, Cert Denc. Ther.

Ms Sharyn Marie Collette, Cert Dent. Ther., B.T.(U.S.A.)

Clinical Associate Fellow

Mr Geoftrey S Heithersay, B.D.S., F.D.S.R.C. . (Edin.), M.D.S., E.R.A.C. D.S. (Inaugural)

Higher Education Officers

Ms Joan Helen Allister, B. A.(Fin.)

Mr Gary Briscoe

Mr Neville James Gullv, B.Sc:(Hons)

Mr Victor Marino, B.Sc. (Filin.)

Mrs Antonietta Silvana Marveggio

Ms Cheryl Margaret Pomeroy, 8.A.

Ms Sandra Kay Powell

Ms Mary Rhodes

Mr James Robert Rogers, B.A., B.Sc. Dent, Dip.Ed.

Mr Graham Edwin Seriven

Mr George Travan, B. sc.,(FIIn.), M.Sc.(Texas)

Mr Peter Stephen Zlim, B.Sc,(Hons)(Filn.)

Australian Institute of Heaith and Welfare Dental Statistics and Research Unit

Director

Professor Andrew John Spencer, M.D.Sc.(Melbourne), M.P.H. (Michigan), Ph.D.(Melbourne)

Research staff

Mr Anthony Bevan, B.D,S, M.SE.

Mr David Simon Erennan, B.A. (Hons)(Flinders), Grad.Dip Comp.inf.Sc. (S.Aust)

Mr Knute Derek Carter, B.SC.(Hons)(Ma.\& Comp.SC.)

Mr Michael John Davies, 8.A. (Hons), M.P.H.

Ms Danae Kent, B.OS

Mrs Anna Puzio, B.D.SC.(Poland), B.D.5.

Mrs Kaye Frances Roberts-Thomson, B,D.SC (Melboutne). L. B S.

Mrs Judy Frances Stewart, B.SC.

Mr Fearnley Stefan Pym Szuster, B.A.(Hons)(Flinders) 


\section{1}

The University of Adelaide

Dental School

Academic 5taff List 2001

Dr PG ARROW

Dr AJW BEVAN

DI VB BURGESS

Di AJ COATES

DI CW OREYER

DR IM FUSS

Prof AN GOSS

Dr RS HIRSCH

Or OR HUNT

Dr r JAMES

DI RHB JONES

Dr J KAIDONIS

DrI KIBQLE

DT O LEKKAS

DRRLOGANA

DR 5 MODRE

DI DAS PARKER

DI OPACKER

DI AM PIERCE

A) PROFLCRICHARDS

Dr KF ROBERTS-THOMSON

A/PRO AH ROGERS.

PROF WI SAMPSON

Prof AU SPENCER

Dr JATAYIOR

Dr PJ SAMBROOK

Dr P REED

DI R SLATER

DrFVASKAS

Visiting Lecturer

Dr P TELFEA

Prof GC TOWNSEND

DrI WETHEPELL

OrIWHITE

DETM WIUKINSON

A/Prof OFWILSON

DIT WINNING

Visiting Research Fellows

Dr M BRAVO

Emeritus Prof T BROWN

Dr TEBRIDGES

DOBDIGI

Dr AP GAFFNEY

Dr SP GRATIAEN

DH LF GREENWOOO

DIP HAWXER

DrJFL LAVIS

DR OF MAKINSON

DI JM MCINTYRE

DI HMIYAMOTO

DIG MOUNT

DIPNAMBIAR

DEHNGO

Dr MASIMS

Prof RU SMALES
DrI TOMO

or stamo

Dr R UENO

DO B WALKER

Or SH ZAREIE-ABARGHOUI

Consuitant

DrKEROWN

Clinical Lecturers

DRTL BERERALLY

DTPBURGESS

DO I CAMERON

DIE COATES

DIME DODORIDGE

DR PR DUKE

DT MEI GRYST

MISS X. HASENOHR

DI G METTHERSAY

Dr A IELASI

D. II ISHIMARU

OT BJA KARDACHI

Dr BWLEE

DIS LUBERALI

DITMAVROICOKKI

DiTMILES

DIMGPOWELL

DIM DALIDJAN 
2008/2009

\begin{tabular}{|c|c|c|c|}
\hline Prof & Johañn & de Vries & Dean, Dental School \\
\hline Prof & Alastair & Goss & Professar (Level E) \\
\hline Prof & Wayrie & Sampson & Professor (Level E) \\
\hline Prof & Lindsav & Richards & Professor \\
\hline Prol & Andrew & Spencer & Professor (Level E) \\
\hline Prof & Peter & Bartold & Professor/Director of Colgate \\
\hline Prof & Grant & Townsend & Proiessor (Level E) \\
\hline Prof & yivan & Burgess & Professor (Level E) \\
\hline APrf & Tracey & Winning & Associate Professor \\
\hline APtf & John & Abbott & Assodate Professor (Level D) \\
\hline APrt & Pecer & Cathro & Associate Professor \\
\hline APIf & Richard & Logan & Associate Professor (Level D) \\
\hline Dr & Diane & Hunt & Senior Lecturer (Level C) \\
\hline Dr & Robert & Hirsch & Senior Lecturer (Level C) \\
\hline Ms & Catherine & Snelling: & Senior Lecturer (Level C) \\
\hline Ms & Sophia & Karanicolas & Senior Lecturer \\
\hline Dr & Richard & Logan & Senior Lecturer Level c. \\
\hline Di & Nevilie & Gully & Senior Lecturer \\
\hline Dr & Janet & Fuss & Senior Lecturer, Level C \\
\hline Dr & Craig & Drever & Senior Lecturer (Level C) \\
\hline or & Paul & Samibrook & Senior Lecturer \\
\hline Dr & Johin & Kaidonis & Senior Lecturer \\
\hline Dr & Phillip & Pireousis & Senior Lecturer \\
\hline Ms & Jennifer & Miller & Coordinator BOW \\
\hline Dr & Anthonin & Coates & Lecturer \\
\hline Dr & Loreta & Rupinskas & Lecturer (Level B) \\
\hline Mrs & Margaret & Steffens & Lecturer \\
\hline Mrs & Suzanne & Gardner & Lecturer (Level 8) \\
\hline Ms & Vicki & Skinner & Lacturer \\
\hline Ms & Katrina & Plastow & Lecturer \\
\hline Dr & Erika & Vinczer & Lecturer (Level B) \\
\hline Miss & Dimitra & Lekkas. & Lecturer Level B \\
\hline Dr & Samuel & Jevaseelan & Student Placement Coordinator \\
\hline Dr & Michael & Maiandris & Lecturer \\
\hline Dr & Suzanna & Mihailidis: & Lecturer \\
\hline Dr & Eleanor & Parker & Lecturer \\
\hline $\mathrm{Mr}$ & Peter & Zilin & Lecturer (Level B) \\
\hline Dr & Elizabeth-Anne & Farmer & Lecturer (Level B) \\
\hline Dr & Ingrid & White & Lecturer (Level B) \\
\hline or & Helen & lames & Lecturer, Level B \\
\hline Dr & Toby & Hughes & Lecturer \\
\hline Mrs & Rosemary & Coopet & Lecturer (Level 8) \\
\hline Ms & Mignon & Watson & Lecturer \\
\hline Ms & Susan & Aldenhoven & Lecturer (Level B) \\
\hline Mrs & Michelle & Bennett & Lecturer \\
\hline
\end{tabular}




\begin{tabular}{|c|c|c|c|}
\hline Dr & Haiping & $\operatorname{Tan}$ & Lecturer \\
\hline Dr & John & Kibble & Associate Lecturer (Level A) \\
\hline Mr & Clinton & Kempster & Associate Lecturer (Level A) \\
\hline Dr & Mohamed & El-kishawi & Associate Lecturer (Level A) \\
\hline Dr & Lyndall & Smythe & Associate Lecturer (Level A) \\
\hline Dr & Sarbin & Ranjitkat & Associate Lecturer (level A) \\
\hline Dr & James Edward & Dudley & Associate Lecturer (Levei A) \\
\hline Dr & Pingztiou & Liu & NHMRC Pdoc Bes off (A) (Cat 2) \\
\hline or & Naohisa & Wada & NHMRC Pdot Res Off (A) (Cat 2) \\
\hline Ms & Kelly & jones & University Res Associate (A) \\
\hline Dr & Kamila & Plutzer & University Res Associate (A) \\
\hline Dr & Diep & $\mathrm{Ha}$ & University Res Assoc (A) \\
\hline Dr & Tracy & MCNamara & NHMRC Pdoc Res'r (B) (Cat 2) \\
\hline Ms & Liana & timni & NHMRC Pdoc Res'r (B) (Cat 2) \\
\hline Ms: & Jane & Harford & NHMRC Pdoc Res' $f$ (B) (Cat 2) \\
\hline Dr & Giang & Do & NHMRC Pdoc Res'r (B) (Cat 2) \\
\hline Dr & Lisa & Jamieson & NHMRC Pdoc Res'r (B) (Cat 2) \\
\hline APr & David & Brennan & University Snt Res Fellow (D) \\
\hline Dr & Kaye & Roberts-Thomson & University Snt Res Fellow (D) \\
\hline Dr & David & Parker & Visiting Research Fellow \\
\hline APtf & John & Patterson & Adjunct Associate Professor \\
\hline APrf & Anthony & Rogers & Visiting Research fellow \\
\hline $\mathrm{Mr}$ & Graham & Scriven & Visiting Research Fellow \\
\hline Dr & Roger & Smales & Visiting Research Fellow \\
\hline APrt & Geoffrey & Heithersay & Dinical Professor \\
\hline $\mathrm{Mr}$ & Thomas & Wilkinsan & Clinical Senior Lecturer \\
\hline Dr & John & Mantyre & Visiting Research Fellow \\
\hline Dr & Kenneth & Brown & visiting Research Fellow \\
\hline ar & Paul & Duke & Cinical Senier Lecturer \\
\hline Dr & Brven & Kardachi & Cinical Senior Lecturer \\
\hline $\mathrm{Mr}$ & Thomas & Berekally & Cinical Senior Lecturer \\
\hline Mr & David & Miles & Cinical Lecturer \\
\hline Dr & Soichiro & Tomo & Visiting Research Fellow \\
\hline Dr & Tony & Mavrokokki & Clinical Lecturet \\
\hline Dr & Ikuko & Tomo & Visiting Research Fellow \\
\hline Dr & Ryuji & Ueno & Visiting Research Fellow \\
\hline Mr & Maxwell & Meaney & Visiting Research Fellow \\
\hline Dr & Mark & Gryst & Cinical Lecturet \\
\hline Dr & Robert & Shea & Clinical Lecturer \\
\hline Ms & Cathy & Lagnado & Affiliate Lecturer. \\
\hline Mr & Christos & Pazios & Clinical Tutor \\
\hline Mr & Troy & Longbottom & Cinical Lecturer \\
\hline Dr & Juntechi & ishimaru & Clinical Senior Lecturer \\
\hline Dr & Sumant & Gue & dinical Senior Lecturer \\
\hline Dr & Samuel & Jevaseelan & Clinical Lecturet \\
\hline Dr & James & Dudier & Clinical Lecturer \\
\hline $\mathrm{Dr}$ & John & Cameton & Clinical Lecturet \\
\hline or & David & Chu & clinical Lecturer \\
\hline
\end{tabular}




\begin{tabular}{|c|c|c|c|}
\hline Dr & Dinah & Fitzgerald & Cinical Lecturer \\
\hline Mr & Errot & Kilov & Clinical Lecturer \\
\hline Dr & Tim & Allen & Cinical Lecturer \\
\hline Dr & Karen & Barton & Clinical Lecturer \\
\hline Dr & Jane & Boroky & Clinical Lecturer \\
\hline Dr & Matthew & Clougher & Clinical tecturer \\
\hline Dr & Vicki & Drivas & Clinical Lecturet \\
\hline or & Alexaridre & du Bois & clinical Lecturer \\
\hline Dr & Stephen & Eart & Clinical Lecturer \\
\hline Dr & Guy & Freeman & Clinical Lecturer \\
\hline Dr & John & Gericke & Clinical Lecturer \\
\hline Dr & Henry & Gilkes & Clinical Lecturer \\
\hline Dr & Sarah & Howells & Clinical Lecturet \\
\hline Dr & Steve & Mason & Clinical tecturer \\
\hline Dr & Greg & Miler & Clinical tecturer \\
\hline Dr & Jonathan & Hogers & Clinical Lecturer \\
\hline Dr & Robert & South & Clinical Lecturer \\
\hline Dr & Michelle & Stone & Clinical Leaturet \\
\hline Dr & Marcus & Barton & Clinical Associate Lecturer \\
\hline Ms & Sandră & Pinkerton & Visiting Research fellow \\
\hline Mr & James & Ropers & Visiting Research Fellow \\
\hline Dr & Angela & Pierce & Honorary Visiting Res Fellow \\
\hline Mr & David & Mann & Cinical Lecturer \\
\hline Dr & Graham & Mount & Visiting Research Fellow \\
\hline Dr & Edward & Gorkic & Dinical Lecturet \\
\hline Dr & Jane & Taylor & Clinical Semior Lecturer \\
\hline Dr & Miles & Doddridge & Clinical Senior Lecturer \\
\hline Dr & Sharon & Liberali & Clinical fecturet \\
\hline $\mathrm{Mr}$ & Bingkui & Ma & Visiting Research Fellow \\
\hline Mr & Brett & Thompson & Affiliate Lecturef \\
\hline Dr & Colin & Twelitree & Clinical Lecturer \\
\hline or & Susan & Dooland & Cinical Lecturer \\
\hline Dr & lan: & Dangerfield & Clinical Lecturer \\
\hline Dr & Lee & 5wee & Cinical Lecturet \\
\hline Dr & Norman & Vowles & Visiting Research Fellow \\
\hline Di & David & Netherway & Affiliate Senior Lecturer \\
\hline Dr & John & Barker & Visiting Research Feflow \\
\hline Dr & Robert & Hutton & Clinical Lecturer \\
\hline APrf & Richard & Widmer & Clinical Associate Professor \\
\hline Dr & Simrit & Malhi & Clinical Lecturer \\
\hline APrf & Angus & Cameron & Clinical Associate Professor \\
\hline Dr & Patriciá & Fairbairn & Clinical Tutor \\
\hline Prof & LIU & Qi & Visiting Professor \\
\hline Dr & Vinicio & Piscino & Clinical Lecturet \\
\hline $\mathrm{Mr}$ & Peter & Anderson & Clinical Senior Lecturer \\
\hline Dr & Anthonv & Lake & Clinical Lecturet \\
\hline $\mathrm{Dr}$ & Brian & Wheeler & Clinical Lecturet \\
\hline Ms & Jane & Rossi & clinical lecturer \\
\hline
\end{tabular}




\begin{tabular}{|c|c|c|c|}
\hline Dr & Dymphna & Cudmore & Cinical Lecturer \\
\hline Dr & Heidi & Barlow & Clinicaltecturer \\
\hline Ms & Janet & McKinnie & Cinical Lecturer \\
\hline Dr & Mark & Penrose & Cinical tecturer \\
\hline Dr & lan: & Ferguson & Adjunct Senior Lecturer \\
\hline Dr & Christopher & Redwood & Clinical tecturer \\
\hline Dr & Thamas & Higgins & Dinical Senior Lecturer \\
\hline Dr & Adrian & Birkett & dinical Senior Lecturer \\
\hline Dr & David & Butler & Clinical Lecturet \\
\hline Dr & Richard & Annis & Clinical Lecturer \\
\hline Dr & Janice & March & Clinical Lecturer \\
\hline Dr & Patrick & Collette & Clinical Senior Lecturer \\
\hline Dr & Jeffrey & Young & Clinical Senior Lecturer \\
\hline Dr & Peter & Burpess & Clinical Senior Lecturer \\
\hline Prof & Tasman & Brown & Emeritus Professor \\
\hline Mrs & Vivien & Joseph & Counsellor/Staff Dev OIf \\
\hline Mrs & Judith & Stewart: & Research Officer \\
\hline Mr & Victor & Marino & Senior Research Olficer \\
\hline Ms & Navarat & 5achavarssrisakul & Business Manager \\
\hline Ms & Lisa & Smith & Student Manager \\
\hline Ms & Michelle & Bockmann & Research Officer/Lab Manage I \\
\hline Mr & Krzysztof & Mrozik & Research Officer \\
\hline Ms & Dana & Teusner & Research Officer \\
\hline Mr & Adam & Townsend & Computing Officer \\
\hline Ms & Anne & Ellershaw & Research Officet \\
\hline Ms & Sandra & Hughes & Technical officer \\
\hline Ms & Heather & Lewis & Adovinistrative Assistant \\
\hline Mrs & Jane & Burns & Senior Dental Assistant \\
\hline Ms & Julie & Rossi & Dental Assistant \\
\hline Ms & Danae & Baker & Program Manager \\
\hline Ms & Catherine & Offler & Director's Assistant \\
\hline Mrs & Karen & killer & Personal Assistant: \\
\hline Mrs & Lorna & Lucas & Publications Officer \\
\hline Mrs & Leonie & Jeffery & Higher Education Officer LvIA \\
\hline Mrs & Antonietta & Marvepgio & Personal Assistant \\
\hline Mrs & Dragica & Rapaic & Graduate School Administrator \\
\hline Mrs & Lucia & Hatch & Administrative Assistant: \\
\hline Mrs & Lorraine & MeMahon & Administration Officer \\
\hline Mrs & Deborah & Hanney & Dental Assistant \\
\hline Mrs & Valentina & Pejakovic-Knezevic & Dental Assistant. \\
\hline Mr & David & Harley & Administrative Asst/Reception \\
\hline Mrs & Janet & Haat & Dental Assistant \\
\hline Ms & Alison & Mctean & Adninistrative Asst/Reception \\
\hline Mrs & Thanh & Nguven & Admin Assistant \\
\hline Ms & Ngoc & Nguyen & Receptionist \\
\hline Ms & Narmà & Russa & Administrative Assistant \\
\hline Miss & Gemma & Stanger & Administrative Assistant \\
\hline Ms & Léenáa & Neeskens & Schiool Manaper \\
\hline
\end{tabular}




$\begin{array}{llll}\text { Ms } & \text { Karen } & \text { Squires } & \text { Administrative Officer } \\ \text { Ms } & \text { Gillian } & \text { Kemeny } & \text { Administrative Assistant } \\ \text { Ms } & \text { Ruthie } & \text { Ostah-Jenner } & \text { Finance/HR Officer }\end{array}$

2016

\section{Name}

Aldenhoven, Susan Mary

Anastassiadis, Poppy Marcella

Armfield, Jason

Bartold, Peter Mark

Brennan, David Simon

Cheung, Wendy Wai-5au

Coates, Anthony John

Do, Glang Loc

Dopramaci, Esma

Drever, Craig William

Dudley, lames Edward

Farmer, Elizabeth-Anne Loulse

Fung, Lesley

Gardner, Suzanne Patricia

Goss, Alastair

Grave, Benjamin Gerard

Guliy, Neville James

Harfard, Jane Elizabeth

Heithersay, Geoffrey

Hughes, Toby Estcaurt.

Ibrahim, Amal Mamdouh Baker Rizk

Jàroieson, Lisa

Kaidonis, John Anstidis

Karanicolas, Sophia

Kaur, Sashil

Kempster, Cinton

Lekkas, Dimitra

Lerche, Derek Cart

Logan, Richard Martin

Luzzi, Liana

Minalidis, Suzanna

My Anh Vu Thanh

Parker, Eleanor Jane

Peres, Karen

Plastow, Katrina Louise

Ranjitkar, Sarbin

Richards, Lindsay Clem

Rossi-Fedele, Giampiero

Rupinskas, Loreta

5imbrook, Paul John
Position

Lecturer

Lecturer

Snr Research Fellow

Professor \& Dir, Colpate

Professorial Res fellow

Lecturer

Lecturer

Snr Research Fellow

Lecturer

Professor of Orthodontics

Associate Prof

Senior Lecturer

Senior Lecturer

Lecturer

Professor of OMFS

Senior Lecturer

Associate Prof

Senior Lecturer

Clinical Professor

Associate Ptof

Lecturer

NHMRC Research Res

Associate Professor

Senior Lecturer

Senior Lecturer

Lecturer

Senior Lecturer

Lecturer

Professor.

Sni Post Dóc Researcher

Lecturer

Senior Lecturer

Senior Lecturer

Associate Professor

Lecturer

Senior Lecturer

Desn \& Head of Scriol

Assodate Professor

Lecturer

Senior Lecturer

\begin{tabular}{|c|c|}
\hline Level & FTE \\
\hline Level B & 0.8 \\
\hline Level 8 & 0.5 \\
\hline Leveld & 1 \\
\hline Levele E & 1 \\
\hline Level E & 1 \\
\hline Level B & 0.7 \\
\hline Level B & 0.4 \\
\hline Level D & 1 \\
\hline Level 8 & 1 \\
\hline Level D & 1 \\
\hline Level D & 1 \\
\hline Levelc & 1 \\
\hline Levelc & 0.5 \\
\hline Level B & 0.7 \\
\hline Levei E & 1 \\
\hline Levelc & 0.5 \\
\hline Levei o & 1 \\
\hline Levelc & 1 \\
\hline Level E & 1 \\
\hline Levelo & 1 \\
\hline Level B & 0.4 \\
\hline Levelo & 1 \\
\hline tevei o & 1 \\
\hline Levelc & 1 \\
\hline Leveic & 1 \\
\hline Level 8 & 0.8 \\
\hline Leveic & 06 \\
\hline Level B & 0.4 \\
\hline Level E & 1 \\
\hline Levelc & 1 \\
\hline Level 8 & 0.5 \\
\hline Levelc & 0.6 \\
\hline Levelc & 0.6 \\
\hline Level D & 1.0 \\
\hline Level 8 & 0.8 \\
\hline Leveil c & 0.6 \\
\hline Level E & 1 \\
\hline Level o & 1 \\
\hline Level 8 & 0.6 \\
\hline Leveic & 0.6 \\
\hline
\end{tabular}




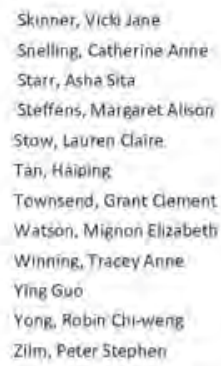

Senior Lecturer
Senior Lecturer
Lecturer
Lecturer
Lecturer
Seniar Lecturer
Professor of Dental Science
Lecturer
Associate Professor
Lecturer
Lecturer
Senior Lecturer

Senior Lecturer

Research Fellow

Research Associate

Research Associate

Research Assistant

PhD Candidate

PhD Candidate

Research Associate

PhD Student

Professor

PhD Candidate

Researchi Scholar

$\begin{array}{ll}\text { Leveic } & 0,7 \\ \text { Level C } & 1 \\ \text { Level B } & 0,4 \\ \text { Level 8 } & 0.7 \\ \text { Level 8 } & 1 \\ \text { Level C } & 0.75 \\ \text { Level E } & 1 \\ \text { Level B } & 1 \\ \text { Level D } & 1 \\ \text { Level B } & 0.4 \\ \text { Level 8 } & 0,5 \\ \text { Level C } & 1\end{array}$




\section{Appendix 2: $\mathrm{BDS}$ and $\mathrm{BOH}$ graduates}

Bachelor of Dental Surgery (BDS) graduates (1921-2016)

This is the first attempt to provide a consolidated list of all BDS graduates from the University of Adelaide from 1921 until the present. A variety of sources have been used, including the list of graduates from 1921 to 1986 provided by Mervyn Wyke Evans (1988) in The History of the Dental Students' Society of the University of Adelaide, 1919-1979, published by the author, Calendars and Commemoration Ceremony booklets from the University of Adelaide, Probe magazines, class lists from the Adelaide Dental School, lists of registered dental practitioners provided by the Australian Health Practitioners Registration Authority (AHPRA), and personal recollections of individuals.

This new list provides readers with an opportunity to look at trends over the years, for example, in total numbers of graduates per year, numbers of males and females, and ethnicity of graduates. It also will enable graduates to reminisce about their time in the Adelaide Dental School with their classmates.

We have decided to list cohorts of students under the year in which they completed the final year of their BDS degrees, as this tends to be the year that most graduates identify as 'their year' - for example, 'The class of 1950'.

The timing of the award of BDS degrees at graduation or commemoration ceremonies has varied over the years. Initially, with very small final-year classes, degrees were awarded usually in December of the same year as students successfully completed final year. Later in the 1960s and 1970s, the graduation ceremonies were held in May of the year following completion of the BDS course, with another ceremony often held in September, and sometimes further small ceremonies. More recently, the Commemoration ceremonies were moved back to December of the same year as completion of the BDS course, in order to enable international students to receive their certificates before returning to their own countries. Given the difficulties caused for academic and administrative staff in completing marking of exams and preparing and checking all documentation in a very short time frame, in recent years the main Commemoration Ceremony has been moved back to May of the following year. 
There are now also graduation ceremonies held overseas for international students, for example, in Malaysia and Singapore.

Every effort has been made to include all graduates and to ensure that names have been spelt correctly. However, errors and inconsistencies were found in many previous lists, so it is inevitable despite our efforts that there will be some errors in the list we have compiled. Where students have been required to repeat the entire final year, we have included them in the cohort of students for their repeating year. However, where students have been required to complete a further three or six months of the final year, we have tried to keep their names with their original cohort.

Should any errors or inconsistencies be found, including names being omitted or spelt incorrectly, the authors apologise sincerely. Please notify us of any errors and we will record them and make the necessary corrections in any subsequent editions.

1921

Thomas Draper CAMPBELL Hurtle Thomas Jack EDWARDS John Leonard EUSTACE Arthur Pariss Reading MOORE John Andrew O'DONNELL Robert James Brazil SMITH 1922

John Francis CLARKE

1923

Harold Robert COOMBE

Rowland Francis GEORGE

James Michael MALLAN

Max Ernest Hannaford

SCHAFER

1924

Alec Douglas COCKS

Cecil Boase MADDERN

Leslie Carrington MAIDEN

Wesley Melvyn Tiller

MARSHMAN

John William Elliott

MONFRIES

1925

Sydney Gordon COCKS Cyril GROSVENOR
1926

John Cumming BURNS

Roy Gilmore ELLIS

Malcolm Stewart JOYNER

Charles Leslie PHILLIPS

Linda Lovibond THOMSON

1927

Jack Vivian

CHRISTOPHERSON

Adalbert James GEORGE

Morven McEACHERN

Winifred Edna PREEDY

1928

Ernest Stirling CHAPMAN

Walter Alfred Wyke EVANS

Charles Rex FORDER

Harry Max WILSON

1929

Chester Arnold BURNS

Mervyn Wyke EVANS

Robert Herbert George

TAYLOR

1930

Thomas Dennis HANNON

Walter Raymond PHILLIPS
Herbert Frederick SUDHOLZ

Sydney William THOMSON

1931

No graduates as 4-year BDS course extended to 5 years in 1928.

1932

William George DELMONT

Gerald FITZGERALD

Gwenyth Elizabeth HANNON

(LEWIS)

Janie Christobel PELLEW

James SCOLLIN

1933

Graham Arthur FRAYNE

Lorenz Wilfred JUNGFER

Kevin Joseph LEWIS

Mina PACKER

Ernest Phillips TIDEMANN

1934

Harold Vernon CLARKE

Anne Catherine FUNDER

Desmond Montague W SANDS

1935

(No graduates listed) 
1936

Ross George JOHNSON

1937

(No graduates listed)

1938

Cedric Norman CLAPP

Arnold Broughton ECKERSLEY

Frederick Christopher FRASER

Robert Douglas HUGHES

Colin George KING

Roger George WILLOUGHBY

1939

Murray James BARRETT

Allan John BLOOMFIELD

Thomas Bruce LINDSAY

Arthur Keith TROTT

Dudley William TROTT

1940

Edward Sampson BURRELL

Harold Bruce FRAYNE

Geoffrey Wilton PAGE

Ronald Frank PORTER

Philip Herbert REILLY

Kenneth James ROBERTSON

Richard Adrian W SNOW

1941

Robert Stewart BLACKBURN

Herbert Edward COCK

John Francis MORAN

Alexander Philip PLUMMER

John Robert THOMPSON

Frederick Lionel TROTTER

1942

Regina URBAN

Barbara Joan WAGNER

1943

Lester Robert BOYLE

Ian Mackinnon DISHER
Reginald Frank

HARRINGTON

Colin Hamilton LEWIS

Ronald Wayland TIVER

1944

John Brice DAY

Naomi June EDWARDS

Maxwell Wright STAIN

1945

Brian Correll CRISP

Max Thorley FRAYNE

John Frederic LAVIS

Clement James TYMONS

John Gabriel WATERSON

1946

Geoffrey Ivan BROWN

Glen Donald DUNSTONE

Kenneth Frederick FILMER

Ivan Stanley McGRATH

John Rutherford SMERDON

Bartley James VANSTONE

Franklinna Sisley

WESTERMAN

1947

Malcolm Bruce BILLS

John Brian LEACH

1948

Glenn MILLHOUSE

Eric Desmond MORGAN

Reuben John MYHILL

RaIph David OCKENDEN

John Alfred Partington

STEVENS

1949

Peter Glynn DELLOW

Carl William HEYNE

Bruce NAPIER

Gordon James PFEIFFER

David James VINCENT
1950

Kenneth Aylesbury BROWN

Tasman BROWN

Trevor Murray CLEMENTS

Robert John COOMBE

Lachlan Lewis DAENKE

Ian Henderson DUNSTAN

Ian Harold HODGSON

Vivian George HOOD

Hugh Daley KENNARE

Blair Hingston LAKE

Raymond Basil LEACH

Trevor Wallis MARTIN

Andrew Mackinnon

MUIRHEAD

Herbert Ahern NICHOLAS

Basil Wright PHILLIPS

Donald Edward PYNOR

John Alexander REINERS

Ian Douglas RONALD

Milton Reginald SIMS

Lawrence Maxwell SMART

Robert Anthony STANTON

Leonard Arthur THOMPSON

John Richard TROTT

Paul Frederick VAWSER

Francis Richard WHITE

\section{1}

Ralph Edward ANNELLS

Keith William BAILEY

John Francis BURROW

Arthur Francis DAVY

Graham John DAY

Bruce Henderson DUNSTAN

Colin Dominic EBLEN

Geoffrey Gordon Llewellyn

EVANS

Brian Leitch HUSSEY

John Francis IRWIN

Colin Barry KOCH

Murray Lyall KRANZ

Rex John LIPMAN

Bruce Alexander McDONALD

John Desmond McKINNON

Cecil Pomeroy MADDERN 
John Edward MARRIOTT

Kevin Reading MOORE

Robert Ian NAIRN

Patrick Damian O'LEARY

Graham Steven PATER

Ian Frederick ROGERS

John Coffey SAMPSON

Richard Henry SANDOW

David Rutherford SMERDON

Ronald Robert SOUTH

Richard Clarence STEPHENS

Robert Seymour TANKO

Rex Horton WALLMAN

\section{2}

Kevin Reginald ALLEN

Harold Lance AUSTIN

Peter Noel CHAPMAN

John Tothill CHILDS

Bruce Gordon COCKS

Peter John O'CALLAGHAN

Peter Clarence READE

Elfrida SAULITE

Christopher Malcolm

SOMERVILLE

Norman Stuart WALMSLEY

1953

Thomas Bruce BERRY

David Michael FOX

Lewis Clive HARMAN

Rowland James KIDD

Richard John KIMBER

Jaroslaw KRYVOVIASA

Peter de Paul McDONALD

Malcolm Joseph MUNDAY

Garth Derwood PETTIT

Bruce Goodman WARK

1954

Vera ALEKSANDRAVICIUS

Malcolm James Layton BEAN

Dagmara Eleonora KRUMINS

Peter Anthony LEANEY

Patrick Lawrence MARTIN

Donald Newbery WILLIAMS
1955

Richard Voules

BARTHOLOMAEUS

Austin Joseph BAZELEY

John BLUM

William Harley BRINDAL

Richard John BURGESS

Geoffrey David CLARKE

Lindsay Talbot COLQUHOUN

Ethel Firl FAIRWEATHER

William Frederick HOLLIS

Robert John KLAEBE

Sea Yoong KWONG

Colin Albert REUTER

Bimal Chandra ROY

Dene Martindale SMITH

Bruce Allison TIDSWELL

Ilmar TOHVER

1956

Dean ANDARY

Kustas ARULA

George McClelland

CAMPBELL

Regina FREIDENFELDS

Richard John GLUYAS

Andrejs GRAVA

Keith Cyril GRAVE

Keith Walter GROTE

Geoffrey Sinclair HEITHERSAY

John Lewis KAUFMAN

Colin Ralph KETTERIDGE

Kwoh Poh LEE

Brian Heylen SOUTER

Donald Stuart WORLEY

1957

Peter Ronald APPLEBEE

Soo Bin $\mathrm{CHOO}$

Ian Ridgeway DINGLE

Dougal FRASER

Ian Donald McINNES

Beresford John Rodger

THOMSON

Bruce William THOMSON

Norman Joseph VOWLES
1958

Geoffrey Charles HALL

Stuart Barry SYMONS

1959

Brenton Graham BURFIELD

Barrington Horace KIDD

Judith Lorimer KAY (PACKER)

Stase PACEVICIUS

Bevan William REYNOLDS

1960

Robert Vincent BLANDEN

Maija FREIDENFELDS

Inga KEDA

Anthony Ian KINGSTON

Thomas Egon KRASSAY

Tack Ming LIEW

Roderick Stuart MILLER

Paul PFITZNER

Andrew Derek ROBERTSON

Maija Alma STIPNIEKS

Shing-Gaye Andrew YIP

1961

Gordon Neil BILNEY

Chung Kwong Peter CHENG

Hok Hoi CHEUNG

Huk Wing CHOW

Alan Gordon HANNAM

Nevena MARINOV

Irene Anna MINKIEWICZ

Karl John Matthew SKOPAL

Kwok Kuen Willie WAN

Paul Rigby STEWART

Hon Yin Stephen WEI

1962

Mai Fai CHAN

Pauline Mary HANNON

James Ian LUKE

Malcolm Ross MACDONALD

Rodney Barrington ROACH

David John RUGLESS

Lin You YONG 
1963

Solmi Binti ABDULLAH

Gabor ARATO

Shun Chi CHAN

Kai Kin CHAU

Theo GOTJAMANOS

Ian Andrew MACKENZIE

Hin Yueng Patrick POON

Mong Yue Thomas POON

Robert Louis Von DOUSSA

Michael William

WAINWRIGHT

1964

Ronald Teasdale BOWERING

Vincent John BRAZIER

Lester Milton DUTHY

Keith Lewis Jarrett ELPHICK

Sven KUUSK

Nai Wing Owen KWONG

Brian Nathan LUKE

Ines LIEPINS

Grahame John MOORE

Ivars Valdis OZOLS

Ross Steven REID

David Murray RODER

Ian Arthur STEAD

Ching Kwong Kenneth TUNG

Peter Morris WARNER

Robert Napier George

WEIDENHOFER

Jeffrey John WRIGHT

See Yu Eric YIU

1965

Anthony IELASI

Kwok-Wai Wilson KWONG

Shiu-Shiek Albert LU

James Percy LUND

Margaret Rose MILLER

Graham Sydney PARRY

Paul Russell PAXON

Gregory John ROHAN

Robert Frank Edison WELSH

Sing-Mo Samuel YIU
1966

John Hugh BARKER

Ian William BAYNE

Peter Matthew CADDY

Bee Lee CH'NG

Howard John CLAPSON

John Donovan DARWENT

Brenton James FELSTEAD

Jeffrey Robert HOOPER

Choon Fah Gabriel LIAU

Rain PAPLI

Michael Lawrence ROBERTS

Robert Thomas STOREN

Robert Edwin THOMAS

Colin Croft TWELFTREE

Angelo Ralph VARTULI

Trevor Barrie WILLIAMS

David William Robert

WRIGHT

1967

James Frederick BALL

David Caryl BLAIKIE

John Olliver BROOK

Geoffrey Keith BROWN

Donald Kenneth CHANDLER

Harold Temple CLARKE

Scott Raymond DAVIES

Clive Michael DURNEY

Richard John EDWARDS

Maxim Manfred GREBNEFF

Brian Kingsley HANNATH

Ivanka Marie HLADKY

Rudolf Georg IVKOVIC

Vladimir JANENKO

Sven Bjarne JOHANSEN

James Michael McNAMARA

Rodney Lewis MOORE

Algis Vladas PETRENAS

Michael PORRA

Robert William WENZEL

\section{8}

Douglas Thomas CASTLE

Fah Son CHOONG
Ian Charles DANGERFIELD

Paul Raymond DUKE

Godfrey David EVANS

Margaret Aline EVANS

Mary Cecilia GIBBERD

(HORSNELL)

William Henry HOLMES

Wyatt Roderick HUME

Neil HUNTER

Byron Joseph Ross KARDACHI

John Franklin KEARNEY

William KYROS

Patrick George LUND

John Joseph McAULIFFE

Colin Peter McROSTIE

Emilian Peter MAKOWIJCZUC

Christopher David

MANSFIELD

Timothy Stuart MILES

Russell Leslie MILLS

Geoffrey Ronald

MUGGLETON

Peter Carey MUGGLETON

David Winfield NOTTAGE

Waro Purwaningsih SRIKANDI

Peter STRAZDS

Bruce Ian WATSON

Graham Maurice WEBSTER

Bill WESTERMAN

John Digby WETHERELL

Richard Leighton WHITE

Thomas Maynard WILKINSON

James Allen WISSELL

Chung Hon Stephen YEUNG

1969

Roland Anthony ADAMS

Neil Claude BEAGLEY

Neil Joseph BLAKELEY

Valentine John BONDAR

Stuart Ashton BRASTED

James Leeson BURKE

David Victor BURROW

Guiseppe CERAVOLO

John Wallace CLEGG

Anthony John COATES 
Andrew Samuel COTTELL

Donald Richard GILCHRIST

Fraser George GURLING

Trevor John HARRINGTON

Anthony Charles JACKSON

Rudy Victor JANSEN

John David JENNER

Leslie Steven KOCSIS

Anthony William LAKE

William Kui Po LAM

Ying Ching LEE

Jean LEWANDOWSKI

Ian Alexander LIDDELL

Luigi LIPPIS

Anthony McINERNEY

Michael Damien McINERNEY

Alex Rimas MORKUNAS

Bruce Derek NOBLE

Peter Ronald NOBLET

Colin Frank O'DONNELL

Jeffrey Ross PARHAM

John Martin PICKUP

Miodrag POPOVICH

Peter Edward REED

Geoffrey Stuart ROBSON

Geoffrey Maxwell ROSS

Paul Renato RUBINICH

Inta Baiba RUDAJS

Anthony McKinnon

SEDSMAN

Colin Lindsay SIEGERT

Gytis Jonas Peter SIMKUS

Bruce Richard SIMMONS

Ian McInnes SMYLIE

Elizabeth Rosemarie

SOKOLOWSKI

Peter John TELFER

Lincoln Newton TIVER

Valdis TOMANIS

Valerie Jean TOMPSON

Frank John Van der LINDEN

Alfred George VASKAS

Susan Jean WATT

Brian Charles WHEELER

Andrew George WORON

Wai Keung Terence YUEN
1970

Elizabeth Ann COATES

(WOODS)

Susan Jennifer DOOLAND

Warwick Grant DOOLAND

Felix William FRAYNE

John Reginald GOODHART

Roger William HIGGINS

Diana Rosemary HUNT

(COOPER)

Robert Hillary Boucaut JONES

John Alvic KIBBLE

John Alexander Hugh KIMBER

Paul Brenton LAWRENCE

William Neil McCONNELL

David MILES

John Graham PANNELL

Christopher John REDWOOD

Brian Charles SHEPHARD

Boris SOAVE

William Peter George SYLOW

Andrew Steven TROTT

Robert William WEAVER

Oleg ZARUCKI

1971

Leon ANAF

Donald Keith BARTRAM

Igor CERNAVIN

Ian Temple CLARKE

Paul William DRUMMOND

Julie May FAIRBANK

Edward GORKIC

John Gregory Bruce HARRIS

Desmond Andrew HAYES

David Robert HENDERSON

Choon Kiat LIM

Roman Ewhen LOHYN

Jon Reading MOORE

Graham Bruce PASCOE

David Anthony POTTER

Colin Peter ROBERTSON

David Malcolm ROWE

Wayne John SAMPSON

Margaret Lynn SIMMONS

Malcolm John SMITH
Derick THOMAS

Anthony Ronald

WEIDENBACH

Ian Bannister WILLIAMS

1972

Robert Leslie BICKMORE

Jeffrey Lyall BRIGDEN

Inta Baiba CABULIS

Patrick Roy CALLAGHAN

Stephen CARAPETIS

Jimmy CHOIMES

Hoo-Seng CHONG

David Anthony CLARKE

James Michael DUNDON

Stephen Timothy DUNSTONE

Roger William EDWARDS

Isabella FADEJEVS

(EDWARDS)

Meredith Maurice FANTHAM

Vaike FRANDL

Karen Norma GLOVER

Willem Hendrik HALM

Richard Duncan HANCOCK

Laurence James HENBEST

Robert Steven HIRSCH

Brian Ka Ki HOO

Peter Alan Eric HUTTON

Gregory John JAUNAY

Mark William KNAPP

$\mathrm{Ku}$-Fong Peter LI

Keng Seng Kim LIAN

Keith Robert LINDSAY

John Robert LYKKE

George Peter MANOS

Peter James OLIVER

John William PACKER

Barry PAPAELIA

John David RICHMOND

Dennis Mowat ROWAN

Anthony Harold SANDER

Richard James SAWERS

On Andrew SI

Christopher John STEVENS

Hong Pin TAN

Grant Clement TOWNSEND

Peter Joseph Willis VERCO 
1973

Michael Phillip ADAMS

Ruth Helene BURNS

Cherie Rosemary CALDICOTT

Giuseppi CARETTI

John Mario Richard Leonard

CASTLE

Damir CULIC

Raymond John DANTON

John Kingsley DENTON

John DIVAK

Thomas Charlton John

DONOVAN

Martin Bryn DOOLAND

Craig William DREYER

Keong GAN

Dale Courtney GERKE

Michael Romilly HARRY

Phillip Francis HOWES

Catherine JANENKO

Geoffrey Charles KIRKMAN

Nicola LIPPIS

Wayne John LOWE

Harry MAGET

Jacques MESCHEMBERG

Jeffrey Douglas MOUNT

Taras MULAR

Ashley Richard NICHOLLS

Ian Donald RIDLEY

Bruce Wayne ROBINSON

Kenneth John RUSSELL

Dewar Kym SAWERS

Michael Watson SHEARER

Anthony Thomas SMITH

Lynn Brendon STEWART

Kok Hoong WOO

1974

John Russell ABBOTT

Anthony James BENNETT

Peter John CLARKE

Paul Richard CROWE

Richard Michael ELSEGOOD

Douglas Norman ERSKINE

Damian Paul GALLAGHER

Leigh Anthony HALL
David HEW

Lionel Dean HEWLETT

Chee Kong Anthony HOOI

Robert Mark HUTTON

Michael KELDOULIS

Yee Chew Andrew KONG

Peter KOUTSIKAS

Choon Chan KOW

Brian Arthur LANGE

Stephen Roderick LANGFORD

Robert John LAVIS

Michael John LEACH

Teow Hock LIM

Rudolf George LINKER

David Sinclair MANN

Michael Voules NASH

Victor Anthony NICOLAS

Stephen Victor OLESCHENKO

Ronald Mark PENGLASE

Geoffrey Russell PITCHER

Michael John REILLY

Phillip John Letcher

RICHMOND

John Gordon ROGERS

John Kenneth SINCLAIR

Andrew Brian STONNILL

Andrew Paul Alexander TOTH

Spiro Con TZERFOS

John Robert WALLACE

Donald Charles WILSON

Iu-Chun John WONG

Christopher Noel

WOOLLACOTT

Mark Frederick WOTZKE

\section{5}

William Paterson BAILEY

Steven Royden BAKER

Zoltan Joseph BAKONYI

Vita Angela BARDAUSKAS

Vivian Brian BURGESS

Guy John BURNETT

Stan CHOIMES

Peter Edward COLES

Norbert Joseph de ROZARIO

Gregory DOUCAS

Rodney John FERRY
Brenton Maurice Wilshire

HEARN

George Stanley HERGOTT

Anthony David HOBBY

Susan Jane HOWELL

Stephen Reginald IVETT

John Aristidis KAIDONIS

Stephen Bernard KELLY

Leslie KRASSOVICH

Gregory KREIS

David John LEANE

Paul David MARIN

Basile MAVROUDIS

Christopher John MELLOWS

Craig Perry MOFFAT

Julie Ann MONIS (IVETT)

Soo Choo OH

Kim Edward PENGLASE

Jonathon Percy Howard

ROGERS

Peter Raymond ROGERS

Ligija Anna ROZITIS

Scott Heywood SHERWELL

William James VERCO

William Tennyson WEEKES

1976

William Garton ABBOT

Andrew Charles BILLS

Ian Gregory BILLS

Lars Albert BRODERS

Patrick David COLLETTE

Dymphna Jane CUDMORE

Robin Henry John

D'ROZARIO

Grant Walter DUNCAN

Lindsay Allen DYSON

Arthur Tom

GENIMAHALIOTIS

John William GURNEY

Dale Francis HENRICH

Samuel Bernard Isidore

HIGGINS

Andrew John HINCHCLIFFE

Janette Yvette HOLY

Richard Douglas HUEBL

Timothy HORTON 
Erkki Arvo Juhan HUUPPONEN

Mark Francis IRWIN

Juris Ansis KAIMINS

Gabrielle Mary KINNANE

Jane Frances MORAN

Michael Thomas MORAN

Daniel Francis MULVIHILL

Simon Paul NAYLOR

Leon Joseph NICOLAS

Gek Kiang NG

Robert William OMSBY

George PAGONIS

Lee Diane PHILP

Robert Alexander PLUNKETT

Mira RADINOVICH

John Sidney REED

Rodney John SANDERSON

Mark Lynton SCRIVEN

Neil Robert SLATER

Robert William SOUTH

Leslie David William

STEWART

Kym Murray STOCK

Donald Keith URQUHART

Vladimir VESCOVO

John Von THOMANN

Ian Kenneth WADDELL-

SMITH

Peter Lindsay WALTHAM

\section{7}

David Ross ABBOTT

Christine Anne ADAMS

Thomas Louis BEREKALLY

John William BERKETA

Nils Patrick BRODERS

Alan Mark BROUGHTON

Carmine Frank

CAMERLENGO

Swee-Po CHEAH

Peter Graham CLIFF

Richard Charles COWARD

Nigel Monfries DAVIDSON

John Phillip DAY

Ioannis Andreas DIAMANTI

Miles Edward DODDRIDGE
William MacGregor DUGUID

David John EASTERBROOK

Geoffrey David FRANKLIN

John Richard FRAYNE

Milan HARDI

Vladimir HARDI

Andrew Paul HARMS

Garry Ross HIBBLE

Hoe Khin HUM

James Gordon IRONSIDE

Geoffrey John LYNCH

Tony MAVROKOKKI

Vincent Thomas McCABE

Allison Mary McFARLANE

John Alastair McKINNON

Deborah Anne MILLER

George Henry NAK

Wai Huen Eddie NG

George Allen PATIENCE

William John Graham PATTEN

Angela Mary PIERCE

Lindsay Clem RICHARDS

Dennis John ROBINSON

Loreta RUPINSKAS

Brian Geoffrey SAINSBURY

Roderick Brook SAWFORD

Wan Kim SEOW

Robert Delbridge SHEA

Stuart Christopher SPENCER

Christopher Mark STANLEY

Geoffrey Edward STEVENS

Jaromir Antoni SZOKALSKI

Kym Gregory TREWIN

Robert Van ZANTEN

Jeffrey Alan WILLIAMS

Jeffrey Kym YOUNG

Imants Robert ZIEBARTS

\section{8}

Peter Mark BARTOLD

Blake John BIRDSEYE

Helen Margaret BIRDSEYE

Richard Seeley CHANNON

Harry CRAVEN

Ronald CZERNEZKYJ

Richard William Russell DALEY

Michael DELLAMALVA
Ralph Stuart DIBDEN

Isaia DOUVARTZIDIS

Arthur DROUGANIS

Andrew Robert DUNCAN

Mark Stephen Alfred EARL

Mark Nicholas GALAZOWSKI

Linden HAMIDON

Steven Paul HELVIG

Paul HENDERSON

Gregor David Copley HYDE

Olaf Christiaan JENSEN

Michael John KETTERIDGE

Peter Arthur KING

Steven Andrew KING

Shinta KUSWADI

Mark David LEEDHAM

Cosimo MAIOLO

Helen Diana McLEAN

Carmine MIGNONE

Michael Charles MORAN

Eng Seng ONG

Christopher Mark OVERALL

Vinicio Tiberio PISCINO

Marek ROHOZINSKI

Marion Christine ROYALL

Robert Edward SIMPSON

Maurice Jonathan SOMMER

Jeffrey Ian SWANN

Andrew Treasure SWINCER

Ian Pelton TAPP

Barbara Anne TAYLOR

Robert Bruce TAYLOR

Kim Maxwell THOMAS

Gerald Anthony

THURNWALD

Jeffrey Mark TREGEAGLE

Bronwyn Heather TUCKER

Michael Brian TUCKER

Stavros VARVOUNIS

Dean John VIEZZI

Beverley Lynette WALKER

Peter Gordon Stuart

WALMSLEY

1979

Akira AMAFUJI

Jane Caroline BELL 


$\begin{array}{ll}\text { Gregory Michael BENNETT } & \text { Kees Jozef Van Der PENNIN } \\ \text { Christopher Joseph BILL } & \text { Ian Robert WALLACE } \\ \text { Andrew Donald CHARTIER } & \text { Andrew John Lempriere } \\ \text { Roger Malcolm COLLIER } & \text { WESTBROOK } \\ \text { Janine Patricia CROTTY } & 1980 \\ \text { Alan Lintern DAVEY } & \end{array}$

Raymond Leigh DENNIS

Bernadette Eileen DODSON

Gregory James DUNCAN

Timothy Raymond FOLWELL

John Henry FORREST

Geoffrey Max FRAYNE

Robert Leon GENIKAS

Peter Ivan GEORGE

Robert Ashley Clive GOODE

Martin James HALL

James Andrew HARRIS

Karin Elisabeth HELDER

Peter James HILL

Anthony HOIMES

Gregory Wayne HOSKIN

Joanna Ruth JEPSON

Alec Tim KUSMANOFF

Siew Boon LEE

Richard LAVEY

Dale Trevor Le POIDEVIN

Ian Stewart Anderson LEMMEY

Kym Walter Irvin

LOCKWOOD

Dale Andrew LYMN

Katina MAROULIS

Paul Leo McHUGH

Stephen MILLER

Mark Ward NEWMAN

Susanne Mary NICHOLLS

Michael Andrew

NORDSTROM

Justin Michael O'LOUGHLIN

Steven OPPES

Sandra Christine OSIS

Christine PATRICK

Peter Rudolf PLEUNIK

Mark Graham POWELL

Craig Mathew SMITH

Geoffrey Robert STANTON

Nereo TESSARI

Gregory VANDEPEER
Kees Jozef Van Der PENNIN

1980

Stephen Ronald ALLEN

John Malcolm APPLEYARD

Peter ATHANASAS

Nicholas Ivan BARANIKOW

Adrian Damas BERCE

Robyn Margaret BOASE

Mark Lyndon BRATCHELL

Michael Francis BURROW

Steven Ronald CARR

Gregory Charles COCKS

Deborah Jane COLE

Noel DANTON

Anthony Stewart DAWSON

James Iain DOUGLAS

Christopher David ELDRIDGE

Simon Richard FREEZER

James Francis GARRETT

Gregory Damian GEE

Rodney Phillip GEELAN

Timothy Mark GRUMMET

Mark Edward Ingram GRYST

Adeline Selvarani

GUNARATNAM

David HUNT

Georgios KARASARIDIS

Mary Elizabeth KOENNECKE

Wolfgang Willi KROPF

Philip Robert LEITH

Stephen John LEWIS

John Gerald Paul LYSTER

Thomas Joseph MORAN

Wayne Roy MURISON

Richard Mark MYHILL

Kin-Wai NG

Thomas NYERGES

Paul Damien O'LEARY

David Scott POTTER

Martin John PYNOR

Candida Jane REMILTON

Anja Agnes Adriana Jacoba

RICHARDS
Richard William SALTER

Jeremy John SCHOCROFT

Paul Anthony SMITHSON

Susan Mary SPRINGBETT

Phillip John STACEY

Benjamin James TIDSWELL

Donald TINGEY

Jonathon TVERSKY

Stephen Maxwell TUCK

Geoffrey Douglas WALLMAN

Simon Charles WILLCOX

Simon Dale WOOLEY

\section{1}

Maria Elisa ANGELINI

Timothy John ASTLEY

Anthony Voules

BARTHOLOMAEUS

Helen Ann BEST

Jane Elisabeth Emese BOROKY

Nicholas Michael BOYD

Michael Ian BROADBENT

Eugene Dominic CLARK

Mario De IESO

Varothayan Kurunanithi

DHARMARAJAH

David James Caire DREW

Guilio FANTARELLA

Eda FRANCO

Michael Bruce FRAYNE

Simon Peter FULLER

David Charles GALLOWAY

Henry Limbert GILKES

Dean GOLDING

William HACKETT

Anthony Dean HALSTEAD

Sri Vannithanby

KATHIRIGAMATHAMBY

Thomas George KEAN

Shane Michael LUCEY

Alia MAYSTRENKO

David James MUNRO

Andrew Linas NAVAKAS

Chi- Hien NGO

Benjamin Ireneusz NOWICKI

Martyn Allan PARRY 


Mark Colin PENROSE
David Michael PETERS
Christopher Ralph Jacques
POTTER
Meera PUNITHAM
Enzo RICCI
Donald Keith RICHARDS
James Peter RUSHTON
William Charles SCARFE
Gary Steven SECOMBE
Eugenia Helen SKARLET
Antanas Vytenis

STANKEVICIOUS

Nandini SUBBIAH

Michael VINCI

Richard James WILKIE

Ross Anthony WINGROVE

Ka Leung YIP

Trevor Paul ZIEGLER

\section{2}

Karin Jeanette ALEXANDER

William ALMASI

Christopher George BALOG

Gregory Peter BARANIKOW

Andreas BECHLER

Kim Simon BOWEN

Amanda Helen CARROLL

Anthony John CHAPLIN

Andrew Briton CLARK

Marcus Phillip COONEY

Stephanie May COOPER

Peter CRAVEN

Iain FERGUSON

Aris James GATOUDIS

Timothy Noel HALLORAN

Christopher Payne HODGE

Caroline Hoi Fah HONG

Nigel Adrian LEWIS

Susan Margaret MACKAY

Ward Levingstone Kibby

MASSEY

Mark Lewis MOORE

Belinda MUNDAY

Kym Brenton NUNN

Julian John PAINTER

Brigitta Eva PANNELL
Mark Gerald PANNELL

Stephen John PEARSON

Stratos PUPULAS

Silvana ROSITANO

Michael John STACEY

Helen Patricia STOKES

Allan VREUGDENBURG

Ashley Douglas WHITE

Ingrid Louise WHITE

Sui Kin WONG

Phillip Charles WRIGHT

\section{3}

\section{Karyn ALTON}

Antonio Claudio Paul ALVINO

Roger David ANTONIAZZI

Andrew Nicholas CAREY

Craig Nicholas CARTER

Mario CARUSI

To Wang William CHAN

Therese Margaret COLEMAN

Steven John EDWARDS

David James FAULKNER

Norman Arthur FIRTH

Ian Alexander GURNER

Yow Lin Coreen HO

Gregory Scott JONES

Siu Sui Wing JOSEPH

Paul William KITTEL

John Bill KOSTA

Phillip Guy LEEDHAM

Mark Conrad LERCHE

Lien Hin Aylwin LIM

Lisa Jane Alice MAYFIELD

Gregory Bruce McHUGH

Janet Lynn McKINNIE

Gordon Rupert McLEAN

Trevor John MORRIS

Andrew Mitchell MURRAY

Ean Russell John NICHOLLS

Nicholas Michael POTEZNY

Marie Louise REICHSTEIN

David Alexander ROBERTSON

Ksenija Andrea SELISAK

Frank SERGI

Mary-Anne SLATER

\author{
Bohdan Wolodymyr \\ SLOBODIAN \\ Jane Amelia TAYLOR \\ Lukas Angelo TSAKALOS \\ Peter Gregory WAWRYK \\ Miroslawa WIECZOREK \\ Ravendra Udeni WIJESINHA \\ Deborah Ann ZINT
}

\section{4}

Nicholas AGIANNIDIS

Katherine Ruth ALLEN

Kathryn Jane BASTIAN

Darrel Wayne BECKLEY

Helen Michelle Yasmin

BONDARENKO

Gregory BROESDER

Edwin Emanual BROMFIELD

To Wang William CHAN

Neofitos DOUVARTZIDIS

Diana Joan FABIJAN

Victoria FARMER

Brian Peter FINN

Andrew Gordon FRASER

Paul Simon HEIJKOOP

Gordon Charles HENRY

Martin John HORWOOD

Timothy Gerard HURLEY

John KOTAIDIS

Wai Sum Eilly LAU

Man-Piu LEE

Aldo LEOPARDI

Arnis LIDUMS

John Leslie LINN

Karen LORENZEN

Charles Robert MARSH

Lynette Sue MAYNE

Kathryn Ann PILOWSKI

Paul John SAMBROOK

Nicholas Mark SMITH

Kazik SZEWC

Andrew Paul TINDALL

Paul TOUMAZOS

Richard Anthony VICKERS

Jason Arnost VOCHALA

Samual Latimer WHITTLE

Peter Raymond WILKIE 


\section{5}

Tom Anastasios ANDRITSAKIS

David Yun Kun CHAN

Elizabeth CHRYSSIDIS

Peter Rodney DAWSON

Gino Gustavo FLORIO

Teresa Krystyna GRUSZEWSKI

Peter HADDAD

Susan Gai HALL

Heather Jane HEINRICH

Trigoni Woni KERAMIDAS

Derek Carl LERCHE

Joanna Sharon LINN

Andrea Jane MILLER

Simon Reading MOORE

Jennifer Mary NICHOLLS

Jim John PALLIS

Nichlaos PANAYIARIS

Hans William RAETS

Anthony Peter Laurence

SHAKES

Anthony Paul Christiaan

SIMEONE

Denise SIMEONE

Timothy Martindale SMITH

Wai Ling TSANG

Louise Joan UPTON

Christian WEBER

\section{6}

Olga ANAGNOSTOPOULIS

Anthony John William BEVAN

Karen BLUMENTHAL

Dino Adrian DONATI

Linda Jane FARAONIO

Karzhan GILL

Michael IKONOMOS

Azalina JAMALUDDIN

Rosemarie Joan KIRKLAND

Swann Nhu Xuan LAM

Dinh Thi Thuy LE

Rosario Rudolfo MUSOLINO

Andrew Oleh NAKONE

Sateria PAPAGEORGIOU

Christos PAZIOS

Robert PISCIONERI
Sharon Andrea Corinne

SCHOKMAN

\section{7}

Spyro BOURAS

Eugene Kin Keung CHAN

Randall Sydney CHIN

John Alan CROPLEY

Mark HOLCROFT

Kathryn Rosalie HOLLITT

Donal James Fergus KELLY

Constantinos LAPARIDIS

Adrian Lien Kheng LIM

Lien Tu LU

Hong-An NGUYEN

Tung Thanh NGUYEN

Spiro PAZIOS

David Geoffrey PETERS

Simone Rebecca RICKETTS

Paul Rich SCHREITER

Helen SINCLAIR

Freda STUPPOS

Michelle Louise THOW

Diana TSIOPELAS

Hong Thi Thu VO

Dimitra VRASTIMINOS

\section{8}

Con Jack BALASIS

Maria BIKOS

Ornella CAIAZZA

Jane Margaret CUSACK

Flora DAVID

Nedo De ANGELIS

Nella DELLAMALVA

Peter DONGAS

Owen James Douglas HALES

Nicholas Winston HOCKING

Diana Mariko HUMPHERY

Emmeline Yuen-Ping KHOR

Carol-Ann $\mathrm{KOCH}$

Toan Man LU

Steve Christian MASON

Lisa Margaret McCLEAN

Chen EE PEH

John Dominic QUIGLEY

Tony RICCI
Dorothy SAWCZUK

Michelle Dianne STONE

Michael Anthony STUBBS

Konstantina TSIOLIS

Jimmy VAGIONAS

Sunia Tabuanitoga

VUDINIABOLA

Graham Warren WARD

Kevin Roy WARD

\section{9}

Jonathon Flavell ASHWORTH

Abdul Afroze AZAM

Bojanka BLAGOJEVIC

Christina Karin BRADFORD

Shally Oi-Yee CHAN

Caroline Mary Helen

CROWLEY

Paul Joseph DANENBERG

Khalil DIRANA

Janet Megan FUSS

Santhiapillai Paul GRATIAEN

Jacqueline KEARSLAKE

Anna KOUTSONIKAS

Hoa Thi MONG LEE

George MANIATIS

Justin Patrick MARTIN

Tony MONACO

Anthony Thomas MOORE

Helena Krystyna POLGAR-

GEBALA

Roger George PUCKRIDGE

Sarah Louise RAPHAEL

Anthony David SMERDON

Rachel Catherine Anne THAM

Trung Nhon TRAN

Arthur Howard WIGELL

1990

Sophie Louise BEAUMONT

Constantine BOURLIOUFAS

Mark Anthony BRAZIER

Patrick Francis BYRNE

Adeline Yang Li CHONG

Damian Anthony CHUNG

Khalil DIRANI

Guy Laurence FREEMAN 
Bridget Jane HAMILTON

Kenneth John HEATH

Ramzi JABER

Danae KOTANIDIS

Haralambos LAPARIDIS

Martin Cameron LEE

Sook Kuan LEE

Nathan Brian LUKE

Stella Leigh Janet MILLER

David Reading MOORE

Anh-Thu NGUYEN

Eva Maria PIEKARZ

Anna PUZIO

Jocani TUISUVA

\section{1}

Peter James ALDRITT

Lynley Mary COUZNER

Khodr EL-MASR

Floria FARHADI

Matthew Ted Phin FOO

Daiva Cecilia FULLER

Mary GOSIS

George GRIGORIS

Walled HASSOUN

Anh Dung HUYNH

Dieu Quang HUYNH

Shiu KARAN

Barbara-Anne KERSLAKE

Ismail KHOR

Sonja Velma KUEHL

Trinh LE

Catherine Tong How LEE

Charles LEE

Dimitra LEKKAS

Aaron Lien Seong LIM

Sandra MALFIORE

Alison Josephine McKITTRICK

Paramaswaami PARAMASIVAM

Apenisa Tolevu RATU

Daveena SIDHU

Vikash Jagat SINGH

Ian Scott SMITH

Elzbieta Dorota SOKOLOWSKI

Erica VINCZER

Simon Gregory WALSH

Kong YEN

\section{2}

Martin John ACKLAND

Mark Edwin BADCOCK

Alison BUTT

Tarek CHEMAISSE

Lisa Ann CRIGHTON

Vicky DRIVAS

Daniel Swithin FARMER

Dianne HADDAD

Wei Fong HOE

Arjun JEGANATHAN

Simela LAPARIDIS

Trinh Thi Mai LE

Briony Helen LEACH

Richard Martin LOGAN

James Burton McGOWN

Zac MORFOPOS

Evangelos Vasilios

PAPAGEORGIOU

Alison Victoria PARTINGTON

Maheshwari Sen PILLAY

Narayan PRASAD

Walid RAFEH

Leap SON

Jason SPOOR

Cam Trang TRAN

Belinda Dawn WYTHE

Mamdouh ZEIDAN

1993

Samanmali Windhya

ABEYWARDENA

Fatima Bt ARSHAD

Christopher William BATES

Wojcieh Marek BILSKI

Michael Victor BRADLEY

Loke Min CHAN

Yu Hong CHAN

Dinh Dang DZUNG

Zlatko EFTIMOSKI

Patricia GARCIA

Helen Joan HEAVER

Rozita Bt Hj HUSSAIN

Mark Andrew HOPKINS

Ann HOU

Katherine Laura JANNEY
Ranjith JAYASINGHE

Damien Brae KENT

Chooi Mii LAM

Tu An LE

Camilla Kate LOCK

Michael Platis LUCAS

Sophie Thuy NGUYEN

Tuan Nguyen NGOC

Chong Meng ONG

Mansoor RASEHKI

Alistair Matthew REID

Tina Annette RYAN

Kylie Linda SALU

John David SCHAEFER

Kalaichelvy

SIVARAMALINGAM

Paul STAMATI

John Gima STOLZ

Kirk James TABALOTNY

Deanne Elizabeth THOMAS

Nicholaos TOLIS

Darren Matthew TOWNSEND

Ngoc Toan TRAN

Leo Chi Yui TSE

Melissa Wen-May WU

Apiramy YOGANATHAN

Marzuki B Zainal ABIDIN

1994

Asreza Bt Abdul RAZAK

Ayu Bt ABDULLAH

Zakiah Bt ABDULLAH

Rocky ARENA

Nor Adinar Bt BAHARUDDIN

Peter John BERTOSSA

Arthur Georg BILSKI

Dawn Lynn CARROLL

Hayfa Muhammad Said HADI

Suzana HALL

Noor Hayati Bt Che HASSAN

Shin Chyuan CHEN

Marion D'SOUZA

Fabrizio DAMIANI

Daniel De ANGELIS

Arlene ESMAQUEL

Matthew Steven FRACARO

Awny El GHITANY 


Ehab HENNIEN
Lisa JONES
Vasilios KARAPETIS
Danae Leda KENT
Angela KIRGIANIS
Loucas KYRIACOU
Igor George LAVRIN
Troy Bronte LONGBOTTOM
Nor Sitah Bt MARKOM
Miriam Jane MATTHEWS
Marcela Missene-KAHAN
Sarimah Bte Mohd MOKHTAR
Sharma NAND
Ma Roxane Angela NICDAO
Vincent John PARLETTA
Lakshmi RAMALINGAM
Rasaratnam RAVINDRAN
Souchin SAM
Karl Mark SCARPIN
Robert Fortunato SERGI
Arthur SHIZAS
Tony SIGNORIELLO
Angela SKOPAL
Pelayia SOUPOURZIS
Rohana Bt SUJAK
Salwana Bt SUPAAT
Sofia TSAVTARIDIS
Dai Vu VAN
Con VANCO
Mehri ESHRAGHI-
VARNAMKHAST
Brendan John WHITE
1995
Mat

Katherina ATMADJA
Yelena MAGIT
Tan Phat CHAU
Genevieve Woon Yin CHONG
Elizabeth CHRONOWSKI
I-Hsun CHU
Helen Louise CORNWELL
Darren Scott Di IULIO
Cornelia Angelica ESMAQUEL
Leonie Patricia FAULKS
Ka Hing Wendy FOK
Vera GEORGHY
Gavan John GORDON

Benjamin Gerard GRAVE

Dragan GRUBOR

Haniza Bt HAMID

Hazudin B HASSAN

Bruce HOOSHMAND

Adam HUSEIN

Carlo IADANZA

Nassib Nouhad JAWHARI

George KARAGIANNIS

David KARWARZ

Petrina Sai Peng KAT

Cheryl Su-Ming KOH

Joseph Wei-Chee LEE

Nicholas Platis LUCAS

Jadwiga-Maria MILOSEVICH

Kylie Michelle MOORE

Sophia MOUGOS

Dimitrious MOUTOS

Neela NATH

Tuan Tran Anh NGUYEN

Monika Kinga PAWLOWSKI

Jane Rosemary PELLEW

Alessandro PIANTADOSI

Belinda K A Mun POON

Grazyna RADZIKOWSKA

Kalaiselvi RAJAGOPALAN

Osvaldo Antonio REYES

Asha SAVARIRAYAN

Payam SOBHI

Arnold Maciej STARCHURSKI

Eng Yang TAN

Eric Hua Yu TAN

Linh Thuy Thi TRAM

Dionysios TSIMIKLIS

Jacob VARUGHESE

Wan Noorina Bt Wan AHMAD

Asfaliza Bt WARZUKNI

Jerome Edwin WIDJAYA

Kee Toh WONG

Ranouf Iskander YANES

Marcin Jerzy ZIELINSKI

\section{6}

Timothy James ALLEN

Rachel Joy BISHOP

Eugene Jin Khing CHEAH

Daniel Andrew Vu F CHIN
John Tze Kong CHUNG

Giacomo Nicholas CIRILLO

Geoffrey Richard COLLINS

Xuan Dong Thi DAO

Clarence De SILVA

James Edward DUDLEY

Gustina Wadu Samantha

CHANDRAJITH De SILVA

Daniel Andrew Chin Vui FONG

David Keith FULLER

Farag Samwil Farag GIRGIS

Timothy Yew Aun GOH

David John GORDON

Sumant GUE

Azuhashuhada Bt HABIB

Hamedah Bt HASHIM

Meor Ahmad Isharra ISHAK

Samuel Dayaal JEYASEELAN

De Jun JIANG

Sunita KAPALI

Gregory KASDAN

Paminder Kaur KHAIRA

Trang Hoang Xuan LE

Cheryl Poh Leng LIEW

Tania Simone LUCAS

Michael MALANDRIS

Mazlina Bt MAMAD

Sharon Andrea M

MARINUCCI

Tong B MOK

Chi NGUYEN

Phuc NGUYEN

Klaudia NIZNIK

Anand Kumar PATEL

Tan Khanh PHAM

Phillip PIRGOUSIS

Archana PRADHAN

John PSARROS

Robert Erwin SANTOSA

Steven SOUKOULIS

Balaranjini SRIHARAN

Robert John STEWART

Manuv Gaurav SURI

Francis Chen Tai TAN

Chin-Hui TANG

Fiona Jane TANN

Evangelos VRODOS 


Wally Peter WANIARCHA
Nicholas Michael
WEIGHTMAN
Michael Standford WILSEN
Dieu YONG
Angelina Wen Tzu ZEA
Zalmee ZID
1997

Shariffah Shuriana B Abd SHUKOR

Menaka Arundathi ABUZAR

Phillip Mahesh Verghese

ALEXANDER

Maria ANGELOPOULOS

Yioryos ATSIKBASIS

Adrian John BALESTRIN

Natalia BURAK

Ryan Scott BUTLER

Madeleine Mei Ying CHEAH

Tak Wai CHEUNG

Sharon Ngie Mien CHUA

Alice CHUANG

Steven James CLUBB

Mathew Christopher DAWSON

Neena DURAIRAJ

Alan FASSINA

Somasundaram

GANESHARATNAM

Anastasia Fotini GEORGIOU

Hung Tuan HUYNH

Khang Huy LE

Norhayati Bt LUDDIN

Rozaimah Bt Mat SHAFEI

Rachael MATHEW

Manjiri MEHENDALE

Shivanthie NANDAKOBAN

Mohini Lata NARAYAN

Gio Quynh NGUYEN

Khanh Thi Lan NGUYEN

Toan NGUYEN

Svetlana NIKOVA

Nita PAI

Tien Khanh PHAM

Chad Lewis PHILLIPS

Jasmina Bt Qamaruz ZAMAN

Dusica RAJCEVIC

Kain Myles ROWLINGS
Nerita SIDHU
Jaroslaw SNUSZKA
Nigel Joseph SOUTER
Kala Siva SUBRAMANIAM
Irene Wee Ling TEO
Tuhuy TRAN
Van TRINH
Manveen UBHEY
Michael Kok Wai CHONG
Zuriani Bt ZAINAL
1998

Normaliza AB MALIK

Bijun CAI

Daniel Eng Quo CHU

Thomas Norman CORFIELD

Danh Tran DANG

Norris Ping FENG

Frank Chun Wen HUANG

Thomas Cameron JAUNEY

Elizabeth Silvia JAY

Ioana Mirela JELEASCU

Grant Andrew JOHNSTONE

Ching-Hui KAO

Bertie Raman KAPOOR

Van Vu LE

Shirley Hsaio Chia LEE

Khanh Cecilia MAI

Nicholas James MAXTED

Susanna MIHAILIDIS

Yeti Rosalina Muslim

TANDJUNG

Michael NAZHA

Lan Thi Xuan NGUYEN

Mark PANERAS

Manjeet PATIL

Joannes PHAM

Marta Joanna PIETRZAK

Sanjiv Vijendra RATNESER

Nirej REWAL

Nitayati SABARI

Pinky SINGH

Martin James SWEET

Navenka TADIC

Katherine Hue THAI

Marcus Kean Mun THAM

\author{
David Man TRAN \\ Danh Thanh VO \\ Adrian WONG \\ Djordje ZLATKOVIC \\ 1999
}

Azwatee Abdul AZIZ

Farah Salwa Abdul RAHIM

Anna BARTLINSKA

Rocco BUETI

Steven Hugh BURLINSON

Kelly CHAU

Adam Raphael DAVIDSON

Tuyet Tram DANG

Alister James DICKSON

Mikhail GRIGOREV

Oanh Thi Mong HA

Dylan Richard HOLLAND

Stephen Zhidong HUANG

Bela JOSHI

Renu Kumari KARN

Nectarios KATSIKAS

Rabindra Pratap SINGH K C

Kathy KOTATIS

Martin LAO

Eden Yu-Tung LAU

Michael LE

Despina LIPAPIS

Ivy LUCERO

Monica Joy MALONE

Hiromi MATSUOKA

Megat Zuhairi Megat

AMANUDDIN

Mihailo MITRIC

Kasmawati MOKHTAR

Anita MORIC

Heidi Anna MUNCHENBERG

Td Hanh NGUYEN

Christy Lisa NORTON

Tuan Khan PHAM

Christopher Alan

POSSINGHAM

Giovanni SANTILLO

Asmak SHAARI

Lillian SHI

Rekha SHRESTHA

Niti SIOW 
Wendy SONG

Asha SUBRAMANIAM

Marie TADIC

Sue Suedabeh TAJI

Melinda Jane TAM

Raheil Togyani FARSHID

Aden Lu-Huy Khanh TRAN

Jason Cheong Tze YEEN

Bich Khe VU

Mario Juan WAIS

\section{0}

Sabahat Gholamian ABHARY

Phillip Gregory ALLEN

Mahyar AMJADI

Roshanak AMREIN

Peter Ryan BATTYE

Emma Jane BELL

Nabina BHUJEL

Graeme Neil BURLINSON

Connie Sze Wai CHEUNG

Wendy Wai-Sau CHEUNG

Tram Tinh CHIEM

Tony Wayne ELDRIDGE

Nadia ESKANDARI-NAZHA

Olivia Claire EVANS

Nima FERDOWSKI

Amy Yeuk Shuen FONG

Wan Ida Nooryani HJ Wan

YUSOF

John Denis GAFFEY

Hai Duy HO

Jeanette Su Yin HO

Angela Ming Choo $\mathrm{HOH}$

Marjan HORRIAT

Nuha Fawzi KAMIL

Anup Jung KARKI

Kantara Eddie KAROUA

Donghyun KIM

Quy Dieu Thi LE

Su Ming LIM

Esmat LOUIS

Thanh Huong MAI

Mark MANN

Suhaila Bt Mohd YUSOF

Galina MYAGKAYA

Susan Patricia NADEBAUM
Saniyya NAJEE

Romesh NALLIAH

Ross Damien NAPOLI

Thanh Thi NGUYEN

Toan BA NGUYEN

Katherine Pamela

O'DONOGHUE

Brendon Russell PARKER

Eleanor Jane PARKER

Marian Siva PAYNE

Tu Khuong PHO

Sarbin RANJITKAR

Lindsay Ronald J ROSENTHAL

Toby Crawford ROWE

Bernard SIEW

Daljit Singh SIHOTA

Nevenka STEVANOVIC

Lauren Claire STOW

Dalya TADROS

Peter TKACHUK

Xuan- Phuong TRAN

Vadi VOJDANI

Guy Julian WILLIAMSON

Simon Wai Ming WONG

Mandy Xiang Zhen ZHENG

\section{1}

Ramzalinda Bt Abd RAHMAN

Sue Izadora Bt ABDULLA

Rabihar Bt ALAWI

Andrew Lawrence BARBERA

Andrzej BENDYK

Alison Jane BETTCHER

Peter John BILLS

Siri BJELLAND

Penelope Marie BRAY

Adrian David CARR

Andrew CHENG

Wei-Yi CHIAM

David Wing Keung CHU

Maria DAYCH

Benjamin James GAFFEY

Ankit GARG

Kiran GUPTA

Nitu GUPTA

Rory Angus Richard

HANCOCK
Ryan HEGGIE

Shahriar KASSIRI

Sui Wei KONG

Benjamin Ronald Bruce

LAWLER

Thien LE

Jonathan David LEACH

Shermin LEE

Nichola Kathleen MATTO

Greg James MILLER

Nurfadzilah Bt Mohd HASHIM

Khashayar NASSERY

Aezy Noorazah Bt OMAR

Andrew Tjin-Chiew OW

Gregory John PATON

Barabara Elizabeth PLUTZER

Rohini PRABHU

Husniyati Bt ROSLAN

Hassiah Bt SALLEH

Bikram SETHI

Pawel Tadeusz SLOMKA

Anjella SRITHARAN

Smitha SUKUMAR

Stephen Ka Yip TANG

Samuel Joseph VERCO

Michael Shaw WHITFORD

Jun YANG

Adelyn Chrisina YEO

Mohamed Aleem YUSEF

2002

Izwan Bin Abd HAMID

Britta BOETTINGER

Maria Pia BORG

Marcel BROSTEK

Michael Anthony BURLINSON

Emily Celia DEEN

Cindy DENNIS

Brent Michael DICKMAN

Anh Tran Van DO

Martin FERNANDO

Cathryn Sarah GILL

Meena HEGDE

Nicholas PauI HEIDE

Mitchell Renee HOFFMAN

Vilia HOLLFELDER

Lulu IHSHEISH 
Jeffrey KAIBU

Michael KOUSARI

Emily Amarcho KYAW

Hendrik Bryan LAI

Simon LEW

Elaine LIM

Nael MALIK

Sarah Vanessa NEITZERT

Justin Abraham PAKIN

Christopher Raman PATEL

Elina SAM

Elizabeta SARKIC

Krzysztof Sebastian

SOKOLOWSKI

Amanda Jane STEWART

Imelda Anak STEWART-SAIN

Suma SUKUMA

Daniel Owen TANKARD

Eugene Mark Hsien Wei TJIA-

LEONG

Luoura Karlovna TROUKHINA

Wan Maliha binti Wan Abdullah

A W

Edward Lee WILSON

Kui Siang Lucy YONG

2003

Imran ALI

Mariella ALVARO

Ben ARMENORES

Neha ARORA

Samuel Colin BENNETT

Charles Christopher St John

BOAST

Timothy Walter BURTON

Wayne Chuo Wei CHEN

Angelina Wing Chi CHEUNG

Keng Koon CHUA

Maria Josephina

CLAUDIANOS

Justin Graeme COLLUM

Ryan James CORNISH

Ngoc Diem DANG

Tuan Minh DOAN

Clint Ross HADDON

Sue May Gina HO

Sue Ting Brina HO
Jivajothi JEYATHEVAN

Avanti Parul KARVE

Gopal Krishan KATARIA

Asif Nawaz KHAN

Julia KHUOC

Jaehong KIM

Kere Richard KOBAYASHI

Kevin Ti-Jin KOK

Eva KOT

Osman Chee Seong KUA

Salmin Khudabux LADHANI

Lincoln LAW

Jane Georgiana LEE

Vivian LIU

Rai Singh MANKU

Jonathan Charles MARIN

Terry Man-Fai NG

Thi Hong An NGUYEN

Ashley Morteza Laleh PARVAR

Aashul Yashwin Kumar PATEL

Ai-Nhi Huu PHAN

Hoa PHUNG

Hana Khalid QIDWAI

Jonathan Peter RACE

Christopher Robert SANZARO

Rano Simerjeet SHARMA

Jeya Rajah SIVENDRA

Lyndall Kate SMYTHE

Balya SRIRAM

Alexander Lewis STABOLIDIS

Thuc-An LE TAT

Joshua Simon TIRRELL

Nhung Tuyet Thi TRAN

Long Yan WONG

Bradley XUE

Alexis Nicole ZANDER

\section{4}

Mary Victoria APPS

Christopher William Durban

BARKER

Lin-L Emily CHEN

Chun Sing CHOI

Lu Ling Doreen CHUA

Linda G CURL

Nadia Anna DOBROMILSKY

Lincoln Jed FLEETWOOD
Sima Sylvia GOLESTANI

Haslinda binti HAMID

Geoffrey HARVEY

David Ming Keong $\mathrm{HOH}$

Devesh Kumar KAPADIA

Nupur Grover KATARIA

Ales KRECINIC

Ni-Hing LIN

Zhibin LIN

Rebecca LIU

Hannah Sosamma MATHEW

Peter John NORTON

Eleanore Lucy OWEN

Sam Sang-Do PARK

Zubeida POTRES

Anuradha REDDY

Sara Anne ROBERTS

Jasmina RUJNIC

Sonia SACHDEV

Aaron Nicholas Shiao Ming

SEET

Chee Khoon SIA

Trudy Ann STEWART

Karen Elaine SUCH

Miang Chneh TEO

Ashleigh James THOMSON

Michael John TURNER

Joyce Vui La VUN

Jamie Michael WEBBER

Eliana Angelica WILCHES

Nancy Jing Wen XU

Evelyn Kar-Yun YEUNG

Michael ZANINOVICH

\section{5}

Sabrina ALI

Jessie ARMENORES

Renee Antoinette ASHBY

Celia Genet BAKER

Seran Kuan BOEY

Matthew James BURKE

Peter CARETTI

Mei Ying CHEAH

Melinda Wai Yan CHEUNG

Francine Joy CHIA

Choi Mun $\mathrm{CHO}$

Jonathon Elias CHRISTO 
Helen Alexis CLANACHAN

Robert Charles COX

David Charles CRADDOCK

Kim Victoria DOOLAND

Kristen ENDRES

Shadi FASHKA

Andrew James Michael

FIRGAIRA

Holly Rachel FLEET

Antonio GAGLIARDI

Anjali GUJADHUR

Patrycia Anna HABERSISSONS

Anna Susan HACKET

Phalika HING

Choong-Qin HWONG

Kimberley IVETT

Shane Paul JOHNSTONE

Sung Wai KHOO

Ki Hyun KIM

Shelly KUKREJA

Lisetta Oi Yan LAM

Tony Ting Fai LEE

Mei-Yan LIM

Beth Louise LOVEDAY

Gaurav MADAN

Ena OBEROI

Yong Yit OOI

Brooke Melissa PARKER

Fleur PUGLISI

Anthony Srecko PULJICH

Reshma Ghousebi RAHMAN

Saumya RANA

Deborah Anne REA

Juan Fernando Restrepo

MONTOYA

Helen Teri SCHOFIELD

Benjamin David SHARPE

William John Watson SOUTH

Michelle Ann SPIEL

Thuy Thanh NGUYEN

Alice TSANG

Sophia Caroline VICKERS

Anthony Michael VINCI

Julie VO

Amanda Jane WALDOCK

Amanda Wye-San WONG

Meng-Meng ZHANG
2006

Hui Ching ANG

David Gordon ASHFORD

Gayanie Chandima

BASNAYAKE

Lloyd Michael BUCK

Robert John BURNETT

Tim Ting-Kang CHANG

Mei-Yi CHEW

Elena DONETS

Timothy Grant EATON

Michael James FILOSI

Penelope Kate GALAZ

Phaloeuk HING

Daniel Geoffrey HORNE

Kosha Shirishkumar JHALLA

Evelyn Lek Yun KHONG

Erica Min Jee KIM

Andrew James KING

Tina LE

Ying Ying LEE

Keith Jianwen LEW

Anna Tess LOGOS

Chang Hong LOY

Anjali MADAN

George MANDRANIS

Adele Christiane MILLER

Yvonne Maria MONTE

Sridhar NANNAPANENI

Tharaka Somaratne

NARAYANA

Hock Nien NG

Jian Zhang NG

Caroline Thanh Mai NGUYEN

Bill Guglielmo OBERDAN

Aarthi PARANJOTHY

Anuj PAWAR

Caroline PIEKARZ

Amy Hoi-Ying PUN

Catherine REEVE

Michael Glenn ROBINSON

Jason Paul SAVAGE

Greta Jane SCHULZ

Salar SINAI

Daniel Chia Ming TAN

Nicholas Christopher TEO

Ramya THANIGAIVEL
Yohan John THOMAS

Le Minh Tuong TRAN

Nhan Minh Tuong TRAN

Elaine Li Ken TSEU

Narelle Jane Van VELZEN

Robin Chi-weng YONG

\section{7}

Abishek AGGARWAL

Wing Yew Benjamin KU

Aakriti BHOLA

Mark Christopher BLANDY

Michael James Gordon

BOOTES

Robert Luciano BUBNIC

Hussein CHAMAS

Mei San CHAN

Shelly Tse Yean CHEE

Min Yen CHIA

Chung Ming CHIN

Won-Hyuk CHOI

Benjamin Joseph CLOTHIER

Timothy John Rodgers

CURRAN

Hung Quoc DANG

Quoc Anh DO

Julian FRENCH

Richard Bernd FREYTAG

Erika Marcella GUERRA

Ying Nan GUO

Ann Gie HO

Cindy Ee-Lin HO

Peter Duc HOANG

Jun-Yi HU

Eun-Jae HWANG

Nicholas Geoffrey JACKMAN

Dhanupriya JEYAKUMAR

Valda Chee Ling JING

Joseph Tuan

JNGUYENPHAMHH

Kitirat JUNGPAKDEE

Sadia Majeed KAJANI

Wing-Yee Deborah KONG

Wil Fred KOON

Priya Hellen LAL

Hieu LE

Lydia Jia LING

Tsui Ong LING 
Edwin LU

Katie Jun-Huan LU

Jason MICHAEL

Anne Phuong NGUYEN

Michael Christopher O'LEARY

Ai Fen OOI

Maria PANDEY

Nicholas PAPAGEORGIOU

Sherina Sue PARMAR

Angie PASPALIARIS

Susma Shridhara PAWAR

Mayuri SAHGAL

Joel SORIANO

Liping SU

Chien Wei TAN

Ivy Siang YEE TAN

Daniel Tuck Chung TANG

Nikki TZIAVARAS

Hsuan-Yu WANG

Sabrina Natalie WOODROFFE

Ping Ping YEOH

\section{8}

Reschard ABDULLA

Dong-Guen AN

Seerone ANANDARAJAH

Paul Thomas BUDDEN

Chan Hui Ping BERENICE

Kwun Chung CHAN

Tsing May CHAN

Priyanka CHANDRA

Kalyani CHITRAPU

Catherine Cheng-Lai CHOW

Yuen Ling CHOW

Sravan CHUNDURU

Ashley David FREEMAN

Daniela GAGLIARDI

Tata Michelle GARDINER

Stephen Mounir Nessiem

GHABRIEL

Penelope Anne HAY

Lisa HIRAI

Hsin-Ying HSIEH

Michael IBRAHIM

Richard McLeod JACK

Anna KANTER

Sushil KAUR

Amna Zahrah KHAN
Yong Tze KHO
William Peter KING
Kate Louise LINDSAY
Leah Qian LIU
Kaibo LU
Alan MANN
Dusan MARKOVIC
Vesna MILANKO
Shina Binti MOHD ARIFFIN
Ha Na RYU
Tanuja NEKKALAPUDI
Thanh-Xuan NGUYEN
Sindhuja RAJADORAI
Gaurav SHARMA
Wei SHEN
Reuben SIM
Hardev SINGH
Gurjai Singh SOIN
Reuben Kah Chuan SUIT
Johnson Hung Kit TANG
Laura Elizabeth TAORMINA
Christopher THORNE
Loan Thi Bich TRAN
Quoc Ly TRAN
Natalia VOIN
Richard Charles WARK
Melissa Joan WILSON
Daniel Wye-Hoong WONG
Giny Meng-Hwa WOO
Yap Ern CHEE
Lillian YAP
Richard YAP
2009

Genghis ABAD

Kathryn Alexandra ADAMSON

Qian AN

Poppy Marcella

ANASTASSIADIS

Elizabeth Claire ARNDT

Kristen Anna BAYETTO

Elizabeth Ann BERNIE

Sarah Marie CARUSO

Andrew Jonathon CHAN

Ying Qi CHAN
Anthony Dyalan

CHELLAPPAH

Adrian Wei Yee CHEN

Ting Ting CHEN

Sarah Jane CRANWELL

Kylie Jane CURETON

Youssef DAKKAK

Purobi Tithi DATTA

Laura Olwyn DUNCAN

Tennent Michael EMERSON

Evelyn Teo Siaw SZE

Andrea Louise FEJER

George FORREST

Peter Mounir GHABRIEL

Karen Maree GRIFFIN

Sakshi GUPTA

Tirza Clair HARLEY

Ludhara Lakna

HETTIARACHCHY

Vanessa Margaret HOLM

Jae-Man Zhuzhong HONG

Madeleine Jane HOOPMAN

Rylie Jane IVILL

Jolvin Lee Yin Hou

Sun Ae JUN

Jayant KAPOOR

Jason Nathaniel KHOURY

Lauren Elise KOMOLL

Shruti KULHALLI

Alexander Khoi LAM

Jennifer LAN

Sally Hui Ying LAW

Marcel James LEE

Mathew Albert LIM

Jin Wei LING

Elizabeth Kate LOU

Aja MACKENZIE-BURDON

Sejal Madhukar

MAHAGAONKAR

Mas Linda Mohd OSMAN

Duong Thai NGUYEN

Hoang Minh NGUYEN

Qunh Huong NGUYEN

Jana NIKOLOVSKI

Jun Yi OOI

Theodore Yeow Chon PANG

Aaron William PARKER 


Hannah PROUSE
Kainan QU
Andrea Ruth ROUSE
Jeeson George SAJEEV
Sagnik SENGUPTA
Nidhi SHARMER
Yea Lee SHU
Alice Molly SIDEY
Catherine Alexandra SIMS
Tina Sang-A SON
Timothy SURMAN
Suat Hua TAN
Katherine Angelina
THEODORE
Ayesha TIWARY
Daniel Wye Keen TOH
Daniel Tuong TRAN
Buu Ngoc Linda TRANG
Willian TRIEU
Kim TRINH
Amanda Louise TSUN
Shreya VERMA
Arjun VITHIYANANTHAN
Jeremy Hoai Viet VO
Mei Lynn WAN
Chen WANG
Shammi Anushka
WEERASINGHE
Alice Elizabeth WILSON
Morgan John WISHNEY
Pui Lam Erica WONG
Bing Ik YAP
Keng Soon YEOH
THA
THA

\section{0}

Eun Jin AHN

Gabrielle Janet ALLEN

Peter John ALVINO

Asma Bt ASHARI

Clare Jane BAILEY

Natasha Hsui Tuan

BENTKOWSKA TEOH

Lisa Ann BROWNFOOT

Sarah Diane CARPENTER

Vivien Ying Ying CHAI

Bell Diane CHAMBERLAIN

Emmanual CHAN

Joanna Lee Ann CHEN
Wei CHENG
Ying Ying CHONG
I-Ee Jovina CHUA
Julie Elizabeth CLIFFE
Jarod Ken DEAN
Phi DO
Vyla Emma-Louise ELLIS
Christopher Simon GALVIN
Sue Anna GOH
Jasmine Megan GREEN
Ying GU
Kum Bin HA
Jennie Eun-Soo HAN
Gwendoline Lauren HUANG
Meagan Deborah HUEBEL
Lloyd Reaveley HURRELL
Prabha Ramani IYER
Jamie Wayne JACKSON
Michelle Sujenie
JEYARATNAM
Lakshy Nivetha JEYASEELAN
Yu JI
Samuel Gwynne JONES
Francis Mona KEEN
Heshani Tharuka
KELLAPATHA
Marya KHAN
Lee Peng KONG
Allan LAM
Gillian Ann Jia Wen LEOW
Pui Ki Sara LI
Isaac Jian Xiang LIAU
Xin Yee LIM
Yinan LU
Jeremy Joel LUNG
Daniel MARCUS
Ezani Farhana Md MONOTO
Conor Christopher MEEHAN
Nur Adila Bt Mohd Nor WIR
Patricia Anna MULLANEY
Daniel Francis MULVIHILL
Larasati NURHADI
David Stuart OETJEN
Edward Lloyd OUNAPUU
Vaishnavi
PARIMALANATHAN

Melanie PATNEY

Harold Kingston PRADHAN

Alisa PRICE

Miriana Kate RADIN

Nirosha Ivanthi RAJAPAKSE

Brittny Clare ROBERTS

Danushan SAMPANTHAR

Sebastian Hope SEKULIC

Samuel Richard SPENCER

Kim TSAO

Julian Delano VEERASINGAM

Cynthia Hui Shing WONG

Tien Li WONG

Chun-Chang WU

Jae Hoon YOON

David Steven YU

Yujia ZENG

Jingting ZHAO

\section{1}

Siti Nuramanina Abdul

SHUKOR

Kaitlyn Eleanor BEERS

Sharyn Lee BORRETT

Xiao Wei CHAN

Kai Liang CHEAH

Lap Lan CHENG

Yun Ho CHU

Liesl Dawn COLLINS

Anina De VRIES

Alexander DELLAMALVA

Han DENG

William DOVAN

Deborah Daphne ELIJAH

Jarrad Brian ELSON

Kenneth Roy FARMER

Sanjaya Nilantha GAMAGE

Vaibav GARG

Barun GHOSH

Sidharath Kumar GUPTA

Jia Jing HA

Zhee Enn HENG

Rachel Jane HOGEN-ESCH

Isabel Margaret HOLMES

Joseph Henry HOOPER

Matthew Anthony JUDE

Maansi JUNEJA 
Rami Theja KAMISETTY

Michael Liam KELLY

Amir Hossein KIAEE

Melissa Nalyana LAOHACHAI

Jason Tchun Yih LEE

Lyn Tze LEE

See Hwee LEE

Eugene Fuyou LIM

Su Fei LING

Xiang Fei LIU

Nirosha LIYANAGE

Emily Woon Fong LOH

Adeline Shyen Ai MAH

Zanab MALIK

Charlotte Helen MARRIOT-

SMITH

Elise Katherine McCONNELL

Clementine Rose MELLOR

Patricia MICHAEL

Julia MOLDAVTSEV

Aranan MURUGAMOORTHY

Teck Leong ONG

Silvia PARK

Nathanael Stephen ROWETT

Eun Ji SHIN

Gavindev Singh SIDHU

Vivian Ka Yan SIU

Majuri SRIHARAN

Irene SUBAGIO

Helena Sharmaine TEE

Tinu THOMAS

Kim Long TRAN

Stephanie Maria WALLS

Kylie Joanne WOODS

Huanrong XU

Benlee YAP

Wai Po YIP

Chin Howe YONG

\section{2}

Sarah Catherine ANDERSON

Laura ARNDT

Nishvanna Esther ARULIAH

Michael Stewart BACK

Edward Alastair BELL

Kathryn Florence BURNS

Yin Fei CHAN
Ting-Yu Alice CHEN

Chng Ren HAO

James Alexander CYMERMAN

Sofia Margaret DANCE-HOOI

Jamie Bach Duc DO

Jennifer Jin FENG

Michael FRAZIS

Wei Chien Shaun GOH

Alice Primrose GUBBINS

Sahani Udara GUNATHILAKE

Sophie Claire HALPIN

Sanglye HAN

Justin Ean Wei HUANG

Kimberley Sue HUMPHREY

Monica IBRAHIM

Sven William Christian

JENSEN

Ella JIN

Angela Anchee JOU

Ashminder KAUR

Shi Qi KHOO

Seung-Hyun Peter KIM

Yae Lin KIM

Gabrielle Simone KLINGBERG

Naomi Surekha KOTTEGE

Yong Zhi LAU

Anna-Marie Ee-Mun LEE

Chung Wai LEUNG

Oliver Po-Po LIAO

Yee Che LIM

Nadine Li Wen LIM

Carl Oliver MADDERN

Jessica Dillon Tohi MANUELA

Alexine Amy Livingstone

MOLLER

Shayda Vafai MORTAL

Luisa Hui-Lin NEO

Emily Lei-Chem NG

Guru Murthy O

Pan KAIXUAN

Edward James PITTS

Emilija Daina PORTS

Tianjiao Helen QI

Dihan Adrian RAJASINGHAM

Stuart Jack Ivars RENIGERS

Jang-Hyun Andrew RYU

Christine SAID
Ebonie Rianna SALTER

Mojdeh SASSANI

Sadaf SASSANI

Bhavnik Sharad SHAH

Laura Linzi SIEBELS

Andrew Steven SIMMONDS

Radhika SINGH

Nishit Bharatbhai SONI

Andrew John SOUTH

Justine Elizabeth STAMFORD

Sara STOCKHAM

Vui Leng TAN

Daniela TCHERVENIAKOVA

Fiona Nguyen Ngoc THUY

Christian John TOLL

Simon Andrew TOMS

Agnetha Eloise VALLADARES

Mohd Mansor WALIPOOR

Amelia Clare WIESE

Chamika Chathuranga

WIJAYASENA

Scott David WILLIAMS

Claire Elizabeth WILSON

Tchen Terk WONG

Dong Heuk YANG

Yi Fan YANG

Xiao Zhou ZHAN

Sanjia ZUBCEVIC

2013

Laura Anne AVERY

Nirosha Ambika

BALASUBRAMANIAM

Dominic Patrick BARLOW

Kathryn Anna BRIGGS

Pei San CHAN

Shai Main CHAN

Wing Chuan CHAN

Amy She Min CHEN

Tallan CHEW

Jaina CHHANABHAI

Iona Ji Whui CHUA

Tee-Ni CHUA

Mariam CHUNG

Matthew Joseph CLARKE

Susan Elizabeth CLIFT

Simone Elise CROMARTY 
Yee Lin DAN

Rafael Arthur DANCE-HOOI

Cory Wolf DEAN

Anni Phuong Nghi DO

Thi-Giang Ngoc Jennifer DO

Nicole Marie DODD

Li Wen FOO

Lauren Grace FOWLER

Vaibhav GARG

Ramy GEORGY

Lauren Jane GILL

Shweta GULVADY

Preshani GUNATILAKA

Danielle Elizabeth HARVEY

Teng Sian HOW

Wang Nian HUANG

Rami Adil HUSSAIN

Laura Anne HUXTABLE

Andrew Howing IP

Cecilia Cam Linh

JNGUYENPHAMHH

Evan Keith JONES

Karen KER

William Teck Yeow $\mathrm{KOH}$

Michael Franco LAVORATO

Ivan LEUNG

Jiao LI

Yi-Ning LIN

Keyi LU

Ho Kwan MAK

Sasha Trish McLEAN

Kumeran MOHAN

$\mathrm{Ng}$ Yao QUAN

Fong Yit OOI

Laura Louise PETROFF

Julie PHAM

David Julian POWER

Morgan Mitchell PRPIC

Prathayini PUVANAKUMAR

Alen RAHULAN

Purna Chamali RAJAPAKSE

Mark Christopher

ROZENBILDS

Heejn RYU

Mark Nicholas SCOPACASA

Boon Hong TAN

Adrian Swee Sing TANG
Tengu Maryam Fatimar Tengu

Ab MALEK

Wei Ling TIN

Elisabeth Hui Fen TOH

Yuichiro TOMO

Steven TRAN

Thuy Quyen TRAN

Gaurav Rajeev VAGHMARE

Hannah Harshita VASKA

Gunjan VERMA

Phung-Lan VO

Olivia Renee VONOW

Samual Joseph WILLIAMS

Deborah Hin-Yung WONG

Ee May WONG

Nicholas James WOOD

Rui Ming YAP

Cecilia Sat Yee YONG

James Ginkyu YOU

Laura Chia-Jung YU

Sheng ZHANG

\section{4}

Raifana Binti Abd RASHID

Gina ABDELMALEK

Aisyah Binti Ahmad FISAL

Amylia Kesha BAL

Daniel Jean BAUME

Vishal Mahesh BULSARA

Victor BUTNEJSKI

Hayley Pei San CHAN

Emma Rose COLOMBO

Larissa Anne De SAVI

Mayank Kumar DOGRA

Andrea Han Mai DOVAN

Caitlyn Margaret DUNCAN-

RYENBAKKEN

Merengege Kishan Sachintha

Samarakkody FERNANDO

Mira GERGES

Nabil Assad Gali GERGIS

Arun Karthick

GNANACHELVAN

Pik Ching GOH

Erwin Adinata HALIM

William Alexander HARIMAN

Alex Wern Juin HONG
Hua Ngik LING

Chu Yin HUANG

Tian HUANG

April Evelyn Cecilia

HUTCHESON

Jonathon Tzen Young

CHOONG

Shivani KAMALAINATHAN

Adam Joshuah KARSZ

Cham Nipunika

KARUNARATHNE

Seung Hyun KIM

Lasni Samalka

KUMARASINGHE

Jason Lai Chung LAU

Rene Andre LAUVEN

Uyen Huong Jennie LE

Lin Ching Krystle LEE

Wei Lin LEE

Suet Yen LEONG

Olivia Lee Hwa LIEN

Jun Seok LIM

Mian Jun LIM

Trudy Ying Hua LIN

Oi Kit LO

Kay-Win LOH

My Diep LUU

Mae Yee TAN

Chelsea MANN

Carine MAXWELL

Helen Claire McINNES

Sophie Alexandra McNEIL

Melissa lim Hui JUAN

Franco Daniel MIGNONE

Bernice Si Rong NG

Song Ping NG

Lucy Jane NIXON

Constantine NOER

Caroline Jean PETROFF

Katherine Jessica RAO

Benjamin Michael SCHAPEL

Sharon Xue Rong KWEK

Peranada SIRICHAI

Kate Victoria SNELL

Samuel David SOH

Colin Tchung-Lek SOON

Bianca Jane STARK 


Katie Natalia STELLON
Joanna Yu Ting TAN
Kevin Kian Howe TAN
Ching Ching TANG
Mary Wenjia TANG
Alexander Ji Chien THE
Emmanuel Min Foong TING
Joshua Yee Ming TING
Davide TONIZZO
Theophilos TOUMAZOS
Xinwen WANG
Jocelin WEN
Matthew Samuel WOLIANSKY
Stephanie Wan-Ling YAP
Hyung Muk YEUN
Michael Meng YUAN
Lucy Lu ZENG

\section{5}

Rose ALLEN
Marcus James ALVINO
Laura Astrid ASENSTORFER
Vishesh Sunil BHOJWANI
Julia Grace BRADSHAW
Ji Min CHA
Henan CHEN
Natalie Zi Xin CHENG
Leo Tien-Howe CHEUNG
You Xian CHONG
Marcus Ze Yuan CHUA
Anthony Christopher
COLELLA
Galappathige Shamalka Ushani
De SILVA
Shannon Nilusha De SILVA
Manisha DHANJI
Anh Van DIEP
Sarah-Jane Joanna ELIASSEN
Samantha ENNELS
Emma May FREEMAN
Amir Hossein HATAMI
Xie HE
Bernadette Yining HO
Kenneth Shou Bin KOH
Ki Hwan KWON
Kyungin LA
Ching LAI

Felicity Quynh-Nhu LAM

Hai Ying LEE

Su Min LEE

Yan Jun LI

Yinghui LI

Mark Weiyang LOW

Yue LU

Lisa-Marie MARTIN

Raoul Julio MASCARENHAS

Mohamad Sufrie Mohamad

ISHAK

Mustafa Kahil MIAN

Gyuweon MOON

Elizabeth Jing Jing NG

Jonathon Chee Keong NG

Sarah Hong Zhe NG

David NGUYEN

Dona NGUYEN

Peter Binh NGUYEN

Abirami PARAMESWARAN

Nathan James PARKER

Harry Thomas George

PERKINS

Rav Angelo RAMOS

Norman SADICK

Tina SANGHA

Sara Tan Min LING

Kevin Chun Kit SIN

Ramiya SRIHARAN

Saranya TALLURI

April TAM

Ee Xian Adyna TAN

His Ying Samantha TAN

Min Ling Sara TAN

Fady TAWADROUS

John Anh Quan TRAN

Vivian Kim Le TOH

Edward VUONG

Tibby Man Sum WAI

James WATERS

Yian Gee WONG

Michael WU

Gina Jingyang YANG

Angeline YEE

Erica Suki YEUNG

Jun Wen YONG

Bryan Xun Hui YU

Katrina ZHAO
2016

Timothy Luke ABRAHAM

Ramya AVVARI

Aleisha Imogen BASSETT

Matthew Robert BODO

Emma Kathleen BRANSON

Michael Archie BROOKS

Sarah Jane BRUNSKILL

Binh (Richard) Thanh Nguyen

BUI

Luke Jin Dong CHENG

Chim Wen Paul CHIN

Delia Kar Pei CHIN

Emma Yan Ling CHIN

Jung Youn CHOI

Sureka COULTHARD

Jannik Michael DE SILVA

Seth Navinda DELPACHITRA

Hannah Claire DOLBY

Patrick Anthony Wei Chuen

DOUGLAS

Max FERTMAN

Petronilla GRACE

Richard HARVEY

Leonard Arpad HEGEDUS

Denise Hui Yun HSUEH

Caitlyn Megan HUANG

Vivian Vi Anh HUYNH

Aarushi JOSHI

Jeong Woo KANG

Jian Xing KIEW

Dong Jin KIM

Suhyeon KIM

Young Joo KIM

Fung Shek Samuel KONG

Michael KOPESTENSKI

Jessica Agnes KUK

Kym LE

Andy Won Jun LEE

Felicia Ziying LEE

Henry Hongfu LEE

Ning Han LEE

Victor Chak LEE

Jocelyn Hwei Yen LIEW

Jonathan Ben Yuan LIM

Melvis Zhi Min LIM

Zi Wei LIM 
Chelsea Boon Ping LOO

William Weng Nian MAK

Andrew Michael MANOV

Nikki Joy MORGAN

Brett MORRIS

Jarrad NEWBOLD

Hang NGO

Nathaniel Tristan James

NOWICKI

Mitchell Thomas O'NEIL

Yuan Ren OOI

Rachel Hui Yi PANG

Hyung Jun Paul PARK

Christine PHAM

Luke Francis PHILLIPS
Saanchi RAMPRAKASH

Komal SHAH

Bryan Shiao Wun SIM

Saloni SINGH

Laura Kate SMITH

Joshua Su Lih Jye SOH

Rebecca Ann SPAGNOLETTI

Jemma Anne STERRICK

Raena TABESH

Chee (Careena) Yunn TAN

Jessie Jiale TAN

Joo Ping Emily TAN

Mei Wei TAN

Neil Yihao TAN

Sophie Jane TEAGER
Jia Jing TEH

Payal THATIKONDA

Keyuan TIAN

Stan VORSOVSKII

Eunice Shiuh Shyuan VUN

Daniel Robey WALLER

Annabelle Claire WAREHAM

Chor Wing WONG

Victoria Vanessa WRIGHT

William John WURF

Phei Ching YAP

Austin Jaehyun YOO

Minzhe ZHANG

Yang ZHAO

Bachelor of Oral Health (BOH) graduates (2004-16)

\begin{tabular}{ll}
2004 & Krystal PORTER \\
Jenny BAKER & Kirsty ROBERTS \\
Kim BICKERSTAFF & Karen ROLLS \\
Andrea BOSELEY & Nathanael ROWETT \\
Kyla BURMAN & Kesaobaka SELEDI \\
Renee EDWARDS & Ling TAY \\
Joshua GALPIN & Inge VON EINEM \\
Carly JONES & 2006 \\
Kylie LARSSON & Georgina ABBOTT \\
Monique LEWIS & Cameron ABBOTT \\
Natalia MATRONITSKY & Claire BATTERSBY \\
Lisa-May TRAN & Alicia GORDON \\
Melissa WHITE & Amy GRAHAM \\
Tika WORTH & Renee GRANT \\
2005 & Michelle HADDAD \\
Stacey ARNOLD & Lauren JARRETT \\
Annie BAKER & Marcelle JOHNSON \\
Jemma BARTON & Kostas KAPELLAS \\
Amanda BLUM & Gayathiri KUMARALINGAM \\
Sharyn BORRETT & Matthew LEACH \\
Violetta FELISZEK & Sedibelo LEBOTSE \\
Georgia FLYNN & Edward NASHAR \\
Donna FURLER & Kate NEVILLE \\
Isabel HOLMES & Natalie OLSSON \\
Blanca ISAAC & Kim OM \\
Kim Nhan NGUYEN & Lynda PROBERT \\
& Jennifer SLATER \\
& \\
\hline &
\end{tabular}

Diem TANG

Monique TOSATO

Mai VUONG

Melissa WILSON

2007

Emily CHALMERS-

ROBINSON

I Chen CHEN

Malvina FILIP

Joseph GALERAGWE

Tarnya HARKNESS

Alison JENNINGS

Rachelle KERR

Khalid KHAN

Victor LEE

Maria LUCAS

Nicole MASTERS

Emily McGUIRE

Noelene MOYLE

Danielle NEWBERY

Linda NGUYEN

Hannah PALMER

Andrea PAUL

Sally PICKMERE

Corinna REID

Sara ROBERTS

Kathryn SAUNDERSON 


Lisa SHI
Xiang SOH
Daniel TARASIUK
Lavanija THEVARAJAH
Anh Tuyet TRAN
Stamatoula TSANTES
Kavita TUTEJA
Mayomi WALISUNDARA
Zoe WHITEWOOD

\section{8}

Anita BALLARD

Anne-Marie BINI

Linda BUI

Michael CALAVA

Amelia CANDY

Judy CHIANG

Jeremy CHRISTIANSEN

Kate CREWDSON

Bianca ESPOSITO

Michelle HARRIS

Olivia ILBA

Lori Lee JAGGARD

Kathryn LANE

Katie MCKIERNAN

Catherine MOULT-SMITH

Lisa MULAR

Hung NGUYEN

Nathaniel NOWICKI

Laura PETROFF

Vy Thuy PHAM

Deanne PRICE-BURGESS

Luke REES

Nicole RENDELL

Jenna SAUER

Brooke SAUNDERS

Amanpreet SUAAN

Maria TSONIS

2009

Parwin AHMADI

Jennifer CAO

Duo CHEN

Alex CONDINA

Karina GEBHARDT

Tarnya HARKNESS

Stephanie HARRER
Luke KNOLDER

Meg LUMSDEN

Jasmina MASLO

Amy MCMAHON

Robyn PAVY

Nicole PERRIN

Julia SHARPE

Rachel SPILLMAN

Amanpreet SUAAN

Belinda TANK

Jesse TRENTO

Dimitri TSIMOPOULOS

Robert ULIVIERI

Acacsia WASTELL

\section{0}

Emma BRETTIG

Aaron BULNER

Cecilia CAO

Rebecca CHOIMES

Thu Huong Bao CHUNG

Sarah CUMMING

Nathan DABEK

Emily DEAN

Hue Kim DO

Danielle FEUTRILL

Leticia GOSS

Lisa-Maree HENRY

Alexander HILL

Dianne HOANG

Naomi HOOPMANN

Niloufar KARAMI

Steffany KWOK

Truc Anh Thi LAM

Julia MATTHEWS

An Kim NGUYEN

Mark NOOR

Chantelle NOWICKI

Elizabeth PEGLIDIS

Danielle PESATURO

Matthew PREECE

Jennifer RIDLEY

Nikole ROZAKLIS

Kate SCHOMBURGK

Tessa SMITH

Katie STANDISH

Elvina STANKOVIC
Anh Thao TRAN

Ria TURNER

Emma VASILEFF

Nicholas WATTS

2011

Dimitra AGINARTZIS

Emma BAILEY

Nicole BRZEZINSKI

Timothy BUDDEN

Spencer CLOSE

Candice DE BLASIO

Bethany HARVEY

Hong Nguyen HUA

Sahba KAZERANI

Jessica LI

Duncan LU

Amanda MORELLO

Mai Thuy Thi NGUYEN

Vivian NGUYEN

Mia Hye Rim PECK

Patricia RONCAL

Shelley TRAN

Tony VO

Heidi-Lee WOODFORDE-

HEARNE

\section{2}

James AGIANNIDIS

Kimberley BARBETTI

Hannah BERMAN

Jaqueline BIGGAR

Jade CAMPBELL

Joanne CHEN

Thomas COCKS

Hannah COLANTONI

Rachel COOPER

Lauren CROSS

Connie-Sue DROGEMULLER

Lina FARES

Lucinda FOSTER

Madeleine GILKES

Jessica GOODALL

Steven $\mathrm{HO}$

Nara JOHNSON DE

CARVALHO

Greta KERNICH 
Renae KUMAR

Gulfeira KURBAN

Karen LAM

Julie LE

Matthew MICIAN

Catherine NEWSHAM

Nhi (Nita) NGUYEN

Maria OBAJDIN

Shubhangini PATIL

Jimmy PHAM

Thu-Huu PHAM

Linda QUANG

Jane REYNOLDS

Thomas ROGERS

Patricia RONCAL

Francesca SMERDON

Emma WOHLERS

2013

Mikaela ALDENHOVEN

Emma BALL

Olivia BEARE

Erin BROWN

Leanne CHAO

Stella FRIGO

Celia GAJDA

Ania GHODRATI

Georgia GUGLIELMUCCI

Teghan HARMES

Elise HENKGEN

Sophie HOGARTH

Mirela HORAN

Linh My HUYNH

Sally JEFFRIES

Jasmine KEELER

Amy KNOWLES

Gulfeira KURBAN

Nhung Bich (Sylvia) NGUYEN

Nikita NGUYEN

Emma NOBLET

Alexandra NORRIS

Georgina ORMANDY

Ellen OWCZAREK

Monique POTOCNIK

Sarah SMITH

Madeline STEFAN-RASMUS

Kimberly VASQUEZ

\author{
Toni VERHOEVEN \\ Denny WEBBER \\ Brandon WENTZEL \\ Edwina WILLIAMS \\ Yuetong (Tracy) ZHENG
}

\section{4}

Julie AITCHISON

Vanessa ANFITEATRO

Jenna ATHERTON

Chloe BARTSCH

Lauren BAXTER

Kelsey BIRKIN

Georgina BRADLEY

Claire DAMIN

Akrati DWIVEDI

Kate FOULIS

Nicholas GALIMITAKIS

Chloe GALPIN

Elizabeth HARBISON

Brianna HOLMAN

David LORD

Karla MEJIA RAMIREZ

Veronica PLETIAK

Louise READ

Jessica RIDGWAY

Beth RISCHMUELLER

Grace SMITH

Kate SPICER

Alba TESSITORE

Cassie TODD

An Ngoc TU

Emma WOJCIECHOWSKI

\section{5}

Meghan ARMITAGE

Lauren BACHLI

Courtney BARKER

Edwina BIRDSEYE

Dannielle BROUGHAM

Jessica BROWN

Reaghan EDMONDS

Rebeca FANDINO

Steven GAITANERIS

Samantha GALPIN

Preethy GEORGE

Sally HOARE
Melissa LUDWIG

Madeleine MCLAREN

Jade MOORE

Kym NGUYEN

Lam NGUYEN

Ian Vic NICDAO

Tessa PATE

Bonnie PETROFF

Shin QUACH

Chloe REIMANN

Danielle RITCHIE

Angela SACCO

Kirsty SCHNEIDER

Nhung TRAN

Rachel VORAKOUMANE

2016

Bethany BOWSHALL

Amelia BRATOVIC

Ly CAO

William CARLSON-JONES

Brittany COKER

Jasmina CULIC

Ziyin DENG

Huu DINH

Joanna DO

Madeline DUCKER

Sarah FU

Kate HARCOURT

Chih-Yi (Kevin) HSIAO

Mukhlisah KAFRAWI

Alicia KEANE

Karen KENNEDY

Annie LUKE

Haroula MANOLAS

Donna MCMAHON

Lana MUSTAFA

Huong NGUYEN

Michael OWENS

Rhett PEEREBOOM

Larishna RAMASAMY

Sanam REZAEI

Shanti TOH

Alesha TRAN

Jasmine VIKOR

Michael WONG 



\section{Appendix 3 \\ Selected documents}

The opening of the new Royal Adelaide Hospital Dental Department and the University of Adelaide School of Dental Science (1969)

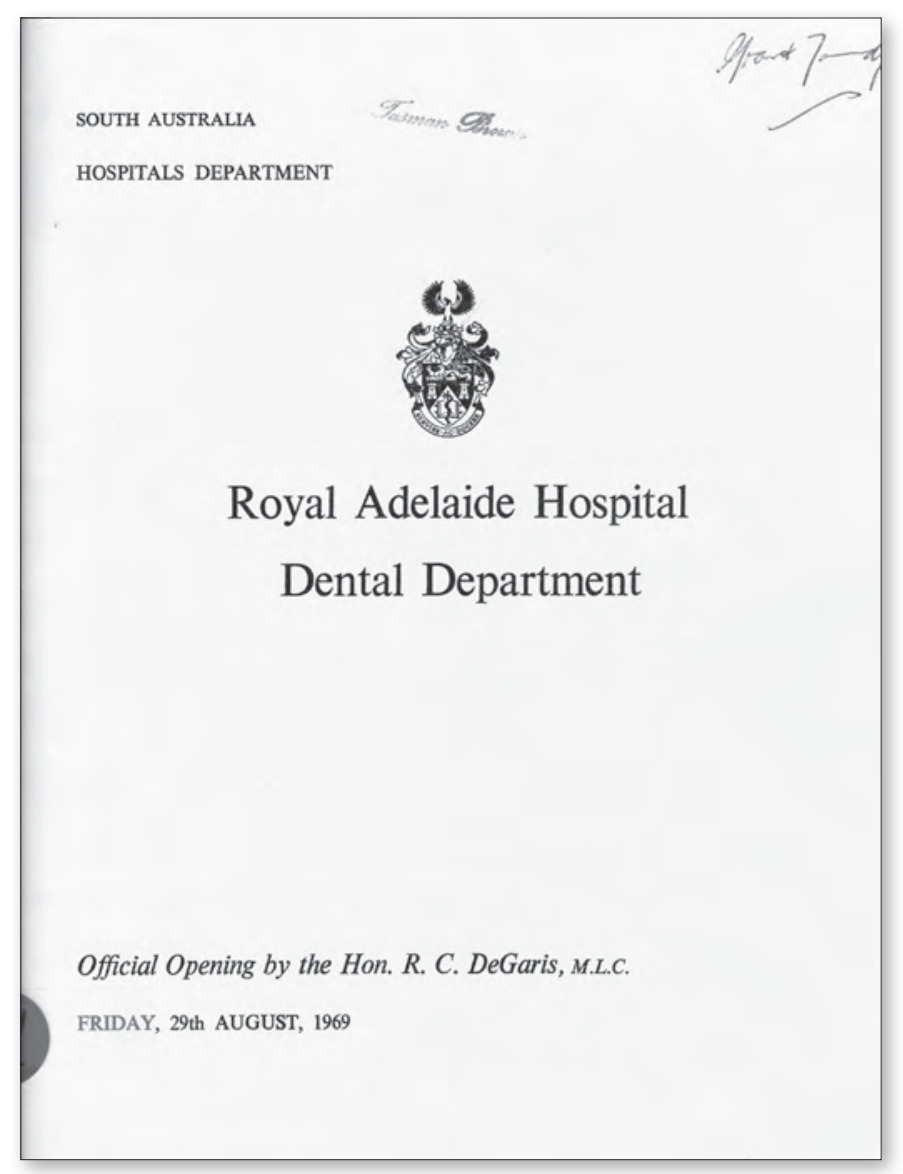

Figure A3.1 The programme to mark the opening of the new Royal Adelaide Hospital Dental Department and the University of Adelaide School of Dental Science (1969), (this page, and as follows). 


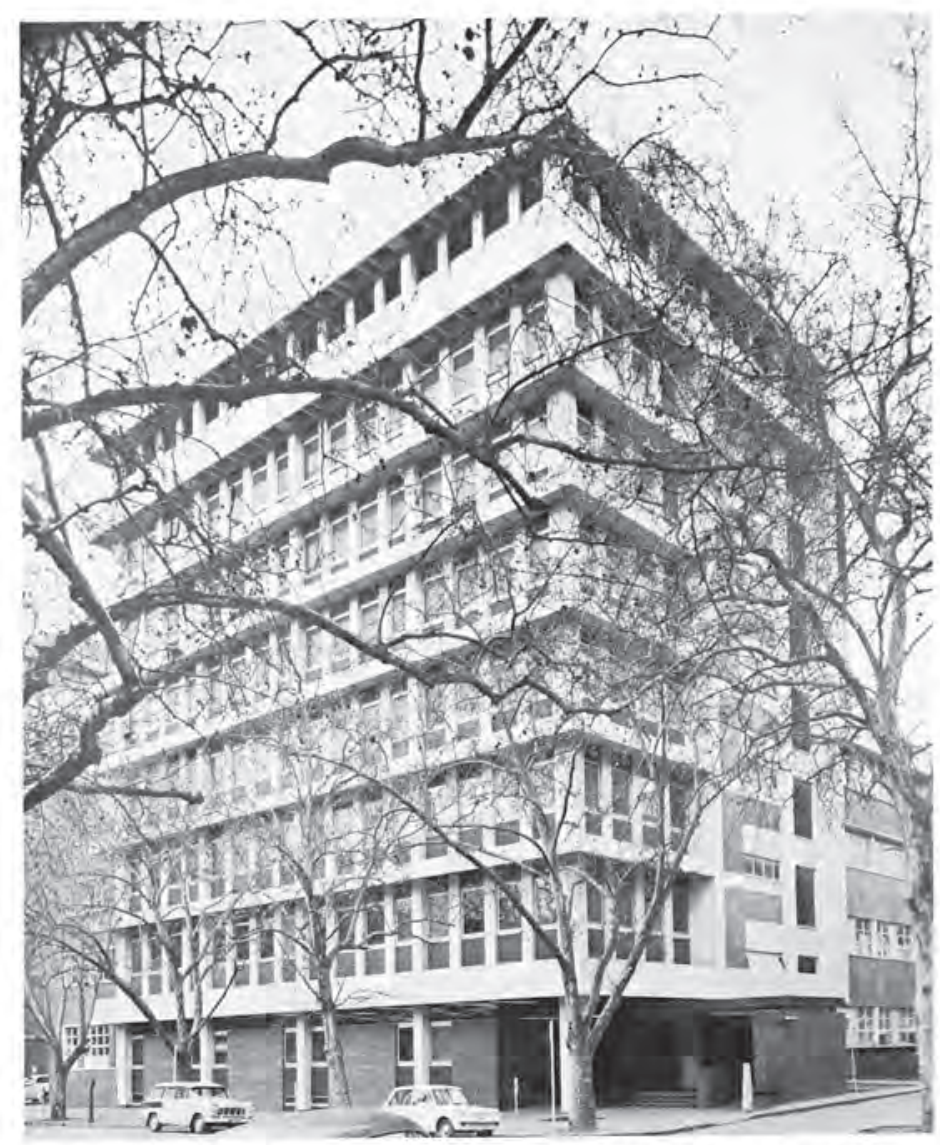

Royal Adelaide Hospital Dental Department and The University of Adelaide School of Dental Science 


\section{SOUTH AUSTRALIA}

CHIEF SECRETARY AND MINISTER OF HEALTH

Hon. R. C. DEGARIS, M.L.C.

\section{HOSPITALS DEPARTMENT}

Herad of Deparment: Dr B. J. SHEA, M.B. B.S. D.P.M. F.A.N.Z.C.P. F.A.C.M.A. DirectorGeneral of Medical Services

Assistant Directer-Generai (Planning and Development) : C. G. R.ANKIN, E.D. F.A.S.A. F.C.I.S. T.H.A. F.A.M.

Assistant Dirctor-General (Finance)! J. L. MOULE, A.A.S.A. (Senior)

Assistant Director-General (Hospital Services) † H. J. V. L.LOYD. A.A.S.A.. A.C.IS., A.H.A.

ROYAL ADELAIDE HOSPTTAL.

BOARD OF MANAGEMENT

Chairman:

Dr. B. J, SHEA, M.B., B.S, DPM. F.A.R.C.P. FA.C.M.A.

Member:

Mr. E, R. DAWES, C,M.G.

Mrs, T. R. WILLLAMS

Acting Administrator:

Mr. R. L. HOOPER, A.U,A., A.A.S.A. (Senior), A.H,A., J.P

Medical Superintendent:

Dr. B. NICHOL.SON, M.R.C.S. L.R.C.P.. L.H.A., F.A.C.M.A.
Matron:

Miss 1. M. KENNEDY. F.C.N.A., S.T. Dip. (Univ. of Lond.), Dip، Nursing Admin. 
ROYAL ADELAIDE HOSPITAL

STAFF OF DENTAL. DEPARTMENT

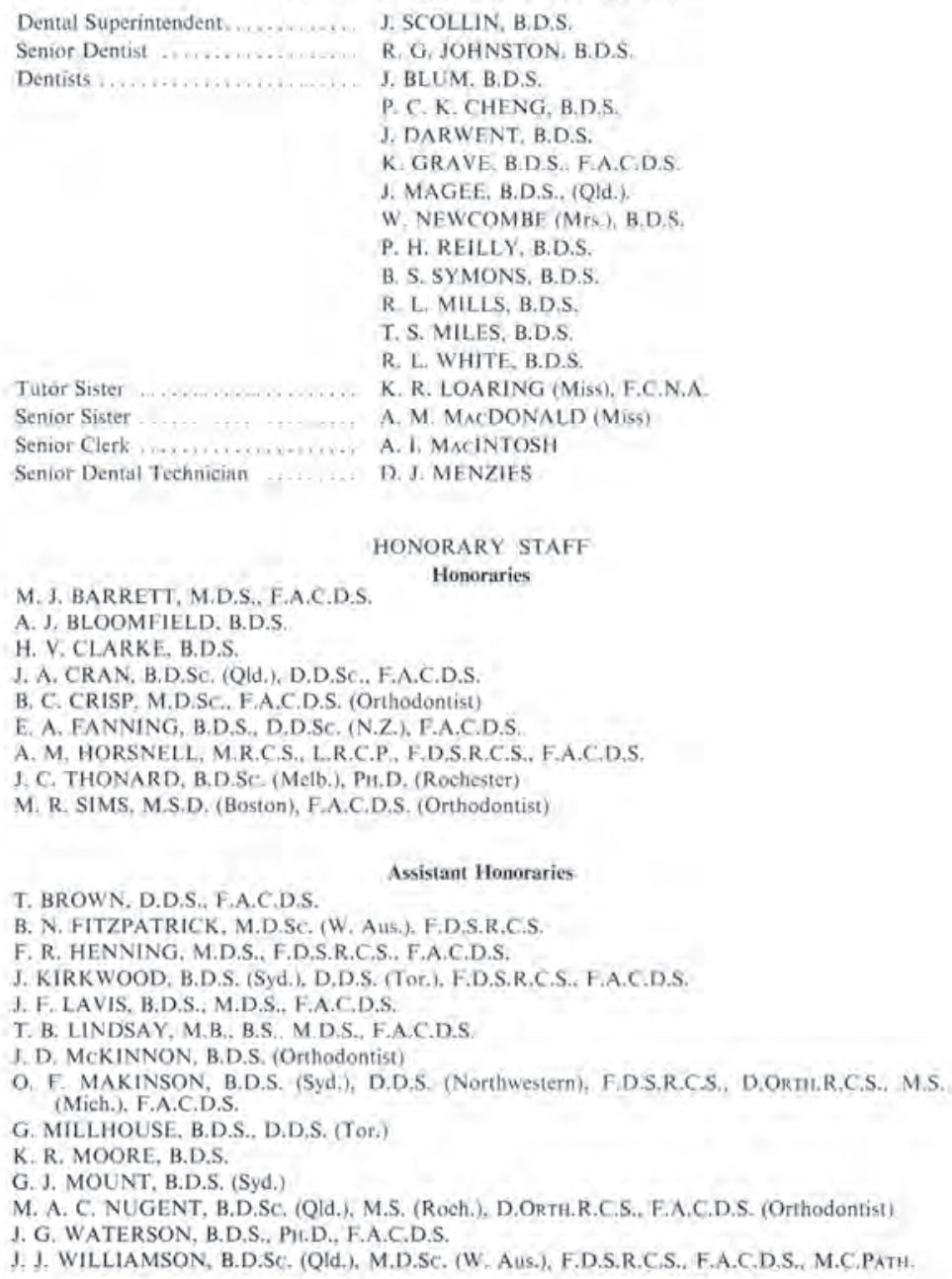

Assistant Honoraries.

T. BROWN. D.D.S., F.A.C.D.S.

B. N. FITZPATRICK, M.D.SC. (W. Aus.). F.D.S.R.C.S

F. R. HENNING, M.D.S., F.D.S.R.C.S., F.A.C.D.S.

J. KIRKWOOD, B.D.S. (Syd.), D.D.S. (Tor.), F.D.S.R.C.S., F.A.C.D.S.

J. F. LAVIS. B.D.S., M.D.S., F.A.C.D.S.

T. B. LINDSAY, M.B. B.S M.D.S. F.ACDS

J. D. MCKINNON, B.D.S. (Orthodontist)

O. F. MAKINSON, B.D.S. (Syd.), D.D.S. (Northwestern), F.D.S.R.C.S, D.ORTI, R.C.S., M.S. (Mich.). F.A.C.D.S

G. MILLHOUSE, B.D.S., D.D.S. (Tor.)

K. R. MOORE, B.D.S.

G. J. MOUNT, B.D.S. (Syd,)

M. A. C. NUGENT, B.D.SC, (Qld.), M.S. (Roch.), D.ORTH.R.C.S., F.A.C.D.S. (Orthodontist)

J. G. WATERSON, B.D.S., PII.D., F.A.C.D.S.

J. J. WILLIAMSON, B.D.SC. (QId.), M.D.SC. (W, AUS.), F.D.S.R.C.S., F.A.C.D.S. M.C.PATH. 


\section{The University of Adelaide}

\section{STAFF OF THE DEPARTMENT OF DENTAL SCIENCE}

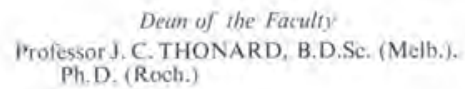

\author{
Head of Department \\ Professor A, M. HORSNELL, F.D.S.R.C.S., \\ M.R.C.S. (Eng.). L.R.C.P. (Lond). \\ F.A.C.D.S
}

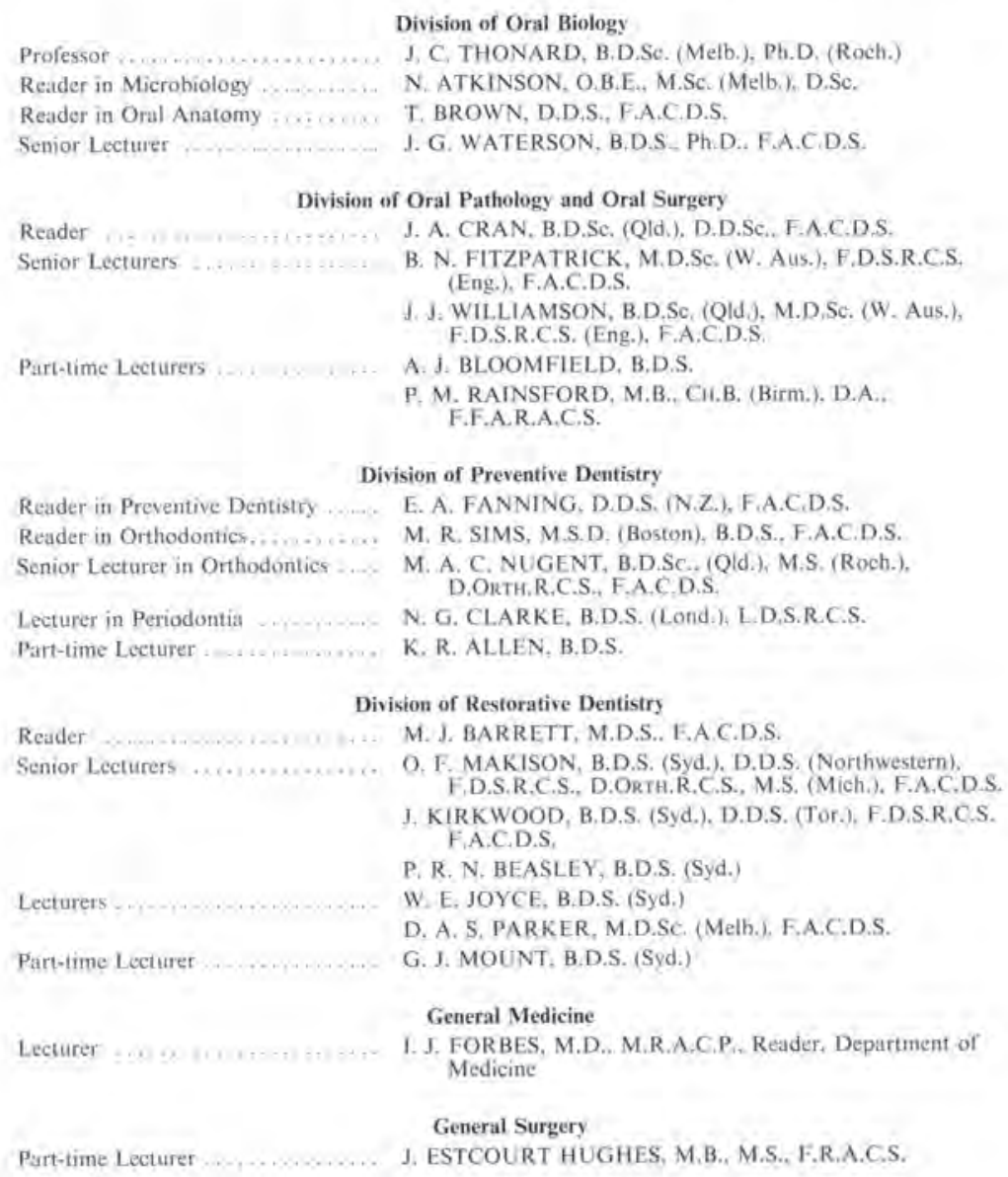


PART-TIME TUTORS

Oral Pathology and Surgery

R. E. ANNELLS, B.D.S.

K. W. BAILEY, B.D.S

D. BLAIKIE, B.D.S.

J. F. HOWELL-PRICE, B.D.S. (Syd.)

T. B. LINDSAY, M.B. B.S. M.D.S.,
F.A.C.D.S.

B. A. MeDONALD, B.D.S.
P. deP, MCDONALD, B.D.S.

K. R. MOORE, B.D.S

J. P. MORECROFT, L.D.S. (Mane.)

G. S. PATER, B.D.S

D. J. RUGLESS, B.D.S.

B, H. SOUTER, B.D.S.

R. C. STEPHENS, B.D.S.

Preventive Dentistry

M. BEVAN (Mr5.), B.D.Sc. (Melb.)

J. O. BROOK, B.SC, B.D.S.

G. I. BROWN, M.D.S. F.A.C.D.S

J. F. BURROW, B.D.S.

P. M. CADDY, B.D.S.

B. C. CRISP, M.D.S., F.A.C.D.S.

C. M. DURNEY, B.D.S

T. GOTJAMANOS, M.D.S.

F. R. HENNING, M.D.S.. F.D.S.R.C.S.. F.A.C.D,S

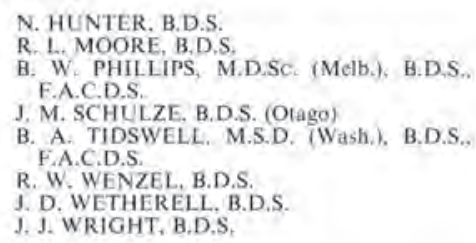

Restorative Dentistry

P. R. APPELBEE, B.D.S

R. V. BARTHOLOMAEUS, B.D.S.

A. J. BLOOMFIELD, B.D.S.

J. BLUM, B.D.S

K. A. BROWN, B.D.S.

J. D. CHEETHAM, L.D.S.R.C.S.

H. V. CLARKE, B.D.S.

L. L. DAENKE, B.D.S., F.A.C.D.S.

A. F, DAVY, B.D.S.

B. H. DUNSTAN, B.D.S

G. D. DUNSTONE, B.D.S

G. G, L. EVANS, B.D.S

M. T. FRAYNE B.D.S

M. C. GIBBERD (Mrs.), B.D.S.

G. C. HALL, B.D.S.

R. F HARRINGTON, B.D.S.

G. S HEITHERSAY M.D.S. FD.S.R.C.S (Edin.), F.A.C.D.S

I. H. HODGSON, B.D.S.

W. H. HOLMES, B.D.S

H. D. KENNARE, B.D.S

R. J. KIDD, B.D.S.

T. E. KRASSAY, B.D.S.

J. F. LAVIS, M.DS. F.A.C.D.S

J. B. LEACH. B.D.S

P. A. LEANEY. B.D.S.

B. N. LUKE, B.D.S

J. I. LUKE, B.D.S.

1. A. MCKENZIE, B.D.S.

J. E. MARRIOTT, B.D.S

P. L. MARTIN, B.D.S.

T. W. MARTIN, B.D.S.

G. MILLHOUSE, B.D.S. D.D.S. (Tor)

A. M. MUIRHEAD, B.D.S.

R.J MYHILL. B.D.S.

B. NAPIER, B.D.S.

G. S. PARRY, B.D.S.

G. J. PFEIFFER, B.D.S.

I A REINERS, B.D.S. F.A.C.D.S

D. R. SMERDON, B.D.S.

R. A. W. SNOW, B.D.S.

C. M. SOMERVILIF, B.D.S.

I. A. STEAD, B.D.S

P. R. STEWART, B,D.S,

J. R. THOMPSON, B.D.S.

R. L, VON DOUSSA, B.D.S

B. N. WALKER, B.D.S. (N.Z)

B. G. WARK. D.D.S. (For.), B.D.S. L.D.S.R.C.DS (Ont.). F.A.C.D.S.

R. F. E. WELCH, B.D.S

General Medicine

A. M. MACKINNON, M.B., B.S, M.R.A.C.P,

R. WILLING, M.B.. B.S., M.R.A.C.P.

E. G. WILMSHURST, M.B., B.S. M.R.A.C.P.

General Surgery

P. G. CARNEY, M.B., B.S

G. R SINCLAIR, M.B. B.S

A, N. VORBACH, M.B, B.S 


\section{Development of the Dental Department}

In A History of the Royal Adelaide Hospital, 1967, the author, J. Estcourt Hughes, V.R.D., M.S.. F.R.A.C.S., wrote:-

"In 1917 the first steps were laken towards making a major addition to the Hospital services. The University of Adelaide and the Board of Manigement of the Hospital were approached by the Odontological Society and the Dental Graduates' Society with a view to estublishing in Adelaide a Dental School, which would enable stodents to be trained and to qualify here instead of having to go to another State for this purpose.

The various interests were represented on a committee which was set up to deal with this proposal. The Hispital Beard was represented by Mr. W. G. Coombs and Dr. R. S. Rodgers, the University by Professor E. H. Rennie and Dr. A. M. Cudmore, and the two dental societies by Messrs, E, J. Counter. H. Gill Williams. W. A. Harrop and Alexander Swan.

These negotiations began while the country was still at war and it is not surprising. therefore, that. although the committee beld many meetings, progress was slow, but by 1919 the scheme was sulticiently advanced for the Government to have approved it. to have made a financial allstment and to have authorized the Superintendent of Public Buildings to prepare plans tor consideration.

The project received at considerable fillip when on oth February, 1920, the South Australian Dixision of the Red Cross Society received a leiter from the Secretary of the Australian Red Cross Society in Melhourne to sily that the British Red Cross Society had decided to give to Australia the large sum of $E 150,000$, which wats to be distributed at the discretion of the Ginvernor-General of Australia. Each State was to receive a share and was asked to suggest to the Governor-General how the amount should be spent. Sir Joseph Verco was granted an interview with His Excellency and he discussed with him the South Australian suggestions. The outcome of this conference was that this State received 15.000 towards the erection of a Dental Hospital within the Adelaide Hospital grounds. The State Government agreed to give it further $£ 10,000$

No time was lost in starting the building which was completed in 1923 and was opened to the public on 10th July, in that year. The Dental Hospital was a red brick building of two Hoors with a tiled roof and a portico-style entrance facing Frome Road. The ground floor accommodated a waiting hall. the administrative offices and the operating surgeries with their associated preparation and recovery rooms. Also on this floor was the extensive prosthetic section. which consisted of the prosthetic laboratory with side rooms for plaster and metal casting, a demonstrator's room and a storeroom. The first floor was devoted to conservative treatment, the main treatment room being targe enough to take forty-eight dental chairs. There were also an X-ray room, a lecture theatre, a library and roms for students and nurses. The appoinuments and equipment were said to be of the highest standard.

Immediately after the end of the Second World War consideration was given to the enlargement and modernizing of the Dentil Hospital. This led to an enquiry by the Standing Committee on Public Works in 1949 and again in 1953. Approval for extensive changes in the buiding was given. but a variety of considerations prevented the work being begun until 1958 .

The extensions consisted of a new north wing of five storeys and a south wing of four storeys. The original hospital linked these wings but it has now, in 1965. been demolished and in its place will be built a six-storey structure to the design of which the architects and members of the staff have given minute and painstaking attention," 
Subsequently. predictions for the growth and future requirements of the Department were reviewed, and recommendations for the ultimate development on the present site were submitted to the Public Works Standing Committee and adopted in 1964.

The recommendations provided for the demolition of the original building, and for the erection of a new eight floor building on the site, eonnecting with the North and Sisuth wing additions. which hud been huilt earlier. Limitations of the site conditions with the established floors in the North and South Wings. the difficulties involved in maintaining the services to the public of the Dental Department and the Dental School whilst erecting a new building in the centre of the site, together with the usual problems of noise. dust, vibration and protection complicated the task of the Afchitects, Engineers and Contractors.

The finished huilding provides complete facilities for the reception, exumination and treatment of patients, the training and teaching of undergraduate dental stodents, training of dental uurses and technicians, and post graduate research in various fields of dental science and clinical dentistry.

Architects for the recently compleled building were Cheesman. Doley. Brabham and Neighbour. with Structural Engineering Consultants. Barnes and Associates. Mechanical. Electrical and Air Conditioning design was by the Engineering Office of the Public Buildings Department, and Quantity Surveyors were Crisp, Kavanagh and Partners.

Construction was carried out by A. W. Baulderstone Pry, Lid, with major services subcontractors, Alfred Martin and Sins Pty Lid., Carrier Air Conditioning Pty. Ltd., Baulderstone Electrical Pty. Ltd. and Elevators. Pty. Ltd. Dental Equipment, and locse fumiture was supplied and installed by separate coniracts. The final cost of the new buildings with equipment, is estimated to be $52,750,000$.

\section{NOTE FROM THE VICE-CHANCELLOR}

Emeritus Professor G. M. Badger. M.Sc. (Melb,), Ph.D. (Lond.), D.Sc. (Glix.). F.A.A.. F.R.T.C.

E.R.A.C.I.

The Hospitals Act imposes special and serious responsibility on the teaching hospitals in relation ta medical and dental students. The provision of lecture theatres. laboratory accommodation and special clinical facilities in the new dental building demonstates clearly that the Board of the Royal Adelaide Hospital recognizes these responsibilities in regard to dental students.

Through its location in the new building the Dental School is most favourably situated in relation to the main campus of the University, the preclinical Medical School and the Institute of Medical and Veterimary Science as well as to the wards and special departments of the Royal Adelaide Hospital.

Remarkable advances have occurred in medicine and science generally, and dental science is not excepted from these changes. Its contributions are notable in the development of public health programmes to prevent or reduce dental disease as well as in the altered pattern of dental treatment in clinical practice. Dental education has changed considerably in the last two decades and no doubt, with the present greater emphasis on the basic biological aspects of the course, further changes can be anticipated.

The fact that the research facilities for staff and graduate students provided in the new building are already utilized fully and likely to prove inadequate soon is ample proof of the vigour of the University's Department of Dental Science: It also indicates the continuing need for close collabora. tion between the Hospital Board and the Council of the University.

$x^{2}$ 


\section{Description of Accommodation}

BASEMENT

Records Department-Houses all patient treatment records, and Orthodontie Model Store.

Nurses' Amenities, including Nursing and Fernale Staff locker fowms and toilets.

Stores-General hospital and dental supplies, and linen store.

Dental Maintenance Workshop for the repair and servicing of the dental equipment.

Plant Room-Engineering Services including Dental oral evacuation plant. uir conditioning, and hot water-calorifiers.

Students' Amenities, including Common Room. lockers and toilet facilities.

GROUND FLOOR

FIRST $\mathrm{TIOOR}$

SECONI FLOOR

Admission and Examination, including main entrance, general waiting hall and lift lobby, admission office, assessors rooms, and three dental examination rooms.

Diagnostic Radiography Department, including waiting area, office and records, three intra-oral radiographiy rooms, extra-oral radiography room. seminar and viewing room, radiography processing darkroom, equipped with automatic film processor, and con. nected to all clinics with a film hoist.

Oral Surgery clinics, including kix clinic surgeries. operating theatre suite, and elective Oral Surgery theatre, recovery room, patient waiting room, stores, sterilizing and decontamination room.

Prosthetic Clinic, with two clinic operatories, offices, waiting roon, and Dental Technicians Laboratory.

Stafi Amenities, including Professional Staff comnon mom. staff locker rooms and toilets. Technical Staff common room. lockers and toilets.

Fuur Dental Treatment Clinics, with 80 undergraduate clinic operatories, and ancillary mursing service and store rooms. consulting rooms, radiographic. totors, and demon. stration (teaching) rooms. Special Treatment Clinic, with four surgeries for use by graduate students. Hospital and Professorial Staff. General waiting area serving all clinics.

Dental Photography Department. housing photographic studio and office, general purpose darkrooms, chemical mixing and camera rooms, and research darkrooms.

Two Dental Treatment Clinics, with 40 undergraduate Clinic operatories and support facilities as provided on the First Floor.

Special Treatment Clinic, with six Clinic Operutories, Registrars Room and nursing service rooms, patients' waiting area. 
Central Sterilizing Department with three ultru-sonic dental instrument und handpiece cleaners, three high pressure sterilizers and two autoclaves, sterile store for dental instrament kits, staff change fooms and office, and a separate Prosthetic Sterilizing Area. Department of Preventive Dentistry, houses the oflices and laboratories of the Professor and Staff of this Deparment, together with materials research laboratories, Survey Ollice and Seminar Roum.

TIIID FLOOR

FOURTI FLOOK

FIFTH FI.OOR

SIXTH FLOOR

SEVENTH FLOOR
Restorative Division, includes laboratory teaching facilities for undergraduate students, with two major laboratories, and associnted service facilities, lecturers oflices and taboratories and television studio unit, dental technician laboratories with full facilities for hospital dental technicians, including a Ticonium Laboratory and Acrylics Processing section

Administration, including oflices for the Dental Superiniendent and Administrative Officer. Dean of the Dental School. Senior Dental Sister and waiting area. Dental Nurse Training School, including a classroom and Tutor Sister's Office.

Conservative Surgeries, including 16 clinic operatories for Hospital Dental Surgeons. with assotiated nursing and service facilities, reception and waiting area.

Orthodontio Clinic; including 10 clinio operatories, reception and waiting area, Seminar and tracing room. dental hygiene rooms. technicians and post-graduate students laboratories, consulting and radiography rooms. Plan Room and Lift Machine Room INorth Wing section).

Departmenis of Oral Biology and Oral Pathology. including offices and labonitories for the Professor and University staff. research laboratories ind service laboratories for microbiology, histopathology and histochemistry, special laboratory equipment room. darkroom, balance room. incubator and cold rooms. animal holding and operating rooms.

Departments of Dental Anthropology and Histology, including media preparation. sterilizing and storage rooms, histology laboratory and classroom, stuff offices: anthespology research and study rooms.

Lecture Theatres and Museum, including a major lecture theatre with a seating capacity of 90 persons. a smaller leciure theatre seating 60 persons. a dental museum and work room.

Engineering. Plant including Air Conditioning. Wuter Supply tanks, Lift Machine room. 


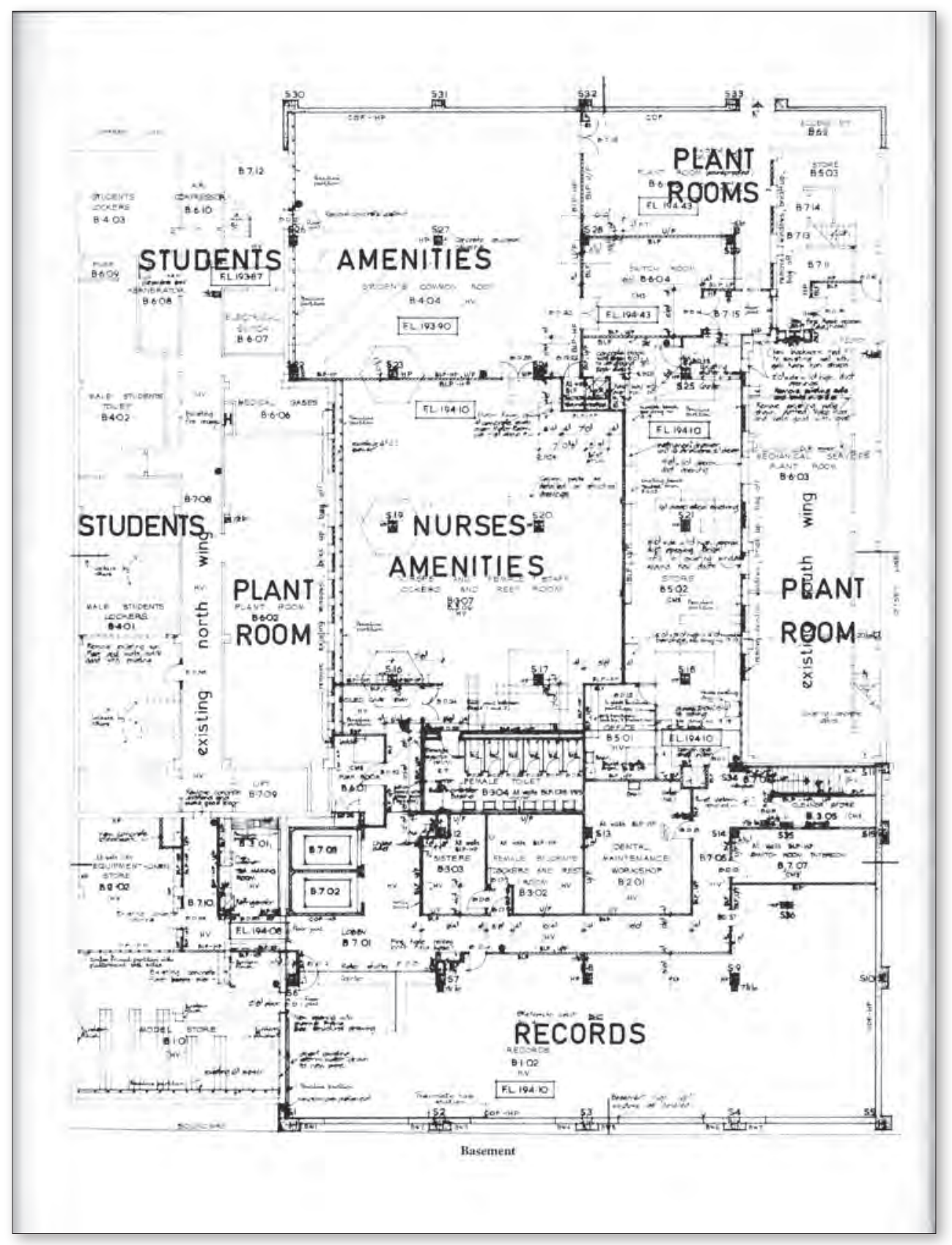




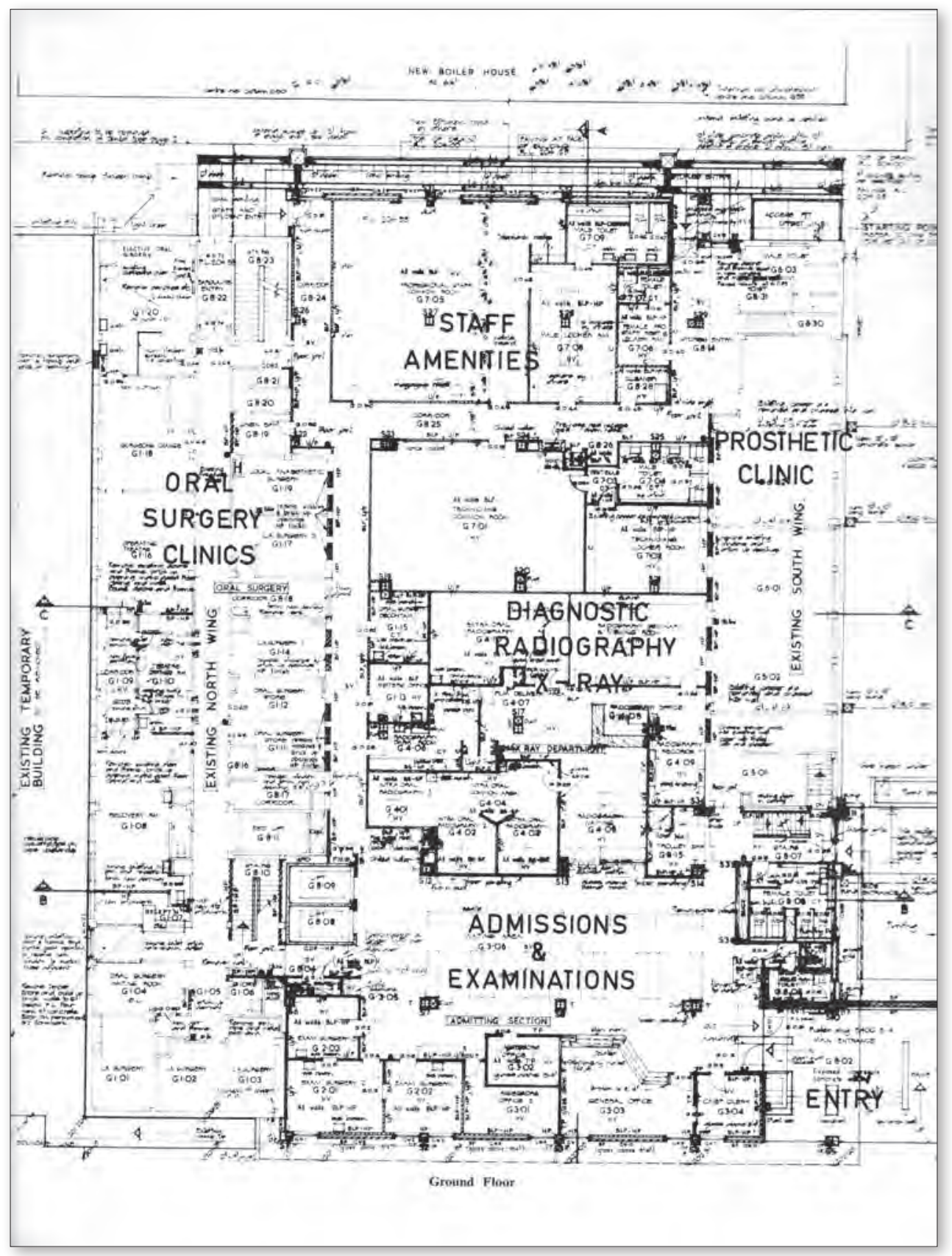




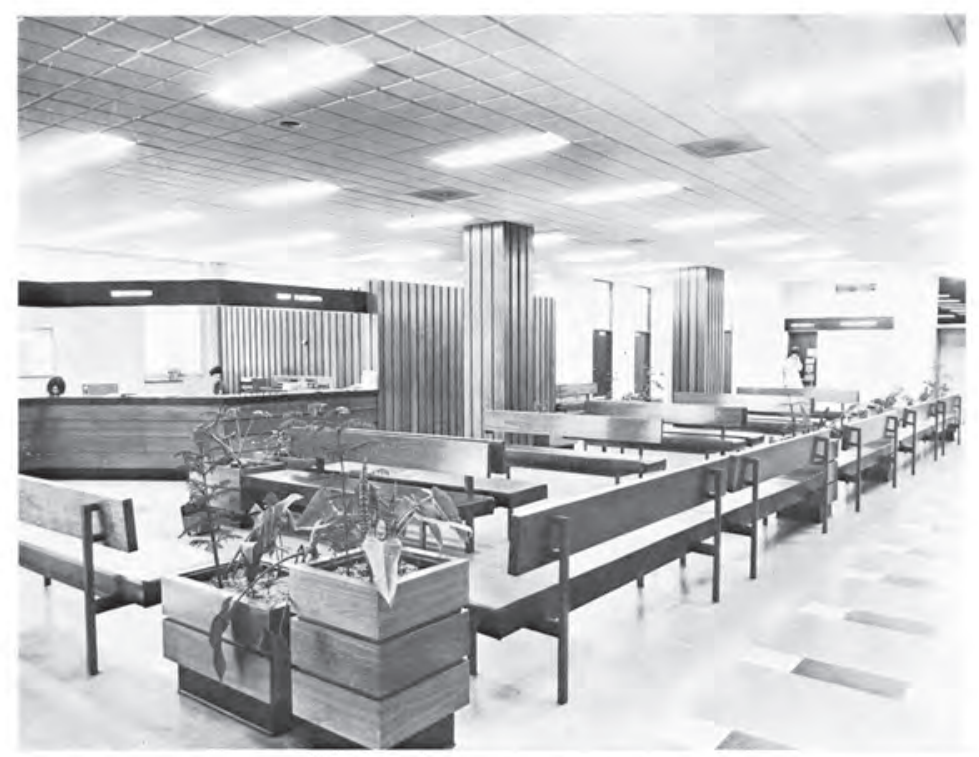

Ground Floor: Admission and Examination Centre

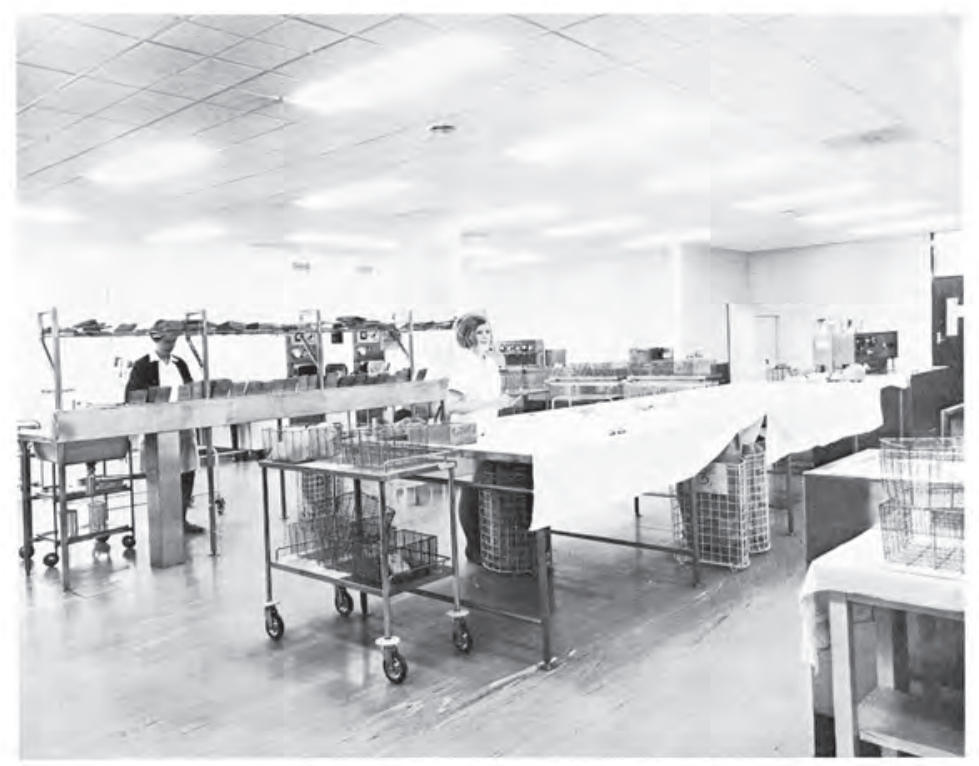

Second Floor: Central Sterilizing Department 


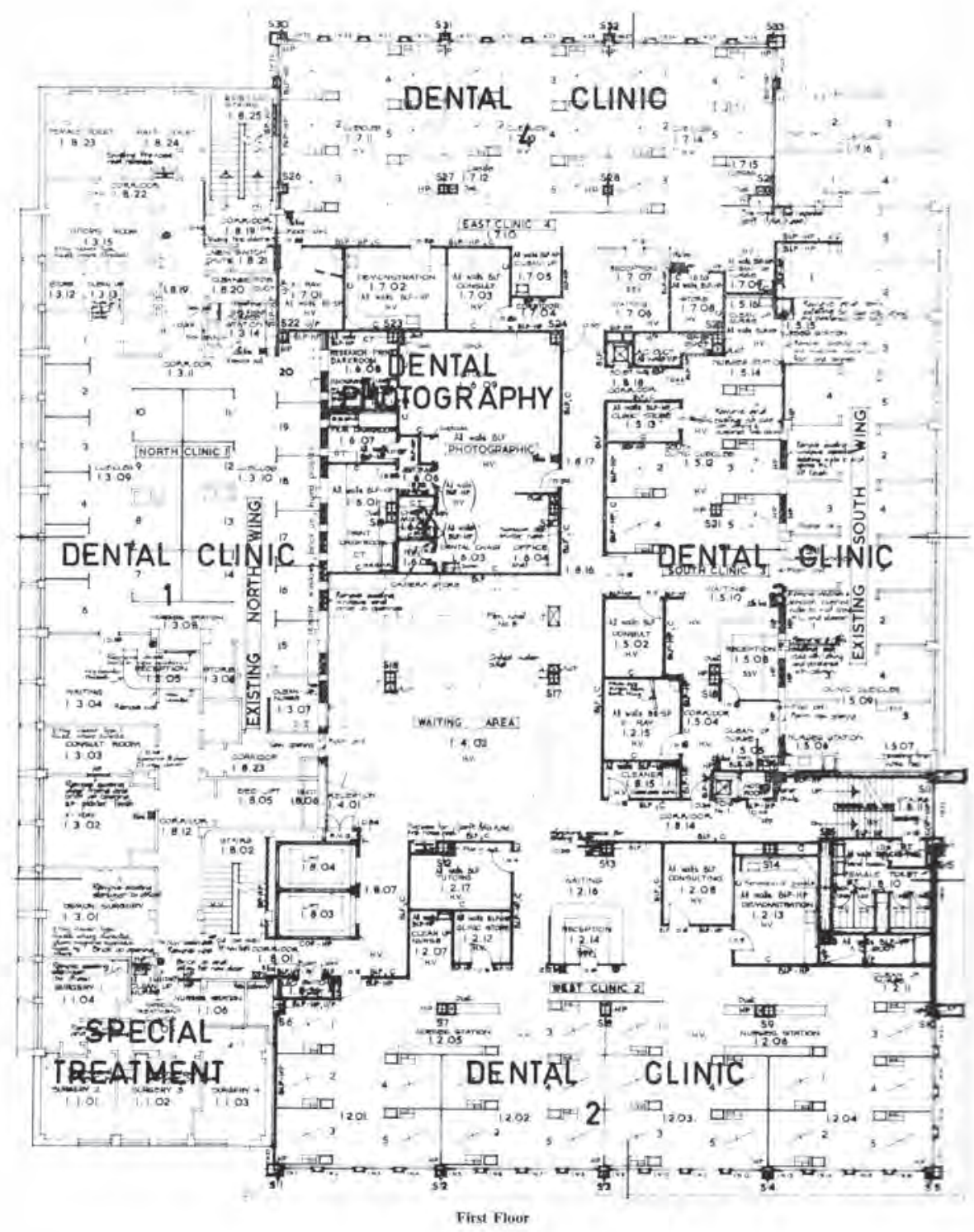




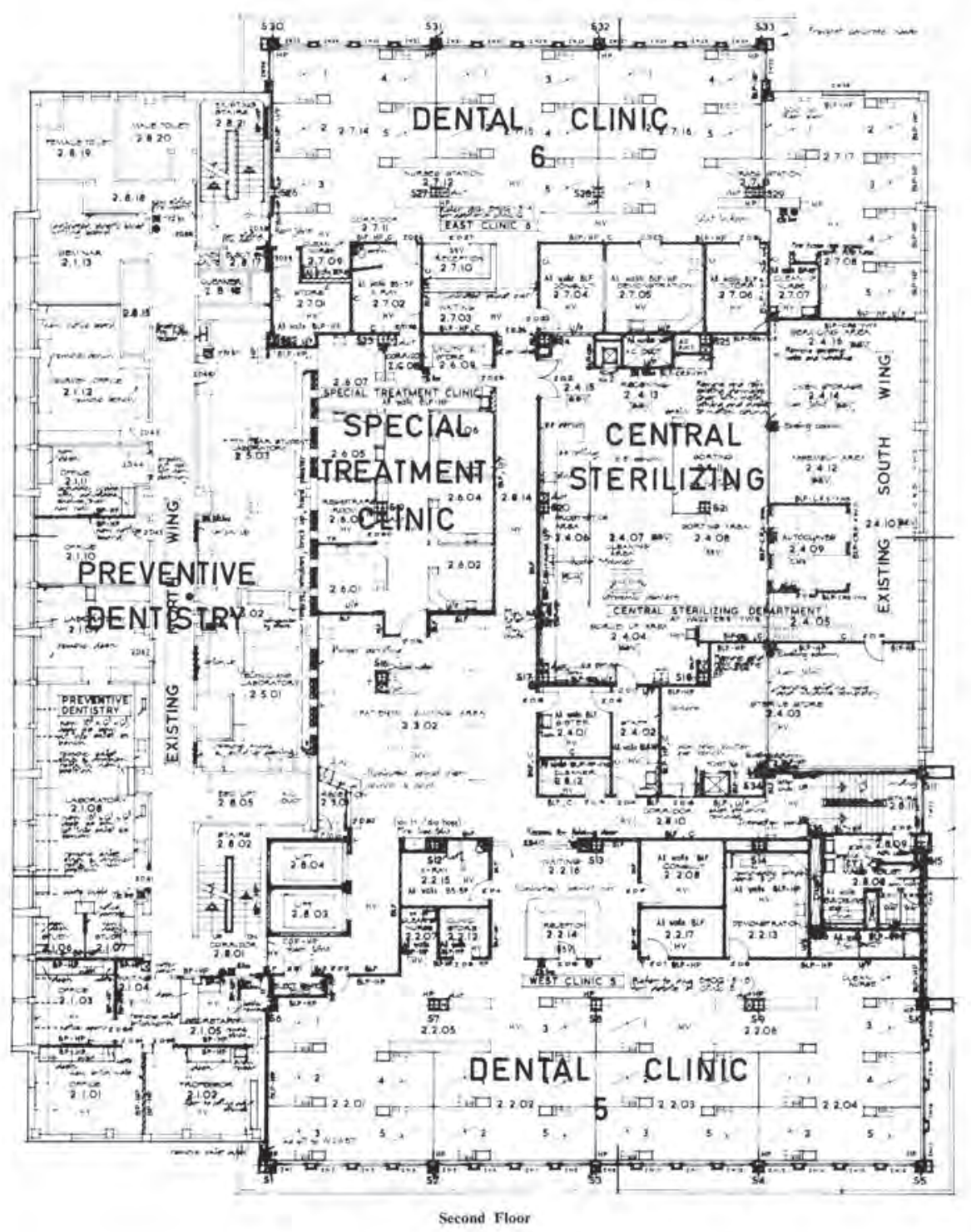




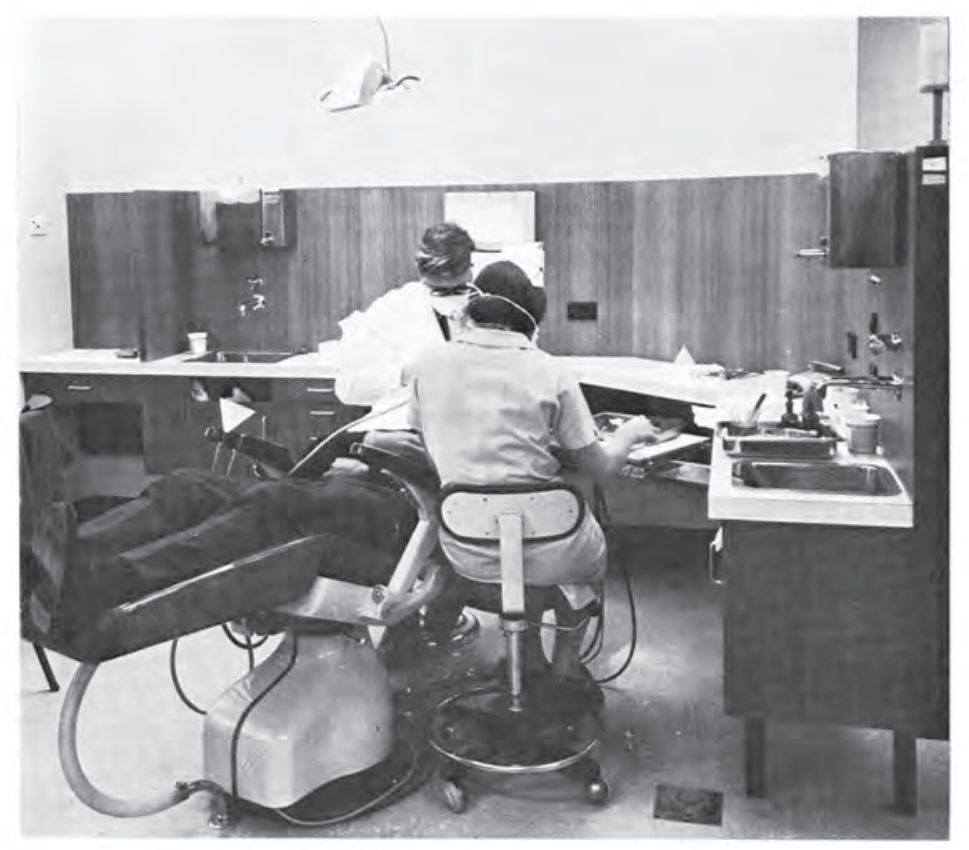

Fourth Floor: Typical Conservative Surgery

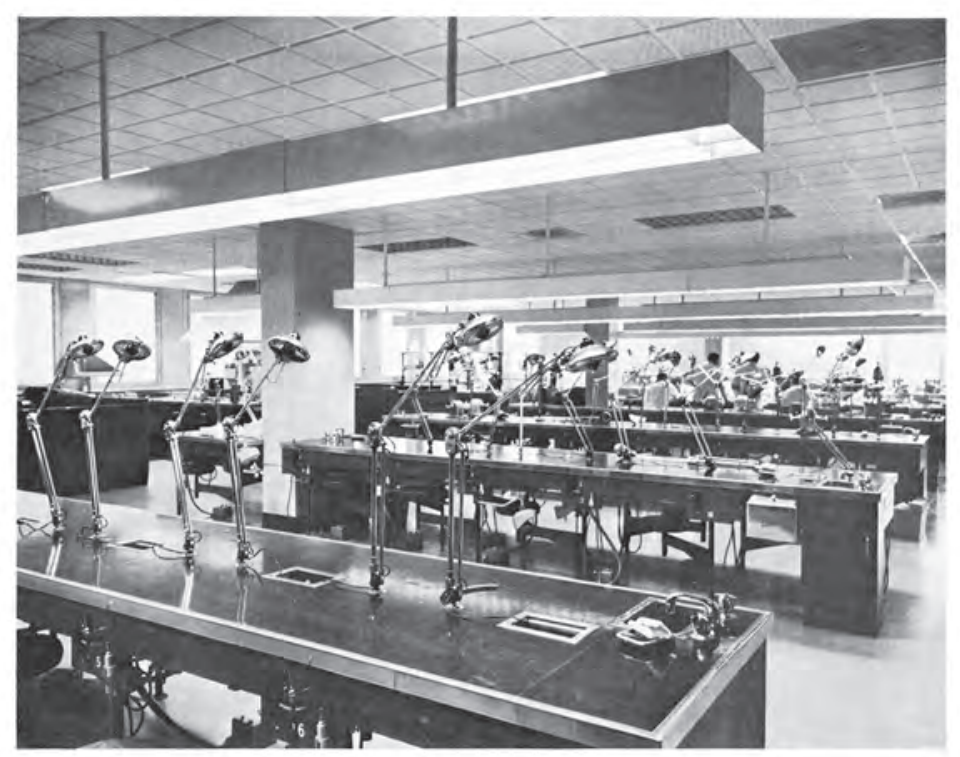

Third Floor: Student Laboratory No. 2 


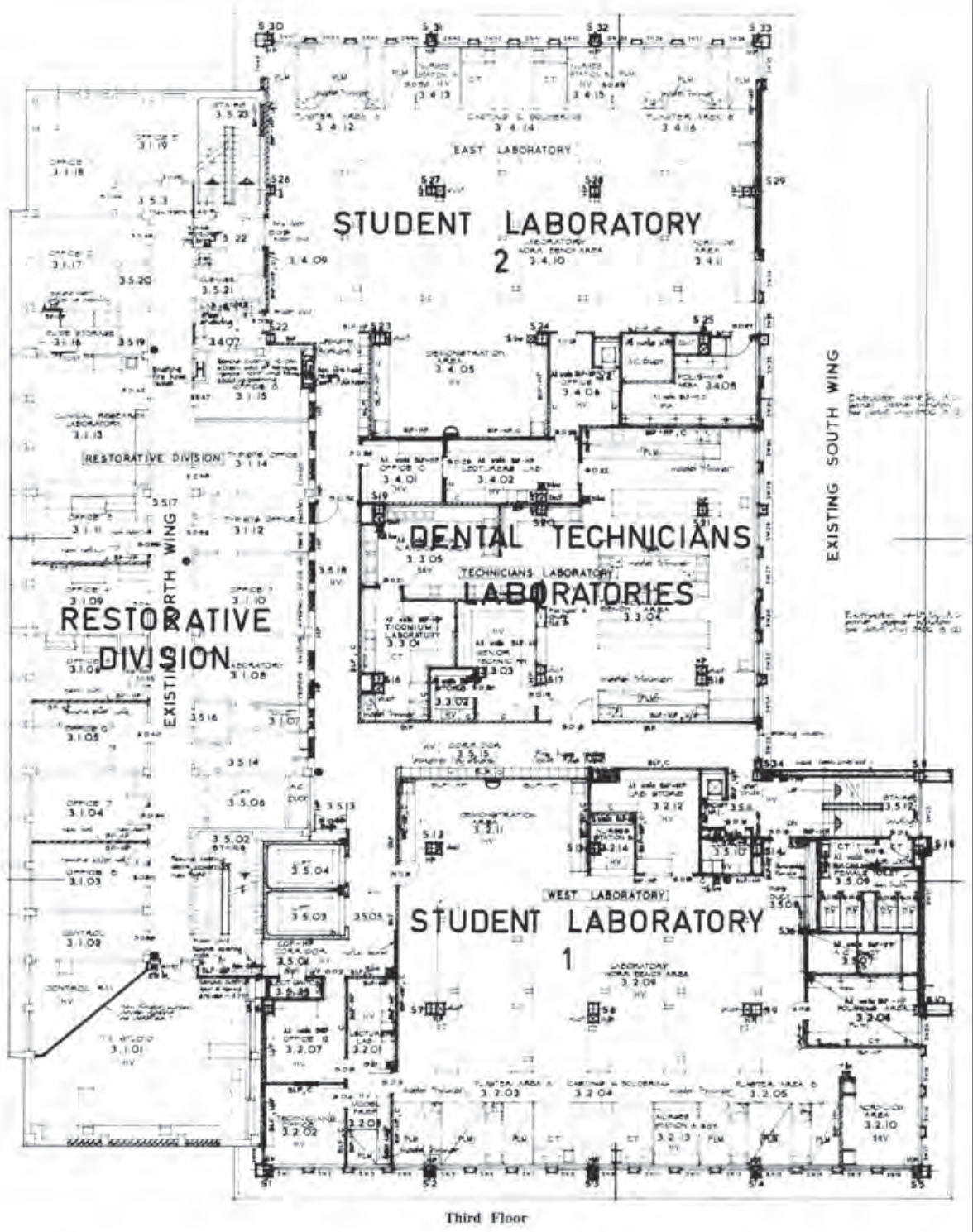




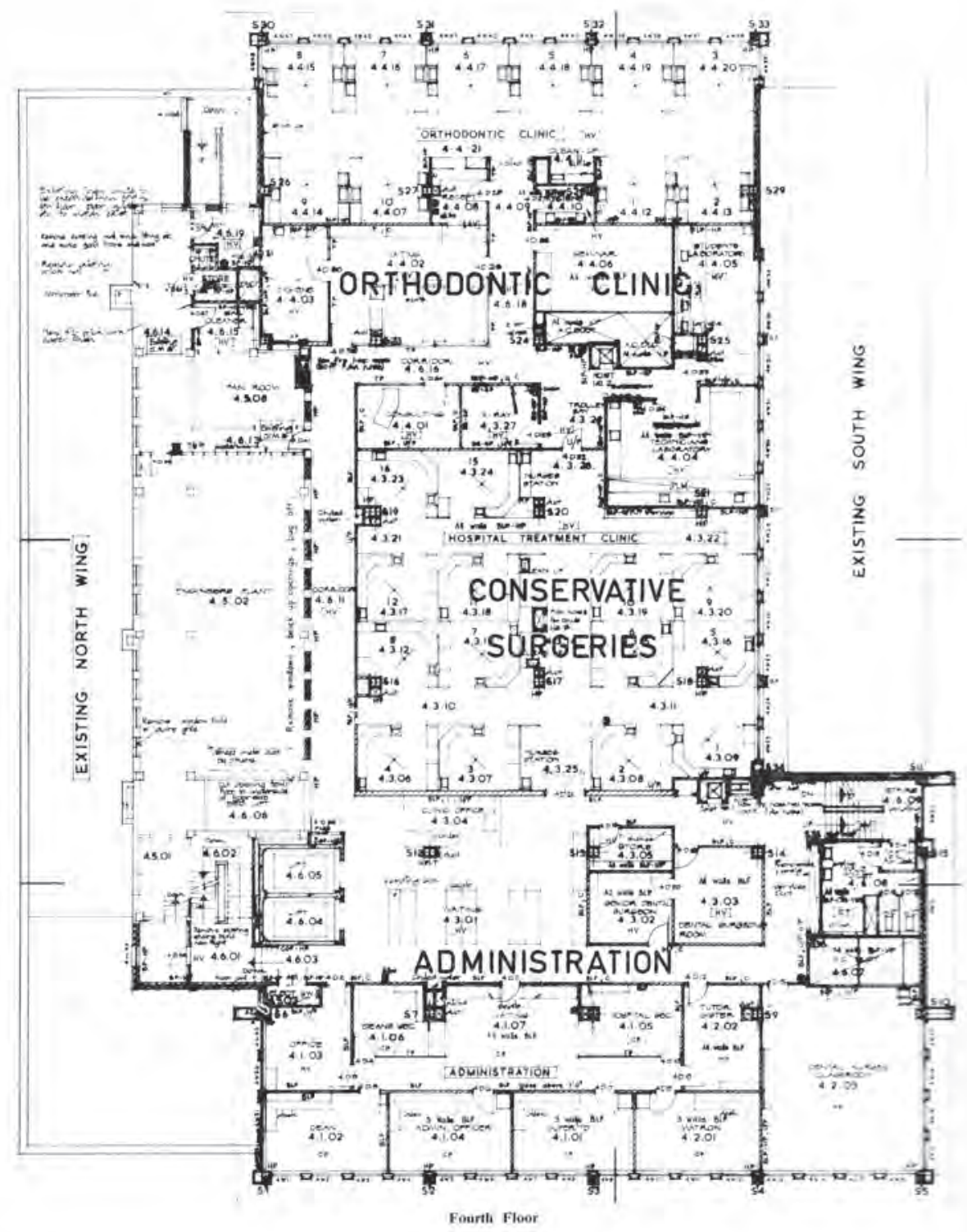




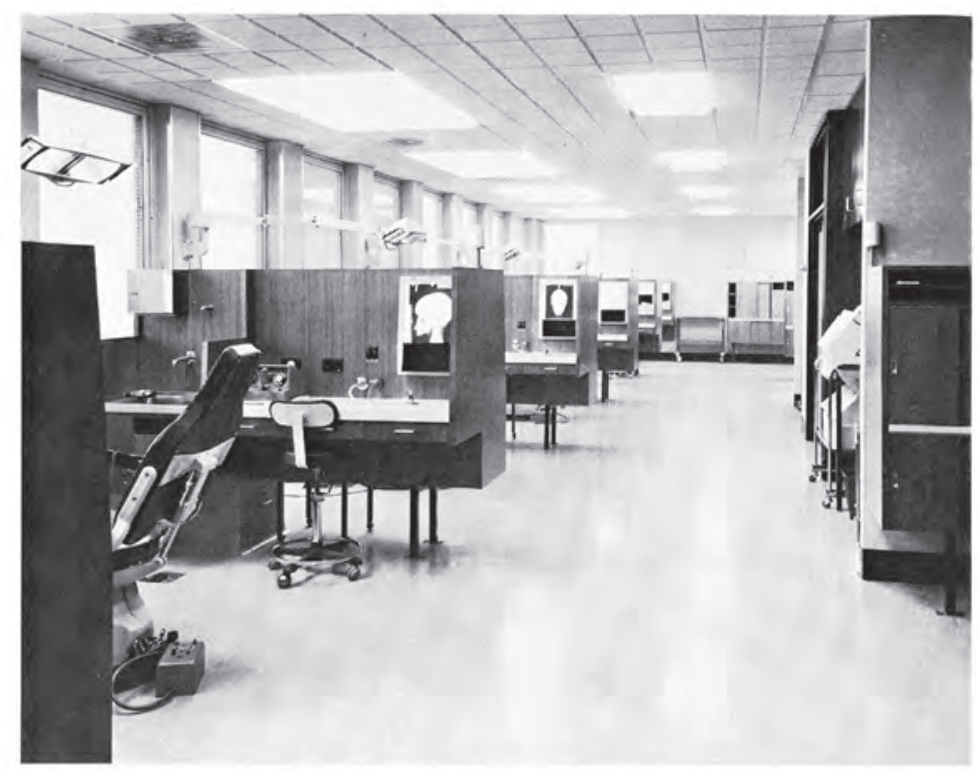

Fourth Floor: Orthodontic Clinic

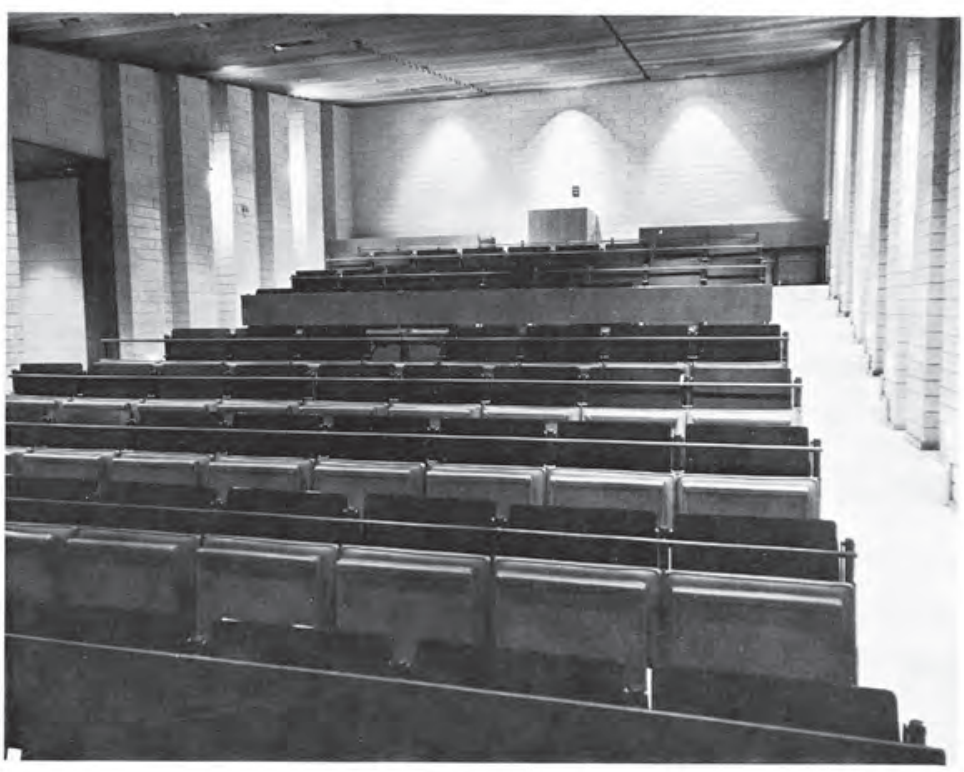

Sixth Floor: Lecture Theatre 


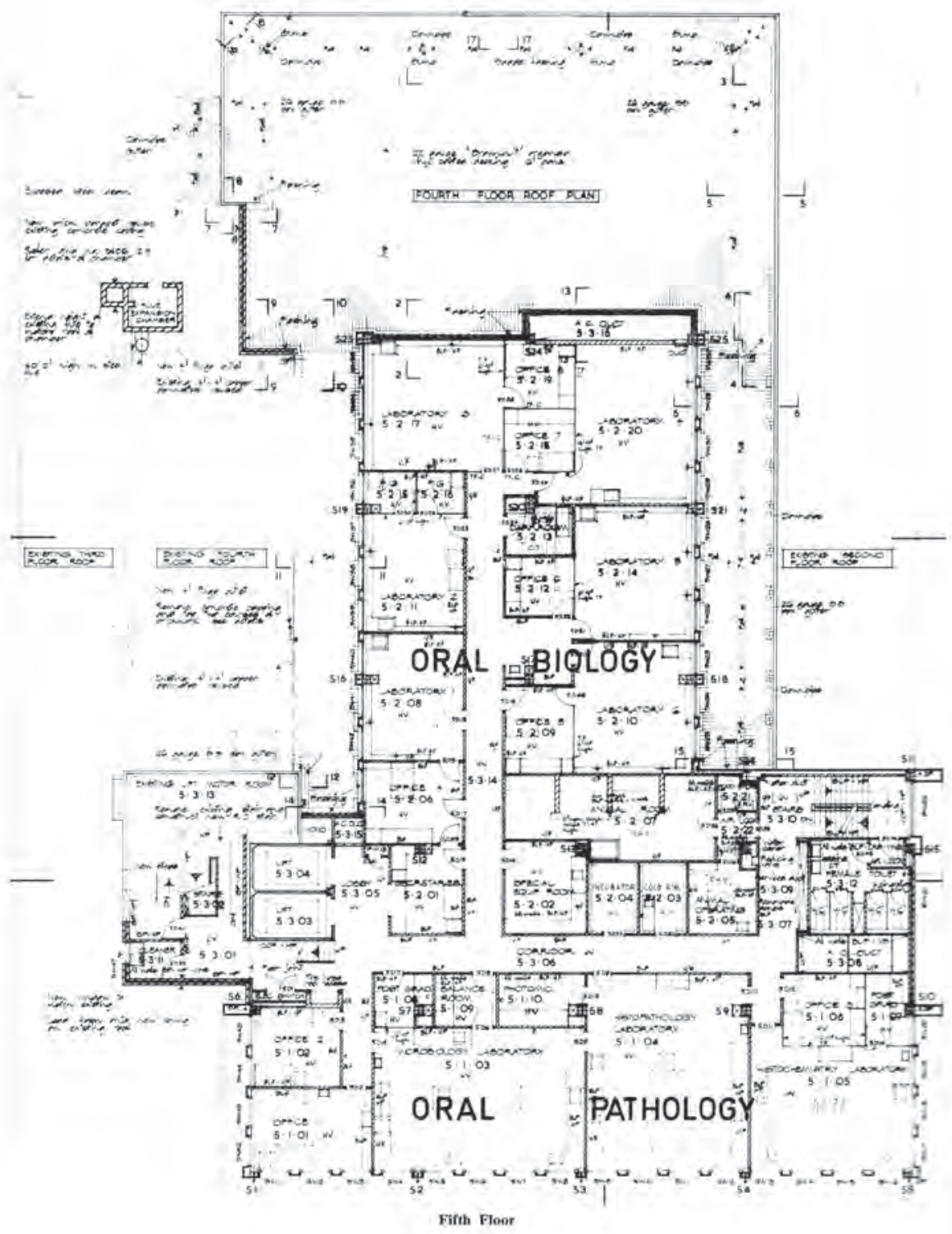




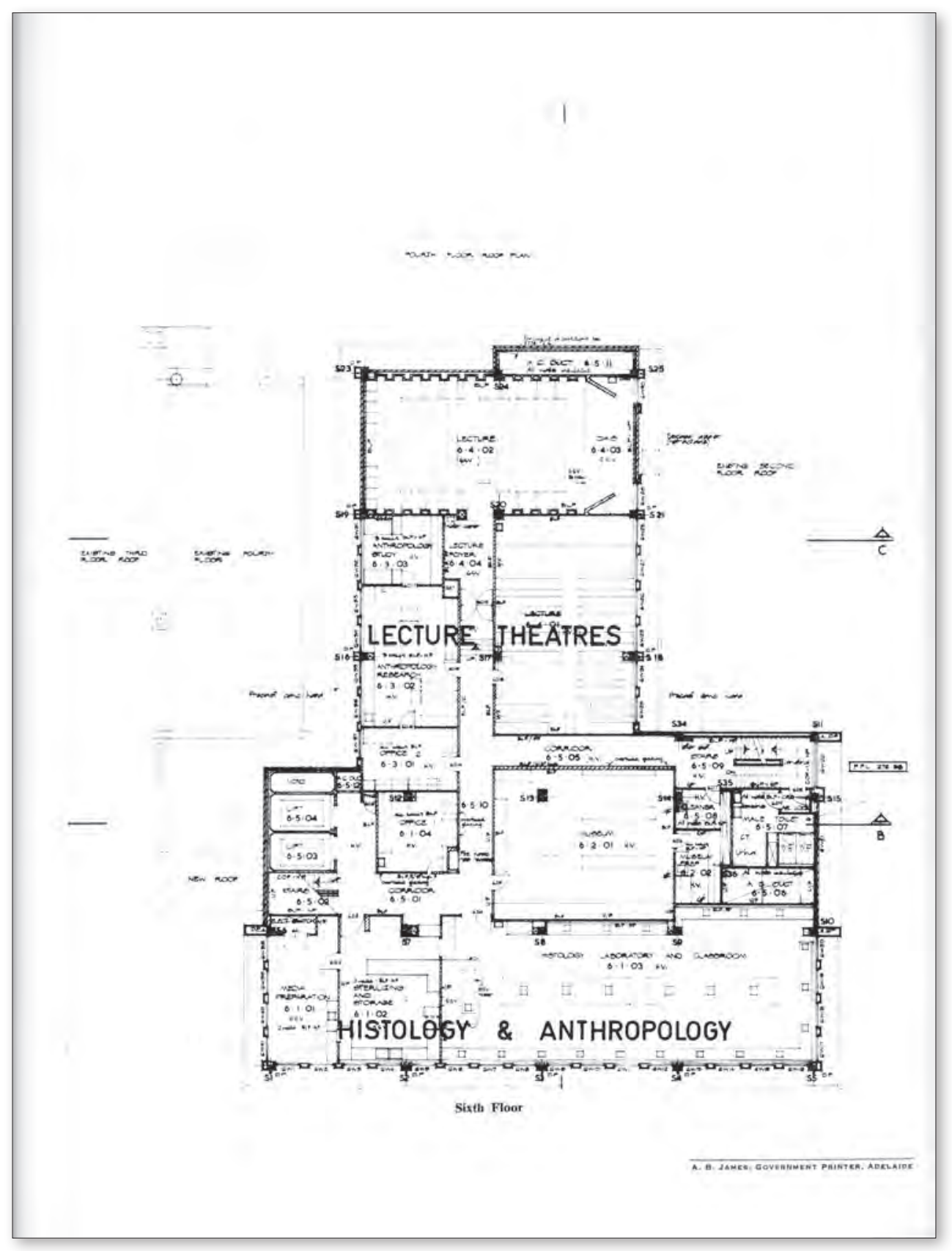




\section{Appointment of a professor of restorative dentistry - correspondence from the registrar to the dean, 16 March 1965.}

This letter provides some explanation for why the chair in restorative dentistry, which had been listed as the Faculty of Dentistry's first priority in the 1960s, was not filled. Instead, Professor John Thonard was invited to take up the position of professor of dental science and then subsequently he became the head of a newly formed Department of Oral Biology.

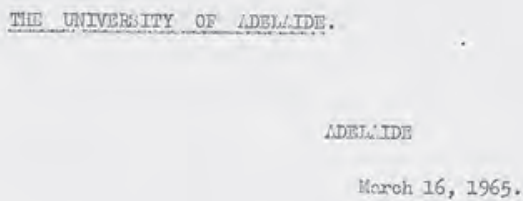

\section{Choir in Rostoritive Dontiatry}

The Council, nt its last nooting, rooolvod o roport from tho ippointront Corvittoe for the Chrir of Rostorative Dentistry. The Cosnittoo roportod that it belicvod thet ddaltionrl profossoricl aprointronts should bo mido not in rolction to e perticular fivision or dopertmont, but in rolation to the Dontal School as a tholo. cocordingly it dia not rocomond an oppointwont to $\varepsilon$ Chnir of Rostorativo Dontistry but sugesostod thet tho Council sook the viows of the Fooulty on tho quostion of tho enling of anlicetions for socond Chair in Dontel Soicnec withous oxprossing eny proforonoc for a porticular soction or division of that scionoo.

The folloring is $\mathrm{x}$ ahort cecount of tho considorstion thich hes boen givon to this anttor:

Whon tho Appointnont Cornitto consillorod tho ampliortions for the Chair in Restorotivo Duntistry Profossor Horsnoll was obsont fron the Univorsity on Study Lopvo. The Comatitec theroforo conforrod with an oxtornnl nsaussur fron cnothor lustring Dontel sohool. In the procoss of the consultetions tho Connittoo discuesed tho gonorn dovolopront of tho School and the following viotrs onorgod:

(c) The gonorrl tondoncy in univorgitios todey is for 'Schools' to dovolon as uniflod wholos rethor thon ovolvo into sorios of soparato dopertionts.

(b) In viou of dovoloprents now trking plece vithin tho flald of Dontel. Sclonen cnd the profosision of Dontistry,
tho furthor sdvanconont of the School of Dentistry in tho Univoraity of Adolnido alght bo sorvod bost if it woro troctoci as a sinelo mult:1-Chnir Dopartant.

The Coturittuo thon doforrod furthor considoretion until aftor Frofossor Forsnoll's return. Following of further mooting of tho Curritioc at wifich both tho oxtomn nssossor and Profossor Horsnoll woro prosent, the Comittoo ando tho rccomondetions sot out abovo. Tho Council adoptod the Connitteo's roport and the Faculty is now nsiked to exprose ite views on the nottor.

\section{Yours sincoroly,}

$$
\text { V. L. BDGSIOE, }
$$

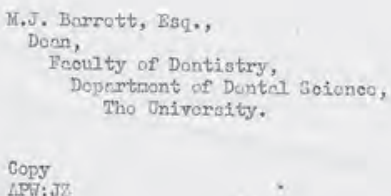

Figure A3.2 Correspondence from the registrar to the dean (1965). 


\section{Grant Townsend's notes from one of the lectures in biochemistry in 1969}

These notes are reproduced in full (all thirteen pages) to emphasise several points about the way in which teaching (and learning) has changed in the Adelaide BDS programme over the years. The topic of this lecture involved energy production and the citric acid cycle (also referred to as the tricarboxylic acid cycle or the Kreb's cycle). Without doubt, this is one of the most important concepts in biochemistry, but what level of detail is needed for dental students?

In terms of teaching:

- The content of this lecture was presented with the lecturer writing out the various equations on the blackboard using chalk (sometimes of different colours to emphasise certain points).

- There was no dental context provided at all. There is no heading in the notes, consistent with one lecture merely following on from the previous one.

- The lecturers in biochemistry were generally all strong researchers, but their lecturing approaches usually involved transmitting as much material as possible in the allocated fifty minutes, with rarely any time provided for students to seek clarification or ask questions.

- No handouts were provided, certainly no PowerPoints, and there were no computers.

In terms of learning:

- Students rarely 'prepared' for any lectures.

- Lectures, such as this one, included new concepts and new terminology but students generally did not have any background in the topic, so everything was new.

- The student's usual approach adopted was to take down as much as possible in the lecture. This required prolonged concentration and skills in notetaking, as there were often four lectures in a row.

- After the class, some students would rewrite their lecture notes entirely, while others would try to fill in the gaps and correct errors, or look up the correct spelling of words that had been noted phonetically in a medical dictionary.

- Some students would supplement their lecture notes by reading the relevant chapters in the prescribed text and adding relevant sections.

Did this approach lead to a real understanding of the Kreb's cycle or merely to rote learning in an attempt to pass the examination?

One way to consider this point is to ask yourself (if you are an oral health professional): How do I apply my knowledge of the Kreb's cycle to my practice of dentistry? It is suggested that most, if not all, would respond by saying that they do not apply any knowledge of the Kreb's cycle. It would also be worth asking oneself: What is 
the Kreb's cycle about? Today's students are not expected to remember and regurgitate the Kreb's cycle in detail, but the concepts are presented in a relevant context. In a crowded curriculum and with ever more 'information' available at our fingertips, it is important to distinguish between what it would be nice for students to know and what students really need to know.

Certainly, a challenge for dental academics will be to effectively use modern technology to enhance the education of future oral health professionals who have grown up in an era of smartphones and iPads, which may not be not conducive to enhancing attention spans or communicating face to face with others.

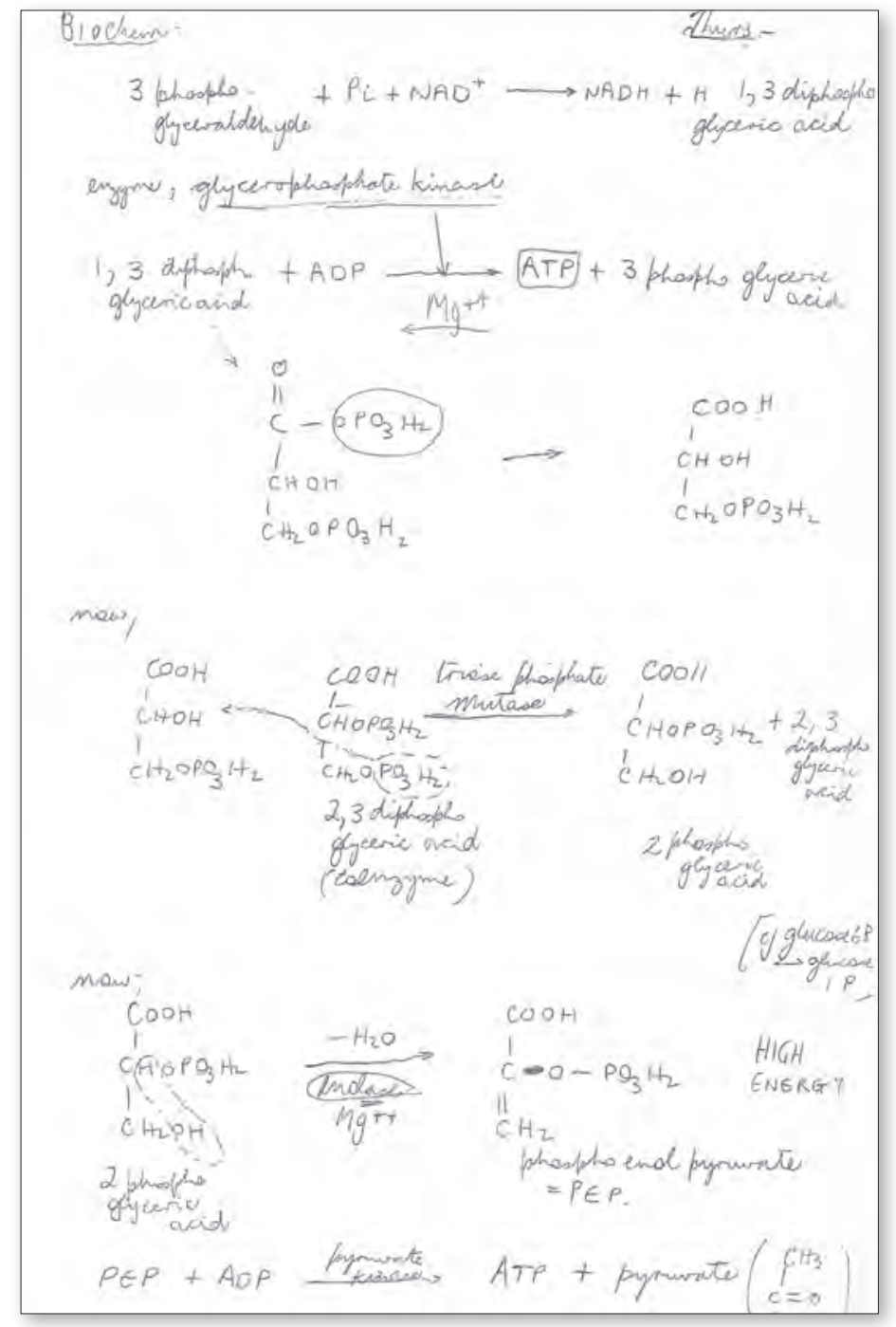

Figure A3.3 Grant Townsend's biochemistry lecture notes (1969), (this page, and as follows). 
Ind prodinct could be loctates

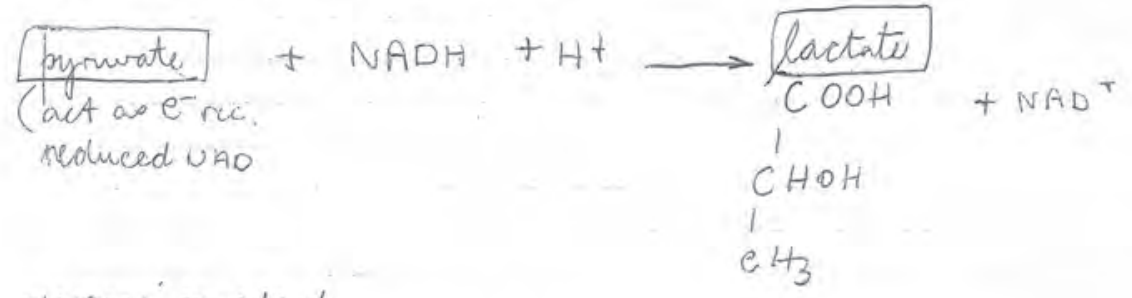

i) NADH reanidized

ly othes meamo pthis mightit oecur.
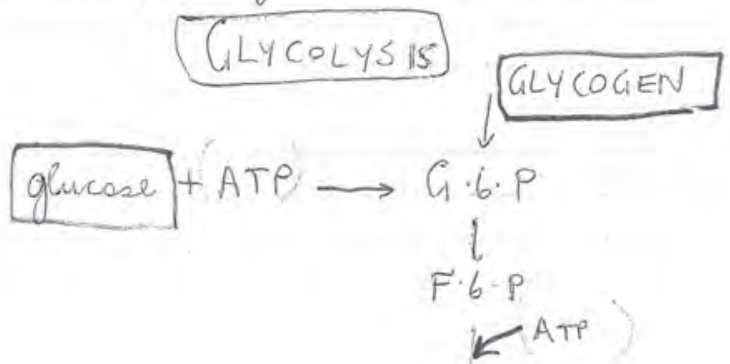

Fi, 6 dif

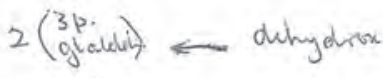

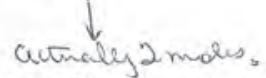

as all comented
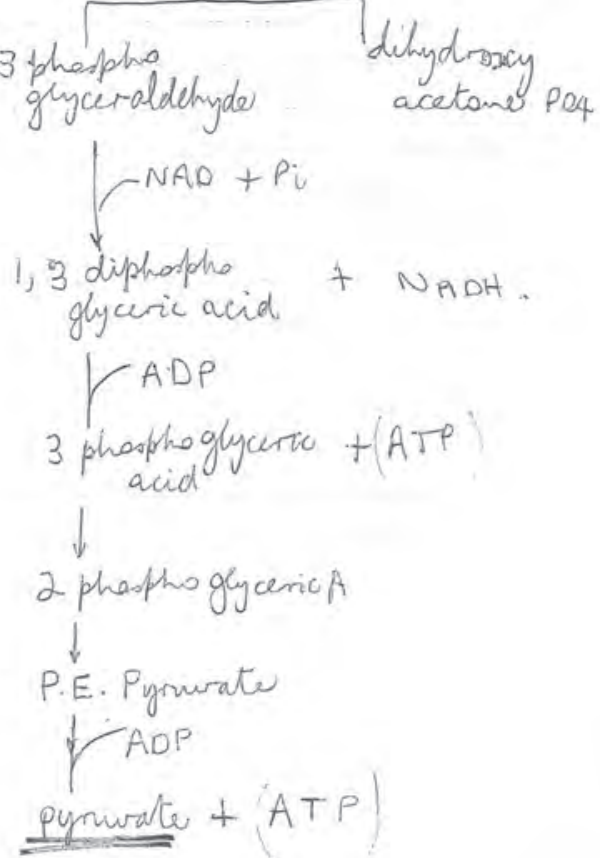
390

THE ADELAIDE DENTAL SCHOOL 1917 TO 2017

Sinergy yold $f=$ glycalysis :

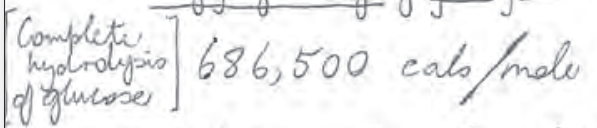

mist use 2 moles of ATP. 4 ATT 2 ATTP.

$28,000 \mathrm{ck} / \mathrm{md} / \mathrm{H} / \mathrm{f}, 0.00 \mathrm{cal} / \mathrm{min}$

not very effecient:

$$
\text { Nettigain }=14,000 \text { cals } / \text { inde }
$$

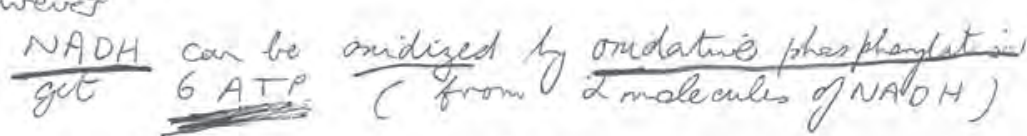

if NADK reosidized anaerdically $\rightarrow 14,000 \mathrm{col}$ of $\mathrm{h}$. if acrabically $\rightarrow$ entras 42,000 cals/meles

total 56,000 calo/mole

$\simeq 10 \%$ recovery

Mang bactera parmive, excreting lactate (a) accuptar).

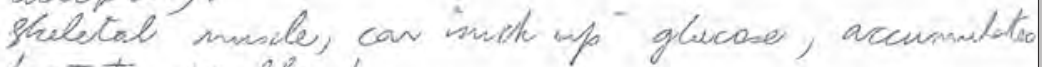
factater to blead

ie lactate $\rightarrow$ blood $\rightarrow$ liver: (get lotof encigy))

Citric Aciol byde - Mrebs bycle - AricaltarylieAff process elvidated in 1930's - Izent Gergi; Tinels $\rightarrow 6$ ambings

Goumal 1935:-

Enzymologia 4145 (1937)

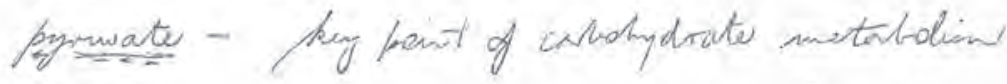

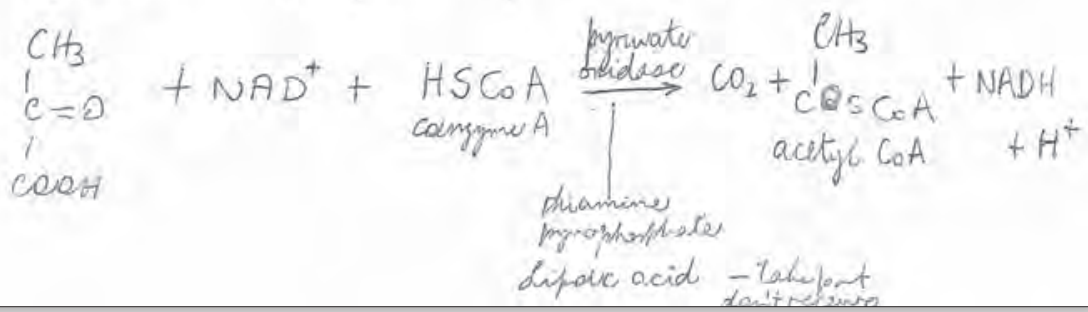


THE ADELAIDE DENTAL SCHOOL 1917 TO 2017

391

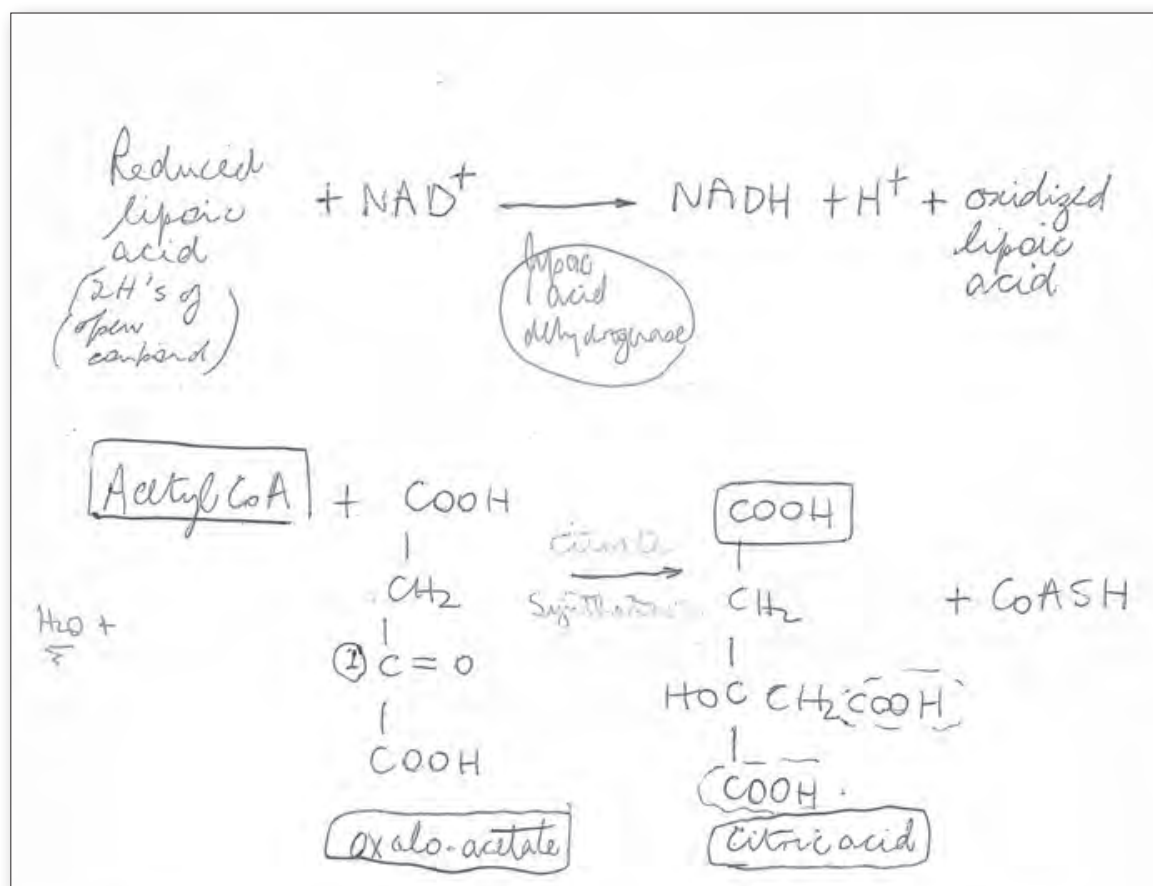

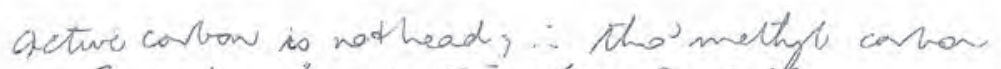
3 corbanglo $\rightarrow$ Tricartinaytio cycle.

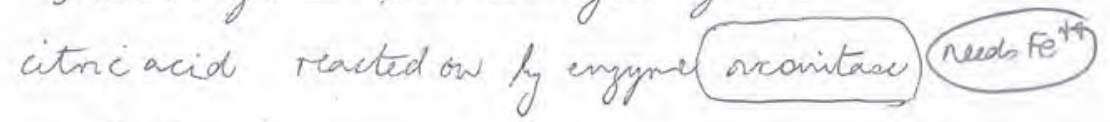

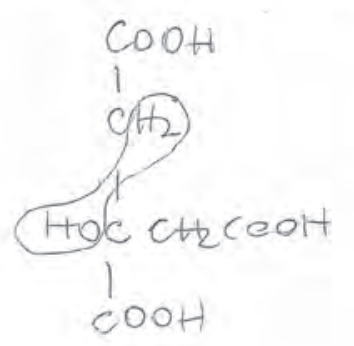

citric avid

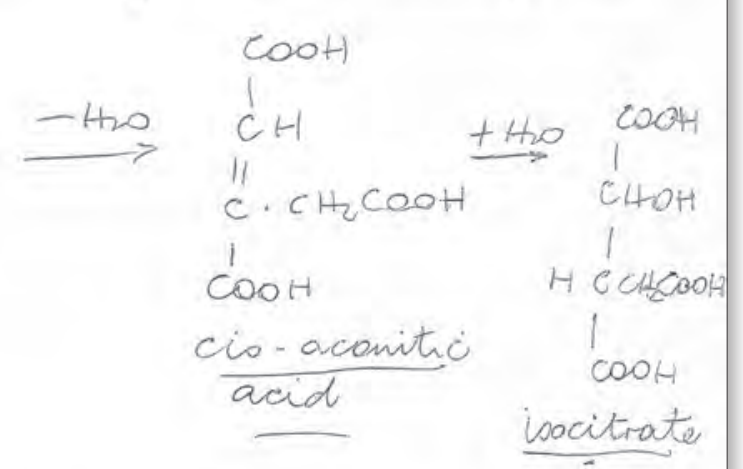
* AB AMP act as an alleateric isocitrate onabosuccinate if ATP law thew AMP high $\rightarrow$ stimulates cycle

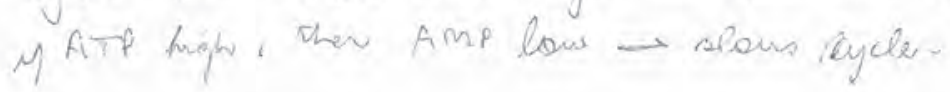




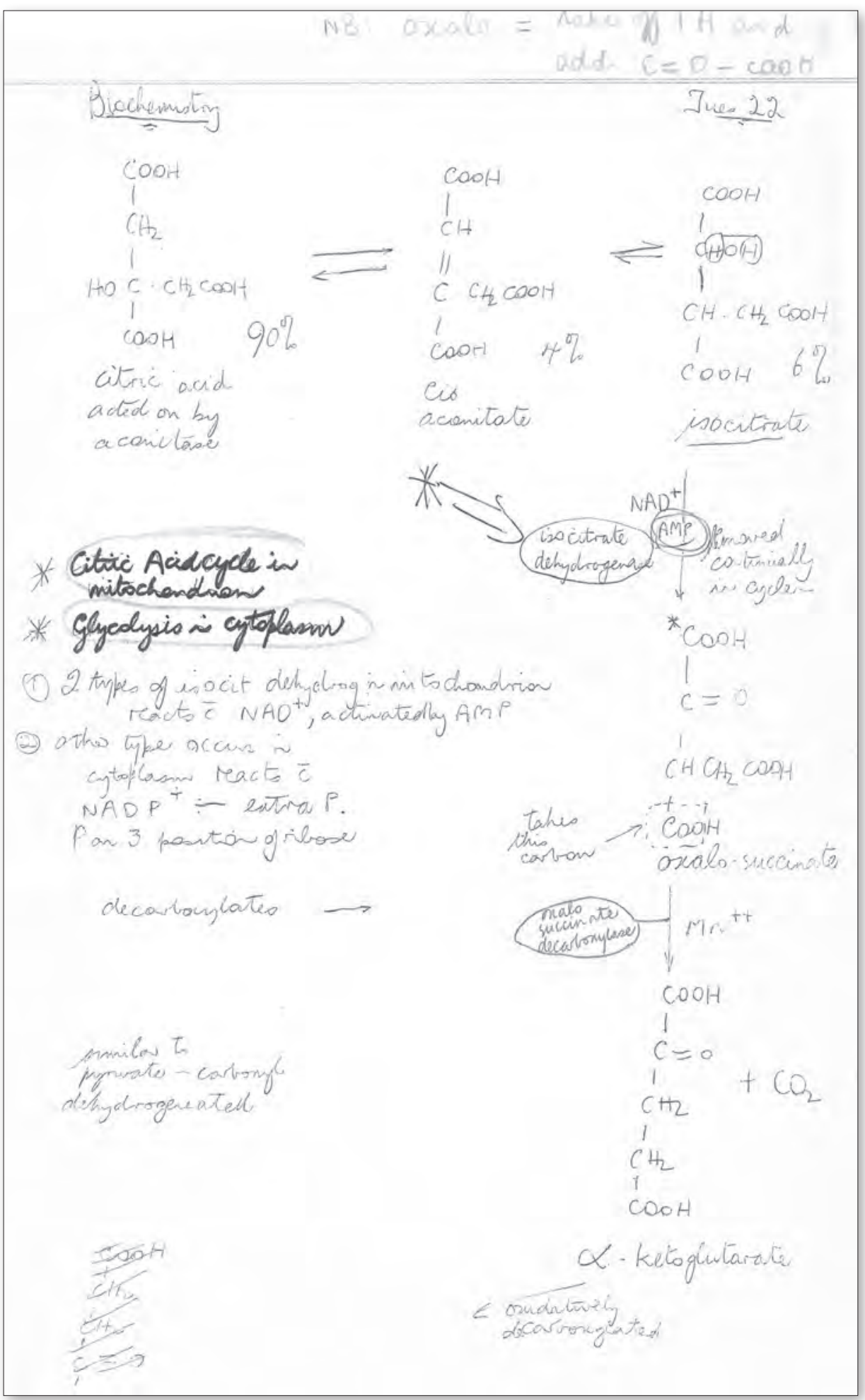


THE ADELAIDE DENTAL SCHOOL 1917 TO 2017

393

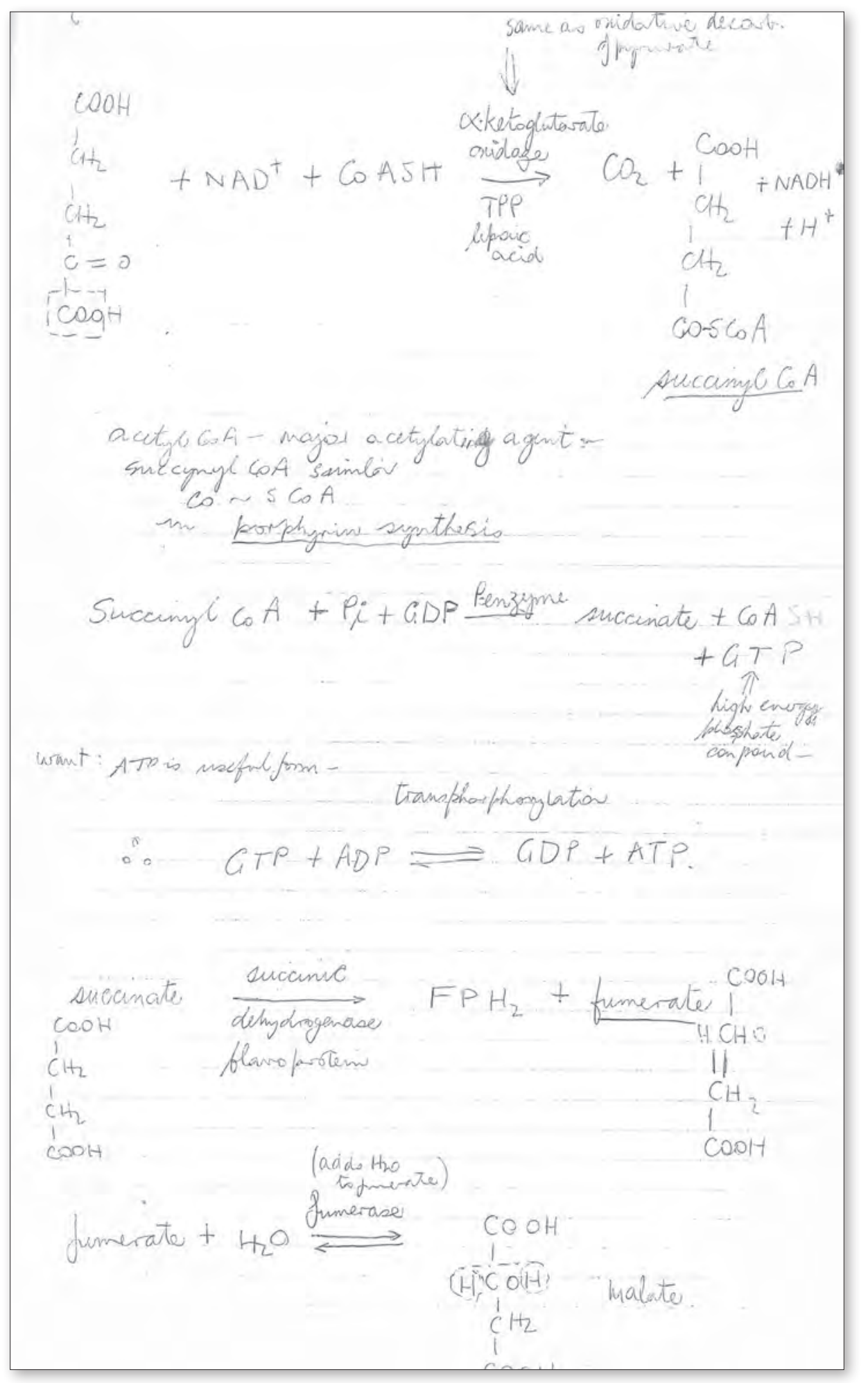




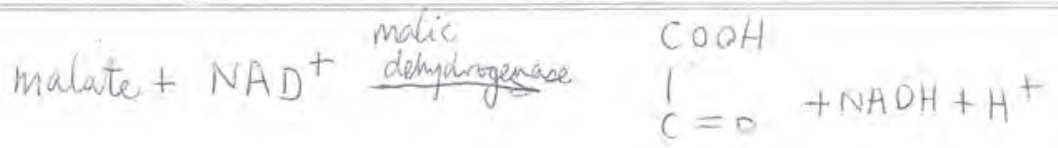

$$
\begin{aligned}
& \text { I } \\
& \mathrm{CH}_{2} \\
& 1 \\
& \mathrm{COOH} \\
& \text { oxaloace tate }
\end{aligned}
$$

aychic process, acetyemaity decartonglated $\rightarrow \mathrm{CO}_{2}$

CITRIC CYCLE
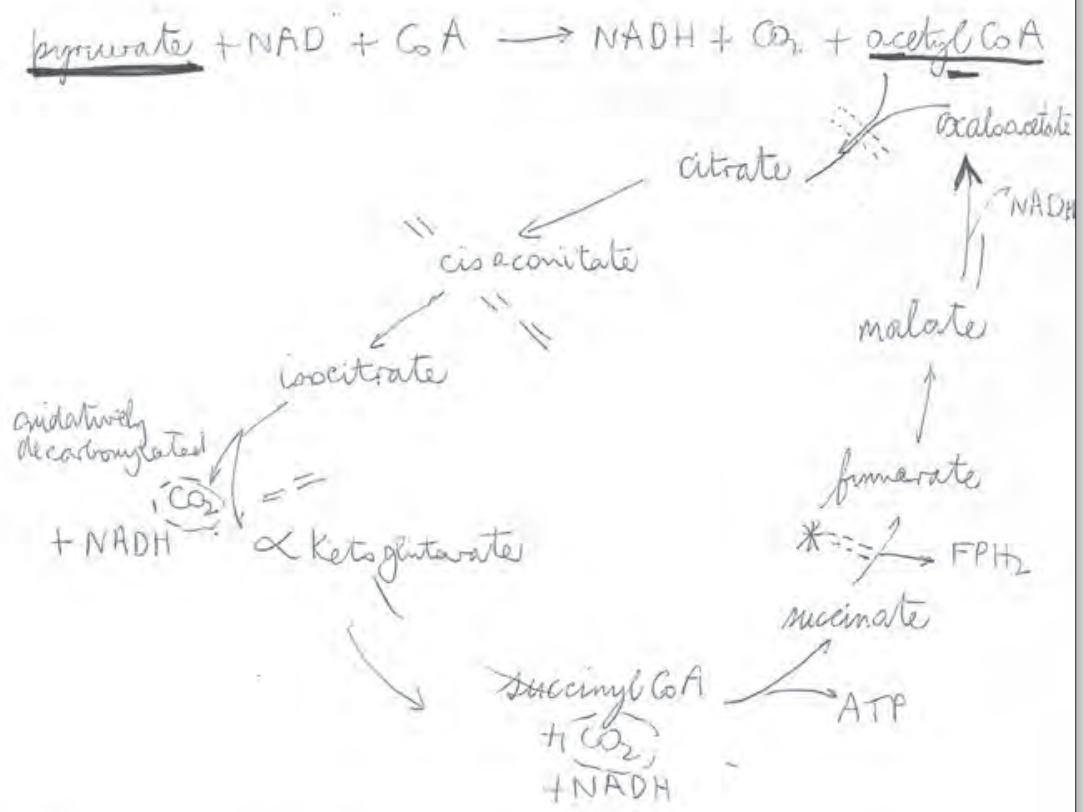

malates

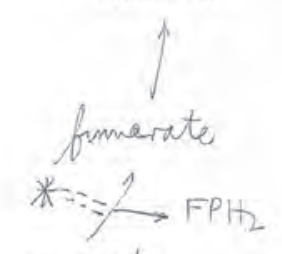
succimate

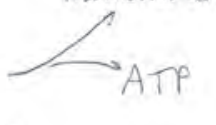
+ NADH

2 callows i acetgl cos $A$;

2 decarvorylontional:

eanit get from jaltig acid - cakohydrate synthesis (wrong costorse)

Mang wilitiono can stop C.A.C.

(1) NHzOH - hydronglamine - stops becanse reaits ć acetgi io $\rightarrow$ acechydronammite 
THE ADELAIDE DENTAL SCHOOL 1917 TO 2017

395

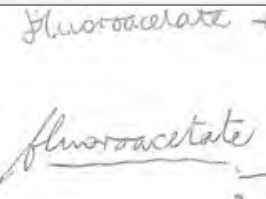

Herorventrale

chis intibit acenilowe

(2) flinaracetate $-\mathrm{CH}_{2} \mathrm{FCOOH}$

$\therefore$ ciltiate accummlate

in trisine of winer $\exists$ acetate activaling nuype, canses

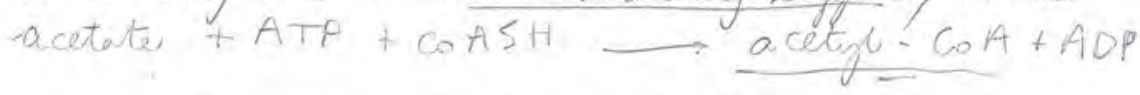

$\therefore$ acetate can go diectly into TCA rimen of cows elc engyine cait tell diff. bekweer acetate a flowracelate

$\therefore$ from fluors-acetyc 6 H

$$
\mathrm{CH}_{2}=\mathrm{F} \text { COSCOA }
$$

mext enzyou con't eilthis

$\therefore$ get finarocitrate - Chis reacto with a contantae jams up T.CA

engyme. nublita conplen doesit breal doun cutrate bivids mp; $\rightarrow$ death.

Transacomitate - like F. cutrate conbies inth mhibutiono diffecult to detect by antopsy -

voentrate $\rightarrow \propto$ Keto

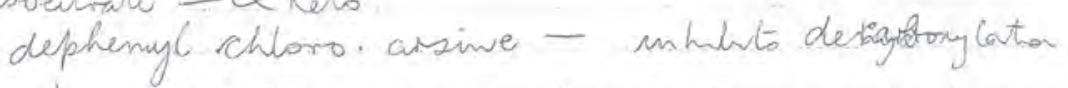
prysophosphate - good compleners $\mathrm{Mn}^{+}{ }^{+}$meeded here, fisached by pyro-phosphate.

pace: $\rightarrow$ funwate

malowate<smiles>O=C(O)CC(=O)O</smiles>

pimilas to syccirate

$\mathrm{cosh}$

Hock pathwiry =

vevesible whititos I mec $\gg$ can fomet 
add malonate $\rightarrow$ mucinate accamilate

fimarnte acemiated succinarte too =

add malate; tione mould andaige, in binid up-

Malo-sicetate Fmalic dingarogemase

体 (Mbuild wp of malacutate

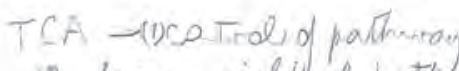

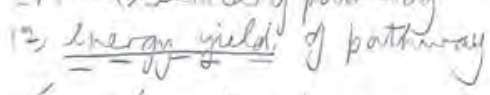

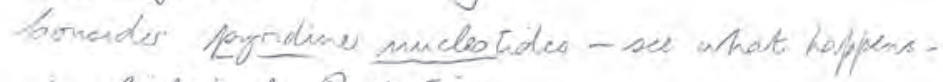

is Budogical Emintata

in muscles 9 carb. metabolion want to know

how enery produced i wat it to be witilizable Motatuely dependect on $O_{2}$

storages of ATP and creatime phasphate

Gaatie $\mathrm{PO}_{4}$

, $\mathrm{NHPO}_{3} \mathrm{H}_{2}$

$C=N H$

lingh enorgy

$\mathrm{N}-\mathrm{CH}_{2}-\mathrm{COOH}$

$\mathrm{CH}_{3}$

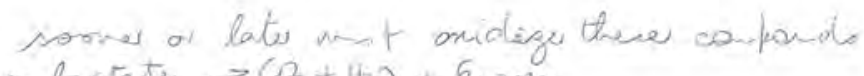
ey lavtate $\rightarrow C D_{2}+i_{i} D+E_{1}=2 y$

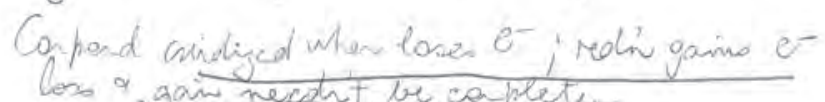

los a gaw mexht be copplete.

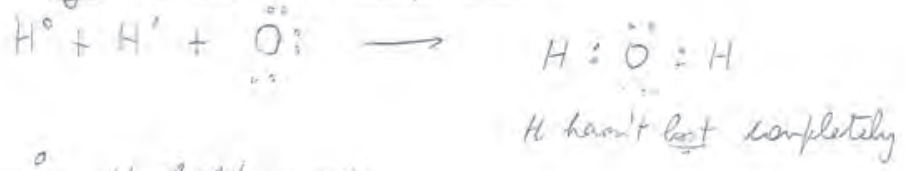

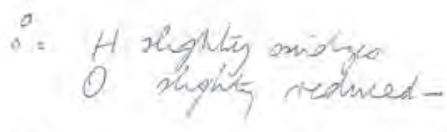

$\mathrm{Fe}^{++}+\mathrm{Cl}^{-}+\mathrm{Cl}^{-}+\mathrm{Cr} \rightarrow \mathrm{Fe}^{+}+\mathrm{Cl}^{+}+\mathrm{CF}^{+} \mathrm{Cl}^{-}$

pron la anidyed, coste-

cheorne gaved é - 
THE ADELAIDE DENTAL SCHOOL 1917 TO 2017

397

mest coniow form of oxdi is remaval of $H$ i bial sippter Not ofler do got oxyger added

$$
\begin{aligned}
& A+O \rightarrow A O \text { rare } \\
& \mathrm{A}+\mathrm{H}_{\mathrm{O}} \rightarrow \mathrm{AHOH} \\
& \mathrm{HHOH} \longrightarrow \mathrm{AO}+\mathrm{H}_{2}
\end{aligned}
$$

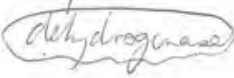

lg atric acid

finerate $\rightarrow$ malate

(blindory)

doen't mottor is conndo $H$ or e

$$
\mathrm{H} \rightarrow \mathrm{H}^{+}+\mathrm{e}^{-}
$$

if bial eyptems i need stadard; WHAT OXIDIZESWHAT? velative eiffeiencies etc.

Kunamas

Redon-Potertial Scala

Phancists used $H$ as stidad pH 0.0

$$
\frac{1 / 2 H_{2} / H}{1 /}+\frac{\text { Redox } P_{0} t=E_{0}}{0 \text { valts }}
$$

bologists mever use $f H=O$ wite $H_{2}$ get $H^{+} \cdots$ pHt changea -

moed $E_{0}^{\prime}$ Mydroger/protou syitem $a t \quad \not H=7$

$$
E_{0}^{\prime}=-0.420 \text { walto }
$$

ato ther end; mast asudized syptem tho / $/ 2$

$$
E_{0}^{\prime}=0.812 \text { volits. }
$$

all other systems between

ig kmaw E' my.tin car tell whath onch' ar red' occurs:-

In biochem; $\mathrm{O}_{2}$ a $\mathrm{H}_{2}$ inpaitat

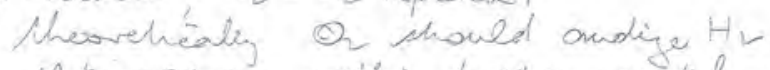

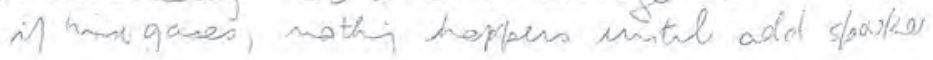


H\& O themedynawilly posible - need sporker$\mathrm{O}_{2}$ shoggish bidagically - wont to cirmifes eleartiona

$$
O_{2} \rightarrow O_{2}^{-} \longrightarrow O_{2}=\rightarrow O_{2} \equiv O_{2}^{4-}
$$

cleent natiow wher wae this or

$$
\mathrm{O}_{2} \rightarrow \mathrm{HO}_{2} \rightarrow\left(\mathrm{H}_{2} \mathrm{O}_{2}-\mathrm{H}_{3} \mathrm{O}-\mathrm{H}_{\mathrm{O}} \mathrm{O}_{2}\right)=2 \mathrm{H}_{2} \mathrm{O}
$$

$$
\therefore N B \text { in } \operatorname{tin} t \text { step }- \text { f TCA. }
$$

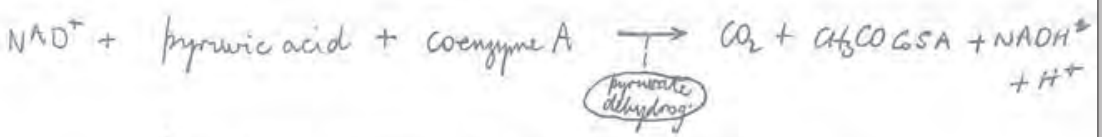
this tefp is compered of several reactionis juidong 1) elpoic acid

$$
\text { 2) } T P P \text { - thamine propophesphate. }
$$
then

1) pprowate $+\operatorname{Eng}(T P P) \longrightarrow \mathrm{CO}_{2}+\varepsilon$ ng $\left[T P P-\mathrm{CH}_{3} \mathrm{COH}\right]$

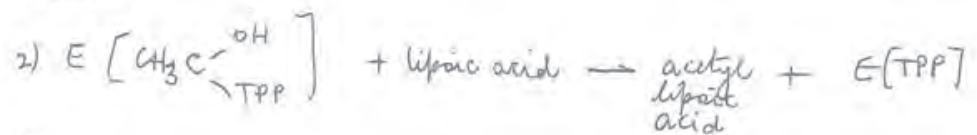

3)

acetgl lipaic acid + Coemume $A \rightarrow$ red lipoic + acetylco $A$

4) red lipoir acid $+\mathrm{NAO}^{+} \longrightarrow \mathrm{NAOH^{* }}+\mathrm{H}^{+}$+oxidlipaica 


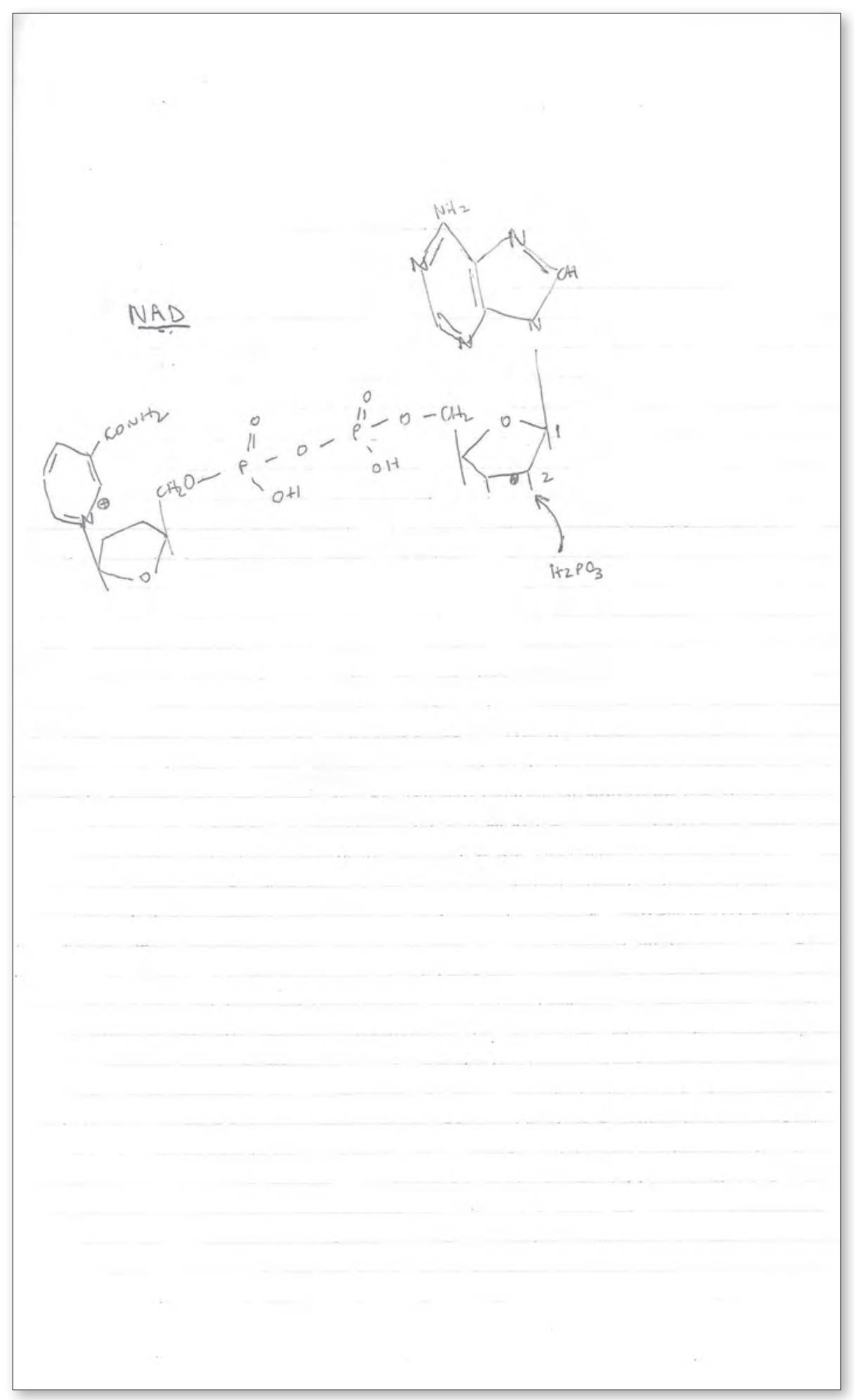


Programme and written examination in biochemistry in 1969

\section{The programme}

As can be seen on the following pages, biochemistry was taught as a separate subject to medical and dental students in 1969. The course comprised three lectures a week, covering all of the topics one would expect to find in a programme for science students.

The lecture for which an example of note-taking has been provided was one of two lectures on the citric acid cycle under the general theme of the biochemistry of muscle. The first lecture in the course, entitled Biochemistry in Medicine, did not include any mention of dentistry and there was no dental relevance provided at any stage during the course.

The sixty-six hours of lectures in biochemistry presented in 1969 far exceed the amount of general biochemistry in the present Adelaide BDS programme, but today's students are exposed to various concepts in biochemistry related to dentistry, often in the form of clinical scenarios.

Rather than all of the biochemistry being taught in one year (it was the second year of the BDS in 1969), students are now exposed to biochemistry throughout the first three years of the BDS and they participate in various Integrated Learning Activities (ILA) that enable them to learn aspects of physiology and biochemistry related to related dental scenarios.

The reader is left to reflect on which approach — that is, the traditional separate subject in biochemistry or the inclusion of basic dental sciences within clinically relevant scenarios - he/she would prefer and what might be the most appropriate in a $\mathrm{BDS}$ or $\mathrm{BOH}$ programme. 


\section{THE UNTVERSITY OF ADELATDE \\ Departient of Biochenistry \\ ITIDICINE II AND DENTISTRY II \\ TERM I - 1962}

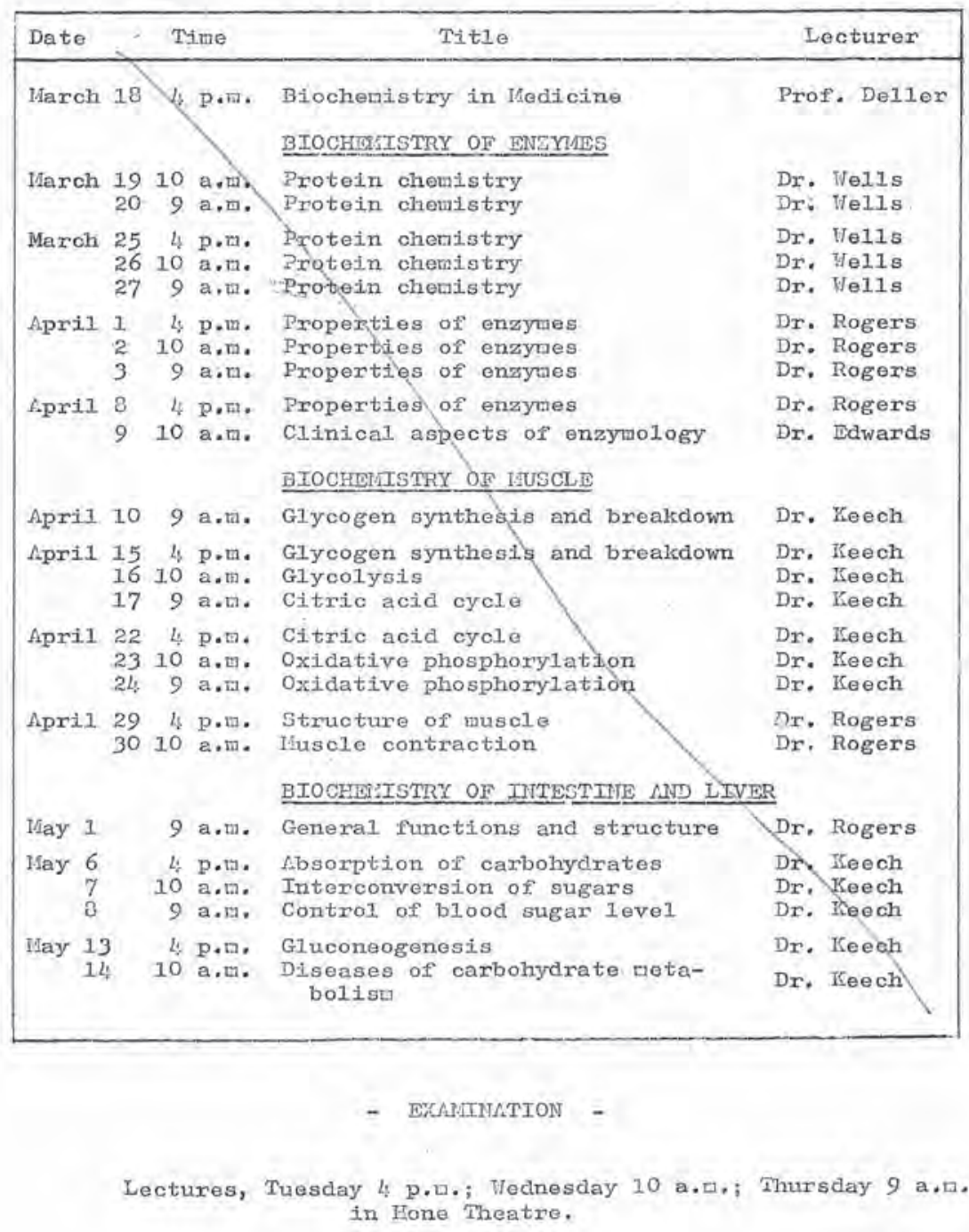

Figure A3.4 Biochemistry programme (1969), (above, and as follows). 


\author{
THE UNTVIRSITY OF ADELAIDE \\ Departaent of Biocheristry \\ IIFDICIIIE II $\triangle N D$ DENTISTRY II \\ TERI III -1969
}

\begin{tabular}{|c|c|c|c|c|c|}
\hline Date & & & ine & Titie & Lecturer \\
\hline June & $\begin{array}{l}10 \\
11 \\
12\end{array}$ & $\begin{array}{r}4 \\
10 \\
9\end{array}$ & $\begin{array}{l}\text { p.r. } \\
\text { a.r. } \\
\text { a.r. }\end{array}$ & $\begin{array}{l}\text { Clinical recognition of diseases } \\
\text { of carbohydnate notabolism } \\
\text { Nitrogen votabolisu } \\
\text { Nitrogen betabolist }\end{array}$ & $\begin{array}{l}\text { Prof, Haxwe11 } \\
\text { Dr. We1ls } \\
\text { Dr, He11s }\end{array}$ \\
\hline June & $\begin{array}{l}17 \\
18\end{array}$ & $\begin{array}{r}4 \\
10\end{array}$ & $\begin{array}{l}\text { p.ra. } \\
\text { a.mi. }\end{array}$ & $\begin{array}{l}\text { Nitrogen wetabolisn } \\
\text { Nitrogen vetabolisa } \\
\text { LIVIR MND ADIPOSE TISSUE (FAT IIETA }\end{array}$ & $\begin{array}{l}\text { Dr. Velis } \\
\text { Dr. Vells } \\
\text { DOLISI) }\end{array}$ \\
\hline June & $\begin{array}{l}19 \\
24 \\
25 \\
26\end{array}$ & $\begin{array}{r}9 \\
4 \\
10\end{array}$ & 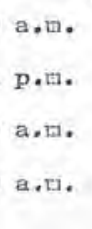 & $\begin{array}{l}\text { Lipid netabolisa, absorption and } \\
\text { transport } \\
\text { Lipid netabolisa, absorption and } \\
\text { transport } \\
\text { Iipid netabolisn, absorption and } \\
\text { transport } \\
\text { Lipid netabolisn, absorption and } \\
\text { transport }\end{array}$ & $\begin{array}{l}\text { Dr. Syrions } \\
\text { Dr. Symons } \\
\text { Dr. Symons } \\
\text { Dr. Symons }\end{array}$ \\
\hline Juiy & $\begin{array}{l}1 \\
2\end{array}$ & $\begin{array}{r}4 \\
10\end{array}$ & $\begin{array}{l}\text { р.๘. } \\
\text { а.t.. } \\
\text { а.т. }\end{array}$ & $\begin{array}{l}\text { Lipld metabolist, absorption and } \\
\text { transport } \\
\text { Iipid metabolist, absorption and } \\
\text { transport } \\
\text { Iipid netabolist, absorption and } \\
\text { transport }\end{array}$ & $\begin{array}{l}\text { Dr. Syrions } \\
\text { Dr. Sywons } \\
\text { Dr. Syrons }\end{array}$ \\
\hline July & 8 & 4 & p.ra. & $\begin{array}{l}\text { Diseases of lipid netabolist } \\
\text { BLOOD }\end{array}$ & Dr. Kneebone \\
\hline July & 10 & 10 & a.ta. & $\begin{array}{l}\text { Haen synthesis, porphyrias, bile } \\
\text { pigments and iron tietabolisa, } \\
\text { plasna, transport of vaterials } \\
\text { Haen synthesis, porphyrias, bile } \\
\text { piguents and iron netabolism, } \\
\text { plasna, transport of naterials } \\
\text { THE BRATI GID THE TYE }\end{array}$ & $\begin{array}{l}\text { 14r. A. Edwards } \\
\text { 14r. A. Edwards }\end{array}$ \\
\hline July & $\begin{array}{l}15 \\
16\end{array}$ & $\begin{array}{r}4 \\
10\end{array}$ & $\begin{array}{l}\text { р.เ. } \\
\text { а.ㅁ. }\end{array}$ & $\begin{array}{l}\text { Metabolisu of glutamate and } \\
\text { anmonia, vitamins and the brain } \\
\text { The visual process } \\
\text { BIOCHE:TSTRY OF REPRODUCTIOU }\end{array}$ & $\begin{array}{l}\text { Dr, Rogers } \\
\text { Dr. Rogers }\end{array}$ \\
\hline JuIy & 17 & 9 & a.t. & $\begin{array}{l}\text { Nucleotides and their biosyn- } \\
\text { thesis }\end{array}$ & Dr. Wheldrake \\
\hline July & $\begin{array}{l}22 \\
23 \\
24\end{array}$ & $\begin{array}{r}10 \\
9\end{array}$ & $\begin{array}{l}\text { R.t. } \\
\text { a.t.. } \\
\text { a.t. }\end{array}$ & $\begin{array}{l}\text { ITucleotides and their biosyn- } \\
\text { thesis } \\
\text { Structure and replication of DII } \\
\text { Structure and replication of DNA }\end{array}$ & $\begin{array}{l}\text { Dr. Wheldrake } \\
\text { Dr. The1drake } \\
\text { Dr. Theldrake }\end{array}$ \\
\hline July & $\begin{array}{l}29 \\
30 \\
31\end{array}$ & $\begin{array}{r}4 \\
10\end{array}$ & $\begin{array}{l}\text { p.tr. } \\
\text { a.t. } \\
\text { a.t. }\end{array}$ & $\begin{array}{l}\text { Gene action and PNA synthesis } \\
\text { Fucleotide biosynthesis. Struct- } \\
\text { ure and replication of DNA } \\
\text { Gene action and FUI } \Lambda \text { biosynthesis }\end{array}$ & $\begin{array}{l}\text { Dr. Wheldrake } \\
\text { Dr. Theldrake } \\
\text { Dr. Wheldrake }\end{array}$ \\
\hline Aug. & & 4 & p.t.i. & Protein biosynthesis & Dr. Theldrake \\
\hline
\end{tabular}


THE UNIVERSITY OF ADRL, $\triangle I D E$

Departwent of Biochemistry

MEDICINE II AND DENTISTRY II

TERM III - 1269

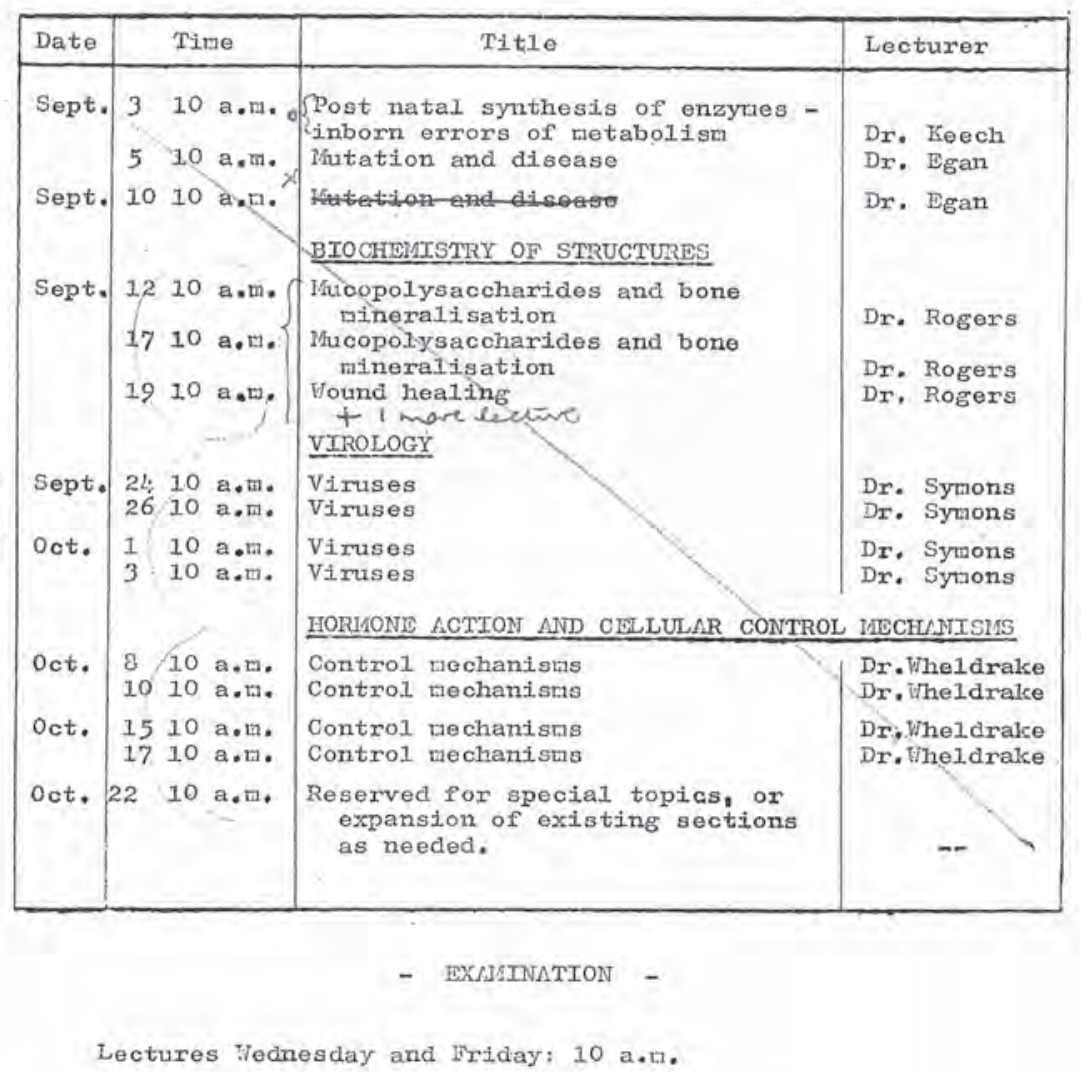


The written examination in biochemistry for medical and dental students in 1969

The examination was traditional in its format, including questions that asked students to 'give briefly', 'describe diagrammatically' and 'write notes on ... '. None of the questions asked students to apply their understanding of biochemistry to dental situations.

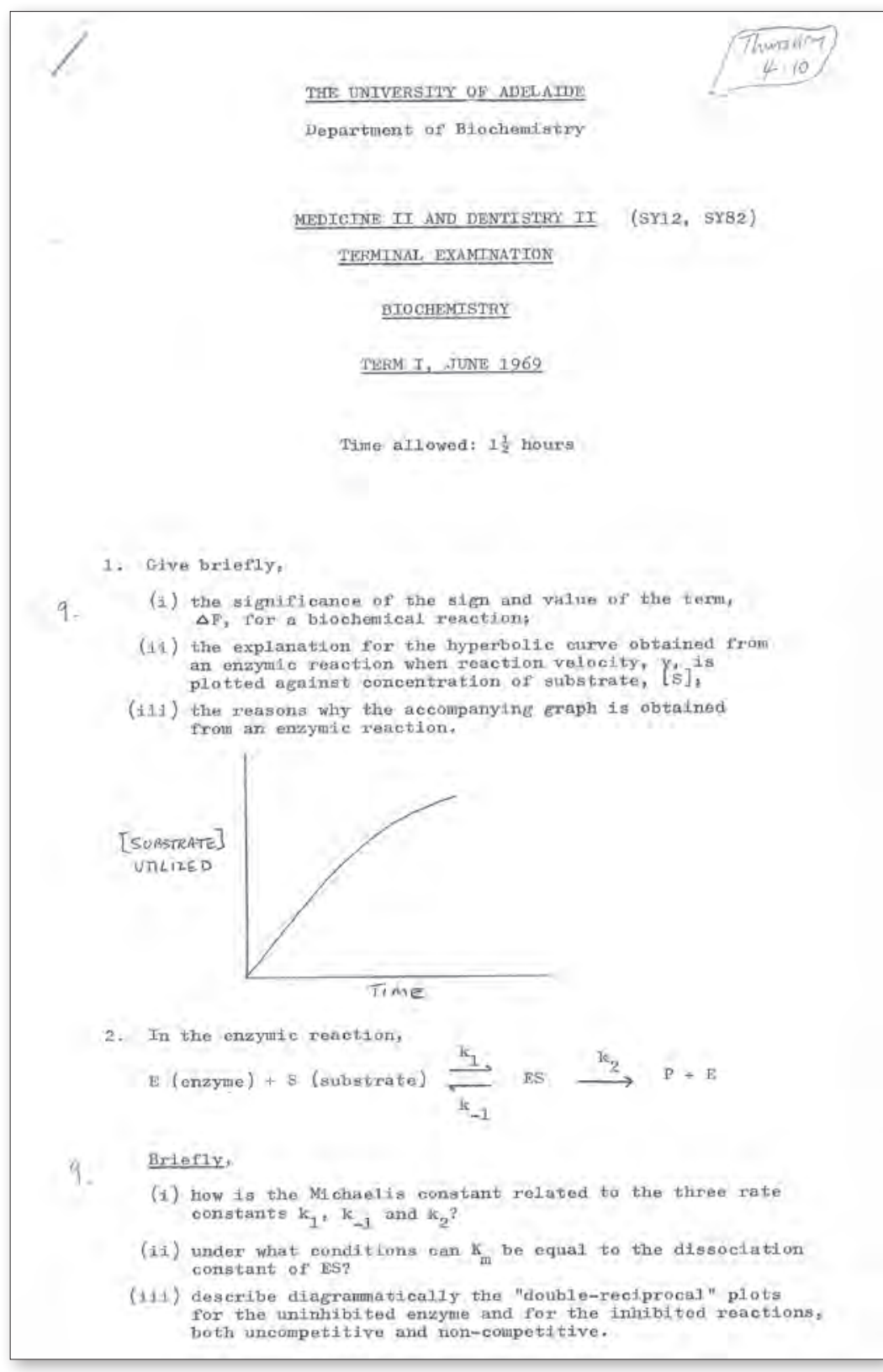

Figure A3.5 Biochemistry exam (1969). 
3. (a) With the significance of the parameter $K$ in nind, briefly describe why methicilin is a more effective antimbiotic for treating infections involving penicilin-resistant organisms,

$\underline{\underline{O F}}$

(b) The majox proteins involved in contraction of mucle are myosin and actin. For one of these briefly outline,

(i) where it is located in the sareomere of vertebrate-striated muscle

(ii), the physical structure of the molecule and the way in which many of these molecules are packed together to give the macromolecular unit (the myosin filament or the actin filament),

4. Writte notes on,

Glycogen storage diseases

6. Galactosaemia

NADt

Glucose 1,6-diphosphate

2, 4 -dinitroplienol.

5. Describe the sequence of reactions by which pyruyate is, converted in the cell

(a) to acety $1-\operatorname{CoA}$

(b) to phosphoenol pyruvate.

6. Write notes ong

Isocitrate dehydrogepase

Cytochrome oxtdase

Phosphorylase

ELavo-proteins.

7. Indicate by recoxding the appropriate letter(s) in your Blue Book which of these statements is substantially CORRECT.

(a) Free Blpha-amino and alpha-carboxyl groups are present in substantial numbers in a single polypeptide chain molectile.

(b) X Valine residues are likely to be involved in ionic linkages

9. (c) $\times$ The iso-ionic (or iso-electric) point of a basic) amino actd will be in the alkaline $\mathrm{pH}$ range.

I (d) Organo-phosphates of the DFP type react randomly with serine residues in proteins.

$x$ (e) Cystine (S-S) residues are incorporated into protein chains during protein synthesis on the ribosome.

B. Two pire protetn preparations, $A$ and $B$, were dried to constant weight, They were then dissolved in dilute buffer to give a final concentration of precisely $2 \mathrm{mg} / \mathrm{ml}$. The optical density at $280 \mathrm{~m}$ of of each
solution was determined with a spectrophotoneter. Indicate in your

3. Blue Book whether the optical density readings for solutions $A$ and B will be the same, different or urpredictable.

Briefly explain the rationale for your answer.

- Write notes on,

(a) The slenificance of regions of low dieleotric constant in proteins.

(b) The hydrogen bond and atabilisation of protein structure. 



\section{Glossary}

$\begin{array}{ll}\text { AAPD } & \text { Australian Academy of Paediatric Dentistry } \\ \text { ACODS } & \text { Australian Council of Dental Schools } \\ \text { ACOH } & \text { Australian Centre for Oral Health } \\ \text { ACUE } & \text { Advisory Centre for University Education }\end{array}$

ad eundem The awarding of an honorary degree in acknowledgement gradum of a qualification obtained in another institution which is considered to be of the same rank or standing to that approved by the University of Adelaide

ADA

ADC

$\mathrm{ADH}$

ADJ

ADASA

ADRF

AGH

AHMS

AHPRA

AIF

AIHW DSRU

$\mathrm{AM}$

ANZAOMS

ANZSPD
Australian Dental Association

Australian Dental Council

Adelaide Dental Hospital

Australian Dental Journal

Australian Dental Association, South Australian Branch

Australian Dental Research Foundation

Australian General Hospital

Adelaide Hospital Medical School

Australian Health Practitioner Regulation Agency

Australian Imperial Force

Australian Institute of Health and Welfare Dental Statistics and Research Unit

Member of the Order of Australia

Australian and New Zealand Association of Oral and Maxillofacial Surgeons

Australian and New Zealand Society for Paediatric Dentistry 
$\mathrm{AO}$

ARC

$\mathrm{ARCPOH}$

ATAR

ATHS

AUDSS

AUQA

BDS

BHSc

BSc

BScDent (Hons) Bachelor of Science in Dentistry (Honours)

$\mathrm{BOH}$

CACDRC

$\mathrm{CO}$

Cons

CORAL

CMF

CPD

CRTS

CSM

DASI

DBA

DClinDent

DDSc

DSc

DDS

DLP

DNA

DPERU
Officer of the Order of Australia

Australian Research Council

Australian Research Centre for Population Oral Health

Australian Tertiary Admission Rank

Adelaide Technical High School

Adelaide University Dental Students Society

Australian Universities Quality Agency

Bachelor of Dental Surgery

Bachelor of Health Science

Bachelor of Science

Bachelor of Oral Health

Colgate Australian Clinical Dental Research Centre

Commanding Officer

Conservative Dentistry

Centre for Oro-facial Research and Learning

Citizen Military Forces

Continuing Professional Development

Commonwealth Reconstruction and Training Scheme

Company Sergeant Major

Dental Advancement Study Incorporated

Dental Board of Australia

Doctor of Clinical Dentistry

Doctor of Dental Science

Doctor of Science

Doctor of Dental Surgery

Dental Learning Package

Deoxyribonucleic Acid

Dental Practice Education and Research Unit 
DREF

ENT

ERA

FADI

FICD

FRCS

FRACDS

GA

GDC

GDP

HEDI

HSRU

IADR

IAP

ILA

IMVS

IOHU

IT

$\mathrm{Kt}$

LA

LDS

MATES

MD

MDS

NAD

NHMRC

NHS

OMS

Op Tech
Dental Research and Education Fund

Ear, Nose and Throat

Excellence in Research for Australia

Fellow of the Academy of Dentistry International

Fellow of the International College of Dentists

Fellow of the Royal College of Surgeons

Fellow of the Royal Australian College of Dental Surgeons

General anaesthetic

General Dental Council

General Dental Practice

Health Education, Development and Innovation Unit

Health Services Research Unit

International Association for Dental Research

Individual Academic Profile

Integrated Learning Activities

Institute of Medical and Veterinary Science

Indigenous Oral Health Unit

Information Technology

Knight of the United Kingdom

Local anaesthetic

Licentiate of Dental Surgery (Eng)

Malaysian Australian Tertiary Education Scheme

Doctor of Medicine

Master of Dental Surgery

No Abnormality Detected

National Health and Medical Research Council

National Health Scheme (Eng)

Oral and Maxillofacial Surgery

Operative Techniques 


\begin{tabular}{|c|c|}
\hline PAC & Prince Alfred College \\
\hline PBL & Problem-Based Learning \\
\hline PGCD & Postgraduate Committee in Dentistry \\
\hline $\mathrm{PhD}$ & Doctor of Philosophy \\
\hline PIA & Progressive Integrated Assessment \\
\hline Pros & Prosthetic Dentistry \\
\hline PSR & Professional Services Reform \\
\hline QS ranking & $\begin{array}{l}\text { Annual ranking of universities by Quacquarelli Symonds } \\
\text { publishers }\end{array}$ \\
\hline RAAF & Royal Australian Air Force \\
\hline RAH & Royal Adelaide Hospital \\
\hline RCS & Royal College of Surgeons (Eng) \\
\hline SA & South Australian \\
\hline SADB & South Australian Dental Board \\
\hline SADS & South Australian Dental Service \\
\hline SAFDER & South Australian Foundation for Dental Education and Research \\
\hline SATAC & South Australian Tertiary Admissions Centre \\
\hline SET & Site Evaluation Team \\
\hline SSR & Student to Staff Ratio \\
\hline STT & School of Technical Training \\
\hline TAFE & Technical and Further Education \\
\hline TER & Tertiary Entrance Rank \\
\hline UK & United Kingdom \\
\hline UMAT & Undergraduate Medical and Health Sciences Admissions Test \\
\hline UCSD & University of California, San Diego \\
\hline USA & United States of America \\
\hline Viva & Oral Examination \\
\hline WAAF & Women's Auxiliary Air Force \\
\hline WHO & World Health Organization \\
\hline
\end{tabular}




\section{About the authors}

\section{James R Rogers BA, BScDent (Hons), Grad Dip Ed}

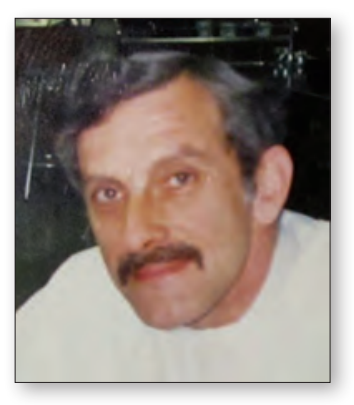

James R Rogers was trained as a dental technician in London. After his studies were completed he was appointed as a dental technician at St Bartholomew's Hospital, London. Later he became maxillofacial technician-in-charge at The Royal Northern Hospital, London. On his arrival in South Australia in 1968 , he was employed as a crown and bridge technician in private practice and, later, as an instructor in dental technology at the University of Adelaide from 1974 to 2005.

During his employment at the University of Adelaide, he acquired a Bachelor of Arts, a Bachelor of Science in Dentistry (Hons) and a Postgraduate Diploma in Education. His role as a teaching technician in the Adelaide Dental School involved small-group teaching and mentoring of students in all years of the BDS programme over a period of more than thirty years.

His interest in South Australian dental history has been an important part of his professional life, as he was for many years a member and, later, chairman of the History and Heritage Committee of the South Australian Dental Service.

Since his retirement he has been part of the teaching and research team in the Craniofacial Biology Group in the Adelaide Dental School, and has played an active part in co-authorship of both books and refereed articles published by the group. $\mathrm{He}$ holds the honorary title of visiting research fellow in the University of Adelaide.

\section{Grant Townsend BDS, BScDent (Hons), PhD, DDSc, FICD, FADI, AM}

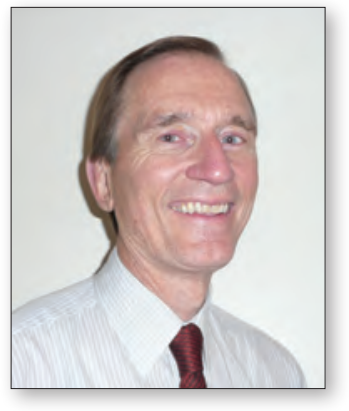

Emeritus Professor Grant Townsend was an undergraduate student in the Adelaide Dental School from 1968 to 1972 and then completed his honours degree and $\mathrm{PhD}$ after graduation. He was appointed as a lecturer in the School in 1977 and then as professor of dental science in 1994, the position he held until he transitioned to an emeritus role in July 2017. He was awarded a DDSc in 1994 and has authored over 300 papers in refereed journals, as well as many books and book chapters. 
Grant's main teaching responsibilities have been in the areas of dental anatomy, head and neck anatomy, dental occlusion and local anaesthesia. He has been invited to be a keynote speaker at many international and national meetings to present his research relating to twin studies and dental education. He has been awarded the Medaille de la Ville de Paris, membership of the Finnish Dental Society, the IADR ANZ Division Alan Docking Award, and the IADR International Distinguished Scientist Award in craniofacial biology for his contributions to dental research. He was also awarded the Lifetime Commitment to Education Award by the Adelaide University Dental Students' Society in 2013.

Grant was Associate Dean (Academic) in the Adelaide Dental School from 1994 to 2003, Director of Assessment from 2007 to 2016 and Chair of the Australian Dental Council Accreditation Committee from 1999 to 2006. He has been heavily involved in curriculum review, implementation and evaluation in Adelaide, as well as nationally and internationally, throughout his career and became a Member of the Order of Australia in January 2018 in recognition of his significant service to dentistry in the field of craniofacial biology, and to dental education through research, teaching and mentoring roles.

\section{Tasman Brown BDS, MDS, DDSc, FRACDS, AM}

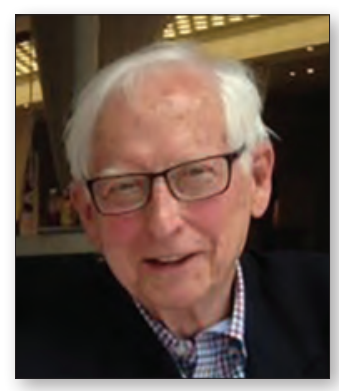

Emeritus Professor Tasman (Tas) Brown was a student in the Adelaide Dental School from 1946 to 1950. After graduation, he was a dental practitioner in a country town until 1960, when he was appointed lecturer in dental anatomy. In 1976, he became professor in the Department of Restorative Dentistry and after retirement in 1991, Tas was part-time consultant research director at the Australian Craniofacial Unit for a further seven years.

His main teaching and research interests have been dental anthropology, anatomy and craniofacial growth, fields in which he has published books, chapters and over 100 journal articles. Tas joined the late Murray Barrett in a long-term growth study that involved him in annual field trips to Central Australia. He was recipient of the inaugural IADR ANZ Division Alan Docking Award in 1978 and has lectured overseas and examined many external theses.

Tas served on university and government committees and was dean of the Faculty of Dentistry from 1977 to 1978, chairman of the Curriculum Review Committee in 1970, a member of the Dental Board of South Australia from 1975 to 1982 and president of the IADR ANZ Division from 1982 to 1983. Tas also served as a visiting professor in Japan and New Zealand. In 1994, he became a Member of the Order of Australia, in recognition of his contributions to dental research and postgraduate education. 


\section{Acknowledgements}

Many people have helped us to put together this book, celebrating 100 years of the Adelaide Dental School, and we thank them all.

We would like to thank especially Dr Tony Lake, the archivist at the Australian Dental Association SA Branch, for his help and willingness to allow written and photographic material to be used in the book. We would also like to thank the Australian Dental Association, South Australian Branch Inc., for its financial contribution towards the publishing costs of the book and for its support throughout the whole process of writing the book.

Our thanks go to Mr Andrew Cook, archivist officer from the University of Adelaide Archives and Recordkeeping Department for his assistance in finding and granting us access to the recorded Minutes of meetings of the Faculty of Dentistry. We are also indebted to Cheryl Hoskin, Lee Hayes and Marie Larsen at Rare Books and Special Collections, the University of Adelaide, for their help in tracing University Calendar and Commemoration Lists of names of dental students.

To Mr Alexander Khominsky, the 2017 President of the Adelaide University Dental Students' Society, our thanks for allowing us to use photographs, articles and cartoons published in the Probe magazine.

Where no attribution is given for figures, they have been provided by contributors to the book.

A big thank-you to those bastions of dentistry Clinical Professor Geoffrey Heithersay and Emeritus Professors Alastair Goss and Wayne Sampson, who offered information, personal recollections and critical comment as the book passed through its many drafts.

Thanks also to previous deans and leaders of the School who contributed their thoughts to Chapter 8 and to Dr Jenny Miller, who provided information about the $\mathrm{BOH}$ programme and lists of graduates. We would also like to acknowledge the graduates who have provided comments about how the BDS and $\mathrm{BOH}$ programmes prepared them for their future careers.

It has been a pleasure to renew contact with the senior members of the profession to ask for their help in relating stories, either of their own experiences or those of their families. Dr Kevin Moore was very helpful in discussing his father's substantial 
contribution to dentistry (Arthur Pariss Reading Moore) and he also spoke of his time as a dental student.

A very special mention must be made of Karen Squires, Sandra Pinkerton and Corinna Bennett for their assistance with formatting the text, scanning figures and carrying out editorial work on the various drafts.

We would also like to thank John Emerson, Julia Keller and Rebecca Burton from the University of Adelaide Press for their advice, support and editorial work throughout the publication process. 
This book is available as a free fully searchable ebook from www.adelaide.edu.au/press 